过ibrarn of the attuscum

OF

\section{COMPARATIVE ZOÖLOGY,}

AT BARTAPD COLLEGR, CAMBRIDGE, IIASS.

1) oundeð by pribate subscription, in 1861.

Deposited by ALEX. AGASSIZ.

March 29,1911 





\title{
DIE MEDUSEN
}

\author{
PHYSIOLOGISCH UND MORPHOLOGISCH
}

AUF

IHR NERVENSTSTEM

UNTERSUCHT

VON

Dr. THEODOR EIMER

PROFESSOR DER ZOOLOGIE UND VERGLEICHENDEN ANATOMIE AN DER UNIVERSITÄT ZU TÜBINGEN

T ÜBING EN, 1878

VERLAG DER H. L A U P P'SCHEN BUCHHANDLUNG 
$C-t$ 


\section{SEINEM LEHRER UND FREUNDE}

\section{HERRN Dr. AUGUST WEISMANN, \\ PROFESSOR DER ZOOLOGIE AN DER UNIVERSITAT ZU FREIBURG i./Br.}

IN VEREHRUNG GEWIDMET

VOM

VERF ASSER. 



\section{Vor W o r t.}

Das schon vor mehr als Jahresfrist angekündigte baldige Erscheinen meiner Arbeit haben Umstände, deren Beseitignng nicht in meiner Macht lag, verhindert. Seitdem die kürzeren Nachrichten, wetche ich über verschiedene Ergebnisse derselben

bekannt gegeben habe, veröffentlicht worden sind, hat der Gegenstand sowohl nach der physiologischen als nach der morphologisehen Seite mehr oder weniger eingehende Bearbeitung erfahren. Der ächt wissenschaftliche Geist, in welchem der eine meiner Mitarbeiter, Herr komanes, der den ersteren Weg betrat, unsere Beziehnngen behandelte, führte zu privatem Austanseh der Meinnngen, welcher unsere Arbeit wesentlich gefördert hat. Der morphologische 'Theil derselben dagegen ist von ähnlichem Einfluss unberührt geblieben und ich stelle die bezüglichen Thatsachen in Folgenden durchans so dar, wie ich sie beobachtet hatte zn einer Zeit, da ich nicht ahnen konnte, dass ich binnen Kurzem mehrere Nachfolger in der Bearbeitung des Nervensystems der Zoophyten finden würde. Ein Abschnitt - der von Carmarina handelnde - ist sogar fast ganz in der Form gegeben, in welcher ich ihn schon vor zwei Jahren niedergeschrieben hatte. Deshalb und weil die zugehörigen Tafeln theilweise schon seit nahezı ebenso langer Zeit ausgeführt waren, ist anch hier, wo meine Beobachtungen am meisten mit denjenigen Anderer zusammenfallen, die Darstellung eine von diesen röllig unabhängige geblieben. 
Bei der Austührung der Abbildungen habe ich vielleicht zu peinlich das Princip verfolgt, nur genau nach vorliegenden Präparaten darzustellen, allein ich hielt es für geboten, alles Schematisiren bei Zeichnungen zu vermeiden, welche zur Zeit ihrer Anfertigung eiri fast unbebantes Gebiet zum Gegenstande hatten.

Da ich an der Besorgung eines grossen Theils der Correctur verhindert war, so hat mein Assistent, Herr Dr. Fickert, die Güte gehabt, sich dieser Mühe zu unterziehen und ich sage ihm dafür den besten Dank. Ebenso danke ich meinem Freunde Professor Flemming in Kiel für Einräumung der Hülfsmittel seines Laboratoriums und fïr wiederholte Zusendung ron lebenden Medusen, sowie dem Herrn Verleger für die Ausstattung des Buches.

J $n$ genheim a. a. Bergstrasse in November 1878. 


\section{Inhaltsverzeichniss.}

Einleitung . . . . . . . . . . . . . . . . . . . . . . . 1

I. Theil: Physiologische Beobachtungen und Versuche . . . . . . . . 15

I. Die vier Grundversuche . . . . . . . . . . . . . . . . . . . 17

II. Von den normalen Bewegungen des unverletzten Thieres . . . . . . . . 18

III. Einfluss von Sanerstoffmangel auf die Bewegungen der Medusen . . . . . 23

IV. Operative Versuche zum Zweck der Feststellung der Ausgangspunkte der rhythmischen Contractionen und damit der Nervencentren . . . . . . . . . 24

V. Halbiren, Viertheilen und Achttheilen von Aurelia mol Cyanea . . . . . . 27

VI. Versuche zum Zweek der Feststellung der Art del Verbindung der verschiedenen Theile des Körpers der toponeureu Medusen durch Nervenfasern . . . . . 28

VII. Zerstöreu oder Terletzen der Raudkörpel . . . . . . . . . . . . . 32

VIII. Erholung gelähmter Thiere. Widerstandsfähigkeit gegenïber operativen Eingriffen 38

IX. Im freien Leben verstümmelte Aurelien . . . . . . . . . . . . . . 49

X. Folgen des Durchschneidens oder der Loslösung der Muskelschichte . . . . 51

XI. Art des Absterbens der Aurelien mul ihrer Theilstiicke . . . . . . . . 61

XII. Beherrschung der vegetativen Thätigkeit durch die contractilen Zonen . . . 65

XIII. Einige Operationen an Aurelia aurita mit Bezug auf las bisher Geschilderte in ihrer Wirkung fortlaufend beobachtet . . . . . . . . . . . . . . 74

XIV. Verhältniss zwischen der Grösse der Thiere und der Anzahl der in der Zeiteinheit von ihnen ausgetührten Contractionen und Verhältniss dieser Zahl zum Formwerth getheilter Thiere . . . . . . . . . . . . . . . 84

XV. Versuche an Cycloneuren . . . . . . . . . . . . . . . . . . 90

XVI. Untersuchungen Anderer. Vergleichung der Ergebnisse derselben mit den mei* nigen . . . . . . . . . . . . . . . . . . . . . . . . . . . . . . . . . .

XVII. Hauptsächlichste Ergebnisse . . . . . . . . . . . . . . . 128 


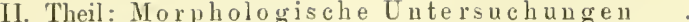

Toponenre Nledusen . . . . . . . . . . . . . . . . . . . . . . . . 137

Literatur . . . . . . . . . . . . . . . . . . . . . . . 137

Methoden der Untersuchung . . . . . . . . . . . . . . . . . 141

1. Gröbere Bauverhältnisse der Randlappen . . . . . . . . . . . . . 143

II. Feinerer Bau der Randkörper . . . . . . . . . . . . . . . . . 155

III. Feinerer Bau der Randlappen . . . . . . . . . . . . . . . . . 171

IV. Zellen und Fasern des äbrigen liörpers . . . . . . . . . . . . . . 185

Cycloneure Medusen . . . . . . . . . . . . . . . . . . . . . . . . 194

I. Allgemeine BauverhäItnisse von Schirmrand und Segel . . . . . . . . 202

II. Der Ringuerr . . . . . . . . . . . . . . . . . . . . . . 209

III. Typische Ganglienzellen des Schirmrandringes . . . . . . . . . . . . 211

IV. Nerrenepithel der Wand des Schirmrandringes . . . . . . . . . . . 213

V. Belegzellen des Stützblattes des Schirmrandringes. Ringganglion. Radialganglien. Spangenganglien . . . . . . . . . . . . . . . . . . . 216

VI. Die Hörbläschen . . . . . . . . . . . . . . . . . . . . . 222

VII. Untere Schirmoberfläche, deren Epithelien, MuskeI- und Nerrenelemente • . 230

VIII. Das Nervensystem der übrigen Cycloneureu . . . . . . . . . . . . 240

Zusammeufassung und Schlussfolgerungen . . . . . . . . . . . . . . . . . . . . . . 246 


\section{EINLEITUNG.}

Längst schien mir kaum eine unter den ungelösten Frigen der zoologischen Wissenschaft einer eingehenden Bearbeitung würdiger zu sein, als die nach den Anfängen des Nervensystems im Thierreiche. Dies nicht etwa allein wegen der Ansbeute, welche solche Arbeit der Feststelhung der Beziehungen zwischen Ontogenie und Phylogenie, den vielnmworbenen Grössen des Tages, zn bieten versprach: wohl achtete ich auch solchen Gewinn hoch und setzte ihn bei meinem Plane voraus; allein nicht minder wichtig und lohnenswerth schien es mir, anf Grund morphologischer Untersuchung und zugleich an der Hand des Experiments, eine Vorstellung zn gewimnen uber die Art und den Gral der Ausbildung des psychischen Vermögens der nicderen Thiere.

Ich wünschte demnach vor Allem zu erfahren: wo treten im Thierreiche zuerst Einrichtungen auf, welche nnzweifelhaft dem Nervensystem zuzurechnen sind und welche Schlüsse lassen uns diese Einrichtungen, gestützt anf Vergleichung mit entsprechenden, bei höheren Formen vorhandenen Organen, anf den Werth des durch sie vermittelten intellectuellen Lebens ziehen? - Sodann: in welchen Beziehungen stehen diese definitiven Einrichtungen zn den Entwicklnngsphasen des Nervensystems der höheren Thiere und wie lassen sie sich für die Lehre vom ursächlichen Zusammenhang zwischen Entwicklungs- und Stammesgeschichte verwerthen?

Bei solcher Fragestellung mussten die Protozoën ansser Betracht kommen. Nur die Untersuchung der Metazoën komnte für die Lösung des letzten Theils der Aufgabe frnchtbar werden; allein anch dem ersten liess sich nur an Thieren näher treten, in deren Körper, anf Grund der gemeinsamen Anlage in Keimblättern, nach fraglicher Richtung Differenzirungen erwartet werden mochten, die sich unmittelbar und vollständig mit denen der übrigen zusammenstellen und vergleichen lassen. Als Object meiner Studien drängten sich mir daher zmäichst die Zoôphyten auf. 
Das Feld lag hier weithin brach und an den wenigen Stellen, wo es bebaut schien, fand ich hald meist tauben Weizen. Nu die ausgedehnteste Anwendung der listologischen Methode kounte, so zeigte sich in Kurem, zum Ziele führen. Diese Methode war aber vorher kaum an dem Gegenstande versucht worden. Mit mehr oder weniger grosser Bestimmtheit hatte man "Nerren" und "Ganglien" im Körper unserer 'Thiere erwälnt, aber durch keine sorgfältige histologische Untersuchung war die Ammahme solcher als eine berechtigte hingestellt. In dem einzigen Falle, in welchem Nervenzellen besehrieben worden waren - von Häckel bei den Geryoniden ${ }^{1}$ ) - war dies mit so mangelhaften Belegen geschehen, sowohl was Angabe charakteristischer Merkmale in der Darstellung, als was Abbildungen anbetrifft, dass eine sichere Ueberzengung von der richtigen Deutung des Geschilderten bei Dritten kaum bewirkt werden konnte, dies um so weniger, als der Autor selbst vielfach zweifelnd und unsicher sich anssprach.

Zufällige Umstände - der Reichthum an Untersuchungsmaterial, den ich bei einem auf der Insel Capri im Jahre 1871 genommenen und 1872 wiederholten längeren Aufenthalte antraf - hatten mich veranlasst, meine Studien an den Rippenquallen und zwar an Beroë ovatus zu beginnen. Da die bis dahin gültige Beschreibung des Nervensystems dieser Thiere sich als nicht richtig herausstellte, da ïberhanpt bald alle Anhaltspunkte, welche die gröberen morphologischen Einrichtungen dieses Systems bei den höheren Typen uns an die Hand geben, mich hier rollstündig im Stiche liessen, so musste die Arbeit gleichsam ab ovo beginnen: gewissermassen Zelle für Zelle, Faser für Faser musste im Körper des Thieres untersucht werden und da die Differenzirung der Gewebe sich, wie von vornherein zu erwarten war, als eine wenig vorgeschrittene erwies, so dass Bindegewebselemente einerseits und Muskel- und Nervenelemente andererseits, in so hohem Grade sie zum Theil charakteristisch ausgebildet sich fanden, doch zum anderen Theile vielfach als morphologisch kam mnterscheidbar sich darstellten, so musste es höchst schwierig und mühevoll sein, auf so mngehahntem Wege zum Ziele zu gelangen. Dafür ergab sich die Feststellung eines Nervensystems, welches so primitiver und eigenartiger Natur ist, dass demselben sonst nirgends in der Thierreihe irgend Aehmliches bis dahin an die Seite gestellt werden konnte ${ }^{2}$ ).

Die früher gültige Annahme eines am aboralen Pole des Körpers der Rippen-

1) E. IIäckel, die Familie der Rüsselquallen, Jenaische Zeitschrift für Medicin und Naturwissensehaft I. und II. Bd. 1865.

2) Th. Eimer, Zoologische Studien auf Capri 1, Ueber Beroë ovatus, eiu Beitrag zur Anatomie der Rippenquallen, Leipzig, Euge lma n n 1873. 
quallen gelegenen Gehirns und acht von demselben, mit den liadiärgefüssen verlaufenden „Nerven“ ist demnach nicht dem Thatsächlichen entsprechend. Ein körperlich umschriebenes Nervensystem im Sinne desjenigen der höheren Thiere ist überhaupt bei diesen Zoophyten nicht vorhanden: es fehlt ein streng umgrenztes Gehirn ebenso wie aus Bündeln von Nervenfasernn bestehende "Nerven." Dagegen steht jede der die convexe Anssenfläche von Beroë deckenden Elitodermzellen mit einem ausserordentlich feinen Nervenfädchen in Verbindung, deren sich je eine Anzahl benachbarter in unterhalb des Ektoderms in Gallertgewebe gelegene gröbere Nervenfäden sammelt, die wieder mit zahlreichen Nervenzellen in Znsammenhang stehen; von letzteren aus durchziehen Nervenfasern, ohne irgend in gröbere Stränge, nach Art der "Nerven" der höheren Thiere, vereinigt zn sein, die Körpersubstanz nach den verschiedensten Richtungen, um sich schliesslich, durch Vermittelnng von motorischen Ganglienzellen, an die Mnskelfasern, insbesondere an die unter der Epithelialkleidung der Magenhöhle gelegene Muskelschichte anzusetzen. - Andere der vom Ektoderm entsprungenen Nervenfädchen sammeln sich unmittelbar in dem mehr oder weniger ausgesprochen ganglienzellenartig umgewandelten Ende einer Mnskelfaser, oder der aus ihrer Vereinigung gebildete Nervenfaden setzt sich unmittelbar in eine Muskelfaser fort: Ne uromuskelfasern. - Die Nervenzellen stehen vielfach durch ungemein feine, theilweise mittelst höchst eigenartiger Anastomosen netzförmig verbundener Fäden untereinander in Zusammenhang. Die peripherisch gelegenen derselben müssen als Gehirnzellen anfgefasst werden: der Centralapparat des Nervensystems ist somit über den ganzen peripherischen Theil des Körpers verbreitet, indessen: der Beginn einer engeren Lokalisirung desselben - einer höheren Centralisation - ist dadurch angedentet, dass in der Gegend des Afterpols eine grössere Ansammlung von Ganglienzellen stattfindet als anderwärts. Von dieser Gegend ans ziehen nun auch acht Züge von mikroskopisch feinen Nervenfüdchen unter den Schwingplattchenreihen gegen den Mund hin.

Die als Epithel die Körperdecke hildenden Ektodermzellen werden der Tastempfindung dienen; besondere Tastzellen finden sich ansserdem am Mundrande. Da auch die übrigen Sinnesorgane und ebenso die Nervenzellen selbst als aus dem Elitoderm hervorgegangen betrachtet werden müssen, demnach so zu sagen die Körperdecke das Nervensystem bei Berö herstellt, so haben wir hier Einrichtungen vor uns, welche jenen vorübergehenden Znständen in der Entwicklung höherer Thiere entsprechen, da das änssere Keimblatt, das Ektoderm, als Nervensystem thatig ist, die animalen Bezielungen des Organismus zur Anssenwelt besorgt - ein Blatt- 
nervensystem, wie man es in Gegensatz zu dem ausgebildeten Apparat der höheren 'Thiele, weleher strangförmig ist, nennen könnte.

Während die Rippenqnalle anf der eimen Seite durch den Besitz eines, wenngleich tiefstehenden Centralappirates als zu williürlichem Handeln befähigt erscheint, weist die von einer tieferen Stufe ler Entwicklung des Nervensystems erübrigte Eimichtung des Nenromuskelapparates darunf hin, dass ihre Reaktionen gegenüber der Aussenwelt woeh zu einem sehr grossen Theil in das Gebiet der Reflexthätigkeit fallen, welehe bei 'Thieren ohne nervösen Centralapparat ansschliesslich herrschend ist, während sie mit steigender Ausbildung dieses $\Lambda$ prarates mehr nnd mehr zurücktritt.

Was das von verschiedenen Autoren für das Gehirn der Rippenquallen erklärte, am aboralen Körperpole gelegene ganglienthinliche Gebilde angeht, so habe ich dasselbe aus Zellen zusammengesetzt gefunden, an welchen ich Eigenschaften von Nervenzellen nicht festzustellen vermochte. Insbesondere bin ich nicht im Stande gewesen, daran irgend welche Ausliufer nachzuweisen. leh habe desshalb in meiner Beroë-Arbeit gesagt: "So sehr nahe es liegt, diesen Körper; wenn auch nicht als Gehirn, so doch wenigstens als specifisches Sinnesganglion aufzufassen - ich dürfte ilım auf Grund meines anatomischen Befundes nicht einmal diese Bedeutung zugestehen" (Seite 62). Durch diese ledingte Ausdrucksweise wollte ich meinem Urtheil in Betreff der endgilltigen Entseheidung eine gewisse Reserve auferlegt wissen. Das Lageverhïltniss des Körpers zu den Simnesorganen und die Unmöglichkeit, ihm irgend andere Ledentung, wenn nicht die eines Sinnesganglion zuzusehreiben - wesshalb ich ihn auch als "Sinneskörper" bezeichnete - veranlassten zu sulcher Reserve. In einem oder dem anderen Referate meiner Angaluen ist kurzweg gesagt, dass ich „das Ganglion nicht anerkenne" oder selbst dass ich dasselbe leugne. Daraus möchten Dritte schliessen, ich lengne die Existenz des Simeskörpers selbst, während ich in Wirklichkeit nur nicht im Stande war, seine Zellen als Nervenzellen zu erkennen. Jetzt, seitdem ich die heziiglichen Verbältnisse bei dem Medusen untersucht habe, möchte ich vermuthen, dass in dem Simmeskörper doch Nervenzellen gesucht werden mïssen, welche morphologisch kaum als solche gekennzeichnet zu sein brauchten, deren Ausläufer sehr schwer nachzuweisen sein könnten. Denn : ahnliche Nervenzellen finden sich in den die Sinnnsorgane tragenden Anschwellungen des Nervenringes von Craspedoten und sehr niedrig gebildete reiehlieh auch auf den Randkörpern der Acraspedoten. Es würde dann der Sinneskörper ein Sinnesganglion bilden. Dass durch solehe Lösung meine übrigen Auffassungen in Betreff des Nervensystems der Ctenophoren nicht berührt würden, wird aus dem Folgenden hervorgehen.

Zn der Zeit, als ich mit Beroë beschäftigt wall, erschien die Abhandlung von

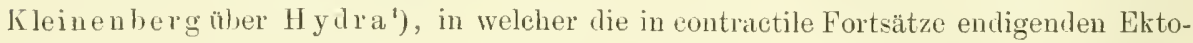
dermzellen dieses Zoophyten als "Nenromuskelzellen“ erklärt wurden, inden der Antor den äusseren, nicht contractilen 'Theil dieser Zellen als Nervenapparat in Anspruch nahm. So sehr allgemeine, ans dem Gesetz der Beziehnngen zwischen der individuellen und der Stummesentwicklungsgeschichte eutnommene Gesichtspunkte diese Auffassung ats berechtigt erscheinen liessen, so musste sie doch so lange als Hypothese angesehen werden, als sich die Zugehörigkeit des äusseren Ektodermzellenabschnittes zum Nervensystem durch keine ansgesprochene morphologische oder chemische

1) Nikola us Kleinenbergo, Hydra, eine anatomiseh-entwicklungsgeschichtliehe Untersuchung, Leipzig 1872. 
Eigenschaft nachweiseu liess oder so lange als dieser Nachweis nicht wenigstens an verwandten Formen geführt werken kounte. Heine Beobachtungen an Beroë, insbesondere die Auffindung ron Nemromuskelfasem bei diesem Thiere, lieferten den thatsächlichen Beweis für die Berechtigung der Kleinenberg'schen Anffassnug: bei Beroë sind die die Ektodermzellen mit den Mnskelfaser'n verbindenden Fäden als unzweifelhafte Nervenfäden morplrologiseh zu erkenmen und es erweist sich die ganze hier vorliegende Eimrichturg einfach als eine durch bedentendere Differenzirung aus der Stufe der Neuromuskelzellen abzuleitende.

Während aber bei Beroë ausser dem Neuromuskelfasersystem ein gesonderter nerröser Centralapparat entwickelt ist, haben wir diesen bei Hydra noch nicht und liefert gerade letzteres Thier einen Repräsentanten für jene tiefer stehenden Organismen, deren Handeln ausschliesslich in den Bereich des Reflectorișchen fällt.

'Trotzdem dass die Beziehungen zwischen der Form des Nerrensystems bei Beroë und bei Hydra so unverkennbare sind, liegt zwischen beiden doch eine ziemliche Kluft und musste sich mir auf das Lebhafteste der Wunsch aufdrängen, andere Zoopliyten zu untersuchen, $\mathbf{m}$ zu erfahren, wie die Verhältmisse hier gestaltet seien, und ob sich nicht speciell Einrichtungen auffunden liessen, welche jene beiden Formen verbinden. Ausserdem war es mir anch desshalb Bedürfniss, die Untersuchung anf andere Gruppen anszudehnen, weil die Verwerthung der vergleichenden Methode die Aussicht bieten musste, die ron mir gegebene Dentung meiner Beobachtungen zn festigen. Endlich gehören sehr wichtige unter den von mir geschilderten Thatsachen zu den feinsten und schwierigst zu erkennenden und zu beurtheilenden histologischen Dingen, so dass ich eine Bestätigung selbst von der Existenz derselben keineswegs von jedem meiner Nachfolger in der Untersuchung erwarten durfte, und so musste mir schon ans diesem Grunde daran liegen, meiner Auflassung durch Herbeiführung weiteren Materials eine breitere Basis zu schaffen.

Als nächsten Gegenstand der Untersuclnung wählte ich die Medusen. Am 13. Dezember 1873, also noch in demselben Jahre, in welchem meine Arbeit über Beroë erschienen war, hielt ich in der physikalisch-medicinischen Gesellschaft $\mathrm{z}$ Würzburg einen Vortrag über im September vorher an cler schleswig'schen Ostseeküste an A urelia arrita und Cyanea capillata von mir angestellte Versuche. Diese Versuche bestanden darin, dass ich die genamnten Thiere, 1 m ein Urtheil über die Ausbildung und über den Grad und die Art der Lokalisirmng eines Nervensystems in ihnen zur gewimner, nach rerschiedenen Richtungen durchschnitt und zertheilte ').

1) Sitzungsberichte der physikalisch-medicinischen Gesellschaft zu Würzburg für das Gesellschaftsjahr 1873/74, Seite II; erste Sitzung am 13. Dezember 1873. 
Der Inhalt jenes Vortrags wurde wiedergegeben in einem in den Würzburger Verhandlungen erschienenen Aufsatz, überschrieben „Ueber künstliche Theilbarkeit von Aurelia aurita und Cyanea capillata in physiologische Individuen" 1). Auf Grund des Experiments war es schon jetzt möglich zu schliessen, dass bei den acraspedoten Medusen der wesentlichste Theil des Nervensystems in acht je in der Umgebung der Randkörper gelegenen Bezirken sich finde, dass weder am Schimrande noch sonstwo ein Nervenring vorhanden sei, diss überhanpt Nervenstränge im Sinne derjenigen höherer Thiere nicht existiren, vielmehr Nervenfasern wie bei Beroë einzeln und nach verschiedenen Richtungen das Gallertgewebe durchziehen, kurz, dass das Nervensystem dieser Medusen beschaffen sei, ähnlich dem von mir bei den Rippenquallen beschriebenen.

Auch über die Bestätigung dieser Schlüsse durch die anatomische Untersuchung komnte in jenem Vortrag schon Nachricht gegeben werden: ich vermisste, ganz wie bei Beroë, im Körper von Aurelia und Cyanea umschriebene Centralorgane des Nervensystems, entsprechend dem Gehirn der höheren Thiere; fand dagegen, wie dort in der Gegend des Afterpols, so hier in der Umgebung der Randkörper, durchaus so wie das Experiment es verlangt hatte, „ungewöhnlich zahlreiche Nervenelemente, Easern und Zellen" ${ }^{2}$ ).

Ich habe nun seitdem die Untersuchung an Medusen fortgesetzt und die vorliegende Schrift befasst sich mit den Ergebnissen dieser Untersuchung.

In den Honaten August und September 1874 verfolgte ich meine Aufgabe, - und zwar abermals an der Ostseeküste, in dem kleinen Bade Niendorf an der Travemünder Bucht, zunächst an Aurelia und Cyanea weiter. Was an physiologischen wie an anatomischen Thatsachen im Folgenden in Betreff dieser Thiere mitgetheilt wird, ist, abgesehen von einigen Einzelheiten, welche an conservirt mit nach Hause genommenem Material noch ergänzt worden sind, schon in der genannten Zeit gewonnen. Die Hauptergebnisse meiner Untersuchungen, so z. B. die. merkwürdigen Banverhältnisse der Randkörper, das Vorhandensein von zapfenartigen Bildungen zwischen den Pigmentzellen des äusseren Augenfleckes und ebenso zwischen den übrigen Geisselzellen der Raudkörper, den Uebergang aller dieser Zellen in feinste dichotomisch verzweigte Nervenfädchen, deren Gesammtheit einen Nervenfilz unter dem Epithel bildet, unter welchem wiederum Ganglienzellen liegen, die interessante Umbildnng der gewöhnlichen Ektodermzellen zu den percipirenden Elementen der speci-

1) Verbandlungen der physikal.-med. Gesellschaft zu Würzburg N. F. V1. Band 1874. Auch erschienen in: Th. Eimer Zoologische Untersuchungen I. Heft, Würzburg Stahel'sche Buchhandlung 1874.

2) Würzb. Verhandl. a. a. O. S. 155; Zoologische Untersuchungen S. 63. 
fischen Sinnesorgane, die allmälige, höhere Ausbildung des Nervensystems in der Umgebung der Randkörper ïberhaupt, als einer Modification der allgemeinen Eigenschaften des Elitoderms - alle diese Thatsachen habe ich damals (1874) sehon verschiedenen Fachgenossen, u. a. meinen Freunden und damaligen Würzburger Collegen Wiedersheim und Fleseh, sowie meinem Freunde Flemming mittheilen können.

Seitdem habe ieh, 1 m einiger nachträglich anfgetretener physiologiseher Fragen willen, wiederholt den Versueh gemaeht, mir Sendungen von lebenden Aurelien aus Kiel zu verschaffen, welehe mein Freund Flemming dortselbst mir besorgt hat. Allein die Versuche haben erst naeh vielem Misslingen zum Ziele gefühıt. In einer grossen Blechbüchse mit durehlöchertem Deckel in viel Seewasser versendete Thiere kamen fast immer todt oder gar vollständig zerfetzt an. Nur einmal waren ihrer eine Anzahl - kleine Individuen von nur etwa $2 \mathrm{~cm}$. Durchmesser — ziemlich lebensfriseh geblieben und sie waren es, welche ich zu den zu besehreibenden Versuchen über das Absterben in Jodserum verwendet habe. Dieser Erfolg wurde erst erreicht, als man kleine Individnen, wie sie nur im Frühling zu haben sind, zur Versendung verwendete und als die Vorsieht gebrancht worden war, ihrer nur wenige in unverhältnissmässig grosser Menge Seewassers auf die Reise zu schicken. Abgesehen von der Unzuverlässigkeit ist diese Methode zn kostspielig. Als zweckmässig und sicher erwies sich späterhin die Versendung anf folgende Weise: ein etwa 3 Liter haltendes Glas wird zu zwei Drittheilen mit Seewasser gefüllt und mit nur zwei oder drei kleinen Amrelien oder mit einigen Sarsien auf die Post gegeben.

So hatte ich zuerst im Frühjahr 1877 die Frende, Sarsien hierher nach Tübingen lebend zu erhalten und während längerer Zeit in ibrem munteren Treiben beobachten und Anderen zeigen zu können. Darauf gelang dasselbe mit Aurelien und später mit der am meisten empfindliehen Cyanea. Aurelien habe ich fast olme Nahrung volle acht Tage lebend im Aquarim erhalten, Cyanea ebenfalls mehrere Tage.

Ehrenberg hat sich schon in den Jahren 1835 und 1836 Aurelien aus Wismar und Stralsund und Cyanea aus Copenhagen nach Berlin schicken lassen und gelang es ihm nach wiederholten Versuchen, erstere lebend zu erbalten, nachdem viel Wasser fassende lange Cylindergläser „mit Ausschluss eines Verbandes von Blase und mit Einschluss von etwas, aber wenig Luft" angewendet worden waren. Bei der kühleren Witterung im November, sagt Ehrenberg, gelang der Versuch so wohl, „dass Sonnabend am 12. November 7 Stiick 2 bis 4 Zoll grosse Exemplare ganz unversehrt und lebend von Stralsund in Berlin nit der Post ankamen, die noch Montag den 14. und Dienstags am 15. so deutliche Bewegung zeigten, dass sie in der Sitzung der physikalischen Klasse der Akademie und in der Versammlung der naturforschenden Gesellschaft als lebende Thiere vorgezeigt werden konnten" ${ }^{\text {3)}) . ~}$

1) Ehrenberg: Ueber die Akalephen des rothen Meeres und den Organismus der Medusen der Ostsee. Abhandl. d. kgl. Akad. d. Wissenscb. zn Berlin aus dem Jahre 1835, Berlin 1837, S. 257 und 258. 
Der wiederholte Wechsel meiner Stellung, zmerst im Jahre 1874 und danu 1875, hat die alsbaldige Veröffentlichung meiner Untersuchungen unmöglich gemacht. Als ich aber in der Lage war und angefangen hatte, mich mit dieser Aufgabe zu beschäftigen, schien es mir mehr und mehr preiswürdig und machte sich theilweise auch im Interesse des schon bearbeiteten Stoffes selbst das Bedürfniss geltend, durch noch ausgedehntere Untersuchungen, insbesondere anch an (raspedoten ${ }^{1}$ ), mil ein manchfaltigeres Material zur Lösung verschiedener Fragen auf dem Wege der Yergleichung zu verschaffen. Solche Art der Behandlung allein bot mir die Aussicht, eine nach verschiedenen Richtungen hin vollständige und erschöpfende Arbeit zu liefern. - Im März und April 1876 benützte ich desshalb die zoologische station zu Neapel nnd gewann dort die im Folgenden dargestellten Ergebnisse an C'armarina hastata, Geryonia exigua und anderen Cyclonemren, sowie nuter den Toponemren an Pelagia noctiluca und Rhizostoma Cuvieri. Es beschätigte mich diesmal rollanf die morphologische Untersuchung. Besonders die in zahlreichen Exemplaren vorkommende Carmarina war es, deren Anatomie mich fesselte. Um aber an diesem Thiere die durch die anatomische Untersuchung erkannten Einrichtungen des Nervensystems physiologisch zu belenchten und zu verwerthen, ging ich im August 1877 nochmals nach Neapel. Während meines freilich nicht mehr als dreiwöchentlichen Anfenthaltes erhielt ich jedoch jetzt nur 2 todte, noch dazu halbverstümmelte Exemplare von Carmarina. Dafür war ich in der Lage, einige Experimente an Rhizostoma und besonders an Cassiopea borbonica muchen, von welchen die letztere nun sehr reichlich rorkam, während sie im Frühling des vorhergehenden Jahres gänzlich gefehlt hatte. Wenngleich die Versuche, welche ich anstellen konnte, mir werthroll gewesen sind, so erschwerte doch die ansserordentliche Hitze, unter deren Einfluss die Lebensfähigkeit der Thiere litt, deren consequente Verfolgung und schliesslich war ich genöthigt, meinen Aufenthalt ror Abschluss meiner Studien abzubrechen. So wäre es in Folge dieser Ungunst nöthig gewesen, die Veröflentlichung meinel Untersuchungen noch weiter hinanszuschieben, wenn ich anders meinem ursprünglichen Plane treu bleiben wollte; und in der. That komnten mich nu besondere Grinnde dazu veranlassen, von ihm abzuweichen.

1) Statt der so ungemein schwerfällig klingenden Bezeichnungen (Uraspedoten * und sAcraspedoten erlaube ich mir im Folgenden, indem ich der Darstellnng meiner über das Nerrensystem unserer Thiere erlangten Ergebnisse rorgreife, die von Cycloneuren (Craspedoten) und Toponeuren (Acraspedoten) zu gebrauchen. Bekauntlich ist - von der Schwerfälligkeit des Ausdrucks abgesehen - jene von G e ge u ba u r eingeführte Nonenklatur keine tadellos richtige. So besitzt gerade die rou mir vorzngsweise untersuchte scraspedote Aurelia aurita ein kleines Segel. Auch bei den Charybdeiden, die gewöhnlich 21 den Acraspedoten gestellt werden (siehe freilich später) findet sich nach Fritz Müller ein solches. Bezïglich der Gründe, durch welche die bedingte Aufstellung jener Nomeuklatur trotzdem gerechtfertigt war, vergleiche Gegenbaur, Grundzüge der vergl. Anat. S. 125. 
Nur in einem vor Kurzem im Archiv für mikroskopische Anatomie veröffentlichten Aufsatze über den Zellkern ${ }^{1}$ ) hatte ich inzwischen gelegentlich verschiedene Ergebnisse meiner morphologischen Untersuchungen an Hedusen unter Hinweis anf das Erscheinen dieser Arbeit mitgetheilt, auch histologische Abbildungen gegeben, u. A. von Nervenelementen. Bei meiner Rückkehr von Neapel, Anfangs September, traf ich die Arbeit von Claus: "Studien über Polypen und Quallen der Adria“" 2), welche einige vorläufige Mittheilungen über das Nervensystem des Toponeuren, sowie Bemerkungen über meine physiologischen Versuche an denselben enthält, eine Arbeit, auf deren Inhalt ich zurückkommen werde.

Durch diese Publikation veranlasst, die Hauptergebnisse meiner Untersuchungen bekannt zu geben, that ich dies, wenige Tage nachdem ich von derselben Kenntniss genommen hatte, auf der Münchener Naturforscherversammlnng in einem Vortrag, welcher unter dem Titel „Ueber künstliche Theilbarkeit und über das Nervensystem der Medusen" im XV. Band des Archivs für mikroskopische Anatomie erschienen und anch in den amtlichen Bericht über die Naturforscherversammlung aufgenommen ist. Da der über Carmarina handelnde Theil dieser Abhandlung schon damals zur Ansgabe vorbereitet war, so war ich im Stande, gelegentlich dieses Vortrags schon einige der bezüglichen Tafeln der zoologischen Sektion lithographirt vorzulegen. - Einige Wochen später erschien eine weitere vorläufige Mittheilung „Ueber das Nervensystem und die Sinnesorgane der Medusen" von 0. und R. Hertwig ${ }^{3}$ ). Die Verfasser haben ebenso wie ich unter den Cyclonemen vorzugsweise Carmarina untersucht und ihre Angaben lieferten mir eine erfreuliche Bestätigung der wesentlichsten der von mir vorher veröffentlichten Ergebnisse. Ueber die Toponeuren sind ihre Untersuchungen weniger weit gediehen, indem sie hier den Epithelbelag der Randkörperstiele ansschliesslich für das Nervensystem halten. - Was im Uebrigen die Beziehnugen des Inhalts dieser vorläufigen Mittheilung zu meinen Arbeiten über den Gegenstand angeht, so habe ich mich darüber in einem Znsatz zu dem Nünchener Vortrag im Archiv für mikroskopische Anatomie ausgesprochen ${ }^{4}$ ).

Eine nicht minder erfreuliche Bestätigung hat der physiologische Theil meiner bisher veröflentlichten Untersuchungen in seinen Hauptsätzen durch einen englischen

1) Th. Eimer, „Weitere Nachrichten über den Bau des Zellkerns, nebst Bemerkungen über Wimperepithelien « Arch. f. mikr. Anat. XIV. Bd.

2) Denksehr. d. kais. akad, d. Wissenschaften, math. natw. Cl. KXXVII. Bd. I. Abth. Wien 1877.

3) Jenaische Zeitschrift f. Med. und Naturw. Bd. Xl. N. F. Bd. IV.

4) Nachträgliche Bemerkung: Die inzwischen erschienene ausführliche Arbeit Hertwigs: „Das Nervensystem und die Sinnesorgane der Nedusen«, Leipzig, Vogel, 1878, wird mir Veranlassung geben, auf diese Beziehungen zurückzukommen. 
Forscher, George J. Romanes, erfahren. Derseblue ist, ohne von meinen in den Würzburger Verhandlungen, freilich einer wenig gangbaren Zeitschrift, bekannt gegebenen Versuchen etwas zu wissen, gleich mir auf den Gedanken gekommen, Medusen zum Zweck der Erforschung des Nervensystems kiüstlich zu zertheilen und die Ergebnisse seiner Studien stimmen nicht nu in der Hauptsache mit den von mir geschilderten Thatsachen überein, sondern es ist sogar die Art der Frigestellung und der Behindlnng des Gegenstandes bei nus Beiden hänfig eine merkwürdig gleichartige, während wir uns andere Male wieder gerude durch die Verschiedenheit der letzteren passend ergänzen. Die ersten seiner Versuche hat Romanes um ein Jahr später als ich, nämlich $1 S 74$ angestellt nnd bekinnt gegeben. Die erste Mittheilung darüber veröffentlichte er in der Zeitschrift "Nature“ ${ }^{1}$ ), zn einer Zeit, da ich schon die zweite Reihe meiner Untersuchungen an der Ostsee gemacht hatte, über welche n. A. im Folgenden, ausführicher als schon geschehen, berichtet werden soll. Romanes beobachtete nach dieser. Mittheilung, dass wenn er an Slabberia conica eines der vier Sinnesbläschen ansgeschnitten hatte, vollständige Lähmung des entsprechenden Schirmabschnittes entstand. Schuitt er zwei nebeneinander gelegene Bläschen aus, so erschien die Hälfte des 'Thieres gelähmt „the loss of motion being quite as decided, and the area of its occmrence quite as well defined, as in the case of hemi-section of the spinal chord." Schnitt er zwei gegenüberliegende Bläschen ans, so entstand an den zwei gegenüberliegenden Seiten Lähmung; schnitt er ihrer drei ans, so bewegte sich nur noch der vierte Theil des Schirmes mnd endlich, nach Ansschmeiden aller vier hörte jede Bewegungsfähigkeit auf. Kein mechanischer oder chemischer Reiz sei im Stande, jetzt noch auch nur die leichteste Contraction in irgend einem Theile des Körpers herbeizuführen. Werde dagegen irgend ein Gewebsstückchen, gleichviel wie gross, mit einem der Sinnesbläschen in Verbindung belassen, so setze es seine rhythmischen Contractionen fort.

Unter diesen Angaben nun stimmt freilich diejenige, welche besagt, dass jeweils jedes Segment einer Meduse, dessen Simeshläschen ausgeschnitten worden, für sich gelähmt sei, mit meinen Versuchen ebenso wie mit den späteren, von Roma nes an anderen Formen angestellten, durchans nicht überein - nach diesen contrahirt sich, bei Cycloneuren wie bei Toponeuren, stets das ganze Thier sogar dann noch, wenn alle locomotorischen Centren bis anf eines ausgeschnitten sind, indem sich die Wirknng dieses einzigen Centrums über das ganze Thier fortpflanzt, und bei den Cycloneuren contrahirt sich der ga nze Schirm selbst damn noch, wenn nur irgend ein Stückchen

1) Vol. XI. November 1874 to April 1875. Nummer vom 5. November 1874, S. 29. 
des Randes daran belassen worden ist. Auch die Behauptung, dass weder chemische noch mechanische Reize nach dem Ausschneiden der sinmesbläschen noch Contractionen zu bewirken im Stande seien, ist nicht richtig. Es werden diese beiden Sätze in der späteren Veröffentlichung Romanes auch nicht wiederholt, der erste vielmehr so gut wie zurẗckgenommen. Diese zweite Veröffentlichung erschien unter dem 'Titel "Preliminary Observations on the Locomotor System of Medusae" im Jahre $\left.1876^{1}\right)$. Die Abhandlung - im November 1875 an die Gesellschaft eingeschickt - ist trotz ihres Titels ziemlich unfangreich und begleitet von zwei Steindrucktafehn. Sie gründet sich anf ansführliche und zahlreiche Untersuchnngen an Cyclonemen sowohl wie an Toponeuren und die Ergebnisse dieser Untersuchungen sind es, deren Uebereinstimmung nit den von mir schon bekannt gegebenen ich erwähnt habe. Zwar weiss der Verfasser anch bei Abfassung der nenen Publikation von den letzteren noch nichts, theilt jedoch in einer Nachschift mit, dass ihm meine Abhandlung nachträglich (im Februar 1876) bekannt geworden sei und bespricht dieselbe.

Aus dem Mitgetheilten ist ersichtlich, in wie hohem Grade das vorliegende Thema die Aufmerksamkeit erregt hat, sei es auf Grund meiner Arbeiten, sei es unabhängig von denselben. Was meine eigene Leistung angeht, so kam ihr wenig zu statten, dass meine Thätigkeit duch äussere Verhältnisse wiederholt so sehr unterbrochen wurde, sowie dass ich uu je kurzen Anfenthalt an der See zu nehmen im Stande war.

Leider ist an und für sich der Bimnenländer bei der Beschäftigung mit Seethieren in Rücksicht auf die Ausführung einer vollendeten Arbeit sehr im Nachtheil, schon desshalb, weil dieser ein bestimmter 'Termin gewöhnlich von vornherein gesetzt werden muss. Ganz besonders muss dieser Nachtheil dann zu Tage treten, weun es sich, wie in vorliegenden Falle, um Bebaumug noch fast gänzlich brachliegender Felder handelt. Dis stellt sich der richtige Angriffspunkt oft erst mach einer Anzahl vergeblicher, mühevoller Vorarbeiten - je eine neue Frage ergibt sich jetzt erst aus der Lösung der vorhergehenden und vor einer Reihe der wichtigsten steht der Forscher vielleicht erst unmittelbar vor dem gebotenen Abbrechen der Arbeit. Und was besonder's physiologische Untersuchungen angeht, so trat mir die Unmöglichkeit der Controle einzelner Versuche in Rücksicht auf nene Gesichtspunkte, oder des Anstellens nener Versuche beim Niederschreiben auch der vorliegenden Abhandlung wiederholt empfindlich entgegen.

1) Philos. Transact. Roy. Soc. Vol. 166, pt. I. S. 269 ff. 
Dies schien mir nöthig hervorzuhelsen gegenüber den Stimmen Solcher, welche berechtigterweise nachträglich finden, dass ich Jies und Jenes im Folgenden nicht berücksichtigt. diese und jene Frage unbeantwortet gelassen habe. Wenu ich anch glanbe erreicht zu haben, was unter gegebenen Terhältnissen möglich war, so bin ich mir doch wohl bewusst, wie sehr viel mehr an abschliessenden Ergebuissen Forscher erreichen können, welche in Beziehung anf die Möglichlieit andanernder oder gar ständiger Benützung des Materials glücklicher gestellt sind als ich.

Meine Abhandlung wird sich naturgemäss in zwei Theile theilen, einen physiologischen und einen morphologischen, entsprechend dem Gange meiner Untersuchung, welche mit dem Experiment begann und anf Grund der Ergebnisse desselben nach morphologischen Einrichtungen suchte.

Was den physiologisehen Theil anbetrifft, so werde ich meine bezüglichen Beobachtungen und Tersuche als Ganzes vorführen, indem ich die ron mir schon veröffentlichten 'Thatsachen kurz wiederhole und die neven an dieselben anknüpfe es ist dies schon desshalb nothwendig, weil jene, wie ans dem Mitgetheilten herrorgeht, nicht allenthalben hinreichend bekamnt geworden sind. Mit meinen Ergebnissen werde ich sodann insbesondere diejenigen von Romanes vergleichen und ferner werde ich eine Anzahl älterer Arbeiten oder gelegentlicher Beobachtungen — darunter recht wichtige - über denselben Gegenstand vorführen, die mir, da und dort zerstrent, und nirgends bisher sachgemäss berücksichtigt, erst nachträglich bekaunt geworden sind.

Nachdem Vorstehendes und der grösste Theil des Folgenden noch im Jahre 1877 niedergeschriebeu worden war, hatte Herr Romanes, mit welchem ich anf Grund unseres gemeinsamen Arbeitsfeldes in briefliche Correspondenz getreten war, die Güte, mir unaufgefordert einen Theil des Mannscripts einer neuen von ihm verfassten Abhandlung ${ }^{1}$ ) über die Locomotionscentren der Medusen zuzusenden. Darans schien hervorzugehen, dass wir uns über einen wichtigen Punkt nicht einigen könnten, nämlich darüber, ob, wie liomanes behauptet, in der liegel schon Abschneiden der Randkörper Bewegungslosigkeit der Toponeuren (Anrelia) herrorrufe oder, wie ich gefunden habe, erst Ansschneiden der Randkörper mit Úmgebung. Da sich unsere Befunde in dieser Beziehung räthselhafter Weise schroff und unvermittelt gegenüber standen, so entschloss ich mich, meine Arbeit nicht zu reröffent-

1) Der bald daranf in den Philos. Transact. Vol, 167 erschienenen Arbeit: „Further observations on the Locomotor System of Medusae. 
lichen, bis ich durch einige weitere Versuche womöglich heransgefunden hätte, welche Ursachen unserer Differenz zu Grunde liegen möchten. Sprach sich einerseits Romanes sehr bestimmt in seinem Sinne ans, so musste ich andererseits ebenso fest auf meinen Exfahrungen bestehen. Ich beschloss also mit der Veröffentlichung meiner Arbeit noch zn warten und setzte auf den Monat April 1878 einen Aufenthalt in Kỉel zum Zweck weiterer Untersuchungen fest. Kurz vor der Abreise klärte sich durch brieflichen Verkehr die Sache, indem sich die Meimmgsverschiedenheit als auf einem Missverständniss beruhend herausstellte: ich hatte, wenn ich von der Enternung des Randkörpers sprach, ein Abschneiden desselben an der Wurzel seines Stiels ${ }^{1}$ ) - ohne Verletzung des Gallertgewebes, welchem er ansitzt - im Auge und stellte diese Operation in Gegensatz zum Ausschneiden anch des ihn umgebenden Schirmrandstückes (contractile Zone); Romanes erklärte mir dagegen, dass er bei der Operation. die er als Entfernung des Randkörpers bezeichnet hat, jeweils anch ein Stück des Gewebes, welchem letzterer ansitzt, mit weggenommen hatte, während er sich, was den Begriff „contractile Zone“ angeht, im Gegensatze hiezı wörtlich an die von mir zum Zweck allgemeiner Orientirung znerst gegebene Beschreibung hielt, wie sie sogleich wiederholt werden wird. So ergab sich, dass wir thatsächlich unsere Resultate in diesem Pnnkte wohl als vereinbar ansehen durften.

Freilich hatte Romanes behauptet, dass sogar schon Zerstören der Otolithensäckehen in der Regel Lähmnng hervorrufe und dass daher in diesen der Sitz der lokomotorischen Nervencentren zn suchen sei. Diese Angabe des englischen Forschers dürfte somit nach jener Erklärung, welche er inzwischen anch öffentlich in seiner seitdem erschienenen zweiten Abhandlung in den Philosophical Transactions gegeben hat ${ }^{2}$ ), wohl selbstverständlich als nicht begründet hinwegfallen.

Trotz der Lösung der Differenz ging ich nach Kiel und habe dort während eines zehntägigen Aufenthalts noch einige physiologische und morphologische Beobachtungen gemacht, welche ich, da die betreffenden Abschnitte des Textes schon vorher geschrieben waren, diesem noch nachträglich beifügte unter besonderem Hinweis anf die Zeit ihrer Entstehung. Es wird sich zeigen, dass die Resultate von mir neu ausgeführter Operationen vor Allem in hohem Grade wichtig waren gerade für die Frage vom „Knicken“ der Thiere, d. i. vom lähmenden Erfolg des Ansschneidens von Stücken des Schirmrandes sammt Randkörper.

1) Ich unterscheide im Folgenden stets am Randkörper den oberen Theil oder Stiel und deu unteren oder das Krystall- oder Otolithensäckchen. Unter den von mir untersuchten Arten sind nur bei Cyanea capillata beide Abschnitte nicht deutlich auch in der äusseren Form von einander abgesetzt.

2) a. a. O. Vol. 167, S. 750. 
Das Gewebe in der Ungebung des Randliörperansatzes, dessen Ausschneiden jene Lähmung hervorruft, habe ich in meinem Anfsatz „Ueber künstliche Theilharkeit von Aurelia aurita und Cyanea capillata“ als contractile Zonen bezeichet. Nach meinen damaligen Beobachtungen schilderte ich diese bei Aurelia aurita als „nur wenige Hillimeter breite Gewehszonem, welche in ihrer Lüngenansdehnung die Ungrenzung des halbkreisförmigen, je ein liandkörperchen bergenden (kand-) Ausschnittes bilden " $\left.{ }^{2}\right)$. Es muss zur richtigen Beurtheilung des Folgeuden hervorgehoben werden, es solle diese Beschreibung nicht etwa so gemeint sein, als ob ich unter "contractiler Zone" einen morphologiseh scharf umgrenzten Bezirk verstehe. Ich verstehe darunter eben nur jene Gebiete der Umbrella in der Gegend des Ansatzes der Randkörper, welche durch so grossen Reichthum an Nervenzellen ausgezeichnet sind, dass ihre Eutfernung gewöhnlich länger danernde oder absolute Bewegungslosigkeit der Medusen zur Folge hat. Da aber diese Nervenzellen nur allnälig nach allen Richtungen hin spärlicher werden, so ist eine scharfe Grenze für die contractile Zone nicht festzustellen. Die im Folgenden mitzutheilenden neuerdings von mir beobachteten Thatsachen werden aber auch eine ausserordentlich grosse ind ividuelle Verschiedenheit der Thiere im Verhalten gegenüber dem in Frage stehenden operativen Eingriffe nachweisen: sie werdeu zeigen, dass jenes früher angegebene Mass der Länge und Breite der contractilen Zone durchans nicht für alle Falle, selbst mer Voraussetzung gleichgrosser T'hiere gilt, dass vielmehr manchen nur ein kleinstes Stückchen des Gewebes, welchem die Wurzel des Randkörperstieles ansitzt, weggenommen zu werden braucht, $1 \mathrm{~m}$ länger danernde Lähmung hervorzurnfen, wälrend anderen grosse Stücke desselben ansgeschnitten werden müssen, wem Dasselbe erreicht werden soll, wieder andere aber die bedeutendsten Verstümmelungen ertragen. Höchst Bemerkenswerthes im letzteren Sinne führten mir gerade die Kieler Versuche vor Augen. Sie bestätigten vollauf meine Ansicht, dass die Raudkörper allein für die Leitung der rhythmischen Contractionen nicht massgebend seien.

1) Würzb. Verh. N. F. Vl. Bd. S. 138. Zoolog. Unters. S. 46. 


\section{THEIL.}

\section{PHYSIOLOGISCHE BEOBACHTUNGEN UND VERSUCHE.}




\section{Die vier Grundversuche.}

Erster Versuch. Die Grundlage aller meiner späteren Versuehe und damit aller im Folgenden mitgetheilten physiologischen Thatsachen bildete die am 5. September 1873 von mir gemachte Beobachtung ${ }^{1}$ ), dass sich ein Randstückchen einer Aurelia anrita, welches ich im Zusammenhang mit einem Randkörper ausgeselnitten hatte, anf das Lebhafteste rhythmisch contrahirte, ählich dem herausgelösten Herzen eines Frosches.

Zweiter Versuch. Durch allmäliges Verkleinern dieses Stückchens und schliesslich durch Herausschneiden des Randkörpers selbst liess sich feststellen, dass die rhythmischen Contractionen ausgingen von der Gegend des Ansatzes des letzteren an den Sehirmrand, genaner: von einer nur wenige Millimeter breiten Gewebszone, welche in ihrer Längenausdehnung die Umgrenzung des halbkreisförmigen, je ein handkörperchen hergenden $\Lambda$ nsschnittes bildet. Denn alle diejenigen Abschnitte des Stückchens, welche nicht mit jenerGewebszone in Zusammenhang waren, erschienen regungslos; ebenso alle anderen aus gleichviel welchem Theile des Mednsenkörpers ausgesehnitenen Stücke, die dieses Zusammenhangs entbeh te te n.

Jene in der Zahl von acht an Schirmrand vorhandenen wichtigen Bezirke belegte ich mit dem Namen der contractilen Zonen.

Dritter Versuch. Sehnitt ich einer Meduse alle acht contractilen Zonen aus, so vermochte sich dieselbe unmittelbar nach der Operationgar nicht mehr zu contrahiren, war nnbeweglich, wie todt.

1) Vergl, „Ueber künstliche Theilbarkeit von Aurelia aurita etc. a. a. 0. 1874. 
Vierter Versuch. Wurden einer Aurelia alle contractilenZonen mit Ausnahme einer einzigen ausgeschnitten, so contrahirte sich das Thier wie vorher.

Aehnliche Experimente an Cyanea capillata hatten dieselben Erscheinungen zur Folge und gilt dies anch für alle wesentlichen der weiterhin mitzutheilenden Thatsachen.

Der ans diesen Experimenten von mir gefolgerte Hauptsatz lantete: Die rhythmischen Contractionen der toponemen Medusen werden angeregt von den contractilen Zonen.

Die Beobachtung der Bewegungen des normalen, unverletzten Thieres zeigte in der That, dass die Znsammenziehnngen des Schirmes von der Gegend der liandkörper ausgehen.

Es sei gleich hier bemerkt, dass eine Betheiligung der Raudkörper selbst an der Anregung der rhythmischen Contractionen durch die erwähnten Versuche nieht ausgeschlossen wird. Diese Versuche berücksichtigen nicht, ob die Zahl der in der Zeiteinheit ansgeführten Contractionen, sowie deren Kraft, durch das Wegschneiden der Randkürper allein nicht verringert worden ist. In der That bin ich, wie sich aus dem Folgenden ergeben wird, der Ansicht, dass die Randkörper bei jener Anregung mit betheiligt sind.

lndem ich die vier Grundversuche an sich genaner in ilnen einzelnen Wirkungen verfolgte und zur Grundlage weiterer Experimente, sowie von Beobachtungen über die Bewegungserscheinungen des unverletzten Thieres nahm, erhielt ich für die Erklärung der letzteren, sowie für die Vorstellung von der wahrscheinlichen Gestaltung des Nervensystems zahlreiche sichere Anhaltspunkte. Im Folgenden schicke ich die Hauptsätze vorans, welche sich mir in ersterer Beziehung ergeben haben.

\section{Von den normalen Bewegungen des unverletzten Thieres.}

Die Zusammenziehungen des Medusenschirmes sind nicht, wie man wohl ziemlich allgemein bisher angenommen hat, aussehliesslich willkürliche, sie werden vielmehr, gleich nuseren Athemzügen, gewöhnlich unwillkürlich ansgeführt, künnen jedoch, wie diese, unter die Herrschaft des Willens gebracht werden.

Dazu muss von vornherein ausdrücklich bemerkt werden, dass ich beim Gebrauch der Bezeichnungen "willkürlich" und „unwillkürlich" durchaus nicht an principiell verschiedene, stets absolıt anseinanderzuhaltende Erscheinungen denke. „Unwillkürliche und willkürliche Thätigkeit sind nicht principiell, sonderu nur insofern verschieden, als die letztere ein Sammeln, Aufspeichern von Eindrücken in einem gemeinsamen 
Organ (Gehim) und die Möglichkeit einer Wechselwirkung derselben voranssetzt" habe ich bei Gelegenheit der Erörterung derselben Frage in meiner Beroë-Arbeit bemerkt ') und erlaube ich mir betreffs specieller Motivirung dieses Satzes auf die weiteren dort gemachten Aeusserungen hinzuweisen.

Das Nächstliegende war es wohl anch, dass man die Bewegungen der Medusen für willkürliche erklärte. Man vergleiche in dieser Beziehnng den später zu besprechenden Aufsatz von Metten heime $\mathbf{r}^{2}$ ) Spallanzani ${ }^{3}$ ) neigt dazu hin, dieselben für unwillkiirliche zu halten, ist jedoch zweifelhaft, weil er auch solche sieht, die er für willkïrliche erkennen zu müssen glaubt. Romanes ${ }^{4}$ ) nimmt aber, in Gegensatz zu meiner Aeusserung an, dass man die Bewegungen unserer Thiere gewöhulich für unwillkürliche halte. Er sagt: „It may not be so generally known, however, that these swimming-movements, although ordinarly rhythmical, are, at any rate in the case of some species, to a limited extend voluntary, using the latter term in the same sense as it is applicable to invertebrated animals in general". - Denn - fügt er hinzu - sie beschleunigen ihre Bewegung auf leichten Reiz und die Beschleunigung dauert tort, auch nachdem der Reiz aufgehört hat. - Auf desshalb an Romanes gerichtete briefliche Anfrage erwidert er mir, dass die von ihm ausgesprochene Auffassung sicherlich in England die allgemeine sei: „so much, that I have justingly deemed of anthropomorphism for maintaining that these movements are partly voluntary" und verweist auf Carpenter's Comparative Physiology, 4. Auflage, Seite 656: "It is considered by Prof. Agassiz that the movements of these Acalephae (i.e. Sarsia) are voluntary and exhibit a "purpose"; but his statements on this subject exhibit a very strong confusion of ideas; and the Author (i. e. Carpenter), is assured by Mr. H uxley that he has never seen the slightest evidence of anything beyond "automatic" action in these animals".

Die Zusammenziehungen finden bei Tag beständig statt und ruhen ebensowenig bei Nacht. Sie bestehen fort auch wenn die Thiere sich nicht von der Stelle bewegen; in diesem Falle zeigen sie oft eine ausserordentliche Regelmässigkeit und geschehen dann wohl wesentlich umwillkürlich.

Die unwillkülichen Contractionen sind reine Erü̈hrungsbewegungen, d. h. sie dienen in erster Linie der Athmung, führen aber auch mit dem Wasser Nahrungsmittel in den Magen ein.

Gä $\left.\mathrm{de}^{8}\right)$ nahm an, dass die Contractionen des Schirmes Wasser in die von ihm beschriebenen Athemhöhlen (4 Säcke, welche unter den 4 Mägen liegen sollen. Aurelia.) hinein und wieder herauspumpen, durch eine besondere Oeftnung, welche am Boden jeder Athemhühle liegen soll - und dass sie auf diese Weise der Athmung dienen. $\mathrm{Oken}^{6}$ ) sagt dazu: „Ob sie (die Siicke) wirklich zum Athmen dienen und ob die Zusammenzielhungen der Quallen Athembewegungen sind, ist übrigens sehr zweifelhaft". An einer anderen Stelle $^{7}$ ) meint er, man habe vielleicht den Schirmrand mit seinen vielen Gefüssverästelungen für das Athemorgan zu halten. - Der Gedanke, dass die Contractionen der Medusen mit der Athmung zusammenzubringen seien, wird naturgemäss sehr früh auftreten. Es wäre wunderbar, wenn Aristoteles, wie Gäde citirt, geglaubt hätte, dass die Medusen ohne den Respirationsprocess lebteu. Die bezügliche Stelle ${ }^{8}$ ) lautet:

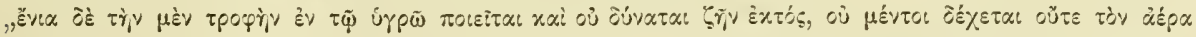

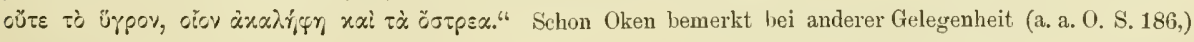
1) S. 80 .
2) Metten heimer: Archiv f. Anat. u. Physiol. 1862.
3) Spallanzani: Viaggi alle due Sicilie T. III. Milano 1826.
4) Transact. of the Roy. Soc. Vol. 166. S. 271 u. 272.
5) Gäde: Beitrïge zur Anatomie und Physiologie der Medusen. Berlin 1816.
b) Oken: Allgemeine Naturgeschichte. V. Band. I. Alth. S. 238.
7) ebenda S. 215.
8) Aristoteles: Histor. animal. I. Cap. I, 6. 
dass Aristoteles unter dem Namen "Acalephae" nirgends mit Sicherheit die Quallen versteht. Das Wort ist denu auch im speciellen Falle in der Ausgabe von Aubert und Wimmer mit "Seeanonone" ibersetzt. Ganz im Gegensatz zu Giide's Auffassnng besteht die Thatsache, dass man schon zu Aristoteles Zeiten, wie auch später (man vergleiche die im Folgenden besprochene Arheit von Macri), die Medusen als "Lungen" he-

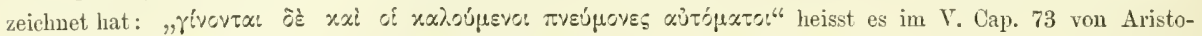
teles Thiergeschichte. - Sehr consequent behandelt, wie noch näher berährt werden soll, Tilesius ${ }^{1}$ ) die Contractionen der Medusen als Respirationsbewegungen.

Das Thier arbeitet so nach Art einer. Saugpumpe, welche zum Zweck der Ernährung beständig in 'Thätigkeit ist.

Der dänische Name für Quallen: „Vaudstappers", Wassersauger, würde, in diesem aktiven Sinne rerstanden, ein vorziiglicher sein und mehr hesagen als die deutsche Bezeichnung, welche die Folge des Aufsaugens für das Volnmen des Körpers, das "Gequollensein" der Körpersubstanz andentet.

Die nnwilkürlichencontractionen folgen sich nnter ül,rigens gleichen Verhältuissen beim ruhigim Wassersehwebenden Thiere in regalmässigem th hy hm $\mathrm{m}$, oft so regelmässig, dass man im Stande ist, ilnnen während längerer Zeit zählend zı folgen, ohne das Thier anzusehen, nachdem man sich einmal die Grösse des je zwischen ihrer zwei gelegenen Zeitintervalls gemerkt hat. Sie setzen von Zeit zu Zeit einen Angenblick aus. Die Zeit des Eintritts mol die Daner dieser Pausen sind einer gewissen liegel unterworfen: je einer bestimmten Anzahl gleich rascher und gleich starkes Contractionen folgt gewöhnlich eine Punse von annäherud derselben Daner. Auch ohne dass das Thier sich von del Stelle bewegt, tritt nämlich hänfig eine zeitweilige Beschleunigung oder Verlangsamung der Contractionen ein und entsprechend der eben ansgesprochenen Regel ist erstere häufig damn zu beobachten, wemn sehr lange Pansen vorangegangen sind - ganz ebenso wie langem Anhalten unserer Athemzüge eine Anzahl rascher und kräftiger derselben zu folgen pflegt. Indessen fügen sich die Thatsachen schon desshall, nicht einem bestimmten Gesetze, weil einer der massgebenden Faktoren, die Stärke der Contractionen nicht leicht berechenbar ist, vorzugsweise aber desshalb, weil das, was etwa reine Reflexbewegung ist, von dem Willkürlichen nicht absolut untersehieden und getrennt werden kans.

Die Zusammenziehugen treten deutlich unter die Herrschaft dep̣s Willens sobald las Thier Ortsveränderungen vornimmt. Sie können dam nicht nu beschleunigt oder verlangsamt, sondern, wie weiterhin besprochen werden soll, anch sonst in manchfacher Weise modificirt werden.

Die Athembewegungen erfolgen nicht bei allen Thieren al-

1) T'ilesi us: Beiträge zur Naturgeschichte der Medusen, N. Acta Leop. Carol. XV. 1831. 
selben Art gleich oft in der Zeiteinheit, vielmehr steht ihre Zahl in $11 \mathrm{mg}$ gekehrtem Verhältuiss zu ihrer Grösse.

Dasselbe gilt fïl die Ortsbewegungen.

Schon die Beobachtung des mnverletzten 'Thier'es lehrt, wie bemerkt, dass die Contractionen des Schirmes von dessen Rand und zwar speciell von der nnmittelbaren Umgebung der Randkörper ansgehen. Bei Aurelia aurita, wo jeder Randkörper in einem Auschnitte des Schirmrandes liegt, lässt sich dentlich wahrnehmen, dass die Ränder dieses Ausschnittes sich bei jeder Contraction nähern. Mag die Ursache dieses Verhaltens mun anch theilweise als eine Folge des geringeren Widerstandes aufgefasst werden kömnen, der in der Richtung der Bewegung der Ränder vorhanden ist, so lässt sich doch direkt erkennen, dass der Schirm in jener Gegend überhaupt zuerst Erregung zeigt. Ferner beobachtet man deutlich, dass nicht immer der ganze Schirurand sich anf einmal zusammenzieht, d. i. dass nicht immer alle contractilen Zonen gleichzeitig in Thätigkeit treten, sondern dass eine Contraction vielmehr zuweilen zunächst von einer einzigen oder zugleich von nur einigen nebeneinanderliegenden Zonen ausgeht und sich blitzsehnell anf die übrigen fortpflanzt. Diese letzteren folgen dann entweder alle zusamınen gleichzeitig der ersten oder der Reihe nach, so dass sich, wenn die Uebertragung z. B. von links nach rechts geschieht, in zweiter Linie jene Zone contrahirt. welche von der zuerst thätigen ummittelbar nach rechts gelegen ist, sodann die nächste nach rechts gelegene und so fort; demmach trägt sich die Contraction ungemein rasch von Zone zu Zone über.

Es können somit die Contractionen des Schirmes wohl nach Belieben des Thieres von einem oder von mehreren Antimeren oder. von allen gleichzeitig ihren Ausgangspunkt nehmen.

Unter Antimeren oder StrahIstücken sind die acht Theilstücke des Thieres verstanden, welche begrenzt werden durch ebensoviele, in gleicher Entfernung zwischen je zwei Randkörpern den Schirmrand schneidende Interradien. Somit trägt jeder Antimer in der Nitte seines unteren Randes, welcher einem $\mathrm{Ab}$ schnitt des natïrlichen Schirmrandes entspricht, einen Randkörper.

Dagegen kaun die Zusammenziehung einer contractilen Zone, soviel ich beobachtet habe, niemals stattfinden ohne gleichzeitige oder annähernd gleichzeitige Thätigkeit aller übrigen. Denu stets contrahiren sich alle Zonen entweder synchronisch oder in blitzschneller Folge niemals folgt eine den andern erheblich nach oder setzt gar aus.

Die Fähigkeit der Meduse, willkürlich die Zeitfolge der Zusammenziehung der acht Antimeredes Körpers zu bestimmen und nicht minder das Vermögen, ein Antimeroder einebeliebige Anzahl solcher 
stärker zu contrahiren als die übrigen, bedingt die Möglichkeit manchfachsten Wechsels in der Richtung der Ortsbewegungen - vermittelt das Steuern des 'Thieres.

Contrahirt sich z. B. eine contractile Zone nach der andern in rascher Folge in der Richtung von links wach rechts, so wird eine Drehung des Thieres in entgegengesetzter Richtung durch den Rïckstoss des Wassers stattfinden müssen. Contrahiren sich die Antimere der einen Seite des Schirms stärker als die der anderen, so wird eine seitliche Ortsberegung die Folge sein u. s. w.

In der Nummer der Zeitschrift "Nature" vom 19. Juli 1877 erzïhlt Frl. E. Law less eine Beobachtung an einer Aurelia, welche die Filhigkeit des Steuerns bei diesem 'Thiere in das bellste Licht setzt: Die Aurelia ward bestädig von einem kleinen 1 bis 1 1/2 Zoll langen Fisch begleitet, der unter ihrem Schirme schwamm. Zuweilen nun drehte sich die Meduse durch ibre Pulsationen, um den Schirm umzukelnen, worauf der Fisch schnell herausschwamm. Aber kaum hatte sich die Anrelia wieder aufgerichtet, als el wieder unter den Schirm zurückkehrte. - Mit Bezug auf diese Leobachtung mag hier die folgende, Cyanea capillata betreffende, Enzählung Platz finden, welche Oken (a. a. O. S. 250) nach Baster, (Opuscula If. 1762. S. 60) wiedergilht: „Die hollindischen Fischer, welche im deutschen Jeere an den jütlündischen Kïsten Fische fangen, sehen im Sommer, bei heiterern Wetter und ruhigem Meere, eine Menge dieser Quallen nud nicht selten welche, die 2 Fuss breit sind. Sonderbar ist es aber, wie alle einstimmig bezengen, dass unter diesen Schrärmen von Medusen eine ungeheure Menge kleiner Fische, besonders Dorsche, Kabeliaue, Sehellfische. Kohlenfische, Lenge u. dgl, schwimmeu und sich gleichsam dazwischen verbergen, um der Raubsucht der grösseren Fische $z u$ entgehen; dies thun sie so lange bis sie etwa fingerslang und hurtig genug sind $u m$ sich durch Schwimmen zu retten."

Romanes meint, es sei das sich Nähern der Ränder der Randkörperausscbnitte während der Contraction eintach die Folge des Mangels ron Widerstand zwischen ibnen, gegenüber dem Druck des beiderseits von ihnen gelegenen sich znsammenziehenden Gewebes "). Theilweise ist dies unzweifelhaft richtig - inwieweit, das möchte erst ein Controlerersuch zeigen, der darin bestande, dass man etwa in der Mitte zwischen je zwei Randkörperu kleine Stückehen Gewehe aus dem Rande ausschnitte und nun das Verhalten der Mundränder während der Contractionen beoliachtete. Schon der Verlauf der Muskelelemente bei manchen Medusen zeigt aber, welche Bedeutung die Umgebung der Randkörper gegenüber den übrigen Bezirken des Schirmes für die Contractionen hat: bei Cassiopea z. B. strahlen dieselben geradezu radiür von einem der Raudkörperwurzel gegenüber gelegenen Punkte der Unterseite des letzteren aus. Im Centrum, ron welchem die Ausstrahlung ausgeht, liegt ein ovales, über die übrige Oberfläche hervorragendes, muskelfreies Kinnöpfchen. Ein ähnliches Ausstrahlen der Muskulatur von einem Punkte aus an derselben Stelle finde ich nachträglich bei $\mathrm{Huxley}$ von Cephea ocellata abgebildet in seinem Manual of the Anatomy of Invertebrated Animals, 1877, S. 137. Fig. 20 U. (Seite 25 der Uelsersetzung ron Spengel). Huxley bezeichnet das línöpfchen, von welchem die Ausstrahlnng ausgeht, als „ovale Platte."

Abgesehen von der direkten Beobachtung liegen die Beweise für die anfgestellten sätze einmal in der Art der Wirkung gewisser operativer Eingriffe auf die Thiere und dann - was speciell die Dentung der rhythmischen Contractionen als Athembewegungen angeht - in dem Einthuss des Sanerstofimangels auf dieselben. lch werde zunächst nun die letzte Frage bebandeln und dann erst übergeben zur

1) Philos. Transact. Vol. 166. S. 310. 
Darstellung ron Experimenten, welche ich zugleich zum Zweek der Feststellung der Topographie des Nervensystems gemacht habe.

\section{Einfluss von Sauerstoffmangel auf die Bewegungen der Medusen.}

Der Einflnss von Sanerstoffmangel anf die Bewegungen zeigt sich am Einfachsten in den Veränderungen, welche diese erleiden, wenn die Thiere zu lange Zeit in derselben geringen Quantitat Wassers in der Gefangenschaft gehalten worden sind, in Wasser also, dessen Sanerstoffgehalt durch ihr Athmen verringert ist. Diese Veränderungen sind so gross, dass insbesondere bei der Beurtheilung und Verwerthung aller operativen Versuche die grösste Anfmerksamkeit anf häufige und regelmässige Ernenerung des Wassers verwendet werden muss.

In nicht gehörig ernenertem Wasser werden die Contractionen nnregelmässig: es treten znweilen grosse Pausen zwischen zweien derselben auf und einer solchen Pause folgen dann raseh nach einander oft zahlreiche hastige kurze Zusammenziehungen, dies um so ansgesprochener, je mehr verdorben das Wasser ist. Zuletzt liegen die Thiere oder deren Theilstücke viertelstundenlang und länger unbeweglich, anscheinend todt, bis der Beobachter wieder plötzlich durch eine oder oft durch 5 oder 6 hastig nacheinander folgende kurze Contractionen überrascht wird.

Die Zahl der Contractionen, welche in solch verbranchtem Wasser in der Zeiteinheit gemacht wird, ist bald grösser als beim frischen Thiere, bald wieder viel kleiner. In jenen Fallen geschielıt die Vermehrung der Contractionen angenscheinlich anf Kosten von deren Stärke; es haudelt sich dabei offenbar um jene hastigen, krampfluften Athemzüge, wie sie in Folge der Athemnoth anch bei den höheren Thieren sich zeigen.

Diese Athemnoth wird sofort nach Ersatz des alten Wassers durch frisches gehoben: wie mit einem Schlage tritt mun meist wieder Regelmässigkeit in den Contractionen ein. Stücke von Aurelien, welche todt scheinen, indem sich während langer Zeit der Beobachtung keine Spur von Contraction meln an ihnen zeigen will, erwachen sofort nach Ernenerung des Wassers zu nenem Leben.

Alle diese Thatsachen lassen sich nur erklüren durch die Annahme, dass die Contractioneı der Quallen in erster Linie Athemberegungen sind. 


\section{Operative Versuche zum Zweck der Feststellung der Ausgangspunkte der rhythmischen Contractionen und damit der Nervencentren.}

Unter den als die Grundversuche aufgeführten Experimenten bedürfen zunächst jene einer genaueren Erlänterung in Beziehnng auf die vorliegende Frage, nach welchen 1) ein mit einem Randkörper versehenes, ans dem Thiere ausgeschnittenes Gewebsstückchen sich rhythmisch zu contrahiren fortfährt, während die 2) von diesem Stückchen losgetreunten Abschnitte, welche mit dem Randkörper nicht mehr in Zusammenhang stehen, bewegungslos erscheinen.

Als Beispiel wählen wir einen besonteren Fall: wir schneiden einen Antimer aus einer Aurelia aus, beobachten die Wirkung und beginnen daranf das Theilstück zu verkleinern.

Unmittelbar nach der Operation setzt der Antimer sowohl wie der übrige Rest der Meduse die Zusammenziehungen gewöhnlich einige Angenblicke ans — offenbar eine Periode der Bestürzung, besser: eine kurzandauernde Lähmung, welche Folge ist des Eingriffs in das Nervensystem (Nervenchoc, Nervenschlag) und welche, wie aus dem Folgenden hervorgehen wird, nach jeder eingreifenderen Verletzung des Thieres zn constatiren ist. - Schneidet man num von dem Antimer (A Fig. 1)

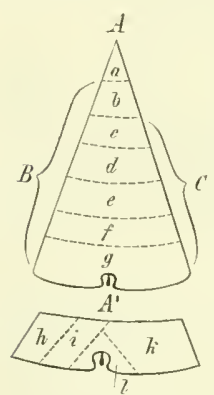

Holzschnitt 1. etwa das Stück a weg, so erscheint dieses bewegungslos, während der Rest B sich rhythmisch weiter contrahirt, schneidet man von $B$ anch $b a b$, so wird dies ebenfalls bewegungslos, während cler liest (' sich weiter contrahirt; fährt man so fort bis g, so bleibt schliesslich unr dieses rhythmischer Contractionen făhig und beginnt man weiter anch diesen Theil zu verkleinern $\left(A^{1}\right)$, so dass man zuerst etwa $h$, damm $i$, dann $k$ abschneidet, so zieht sich zuletzt nur noch 1 rhythmisch zusanmen - alle anderen Theile erscheinen jetzt wie todt und sterben allmälig ab, sind der Anflösung anheimgefallen zu einer Zeit, da l noch munter weiter lebt.

Aber es lässt sich selbst das Stïckchen 1 mit demselben Erfolg noch weiter verkleinern: so lange als nur ein kleinster Rest von Gewebe im Unfange des Randkörpers übrig, mit diesem in Verbindung bleibt, kann die Möglichkeit rhythmischer Contractionen gegeben sein.

Solche kleine, mit dem Randkörper zusammenhïngende Gewebsstückchen sah ich noch nach Tagen sich auf das Lebhafteste zusammenziehen - selbst als ich deren eimnal anf einem Teller zufaillig hatte liegen lassen, in so wenig Seewasser, dass dessen Boden kaum damit bedeckt war, saln ich sie am anderen Tage noch kräftige rhythmische Contractionen ausführen. 
Schneidet man an einer Amrelia einen Randkörper mit der contractilen Zone ans - ich will in Znkunft diese Operation, entsprechend dem Verfahren des Einstechens in eine bestimmte Stelle der medulla oblongata der Wirbelthiere, welches den sofortigen Tod derselben zufolge liat, als "Linicken“ bezeichnen und spreche von dem Knicken eines, zweier . . . acht Antimere, je nachdem ich an einer Mednse eine, zwei .... acht contractile Zonen exstirpire - knickt man also an einer Meduse ein Antimer, so finden, wie nach dem vierten Grundversuche selbstverständlich ist, die Contractionen des Thieres ganz wie vorher statt - natürlich erst nach Ueberwinclen der soeben besprochenen Bestürungsperiode. Was aher auffällt, das ist die Thatsache, dass sich jetzt auch der geknickte Antimer contrahirt und zwar hervorragend dentlich $\mathrm{im}$ freien Rande. Genane Beobachtung zeigt jedoch, dass die Contractionen desselben nicht selbständige sein können, dass sie vielmehr von den mangetasteten contractilen Zonen der übrigen Antimere fortgeleitete sein müssen, denn sie breiten sich augenseheinlich von den letzteren her auf iḥn ans und treten oft sichtbar erst um ein Ninimum später auf, als die der unberührten Antimere. Deutlicher war diese Erseheinung, nachdem ich statt eines zwei und mehr, am deutlichsten, nachdem ich alle Antimere mit Ausnahme eines einzigen geknickt hatte: jetzt ging jecle Contraction von der Stelle des Randes aus, an welcher der liandkörper noch vorhanden war und verbreitete sich von hier über den übrigen Theil des Randes und über das ganze 'Thier, und die Zusammenziehung der verstümmelten lianftheile schleppte sichtlich derjenigen des unberührten Antimers etwas nach, so zwar, dass sie am spätesten an der dem letzteren gegenüberliegenden Stelle erschien.

Nach Kinicken anch des letzten Antimers hörten - wie der dritte Grundversuch es erwarten lässt - die Znsammenziehmigen des Thieres plötzlich anf, die Gallertscheibe breitete sich flach im Wasser ans und stieg in dieser Haltung langsim und willenlos nach ohen, bis sie nnter der Obertläche des Wassers wie todt liegen blieb.

Cyanea sinkt dagegen nach dem Ausschneiden der Randlappen. Als Ursache dieses Verhaltens glaubte ich schon 1873 die Schwere der Fangfiden in Betracht ziehen zu sollen. Nenerdings (1878) in Kiel angestellte Versuche schienen diese Auffassung zu bestïtigen, während sie das an Aurelia früher erzielte Resultat modificirt haben. Die frühereu Versuche waren an kleinen in der Gefangenschaft gehaltenen Exemplaren von Aurelia und Cyanea angestellt und war die Operation jeweils ausserhalb des Wassers vorgenommen worden. Die neuen Versuche machte ich an grossen (20 und mehr $\mathrm{cm}$ im Durchmesser haltenden) Thieren in der freien See vom Boote aus, um alle Fehler zu vermeiden in der Weise, dass ich die Mledusen nicht ans dem Mleere heraus nahm. Ich fuhr irgend einem lebhaft schwimmenden Thiere mit dem Boote wahe und operirte es in der See, während ich es durch einen Gehülfeu unter Wasser halten liess oder indem ich es anf der Fläche der linken Hand im Wasser hielt und mit der rechten Hand, mit Hülfe der 
Scheere, die contractilen Zonen ausschnitt. Nur so mochte vermieden werden, dass etwa kleine Lnftblasen an der operirten Meduse hängen llieben und deren speeifisches Gewicht veränderten.

Der Erfolg dieses Verfahrens war nun der folgende: Cyanea capillata sank regelmaissig nach dem Ausschneiden der Randlappen, wenn sie im Uebrigen intakt belassen wulde, langsam zu Boden und blieb auf dem Heeresgrunde liegen. Wurden ihr aber zugleich die Fangfäden abgeschnitten, so stieg sie an die Oberfläche des Meeres - so in etwa sechs, bezw. zwölf Versuchen. Dies war also in Uebereinstimmung mit meinen frïheren Beobachtungen und mit der Annahme, dass die Schwere der Fangfäden die Ursache des Sinkens sei. Dagegen stieg Aurelia anrita nach der Operation zwar häufig an die Oberfäche, in anderen Fällen aber sank sie auf den Meeresgrund, ohne dass ich dieses versehiedene Verhalten durch irgend eine bemerkbare Ursache zu erklïren im Stande war. Znweilen sanken die Thiere zuerst und schienen dann, ohne dass sie vorher eine Contraction gemacht hatten. wieder zu steigen; andere stiegen zuerst und sanken später, nnd wieder andere sehwebten lange Zeit auf derselben Stelle im Wasser, als ob ihr specifisches Gewicht demjenigen des Wassers gleich wïre. Da dieses Verhältniss nicht ganz, aber doch nahezu zutreffen wird, so müssen die geringfügigsten Ursachen jenes ver'schiedene Verhalten bedingen. Ich werde später auf diese Frage zuritickkommen.

In IVesentlichen wiederholten sich dieselben Erscheinnngen, so oft ich einer Anrelia alle acht Antimere geknickt hatte. Aber ich bemerkte zngleich, es sei die Bellegungslosigkeit an dem verstümmelten Thiere nicht immer bleibend, vielmehr zejgten sich an ihm nach einiger Zeit häufig einige unregelmässige und wirkungslose, schwache Contractionen, welche mehr lokaler Natur sind, und meist bald anfhörten, zuweilen aber am folgenden Tage verstärkt beobachtet wurden — eine Erscheinung, welche, wie wir sehen werden, meine neneren V'ersuche genaner verfolgt haben, mit dem Resultate, dass sie sich zn kräftigen rhytbmischen Contractionen steigern kann.

Reize, z. B. Stiche in die sämmtlicher contractiler Zonen beraubte Qnalle regen in der ersten Zeit nach der Operation die geschilderten mangelhaften Contractionsversuche gleichfalls au.

Lässt man dem Thiere anch nm eine contractile Kone, so scheint, wie der vierte Grundversuch es anch erwarten lässt, seine absolnte Lebensfähigkeit in keiner Weise alterirt zu sein: noch nach Tagen schwimmt dasselbe mnnter umher wie ein ganz gesundes. Die Thiere dagegen, welchen sämmtliche Antimeregekniekt worden sind, sterben allmäig ab, beginnen weiss, undurchsichtigz zu werden und sind längst anfgelöst zn einer Zeit, da nicht gekniekte Controlethiere, die in demselben Wasser mit ihnen gehalten worden sind, noch vollkommen lebenslustig umbersch w im me

Diese Experimente beweisen eimmal, dass die rhythmischen Contractionen unserer Medusen vou den contractilen Zonen ansgehen und ferner erhärten sie die schon auf Grund der vier ersten Versuche ausgesprochene Vermuthung von dem Vorhandensein eimes centralen Aprrarates je in cler Nähe der Randkörper. In letzterer Beziehung stellt sich nur noch die Frage: sind es wicht die Randkörper selhst, in 
welchen der Centralapparat des Nervensystems zu suchen ist, der nun erst mittelbar die entsprechende contractile Zone und damit die Contractionen des Schirmes anregt? Schon gelegentlich meines ersten Besuchs der Ostsee zum Zwecke der Behandlung des Themas bin ich der Lösung dieser Frage näher getreten, indem ich einzelnen Thieren und Strahlstücken die Randkörper an der Wurzel der Stiele ${ }^{1}$ ) ohne Verletzung der contractilen Zonen - abgeschnitten habe. Das Resultat war, wie ich in meiner ersten Abhandlung mittheilte ${ }^{2}$ ), dies, dass die Thiere nach der Uperation augenscheinlich bestürt waren, indem sie die Contractionen für einige Sekunden aussetzten, worauf sie jedoch wieder anfingen sich regelmässig zusammenzuziehen. Die Wiederholnng und ausgedehntere Verfolgung der bezüglichen Versuche zeigte mir aber schon im darauffolgenden Jahre (1874), dass die Zerstörung der Randkörper, ja schon das Einstechen in eine bestimmte Stelle des Randkörperstiels, tiefgreifendere Wirkung haben kann und werde ich die bezüglichen Ergebnisse in einem besonderen, dem Zerstören der liandkörper gewidmeten Abschnitte ausführlich behandeln.

\section{v. Halbiren, Viertheilen und Achttheilen von Aurelia und Cyanea.}

Das Ergebniss, welches diese Operationen liefern werden, lässt sich schon aus dem Mitgetheilten mit Sicherheit construiren - nichtsdestoweniger ist seine gesonderte Behandlung schon wegen des, ich möchte sagen popmlären Interesses, das es bietet, sodamn wegen der allgemeinen sich daran knïpfenden Fragen wohl angezeigt.

Halbirt, vier theilt oder acht theilt man eine Aurelia oder Cyanea durch in den Interradien geführte Schnitte, so class jedes Theilstück entweder vier oder zwei orler einen Randkörper enthält, so contrahiren sich die 'Theilstücke lebhaft rhythmisch weiter'. Unmittelbar nach der Operation zeigen dieselben zwar die geschilderte Bestürzung, bezw. Lähnung (Nervensehlag), dann beginnen die Contractionen wieder, zuerst meist schwach und unregehnässig, bald aber kräftig und regelmässig, wie am ımverletzten Thiere. - Geschah das Halbiren an kleinen Aurelien, so sanken sie nach der Operation zuerst zu Boden, erhoben sich aber bald wieder, sanken vielleicht nach einiger Zeit abermals vorübergehend, während sie zngleich umregelmässige Contractionen machten, schwammen aber am folgenden Tage munter umher wie das

1) Vergl. die Einleitung, seite 13 .

2) Ueber künstl. Theilbarkeit von Aurelia und Cyanea. Würzb. Verh. a. a. O. S. 156 Anmkg. - Zoolog. Cnters. S. $6+$ Anmkg. 
unverletzte Thier dies gethan hatte, wobei die Schirmhälfte wieder, so gut dies eben gehen wollte, zur Glockenform zusammengezogen war.

Grosse Aurelien erschienen durch die Halbirung noch viel weniger gestört als kleine: sie setzten unmittelbar nach der Theilung die Contractionen einen Angenblick aus, schwammen aber damn munter und kräftig umher, als ob nichts mit ihnen geschehen wäre. - Die Viertheile - Zwillinge, wie ich sie nenne, weil jeder derselben, aus zwei Antimeren zusammengesetzt ist - die Zwillinge grosser Individuen vermögen sich noch frei im Wasser zu erhalten und zu bewegen, auch haben sie sich, ebenso wie die Hälften, nach kürzerer oder längerer Zeit, so viel wie möglich, zur Glockenform wieder zusammengezogen, wodurch ilnen das Schwimmen erleichtert wird. Die Achttheile (Einzel-Antimere) dagegen sinken gewöhnlich sogleich nach der Operation zu Boden und contrahiren sich dort fort.

Alle Theilstücke leben tagelang sellsständig weiter.

Aus dem bisher Mitgetheilten geht hervor, dass jede unserer toponeuren Medusen als aus acht mit je emem centralen Nervenapparat versehenen, selbständiger Contraction fähigen Theilstücken zusammengesetzt betrachtet werden kamn. Erst weiterhin zu erörternde Thatsachen werden hervorheben, in welchem Grade die Individualität dieser Theilstücke auch durch andere Eimrichtungen gestützt ist und in wie weit die Möglichkeit danernder selbständiger Existenz für sie in Frage kommt. Für jetzt habeu wir zunächst zu untersuchen, welcherlei Anhaltspunkte das Experiment uns an die Hand zu geben rermag für die Erklärung der Terbindung der einzelnen Strahlstücke untereinander durch Nerven.

\section{Versuche zum Zweck der Feststellung der Art der Verbindung der verschiedenen Theile des Körpers der toponeuren Medusen durch Nervenfasern.}

Die Angaben über das Vorhandensein eines Nervemringes am Schirmrande verschiedener Medusen, wie anch solche über emen zweiten Nervenring, der bei einigen derselben im oberen 'Theil des Schimes verlaufen sollte (bei Bou gain villia, Tiaropsis, Staurophora, nach L. Agassiz) forderten zunächst zur Prüfung an den von mir zur Untersuchung gewählten Thieren heraus.

Zn diesem Zwecke schnitt ich zuerst ans einer frisch ans dem Meere genommenen Aurelia aurita in beiden interradialen Grenzen eines der acht Antimere ich will es A nennen - einige Millimeter weit rom Rande aus in radiärer Richtung ein. Verband ein hier liegender Nerveming die einzelnen Strahlstücke untereinander, 
und war diese Verbindung die einzige vorhandene, so mussten nach der Operation die Contractionen von A völlig unabhängig von jenen der übrigen Antimere stattfinden; bestand jene Verbindung und ausser ihr noch eine weitere, so mochte die Unabhängigkeit der Contractionen beider wenigstens gemindert sein. Allein es zeigte sich, dass nach der Operation die Contractionen des Strahlstücks A in demselben Verhalten zn jenen der übrigen Strahlstücke verblieben wie vorher - die Contractionen sämmtlicher erfolgten nach wie vor ganz oder nahezu synchronisch. Erst nachdem ich die Schnitte bis nahe an die Geschlechtsdrüsen des Thieres hin, in der Fortsetzung der ursprünglichen Richtung, verlängert hatte (bei einem Individunm von $13 \mathrm{~cm}$ Durchmesser bis auf 8 , bei einem anderen, ebenso grossen, bis auf $6{ }_{2}^{1} \mathrm{~mm}$ Entfernung von den Geschlechtsdrüsen), begann der Zusammenhang der Contractionen des Strahlstücks A mit jenen der übrigen aufzuhören, indem dann und wann in A eine Contraction auftrat, welche auf seinen Umfang beschränkt blieb und sich auf die übrigen Theile der Meduse nicht fortpflanzte und ebenso setzten sich umgekehrt die Contractionen der letzteren zuweilen nicht auf A fort.

Ich führte num in folgender Art den Versuch weiter. Bezeichnen wir das Strahlstück $\Lambda$ als das erste, die rechts von ihm gelegenen als zweites, drittes u. s. f. (vergl. Holzschnitt 2), so schnitt ich ebenso wie vorher zwischen 8 und 1 einerseits und 1 und 2 andererseits nun anch zwischen 3 und 4 his nahe an die Geschlechtsdrüsen (g) ein: es wurde also anch auf diese Weise ein Zwillingsstrahlstïck (bestehend ans 2 und 3) ebenso isolirt wie vorher A und es verhielt sich dieses Zwillingsstrahlstück, welches wir B nennen können, den Antimeren 4 bis 8 gegenüber ganz ebenso wie sich früher A gegenüber 2 bis 8 verhalten hatte: erst nachdem der zwischen 3 und 4 geführte interradiale Schnitt den Geschlechtsdrüsen ebenso nahe gekommen war wie die A isolirenden Schnitte, wurden die Contractionen von B gegenüber jenen der Antimere 4 bis 8 selbständige. - Die Znsammenziehungen der zwei contractilen Zonen von B rerhielten sich zu einander wie im unverletzten Thiere.

Ich schnitt hierauf, durch Verlängerung der Interradialschnitte ${ }_{8}{ }_{8}$ und ${ }^{3}{ }_{4}$ (d. i. der Schnitte zwischen Antimer 1 und 8 einerseits und 3 und 4 andererseits)

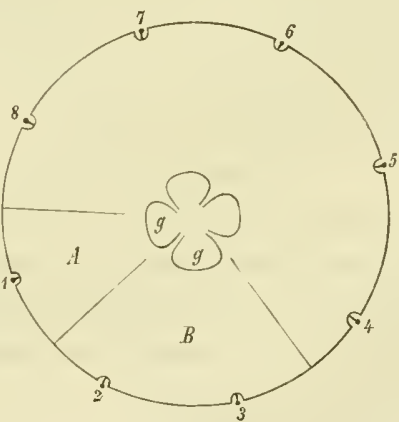

Holzschnitt 2. bis zum Centrum, A und B zusammen ans, so dass ich ein aus drei Antimeren und zwar einem Einzelantimer (A) und einem Zwillingsantimer (B) bestehendes Stück 


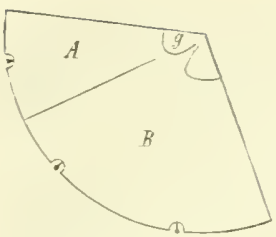

Holzschnitt 3.

vor mir hatte (vergleiche Holzschnitt 3), die Theile $A$ und $B$ waren selbstrerständlich unvollkommen ron einander getrennt - bis anf einen Znsammenhang, dessen radiărer Durchmesser o mm unterhalb der Geschlechtsdritse (g) beginnend bis zum ursprünglichen Mittelpunkte der Meduse als Ganzes reichte. Es waren nun naturrlich, wie vorher, die Contractionen der beiden Antimere ron $\mathrm{B}$ zusammenhängend. Die ron $\mathrm{A}$ einerseits und ron $\mathrm{B}$ andererseits traten zта1 zureilen gleichfalls ganz oder wahezu synchronisch auf, allein mehr wie zufällig. Andere Male contrahirte sich A zuerst und erst auffallend später folgten die zwei contractilen Zonen ron B nach oder umgekehrt. Oder es setzte entweder A oder B eine Contraction aus. machte eine wemiger als der andere Theil: A und B contrahirten sich z. B. bei einer Action nahezu oder ganz gleichzeitig, bei der darauf folgendeu Zusammenziehung ron $B$ rerhielt sich etwa A unthätig, bei der dritten contrahirten sich A und B wieder gleichzeitig. Endlich kam es ror, dass die Contractionen beider Theile während längerer Zeit gänzlich unabhängig ron einander stattfanden.

Später wird ein Fall beschrieben werden, wonach allmäliges Absterben ganz wie der soeben geschilderte künstliche Eingriff nach und nach Trennung eines Abschnittes einer Aurelia rom übrigen Thiere in der Richtung rom Rande nach dem Centraltheil herrorgerufen hat, durchaus mit demselben schliesslichen Erfolg in Beziehung auf die Abhängigkeit der Contractionen beider Theile (rgl. XIII. Abschnitt, Tersuch A und Holzschnitt 15 und 16).

Tach den bis jetzt mitgetheilten Tersuchen war die Annahme ausgeschlossen. dass ein am Schirmrande verlaufender Nerrenring die einzige Verbindung zwischen deu einzelnen Antimeren herstelle. Allein es liessen dieselben die Möglichkeit offen, dass ein Nerreming, etwas mehr als $5 \mathrm{~mm}$ unterhalb del Geschlechtsdrüsen um die Kuppe der Meduse herumlanfend, eine solche Terbindung rermittle - oder dass dieser obere und zugleich ein unterer Nerrenring rorhanden sei.

Cm diese Möglichkeiten zu prüfen, machte ich nun den folgenden Tersuch: ich setzte das Messer im Mittelpunkte einer Aurelia oder Cyanea ein und führte ron hier aus einen Schnitt im rechten und einen anderen in linken Interradius eines Antimers - die vorhin gewählte Bezeichnung beibehalten also z. B. zwischen $1_{2}$ und ${ }^{2}{ }_{3}$ - gegen den Schirmiand hin: es zeigten sich hierauf die Contractionen des betreffenden Antimers so lange ron jenen der anderen abhăngig, bis dasselbe nur noch durch je eine ganz düne Substanzbrücke nach rechts und links mit dem übrigen Thiere verbunden war. Es schien dieser Tersuch zusammen mit den Ergebnissen des entgegengesetzten, in welchem ich rom Rande gegen das Centrum hin eingeschnitten hatte, nu in der That dafür zu sprechen, dass zwei Nerven- 
ringe, ein oberer und ein unterer vorhanden seien, welche irgendwie, etwa in den ladien, mit einander verbunden und welche gegenseitig für einander zu vicariuren im Stande wären.

Um mu abjer beide Versnche zu controliren, machte ich weiter folgenden: ich schnitt aus einer Amelia von $10 \mathrm{~cm}$ Durchmesser die ganze Kuppe in solchem Untange aus, dass ein Randring von $1^{1}{ }_{2} \mathrm{~cm}$ Breite losgelöst wurde. Es zeigte sich die Kúppe, abgesehen von einigen unvollkommenen, bald nach der Operation bemerkbaren Contractionsversuchen, bewegungslos, während der Ring, nach den üblichen Bestürzungserscheinungen, rhythuisch sich contrahirend, munter wie ein ganzes Thier umherschwamm. - Darauf schnitt ich in den distalen - äusseren - Rand dieses linges überall in den Interradien $1 \mathrm{~cm}$ tief ein, so dass die einzelnen, die Randkörper tragenden Antimerenreste nur noch durch acht, dem Innentheile des Ringes angehörige Substanzbrïcken von ${ }_{2}{ }_{2} \mathrm{~cm}$ Breite verbunden waren: die Abhängigkeit der Action der einzelnen contractilen Zonen danerte trotzdem fort. Dasselbe Verhältuiss blieb, nachdem ich zwischen der Hälfte der Antimerenreste die Schnitte bis auf die Dicke eines feinen Bindfadens weiter geführt hatte $\left({ }^{8}{ }_{1},{ }^{1}{ }_{2},{ }^{2}{ }_{3},{ }_{4}{ }_{4}\right.$ Holzschnitt 4). Zwischen den vier übrigen Antimeremresten verlängerte ich min die Schnitte eben so weit, führte aber darauf dicht neben jedeni derselben noch einen Schnitt von innen nach anssen bis kmrz vor den natürlichen Schirmiand hin $\left({ }^{4},{ }_{5}^{5},{ }_{6}^{6},{ }_{8}^{7}\right.$ Holzschnitt 4), Auf diese Weise waren die Antimerenreste 5,6 und 7 nux noch durch je eine wenige $\mathrm{mm}$ breite, rechteckige Gewebsbricke (B) untereinander und ebenso 7 nur noch anf dieselbe Weise mit 8 , 5 mit 4 in Zusammenbung und zwar nmmittelbar nur in der Richtung einer der beiden Diagoualen

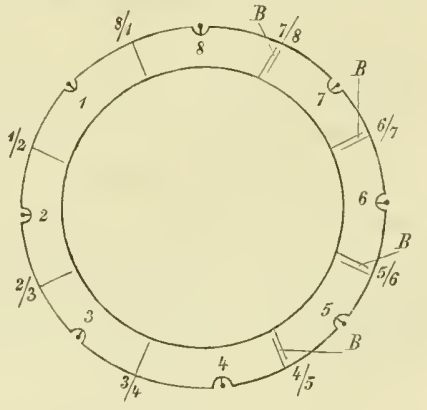

Holzschnitt 4. dieser Stückchen. - Jetzt war die Abhängigkeit der Contractionen dieser einzelnen Antimerenreste mntereinander, sowie die zwischen 4 und 5 einerseits und 7 und 8 andererseits unsicher geworden - um so mehx, je schmaler die die benachbarten Antimerenreste verbindende Gewebsbrücke geworden war. Der kettenartig zerschnittene Randring schwamm übrigens nach wie vor munter umher.

Mehrfache Beobachtungen haben mir gezeigt, dass sich zuweilen die aufgehobene Verbiudung nach einiger Zeit wiederherstellt. Ein solcher Fall ist im XII. Abschnitt u. A. in Versnch F beschrieben. Auch die über das Ausschneiden der Mnskelschichte mitgetheilten Thatsachen mögen hiezu verglichen werden. 
Aus diesen und anderen Versuchen num war ich berechtigt zu schliessen, dass weder ein unterer noch ein oberer Nervenring die einzelnen Strahlstücke der toponeuren Medusen untereinander leitend verbinde, jedenfalls nicht a usschliesslich verbinde, dass diese Verbindung vielmehr hergestellt werden müsse entweder dureh das Gallertgewebe des Körpers an siehoder aberdureh Nervenfädehen, welchedasselbe inverschiedener Richtung durchziehen. Ist das Letztere der Fall, so vermögen die Nervenfädchen in hohem Grade für einander zu vicariiren. Die physiologisehe Verbindung der einzeluen Theile nntereinander aber ist angenscheinlich nur solangesicher, als diesievermittelnde Gewebsbrückenicht nnter ein gewisses Mass der Breite herabgesunken ist. Dieses darf ubeschadet des Vermögens der Vermittelung der Leitung vielgeringer seingegen den sechirmrand hiuals naheder Kuppe, desshalb musdort die Zahl der verbindenden Nervenfädchenviel grössersein als hier.

Somit war ich durch das Experiment zu dem schluss gekommen, dass das peripherische Nervensystem der toponeuren Medusen speciell darin ebenso beschaffen sei wie das von mir bei Beroë beschriebene, dass anch dort nicht gröbere Nervenstränge die Verbindung der Theile des Körpers vermitteln.

Die Frage, wie weit das Muskelgewebe der Subumbrella an sich an der leitenden Verbindung betheiligt sei, habe ich erst in den folgenden Versuchen des Näheren berücksichtigt, welche in den Jahren 187t, 1876 und 1877 angestellt sind, während die bisherigen Mittheilungen sich anf die an Aurelia und Cyanea im Jahre 1873 gemachten Beobachtungen beziehen.

\section{Zerstören oder Verletzen der Randkörper.}

Wie vorhin bemerkt, labe ich schon im Jahre 1873 einzelnen Aurelien die Randkörper, ohne Verletzung der contractilen Zonen, ausgeschnitten und habe beobachtet, dass die Thiere nach der Uperation zwar angenscheinlich „bestürzt“ - gelähmt - waren, indem sie für einige Sekunden ihre Contractioneu anssetzten, dass sie diese aber bald wieder in regehnässigem Khythmus fortzuführen begannen. Im daranffolgenden Jahre machte ich weitere Experimente, welche diesen Satz wesentlich einschränkten. Ich fand nämlich nicht nur, dass alleiniges Zerstören der Raudkörperzuweilen dierhythmische Contrationsfähig- 
keit für längere Zeit aufheben könne, sondern dass dieselbe Wirkung hie und da sogar erzielt werde durch Verletzen einer bestimmten stelle des Randkörperstiels (Aurelia). Diese meine ersten Angaben einschränkenden Erfahrungen waren somit gemacht noch bevor $R$ omanes in demselben Simne Beobachtungen angestellt oder doch veröffentlicht hatte, welchen er freilich eiue viel zn absolute Geltung zuschrieb. Es sagt nämlich dieser Forscher in seiner im Jahre 1876 erschienenen Schrift mit Beziehung anf jene meine ersten Mittheilungen: so viel er sich erinnere, hätten die contractilen Zonen jeweils ihre Contractionen gänzlich eingestellt, sobald er hinreichend Sorge getragen habe, alle Randkörper zu entfernen ${ }^{1}$ ). Von einer Regel in diesem Sinne kann nun nach meinen Erfahrungen keine Rede sein. Nur in noch mehr bedingter Weise kann ich aber mit Romanes übereinstimmen, wenn er fortfährt: "And not only so, but by removing, with the aid of a well-pointed scissors, the little sac of crystals composing the central part of the lithocyst, withont injuring the curions wing-like appendages by which this sac is partly surrounded, and conversely, by removing in other specimens these wing-like appendages alone, withont injuring the little sac of crystals - by these experiments I was able to satisfy myself that the wliole spontaneity of the lithocyst appeared to be exclusively lodged in the minute sac of crystals referred to." Es wären also die Otolithensäckchen, welche Romanes für die Ausgangspunkte der Erregung der Contractionen hält, gegenüber neiner Ansicht, welche die Umgebung der Randkörper, die contractilen Zonen, in dieser Beziehung für wesentlich bezeichnet luatte.

Indessen fügt homanes hei, es seien seine Versuche erst gegen das Ende der "season" und so zu einer Zeit gemacht, als er sich nur kleine und wenig lelhafte Individuen verschafien komnte. In Rücksicht darauf habe er beabsichtigt gehabt, die Veröffentlichung seiner bezüglichen Experimente hinauszuschieben, bis ihm Gelegenheit geworden sein würde, sie an kräftigen Individuen zu bestätigen; „but a perusal of Dr. Eimer's statements appears to render it desirable for me to give an opinion now upon the point under consideration, although I confess that, for the reason just mentioned, I do so with some diffidence."

Es scheint mir aus alsbald mitzutheilenden Gründen nicht gerechtfertigt, gerade die Kleinheit der Individuen als Ursache des von Romanes erlangten Erfolges des Zerstörens der Otolithensückchen anzunehmen. Dagegen wird der kr räftezustand derselben allerdings für diesen Erfolg mithestimmend gewesen sein, denn er ist auch für den Grad der Wirkung aller anderen Operationen von der höchsten Bedentung.

Ich habe freilich, wenigstens an Theilstücken, welche unter übrigens gleichen Verhälnissen empfindlicher sind als ganze Thiere - und zwar von Cassiopea und Rhizostoma - ein sofortiges Aufhören der rhythmischen Contractionen nach Zerstören des Otolithensäckchens beobachtet, und derartige Fälle mögen liomanes zu

1) Philos. Transact. Hoy. Soc. Vol. 166, S. 310. 
der Auffassung gebracht haben, dass die Bewegungscentren in diesen letzteren gelegen seien. Allein wie die speciellen Beispiele zeigen werden, erholten sich die Objekte stets sehr bald wieder und zwar datternd und verhielten sich später so als ob niemals etwas mit jhnen geschehen wäre. Und nicht mur wird, wenigstens an ganzen Thieren, meistens gar kein Erfolg dieser Operation beobachtet, sondern selbst Abschneiden der Randkörper an der Wurzel alterirt die rhythmische Contractionsfähigkeit - von kurzer Bestürzungsperiode abgesehen — in den meisten Fällen durchaus nicht. Darans erklärt es sich, dass meine ersten Nachrichten über diese Operation nur von negativem Ergebniss zu berichten wussten. Jene kleinen Aurelien von nur 2 cm Durchmesser z. B., welche ich zuerst lebend aus liel erhalten hatte, litten sämmtlich durch sie gar nicht, was mir, von der Klẹinheit der Thiere ganz abgesehen, desshalb $\mathrm{nm}$ so auffallender war, als von voruherein wohl angenommen werden durfte, dass dieselben durch die Reise an Widerstandsfähigkeit nicht wenig eingebüsst haben möchten. Erst das Ansschneiden der contractilen Zonen hatte die Wirkung des Einstelleus der rhythmischen Zusammenziehungen.

In anderen Fällen erfolgte dagegen diese Wirkung schon wie mit einem Zauberschlage, sobald ich den liandkörperstiel mit der Präparirnadel ungefährin der Mitte zwischen seinem Ansatzam Schirmrande nnd dem otolithensäckchengequetscht hat e.

An derselben stelle fand ich später, wie schon hier bemerkt werden kann, bei Rhizostoma Cnvieri e in e bedentende polsterartige Verdicknng des den liandkörper umkleidenden Nervenepithels (Taf. Il. Fig. 1 und $2, g)$.

Nach den von mir beobachteten Fällen ist nun aber das Aufhören der Contractionen anch nach dieser. Verletzung des Randkörperstiels oder uach dem Wegnehmen der Randkörper meist nu ein bald vorübergehendes: die Thiere, bezw. die Theilstücke derselben, erholen sich nach kürzerer oder längerer Zeit danernd.

Indessen darf nicht unterlassen werden zu lemerken, dass verschiedene Arten vou Medusen auch gegenüluer den leichteren Eingriffen keineswegs gleich empfindlich sind: es lassen sich demnach bestimmte Regeln nur anfstellen für je eine bestimmte Art und ferner selbstverständlich unter Voraussetzung derselben äusseren Bedingungen, und auch dann stets mit der Einschränkung, dass der Individualität ein grosser Spielraum bleibt. Desshalb muss ieh besonders hervorheben, dass meine nenesten Erfalırungen über den Erfolg einer Verletzung der Randkörper, wie ich sie im Nachstehenden durch Beispiele schildern will, nicht an Aurelia, sondern an Cassiopea und Rhizostoma und zwar unter den Velhältnissen gemacht sind, welche die zoologische Station in Neapel mir geloten hat.

An den acht mitsamnt ihrem Randkörper ausgeschnittenen Antimerenstücken von Cassiopea borbonica suchte ich die Randkörper vollkommen zn zerstören. Unmittelhar nach der Operation waren alle acht Stücke bewegungslos. Nach mngefahr 
einer halben Stunde sah ich an dreien derselben wieder Contractionen anftreten: die mikroskopische Untersuchung wies nach, dass an diesen drei Stücken nur die Otolithensäckehen zerstört, die liandkörperstiele dagegen unverletzt geblieben waren. Die übrigen Stücke, bei welchen die Zerstörung der Randkörper v oll ko m men war, zeigten selbst nach 24 Stunden noch keine Contractionen, aber später traten sie anch an ihnen wieder anf und ich habe diese Stücke noch 8-10 Tage lang lebend erhalten. Entsprechende Theile von Rhizostoma Cuvieri erwiesen sich als empfindlicher. Auch sie waren nach der Operation alle bewegungslos. Unter acht derselben sah ich nur eines erst nach etwa einer Stunde sich wieder contrahiren: es war an ihm wieder nur das Otolithensäckchen zerstört. Die meisten übrigen, an welchen die Zerstörung des Randkörpers eine vollkommene war, erholten sich gleichfalls wieder, aber viel später. Erst Ausschneiden der contractilen Zonen rief an den Antimerenstücken von Cassiopea und Rhizostoma bleibende Bewegungslosigkeit hervor.

Nach diesen und anderen Erfahrungen kann allerdings die ausschliessliche Zerstörung des Otolithensïckchens die rhythmischen Contractionen wenigstens an Antimerenstrucken aufheben, allein es hält die Lähmung nur kurze Zeit an und es stellt sich die normale Funktion bald danemd wieder her. Eingreifender ist die Zerstörung des ganzen Randkörpers. Indessen anch darunf hin kehrt, wenngleich später als nach der vorigen Operation, die normale Funktion danernd wieder zurück, ob - günstige Lebensbedingungen voransgesetzt - immer und bei allen Arten, muss ich mentschieden lassen. Erst das Ausschneiden der contractilen Zonen bewirkt bleibende Bewegungslosigkeit, nachdem, wie noch näher besprochen werlen soll, eine Periode vorübergehender, freilich zuweilen sehr lange andanernder, Erholung eingetreten war.

Auch die Sicherheit, mit welcher der Erfolg des Experiments vorhergesagt werden kann, scheint in derselben Stufenleiter zu wachsen, so dass sie am geringsten ist bei dem ersten, am grössten bei dem dritten der drei Experimente, aber, wie wir sehen werden (VIII. Abschnitt), ist sie selbst im letzteren Falle durchaus keine absolute.

Ich muss bemerken, dass sich, je länger ich experimentirt habe, um so mehr das Bedürfniss liei mir geltend machte, eine noch grössere Anzahl von Beobachtungen unter immer genauerer Berücksichtigung der Gleichheit der äusseren Bedingungen anzustellen. So schien mir im August 1877 die durch die zoologische Station gebotene Gunst der Verhältnisse wegen der herrschenden Hitze, welche an manchen Tagen das Wasser in den Behältern schnell erwärmte, nicht zu jeder Zeit in gleichem Masse uneingesehränkt zn wirken, und Fïlle von raschem Absterben, wie ich sie noch zu erwähnen haben werde, lassen sich, vielleicht ebenso wie Beispiele von eintretendelu Tod, welche Sticke von Rhizostoma nach alleinigem Zerstören des Randkürpers boten, auf jenen Umstand zurïckfübren. Als besonders einflussreich muss aber in Beziehung auf die geringe 
Widerstandsfähigkeit soleher Theilstiicke von Rhizostoma wohl der starre Zustand und der dicke Durchmesser der Umbrella dieses Thieres bezeichnet werden: die Stücke sterken augenscheinlich viel leichter ab als z. B. die von Cassiopea, weil sie sich in Folge ihrer Starrheit durch etwa auftretende Contractionen viel weniger erholen und so dem Genuss belebender Ernenerung des in ihmen enthaltenen Wassers bezw. Sautrstofts hingel)en können. Dagegen halıe ich an operirten ganzen Rhizostomen, wie wir sehen werden, häufig eine grosse Widerstandsfilhigkeit beobachtet, sobald die so sehr ausgiehigen Contractionen dieses Thieres einmal wieder erschienen waren. Mag es also genaueren, systematisch fortgesetzten Untersuchungen vorbehalten bleiben, in Beziehung auf das Mitgetheilte bis ins Einzelne endgültige Regeln aufzustellen, jedenfalls stimmen, was alle wesentlichen Fragen angeht, anch die Ergebnisse meiner anatomischen Untersuchung in hohem Grade mit den aus den Experimenten gezogenen schlüssen äberein.

Auch nach dem anatomischen Befund können, wie vorgreifend hier bemerkt werden soll, die Otolithensäckchen der eigentliche, alleinige Sitz des Bewegnngsimpulses und centraler Nerventbätigkeit durchans nicht sein. Anf den otolithensäckehen liegen allerdings Nervenzellen, ebenso aber anf den Randkörperstielen und im Gebieteder contractilen Zonen. Es wird mit jenensomitnurein kleinster Theil dieser Zellen entfernt, ein grösserer mit den Randkörpern als Ganzes, die Hanptmasse mit den contractilen Zonen. Auf diese Weise erklärt sich leicht die relative Bedeutung der einzelnen Eingriffe in den Organismus für die rhythmische Contractionsfähigkeit. Da nun aber Fälle vorkommen, in welchen selbst das Ausschneiden der contractilen Zonen wenigstens unmittelbar kaum eine Störung dieser Fähigkeit verursacht, und da in anderen Fällen wenigstens eine zeitweilige Erholung: gewöhnlich ist, so wird von vornherein zn erwarten sein, dass centrale actionsfähige Nervenzellen anch sonst über den Medusenkörper, nur in viel spärlicherer Anzahl als im Gebiete der contractilen Zonen, bezw. auf den Randkörpern, vorhanden seien. - Erholung wird sich dann zeigen, wenn die ersteren die centralisirende Thätigkeit. der letzteren mit übernehmen.

Es seien nachträglich noch bier einige nene 1878 in Kiel angestellte Beobachtungen über die Wirkung des Ausschneidens der Randkörper angefügt. Es haben diese Beohachtungen meine früheren Erfahrungen durchans anfs Nene bestätigt, anch ist durch dieselben ferner die soeben ausgesprochene Relativitat in der Bedeutung der einzelnen Nervenzellen führenden 'Theile anf das Dentlichste als thatsächlich erwiesen worden nud sind sie mir daher von besonderem Werthe gewesen.

Ich fülre einfach einge der von mix gemachten Versuche auf:

1) Am 11. April schnitt ich einer Aurelia von $1^{1}{ }_{2} \mathrm{em}$ Durchmesser alle Randkörper je mit einem grösseren Stückchen des Schirmrandes bis anf einen ans. Das operirte Thier contrahirte sich ebenso rhythmisch weiter wie die einzelnen mit je einem Randkörper versehenen Gewebsstückchen. Ich schnitt nun auch den letzten am 
Schirme noch vorhandenen Randkörper an der Wurzel ab. Die rhythmischen Contractionen hörten jetzt anf und es blieben nur Zuckungen. Darauf nahm ich an einem der ansgeschnittenen, sich noch contrahirenden Randtheile den Randkörper ebenfalls weg, sogar mit einem sehr kleinen Stückchen des Gallertgewebes, welchem die Randkörperwurzel ansitzt - die Contractionen blieben bestehen. Erst nachdem ein grösseres Stückchen dieses Randgewebes ansgeschnitten war, hörten die rhythmischen Contractionen auf; nur sehr selten zeigten sich einzelne schwache Zuckungen, welche nach zwei Stunden nur noch andeutungsweise beobachtet wurden.

2) An demselben Tage wird ein Randstück einer gleichfalls $1^{1}{ }_{2} \mathrm{~cm}$ im Durchmesser haltenden Aurelia in zwei Theile getrennt, von welchen jeder einen Randkörper trägt. Beiden Theilen werden die Randkörper abgeschnitten, dem einen an der Wurzel, dem anderen zngleich mit einem kleinen Stückchen des Umbrellarandes. Beide zeigen während mehreren Minuten keine Contractionen mehr. Nach Verfluss dieser Zeit treten an jedem wieder einzelne kräftige Contractionen zwischen leichten lokalen Zuckungen auf. Nachdem anch die contractilen Zonen ansgeschnitten worden sind, zeigen sich nur noch solche lokale Znckungen - die rhythmischen Contractionen haben aufgehört.

3) Derselbe Versuch wird mit allen Randkörpern an einer dritten Meduse mit demselben Erfolge gemacht.

Es hatte somit in den verzeichneten Fälen alleiniges $A b$ schneiden der Randkörper höchstens kurzdanernde Bewegungslosigkeit zur Folge; auch Mithinwegnehmen eines Stückchens des Umbrellagewebes, welchem der Randkörper ansitzt, wirkte in ähnlichem Sinne - erst Entfernung dieses Gewebes in grösserem Umfange lähmte auf längere Dauer. Zuweilen war es sogar nothwendig, um letzteres Ergebuiss zu erzielen, ziemlich weit nach a ufwärts das Gefäss sammt Umgebung in der Mittellinie der Antimere auszuschneiden.

Weiter ist meinen Notizen mit Bezug auf Fall 3) bemerkt: die der contractilen Zonen beraubten, bewegungslosen Stückchen werden nachträglich zusammen in ein Gefäss gebracht; einige derselben fangen nach längerer Zeit an sich zu contrahiren; die Untersuchung ergibt, dass an diesen etwas von dem Randtheil des Umbrellagewebes, an welchem die Randkörper ansitzen, hängen geblieben war. Die anderen, rein operirten Stücke nahmen ihre Contractionen nicht wieder auf.

Herrorgehoben muss äbrigens schon hier werden, dass weitere, im nächsten 
Abschmitte nachzntragende Versuche eine ganz ausserordentliche und auffallende Widerstandsfähigkeit weitaus der meisten bei Gelegenheit meines Kieler Anfenthaltes operirten Aurelien dargethan haben. Die dort noch über das Abschneiden der Randkörper angeführten Thatsachen mögen als für dieses Kapitel wichtig hiezn verglichen werden.

\section{Erholung gelähmter Thiere. Widerstandsfähigkeit gegenüber operativen Eingriffen.}

Die Beobachtnngen über die Thatsache, dass sich Toponeuren nach Ausschneiden der contractilen Zonen derartig erholen kömnen, dass sie wieder kräftige rhythmische Contractionen ausführen, machte ich zuerst im Jahre 1874 an Aurelia aurita'). Aus der Zahl der von mir angestellten Versuche scheint sich zu ergeben, dass eine solche Erholung, wenn man die Thiere nuter möglichst normalen Lebensverhältnissen hält, sogar meistens erfolgt. Stets habe ich indessen gefunden, dass dieselbe nur vorübergehend war, kann aber nicht entscheiden, ob dies ansnahmslose Regel ist.

Wie ich schon in meiner ersten Mittheilung über den Gegenstand geschildert habe, sind die 'Thiere nach dem Aussehneiden der contractilen Zonen gewöhnlich vollkommen bewegungslos, der Schirm, speciell der Anrelien, steigt hänfig flach ansgebreitet an die Oberfläche des Wassers und nach längerer oder kürzerer Zeit zeigen sich unregelmässige und wirkungslose, schwache Contractionen, welche mehr lokaler Natu sind. Es sind diese Contractionen sehr merkwürdig: meist haben sie den Charakter kmrzer Zuckungen, welche auffallender Weise in einem gegebenen Falle stets von einem oder auch von mehreren bestimmten Punkten des Schirmes ansgehen und sich von da ans mehr oder weniger weit in die Ungebung verbreiten. Sie wiederholen sich häufig an derselben Stelle mehrfach hintereinander, oft wie zitternd, in verschiedener Stärke, indem sie längere oder kürzere Pansen zwischen sich lassen. Oefters habe ich beobachtet, dass sie sich von ihrem

1) Vergl, meinen Münchener Vortrag: „Ueber künstliche Theilbarkeit und über das Nervensystem der Medusen«, Arch. f. mikr. Anat. Bd. XV. und Amtlicher Bericht der 50. Versammlung deutscher Naturforseher und Aerzte in Hünchen rou 17. bis 22. Sept. 1877. - Im , Tahre 1873 hatte ich eine solche Erholung nicht beobachtet - ich hätte damals, bei der kurzen Frist, welebe mir zu allen meinen Versuchen gegeben war, vielleicht an und für sich kaum Zeit gehabt, auch noch diese Beobachtung zu machen. zumal da die ausgiebige Erholung hänfig erst längere Zeit nach der Operation eintritt. Ich hatte aber offenbar zugleich selar wenig widerstandsfähige Thiere ror nir gehabt, vielleicht darunter auch solche, welche schon längere Zeit in der Gefangenschaft zugebracht hatten. Das ungemein grosse Gewicht, welches anf sorgfültige Behandlung cler Thiere zn legen ist, lernte ich natürlich erst mit der Zeit kennen, ebenso andererseits die Bedeutung der Individualität. 
Ausgangspunkte aus wie ringförmig, wie im Kreise, parallel dem Schirmrande fortpflanzten ${ }^{1}$ ). So viel ich gesehen habe, sind die Ausgangspunkte dieser secundären Contractionen in verschiedenen Fällen, d. i. bei verschiedenen Thieren, keineswegs dieselben, sie liegen vielmehr bald da, bald dort im Schirme. Mehrere specielle Fälle der Erscheinung sind im XIII. Abschnitte anfgeführt, n. A. z. B. in Versuch C. Uebrigens habe ich dieselbe viel weniger genau studirt als sie es verdient. Wer die Musse hat, wird dazu um so leichter in der Lage sein, als sie auch auf künstlich ansgeübten Reiz hin anftritt. Solcher Reiz, z. B. Einstechen mit einer Nadel, ruft die Contractionen regelmässig nnd zwar oft noch lange Zeit nach der Operation so lange eben, als das Thier nicht todt ist - hervor. Als sehr bemerkenswerth drängt sich dabei die Thatsache auf, dass es nicht nothwendig die gereizte Stelle selbst ist, von welcher die Contractionen ihren Ursprung nehmen müssen, sondern man erkennt als diesen Ausgangspunkt, sofern derselbe überhaupt sicher zu fixiren ist, hänfig eine ganz bestimmte andere stelle - offenbar entsprechend dem nenen Contractionscentrnm, welches die Aufgabe der contractilen Zonen nachträglich in die Hand zu nehmen versucht - dem Ersatz-Contractionscentrum.

Einer $30 \mathrm{~cm}$ im Durehmesser haltenden Aurelia z. B. schnitt ich den Rand etwa $6 \mathrm{~cm}$ breit weg, nachdem ich vorher schon einige anclere Operationen an ihr ausgeführt hatte, und zuletzt halbirte ich noch das Kuppenstïck. Noch als die eive der Kuppenhälften schon theilweise in Auflösung begriffen war, konnte ich an derselben Zuckungen wahmehmen - ich mochte aber einstechen an welcher Stelle ich wollte: immer reigten sich die Contractionen an einem bestimmten Punkte, ungefähr in der Mitte zwischen der unteren Grenze einer der Genitaldrüsen und dem künstlichen Schnittrande.

Abgesehen vou den spontanen Zuckungen nun, welche nur während kurzer Zeit oder während einiger Stumden oder selbst noch am folgenden Tage beobachtet wurden, lagen meine der contractilen Zonen beranbten Thiere gewöhnlich den ganzen ersten oder sogar noch am zweiten und dritten Tage gelähnt. Aber am folgenden öfter erst am dritten oder vierten Tage fand ich sie, nachdem ich einmal gelernt hatte, anf die Herstellnng normaler änsseren Lebensbedingungen grösseren Werth zu legen, häufig wieder in regelmässiger rhythmischer Bewegung, als ob nichts mit ihnen vorgenommen worden wäre. Am Tage nach dieser Erholung konnte wieder Regungslosigkeit eingetreten sein, ja es war dies der gewölnnliche Fall, und stets war das operirte Thier längst aufgelöst, während unverletzte, von Anfang an mit ihm in demselben Wasser gehaltevie Individuen fröhlich weiter lebten. Zuweilen beobachtete ich allerdings, dass eine Mednse sich noch mehrere Tage nach dem Eintritt der Erholung lebhaft rhythmisch zusammenzog,

1) Man rergleiche in dieser Beziehung die später zu besprechenden Versuche von Mettenheimer. 
um aber dann doch - - im Gegensatz zu unverletzten Individuen - plötzlich in den Contractionen zu erlahmen und rasch abzusterben.

Es ist besonders hervorzuheben, dass nicht nur ganze Medusen sich zu erholen vermögen, sondern, trotz ihrer geringeren Widerstandsfähigheit, anch Theilstïcke derselben.

Es sind in XIII. Abschnitte zahlreiche Fälle der Erbolung sowohl von Theilstücken als von ganzen Thieren aufgefübrt, in welchen genau die Periode der Erholung und die Zeit des Absterbens verzeichnet ist. Besonders erwïhnenswerth ist in dieser Beziehung der Versuch A: der kleinere Lappen des Thieres, welcher mit dem grösseren zwar noch in Verbindung steht, aber nicht melır durch die Contractionen ïberleitende Muskel- oder Nervenelemente, erholt sich, nachdem seine contractilen Zonen ausgeschnitten sind, am äritten Tage etwas, am vierten danert die Erholung fort, am fünften geht sie zurück und am sechsten ist er aufgelöst. Der grössere, der Contractionscentren nicht beraubte Lappen schwimmt jetzt, des heschwerenden Genossen ledig, munter davon. Versuch B weist eine schwache Erholung ähnlicher Art am zweiten Tage nach, am dritten aber beginnt die Auflösung. Versuch C zeigt vollkommene Erholung eines gekmickten Thieres am dritten Tage; am vierten, nachdew dasselbe allerdings noch halbirt und weiter verstiimmelt worden war, was aber unmittelbar kemen Einfluss auf die Contractionen ansiibte, hat die Bewegung fast gänzlich aufgehört, und die Meduse geht der Auflüsung in den nächsten Tagen entgegen. In Versuch D tritt eine geringe Erholung erst am vierten Tage ein, am fünften ist diese zurïckgegangen und es beginnt die Anflösung.

Ein Ausdruck der Erholung ist gewöhnlich, abgesehen rom Aufreten von Contractionen, die Wiederherstellung der glockenförmigen Gestaitung des Schirmes, bezw. Schirmtheiles. Sowie die Wirksamkeit der Bewegungscentren aufhört, erschlafft der Schirm wieder und breitet sich flach ans.

Es ist aus dem Mitgetheilten ersichtlich, in wie hohem Grade rerschieden die Zeit des Eintritts der Erholung in den einzehnen Fällen ist. An und für siclı möchte man versucht sein, die Ursache dieser Erscheinung ansschliesslich in änssere Verhältnisse zu legen. Es lässt sich jedoch nachweisen, dass dabei in bedentendem Masse individnelle Zustände mitwirkend sein müssen. Denu es ist mir wiederholt höchst auffallend die Thatsache entgegengetreten, dass von zwei zu gleicher Zeit eingetangenen anscheinend in gleichem Kräftezustand befindlichen, gleich grossen, gleich und gleichzeitig operirten und ganz überemstimmend behandelten Thieren das eine sich erholen konnte, während das andere sich nicht erholte.

Möglich ist es indessen immerhin, dass in einzelnen Fällen irgend eine Ungleichbeit in der Behandlungsweise mit unterlief, auf die kein Werth gelegt worden war, aber es könnte sich dabei nur nm Ausnahmsfälie handeln. Ohne also daduxch eine bestimmte Erklïrung für die Erscheinung an sich geben zu wollen, eher um ein Beispiel datür anzuführen, welche geringen Ursachen vielleicht zuweilen jener 'Thatsache zu Grunde liegen möchten, will ich in dieser Beziehung das Folgende bemerken. Da anf die Gallertscheibe gelïhmter Thiere ausgen̈l,te Reize Contractionen anregen, so könnten derartige Reize, z. B. ein enges Gefäss, dessen Wände die Wundränder einer grossen Qualle leichter berühren, als die eimer kleinen, ein häufiges Auftreten dieser Contractionen veranlassen. Didurch würden die verstümmelten Thiere zum Athmen gebracht und es würde ihnen Zeit gegeben, an Statt der ihnen geraubten, neue centrale Ausgangspunkte der Bewegung in Gruppen der über den Körper zerstreuten Nervenzellen wirksam werden zu lassen. Auch 
könnten kleine Thiere, Crustaceen u. dgl., welche zufällig mit dem Seewasser in das Giefüss eingebracht worden sind, ebensowolıl reizend, wie auch als Nahrung conservirend wirken '). Wenn wir freilich die augenscheinlich individuell verschiedene Widerstandsfiligkeit betrachten, welche unsere lledusen auch gegenüber anderen Eingrifien zeigen, so sind wir bis auf Weiteres beinahe dazu berechtigt, die soeben geschilderte Verschiedenheit mit derselhen Erklärung zu bedenlien. Romanes, weleher die gleichen Erfahrungen nach dieser Richtung gemacht hat wie ich, fasst die Sache in diesem Sinne anf. Unter dieselbe Rubrik müsste dann anch die weitere, nicht minder aufiallende Thatsache gebracht werden, dass sich, wie schon angedeutet worden ist, zuweilen einzelne Medusen finden, welche selbst durch das Ausschneiden sämmtlicher contractiler Zonen in keiner Weise erheblich in ihrer normalen Bewegungsthätigkeit gestört zu werden schienen, eine Frage, auf welche ich alsbald ausführlicher zurïckkommen werde.

Hervorzuheben ist hier nur nochmals die Thatsache, dass die operirten 'llhiere, welche sich, sei es noch so vollkommen erholt hatten, doelı gewöhnlieh früher als die mit ihnen in der Gefangenschaft und nnter übrigens gleichen Verhältnissengehaltenen, unverletzten Controlethiere zu Grunde gingen, ja dass die Periode der Erholung, anch wenn sie die kräftigsten Lebenserscheinungen darbot, bald vollkommener. Bewegungslosigkeit gewichen ist.

In der Regel that ich nämlich ein unverletztes 'Thier, wo möglich von derselben Grösse wie das operirte und mit ihm gleichzeitig gefangen, zu diesem in ein und dasselbe Gefäss, und beobachtete num Tag für Tag die Lebensänsserungen beider vergleichend. 'T'äglich zwei Mal, Morgens und Abends, wurde das Wasser ernenert. Zwar konnte bei solcher Behandhung an den Controlethieren oft nach Ablant einer Woche und nach noch längerer Zeit keine Spur einer Abnahme der Lebensfähigkeit bemerkt werden; dann aber und zuweilen allerdings schon fiüher, begannen auch sie unter den Störungen, welche die Entbehrung des Aufenthaltes in offener See, d. i. zunächst bestandig frischen Wassers, und welche ferner Mangel an ansreichender Nahrung mit sich brachte, zu leiden und sie starben allmälig" ab. Aber dieses Absterben erfolgte, wie wir noch sehen werden, sehr langsan, während der Randkörper beraubte, hewegungshos gewordene Thiere unverhältnissmässig viel rascher zerfielen.

Um beobachten zu können, wie die operirten Thiere sich nnter möglichst normalen Lebensverhältnissen verhielten, insbesondere, wie weit sich die Periode der Erholung damn ausdehnen würde, brachte ich nach verschiedener Art misshandelte, der Randkörper oder des liandes beraubte, radiär eingeschnittene und zerschnittene Aurelien

1) Erst nachdem Obiges sehon niedergeschrieluen war, fand ich eine Pemerkung bei Romanes. welche einen Theil der soeben ausgesproehenen Ausichten sehr stätzen mb̈ehte. Rom manes erwähnt gelegentlich der Schilderung der Wirkung elektriseber Reize auf sarsia, dass zuweilen kleine Crustaceen, welehe den des Schirminndes beraubten und dadureh unbeweglich gewordenen ï̈̈rper jenss Thieres berïluren. Contrationen desselben hervorrufen (Phil. Transaet. Vol. 166. S. 282). 
- ich spreche von gelegentlich meines zweiten Aufenthaltes an der Ustsee ( 1 i4) angestellten Versuchen - sammt Nihrung in durchlöcherte Kisten, welche ich in's Mecr hinmstühren, dort versenken und mit Steinen beschweren liess. Jeden Tag wurde der Inbalt der Kisten mutersucht. - Ich fund nun zwar zuweilen schon am folgenden Tage den herausgeschuittenen rentralen 'Theil einiger Thiere todt, nicht mehr durhsichtig, sondern milchweiss geworden, während alle mit liandkörpern velsehenen Stücke lebten. Viel häufiger, als wem ich die Medusen in der Stube hielt, fand ich jedoch derartige ansgeschuittene Mitteltheile (Kuppen) in der Kiste nach melrejen Tagen noch am Leben. Anch erhielten sich heliehige stücke des Gallertschirms ohne Randkörper und contractile Zonen mehrere Tage lindurch wenigstens klar und Anrehsichtig und zeigten nicht die Trübung, welche mit dem Absterben einhergeht; ja manche solcher Stücke sah ich noch uach vier Tagen sehwache Contractionsversuche ausführen. Da mir aber der strrm immer und immer wieder nach einigen Tagen und hänfig gerade dann, wem die Beobachtung anfungen sollte entscheidend zu werden, meine Kisten umhergeworfen und den Inhalt mehr oder weniger zerstört hatte, da ich endlich in der oftenen Niendorfer Bucht einen dieselben schützenden Ort nicht finden komte, so kam ich mit neinen Versuchen innerhalb der mir für sie gesteckten Zeit nicht zu endgültigen Riesultaten.

Meine beobachtungen zeigen indessen, dass der contractilen Zonen enthehrende Stücke von Aurelia in der See sich lünger zu erbalten vermögen, als unter den ungünstigeren Verhältnissen, wie sie die Gefangenschaft in Wasserbehältern ausserhalb derselben bietet: es wird der Ersticknngstod durch die beständige berührung mit frischem Wasser längere Zeit hindurch hintangehalten werden können, anch bei mangelhafter und sugar bej aufgehobener Beregungsfähigkeit. Ferner zeigen sie, dass sogar der contractilen Zonen entbehrende stücke des Schirmes nuter diesen Bedingungen zu selbstständiger Contractionsthätigkeit gelangen können.

Es musste die zoologische Station treffliche Gelegenheit zum genanen Studium dieser Fragen liefern, und in der That liessen mich im Frühling 1976 zu Neapel angestellte Versnche zuerst hänfiger. Mednsen heobachten. welche durch das $A$ uschneiden der Randkörper sammt grösseren stü cken des Schirmrandes, welchem sie ansitzen, in so geringem grade alterirt wulen, dass sie kurze Zeit nach dieseroperation ihre rhythmischen Contractionen wierler fortsetzten. Es waren clies altere Exemplar von Rhizostona Unvieri. Die einen begamnen nach Ueberwinden einer 
knrzen Lähmungsperiode den Rhythmus der Bewegung wieder, wenngleich umregelmässig, mit sehr ungleich langen Pansen, fortznsetzen. Andere erhulten sich wenigstens bald in ähnlicher Weise. Beide contrahirten sich nach einiger Keit wieder regelmässig wie gesunde Thiere. Zwei crhielten sich in den Behältern der Station acht Trage lang munter. Als ich im Angust des folgenden Jahres dieselben V'ersuche an Rhizostoma in der zoologischen Station wieder vornahus, hatte ich insofern andere Ergebnisse zu verzeichnen, als ich nicht im Stande war, die operirten Thiere länger als 2 Tage lebend zn erhalten, während dagegen, wie anch hier wieder hervorzuheben ist, unverletzte, mit ihnen zur Vergleichung in denselhen Behälteru gehaltene Exemplare viel lüngere Zeit am Leben blieben. Ich will zwei specielle Beispiele aus letzterer Versuchsreihe anführen, welche anch sonst bemerkenswerthe Erstheinungen darbieten.

Am 18. August Vormittags ? Uhr bekam ich zwei frischeingefangene Rhizostomen, von denen die eine 16 , die andere $10 \mathrm{~cm}$ Durchmesser im Lichten der Glockenöffnung mass. Beide schwammen unter lebhaften nnd kräftigen Contractionen umher: die kleinere (A) machte deren bei drei anfeinanderfolgenden Zühlungen genau 56 in der Minnte, die grössere (B) etwas weniger. Es werden ihnen die contractilen Zonen ansgeschnitten. Unmittelbar nach der Operation machen beide nach Ablauf einer kuxzen Lähmungsperiode Contractionen, welche zwar nicht vollkonmen, aber doch stark und lebhaft sind. Dieses Verhalten danert jedoch nur ganz kurze Zeit: in der

5ten Ninute nach der Operation macht A nur noch 9,

$\begin{array}{llll}6 \text { ten } & , & , & 6, \\ 7 \text { ten } & , & 6\end{array}$

Contractionen, während sie mnter der Obertlathe des Wassers schwelst. Diese Contractionen sind schwach, durchaus unvollkommen, indem nur die steheugehliehenen Lappen des Randes eingezogen werden nnd zwar nicht alle acht anf einmal, somlern bald einige an der, bald einige an jener Seite. - B war gleich nach der Operation zn Boden gesunken und verhielt sich znerst wie beschriehen; eine Viertelstnncle später aber machte sie nur von Zeit zn Zeit eine, oder einige Contractionen. - Um 2 Uhr sind die Contractionen bei A nnd bei B sehr selten geworden, es liegt jetzt anch A zu Boden; nm 4 Uhr haben beide die Durchsichtigkeit verloren, haben ein milchweisses Anssehen erlangt. - Am folgenden Tag früh 8'/2 Uhr fand ich beide in diesem Znstinde am Boden liegend, und während 7 Minnten langer Beobachtung vermochte ich keine Contraction an ihnen zu sehen. - Ebenso wenig konnte ich bei wiederholtem Nachsehen während des übrigen Theils des Tages eine 
solche wahrnehmen; um 2 Uhr Nachmittags begamn A schon am Rande zu zerfallen. Weiter findet sich in meinen Notizen die Bemerkung: „um 4 Uhr A und B todt; grosse Hitze." _ Es war angenscheinlich die grosse Hitze, welche den raschen Zerfall der Thiere beschlemnigt hate. Dagegen ist das baldige Nachlassen nnd Aufhören der Contractionen in erster Linie eine Folge des Ausschneidens der contractilen Zonen, wobei anflallend ist, dass die 'T'hiere sich ummittelbar nach der Operation noch so rasch und lebhaft contrahirten, nm lann plötzlich die Contractionsfähigkeit zn verlieren.

Während ich trüher an Anrelien eine ähnliche relative Gleichgültigkeit gegenüber dem Eingrifte des Ansschneidens der contractilen Zonen, wie es vorhin von lihizostoma geschildert worden ist, zwar anch, aber nu sehr vereinzelt kennen gelernt latte ${ }^{1}$ ), boten mir meine nenesten Kieler Versuche (April d. J.) zahlreiche höchst antfallende Beispiele in demselben Simne dar. Es waren diese Versnche, wie schon bemerkt, ursprünglich von mir angestellt worden, um von Nenem Erfahrungen darüber zu sammeln, welche Folgen das Wegnehmen der Randkörper für die Bewegungsfähigkeit habe. lch führe einige derselben hier an.

1) Am 12. April wurden der einen Hälfte einer Amrelia aurita, welche als Ganzes $1^{1}{ }_{2} \mathrm{~cm}$ Durchmesser gehabt hatte, die handkörper abgeschnitten: die so operirte Hälfte contrahirte sich, nachdem sie eine ganz kmrze „Besturzungsperiode“ ïberwunden hatte, wie rorher. (Das Abschneiden war sehr genau, unter dem Mikroskop, ausgeführt worden.) A ber aueh die zweite Hälfte contrahirte sich noch rhythmiseh, nachdem ihr diecontractilen Zonentief a usgeschn itten worden waren, allerdings zuerst nur selten, bald aber so hänfig wie die erste. Selbst nach lem der li and bis anr Höhe des halben bnrehmessers abgeschnitten war, eontrahirtesich der centrale liest der Seheibe noeh zuweilen, dies sogar zwei Stunden nach der Operation. Ls hat dieses centrale Stück des

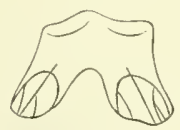

Holzschnitt 5. Thieres die Gestalt und Grösse, welche dmeh Holzschnitt 5 wiedergegeben ist. Bei weiterer Beobachtung zeigte es sich, dass jeder der zwei Lappen dieses stüekes sieh unab hängig rom anderen zusammenzog.

Am 13. April ist das Stück kleiner geworden (Holzsehnitt 6.) Es contrahirt sich jetzt dessen grösserer Lappen zuweilen kräftig, 
der kleinere weniger krïftig, beide unabhängig von einander und zwar (20 Stunden nach der Operation) ziemlich häufig. Alle in a u ch im Centrum des Ganzen beobachtet man selbständige Contractionen. Das Mikroskop zeigt deutlich, dass beirle Lappen dicht unter der ersten Verzweigung des betreffenden liadiärgefässes abgeschnitten sind. Bei der Contraction ziehen sich die Gefässe in ihrer ganzen Ausdelınung

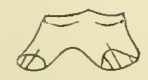
zusammen. Die Wirkung der in den Lappen stattfindenden Contractionsthätigkeit erstreckt sich in jedem derselben anfwärts bis zu der in Holzschnitt 7 angedenteten Grenze.

Am 14ten April Morgens sah ich das abermals kleiner gewordene Gewebstück sich noch schwach contrahiren. Sämmtliche übrigen Stücke der Meduse, welche Randkörper führen, sind freilich relativ und absolnt am grössten und contrahiren sich allein noch lebluaft rhythmisch.

2) Am 13. April ward eine Aurelia ron $\left.\mathrm{l}^{1}\right|_{2}$ cm Durchmesser halbirt. Der einen Hälfte

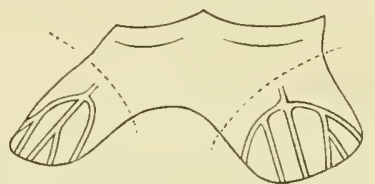

Holuschnitt 7. wurden unter dem Mikroskop die Randkörper Die vorige Figur etwa 3mal vergrössert. je mit einem kleinen Strickchen des Umbrellagewebes, welchem sie ansitzen, weggenommen und darauf wird sie in die vier Antimere zerlegt - nach kurzer "Bestürzungsperiode" treten an allen Stückchen wieder Contractionen anf', an dem einen häutiger, an dem anderen weniger häufig.

Den vier Antimeren der anderen Hälfte, welche gleichfalls isolirt worden sind, werden lie contractilen Zonen in ziemlichem Umfange ausgeschnitten — s päter als jene der ersten Hälfte fangen dieselben ebenfalls wieder Contractionen an, eines zeigt sie häufig, die anderen zeigen sie sehr selten. - Die die Randkörper führenden, aus ihnen ausgeschnittenen contractilen Zonen contrahiren sich nach Ueberwinden der Bestürzungperiode lebliaft weiter.

Genaue Zählung ergab, dass sich während je 5 Minuten Beobachtungszeit zusammengezogen :

I. Die Stückchen ohne contractile Zonen (von der zweiten Hälfte)

unmittelb. nach
der Operation.

nach 20 Minuten. nach 55
Minuten.

nach 83

nach 115

16

20

50

20

50

Minuten.

II. Die Stïckchen ohne Randkörper (von der ersten Hälfte).

23

100

nicht gezählt

100

100

35

III. Die ausgeschnittenen Stïckchen (contractile Zonen) mit Randkörper (von der zweiten HäIfte).

nicht gezählt

130
200

200
110

$325 \mathrm{mal}$. 
Dabei sst zu bemerken, dass die Contractionen von I weitans zum grössten Theile von einem der vier stückchen herrührten, welches sich sonach sehr lebhaft bewegte, während die übrigen sich nur selten einmal zusammenzogen — ohne dass ich in Stande wäre, fïr diese Verschiedenheit eine Ursache anzugeben. Aus den Zahlen aber folgt, dass die Contractionen der Stückchen I zusammen stets vie] weniger zahlreich waren, als die ron $I I$ und $I I l$ und ferner, dass die von II nach kurzer Zeit um das Fünttache zunahmen und sich auf dieser Höhe erhielten, während die von $I I$ noch erheblicher bis zum Schluss der Beobachtung fortwährend stiegen. Nach meinen zahlreichen anderen Erfahrungen darf als sicher angenommen werdes, dass nach längerer Zeit - vielleicht an folgenden Tage - die c'ontractionen von I aufgehört, während III und vielleicht anch II sich lebhaft weiter bewegt haben wïrden.

Tereinzelte Fälle, in welchen an Amelien nach Ausschneiden sämmtlicher contractiler Zonen oder nach Abschneiden des ganzen Randes ausser einer kuzen Bestürzungsperiode keine anderen Störungen während kürzerer oder längerer Zeit nach der Operation zu beobachten waren, sind mir auch früher vorgekommen. Solche Fälle sind im XIII. Absehnitt unter anderen noch speciell aufgeführt. Vor Allem bemerkenswerth ist darunter der unter D verzeichnete. Hatte ich aber, wie gesagt, solche Fälle früher nur vereinzelt beobachtet, so fiel mir um so mehr auf, dass dieselben unter meinen Kieler Versuchen geradezu die Mehrzahl bildeten, so dass ich mir sagen musste, ich würde nur schwerlich durch das Experimeut anf den Hauptsitz des centralen Nervensystems und damit ant die Verfolgung aller hier behandelten Fragen gekommen sein, wenn ich vorzugsweise operationen mit solehem Erfolg bei Beginn meiner Untersuchungen erlebt haben würde.

In welchen Umständen die Ulsache davon zn suchen ist, dass mir zuweilen bei meinen Versnchen in einzelnen Fällen, dann aber wieder in ganzen Versuchsreihen, eine so ansserordentliche Widerstandsfähigkeit der Medusen begegnete, darauf vermag ich eine durchaus erschöpfende Antwort nicht zu geben. Die Aurelien, an welchen ich früher gelegentlich Derartiges beobachtete, waren, wie ich mich genan erinnere, grosse Exemplare gewesen, die in Kiel untersuchten digegen waren sehr kleine, hatten nur $\left.1^{1}\right|_{2}$ bis höchstens $5 \mathrm{~cm}$ im Durchmesser. Die Grösse kann demuach nicht zur Erklärmg beigezogen werden. Wie wiederholt hervorgehoben wurde, sind es zunächst indiridnelle Ursathen, welche eine verschiedene Widerstandsfähigkeit versehiedener 'Thiere einer Art gegenüber operativen Eingrifien bedingen. Man wird diese Ursachen aIs in der .nervösen Constitntion“ gelegen bezeichnen dürfen. Ein Thier ist gegenüber Eingriffen in seine Organisation anf cirund der 
Beschaflenheit seines Nervensystems empfindlicher als ein anderes. Abgesehen ron dieser allgemeinen Anlage wird hervorragend wichtig für die Widerstandsfähigkeit der angenblickliche Ernährungszustand sein, in welchem sich ein Thier zur Zeit der Operation befindet: hat es kürzlich erst reichlich Nahrung aufgenommen, so wird es mehr aushalten können, als wenn es gefastet hat. Allgemein wird aber die Widerstandsfahigkeit angenscheinlich herabgesetzt durch höhere Temperatur des Wassers, in welchem die Thiere gehalten werden: wenn ich jetzt, nachträglich, meine Ergehnisse in Rückisicht auf diesen Falitor ansehe, so finde ich, dass die Versuche, bei welchen meine Thiere die grösste Widerstandsfähigkeit zeigten, in den Frühling fielen, diejenigen mit der geringsten Widerstandsfähigkeit in die heisse Jahreszeit. Die in diesem Frühling in Kiel untersuchten Aurelien insbesondere hatten Tag und Nacht kühles Wasser zum Aufenthalt, indem sie in einem sonnenlosen, nach Norden gelecrenen Zimmer aufgestellt waren. Im August des rorigen Jahres dagegen war das Wasser in der freien See bei Neapel so warm, dass es beim Baden kaum mehr Erfrischung gewährte, noch mehr errärmte es sich selbstverständlich in den Behältern der zoologischen Station. Daher wohl die Verschiedenheit, welche ich damals in den Resultaten meiner Versuche an Rhizostomen gegenüber jenen vom Frühling 1876 erlangt habe. Auch die ersten von mir über Aurelia aurita veröffentlichten Experimente. welche mir nicht einmal eine kräftige, anch nur vorübergehende Erholung der Thiere nach der Lähmung zeigten, fielen in die heisse Jahreszeit und wurden im Zimmer in Wasser ansgeführt, auf dessen Temperatur wenig geachtet worden ist.

Genaue Versuche, systematisch mit verschiedenen Temperaturgraden angestellt, würden wohl hübsche Ergebnisse in Beziehung auf die rorliegende Frage darbieten können, insbesondere wenn dabei zugleich berücksichtigt würde, wie die Thiere sich während der Lähnnung gegenüber von künstlichen Reizen verhalten. Ich fand nämlich, dass mechanische Reize, an gelähmten, übrigens kräftigen Aurelien selbstrhythmische, über den ganzen Schirm sich erstreckende Contractionen - nicht nur jene sehwachen unwirksamen lokalen - hervorzurufen rermögen. So erfolgen anf Einstechen mit der Nadel in die Umbrella häufig einige Contractionen hintereinander, zuweilen allerdings nur eine einzige. Selbst auf Hineinblasen in das Wasser, in welchem die Thiere sich befanden, habe ich solche Reaktion beobachtet. - Derartige Versnche würden wohl zu verwerthen sein für die Feststellung einer genaneren Stufenleiter des Grades der Wirkung verschiedener operativer Eingriffe. Da die Thiere bei höherer Temperatur des Wassers empfindlicher werden, so muisste sich, soweit die individnellen 
Verschiedenheiten dies gestatten, eine Grenze höchster Empfindlichkeit feststelleu lassen und von diesem Punkte ans liesse sich -- durch Beobachtnugen bei mehr und mehr niedrigerer Temperatur - jene Stufenleiter bilden.

Die Widerstandsfäligkeit ist überhaupt selbstverständlich nm so grösser, je normaler die Lebensbedingungen sind, nnter welchen die Hedusen gehalten werden. Eine der interessantesten unter den in diesem Abschnitte mitgetheilten Thatsachen haben mir znerst jene zerstn̈ckelten Thiere geliefert, welche im freien Meere in einer dem frischen Wasser zugänglichen und Nahrung enthaltenden Kiste eingeschlossen waren, die Thatsache, dass selbst der contractilen Zonen beraubte, beliebig ans dem Śchirme geschmittene Stücke von Aurelien mehrere Tage nach der Operation selbstständige Contractionen ausführten. Zu diesem Vermögen haben sich die Stücke erst nachträglich erholt, demn in der ersten Zeit nach der Operation waren sie durchaus regungslos. Es zeigt diese Thatsache noch deutlicher, als dies jede Erholung nach eingetretener Lähmung an sich schon thut, dass Nervencentren nicht nur im Gebiete der contractilen Zonen und auf den Randkörpern, sondern auch in anderen Theilen des Körpers vorhanden sein müssen, Centren, deren Thätigkeit im ganzen Thiere wohl eine sehr unbedeutende ist, die aber, auf sich allein angewiesen, zu kräftigerer Aktion sich aufraffen kann. Und ferner weisen die Kieler Versuche darauf hin, dass diese Ersatzcentren da und dort im Schirme an einzelnen Punkten wirksam werden. Denn ron bestimmten Punkten gehen die rhythmischen Contractionen in solchen Medusenstücken aus, ganz ebenso, wie dies schon von den schwachen, mwirksamen Znckungen früher beschrieben wurde, dentlich insbesondere auf künstliche Reize.

So sehr krältig die Erholung der der contractilen Zonen beraubten Medusen oder Medusenstïcke sein mochte, stets zeigte sich doch, dass sie viel weniger lange Zeit lebteu als unverletzte, zugleich mit ihnen gefangen gehaltene Controlethiere, und bemerkenswerth ist weiter, dass gewöhnlich ron Nenem Lähmung und, nachdem die Erholung auf die höchste Stufe gestiegen war, raseh, fast nach Art einescollapsus, Absterben erfolgte. Indessen habe ich Solches nur an in der Gefangenschaft gehaltenen Objekten beobachtet - ob derselbe Process auch während des freien Lebens erfolgen würde, ob anch hier speciell der contractilen Zonen beraubte Thiere nicht danernd zn leben vermögen, zur Lösung dieser Frage fehlt mir das nöthige Material. Und weun ich zum Ersatz im folgenden Erperimente herbeiziche, welche Sturm und andere feindliche Eingritfe an Mednsen in der freien Natur anstellen, und welche in der That zu beweisen scheinen, dass der contractilen Zonen beraubte Aurelien dort nicht leben können, so wird man mir 
mit Recht einwenden, dass schon die Beraubung der Sinnesorgane die Thiere im freien Leben voranssichtlich in solchen Nachtheil setzen wird, dass sie nicht danernd zu existiren vermöchten, auch wenn ihre contractilen Zonen erhalten wären. Indessen, wenn man die lethalen Folgen berücksichtigt, welche das Ausschneiden der contractilen Zonen bei Aurelia aurita stets in der Gefangenschaft gehabt hat, so mag es gerechtfertigt sein, dass ich die folgenden Thatsachen doch als einen Wahrscheinlichkeitsbeweis für die Auffissung anführe, es sei diese Operation ein Eingriff in die Organisation so schwer, dass er an sich, wenigstens bei diesem Thiere, eine länger danernde Erholung auch in der Freiheit nicht gestatte.

\section{Im freien Leben verstümmelte Aurelien.}

Bei Niendorf traf ich häufig, zuweilen in auffallender Menge an einem und demselben Tage, irgendwie, oft hochgradig, verstümmelte Aurelien in der See an. Manchen fehite nur ein kleines Stück des liandes, andere waren desselben bis auf einen geringen Rest beraubt; wieder anderen fehlte umgekehrt in grösserem oder geringerem Unfang der centrale Theil; viele erwiesen sich als Hälften, andere als Viertheile von Thieren; ja es zeigten sich freischwimmende Krüppel, welche nur ein mehr oder weniger grosses Stück des unteren Theils des Schirmes einer Meduse vorstellten. Die Krüppel schwammen so munter umber wie ganz unverletzte Thiere. Ihre Wundränder waren ineist vernarbt, was daranf hinweist, dass die Verstümmelung schon vor längerer Zeit stattgefunden haben musste. Einmal auf diese verkrüppelten Thiere anfmerksan geworden, traf ich sie viel hänfiger an, als sie mir früher aufgefallen waren: es zeigte sich, dass sie desshalb leicht der Beachtung sich entziehen, weil sie sich stets so vollsommen wie möglich, ähnlich der Form des unverletzten Thieres, zı einer Glocke zusammengezogen haben, denn nur in dieser Form ist irgend ein 'Theilstück einer ILeduse freien Schwimmens fähig. Wie früher bemerkt, habe ich auch an künstlich von mir getheilten Aurelien dieses Sichzusammenziehen zur Glockenform beobachtet, aber, in der Gefangenschaft, niemals an Strucken, welche viel unter dem Werth einer Hälfte standen. Natürlich können sich auch im freien Leben nur grössere 'Theilstïcke noch ganz glockenförmig zusammenziehen, aber selbst Stücke des unteren Abschnittes des Schirms hatten sich durch möglichste Annäherung ihrer Känder soweit ähnlich einer Glocke gestaltet, dass sie wieder schwimmen konnten. 
V rele dieser lirüppel entstehen ottenbar dadurch, dass die Quallen durch die Fäden der Netze, in welchen sie mit den Fischen zufälig heraufgezogen worden sind, durchschnitten und zerfetzt werden, oder durch die Hand der Fischer sellst, welche die Netze unsanft ron den mitgefangenen Quallen reinigen. Die meisten mögen aber entstehen durch Wirkung des Sturms und riele auch dadurch, dass die Medusen den Scheeren der Krrehse oler dem Rachen von Fischen theilweise entgehen. In Kiel, wo ich kürzlirh gleichfalls zahlreiche lírilpel von Aurelia aurita angetrofien habe, erzallten wir Fischer, dass die Jakrelen aus diesen Medusen gierig die "Angen“ wie die Laien gewöbnlich die Geschlechtsdrüsen nennen, herausfressen, und so deren centralen Theil zerstören. Kalm sagt in seiner amerikanischen Reise: „Es schwammen aber riele Jedusen auf dem Waser. . . . . Wir bemerkten an einigen derselven. dass eine Mlenge kleiner Fische. in der Lünge von drei bis vier Zollen, sich daum rerammelt hatten und in eins weg davon ptlückten" "). Oken bemerkt (a, a. O. S. 186) von den Quallen überhaupt: „sie dienen ohne Zweifel vielen Fischen und Walfischen zur Nahrung, wahrscheinlich selhst der schwalle. welche in Ustindien die sstraren Nester haut"(?). Auf Seite 251 führt er mach Iodeer (schwed. Alhandlg. 1791. S. 152) an, dass die Walfische speciell Cyanea capillata sich schmecken lassen sollen. Nach Seite 233 wird Aurelia aurita gern ron den Robben gefressen und vermuthlicb auch ron Fischen und anderen Seethieren nicht verschmäht. Weiterhin beisst es dagegen, Fische sollen keine Angel fassen, woran etwas von diesen Thieren hängt (Mfodeer).

lch selbst habe wiederholt zugesehen, wie ein Bernhardskrelss mit grossem Behagen an einer Meduse frass, indem er ein Stiick derselben um's andere mit der Scheere abriss und zum IIunde führte, während er den Rest festhielt.

Es zeigte sich num die intelessante Thatsache, dass jeder der sich frei bewegenden Krüpel wenigstens eine unversehrte contractile Zone an sich trug. Gewöhnlich war übrigens anch der Randkörper der contractilen Zone unverletzt. Genauere Beoluachtung liess erkennen, dass jeder der Krüppel irgend eine Parallele zu einem der Versuche darbot, welche ich mit dem Messer ansgefïhnt hatte, dass also zufällige äussere Insulte ganz dieselben Experimente gemacht haben, wie ich selist und zwar mit demselben Erfolg. So traf ich Aurelien, welche in zwei nur noch durch einen ganz dünnen Faden znsammenhängende Hälften getrennt waren. Jede Hälfte hatte sich zur Glocke annähernd zusammengezogen und jede contrahirte sich unabhängig bon der anderen. In einem anderen Falle fehlte der Meluse fast ler ganze Rand: nur ein einziger Randkörper sammt contractiler Zone war noch rorhanden. stand aher mit dem Hauptheil des Thieres im Zusammenhang nur durch einen dünnen Gewebsfaden. Und dieser einzige halbabgelöste Randabschnitt rermittelte nun die Coatractionen der ganzen Meduse. Ein anderer Trüppel bestand noch aus 5 Antimeren, von welchen zwei mit den übrigen drei nur durch eine änne rewebsbrücke in Zusammenhang stanclen, und ich war in der Lage, dals Verhältniss der ('ontractionen beider zu beobachten ${ }^{2}$ ).

1) Des Herren Peter $\mathrm{Kalm}$ 's, Professors der Haushaltungskunst in Aobo und Mitgliedes der königlichen Sehwedischen Akademje der Wissensebaften, Beschreibung der Reise, die er nach dem nördlichen Amerika auf den Befehl der gedachten Akademie und öffuntliche Kosten unternommen hat. I1. Theil, Göttingen 1757. Seite 128.

2) Tergleiche Abschniti IIII. 
Die Thatsache, dass die krüppel stets mindestens noch einen liandkörper samnt contractiler Zone besassen, möchte alio wohl datür sprechen, dass liein lirüppel, der sämmtlicher angeborener Contractionscentren beraubt ist, danernd leben und dass eine Erholung der dieser Centren enthehrenden Thiere nur eine rorübergehende Erseheinung sein kann. Wenn fernerhin Ausnahmen von der von mir aufgestellten Regel beobachtet werden, so möchten diese vielleicht auf 'Thiere bezogen werden, welche eben in der Erholungsperiode sich befanden; mir selbst ist unter Dutzenden ron Fällen übrigens eine unzweifelhafte derartige Ausnahme nicht begegnet.

Anffallend war mir die Menge ron fröhlich lebenden Theilstïeken olne Spmr von Mund und Magen. Aus dieser Menge zu schliessen, müssen die Aurelien entweder im Freien lange obne Nalnung leben können, oder es muss die letztere in Gefässötthungen der Bruchstellen des Körper's eingepumpt werden. In der 'That fand ich in einzelnen Fällen, in welchen ich die Anfmerksamkeit anf diesen Punkt gerichtet habe, halbverdante Nahrung in einzelnen Hanptradiärgefässen solcher mundund magenloser hriüpel. Genanere Untersuchnng zeigte, dass die grösseren Gefässe, soweit sie an dem künstlichen Bruchrande quer d ux $x$ c $\mathrm{c} h n \mathrm{it}$ en waren, klaffend geöffnet erschienen, ähnlich querdurchschnittenen Arterien. Es war dies tum so auffallenter, als die Bruchrander im Uebrigen gewöhnlich etwas zusammengezogen, wie schon bemerkt. wie rernarbt aussahen und nicht durchsichtig waren wie ein frischer Durchschnitt des Gallertgewebes. Es sind somit solche Krüppel ohne Zweifel im stande, ihr Leben dadurch zu erhalten, dass sie ilıre Nahrung durch die künstlichen Geffnungen der Gefässe einpumpen. Und dass diese Art der Ernährung selbst für Kirüppel, welche nur noch kleine Medusenstücke - etwa einen Randtheil eines Thieres - darstellen, eine ausgiebige sein muss, das dentet das angenseheinliche Wohbefinden an, in welchem dieselben umherschwimmen.

\section{Folgen des Durchschneidens oder der Loslösung der Muskelschichte.}

Von Bedentung erscheint die Frage, wie sich die Contractionen der Medusen nach alleinigem Durchschneiden der IIskelhant oder nach theilweisem Entfernen derselben verhalten. Schon in der ersten Mittheilung über meine Expẹimente habe ich dieser Frage Erwälnnung gethan, war jedoch mit bezüglichen Versuchen nicht weit gediehen. Was Forbes') durch Ablösung der Muskulatur von einem grossen

1) Edward Forbes, a Monograph of the British Naked-Eyed Medusae, 1818. S. 3. 
T'heil des schirmes beweisen wollte, dass die Bewegungen der höheren Medusen von dieser Muskulatur abhängen, kam dabei, als selbstverständlich, nicht in Betracht. Zu diesem Zweck entfernte Forbes die Muskulatur von der einen Hälfte einer Rhizostuma Aldrovandi und lähmte sie dadurch. Die andere Hälfte contrahirte sich darauf wie gewöhnlich. wemngleich mit grösserer Geschwindigkeit: „as if the animal was alarmed or suffering," Ich selbst ging bei meinen Versuchen von der Frage ans, wie es sich nit der Contractionsfähigkeit derjenigen Theile des Schirmes verhalten werde. deren Muskulatur nicht mehr oder nur noch in beschränkter Weise mit jenen der contractilen Zonen in unmittelbarer Verbindung steht und ferner, wie es mit der Contractionsfähigkeit des ganzen Schirmes bestellt ist, nachdem man die Muskulatur der contractileu Zonen entfernt hat. Da jede contractile Zone ihrer wesentlichsten Zusammensetzung nach besteht: eimmal aus Nervenzellen und Nervenfasern und danu ans den Muskelelenenteu der Subumbrella. welche den die Nervenzellen enthaltenden Abschnitt der Körpersubstanz von unten decken, so frägt es sich, kommt der Muskulatur der contractilen Zonen nicht eine grössere Bedentung zu als derjenigen anderer Gegenden des Körpers? Mit anderen Worten: setzt vielleicht der ron den Nervenzellen der contractilen Zonen und der Randkörperstiele ausgehende Impuls die Muskulatur der entfernteren Schirmtheile nur in beschränktem Maasse unmittelbar in Thätigkeit nud wirkt er nicht viehmehr anf diese wesentlich nur mittelbar in der Weise, dass er zuerst die Muskelelemente der contratilen Zonen erregt und dass diese die Erregung erst sekundär den übrigen Muskelelementen mittheilen? Die Frage nach der Bedentung und dem Grade einer unmittelbaren Fortpflanzung und Erregung durch die Elemente der Muskulatur hatte sich mir besonders lebhaft aufgedrängt, nachdem ich erkannt hatte, lass diese gebaut seien wie die Neuromuskelzellen der Hydra, bei welchem Thiere leitende Nervenfasern nicht vorkommen und wo desshalb nur ron Uebertragnng des Reizes von einem Nenromuskelelement zum anderu gesprochen werden kann. Je dentlicher also durch alleinige Durchschneidnng der Muskulatur die Fortptlanzung der Contraction von den contractilen Zonen aus gehemmit erschiene. um so geringer würde die früher von mir ausschliesslich hervorgehobene Bedeutung von Nervenfäden für die Leitung werden. Allein es zeigen die anatomischen Verhältnisse, dass es nicht möglich sein wird, ohne Verletzung von Nerrenzellen und leitenden Nervenfätlen dort auch nur einen Schnitt in die Subumbrella zu machen. Somit beweisen meine Versuche, so auffallende Resultate sie auch ergeben, nichts für die unmittelbare Uebertragung der Erregung von Muskelelement zu Muskelelement und es wird durch sie im Wesentlichen nichts geändert an meiver ursprünglichen Aunalme: es seien Nervenfäden, welche die physio- 
logische Verbindung zwischen den contractilen Zonen und der Muskulatur vermitteln - dennoch aber wirả anch die Voraussetzung einer gleichzeitigen unmittelbaren Uebertragung von Muskelelement zu Muskelelement aut Grund der bei Hydra vorhandenen Verhältnisse nicht ohne Weiteres von der Hand gewiesen werden können. Trotzdem dass so die folgenden Ergelmisse nicht von der fundamentalen Bedeutung sind, welche man ohne Kenntuiss des anatomischen Banes annehmen müsste, so haben sie doch in solchem Grade mein Interesse erregt, dass ich sehr bedaure, durch die Ungunst der Verhältnisse an erschöpfender Verfolgung der ihnen zu Grunde liegenden Versuche gehindert worden zu sein.

Schon im Jahre 1S74, aber erst am Schlusse meiner Niendorfer Studien, hatte ich an ausgeschnittenen Antimerenstücken von Aurelia bemerkt, dass es nicht des Durchschneidens der ganzen Dicke der Umbrella bis anf eine Verbindungsbrücke von einer gewissen Breite bedurfte, um die Fortpflanzung der Contractionen von der contractilen Zone auf den jenseits der Brücke gelegenen Abschnitt des Theilstückes zu verhindern, dass vielnehr hiezu entsprechende, wenig tiefgehende Einschnitte in die untere, die Muskelschichte tragende Fläche genügen. Modificirte ich also den auf Seite 24 beschriebenen, und durch Holzschnitt 1 illustrirten Versuch derart, dass ich z. B. an der Unterflache des Antimers von rechts und von links je einen Schnitt führte, so leicht, als wollte ich nur die Muskelschicht durchschneiden, so setzten sich die Contractionen der contractilen Zone immer nur so lange anf einen benachbarten Theil fort, als dieser durch ein Streifchen Subumbrella von bestimmter Breite - nur wenige mm mit jener in Verbindung stand. Ward diese Verbindung noch schmäleroder ward sie a ufgehoben, soblieben die Contractionen a uf den mit der contractilen Zone versehenen Abschnitt beschränkt. - Wem also meine ersten Versuche gelehrt hatten, dass die physiologische Verbindung benachbarter Theile ungestört sei so lange als dieselbe durch eine Gewebsbrücke von einer gewissen Breite hergestellt werde, so würden die neneren zeigen, dass diese Gewebsbrücke nothwendig die Muskelschichte unverletzt enthalten muss und dass nach deren Durchschneidung die Fortleitung der Bewegnngen alsbald aufhört - vorausgesetzt, dass mit dem Schnitte nicht anch die unter der Muskulatur gelegenen Nervenfäden durchtrennt worden sind, eine Voranssetzung, welche aber nach dem Mitgetheilten nicht statthaft ist.

An Cassiopea in Neapel gemaclite Versuche führten beispielsweise zu folgenden Ergebnissen:

An dem Antimerenstück A (Holzschnitt 8) führte ich $9 \mathrm{~mm}$ oberhalb des Oto- 
lithensäckchens(o) den 8 mm langen Schnitt aa quer durch die Subumbrella. Sodanm

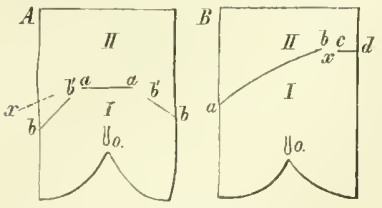

Holzschnitt 8. führte ich jederseits einen schnitt bl' vom Rande des Antimerenstückes so weit gegen a, dass zwischen a nnd $b^{\prime}$ jederseits eine nicht durchschnittene Muskelbrücke von $2 \mathrm{~mm}$ Breite bestehen blieb: Die C'ontractionen pflanzten sich jetzt von I auf II fort wie vor dem Einschueiden.

Dabei ist ïbrigens zu bemerken, dass die Contractionen an solchen Antimerenstücken von Cassiopea sich zuweilen durch kräftiges Einklappen von I gegen Il zuerst anzeigten - zuweilen aber durch Einklappen von II gegen [ insserten. Ersteres rührt oftenhar daher, dass die Musku]atur in II kräftiger ist als in I. Dass die Contractionen immer von I ihren Ausgang nehmen, beweist schon allein der weitere Verlauf des Versuchs.

Waren die Schnitte $b^{\prime}$ gegen a bis auf 1 mm Entlermmng fortgesetzt, so zog sich nur noch I rhythmisch zusammen; fortchanerndes schwaches Einklappen von II, an dentlichsten in der Gegend von $\mathrm{x}$ glanbte ich von vornherein anf Mlithewegung beziehen zu müssen, eine Ansicht, welche die mikroskopische Beobachtung bestätigte. Als ich nämlich den Antimer unter das Mikroskop legte und das Verhalten der Muskulatur von I einerseits und von II andererseits verfolgte, zeigte es sich, dass mu die Fädeu des erstgenamnten Theils sich noch zusammenzogen, nicht mehr diejenigen von II. Es ergab sich aber weiter, dass beide von der Muskulatur gebildeten Verbindungsbrücken keine Fasern mehr enthielten, welche von einem Theil in den anderen hinüberreichten - beide Brücken enthielten vielmehr nur Faser'n ocler Stücke von Fasern, welche genan in der Richtung vom Endpunkte der einen Schnittlinie (a) zn dem der anderen hinüberliefen, so dass eine ausschliesslich durch die Muskulatu vermittelt gedachte physiologische Verbindung zwischen I und 11 num noch möglich gewesen wäre durch Uebertragung von einem Muskelelement zum anderen in einer likchtung, welche zn jener der Längenansdehnnng derselben senkrecht gedacht ist.

Einen anderen Versuch machte ich in der Weise, dass ich an einem Antimerenstück, B, einen Schnitt ab durch die Subumbrella führte. Die undurchschnittene Strecke bd mass $6 \mathrm{~mm}$. Dic Contractionen pflanzten sich wie vor dem Einschneiden von 1 auf $I I$ fort. Daranf machte ich den Schnitt de: die Verbindnngsbrücke x war noch $2 \mathrm{~mm}$ breit - die Contractionen pflanzteu sich jetzt nicht mehr auf Il fort. Die mikroskopische Untersnchung zeigte äbrigens, dass die Verbiudungsbrïcke aus ganz ebenso gerichteten Fasern zusammengesetzt war, wie vorhin.

In einem dritten Falle führte ich an der Untertläche eines Antimerenstüclies jederseits einen schnitt schräg von unten und aussen nach oben und innen, so dass 
beicle Schnitte wieder $6 \mathrm{~mm}$ oberhalb des Otolithensäckchens endigten und zwar in einer Entfernung von $2 \mathrm{~mm}$ voneinander. Die Contractionen pflanzten sich noch von 1 auf II fort und anch damn noch, als che beiden Schnitte bis anf $1_{12}^{1} \mathrm{~mm}$ genähert waren - erst nach völliger Trennung hörte hier die physiologische Verbindnng auf. Ueber den Zug der die Brücke bildenden Muskelelemente habe ich nichts vermerlit. Ob dieser oder ob Reichthum an darunterliegenden Nervenfäden in jener Gegend die Ursache davon war, dass die Leitung in diesem Falle so lange ungestört blieb, vermag ich demnach nicht zn sagen.

Sehr bemerkenswerth ist die Thatsache, dass die in geschilderter Weise behandelten Antimerenstücke von Cassiopea sich in den Behältern der zoologischen Station bald wieder erholten: im Lanfe der folgenden Tage stellte sich die physiologische Verbindung zwischen den Bezirken I und II wieder her und die Contractionen fanden weiterhin ganz ebenso statt wie an Stücken, in deren Muskelhaut ich nicht eingeschnitten hatte.

Von hervorragender Wichtigkeit ist mun die Frage, wie sich das Contractionsvermögen verhält, nachdem man die contractilen Zonen oder einzelne Antimere durch mehr oder weniger tiefe, erstens von der oralen und zweitens vou der aboralen Schirmfläche aus in das Gallertgewebe geführte, aber dieses nicht ganz durchtrennende Schnitte vollkommen abgegrenzt hat. Als ich an einer grossen, etwa $20 \mathrm{~cm} \mathrm{im}$ Jurchmesser haltenden Aurelia aurita durch einen etwas oberhalb des Schirmrandes nnd parallel mit diesem im ganzen Untange des Schirmes verlanfenden Schnitt die Subumbrella und zugleich etwa die Hälfte der Dicke des Gallertgewebes durchtrennt latte, pflanzten sich die Contractionen während längerer Zeit nicht mehr in den centralen Theil des Thieres fort. Ditgegen hatte der Schnitt, welchen ich an einer anderen Aurelia in derselben Richtung und Tiefe, aber in die Aussenfläche machte, viel geringeren Einfluss anf die Contractionen, indem das Thier in Folge desselben kanm Bestürzung zeigte und dann dieselben ungeschwächt fortsetzte. Mehrere ähnliche Versnche habe ich an grossen Aurelien rom Boote ans in der Weise gemacht, dass ich die Thiere zum Zweck der Operation nicht ans der See herausnahm, sondern vielmehr den Cirkelschnitt im Wasser selhst ausfülnte. So war ich am besten im Stande, den normalen Erfolg der Operation zu beurtheilen; nur war es jetzt ummöglich, die Thiefe des Schnittes der Art zu controliren, dass ich sagen konnte, ich hätte ihn ringsum genan etwa dureh ein Drittel oder durch die Hälfte der Umbrella geführt. lch begnügte mich daher bei dieser Art des Experimentirens damit, stets so tief einzuschneiden - sei es von innen nach anssen oder nmgekehrt - als es ohne eine vollständige Trennung herbeizuführen möglich war. 
Durchschnitt ich dabei auch zufällig an der oder jener Stelle die Umbrella vollständig, so konnte dies die Beurtheilung des Erfolges des Experiments nicht wesentlich stören, eingedenk der Thatsache, dass ja ein einziger Antimer in Verbindung mit dem Körper belassen durch seine Randnervencentren dessen Contractionen ebenso regelt, wie wenn alle acht noch daran erhalten sind. Es zeigte sich nun bei diesen Versnchen das Folgende: war ein Schnitt etwa $3 \mathrm{~cm}$ oberhalb des Randes rings $n$ m das Thier (von $20 \mathrm{~cm}$ Durchmesser) an der oralen Seite geführt worden, so dass der Zusammenhang der Theile nur noch durch eine ganz dünne, der convexen Schirmoberfläche aùgehörige Schicht der Umbrella vermittelt wurde, so war die Verbindung zwischen Rand- und Mittelstück gewöhnlich längere Zeit - einige Minuten — gestört. Nach Ueberwinden der Bestürzungsperiode begann das Ringstück sich wieder rhythmisch zu contrahiren, ohne dass die Contractionen sich zunächst anf das Mittelstück fortpflanzten. Sonach war jetzt eine Fortbewegung des Thieres durch Rüchstoss noch unmöglich. Allmälig aber, znerst anscheinend nur von der einen oder der anderen Stelle des Randes ans, pflanzten sich die Contractionen, Anfangs nnvollkommen und dann immer rollkommener über das Mittelstück fort, so dass das 'I'hier mehr und mehr wieder das Vermögen erhielt, sich glockenförmig zusammenzuziehen und nach beliebiger Richtung kräftig davon zu schwimmen.

Es ist dieser Versuch von besonderer Wichtigkeit, desshalb, weil er dentlich zeigt, dass im Gallertgewebe verlanfende Nerven eine Verbindung zwischen den einzelnen Theilen des Thierkörpers thatsächlich herstellen und dass es jedenfalls nicht etwa die contractilen Elemente der Subumbrella oder die ummittelbar derselben angelagerten Nerven allein sind, welchen in jenem simne Bedentung zukommt. Die in der ersten Zeit nach der Operation anfgetretenen Erscheinungen dürfen wohl so gedentet werden, dass die in der aboralen Umbrellaschicht noch unverletzt vorhandenen Nervenfäden zuerst nicht im Stande sind, die Verbindung krätig und in ilırem ganzen Unfange zu vermitteln, dass sie vielmehr erst nach einiger Uebung an ilne Aufgabe gewöhnt und dazu fühig werden, eine vollkommene Brücke für den Nervenstrom über die Schnittwunde hinüberznschlagen - d. h. es vicariiren jetzt aborale Nervenfüden für oral gelegene.

Fülnte ich denselben Schnitt wie vorhin, aber umgekehrt von der aboralen Fläche des Thieres ans, so dass die Umbrella bis nahe zur Muskelschichte durchschnitten war, so waren die in Folge der Operation anftretenden Störungen viel geringere. Das operirte 'l'hier' war mur kurze Zeit gelïhmt und begann bald wieder normale Contractionen. Es frägt sich, ob ans dieser 'Thatsache irgend anf liraftigere Verbindung der lörpertheile durch Nerven an der Subumbrellaseite oder aut gleich- 
zeitige unmittelbare Leitung durch die Muskelelemente der Neuromuskelzellen geschlossen werden darf: der geschilderte Untersehied im Erfolg der beiderlei Experimente ist schon desshalb selbstverständlich, weil im ersten Falle, nach Einschneiden in die orale Fläche, das unmittelbar bewegende Werkzeug verletzt ist, die Coordination der Bewegung der getrennten Theile also eŕst wieder gesucht werden muss. Wunderbarer sogar als der Grad der Störung ist die rasche Wiederherstellung dieser Coordination. In allen Fällen war dieselbe bald so vollständig, dass ich von den um mein Boot herumschwimmenden Thieren nach kurzer Zeit wiederholt solche wieder einfing, welche durch den Subumbrellaschnitt operirt waren, weil ich sie wegen der Sicherheit ihrer Bewegnugen für noch nicht operirte hielt.

In schroffem Gegensatz zu Aurelia amrita verhielt sich Cyinea capillata: vier oder fünf grosse Thiere dieser Art sanken, nachdem ich den Subumbrellaschnitt an ihnen ausgeführt hatte in gleicher Weise auf den Meeresgrund und ich fand sie dort noch eine halbe Stunde nach der Operation in derselben Lage, welche sie zuerst eingenommen hatten. Dazu ist aber zu bemerken, dass es nicht möglich war, diese Thiere in der See zn operiren, dass sie vielmehr zu diesem Zwecke in das Boot hereingenommen werden mussten, ein Umstand, durch welchen freilich der grosse Unterschied im Erfolg des Experiments gegemüber von Aurelia meiner Ansicht nach nicht in seinem ganzen Umfange erklärt werden kann, denn ich fand schon bei meinen ersten Versuchen (1873), dass Cyanea überhaupt viel weniger widerstandsfühig ist als Aurelia.

Bemerkenswerth ist die rasche Erholung von Aurelia auch gegenüler der nachhaltigen Wirkung, welche die an Cassiopea angestellten, früher gesehilderten Versuche gehabt haben, obwohl dieselben viel weniger eingreifend gewesen sind. Allein es darf dies nicht ohne Weiteres auf Verschiedenheit in der Widerstandsfähigkeit der Thierart geschoben werden, vielmehr ist mit zu berücksichtigen, dass ich auch die Operationen an Cassiopea ausserhalb des Meeres gemacht und hier sogar in ihrem Verlanf beolnachtet, ferner, dass ich sie in der heissesten Jahreszeit und endlich, dass ich sie an Theilstiicken angestellt hatte, welche stets weniger widerstandsfithig sind als ganze Thiere.

Um das Vermögen jedes einzelnen Contractionscentrums nach Durchschneiden der Muskulatur zu beurtheilen, machte ich folgenden Versuch: An einer Rhizostoma vou $20 \mathrm{~cm}$ Durchmesser im Lichten der Schirmöffuung schuitt ich um jeden der acht Randkörper in einem Radius von $15 \mathrm{~mm}$ vom Schirmrand bis wieder zum Schirmrand in halbkreisförmiger Linie in die Subumbrella eir. Zum Zweck des Operirens hatte ich das Thier aus dem Wasser heransnehmen müssen, es wurde desshalb, besonders in Folge seiner schwerfälligen Grösse, etwas misshandelt. Nach der Operation wieder ins Wasser zurückgebracht, war es zuerst bewegungslos. Nach einigen Minuteu begannen einzelne der durch den in die Subumbrella gefülnten 
Schnitt begrenzten, die Randkörper umgebenden Theile des Schirmrandes Contractionen zu machen, welche sich auf den liest des Schimes nicht fortsetzten. Die Contractionen der einzelnen Randkörperbezirlie waren nicht synchronisch, sondern jeder derselben contrahirte sich für sich. Die Beobachtung war schwierig, weil die Zusammenziehungen nur vereinzelt und selten auftraten. Zuweilen schienen dieselben sich anch auf die ansserhalb der Schnitte gelegenen Iiandtheile fortzupflanzen. - Nach zwei stunden war es dentlicher, dass sich in der That jeder der umschnittenen Randkörperbezirke für sich contrahirte; wenngleich selten, so beobachtete ich aber doch zuweilen, dass sich der ganze liand zu gleicher Zeit znsammenzog. Die Contractionen erschienen spärlich. Vor der Operation hatte das Thier ihrer 46 gemacht. Am anderen 'Tag war es — bei grosser Hitze - gestorben. Der Versuch - und mit ihm ein anderer mit ähnlichem Erfolg — war im Augnst 1877 in der zoologischen station angestellt worden. Es zeigte sich, wie ums dem Mitgetheilten hervorgeht, zwei Stunden nach der Operation die Erholung, welche bei Anrelia im freien Heere nach gewaltsamerem Eingriffe schon nach einigen Minuten eingetreten war. Die durch die Muskelschichte geführten Trennungslinien begannen durch die Thätigkeit der das Gallertgewebe durchziehenden Nervenfäden so weit überbrückt zu werden, dass die Contractionen der durch die Schnitte umschriebenen Randkörperbezirke sich anf die Umgebung fortpflanzten, dass Gesammt-Contraction des ganzen Schirmrandes, bezw. des ganzen Schirmes wieder begann. Vollständige Erholung würde sicher schon weit früher eingetreten sein, hätte das Thier unter günstigeren Verhältnissen geleht, denn die Versuche bieten in ihrem Erfolg einen bedentenden Gegensatz zu jenen im Frühjahr des vorhergehenden Jahres an lihizostoma angestellten, nach welchen selbst Ausschneiden der contractilen Zouen nur ganz vorübergehende Wirknng gehabt hat. Ls braucht übrigens nicht besonders hervorgehoben zn werden, wie hübsch gerade der beschriebene Versuch zeigt, dass die Zusammenziehungen des Schirmes sich von der Umgebung der Randkörper aus verbreiten und wie sehr zu solchen und ähnlichen Beweisen gerade weniger widerstandsfähige Thiere geeignet sind.

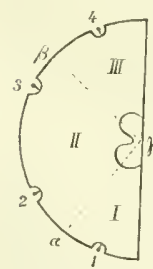

Holzschnitt 4 .

Mit den geschilderten Thatsachen stimmt auch der Erfolg eines weiteren Experiments überein: nachlem ich eine Aurelia aurita ron $20 \mathrm{~cm}$ Durchmesser halbirt hatte. schnitt ich an der Unterseite des Schirmes im Interradius zwischen den Antimeren l mul 2 (Holzschnitt 9) vom Rande bis zum Centrum $(\alpha-\gamma)$ derart ein, dass Muskelschicht und die Hälfte der Dicke der Gallertscheibe getrennt waren. Es zeigte sich nun, dass das in der geschilderten Weise unvollständig ron den äbrigen getrennte Achtel I der Meduse sirh wähend längerer Zeit nicht 
mehr nothwendig gleichzeitig mit jenen contrahirte: zwar konnten die Contractionen beicter gleichzeitig stattfinden, es war dies jecloch offenbal nur Zufall: meist folgten diejenigen des einen 'Theils jenen des anderen nach orler beide geschahen in ganz verschiedener Weise.

Nun machte ich einen zweiten Schnitt $(\beta-\gamma)$ in derselben Richtung wie vorhin, allein diesmal zwischen den Antimeren 3 und 4 and zwar führte ich den Schnitt jetzt nicht über die concave, sondern über die convexe Oberfläche des Schimes, so dass dieser bis zum halben Durchmesser seiner Dicke durchgetrennt wurde. Die Contractionen zwischen dem auf diese Weise unvollständig abgetrennten Antimer 4 und den beiden benachbarten 3 und 4 blieben synchronisch.

Einen sebr bemerkenswerthen Ausualımsfall in der vorliegenden Frage scheint die im XIIl. Al,schnitte, Versnch A, erwïhnte Aurelia darzubieten, welche ich im freien Meere derart verkrüppelt auffand, dass sie wur noch aus zwei Lappen hestand, von denen der eine 3, der andere 2 Randkörper enthielt und weIche beide nur noch durch eine Verbindungsbricke von $13 / 4 \mathrm{~cm}$ Breite zusammenhingen, während 3 Antimere fehlten. Die Contractionen beider Lappen waren nicht mehr syuchronisch, sondern sie geschahen unabhïngig von einander. Genaue Untersnchung zeigte, dass die Verbindungshrücke nur oben unverletzt war, während unten die Muskulatur und sogar ein Theil des Gallertgewebes fellte. Man sollte annelimen, es hätten die zwei Lappen dieses Krüppels lïngst Zeit gehabt, die Leitungsverbindung zwischen sich wiederherzustellen, noch bevor derselbe in meine Hinde kam, sofern diese Wiederherstellung überhaupt möglich wäre. Es steht der Fall also scheinbar nicht in Uebereinstimmung mit den übrigen geschilderten. Es wird dersellbe jedoch dadurch verständlich, dass, wie aus anderen Experimenten zu schliessen ist, der Nervenreichthum im Gallertgewebe vom Rande nach dem Centrum hin abnimmt. Ich erinnere in dieser Beziehung an die früher erwähnte Thatsache, dass zum Zweek der Erhaltung der Continuität der Leitung zwischen zwei unvollkommen getrennten Umbrellagebieten die Verbindungsbrücke in der Gegend des Centrums eines Thieres stets breiter sein muss, als in der Nïhe des Randes ${ }^{1}$ ).

Einen sehr wichtigen Versuch stellte ich endlich an Cassiopea borbonica gleichfalls zu Neapel 1977 - an.

Unmittelbar um die Wurzel aller acht Randkörper herum, also im Gebiete der contractilen Zonen, entfernte ich im Umkiseis von einigen Millimetern die Muskelschichte durch leichtes Schaben mit dem Scalpell. Nachdem erst sieben Randkörperbezirke operirt waren, geschahen die Contractionen des 'Thieres noch durchaus normal - sowie aber anch der achte operirt war, ward dasselbe ebenso regungslos, wie wenn ihm alle 8 contractilen Zonen ausgeschnitten worden wären. Einige Zeit nach der Operation zeigten sich im Rande Spuren von Contractionsversuchen und zwar von durchaus rhythmischen. Diese Versnche wurden bald dentlicher, waren aber nicht im Stande, erhebliche Wirkung hervorzurufen: die Erschei n ung machte den Eindruck, als ob das Thier bei vollem Bewusstsein Contractionen ausführen wollte, ohne im Stande zu sein, das Gewollte

1) Vergl. den VI. Abschnitt. 
a uszuführen. So setzte es den ganzen Tag über seine vergeblichen Versuche fort, schwebte wie verzaubert im Wasser. Zu meiner grossen Ueberraschung hatte es sich aber am folgenden Tage durchaus erholt, schwamm wieder lebhaft umher, als ob nichts mit ihm geschehen wäre. Die Untersuchnng der operirten Stellen zeigte, dass deren Randabschnitt gegen die Unterseite des Schirmes hin umgeschlagen war, so dass man ihn wieder nach aussen umschlagen musste, um den von Muskulatur entblössten Bezirk sehen zu kömnen. Ausser diesem als Folge der Operation leicht erklärlichen Zustande war keine Veränderung an den operirten Bezirken zu bemerken.

Bei Cassiopea ziehen, wie schon gelegentlich erwälnt, von der Umgebung des Randkörpers und zwar ron einem dort an der Subumbrellaseite gelegenen, etwas hervoragenden Krnötchen ans, die Muskelelemente in radiären Zügen ab. Es ist klar, dass nach Zerstörung clieser Muskelzüge der von den Nervenelementen der contractilen Zonen, bezı. der liandköıper, ausgehencle Impuls zur Contraction sich nicht mehr anf die übrigen Schirmabschnitte fortpflanzen kann, sofern die letzteren diesen Impuls, wenn auch nicht ausschliesslich so doch wesentlich, erst mittelbar von der Muskulatur der contractilen Zonen, bezw. von den eventuell deren Elemente verbindenden Nervenfäden zugeleitet erhalten würden. Eine genane Kienntniss der Beziehungen solcher Nerven zur Muskulatur würde nothwendig sein um entscheiden zu können, welche Bedentung in der Frage jenen und welche der Muskulatur an und für sich zukounmt. Jedenfalls ist es auch in diesem Falle nicht möglich, dass das Entfernen der Submmbrella geschehen sein konnte ohne gleichzeitige Verletzung und Entfernung zahlreicher Nervenelemente. Zweifellos war aber der ce ntra 1 e Apparat nm kurze Zeit gestört, wie die Thatsache beweist, dass bald nach der Operation wieder rhythmische Contractionsversuche anftraten und fortdanerten. Alles erwogen, scheinen die folgenden Arten der Erklärung möglich zu sein: der Centralapparat steht in nächster Verbindung mit der Muskulatur der contractilen Zonen und wird dadurch unter normalen Verhältuissen anch die rhythmische Bewegung des übrigen 'Theils des Schirmes mittelbar besorgt. Virekte Verbindung mit dem letzteren ist ausserdem vorhanden, aber gewöhnhch kaum in Gebrauch. Nachdem die Hauptverbindung entfernt, zugleich auch der Centralapparat selbst verletzt ist, ist die sekundäre zunächst zu schwach, um die Leitung zu hesorgen. Erst allmälig, unter dem Druck ihrer Aulgabe, stärkt sich dieselbe und übernimmt allmälig die Hanptleitung: es vicariiren aborale Nervenfasern für orale.

Was die Verletzung des centralen Apparates angeht, so stellt sich die Frage: entweder es waren nur so wenige Nervenzellen im Gebiete der contractilen Zonen zerstört, dass die unzerstörten allein oder zusammen mit den auf den Randkörpern 
gelegenen bald wieder den Impuls zn rhythmischen Contractionen gebeu konnten, oder es sind die massgebenden centralen Nervenzellen in jenem Gebiete gänzlich zerstört gewesen und es haben dafür diejenigen der Randkörper genügt, den Impuls zu geben. Nach dem anatomischen Befund ist das Erstere anzmehmen und würde also aus dem Versuche auf eine Betheilignng der Raudkörper am Bewegungsimpuls nicht mit Sicherheit geschlossen werden können. Ich bedaure, dass ich nicht in der Lage gewesen bin, den interessanten Versuch wiederholt anzustellen. Leider würde es wohl nnmöglich sein, denselben in der Weise zu modificiren, dass man versuchte, denjenigen Theil der contractilen Zonen, welcher die Nervenzellen führt, möglichst zu eliminiren unter Schonung der Subumbrella und der Randkörper, um die Bedentung der letzteren für die ryhthmische Bewegungsfähigkeit festzustellen.

\section{Art des Absterbens der Aurelien und ihrer Theilstücke.}

Hervorragend bemerkenswerth für die Bedentung derjenigen Bezirke des Umbrellagewebes, welchen die Randkörper unmittelbar ansitzen, ist die Art des allmäligen Absterbens der Thiere und ihrer Theilstücke. Bei meinen Beobachtungen handelt es sich nm Aurelien, welche, in Gefässen im Zimmer gehalten, in Folge der Nachtheile der Gefangenschaft allmälig zu Grunde gegangen sind. Wir nehmen zum Ausgangspunkt der Beschreibung die Erscheinungen des Absterbens eines einzelnen, aus dem Thiere ansgeschnittenen Antimers, welcher in der Mitte seines unteren, natürlichen, Randes den Randkörper trägt; gewöhnlich beginnt etwas oberhalb der Mitte der Länge des Antimerenstückes und zwar in dessen ganzer Breite die Gallertmasse znerst zu verderben, sich mehr und mehr zu erweichen, und der Auflösung anheimzufallen. Allmälig schreitet die Zone der Auflösnng nach oben und unten fort, wird höher und höher und bildet so ein mehr oder weniger unregehmässiges Band. (Holzschnitt S, A bei a.) Schliesslich trennt sich der Antimer durch Zerfliessen der Anflösungszone in zwei Stücke, in ein oberes, welches einem Abschnitte des ursprünglichen Centraltheils des Thieres entspricht und in ein unteres, welches den Randkörper trägt. Das Erstere ist schon vor der völligen Tremnung regungslos; es ist Anfangs anch ziemlich fest und prall und verdankt seine Erhaltung wohl der bedeutenderen Dicke, welche der Gallertschirm in der Gegend der Kimpe hat. Es löst sich aber im Verhältniss zum nnteren Stücke sehr rasch anf, ist vollstäudig zu einer

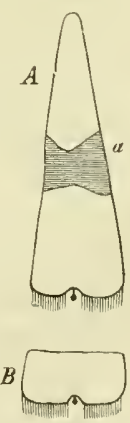

Holzschnitt 10. 
schleimigen Masse zerfallen zu einer Zeit, da das letztere sich noch lebenskrätig rhythmisch contrahirt. Jieses stirbt unterdessen aber gleichfalls weiter ab und zwar zunächst wesentlich von seinem oberen Wundrande aus, also von oben nach unten. Indem es so immer kürzer und kürzer wird, gestaltet es sich allmälig zu einem schmalen Bande, dessen Seitenränder selbstverständlich gleichfalls Wundränder sind, während der untere Rand ein Stäck des natürlichen S'chirmrandes darstellt und in seiner Mitte, wie Anfangs der Antimer, den Randkörper trägt (vergl. Holzschnitt S, B). Allmälig beginnen nun aber. zugleich mit dem oberen, anch die seitlichen Wundränder einzuschmelzen und rückt die Auflösung allseitig gegen das Contractionscentrum mehr und mehr vor. Zuletzt ist von dem gauzen Antimer nichts mehr übrig, als der Randkörper sammt einem kleinen Stückchen Gewebes, welches meist einen nach oben convexen halbkreisförmigen Wundrand besitzt. Lieses dem Randkörperstiele anhaftende Gewebsstrïckchen kann in manchen Fällen so klein sein, dass man die Lupe zu Hülfe nehmen muss, um es deutlich zu erkennen und noch immer macht es rhythmische Contractionen. Solche Stückchen erhalten sich џии muverhältnissmässig lange am Leben, ohne sich weiter zu ver-

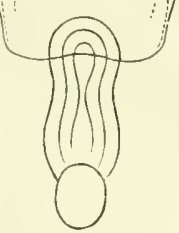
kleinern - sie dürfen wohl bezeichnet werden als die physiologisch präparirten eontractilen Zonen im Zusammenlıang mit dem Randkörper. In Holzschnitt 11 ist ein derartiges Gewebsitückchen abgebildet. Wasselbe mass, ron dem daranhängenden Randkörper abgesehen, $0,015 \mathrm{~mm}$ in der Höhe nnd $0,035 \mathrm{~mm}$ in der Breite und stammt von Holsschnitt 11. einer kleinen, nur etwa $3 \mathrm{em}$ im Durchmesser haltenden Aurelia aurita, welche ich in wenig Seewasser, das ich nicht ernenerte, habe absterben lassen. Das Stückchen stellt einen kleinen Sack dar - ein 'Theil der-später zu beschreibenden 'Tasche, in welcher der Randkörper liegt. Die vordere, dem Beschaner' zugekehrte Wand des Sackes entspricht dem Polster, welches die änssere Riechgrube trïgt (vergl. Tafel I Fig. 2, P). Die punktirten Bogen, welche man dureh sie hindurch sieht, beziehen sich anf die optischen Durchschnitte der Wand der zwei im Innern der Wandkörpertasche gelegenen, nach oben blind endigenden Gruben, welche wir später nnter dem Namen der innern Riechgruben näher kennen lernen werden (vergl. Tafel 1 Fig. 1, gr' nnd die anatonische Beschreibung). Schneidet man, statt eines Antimers, wie im geschilderten Falle angenommen worden ist, irgend ein kleines Randstück mit dem Contractionscentrum in beliebiger Unregelmässigkeit aus, so zeigt sich bald, dass immer diejenigen Theile zuerst absterben, welche von jenem am weitesten entfernt sind, so dass dasselbe bald in die Mitte des natürlichen Randes und in gleiche Entferunng von allen Grenzen n̈berhaupt zu liegen gekommen 
ist, woranf dann die Auflösung weiter concentrisch gegen den landkörper hin fortsehreitet. An den kleinen Aurelien, die mir von Kỉel nach T'übingen geschickt worden sind, machte ich entsprechende Beobachtungen, welche anch nach anderer Seite hin Bemerkenswerthes darbieten. Einige der Thiere hatten von der Reise ziemlich gelitten, manche waren theilweise zerfetzt nnd die Contractionen der meisten waren schwach und selten. Ich zerschnitt dieselben in verschiedener Weise, viele so, dass ich unregelmässige Stückchen bildete, deren jedes ein Contractionscentrum enthielt und legte Alles zusammen in ein Uhrschälchen mit M. Schultze'schem Jodserum, in der Alsicht, gewisse Gewebselemente zu isoliren. Zn meinem Erstannen fand eine alsbaldige Anflösung nicht statt, sondern im Gegentheil, es erholten sich die Gewebsstückchen und was davon Contractionscentren hatte, begann nach einiger Zeit sich kräftiger und rascher zn contrahiren. Allmälig trat Absterben in der Peripherie in der vorhin beschriebenen Weise ein. Aber obgleich ich gar keine besonderen Mittel zur Erhaltung anwendete, abgesehen davon, dass ich zurveilen das Jodsermm ermenerte, in welchem sich aber jeweils bald wieder zahllose Bakterien und Monaden einfanden, danerte es volle 10 Tage, bis die Stückchen so klein geworden waren, dass sie mur schwer und nur an der Hand der als bramen Punkte in die Augen fallenden Randkörper aus dem Detritns heraus zu erkennen waren. Bei genanerer Betrachtung ergab sich, dass den etwas gequollenen aber doch noch lebhaft flimmernden Randkörperstielen wiedermm nur noch je ein ganz kleiner Rest des Schirmrandes anhing. In dieser Gestaltung lebten die Theilchen num noch längere Zeit, bis sie sich rasch ganz auflösten. - Die Thatsache, dass die Gewebsstückchen trotz ungüustiger Verhältnisse Anfangs so langsam abgestorben sind, ist wohl nur dadurch zu erklïren, dass sie sich durch das in Jodserum enthaltene Eiweiss ernährt haben. - In einer dem beschriebenen Vorgange ganz entsprechenden Weise scheinen nun nach den von mir gemachten Beobachtnngen anch ganze Aurelien abzusterben. Ich sah nämlich wiederholt an solchen zuerst eine ringförnige Zone, etwa in der Mitte zwischen dem Centrum nur dem Raude des Schirmes sich auflösen, so dass eine Theilmng in die Kuppe und einen Randring erfolgte. Nachdem der letztere durch Absterben vom Wundrande ans auf eine gewisse Breite reducirt war, entstanden durch Auflösung in den Interradien S Stücke, deren jedes in der Mitte des unteren, natürlichen Randes einen Randkörper trug. Und num schritt das Absterben in der vorhin beschriebenen Weise . weiter fort.

Einige specielle hierher gehörige Fälle werden im XIII. Abschnitte noch erwïhnt werden, in welchem ich nach den Notizen meines Tagebuchs Belege auch für andere der im Vorstehenden ansgesprochenen Sätze beibringen will. 
Ans dem Mitgetheilten wird man mit Recht schliessen, es sei in den geschilderten Thatsachen der Einfluss der Bewegungscentren dadurch gezeichnet, dass das Leben stets an denjenigen Stellen zuerst schwindet, welche diesen Einfluss am meisten entzogen, weil sie von ihnen am meisten entfernt gelegen sind.

Nun habe ich aber beobachtet, dass auch z. B. Achttheile von Aurelia aurita, welche zwischen zwei contractilen Zonen ansgeschnitten worden waren - Zwischenantimere - längere Zeit nach der Isolirung anfingen, rhythmische Contractionen zu zeigen, und, dass dieselben ganz in der Weise der Antimere zuerst in der Mitte zwischen Rand- und Centralabschnitt abstarben und von da nach unten und nach oben sich mehr und mehr auflösten. Dabei muss die Bildung eines Ersatzcentrums vorausgesetzt werden. Eine allmälige Verkleinerung nach einem bestimmten Punkte, nach diesem Ersatzcentrum hin, habe ich aber in solchen Fällen nicht gesehen; es begann gewöhnlich mit einem Male die allgemeine Auflösung und schritt sehr rasch weiter fort. Nur bemerkte ich wiederholt, dass auch in diesen Fällen das centrale Stück vor dem Randstück abstarb. Es wird also das Ersatzcentrum im Randstïck seinen Sitz gelıabt haben. Die Thatsache aber, dass immer - jetzt ebenso wie in den Fällen, wo ein Haupt-Contractionscentrum vorhanden ist - zuerst eine Zone in der Mitte des Antimers abstarb, dürfte sich daraus erklären, dass an jener Stelle bei Aurelia die Umbrella dünn ist, aber ziemlich rasch in den festeren centralen Theil übergeht - sie wird sich dort am ehesten anflösen, weil sie 1) nicht den Vortheil der Dicke des centralen Abschnittes hat und 2) nicht den Vortheil besitzt, jene ansgiebigen, der Athmung dienlichen Contractionsbewegungen, wie das Randstück zu machen.

Es kommt somit bei der Frage vom Absterben nicht allein der mittelbare Einfluss der lokomotorischen Centren an sich in Betracht, sondern auch die noch von andereu Bedingungen abhängige Widerstandsfähigkeit des Theiles, insbesondere das Vermögen, Athembewegungen mit bestimmter Energie unter dem Einfluss der Centren anch wirklich auszuführen. Und von diesen versehiedenen Gesichtspunkten aus sind alle einzelnen Fälle zu beurtheilen.

Auch die in Versuch A des XIII. Abschnittes geschilderte Thatsache, dass ein aus zwei Antimeren bestehender Lappen einer Meduse, weleher mit dieser nicht mehr leitungsfăhig zusammenhängt, nachdem ihm die contractilen Zonen ausgeschnitten worden waren, anfängt, sich der Länge nach zu trennen (vrgl. Holzschnitt 15 und 16) mag sich daraus erklären, dass in der Trennungslinie die Athmung am wenigsten ergiebig gewesen sein wird. Und dies wird in der That bei einer Contractionsthätigkeit, wie sie in Holzschnitt 17 durch die Richtung der. Pfeile angedeutet ist, in einer das Stück der länge nach halbirenden Linie der Fall sein müssen. Der ganze Verlanf der Versuche A und B (Alusehnitt XIII) dürtte besonder's geeignet sein, die Erscheinungen des Absterbens im Einzelnen in gegebenen Fillen vor Augen zu führen, und vergleiche man in dieser Beziehung besonders Holzschnitt 18. 
Wenn noch irgend ein Zweifel bestünde, so bewiesen sicherlich die in diesen Abschnitte mitgetheilten Thatsachen, dass die Contractionsthätigkeit des ganzen Medusenschirmes wesentlich ausgeht von dem Gebiete der contractilen Zonen.

\section{Beherrschung der vegetativen Thätigkeit durch die contractilen Zonen.}

In meiner ersten Abhandlung erklärte ich die contractilen Zonen zusammen mit dem von ihnen zunächst beeinflussten Aste des Gastrovaskularröhrensystems für pulsirende Ernährungsorgane im weitesten Simne des Wortes, welche zu gleicher Zeit Organe der Bewegung sind ').

„Thre Wirkung. änsserte ich, ist diejenige von Saug- nnd Druckpumpen, welche abwechselnd Wasser in die Gastrovaskularrüume hereinsaugen und dasselhe wieder hinauspressen. Durch Vergrösserung und Verkleinerung des von ihnen umschlossenen Raumes ${ }^{2}$ ) werden sie gleich Herzen die Gastrovaskularflüssigkeit hin- und zurïcktreiben, gleich unsern Lungen die Zufuhr des Sauerstoft's und die Entfernung der Koblensïure besorgen und endlich mit dem eingepumpten Wasser anch die animalische Nahrung in die (iastrovaskularränme leiten. Es würde sonit die gesammte Enührung unserer Thiere von einer lestindig in fiang befindlichen, gewöhnlich unwillkürlich arbeitenden, aber dem Einflusse des Willens zugänglichen Maschine besorgt, während in unserem Körper die Aufnahme lester und flüssiger Nahrung eine ansschliesslich willtïrliche Thätigkeit ist und nur die der Athmung ganz ebenso ansgeführt wird, wie diejenige der Frnährungsorgane der Scheibenyuallen. Diese Organe spielen somit in Beziehung auf die Ernilhung die Rolle von Gastrovaskularpumpen oder, um die Gesammtheit ihrer nutritiven Funktionen auszudrücken, von Ėrnähru ngspumpen. Mit einer solchen Auffassung der Bedeutung der contractilen Zonen stimmen die mitgetheilten Versuche vollständig überein. Jedes einzelne Strahlstück des Thieres enthïlt die sümuntlichen zum Leben nothwendigen Organe und es vermögen daher diese Strahlstücke nach ihrer Trennung vom fiesammtorganismus sich leliend zu erhalteu, sie sind physiologische Individuen (Bionten, H:ickel). Das Vorhandensein der Ernährungspumpe ist zur Erhaltung eines solchen Individuuus absolut wesentlicls. Es stirbt das Strallstück, solhald man ilın dieselbe genommen bat, die nächste Veranlassung zum Tode giht offenbar das Aufhören der Athmung. Bestindig fortdanernde Zufulr von Sauerstoffi uni Abseheidung vou Kollensiïure dureh das Pumpwerk sind die erste und hauptsächlichste unter den Lebenshedingungen des Bionten. Nur auf kurze Zeit ist ein Sistiren dieser Thätigkeit müglich. Die Athemcentren sind geralezu Lelenscentren für unsere Organismen.... Ebenso wie ein Strahlstück, vermag ein beliebig ausgeschnittenes Stückchen der (gualle zu leben, sofern es eine Ernälurungspumpe enthält. Ein solches Stückchen ist alsn elenfalls ein physinlogisches Individuum. Bei ihm, wie bei den ausgeschnittenen Strahlstäcken, wird die Verhindung der in demselhen noch vorhandenen Gastrovaskulargefisse mit der Aussenwelt vermittelt werden durch deren Oeffnungen an den künstlichen Schnittflächen und durch diese Oefïnungen wird also das Wasser, und eventuell damit thierische Nahrung, eingesogen. Diejenigen der in Vorstehenden mitgetheilten Thatsachen, welche vorzugsweise auf die Eigensehaft der Ernährungspumpen als Athemorgane hinweisen, brauche ich nicht besonders anzuführen, da sie die Hauptsätze der von mir erlangten Resultate bilden. Nur um dem Gang der Darstellung nicht vorzugreifen, habe ich bei der Beschreibung der Contractionsvorgänge den Ausdruck ,athmen" vermiedeu und es wurde mir dies am schwersten, als ich die schlagenden Erscheinungen der Dyspnoß̈ und

1) Theilbarkeit vou Aurelia und Cyanea, Würzb. Verh. a. a. O. S. 155; Zoolog. Unters. S. 63.

2) d. i. Gefäss-Ranunes. 
Apnoë zu schildern hatte, wie ie hei Mangel an frischem Wasser, d. i. bei sauerstofmangel, eintreten, die Unregehmassigkeit der Athemzüge mit ihrer krampfhaften stossweisen Beschleunigung, ihre Verlangsamung und ihr Aufhören, bis nene Zufuhr des Lebensgases sie wieder belebt und regelmässig macht, und ferner als ich sprach, von dem Verhältniss der Pausen einerseits und der Geschwindigkeit und, wie ich mich jetzt ausdrücken muss, Tiefe der Athemzüge andererseits."

Zu diesen meinen früheren Aeussermngen muss ich einschränkend nud erläuternd das Folgende bemerken: es sind nacl den mitgetheilten Thatsachen im Gebiete der contractilen Zonen sowohl im Wesentlichen die die Contractionen anregenden C'entren als die Muskelbezirke gelegren, welche jene Anregung zuerst und am kräftigsten empfangen. In ihrem Gebiete verden die Gefässe am ausgiebigsten zısammengezogen und erweitert und es wird dort also auch in besonderen Grade das Ein- und Auspumpen direkt besorgt werden. Allein mu in jenem mittelloaren und in diesem numittelbaren Sinne kann man anf sie die Bezeichnung Ernährungspumpen anwenden. Thatsächlich ist der grösste Theil des schirmes bei dem Aus- nnd Einpumpen betheiligt, es ist im weiteren Simne das ganze Thier eine Ernährungspumpe.

Wenn ich feruel sagte, dass die Elnährungspumpen die Zufuhr des Sauerstoffs und die Entfernung der Kohlensäure Jesorgen, so wollte ich selbstverständlich nicht die Meinung änssern, es gesthehe die Athmung unserer Thiere ansschliesslich dadurch, diss mit dem Seewasser Sauerstoft in die Gastrovaskularkanäle eingepumpt und Kohlensäure entfernt werde, es habe aber mit derselben weder das Flimmern der (Gefässkanäle, noch auclı die in Folge der Contractionsthätigkeit stets wechselnde Berührung der Körperoberfläche mit frischem Seewasser irgend etwas zu thun. Es versteht sich von selbst, dass diese letzteren Faktoren beide für die Athmung wichtig sein werden, insbesondere schreibe ich len zuletztgenannten eine grosse Bedeutung zu. Dass aber auch das Ein- und Auspumpen von Wasser in der von mir hervorgehobenen Weise wirksam sein muss, wird bei Leberlegung ron rornherein kaum Jemand bezweiteln mögen; die im Folgenden zu schildernden Thatsachen werden aber, wie ich glaube, auf las Entschielenste meine Ansicht stützen, dass es weitaus den wesentlichsten Nodus der Athmmg bilden muss.

Ehrenberg beobachtete schon 1S33, dass Amelien im Masser rertheilten Indigo spontan in die Gefässe aufnehmen. Er machte diese Tersuche, „um die Ernährungsorgane für das Auge zu isoliren" ${ }^{1}$ ) und er bemerkt, dass der Versuch aut' das Vollständigste geliug, so oft er ihn wiederholte. "Ich erlangte", sagt er, „dadurch die Gewissheit. dass die Kanäle, welche man mit dem Munde und Magen zusammenhängen sieht und die man schon öfter durch Einspritzungen glücklich dar-

1) a. a. U. S. $18 \%$. 
gestellt hatte, über deren Funktion man aber desshalb noch Zweifel haben konnte, weil einige Beobachter eine Circulation von Kingelchen darin gesehen zu haben berichteten, nicht bloss zum Ernährungssystem wirklich gehören, sondern dass sie den eigentlichen zertheilten Darmkanal dieser Thiere dentlich vorstellen." Ehrenberg kam durch seine Versuche auch zur Ueberzengung, dass die allgemein gültige Auffassung, wonach die Jedusen nur eine einzige Darmöffnung, nämlich die des Mundes hätten, welche zngleich zur Aufnahme und zum Auswerfen des Unverdanten diene, falsch sei $^{1}$ ). „Wenn sich nämlich “ sagt er , der strahlenförmig verïstelte l)arm mit Indigo stark angefüllt hatte, so liessen sich am Rande s grosse blaue Punkte erkennen, die gerade in der Mitte zwischen je 2 der $\$$ bramnen Randkörper waren, lierührte ich die 'Thiere, dass sie unruhig wurden, so lösten sich immer sämmtliche oder viele der S bliuen Massen ab und fielen zu Boden. Ich untersnchte nun die Stellen selbst nnter dem Mikroskope genan und fand an den s hezeichneten Punkten ebensoviel Erweiterungen des Randkanals mit einer besonderen Klappe. Schon früher hatte ich Anhäufungen von Räderthierhülsen und kleinen Nuschelschalen in erweiterten Stellen des handgefässes zuweilen bemerkt. Jetzt überzengte ich mich, dass an jenen Stellen Oeffinungen waren und dass mithin jede lleduse 8 Afteröffnungen besitzt. Sobald diese Beobachtung zur Kłarheit geworden war, fing ich nir im Neere frische Thiere so behutsam, lass ich sie von selbst in ein nicht allznweites Glas schwimmen liess, welches ich olne sie zu berühren mit ihnen erhob nud worin ich sie sogleich mit der Lupe beobachtete. Fast immer fand ich so die kleinen Analbentel mit bramen Stoffen so ertüllt, dass ich anstatt der gewöhnlichen 8 bramen Randpunkte 16 derselben sah, woron s abwechsehd die Analbentel und ebensoviel die gewöhnlichen bramen Körperchen bildeten. Nun schnitt ich auch von einigen mit Glück sehr rasch solche liandtheile ab, welche noch gefüllte Anallsentel hatten und sah unter dem Mikroskope, dass der brame Inhalt theils aus Bacillarien-Schalen, theils aus den Hälsen von Räderthieren, theils ans kleinen Lrebsfragmenten oder jungen Muschehn bestand."

Jlerkwürdigerweise sind, soriel mir wenigstens bekannt ist, diese interessanten Versuche Ehrenbergs von Niemanden wiederholt worden, ja sie werden in den meisten Handbüchern gar nicht erwähnt und seine Angabe, dass der Aurelia aurita acht Afteröffnungen am Schimrande zukommen, scheint keinen Glanben gefunden zu haben ${ }^{2}$ ). Ich kann seine Mittheihngen durchans bestatigen. Wie früher schon bemerkt, läuft in jedem Interradins ein Gefäss, nud zwar unverzweigt vom Iagen-

1) a. a. O. S. 188 น. 189.

2) Bronn (Klassen u. Orłnungen des Thierreichs, I1. S.97) bezeichnet dieselbe als ernenter Prüfung bedürftig. 
ranu bis zum Schirmraude - das Afterradiärgefäss. Da wo die Afterradiärgefässe den Schirmiand erreichen, sieht man nun leicht an Thieren, welche man frisch aus dem Meere genommen hat, braune Massen, die sich bei näherer Untersuchung als Fices erweisen, indem sie in der ron Ehrenberg beschriebenen Weise allerlei unverdauliche Dinge enthalten. Aber auch junge Larven von Aurelien sah ich an jenen Stellen mit den Fätes austreten, in so grosser Anzahl, dass ich mich der Annahme nicht verschliessen konnte, es möchten dies die natürlichen Wege sein, auf welchen dieselben das Mutterthier verlassen, nachdem sie in Folge innerer Befruchtung des letzteren entstanden sind.

Ich wiederholte mun die Versuche Ehrenbergs und zwar an kleinen Aurelien von $3-4 \mathrm{~cm}$ im Durchmesser. Schon wenige Augenblicke nachdem ich den Indigo in dem Wasser vertheilt hatte, in welchem die Thiere schwammen, zeigten sich acht blaue Punlite an Schirmande genau zwischen je zwei Antimeren, also in den Interradien. Die Punkte wurden, während der Schirm sich fortanernd contrahirte und während sich das Gastrovaskulargefässsystem, vor allem der Magen, mehr und mehr mit der blanen Farbe füllte, grösser und grösser; sie wuchsen allmälig zu mmegehmässigen Ballen herau, von welchen zuletzt einer nach dem anderen ab- und langsam zu Boten fiel. Indem ununterbrochen neuer Farbstoft rom Thiere anfgenommen wurde, zeigten sich fortwährend anch nene Excretballen am schirmrande, die immer nach einer gewissen Zeit wieder abfielen und es war angenscheinlich, dass Aufnahme wie Abgabe durchaus maschinenmässig gesehieht, dass durch die Contractionen des Schirmes bestandig Wasser mit den darin enthaltenen Stoffen durch die Mundöffumng eingepumpt und Unbrauchbares sofort wieder durch die Afteröfnungen ausgejumpt wird; mud diese Maschine geht ununterbrochen Tag und Nacht fort. Noch kömnte man vielleicht einwenden, dass die die Gastrovaskularräume auskleidenden Geisselzellen es wesentlich seien, welche durch die rom Innd zu den Aftern gehende liichtung der Geissellyewegung den aufgenommenen stoffen den Weg vorzeichnen. Ob diese lichtung innerhalb der Gastrovaskularöhren in der That eine entsprechende ist, habe ich nicht Jestimmt. Ich glatube mich aber zu erimnern, dass das Geisseln in den Rimnen der Mundarme bei Aurelia aurita in diesem Sinne geschieht und wirksam ist. Jeder Arm dieses Thieres ist nämlich an der inneren, dem Centrum desselben zugekehrten Seite, der Länge nach ausgehöhlt und in der so entstandenen Furche sieht man ein kräftiges Geisseln. Fremde Körper, welche in die Nähe der Arme gelangen, finden sieh gewöhnlich bald in diesen Rinnen und nehmen in denselben ilnen Weg nach aufwärts zum Munde. Die Geisselbewegung scheint hier die ortsveränderung der frenden stofie in bestimmter Richtung zu be- 
güustigen. Dass das Geisseln aber jedenfalls nicht die Ursache der geschilderten kräftigen Aufnahme und Excretion ist, das habe ich experimentell nachweisen können. Nachdem ich nämlich eine Aurelia dmoh Ausschneiden der contractilen Zonen bewegungslos gemacht und jetzt in Wasser gebracht hatte, welches Indigo enthielt, nahm sie während 10 Minnten - so lange als sie durchans bewegungslos war keine blane Farbe anf. Erst als sie sich späterhin erholte, schwache Contractionen ansführte, konnte man an einzelnen Aftern blane Punkte auftreten »ehen. aber erst nachrem die Contractionen längere Zeit fortgedanert hatten. Einem anderen Thiere schmitt ich alle contractilen Zonen bis auf eine einzige aus und brachte es in dasselbe Gefäss wie das vorige. Nach schnell vorübergehender "Bestürzung“ begann es sich lebhaft wieder zu contrahiren und alsbald traten die Excretballen an Riande auf.

Es ist somit zweifellos, dass es die Contractionen des Schirmes sind, welche die Aufnahme und Excretion von Stoffen im Wesentlichen besorgen und dass beides, Aufnahme und Excretion durch maschinenmässiges Pumpen geschieht. Aus den früher mitgetheilten Experimenten geht nun zur Genüge hervor, dass die contractilen Zonen im Wesentlichen die Zusammenziehungen des Schirmes anregen, also das Aus- und Einpumpen in letzter Linie vermitteln. Wegen dieser Bedeutung der contractilen Zonen und in der Toranssetzung, dass anch die Nährstoffe wesentlich durch die Contractionsthätigkeit in den Körper unserer Medusen eingeführt werden, dass der Athmung sowohl als dem Kreislauf durch sie vorgestanden wird, habe ich diese wichtigen Bezirke wohl nicht mit Unrecht als Ermährmgspumpen bezeichnet - unbeschadet der Bedentnng anderer Mittel, welche ausserdem der Athmung, dem Kreislauf und der Aufnahme vou Nahrung dienen. Dabei darf aber nicht ans dem Auge verloren werden, was $i c h$ schon früher ausdrücklich bemerkt habe, dass ich die contractilen Zonen nicht als bestimmt abgegrenzte Organe aufgefasst haben will. So wenig wie in ihrem Bereich - in der Ungebung der Randlörper - ansschliesslich Contraction der Subumbrella stattfindet, so wenig ist ron vornherein anzumehmen, dass auch das Einpumpen von Wasser mu in diesem Bereiche geschieht. Es sind aber die dort gelegenen Nervenelemente, welche zur Anregung und Regelung der Contractionsthätigkeit des Schirmes und damit zum Einpumpen unter normalen Ter'hältnissen wesentlich sind und die dort gelegenen Muskelelemente, welche jene Anregung zuerst erfahren. Auch wird den contractilen Zonen dadurch eine Wirkung bein Einpumpen zugeschrieben werden können, dass die 'Zusammenziehungen der Muskulatur derselben augenscheinlich besonders kräftig stattfinden, wodurch auch die Gefüsse in ihrem Gebiete kräftiger zusammengezogen werden müssen, als an anderen 
Orten. Dass das Ein- md Auspumpen äberhanpt nur durch successive Erweiternng und Verengermng der Gefüsse geschehen kamn, ist selbstverständlich. Man überzengt sich num bei mikroskopischer Beobachtung kleiner Aurelien während der Contractionsthätigkeit leicht, dass nicht nur die Gefässe der contractilen Zonen, sondern jene der verschiedensten Gebiete sich mit jeder Znsammenzielıng des Schirmes verengern. Speciell auf den Bereich der contractilen Zonen gerichtete Beobachtungen regten mir aber die Frige an, ob diese Verengerungen und Erweiterungen überall in derselben Weise geschehen, insbesondere, ob die Gefüsse sich dabei überall rein passiv verhalten, indem die Teranderungen ihres Lumens einfarh stets die Folge der Thătigkeit der gewöhnlichen Subumbrella-Mnskulatur sind; oder ob sie zugleich activer, vielleicht durch besondere Muskelelemente vermittelter Erweiterung und Verengermg fähig sind, und ob etwa solche Fähigkeit anf das Gebiet der contractilen Zonen beschränkt ist. Ich habe nämlich wiederholt - und zwar wohl znfällig bei grossen Anrelien — sehr schön miter dem Miliroskop beobachten liönnen. dass ein bestimmter Abschnitt des zum Randkörper hinführenden Radiärgefässes sich im Bereich der contractilen Zone mit jeder Znsammenziehung des Schirmes in viel höherem Grade verengerte und besonder's erweiterte, als das Gefäss dies in seinen übrigen Theilen und als die anderen, benachbarten Gefässe es thaten. Es war dies jener Alschnitt des Radiürgefüsses, welcher ummittelbar ror dessen Ein-

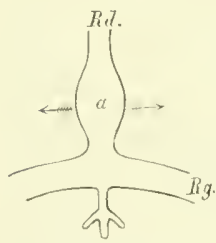

Holzschnitt 12. mündung in das linggefüss liegt (a, Holzschnitt 12). In einem speciellen Falle betrug dessen Durchmesser während der Expansion $0,616 \mathrm{~mm}$, während der Contraction $0.506 \mathrm{~mm}$, was also eine Differenz von $0,11 \mathrm{~mm}$ und im Verhältniss zum mittleren Durchmesser des Gefässes eine Erweiterung desselben von $0,055 \mathrm{~mm}$ ergibt. liese Erweiterung und Verengerung des im Bereich der contractilen Zone gelegenen Gefässabschnittes erfolgte rhythmisch. Sie ward beobachtet an ansgeschnittenen Randstücken nnd machte durchans den Eindruck eines Pulsirens. Meine Beobachtungen lassen mich nicht bestimmen, in wieweit dieses Pulsiren numittelbar abhängig war ron den Contractionen der kireisförmig verlanfenden Subumbrellamaskulatur. Es muss zwar hervorgehohen werden, lass beide stets synchronisch zu sein schienen, allein es wurde bemerkt, dass auch dann, wenn die letzteren kaum dentlich waren, das Pulsiren ausserordentlich kräftig stathaben konnte. Insbesondere trat dann die gewaltige lokale Erweiterung des Gefässes bedentend in die Angen.

Bei manchen anderen daranf untersuchten Aurelien hahe ich ein ähnhches lokales Pulsiren an derselhen Stelle vermisst; unter anderen Medusen habe ich nur 
an Lizzia (Bougainvillea) Köllikeri darnach gesucht und habe es ganz an derselben Stelle auch hier beobachtet (vergl. Holzschnitt 13 bei a). Ob nun derartige lokale Pulsationen auch an anderen Stellen der Gastrovasknlargefüsse vorkommen, ob sie vielleicht sogar allgemein sind, kann ich auf Grund meiner Untersuchungen nicht entscheiden. Würden sie auf jene im Bereich der contractilen Zone gelegene Stelle beschränkt sein, so hätten wir dort wirkliche Gastrovaskularherzen nicht nu physiologisch betrachtet, sondern anch als morphologisch abgegrenzte organe.

Gelegentlich hale ich desshalb nachgeselen, ob sich an dem betreffenden Gefässabschnitte nicht Einrichtungen finden möchten, welche den lokalen Pulsationen vorstehen und welche wiederum in $\mathrm{Zu}$ sammenhang stïnden mit dem centralen Nervenapparat in der contractilen Zone oder im Randkürper. Bei Lizzia sah irh an der massgehenden Stelle des Radiärgefässes im optischen Längsdurchschnitt eine Verdickung der Wandung, welche auf einen lichtbraun pignentirten, in das Gefisshumen hineinragenden Samm zurückzuführen schien, wohl der optische Lüngsdurchschnitt eines in jener Gegend in der Gefüsswand ansgebildeten Ringes von gefärbten Zellen. Es ist dieser Saum im Holzsehnitt 13 A, jederseits gegentiher den Pleilen und dem Buchstaben a durch die dunkle Linie angedentet. Der Einmündungsstelle des Radiärgefüisses gegenüher, an der Wand des Ringgefässes, fand sich ein ihnlicher pigmentirter Saum (Holzschnitt $13 \mathrm{~A}$ zwischen $\mathrm{b}$ und b) ${ }^{1}$ ). Es ist somit wahrscheinlich die Innenwand der Vereinigungsstelle von Radiär- und Ringgefüss bei Lizzia in beschriebener Weise ringsum rerdickt und pigmentirt. Ich habe die Sache nicht genauer mophologisch untersurht, die physiologische Bedeutung der Eimrichtung für unsern Zweck ist aher desshalb von vornherein zweifelhaft, weil dieselhe angenseheinlich nicht Abkümmlingen des Ektoderms, sondern dem Entoderm zugehïrt. Es handelt sich in derselhen somit wahrseheinlich eher um eine mit der Resorptionsthaitigkeit in Beziehung stehende Epithelialverdickung ${ }^{2}$ ).
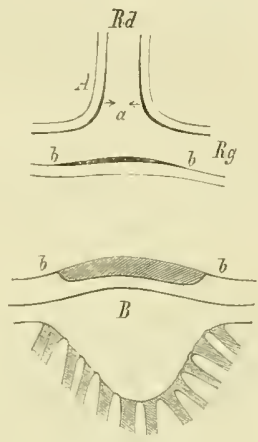

Holzschnitt 13.

Zum Zweck der Erweiterung der Gefässe überhaupt, also auch ausserhalb des Gebietes der coutractilen Zonen, finden sich, wie wir später genaner sehen werdeu. bei den Cyclonemen Muskelzellen, welche parallel der Längenausdehnung devselben gelagert sind. Sie begleiten sowohl die Radiärgefässe wie das Ringgefäss. Bei Anrelia und den übrigen Toponemen habe ich keine der Erweiterung und Verengerung der Gefässe speciell dienende Eimichtung zn rerzeichnen.

1) In Figur $13 \mathrm{~B}$ ist der untere Rand des Ringgefïsses sammt dem Ganglion und dem Anfangstheil der Tentakel seärker vergrössert.

2) Inzwischen hat $\mathrm{R}$. $\mathrm{Böh} \mathrm{m}$ (Helgolander Leptomedusen, Jenaische Zeitschrift f. Naturw. XII. Bd. 1878) eine ähnliche Verdickung und Pigmentirung des Entoderms an der Tentakelbasis bei verschiedenen anderen Formen von Cycloneuren behandelt und spricht die Ansicht aus, odass die Tentakelbulbi als Hauptaufsaugungs- und Aufspeicherungsstellen des im Magen bereiteten Chylusbreies eine hohe physiologische Bedeutung für die gesammte Ernälırung der Meduse haben» (a. a. O. S. 110). Die hier häufig zu beobachtende Vervielfältigung der Entodermzellen scheint ihm nicht nur den Zweck einer festen Stütze für den Tentakel zu haben, sondern anch eine Vermehrung der die Nährflïssigkeit aufnehmenden und weiter verarbeitenden Zellwerkstätten zu bedeuten. 
Erst zm Zeit des Niederschreibens dieses Abschnittes bin ich mit einer Arbeit bekannt geworden'), welche in Beziehung anf die vorliegende Frage, aber, wie bei Gelegenheit der Besprechnug der Literatur gezeigt werden soll, auch nach anderer Richtung für mich von hervorragendem Interesse ist, ich meine einen Aufsatz ron I etten heimer "Ueber die Gesichtsorgane des violetten Seesterns der Ostsee, nebst Bemerkungen über die Ohrenqualle und Tersuche über die Motilität derselben " ${ }^{2}$ ). Darin findet sich die folgende Bemerkung über das Verhalten der Gefüsse der Aurelia aurita während der Contractionen ${ }^{3}$ ): ,bei der Zusammenziehung des Schirimes werden die Gefässe plötzlich dunkler gefärbt und enger; dies bemerkt man besonders dentlich bei sehr jungen Individnen. Doch ist es auch bei älteren wahrzunehmen. Diese hänfige, man darf fast sagen regelmässige Abwechslung in Kaliber der Gefässe ist nicht zu verwechseln mit den lokalen, sinuösen Exweiterungeu, deren bekanntlich die Gefässe der Quallen fähig sind." Es ist mir mbekannt, was II ettenheimer mit den "lokalen, sinuösen Erweiterungen" meint, indessen möchten seiner Bemerkung zufolge solche, rhythmisch auftretend, auch anderswo als an den von mir erwähnten Stellen im Verlauf der Gefässe schon früher beobachtet worden sein; leider' bin ich nicht mehr dazu geliommen, selbst genaner darnach zu suchen, so leicht sie auch zu beobachten sein mögen. Es ist mir seit dem Lesen der IL ettenheimer'schen Schrift mehr wie früher als möglich elschienen, dass ich die Pulsationen mm zufällig, weil ich auf jene Gegend besondere Anfmerksamkeit richtete, gerale im Gebiete der contractilen Zonen beobachtet habe, wie ich sie denn auch hier nicht constant rahnnahm. So möchte es sich in ihnen $u m$ eine allgemeiner verbreitete Eigenschaft wahrscheinlich der Hauptgefässe handeln und bliebe als interessante dufgabe festzustellen, wie sie. wenigstens bei den Toponeuren, herrorgerufen werden und ob und in welchem Grade der Zeit nach mabhangig von den Contractionen der ringförmigen Muskulatur sie etwa anftreten können.

Mag dem sein wie ibm wolle, jedenfalls sind es die contractilen Zonen, welche den rhythmischen Contractionen der Subumbrella vorstehen und diese wiederum sind es, welche -. von den lokalen l'ulsationen für jetzt abgesehen - vorzüglich die Gefässe verengern und erweitern. Durch die Tolumsveränderung der Gefässe wird Wasser, eventuell mit Nahrungsmitteln, in das Gastrovaskuldrsystem eingepumpt, darhuch wixd die Ernährung in weitesten Sinne des Wortes mit besorgt. Mednsen. welche keine weite Mundöfnung haben (Rhizostomeen. Geryoniden), werden ginz

\footnotetext{
1) Auf der Mänchener Naturforscherversamulung durch Herrn Dr. Lndwig.

2) Archiv f. Anatomie u. Physiologie, 1862 , S. $210 \mathrm{ff}$.

3) S. 222 .
} 
selbstverständlich nur auf diese Weise kleine Nahrungsbestandtheile anfsaugen können. Und in demselben Falle sind die mund- und magenlosen Medusenkrïppel, von welchen im IX. Abschnitt gehandelt worden ist. Nun erklärt sich wohl auch die im VIII. Abschnitte in dem auf Seite 44 behandelten Falle hervorgehobene Thatsache, dass kleine Stückchen einer Aurelia, welehe aus dem centralen Theile des Thieres übrig geblieben waren*und lange fortgelebt haben, solange als sie lebten die oberen Enden der Hauptgefässstämme in sich enthielten. Diese Getässe contrahirten sich mit jeder Zusammenziehung des Medusenstückchens und dienten so der Eruährung. Nachdem das Stückchen sich über sie hinaus anfgelöst hat, wird es raseh zerfallen sein.

Da endlich Befruchtung der Eier von Aurelia innerhalb ihres Körper's stattfinden muss, so dürften durch das unter der Leitung der contractilen Zonen stehende Pumpwerk auch die Samenfäden des mänulichen Thieres ins Wasser abgegeben und durch den Mund des Weibchens eingesaugt werden: durch die After wiederum entfernt dieses die Larven. Somit würde das Pumpwerk anch der Fortpflanzungsthätigkeit dienen und demselben sümmtliche vegetative Funktionen nutergeordnet sein, den contractilen Zonen aber ausserdem unter den animalen auch noch die der Ortsveränderung.

Es soll selbstverstïndlich lier nicht eine neue Ernährungstheorie für die ,wurzelmündigen “ Medusen - der Ausdruck im Gegensat/ zu den weitmündigen gebraucht - aufgestellt werden. Schon der Name Rhizostoma ist ja nothwendig der Vorstellung entnommen, dass die Mundöfnungen des Thieres ihnlich den Wurzeln der Pflanzen die Nahrung einsangen, und wir finden schon bei Cuvier diese Ansicht ansgesprochen. Dass dabei die Voraussetzung gemacht wird, es geschehe das Einsaugen durch die Contractionen des Schirms, darf wohl angenommen werden. Freilich ist die Berïhrung derartiger plysiologischer Gesichtspunkte aus unseren heutigen Lehrbtichern der Zoologie vollstiindig verschvunden, - Wenn nun aber auch die weitmündigen Medusen auf dieselhe Weise Nahrung eimpumpen, so soll keineswerss bestritten werden, dass dieselben mit ihren Mundarmen grosse Thiere (Fische) zum Zweck der Aufnahme in den Nlagen ergreifen. Aber auch solche Beute wird, wie etwa mikroskopisch kleme, wesentlich durch das Einsaugen an den Ort ihrer Bestimmung gelangen. Eine mehrfache Bedentung spricht den Schirmcontractionen der Merlusen schon Tilesius zu. wenn auch theilweise auf Grund falscher anatomischer Voraussetzungen und darum nur zufïllig richtig. Die Contractionen erklärt er vorzüglich für Athembewegungen: „ilhre Respiration scheint die Hernschaft üher alle anderen Functionen, welche nur durch die Respirationsbewegung vollhracht werden, auszuiiben. Sie schreiten durch diese Bewegung in Meere fort, sie sonden mittelst der Respirationsbewegung ilıre Süfte ah, sie saugen mittelst derselben ihre Bente aus, assimiliren mittelst derselben den ausgesogenen Saft, sie setzen mittelst derselben ihre Jungen aus, und selbst diese ausgesetzten Embryonen bilden sich erst durch die in ilmen selbst angehenden Respirationsbewegungen aus. Sie hauchen mittelst derselken ein lenchtendes Gas oder ein nichtliches Licht aus, veländern am Tage durch verdoppelte Anstrengung dieser Bewegung ihre Farbe" ${ }^{1}$ ). Er nent sie daher Animalia siphonizantia, eine Bezeichnung, welehe zuerst Forskil ${ }^{2}$ )

1) a. a. $0 . \mathrm{S}, 251$.

2) Forskil, Descriptiones animalium, quae in itinere orientali observavit. Hafniae 1775. 
für "zwei oder drei von seinen neuen Molluskengattungen, namentlich seine Fistularien, Salpen und Plyssophoren" gebraucht lat. - Im Magen von Pelagia noctiluca traf ich oft grosse Stücke von Algen: möglich, dass diese als Nahrungsmittel dienen, verdaut werden; zugleich wit ihnen hatten die Thiere aber sehr oft allerlei unverdauliche Dinge mit aufgenommen, Unrath, wie Stückchen Stroh u. dgl,, welche offenhar nur mechanisch mit eingepumpt sein konnten. So bequem also auf der einen Seite die maschinenmüssige Nahrungsaufnahme unserer Thiere ist, so hat sie auf der anderen doch ihre Schattenseite, indem die angenehme Fähigkeit des Wählens der Nahrung damit nur in geringem Naasse vereinbar sein mag - in wa l chem Gra d e diese Fibhigkeit etwa doch vorhanden ist, bleibt noch zu untersuchen. - Wie weit Afteröfinungen hei den Medusen verbreitet sind, bleibt gleichfalls noch zu untersuchen: bei Cyanea capillata bahen einige von mir darauf gerichtete Beol)achtungen zu keinem positiven Ergehniss geführt, indessen kömen meine bezüglichen Versuche nicht als abschliessende hetrachtet werden.

\section{Einige Operationen an Aurelia aurita mit Bezug auf das bisher Geschil- derte in ihrer Wirkung fortlaufend beobachtet.}

Versuch A. Am 29. August 1874 erhielt ich den Krüppel einer Aurelia, welche im unverletzten Zustande $18 \mathrm{~cm}$ Dnrchmesser gehabt haben musste. Der

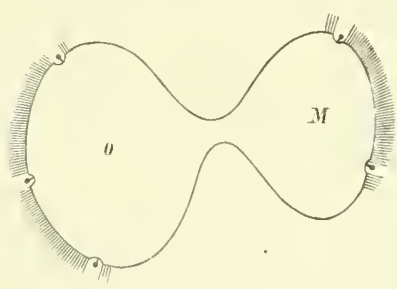

Holzschnitt 14 Krüppel bestand aus zwei Theilen, von weichen der eine, grössere, noch drei, der andere, kleinere, noch zwei Randkörper trug. Beide Theile waren glockenartig zusarnmengezogen und lingen nur noch durch eine $1^{3}{ }_{4} \mathrm{~cm}$ breite Brücke zusammen (Holzschnitt 14). Diese Verbindungsbrücke war jedoch nur oben muverletzt; unten fehlte nicht nur das Epithel sammt der Muskelschichte, sondern sogar ein Theil des Gallertgewrebes. Dem Krüppel fehlte ansserdem der Magen; nur ein Strick eines Mundarmes hing noch an ihm an. Es zeigte sich, dass die Contractionen der beiden Theile nicht synchronisch waren. Ferner war zu beobachten, dass der drei Randkörper führende Theil, welchen ich mit 0 bezeichnen will, um Weniges mehr Contractionen in der Zeiteinheit machte, als der kleinere M, endlich, dass die Contractionen des ersteren energischer seien, als die des letzteren.

Während sich 05 mal zusammenzieht, zieht sich II 4 mal zusammen,

$\begin{array}{rccc}S & , & " & 6 \\ 9 & " & , & 7 \\ 9 & " & & 5 \\ 10 & " & & 5 \\ 11 & " & 9\end{array}$




$\begin{array}{llll}12 & , & " & 10 \\ 13 & " & , & 11 \\ 14 & " & 11 \\ 15 & , & 11 \\ 16 & , & 13 \\ 25 & , & 20 \\ 29 & , & , & 2.2\end{array}$

Jeder Theil setzt zuweilen die Contractionen anf kurze Zeit aus, häufiger der kleinere M als der grössere $O$. Um 11 Uhr Mittags schnitt ich O die Randkörper sammt Ungebung ans. Die ansgeschnittenen Stückchen contrahiren sich rhythmisch weiter, ebenso contrahirt sich II ungestört fort. O selbst ist dagegen nach der (1peration bewegungslos, hat die kngelig zusammengezogene Gestaltung anfgegeben und hat sich flach ausgebreitet. Nach etwa $1^{1}{ }_{2}$ Minuten zeigt sich an ihm schwache Bewegung in den unverletzten Randresten; nach $1^{1}{ }_{2}$ weiteren Minuten tritt eine leichte Contraction auf; nach ungefähr 2 weiteren Minuten folgen 2 solcher Contractionen rasch anfeinander und ebenso zeigt sich fernerhin nach Pausen von ${ }^{1} / 2$ bis 6 Minnten je eine Contraction. Unterdessen contrahirt sich der unverletzte, noch seine Contractionscentren führende 'Theil II fortwährend ungefähr 10 mal in der Minute. Die Contractionen von 0 sind viel unvollkommener als die von M. Jener ist in den Pausen nicht immer ganz ruhig, sondern es bewegen sich häufig seine Tentakel und zuweilen ist auch die Körpermasse in der Gegend des Randes etwas wogend, wie leicht erregt.

II. Tag. 30. August: II contrahirt sich hente:

\begin{tabular}{|c|c|c|c|}
\hline in der & $1^{\text {ten }}$ & Minute & 18 \\
\hline & 2 & 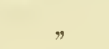 & 21 \\
\hline & 3 & , & 21 \\
\hline & 4 & $"$ & 23 \\
\hline & 5 & , & 16 \\
\hline & 6 & , & 20 \\
\hline & 7 & , & 12 \\
\hline & 8 & , & 7 \\
\hline & 9 & , & 10 \\
\hline & 11, & , & $7 \mathrm{mal}$; \\
\hline
\end{tabular}

0 zieht sich in der $1^{\text {ten }}$, $5^{\text {ten }}$, Sten $u n d 10^{\text {ten }}$ Minute je einmal znsammen; aber seine Contractionen sind im Gegensatze zu jenen von M schwach; er ist, wie gestern, flach ansgebreitet. während II kngelig zusammengezogen bleibt. 
Die Beobachtungen sind gemacht withrend das 'Tlhier sich noch im Wasser rom Abend rorher betindet, daher wohl die Unregelmïssigkeit der Contractionen ron M.

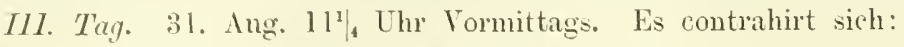

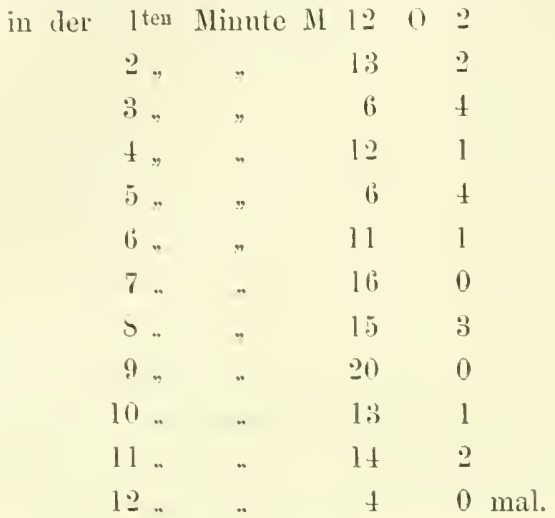

Die Contractionen ron 0 sind kiraftiger als gestern; er hat sich demmach ziemlich erholt. - Die Zühlungen sind gemacht. wïhrend sich das Thier im Wasser rom Abend vorher befindet.

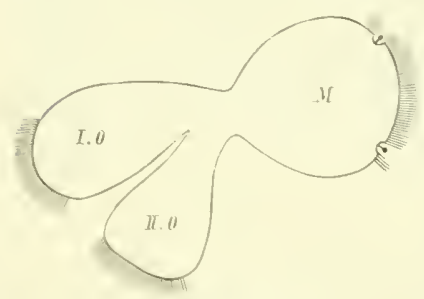

Holzschuitt 15 .

IV. Tag. 1. Sept. $10^{1}{ }_{2}$ Uhr Vormittags. 0 hat sich in zwei Lappen getheilt (Holzschnitt 15.), welche nur noch durch eine Brücke ron $2_{2}{ }_{2} \mathrm{~cm}$ Breite zusammenhangen. Jeder der Lappen ist noch mit einem Stück des natürlichen Schirmrandes rersehen; aber nur einer derselben, welchen ich mit II bezeichne, contrahirt sich und zwar liraftig; der andere (1) nicht. Yur zeigt der letztere zureilen einen schwachen Tachtakt zu den Contractionen ron II, als ob jetzt eine leichte Verbindung zwischen ihm und diesem letzteren wiederhergestellt wäre. Es contrahiren sich:

in ler l ten Nimute $\mathrm{MI} 11$, Lappen II von $0{ }^{2}$

\begin{tabular}{|c|c|c|}
\hline 2. & , & $s$ \\
\hline$\ddot{3}$. & , & 7 \\
\hline 4. & . & 7 \\
\hline 5. & , & $i$ \\
\hline 6. & , & 7 \\
\hline 7 & , & 11 \\
\hline . & . & 13 \\
\hline
\end{tabular}


0 zeigt auf der Oberfläche eingefressene Löcher, Zeichen des beginnenden Zerfalls. - Das Thier befindet sich zur Zeit der Untersuchung wiederum in dem am Abend vorher erneuerten Wasser.

V. Tag. 2. Sept. 0 hat sich jetzt so getheilt, dass es aus zwei langen Lappen besteht, deren jeder mit einem natürlichen Schirmrandstück endet (Holzschnitt 16). In der Mitte dieses liandes befindet sich in II der After, im anderen 'Theilstück scheint ebenfalls ein solcher vorhanden zu $\operatorname{sein}^{1}$ ). I beginnt schon, sich in der Mitte zu zerfetzen (bei a). Nur II hăngt noch unmittelbar durch eine Gewebsbrücke mit M zusammen. Es contrahirt sich hente jeder der drei Theile (also auch I) unabhängig vom anderen. Das Ganze liegt zu Boden. Es contrahirt sich: in der 1 ten Minute I 3 II 0 M 12

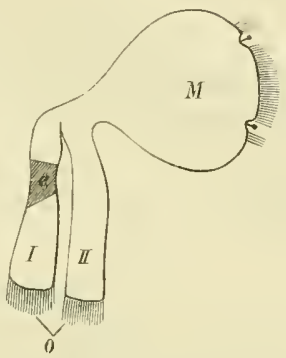

Hol\%schnitt 16.

$\begin{array}{ccccc}2, & " & 0 & 1 & 8 \\ 3, & " & 0 & 0 & 7 \\ 4 . & " & 0 & 0 & 5 \\ 5, & " & 0 & 0 & 5 \\ 6 . & " & 0 & 0 & 5 \\ 7 . & " & 0 & 0 & 6 \\ 8 . & " & 0 & 1 & 6 \\ 9, & , & 0 & 0 & 7 \\ 10, & " & 0 & 0 & 7 \\ 11, & , & 1 & 0 & 10 \text { mal. }\end{array}$

Die Beobachtungen wurden kurze Zeit nach Znsatz von frischem Wasser gemacht, desshalb sind die Contractionen ron M wohl etwas gleichmässiger als sonst und daraus ist es anch wohl zu erklären, dass I, trotz seines heruntergekommenen Znstandes, wenngleich selten genug, selbständige Contractionen macht.

VI. Tag. 3. Sept. Morgens S Uhr. I und II sind zerflossen, M dagegen schwimmt, von der Last befieit, welche ihn gestern zu Boden zog, wieder lebhaft umher.

Versuch B. Am 29. Angust, Morgens 11 Uhr, halbirte ich eine Aurelia von $20 \mathrm{~cm}$ Durchmesser, theilte die eine der Hälften darauf in vier Achtel und schnitt endlich zweien der Achtel die contractilen Zonen ans. Die der contractilen Zonen

1) Es scheint demnach das Absterben des Lappens 0 nach dem Finicken (am IV. Tage) in der IVeise stattgefunden zu haben, dass er zuerst von seinen äusseren Grenzen her eingeschmolzen ist und dass er sich dann von der durch Ausschneiden des mittleren Contractionscentrums verursachten Wunde aus getheilt hat. Hier war nothwendig die Athmung am wenigsten ausgiebig (vgl. S. 64). 
nicht beraubten Theile: die halbe Meduse und die zwei Achtel, contrahirten sich regelmässig, die derselben beraubten Achtel dagegen waren regungslos. Als ich jedoch nach einer Stunde länger danernde Beobachtung anstellte, gewalnte ich an den letzteren selten eine Contraction.

Die Hälfte behandelte ich so wie in dem Abschnitte über die Folgen des Durchschneidens der Muskelschichte auf Seite 58 beschrieben und durch Holzschnitt 9 erläntert ist: ich machte in dem Interradins ${ }^{1}{ }_{2}$ einen Schnitt in die untere, im Interradins ${ }_{i}^{3}$ einen solchen in die obere Fläche des Schirmes, beidemale durch die Hälfte der Dicke der Körperwand.

II. Tag. Am 30. Angust zeigen die Abschnitte der in 4 Antimere zerlegten Medusenhälften ganz dieselben Beziehungen in ihren Contractionen wie gestern. Von den zwei vollständig isolirten Antimeren contrahiren sich die der Contractionscentren nicht beraubten ( $\mathrm{I}^{\prime}$ und $\mathrm{M}^{\prime \prime}$ ) hente in folgender Weise:

\begin{tabular}{|c|c|c|c|c|}
\hline \multirow{11}{*}{ in der } & & & $\mathrm{MI}^{\prime}$ & $\mathrm{N}^{\prime \prime}$ \\
\hline & $1^{\text {ten }}$ & Minute & $\bar{j}$ & 4 \\
\hline & 2. & $"$ & 7 & 4 \\
\hline & 3 & , & 3 & 6 \\
\hline & 4. & , & 4 & 7 \\
\hline & 5 &. & 4 & 5 \\
\hline & 6 & , & 4 & 4 \\
\hline & 7 & " & 3 & 6 \\
\hline & $S$, & , & 2 & 3 \\
\hline & 9 & , & 4 & $t$ \\
\hline & 10 & . & 4 & 5 mal. \\
\hline
\end{tabular}

Auch die der Contractionscentren beraubten $\left(0^{\prime}\right.$ und $\left.\sigma^{\prime \prime}\right)$ contrahiren sich noch, aber viel seltener:

$\begin{array}{cccc} & & 0^{\prime} & 0^{\prime \prime} \\ \text { in der } 1^{\text {ten }} & \text { Minute } & 0 & 0 \\ 2, & , & 0 & 0 \\ 3, & , & 1 & 1 \\ 4, & , & 0 & 0 \\ 5, & , & 0 & 0 \\ 6, & , & 0 & 0 \\ 7, & . & 0 & 0 \\ \text { S. } & , & 0 & 1 \\ 9, & , & 0 & 2\end{array}$




\begin{tabular}{|c|c|c|}
\hline 10 & 1 & \\
\hline $11 \%$ & 0 & \\
\hline 12, & $"$ & \\
\hline & $\cdot \quad \cdot$ & $\cdot$ \\
\hline
\end{tabular}

Eine Stmnde, nachden das Wasser ernenert worden ist, sind die Contractionen entschieden lebhafter geworden:

\begin{tabular}{|c|c|c|c|c|}
\hline \multirow{9}{*}{ es contrahirte sich in der } & & & $0^{\prime}$ & $0^{\prime \prime}$ \\
\hline & $I_{\text {ten }}$ & Minute & 1 & 4 \\
\hline & 2 & $”$ & 0 & 1 \\
\hline & 3 & $"$ & 0 & 2 \\
\hline & 4 & $"$ & 0 & 2 \\
\hline & 5 & $"$ & 1 & 1 \\
\hline & 6 & ” & 0 & 0 \\
\hline & 7 & $\eta$ & 0 & 1 \\
\hline & $S$, & ” & 2 & $0 \mathrm{mal}$. \\
\hline
\end{tabular}

III. Tag. 31. Aug. $\left.\right|_{2} 12$ Uhr Mittags. $0^{\prime}$ beginnt sich aufzulösen, $0^{\prime \prime}$ ist etwas besser erhalten, aber auch schlecht aussehend, während $\mathbf{I}^{\prime}$ und $\mathbf{I}^{\prime \prime}$ prall und frisch sind. Demnoch contrahiren sich jene zuweilen noch $-0^{\prime}$, ein nahezu auseinanderfallender Fetzen Gewebes, macht z. B. einmal nach 7 Minuten langer absoluter Ruhe plötzlich 6 krampfhaft rasch nacheinanderfolgende, unvollkommene Contractionen (Dyspnoë), um daranf wieder durchaus regungslos zı werden.

$I V$. Tag. Am 1. September $11 \mathrm{Uhr}$ Vormittags ist $0^{\prime}$ in ein oberes und ein unteres Stück getrennt, $O^{\prime \prime}$ in cler Mitte zerstört (Holzschnitt 17 bei a); beide zeigen, im Wasser von gestern Abend untersucht, keine Contractionen mehr. Die mit Contractionscentren versehenen isolirten Antimere dagegen contrahiren sich noch folgendermassen :

\begin{tabular}{|c|c|c|c|}
\hline & & $\mathrm{M}^{\prime}$ & $\mathrm{II}^{\prime \prime}$ \\
\hline $1^{\text {te }}$ & Minute & 9 & 4 \\
\hline 2 , & , & 7 & 4 \\
\hline 3 & $"$ & 4 & 6 \\
\hline$"$ & $"$ & 2 & 5 mal. \\
\hline
\end{tabular}

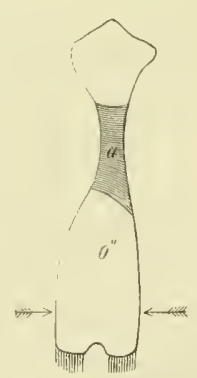

Holzschnitt 17.

Nachdem das Wasser ernenert worden, sehe ich nach 5 Minuten lang danernder Beobachtung an dem unteren Theil des in der Mitte zerfetzten Antimers $0^{\prime \prime}$ eine Contraction, welche parallel dem natürlichen Rand (in der Richtung der Pfeile, 
Holzschnitt 17) verläuft, so dass das Stïck gleich einem Hohlziegel zusammengezogen wird, dessen concave Fläche selbstverständlich die subumbrella bildet.

V. Tag. 2. Sept. $11 \mathrm{Uhr}$ Vormittags: Die beiden Antimere 11 contrahiren sich sowohl im alten, wie im frischen Wasser munter. $O^{\prime \prime}$ ist hente, wie gestern schon $0^{\prime}$, aufgelöst.

VI. Tag. 3. Sept. Beide M bewegen sich anch hente noch im Wasser von gestern Abend, beginnen aber sich anfzulösen und zwar ebenfalls in der Mitte. Auch die halbe Meduse, welche sich gestern noch ebenso verhalten hatte, wie am ersten 'Tag, hat sich jetzt theilweise aufgelöst. Es sind von ihr übrig nur noch drei

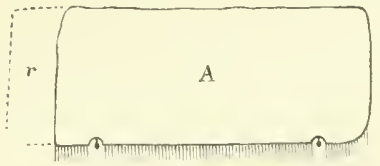

Holzschnitt $18^{\prime}$.

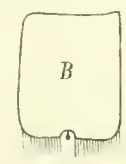

Randstücke je von $3 \mathrm{~cm}$ Höhe, ein grösseres, mit 2 Randkörpern (A, Holzschnitt 1S') und zwei kleine, mit je einem liandkörper (B, Holzschnitt 18', es ist nur eines dieser Stückchen gezeichnet). Es hat sich somit der Rand - entsprechend den in Holzschnitt 9 bezeichneten Interradialschnitten getrennt, aber es ist zugleich jederseits von A und jederseits von B ein Stück entsprechend der Grösse ron 1 abgestorben, so dass $B+A+B$ znsammengelegt nicht mehr den ursprünglichen Rand in seiner ganzen Länge darstellen würden. Jedes der Stücke B trägt genau in der Nitte den liandkörper. Jeder der Raudkörper ist gleichweit ron dem seitlichen Wundrande entfernt.

VII. Tag. t. Sept. Die drei Ringstücke bewegen sich munter, sind jedoch bis auf 1 cm Höhe abgestorben (Holzschnitt $18^{\prime \prime}$

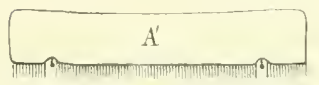

Holzschnitt $18^{\prime \prime}$

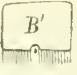

$\mathrm{A}^{\prime}$ und $\mathrm{B}^{\prime}$ ). - Die zwei Antimere $\mathrm{M}$ sind gleichfalls in der lichtung von oben nach unten weiter abgestorben und beide tragen gleichfalls genan in

der Mitte ihres natürlichen Randes den Randkörper.

YIII. Tag. 5. Sept. Das zwei Randkörper führende, von der hallben Aurelie übriggebliebene Ringstück (A') hat sich im Interradius getrennt, so dass es in zwei Theile getheilt ist und dass von der halben Mednse jetzt noch vier Stückchen übrig sind, und zwar ist wieder von jedem der aus $A^{\prime}$ hervorgegaugenen Stückchen A"
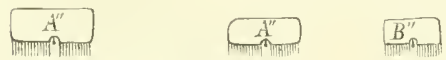

Holz schnitt $18^{\prime \prime}$.
(Holzschnitt $1 \mathrm{~S}^{\prime \prime \prime}$ ) bei $\mathrm{r}$ ein Abschnitt abgestorben, so dass abermals der Randkörper je in die Nlitte des Randrestes zu liegen kam. Alle vier T'heile contrahiren sich noch munter, wie auch die unter dem 4. Sept. beschriebenen zwei Stückchen voll M.

X. Tag. 7. Sept. Selbst heute contrahiren sich alle diese Stückchen, sogar 
in Wasser von gestern Abend, noch lebhaft rhythmisch, sind aber sowohl an den Seiten wie oben noch mehr abgestorben und daher nuch kleiner geworden.

Versuch C. Am 30. Angust $12_{2}^{1}{ }_{2}$ Uhr Mittags schnitt ich einer Aurelia von $30 \mathrm{~cm}$ Durchmesser sammtliche contractile Zonen ans. Was Thier lag nach der Operation flach ansgebreitet, regungstos da. Allein nach $2^{1}{ }_{2}, 6,7,9,10,11$ Minuten beobachtete ich an ihm je eine schwache, unvollkommene, wie im Kreise gehende, d. i. parallel dem Unfang des Schirmes verlaufende, Znckung, später zuweilen auch deren zwei, rasch anfeinander folgende.

I1. Tag. 31. Ang. $12^{1}{ }_{2}$ Uhr Mittags: während 10 Minnten contrahirte sich das Thier im Wasser von gestern nicht spontan, dagegen sofort nach Stechen mit einer Nadel.

III. Tag. Am 1. September schwamm es unter lebhaften energischen Contractionen, vollkommen zum Schirme gestaltet, umher, wie wemn nichts mit ihm geschehen wïre. Es machte 30 Contractionen in der Uinute. Ich schnitt es darauf in zwei Hälften, deren einer ich den ganzen Rand wegnahm, während ich der anderen nur noch an der Stelle der Afterausmündungen ganz kleine Strecken des Randes stehen liess. Beide verstümmelte Hälften machten unmittelbar nach der Operation noch lebliafte Contractionen.

IV. Tag. Am 2. September. Beide verstümmelte Hälften lassen währenul 5 Minuten im Wasser von gestern keine Contractionen sehen. Im frischen Wasser dagegen treten wieder solche auf' - sie gehen jedoch mehr ringförmig und vermögen an clem flach ausgebreitet, mit der unteren Seite nach oben gelagerten Thiere keine Glockenform mehr hervorzurufen, anch nicht, nachdem dasselbe in die natürliche Lage zurückgebracht ist.

V. Tag. 3. Sept. S Uhr Morgens. Im Wasser von gestern keine Bewegungen mehr - nur an der einen Hälfte, an derjenigen, welcher der ganze Rand abgeschnitten worden, sind auf einen stich mit der Nadel unvollkommene Zusammenziehungen (Zuckungen) an einer beschränkten Stelle, ungefähr in der Mitte zwischen Centrum und Rand (das Thier ganz gedacht), zu bemerken.

VI. Tag. Am t. September. An demselben Stück, an welchem sich gestern auf Reiz Contractionen zeigten, erscheinen sie ebenso hente noch, olssehon es Spureu der Auflösung an sich trägt. Die andere Hälfte ist verdorben.

VII. Tag. Am 5. September ist Alles verdorben.

Tersuch D. Am 30. Ang. 12 Uhr Mittags, schnitt ich von zwei Arrelien von 18 cm Durchmesser der einen die Randkörper, der anderen die After mit Umgebung ans. Die erstere ist nach der Operation absolut regungslos, die zweite contrahirt 
sich wie gewöhnlich. Nux wemn ich mit der Nadel in jene einsteche, zeigen sich Znckungen - leichte, unvollkommene Contractionen an ihr.

II. Tag. 31. Aug. 11 Uhr Mittags: das der Randkörper berabte 'Thier (0) liegt flawh ausgebreitet, lie übriggebliebenen Randlappen etwas nach anfwärts geschlagen, regumgslos da. Selbst anf Stiche mit der Nadel reagirt es nur äusserst schwach. Was andere T'hier (II), welchem ich die After ausgeschnitten, contrahirt sich wie gestern lebhaft. Die ansgeschnittenen (Ranakörper-) Str̈ckchen von O contrahiren sich, wie gestern unmittelbar nach ihrer Loslösnng lebhaft, die ansgeschnittenen (After-) Str̈ckchen von II haben im Gegensatz zu jenen das frische Anssehen verloren, sie sind nicht mehr prall, sondern schlapp und dümn — sie scheinen todt zu sein, denn auf lieiz regen sich nicht einmal mehr Tentakel an ihnen.

III. Tar. 31. Ang. M. contrahirt sich (im alten Wasser) auf's Krräftigste, macht mindestens 10 Contractionen in der Minute, gewöhnlich aber viel mehr. An 0 ist anch heute keine einzige Contraction wahrunehnen.

IV. Tag. 1. Sept. 12 Uhr. II contrahirt sich (im alten Wasser) lebhaft. O macht nach $2^{1}{ }_{2}, 1^{1}{ }_{2}, 1^{1}{ }_{2}$ Mimuten je eine leichte spontane Contraction, aber ausschliesslich mit zwei bestimmten der $\$$ Afterlappen und zwar mit beiden gleichzeitig. Die übrigen sechs bleiben vollkommen ruhig. Sticht man mit einer Nadel etwa in die Mitte des Thieres hinein, so contrahiren sich dieselben 2 Lappen, welche anch spontane Contraction zeigen, stark, mur schwach aber einige der übrigen, wälrend noch gestern keine sclbstständige Bewegung und auf Reiz nahezu keine lieaktion an demselben Thiere zu beobachten war - dasselbe hat sich also, a ber nur in einzelnen 'T'heilen erholt: In diesen Theilen müssen sich Ersatz-Contractionscentren gebillet haben, deren Wirkung sieh nicht über deu Bereich derselloen hinaus erstreckt. - Im Uebrigen liegt es flach ausgebreitet da, während M sich vollständig glockenähnlich bei den Contractionen gestaltet. " "Stmuden nach Zusatz von frischem Wasser contrahirt 0 je nach 2, $1^{1}{ }_{2}, 1^{1}{ }_{2}$ Hinnten dieselben zwei Afterlappen wie vorhin. II contrahirt sich sehr lebhaft, beide verhalten sich nahezu ebenso wie im alten Wasser.

V. Tag. 2. Sept. II contrahirt sich in alten Wasser lebhaft, O liegt ruhig nnd begimnt sich aufzulösen: ganz sind nu noch die zwei Afterlappen, welche sich gestern noch durch spontane Contractionen anszeichneten. Die übrigen $\Delta$ fterlappen sind aufgelöst, mit Ansnahme von zweien, von welchen noch Stücke vorhauden sind.

VI. Tay. 3. Sept. $8^{1}{ }_{*}$ Uhr Morgens: Es leben nur noch einige der ansgeschnittenen stückchen von $U$, welche nit Randlörpern rersehen sind, alles Andere 
ist in Anflösung begriffen. - Verwesung im Gefàss, daher ist wohl anch M so rasch abgestorben.

VII. Tag. 4. Sept. Die Ausschnitte mit liandkörper, welche gestem noch am Leben waren, leben noch, sind übrigens ganz schmale $\left({ }_{4}^{3} \mathrm{~cm}\right.$ breite) Streifen geworden, stellen nu je einen Randkörper dar mit daranhängendem Stückchen des Schirmrandes.

VIII. Tag. 5. Sept. Ein Stückchen des Randes mit Randkörpern lebt noch und contrahirt sich, trotzden das Wasser durch eine die Nacht äber mit ihm znsammen befindliche verwesende Qualle gänzlich verdorben ist.

Versuch E. 30. Angust: zwei Aurelien von is cm Durchmesser operirte ich ebenso wie die in Versuch D behandelte. Nach der Operation contrahirt sich $O^{1}$ ) noch, wenngleich wenig wirkungsvoll. Solche schwache Contractionen werden auch in den folgenden Tagen beobachtet, aber meist nur nach minutenlangen Pansen. Sie werden vorübergehend lebhafter nach Zusatz von frischem Wasser und zeigen sich anch anf Stiche mit der Nadel. Am fünften Tag ist $O$ bis auf das festeste, centrale Stück aufgelöst. Von M hat sich die centrale Kuppe heransgelöst, der von ihm getrennte liing liat sich je in den Interradien getrennt, so dass 8 Antimerenstücke entstanden sind, deren jedes ein Contractionscentrum trägt. Diese 8 Antimerenstücke zeigen aber beginuende Zerstörung wiederum in der Mitte ihrer Höhe. Sie contrahiren sich noch lebhaft rhythmisch anch in nicht frischem Wasser.

Versuch F. 31. Angust: gestern hatte ich eine Aurelia von $8 \mathrm{~cm}$ Durchmesser so weit durchgeschnitten, dass zwischen ibren zwei Hälften noch ein Znsammenhang von $8 \mathrm{~mm}$ bestand. Darauf schnitt ich der einen der beiden Hälften die Randkörper aus. Diese letztere contralint sich lreute als Nachtikt zm muverletzten Hälfte, jedoch lange nicht so energisch wie jene, vielmehr schlappend. Hieranf machte ich die Verbindungsbrücke noch un $4 \mathrm{~mm}$ schmäler: die der Ranclkörper beraubte Hälfte contrahirt sich jetzt nicht mehr. Dagegen contrahirt sie sich am folgenden Tage wieder wie früher als Nachtakt zur mnverletzten Hälfte.

Versuch G. 31. Aug. 12 Uhr: von zwei Aurelien von $10 \mathrm{~cm}$ Durchmesser schnitt ich der einen $(O)$ die Randkörper, der anderen (M) die After sammt Umgebung aus. II contrahirt sich nach der Operation wie vorher. $O$ dagegen ist und bleibt absolut regungslos und ist am 4ten Tage bis auf ein kleines centrales Stück vollständig zerflossen, während sich II noch vergnügt umherbervegt. - An II fiel

1) Bezeichnnng in diesem, wie in den folgenden Versuchen, wie bei D. 
mir am dritten Tage aut, dass, obgleich nur kurze Afterecken an ihm ansgeschnitten waren und die Muskulatur nirgends verletzt erschien, doch nicht alle Contractionen der Antimere synchronisch erfolgten, sondern häufig ein oder das andere Antimer allein (oder deren mehrere zusammen) wenigstens schwache Contractionen machten, während die übrigen zurückbliełen.

Versuch I. Am 4. September schnitt ich einer Aurelia ron 8 cm Durchmesser den Rand in der Breite von 1 cm ab. Unmittelbar nach der Operation ist das 'Thier regungslos; nach einer Minute macht es einige hastige Contractionen, welche sich nach einer weiteren Hinute wiederholen. Darauf bleibt es regungslos auf dem Rücken liegen. Aehnlich verhält sich der centrale Theil eines Thieres von $14 \mathrm{~cm}$ Durchmesser, an welchem dieselbe Operation vollzogen worden ist. Die die Randkörper führenden Ringtheile beider contrahiren sich lebhaft. An folgenden Tage beobachtete ich an dem Exemplar von 8 cm Durchmesser zuweilen eine schwache, nuvollkommene Contraction, am anderen, trotz öfters wiederholter, minutenlanger Beobachtung, nicht. Da sich aber hier die Tentakel zuweilen leicht bewegen, so ist anzunehmen, dass auch hier, wenngleich sehr selten, einzelne Contractionen stattfinden möchten.

Versnch J. Am 4. September machte ich an einer Aurelia ron $14 \mathrm{~cm}$ Durchmesser dasselbe Experiment wie gesteru an H. Zum Unterschiede von H begannen aber hier Contractionen am Kuppentheile fast unmittelbar nach der Operation und dauerten, wenn anch ron Zeit zu Zeit aussetzend und überhaupt umegelmässig ausgeführt, lebhaft fort.

\section{Verhältniss zwischen der Grösse der Thiere und der Anzahl der in der Zeit- einheit von ihnen ausgeführten Contractionen und Verhältniss dieser Zahl zum Formwerth getheilter Thiere.}

Im Folgenden möchte ich zunächst noch einige Beispiele aufführen zum Beweise für den frủher ron mir aufgestellten Satz, dass die Zahl der von den Aurelien ausgeführten Contractionen in umgekehrtem Terhältniss zu deren Grösse steht. Einer der aufzuzählenden Fäle, welcher eine Ausnahme von der Regel bildet, aber ein Thier mit 9 Randkörpern betrifft, steht vielleicht in gewisser Beziehung zu der zweiten der hier zu behandelnden Fragen. Es fordert derselbe nämlich zur Untersuchung darüber auf, ob nicht Mednsen mit überzähligen Randkörpern sich stets rascher bewegen als normale und in welchem Maasse? - Die fünt ersten der im 
Folgenden aufgeführten Zühlungen machte ich Morgens an des Abends vorher frisch eingefangenen Thieren, welche die Nacht äber in einem und demselben Gefüsse zugebracht hatten und während sie noch zusammen in dem Wasser vom Abend vorher sich aufhielten. Die übrigen Zählungen machte ich an kurz rorher eingefangenen Thieren, während sie in frischem Wasser sich befanden. Es handelt sich um uwwillkürliche Contractionen, wie sie ausgeführt werden bei ruhigem Schweben der Merlusen. Die Zahlen sind je das Mittel aus einer grösseren Anzahl von Zählungen.

\begin{tabular}{|c|c|c|c|}
\hline & ia & cm Durehmesser & macht Contractione \\
\hline 1 & $>\Xi$ & j & $3 S-42$ \\
\hline 2 & $\bar{\Xi}=$ & 7 & $30-32$ \\
\hline 3 & $\Xi \frac{2}{2}$ & $\left.\mathrm{~S}^{1}\right|_{2}$ & $26-27$ \\
\hline 4 & $\stackrel{\mathscr{C}}{=}$ & 11 & $24-25$ \\
\hline - & 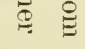 & 16 & $10-13$ \\
\hline 6 & 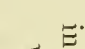 & $1 \mathrm{~S}^{1}{ }_{2}$ & $2 \cdot 2-23$ \\
\hline ? & $\sum_{i=}^{*}$ & 21 & $13-15$ \\
\hline S & $\stackrel{0}{0}$ & 26 (hat 9 Randkörper) & 14 \\
\hline 9 & $\Phi$ & 29 & $10-11$ \\
\hline
\end{tabular}

Der Einfluss des nicht mehr ganz frischen Wassers in 1 bis 5 ist angenscheinlich: die Contractionen sind verhältnissmässig seltener als in 6 bis 9 .

Anch die willkürlichen Contractionen, diejenigen, welche die Ortsveränderung vermittehn, sind bei grössereu Thieren weniger zahlreich als bei kleineren. Ein genaneres Verhältniss hier festzustellen würde, eben weil diese Bewegungen willkü1liche sind, wohl schwer sein. Am nächsten möchte man der Aufstellung einer bestimmter ausgesprochenen Regel dann kommen können, wenn man die Terschiedenheit der Stärke der einzehen Contrationen eines und desselben Thieres zu berechnen oder aber zu beseitigen im Stande wäre. Das letztere würde damn wohl als annähernd erreicht angenommen werden können, wenn man die Untersuchung beschränkte auf diejenigen Momente, in welchen ein Thier sich mit dem Anfwand der äusserst möglichen Kiraftanstrengung vorwärts bewegt. Entsprechende Beobachtungen habe ich nicht angestellt. Aber die Verwerthung genanester Vergleichung verschiedener in dieser Veise sich bewegender Thiere zum Zweck der Aufstellung einer Regel in obigem Sinne würcle trotzdem eingeschränkt sein durch die Terschiedenheit des Vermögens der individuellen Kraftentwicklung. Dies gilt selbstverständlich auch für die unwillkürlichen Bewegungen: ein kräftigeres Thier kamn mit einer gegebenen Contraction mehr für die Athmung erreichen, als ein weniger kräftiges und es wird desshalb 
eben znm Zwecke der Befriedigung des Athembedürfnisses weniger Contractionen in der Zeiteinheit zu machen brauchen, als das letztere. Wenn ich sonach weit davon entfernt bin, den Satz von den proportionalen Beziehungen zwischen Grösse und Contractionsthätigkeit als ein mathematisches liesetz hinstellen zu wollen. so muss ich doch sagen, dass es sich in demselben um eine liegel handelt, welche so wenig erhebliche Ausnahmen und Abreichungen zeigt, als sie - von der individuellen Tariation ganz abgeschen - von Wesen überhaupt erwartet werden kann, welche willkürlichen Handelns fähig und bei welchen ansserdem hänfig zu unterscheiden unmöglich ist, was willkürlicher und was unwillkürlicher Aktion zugeschrieben werden muss. Ich gehe nun über zur zweiten der in diesem Abschnitte zu behandelnden Fragen.

Meine ersten Versuche führten mir wiederholt ein bestimmtes proportionales Verbältniss zwischen der summe der in der Zeiteinheit von der Gesammtheit der Theilstücke eines Thieres, gleichriel, seien sie Vierlinge, Zwillinge oder Einzel-Antimere, gemachten Contractionen zu der Anzahl derjenigen vor: welche das ganze Thier vor der Theilung in derselben Zeit gemacht hatte.

„Doch" bemerkte ich ${ }^{1}$ ) "trat dieses Verhältniss zuweilen erst längere Zeit nach der Theilung des Ganzen ein ..... während unmittelbar nach der Operation die verschiedensten Schwankungen statthatten.

Eine Aurelia, welche sich $44 \mathrm{mal}$ in der Minute contrahirte, zerschnitt ich in zwei Vierlinge, den einen Vierling in Zwillinge, einen der Zwillinge in zwei Strahlstücke.

Nach der Zertlieilung machten alle diese Stizeke eine Zeit lang dieselbe Anzahl von Zusammeniehungen in der Zeiteimheit, welche das nnverletzte ganze Thier gemacht hatte. Nach einigen Standen jedoch contrahirten sich :

$$
\begin{array}{l|l}
\text { der Vierling } 2 \cdot 2 & \text { schwimmend, } \\
\text { der Zwilling } 15 &
\end{array}
$$

die Einzel-Strahlstücke je 8 mal : zu Boden liegend

in derselben Zeit.

Ein anderes Individum machte 88 Contractionen in der Winute. Ich zerschnitt es gleich dem vorigen in zwei Hailtten. Die Hälften machten einige Secunclen lang dieselbe Anzahl von Contractionen wie das ganze Thier. Damn entstand eine Panse und darauf contrahirten sie sich regelmässig 44 mal in der Minute. Darauf schnitt ich eine der Hälften in 2 Theile - fast mmittelbar nach der Operation contrahirte sich jeder lieser Zwillinge nur noch 22 mal in derselben Zeit. Den eimen Zwilling schnitt ich durauf in 2 Hälften - noch nach $1 \frac{1}{2}$ Stunden zogen rich die entstandenen Einzel-Antimere ebenfalls 22 mal in der Minute zusammen.

So autrallend das Zusammenfallen der Thatsachen mit der anfgestellten Regel in rielen Fillen ist, so häufig sind bedeutende Ausnahmen. wie schon der soeben angetührte Fall zeigt. So geht ferner aus einer der früher angeführten Versuchsreihen hervor, dass die Contraetionen sogar gleichwerthiger Theilstücke wenigsten: nnmittelbar nach der Theilung ansserordentlich ungleich sein können und überall zeigt sich, dass die Rückkehr dieser Ungleichheit zu einer für heide amähernd ühereinstimmenden Norm dem grössten Wechsel

1) Ueber künstliche Theilbarkeit von Aurelia aurita und Cyanea eapillata, Wtirzb. Verh. a. a. O. S. 146, zoolog. Unters. S. 54. 
und den grössten Schwankungen unterliegt. Zuweilen schien diese Ungleichmissigkeit ļestehen zu bleiben. In anderen Fällen dagegen leohachtete ich bald nach der Theilung eine solche Gleichmässigkeit in den Znsammenziehnngen von zwei gleichwerthigen Theilstücken. dass das eine sogar z. B. eine Contraction, welehe es etwa ausgesetzt hatte, nachholte, so dass beide wilhrend langer Beobachtung fortwilhrend die gleiche Anzahl von Contractionen in der Zeiteinheit machten. Einen triftigen Grund für diese Verschiedenheit des Verhaltens jetzt anzugeben, hin ich ausser Stande, sotem dieselbe nicht willkührlicher Thätigkeit zugeschrieben werden darf. Poch ist es immerhin möglich, dass sie wenigstens theilweise zurückzuführen sei auf irgend welche von mir nicht beachtete Fehler in Betretf der einheitlichen Durchführung der Experimente."

Meine neuteren Beobachtungen (1574) tührten mir in der Mehrzahl der Fälle die grösste Unregelmässigkeit in der Zahl der Contractionen ummittelbar nach der Theihnng vor: dagegen zeigten sich längere Zeit nach derselben ebenso oft entschiedene Beziehungen zwischen jenen Zahlen und dem Formwerthe der Theilstïcke. Wiederholt traten mir von Nenem Fälle entgegen, in welchen diese Beziehung eine direkt proportionale war und jedesmal war ich von dem Anffallenden der Erscheinung betroffen ebenso wie damals, als ich sie zum ersten Male sah. Allein ich ïberzengte mich mehr und mehr tavon, lass dieselben in ihrem rereinzelten Anftreten zum Aufstellen einer Regel nicht berechtigten. Jene Beziehungen, welche sich längere Zeit nach der Theilung in fraglichem simne feststellen lassen, beschränken sich auf die Thatsache, dass damn die Theilstücke von grösserem Formwerthe zahlreichere Contractionen in der Zeiteinheit machen, als die von geringerem Formwerthe, allerdings antfallend häufig proportionalem Verhültnisse sich nähernd. Abgesehen von meinen eigenen Experimenten zeigten mir ein entsprechendes Verhalten wiederholt auch Krüppel, welche in der Weise getheilte Medusen darstellten, dass die Theilstücke derselben nicht mehr untereinander in leitender Verbindung standen, ähnlich dem Fall, weleher im XII. Abschnitte in Versuch A gesehildert ist. Es fand sich, wie dort, dass diejenigen Theilstücke solcher Kriuppel, welche von höherem Formwerthe waren und mehr Randkörper führten, in der Zeiteinheit eine grössere Anzahl von Contractionen machten als diejenigen von geringerem Formwerthe. Und wenn jch Kr'tippel antraf. welche, ohne weitere Complication, den Werth ron zwei, drei oder mehreren Antimeren hatten, so liess sich, sofern man die nrsprn̈ngliche Grösse des Thieres bei der Vergleichnng mit in Betracht zog, ein ähnliches Verhältniss gleichfalls nicht verkennen. Inzwischen ist liom a ues der Aufstellung einer Regel, welche direkt proportionale Beziehungen in dem vorhin erörterten sinne annehmen würrle, mit Recht entgegengetreten und kommt zu dem Schlusse'), es sei nu so viel Thatsächliches festznstellen, dass im Allgemeinen kleinere Theilstücke einer Amelia die Neigung hätten, sich weniger häufig zu contrahiren als grosse. Nur gibt der Umstand, diss Ro m a nes

1) Philos. Transact. Vol. 167, S. 667 ff. und 746. 
übersehen hat, welche Bedentung ich der nach der Theilung verflossenen Zeit schon in meiner ersten Vittheilung zugeschrieben habe, Veranlassung dazu, dass seine Angaben in einen grösseren Gegensatz zu den meinigen treten, als thatsächlich begrïndet ist. lch hatte, wie schon erwähnt, gleich Anfangs hervorgehoben, dass die Beziehungen zwischen Formwerth und Zahl der Contractionen häufig erst längere Zeit nach der Theilung eintreten. Romanes findet, dass jene Bezielıungen beeinflusst werden von zwei Faktoren, einmal eben von der Zeit, welche seit der Theihung verstrichen ist und zweitens ron der Thatsache, dass zuweilen die Irraft eines oder des anderen lokomotorischen Centrums die der übrigen mehr oder weniger bedentend überwiege. Zwar ist nach seinen Beobachtungen die relative Kraft des lokomotorischen C'entrums in einem gegebenen Theilstück einer Aurelia wichtiger für die Zahl seiner Contractionen als sein Formwerth, aber die Zahl der Contractionen der Theilstücke von geringerem Formwerthe nimmt stets rascher ab, als jene der Theilstücke von grösserem Formwerthe; dies sogar in lem Maasse, dass eines der ersteren, falls es vermöge des Uebergenicht seines Nervencentrums in der Zeiteinheit mmittelbar nach der Operation mehr Contractionen machen sollte, als die letzteren, doch bald langsamer sich contrahiren wird als sie und todt sein wird zu einer Zeit, da sie sich noch bewegen. Die Aurelia aurita entnommenen Beispiele, welche Romanes folgen lässt, beziehen sich auf Fälle, in welchen eben das Nervencentrum irgend eines Theilstückes gegenüber demjenigen eines an Grösse gleichwerthigen an Kraft überwiegt. Es zeigen nm aber diese Beispiele, dass trotz dieses anfïnglichen Missrerhältnisses in einer gewissen Zeit nach der Operation ein sehr auffallendes Terhältniss in der Zahl der Contractionen in dem von mir hervorgehobenen Sinne eingetreten ist :

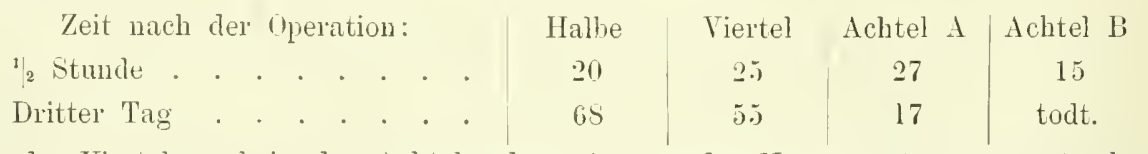

In der Viertel- und in der Achtelmeduse A war das Nervencentrum zuerst übermächtig geresen.

Ein ancleres Beispiel:

\begin{tabular}{|c|c|c|c|c|c|c|}
\hline & & & Halbe & Viertel & Achtel A & Achtel B \\
\hline vier Stunden & nach der & Operation: & 100 & 100 & 5.5 & 90 \\
\hline zweiter 'Tag & . & . . & sS & 90 & 64 & $5 \mathrm{~s}$ \\
\hline dritter Tag & . . . & . . . & $\$ 6$ & $S:$ & 62 & 57 \\
\hline vierter Tag & . . . &.$\quad \cdot \quad \cdot$ & 59 & $4 . j$ & 24 & 20 \\
\hline fünfter Tag & . . . & $. \quad . \quad . \quad$. & 50 & 49 & 20 & 10 \\
\hline
\end{tabular}




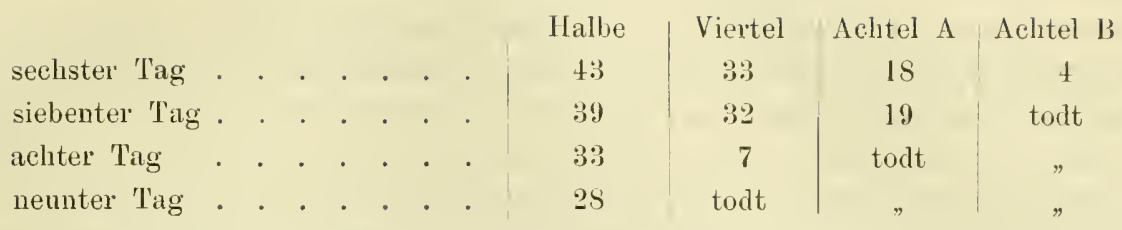

Es ergibt sich aus diesen Beispielen nicht nur dentlich, dass in einer gewissen Zeit nach der Theilung die grösseren Theilstücke mehr Contractionen in der Zeiteinheit machen als die kleineren, sondern das zweite derselben weist Zahlen anf, welche sogar einem proportionalen Verhältniss in dieser Beziehung nicht allzu ferne stehen (sechster Tag), wenn man berücksichtigt, dass die Kiraft der Viertelmeduse von vornherein überwiegend war. Wenn wir in allen Fällen diesen Faktor, das Ueberwiegen einzelner Contractionscentren an Líraft gegenüber anderen, in Rechuıng ziehen, so werden sich überall die Zahlen einem solchen Verhältnisse nähern und ich darf wohl die Fuge schliesslich aufwerfen, ob nicht diejenigen, in welchen ein direkt proportionales Verhältniss sich ergab, als die Normalfalle zu betrachten seien, als solche, in welchen alle Nervencentren gleich kräftig sind? Jedenfalls scheint es mir unzulässig, eine derartige anffallende und wiederholt anftretende Erscheinung als eine zufallige zu bezeichnen, es sei denn, man will unter "Zufall" anch solche Beziehung von Thatsachen verstehen, bei welcher innere Ursachen nicht ansgeschlossen sind, ohne dass man jedoch diese Ursachen kennt.

Romanes kommt in weiteren Verlaufe seiner Arbeit, olne Rücksicht anf die vorliegende Frage zu nehmen, zu einem Satze, welcher offenbar für dieselbe von grosser Bedentung ist. Er findet, dass die Contractionsthätigkeit einer Meduse einige Zeit nach der Operation vermindert wird, wenn nan Stücke von ihr ansschneidet und ferner, dass ein gewisses proportionales Verhältniss,bestehe zwisehen der Grösse des weggenommenen Gewebstückes und dem Grade der Verminderung der Contractionsthätigkeit 1), er kommt so offenbar auf anderen Wegen selbst zur Anfstellung der Regel, dass ein gewisses proportionales Verhältniss besteht zwischen der Zahl der Contrictionen und dem Formwerth der Theilstücke. Denn es wird zu erwarten sein, dass das von Romanes hervorgehobene Verhältniss dann am Reinsten hervortreten müsse, wenn die von der Meduse weggenommenen Stücke Antimere sind. Ein Zerschneiden eines Thieres in 2, 4, S Stücke in den Interradien wird also jenes Verhältniss am Sichersten zum Ausdruck bringen müssen. Sind nun die Beobachtungen von Romanes richtig, und

1) a. a. O. S. 675 . 
da sie sich mit den meinigen in so eigenthümlicher Weise decken, scheint dieses erwiesen. so ist es anch richtig, dass ein gewisses proportionales Verhältniss zwischen Formwerth und Contractionsthätigkeit von T'heilstricken besteht, weun es auch gewöhnlich erst längere Zeit nach der Theilung auftritt. Ein direktes proportionales Verhältniss besteht aber in weitaus den meisten Fällen nicht. Komanes hat anf meinen Wunsch dieses Ergebniss meiner fortgesetzten Untersuchungen in eine Nachschrift seiner letzten Arbeit noch aufgenommen ${ }^{1}$ ), zn welcher ich nur eine Hinweisung anf den Wortlaut meiner ersten Mittheilung in Beziehung auf diesen Punkt hinzufügen möchte, um zu betonen, in wie bedingter Weise ich mich schon damals ansgesprochen habe.

\section{Versuche an Cycloneuren.}

Unter den Cyclonenren habe ich einige Versuche an jeuen Sarsien angestellt, welche ich mir im Frühjahr 1877 lebend halse von Kiel kommen lassen. Auch Romanes hat an Sarsia vurzugsweise Beobachtungen gemacht, ans dem Grunde, rreil dieses Objekt rach seiner Erfahrung dazu vor anderen ganz besonders günstig ist. Es frent mich, sagen zu könuen, dass meine Ergebnisse, welche sich übrigens nur anf einige Hauptfragen erstrecken, mit den seinigen vollkommen äbereinstimmen.

Abschneiden des Schirmrandes hebt, und zwar ohne Ausuahme, die so änsserst lebhaften Contractionen der Sarsia sofort anf. Der Schirmmond selbst contrahirt sich munter fort. Der randlose Theil der Glocke erholt sich nicht wieder. Schneidet man :3 von den 4 je einen Augenfleck tragenden verdickten Stellen, den sogenannten "Ganglien", des Schirmrandes ans, so contrahirt sich die Sarsia weiter. Hat man aber anch das letzte Ganglion ansgeschnitten, so fält sie regungslos zu Boden, um sich jerloch gewöhnlich, wenn anch nicht immer, so zu erholen, dass sie späterhin wieder rhythmische Contractionen ausführt, die allerdings meist wenig kräftig sind.

Bleibt nur irgend ein Theil des Schirmrandes nach Entfernung aller übrigen an dem Thierchen sitzen, so danern die contractionen fort.

Es sind somit hier - und ebenso ist es nach den Angaben von Rom an es anch bei anderen von ihm nntersnchten Cycloneuren - einzelne Bezirke des Schirmrandes nicht in so hervorragender Wreise vor dem übrigen Theil desselben ausgezeichnet wie bei den Toponemen. Ein Schritt zu solcher Anszeichnung ist ange-

1) Philos. Transact. Vol, 169. S. 757 . 
dentet in der höheren Bedeutung, welche den "Ganglien“ zukommt; aber man kann diese mitsammt der anschliessenden IIskulatur nicht etwa als contractile Zonen bezeichnen, vielmehr ist der ganze Schirmrand contractile \%one. Dagegen ist die Bedentung derselben als Centralorgan gegenüber den übrigen Theilen des liörpers eine viel mehr exclusive als bei den Toponeuren. Es schloss schon Romanes aus seinen Versuchen, dass bei den Cycloneuren lokomotorische Centren in jedem Theile des Schirmmandes enthalten seien, in grösserer Menge aher als an anderen Stellen desselben in den "marginal bodies", d. i. in den "Ganglien." Meine morphologischen Angaben werden zeigen, wie sehr die anatomische Untersuchung das Experiment anch hier bestätigt. In Beziehung anf diese Uebereinstimmmig sind ganz besonders auch die schönen Versuche hervorzuheben, welche liomanes, wie später des Näheren erörtert werden soll, mit elektrischer Erregung angestellt hat. Ein noch viel güustigeres Objekt der physiologischen Untersuchmug als Sarsia dürfte Carmarina hastata abgeben und ich bedaure um so mehr, dass ich durch die Ungunst der Verhältnisse daran verhindert worden bin, dieses Thier experimentell zu prüfen, als ich gerade an ihm das Nervensystem unter den Cycloneuren am genanesten morphologisch studirt habe. Ich sehe mit Spannung der ersten Gelegenleit entgegen, da es mir vergönnt sein wird, die plıssiologische Lücke auszufüllen. Einige Beobachtungen indessen, welche ich am unverletzten lebenden Thiere in Neapel im Frühjahr 1576 habe machen können, zeigten mir, dass Carmarina hastata ihre Bewegungen in viel höherem Grade nach willkürlichen Impulsen ausfülıren muss, als irgend eine der von mir genanex beobachteten anderen Medusen, gehören sie der Gruppe der Cycloneuren oder der 'Toponeuren an. Die Carmarina contrahirt sich nicht wie diese hervorragend und andanerud rhythmisch in maschinenähnlich gesetznuässiger Folge, so rlass sogar, wie z. B. bei Anrelia, die Pansen der Bewegung annähernd nach der Zahl und Stärke der voransgegangenen Contractionen in ihrer Daner berechnet werden kömnten. Das Thier schwebt oft Minuten, oft nur einen Augenblick, stets unberechenbare Zeit lang, rulig und mubeweglich anf einer und derselben stelle oder lässt sich ebenso umbeweglich steigen oder sinken. Nur die Fangfäden leicht in der Lage verändernd, bietet das glashell durchsichtige Wesen in dieser Ruhe einen genussreichen Anblick dar. Dann plötzlich macht es eine grössere oder geringere Anzahl balk äusserst raseh, bald langsamer aufeinanderfolgender Contractionen, jetzt dabei anf einer und derselben Stelle verharrend, jetzt mit grösserer oder geringerer Geschwindigkeit und Lebhaftigkeit den Ort verandernd. All das combinirt sich im buntesten Wechsel und macht anf den Zuschaner den Eindınck kräftig überlegter Thätigkeit. Der Reichthum an hochans- 
gebildeten Ganglienzellen im Körper dieses Thieres lässt diese Thätigkeit verstehen, aber erst das Experiment möchte in den Werth der Einzelheiten der Erscheinungen klareren Einblick verschaffen.

\section{Untersuchungen Anderer. Vergleichung der Ergebnisse derselben mit den meinigen.}

Indem ich zuerst zu der Besprechung der Untersuchungen von

Romanes übergehe, brauche ich nach den in der Einleitung und im weiteren Verlanfe meiner Arbeit gegebenen Daten die chronologischen Beziehungen der Veröffentlichungen von ihm und mir nicht näher zn erörtern. Es geht daraus hervor, dass die wesentlichsten der im Vorstehenden mitgetheilten Sätze von mir festgestellt und grösstentheils anch kurz veröflentlicht worden sind, bevor die bezüglichen Untersuchungen von lkomanes gemacht oder doch publicirt waren. Nur als ich meine Versuche an Cycloneuren anstellte, hatte ich Kenutniss von den ausgedehnten Beobachtungen, welche der englische Forscher an denselben gewonnen hatte, nachdem ich meine ersten Mittheilungen über den Gegenstand, Toponeuren betreffend, bekannt gegeben hatte. Da aber die Unibhängigkeit unserer Arbeiten eine gegenseitige ist, so gint die Uebereinstimmung, welche in den meisten Resultaten zwischen uns herrscht, in erwünschtester Weise zngleich die Probe für dieselben ab. Ausserdem hat sich der englische Forscher für den Werth der Priorität in der ganzen Frage durch so ausgezeichnete und eingehende Untersuchungen, wie er sie geliefert hat, sicherlich entschädigt '). Ich behandle die drei P'ublicationen ron Romanes nach der Reihenfolge ihres Erscheinens.

1) Einen Irrthum betreffs djeser Prioritit, welchen Rom anes in seiner ersten in den Philos. Transactions erschienenen Abhandlung (Vol. 166. p. 309) aussprach, indem er, in der Voraussetzung, es sei meine erste Arbeit erst 1874 gemacht, glaubte, die Priorität komme mir zwar für meine übrigen Beobachtungen, nicht aber für die von ihm sogenannte Fundamentalbeobachtung zu (den Lähmungsrersuch, welcher die Grundlage aller äbrigen bildet) habe ich in den Abdrücken meines Nünchener Vortrags zu berichtigen mir erlaubt (Arelı. f. mikr. Anat. MIV. Bd. S. 397. Amtl. Bericht etc. S. 183). Wenn in dieser Berichtigung - und desshalb komme ich auf die Sache hier zurück - unter dem Einfluss anderweitiger, in Beziehung auf den morphologischen Theil meiner Arbeit damals von mir gemachter Erfalırungen vorausgesetzter Art, ein Vorwurf wegen Ignorirens meiner früher veröffentlichten Untersuchungen enthalten ist, so nehıne ich denselhen mit Vergnïgen zurück, nachdem ich durch persönliche Erklärungen und durch die ferneren Beziehungen mit Herrn Romanes überhaupt die volle Ueberzeugung gewonnen habe, dass eine Absicht von seiner Seite nicht vorgelegen hat. Herr R om anes hat mir sofort brieflich jene Erklärung entschuldigend gegeben und hat mir angeboten, seinen nicht einmal durch ihn verschuldeten Irrthum betreff's der Priorität selbst richtig zu stellen, was er denn auch alsbald in der loyalsten Weise gethan hat. lch bin ihm dafür besonders desslıall, in lohem Grade dankbar, weil ich mich daräber freuen kann, dass die in unserer Literatur 
I. Wie schon in der Einleitung erwälnt worden ist, erschien die erste Mittheilung über von ihm angestellte Zerschneidungsversuche an Medusen in cler Zeitschrift „Nature“ 1874 (Nov.). Der Inhalt dieser Mittheilung ist dort gleichfalls schon hertihrt. Stehen auch wesentliche der Angaben derselben nicht in Einklang sowohl mit meinen eigenen Erfahrungen als mit den später von Romanes selbst gewonnenen Ergebnissen, so hat der englische Forscher doch schon damals die von ihm sogenanute Fundamentalbeobachtung an Cyclonemen gemacht, die Beobachtung, dass Abschneiden des Schirmandes dieser Thiere Lähmung derselben hervorruft, und damit waren meine im Jahre vorher an Toponeuren erlangten Resultate mit gewisser Modification auch für die Cyclonemren als gültig erwiesen.

II. Seine im folgenden Jahre an die Philos. Transact. eingeschickten und 1876 (Vol. 166) erschienenen weiteren Mittheilungen erstrecken sich auf beide Gruppen. Indem er in Betreff der Cyclonemen berichtet, dass Abschneiden des Schimmandes sofort vollständige und bleibende Lähmung des ganzen Schirmes zur Folge habe, fügt er hinzu: nichts könue es Sichereres geben als tiese Wirkung; hunderte von Beobachtungen an verschiedenen Arten, in allen Altersstadien und unter den verschiedensten Bedingungen der Frische und Lebensfähigkeit Laben dasselbe bestimmte Ergebniss geliefert. "Indeed I do not know", sagt el. „of any case in the animal kingdom where the removal of a centre of spontaneity causes so sudden and so complete a paralysis of the muscular system, there being no subsequent movements or twitchings of a reflex kind to disturb the absolute quiescence of the mutilated organism." Er schliesst daraus, dass im Rande aller von ihm untersuchten Arten von Cycloneuren ein hochgradig lokalisirtes System von Centren für selbstthätiges Handeh vorhanden sei, welchen zum Wenigsten die Anregung der Zusammenziehungen des Schirmes ausschliesslich zukomme. I)iese Auffassung werde besturkt durch das Terhalten des abgeschnittenen Randes, welcher seine rhythmischen Contractionen mit

nicht seltenen Beispiele entgegengesetzter Art durch Männer aufgewogen werden, welche jene Art ron sStreben «, die auf Kosten der Rechte Anderer Erfolg zu gewinnen sucht, verschmähen und welche an Vorarbeiten in wissenschaftlichen Fragen nicht eine wegzuräumende Concurrenz sehen im Sinne des Gewerbes. Herr $R o m a-$ n es erklärt (Philos. Transact. Vol. 167. p. 665): „But I should like to take this the earliest opportunity of rectifying an injustice which, as I now learn from Prof, Eimer's last paper, I previously did him in my first paper. In my Postscript to that paper I stated that in our independent observations concerning the effect of excising lithocysts I bad a right to claim priority. both as regards observation and publication. Prof. Eim er, howewer, now explains that, in consequence of his first paper haring been bound in the Wuertzburg Verhandlungen without its proper titlepage, the reference to the date of his work which occurs in the paper itself (»d. I. \&) refers, not to the year on the back of the volume, but to the year proceding. Therefore, although $I$ was right in saying that I had anticipated Dr. Eimer in making the wfundamental observation , I was wrong in supposing that I had also anticipated him in publishing this observation. Dr. Eimer has thus a full right to claim priority as regards this and all his other researches concerning the nervous system of Medusae. - 1878.)a 
ganz derselben Kraft und Ansclaner fortsetze, wie vor seiner Tremmug von dem übrigen 'Theile des Thieres. Der Gegensatz zwischen dem durchans bewegungslosen Glocken- und dem lebhaft sich bewegenden Ringtheil sei so gross als möglich. Wenn auch nur ein kleinstes Stückchen contractilen Gewebes mit einem einzigen Angenfleck ${ }^{1}$ ) der Sarsia in Terbindung geblieben ist, contrahirt sich das ausgeschnittene Stückchen noch Stunden und Tage lang. Eine einzige Ansnahme bot Stamophora laciniata; hier blieben nach Abschneiden des Randes noch drei Bewegungscentren übrig: das eine im Muskelgewebe, nahe der Peripherie des Schirmes, die anderen zwei im "polypite“ dieses Thieres, je in einem der lirenzförmig gegenübergestellten Arme. Bei den 'Toponenren findet Rom an es dieselbe Wirkung vom Abschneicten des Randes wie bei den C'yclonemen, nu sei hier die Lähmung nie so sicher, noch auch so vollständig wie dort: obgleich sie in den meisten Fälleu ummittelbar nach der Operation eintritt, so ist dies nicht immer der Fall; man kamn daher hier nicht wie bei den Cyclonemren irgend mit grosser sicherheit vorher'sagen, welches der numittelbare Erfolg eines Experimentes sein werde. Obschon femer die Lähmung so plötzlich und so scharf ausgesprochen eintritt wie bei den Cycloneuren, so muterscheidet sie sich doch von derjenigen der letzteren daduch, dass sie selten bleibend ist. Nach einen Zeitranm von wenigen Sekunden bis zu einer halhen Stunde oder mehr beginnen gewöhnlich schwache und rurhythmische Contractionen sich zn zeigen. Wie die einzelnen Individnen derselben Art, so verhalten sich anch die einzelnen Arten gegenseitig nicht ganz gleich gegenüber dem Experiment. Als Beispiele werden Anrelia amita mol Cyanea capillata gewählt. Die erstere nähert sich an meisten dem Verhalten der Cycloneuren, während die letztere sich am meisten davon entfernt. - Da Romanes bei dieser Beurtheihng offenbar von der weiterhin ausgesprochenen Voranssetzung ansgeht, dass bei Aurelia aurita die lokomotorischen Centren im Otolithensäckchen concentrirt seien, so muss ich dagegen darauf anfmerksam maehen, in wie hohem Grade auch Aurelia anrita nach meinen Versuchen in Beziehnng anf die Lokalisation dieser Centren von den Cyclonemren verschieden ist. - hom a n es bemerkt indessen ferner, dass bei Aurelia und bei Cyanea ebenso wie bei anderen Arten die individuellen Tariationen sehr gross seien. Bei Aurelia amrita hat Abschneiden des ganzen Randes mit Einschluss der Randkörper in der grossen Mehrzahl der Fälle sofortige vollständige Jäh-

1) Zur Ermöglichung des Vergleichs mit meinen Beobachtungen sei bemerkt, diss es sich hier genauer um die ganglienartigen Verdickungen des Raudes, um die Rundganglien bandelt, welche erst den Augenfleck (Pigmentfleck) tragen. 
mung des Schirmes zur Folge. In der Minderzahl der Fälle zeigt ein oder zeigen mehrere überzählige lokomotorische Centren ihre Anwesenheit im Bereich des contractilen Gewebes nmmittelbar nuch der Operation an. Im ersten Falle, wenn vollständige Lähmmg eingetreten ist, hat man wieder zweierlei zu unterscheiden: meistens entwickeln sich längere oder kürzere Zeit nach der Operation lokonotorische Nebencentren, so dass man bis zu einer Stunde nach derselben nicht sicher ist, ob die Lähmung bleiht oder njcht. Weniger läufig bleibt die Lähmung ebenso vollkommen und danernd wie bei den Cyclonenren. Bei Cyanea capillata hat Ahschneiden des liandes in der Mehrzahl der Fälle vollständige Lähmung des Schirmes zur Folge, indessen verhältnissmässig doch nicht so hänfig wie bei Amrelia aurita. - Ich selbst habe dies bei meinen neneren Versuchen so wenig wie bei meinen ersten finden können. So oft ich noch kürzlich in Kiel einer Cyanea den Rand oder anch nur die Randlappen abschnitt, sank sie umbeweglich zu Boden und zeigte keine Spur von Erholung zu einer Zeit, da viele gleichzeitig operirte Aurelien längst wieder munter waren. Indessen schiebe ich dieses Verhalten keineswegs auf eine grössere Lokalisation der Hauptnervenceutren bei Cyanea - dass dies falsch wäre, wird der anatomische Theil zeigen - ich fand nur, dass sie überhanpt gegen alle Eingriffe in ihren Organismus empfindlicher sei als Aurelia, wie sie denn auch in der Gefangenschaft viel weniger anshält als diese. - Falls, findet Romanes weiter, überzählige lokomotorische C'entren nicht ummittelbar nach der Operation entstehen, so entstehen sie doch sicher, wenn das Thier Zeit bat, sich von der durch dieselbe verursachten Erschütterung zu erholen. Nach 5 Minuten bis zn einer Stunde Zeit und mehr zeigt sich die erste Contraction. Wenn die Erholung spät eintritt, so sind die Contractionen schwach und haben lange Pausen zwischen sich, oft von 10 Minnten und mehr, statt dass 20 oder 30 Contractionen in der Minute stattfinden, wie dies beim nnverletzten Thiere der Fall sei. (Dass dabei nach meinen Beobachtungen eine bestimmte Grösse des Thieres vorausgesetzt sein muss, ist selbstverständlich.)

Das Ausschneiden von Theilen des Randes zeigte folgende Wirkungen: Sarsia erträgt das Ansschneiden dreier ihrer "Angenflecke" ohne Störung - sowie aber anch der vierte ansgeschnitten worden ist, fällt das Thier meistens wie bewegungslos auf den Grund des Wassers. Schwächliche Individuen können unbeweglich bleiben: sie sind durch den Nervenschlag getödtet worden; frische und kräftige Individnen dagegen erholen sich nach kurzer Zeit und nehmen ihre Bewegungen wieder auf, allein in den meisten Fällen ist die Kraft dieser Bewegungen sichtlich vermindert. Rom anes schliesst. dass bei den Cycloneuren lokomotorische Centren in 
jedem Theile des Schirmrandes enthalten seien, in grösserer Menge aber als an anderen Stellen in den „Randkörpern“ desselben (in den ,marginal bodies“).

Im Folgenden findet nun der Satz - wie schon vorhin — Verwerthung und wird zuerst ansgesprochen: bei den Toponeuren sei die Concentration der lokomotorischen Centren in die Randkörper ("marginal bodies or lithocysts") ${ }^{1}$ ) noch mehr ausgebildet als bei Sarsia: bei Amrelia werden durch Ansschneiden der S „lithocysts“ allein alle jene Lähmungserscheinungen erzielt, welche das Wegschneiden des ganzen Randes eines Cycloneuren herrorruft. Das Gewebe der zwischenliegenden Randtheile ist von lokomotorischen Centren gänzlich frei. Ob derselbe Grad der Concentration anch bei anderen Arten von Toponenren statt hat, ist nicht entschieden. Von allen, welche darauf untersucht wurden, wirkte bei Aurelia die Entfernung der "lithocyst.s" am empfindlichsten. Bei den übrigen wurde sehr selten vollständige Lähmung durch die Operation bewirkt. - Während ein Stückehen von Gewebe eines Cycloneuren, gleichviel welcher Grösse, in Verbindung mit einem Randkörper sehr luäufig die rhythmischen Contractionen fortsetzt, so ist dies bei irgend einem anderen ansgeschnittenen liandstückchen sehr selten zu beobachten. Bei den Toponeuren ist nach diesen Ergebnissen der Schirmrand der hanptsächlichste Sitz der Spontaneität („spontaneity“) aber nicht, wie dies bei den Cycloneuren der Fall, der ausschliessliche: sie muterscheiden sich von den letateren dadureh, dass bei ihnen gewölnlich eine grössere oder kleinere Anzahl von lokomotorischen Centren dureh das allgemeine, „contractile Gewebe“ ${ }^{2}$ ) ihres Schrvimmorgans zerstreut ist. Dagegen sind im Rande die lokomotorischen Centren bei den Toponenren mehr concentrirt als bei den Cycloneuren.

Nach Entfernung ihres Randes reagiren die Medusen anf jede Art von Reiz. Die so verstümmelte Sarsia z. B. contrahirt sich auf jeden Sehnitt mit einer Scheere hin ebenso einfach und scharf wie ein unverletztes Thier und durch Einkneipen in regelmässigen Zeitintervallen kann man an ihr die Contractionen des letzteren nachgemacht erhalten. Aurelia aurita ist vou allen daranf untersuchten Arten vielleicht die am wenigsten empfindliche: und roch, wem ein kleiner streifen Gewebes olme Bewegnngscentren ans diesem Thiere mit einem anderen selbstständig sich contrahirenden Streifen beschwert wird, so contrahirt er sich mit.

1) Es ist schon besprochen, dass Romanes, wie aus seinen späteren Erklärungen hervorgeht, mit dem Randkörper stets ein Stückelien des tmbrellagewebes, welehem er ansitzt (d. h. die contractile Zone), weggeschnitten hat, und sind seine im Folgenden mitgretheilten Ergubnisse somit unter lieser Voraussetzung zu rerstehen.

2) Dieser Ausdruck ist bei Romanes stets für das gesanımte Umbrellagewebe gebraucht. 
Alle Theile der Medusen sind in hohem Grade für elektrische Reizung empfindlich. Der constante wie der inducirte Strom erregen sowohl den losgetrennten Rand als den verletzten Schirm; der letztere ist indessen mehr empfindlich für jenen, der erstere mehr für diesen, das heisst: während der losgetrennte Rand fortführt, auf schwache Induktionsströme zu antworten, noch nachdem er aufgehört hatte, durch Oeffinen oder Schliessen des constanten Stromes erregt zu werdeu, ist beim verletzten Schirmstück das Umgekehrte der Fall. Sehr interessant sind die speciellen Versnche, welche Romanes über die elektrische Reizung angestellt hat, weil ihre Ergebnisse in hohem Grade mit den dureh Zerschneiden erlangten äbereinstimmen. Als Objekt benützte er Sarsia. Die Spitze der Schwimmglocke von Sarsia ist der bei weitem an wenigsten reizbare Theil des Thieres. Von der Spitze nach abwärts zum Rande hin findet man eine ununterbrochene Zumahme der Rieizbarkeit und es erweist sich diese am grössten, wenn die Elektroden anf deu Ring vou Zellen gelegt werden, die von' A gassiz als Nervenzellen heschrieben worden sind. Hier an Rande wiedernm ist die Erregbarkeit an verschiedenen Stellen verschieden gross. Sie ist am geringsten, wenn die Elektroden in der Mitte zwischen zwei Augenflecken angelegt werden. Sie ist etwas grösser, wenn ein Angenfleck zwischen sie eingeschlossen wird. Noch grösser ist sie, wemn eine Elektrode in einem Angenfleck, die andere ansserhalb desselben angelegt wird, an grössten, wenn man beide Elektroden in jene Hälfte des Angenflecks (,eye-speck" = Ganglion, wie ich voraussetze) bringt, welche oberhalb des Pigmentflecks ("pigment-spot“) gelegen ist. Was die übrigen Theile der Schwimmglocke anbetrifft, so zeigt sich eine grössere Erregbarkeit, wenn die Elektroden auf einen der vier Radiärkanäle, als wemn sie zwischen dieselben gelegt werden.

Weiterhin führt Romanes eine Reihe von Versnchen an über Einschnitte in Medusen, um zn zeigen, welchen Grad von Zerschneiden das „contractile“ Gewebe derselben ertragen könne, ohne Verhust des physiologischen Zusammenhangs. Es bieten diese Versnche nach Ausführung und Erfolg eine sehr hübsche Ergänzung der meinigen und in vielen Punkten eine vollkommene Bestätigung derselben. Die Schnitte sind in ganz anderen Richtungen ausgeführt als die meinigen, aber überall ergibt sich als Resultat, dass eiue sehr schmale Verbindungsbrücke, gleichviel in welehem Theile des Schirmes, die physiologische Verłindung der einzelnen Bezirke des letzteren aufrecht erhalten kann. Unter Anderem wurde einer Aurelia der centrale Theil ansgeschnitten, ebenso alle Randkörper bis auf einen entfernt. Der übrigbleibende Ring ward durch einen ungefähr in der Hälfte seiner Breite geführten Schnitt bis auf eine schmale Brücke in zwei linge getheilt. Durch diese Brücke 
wurden nun die durch das übriggebliebene Contractionscentrum erregten Zusanmenziehnngen des äusseren Kinges auf den inneren übertragen. Da die verbindende Gewebsbrücke nur ; s engl. Zoll breit war, der imere Ring dagegen 16 Quadrat-Zoll mass, so ergibt sich, welch grosse Flächen durch kleinste Bahnen hindurch erregt werden können. Intessen hemerkt Romanes, dass dasselbe Experiment anch angestellt werden konnte, ohne dass der geschilderte Ertolg erzielt wurde und er bedanert, dass er nicht versucht hat, welche Wirkung eine weitere Verschmälerumg der Verbindungsbrücke gehabt haben würde, da er vermuthet, dass die Bräcke von Linien Gewebes besonderer Art ( functionally tissne“, „differentiated tissne“ - or meint Leitungslinien, Nerven) durchzogen sei, welche allein undurchschnitten bleiben mussten, wenn die physiologische Terljindung bestehen bleiben sollte. Sehr bemerkenswerth ist in dieser Bezielnng anch folgender, gleichfalls an Amelia angestellter Versuch: sieben Randkörper wurden ausgeschnitten, vom achten an wurde ein Schnitt spiralig bis gegen das C'entrum des Thieres hingeführt, so dass der Körper đlesselben in ein langes Band geschnitten war, dessen eines Ende von dem letzten Tandkörper, dessen anderes von dem Centraltheile der Scheibe eingenommen ward. Es zeigte sich nun, dass die von dem Randkörper angeregten Contractionswellen sich durch die ganze Spirale bis zu deren Ende hin fortpllanzen konnten. Iudessen hatten Länge nnd Breite des Bandes einen grossen Einfuss auf das Resultat und es zeigten sich sehr grosse individuelle Verschiedenheiten. Der üusserste ron Rom a nes beobachtete Fall ununterbrochener Leitung was der, in welchem die Spirale zwei mnd eine halbe Windungen machte. Der die Spirale bildende Gerrebsstreifen war dann mugefähr einen Zoll breit und nahezu eine Elle lang. Aehnliche Versnche wurden an sarsia gemacht.

Darauf, zn lestimmen, wie breit in den einzelnen Fällen bei verschiedenen Arten mu an verschiedenen Körperstellen derselben Art die Terbindungsbülke sein musste, um noch eine Leitung zu vermitteln. scheint Romanes kein weiteres Angenmerk gerichtet zu haben. T'rotzdem gelangt er zu denselben Folgerungen ïber die Art der Terbindung, wie ich sie schon in meiner ersten Abhandinng ansgesprochen habe. Welcher Natnr, frägt er sich, ist die „Contractile" Substanz des Medusenkörpers? Ist das contractile Gewebe des Schwimmorgans durchzogen von einem System umschriebener sensibler und motorischer Fäden, welthe zu, bezw. von den Randkörpern ausstrahlen oder ist dasselbe mehr primitiver Natur, indem es die Funktionen von Nerv und Muskel in sich vereinigt?

Bei Amrehia war es die Ansmahme, nicht die Regel, dass der Spiralschnitt in nehr als einer Windung ausgeführt werden konnte ohne Verlust der physiologischen 
Contimuitat. Die individuelle Verschiedenheit ist so gross, dass die Contractionswelle zuweilen stockt, wenn der Streifen nur einen Zoll lang ist, während or in anderen Fällen mehr als dreissigmal so lang sein kann und zwischen diesen zwei Extremen finden sich alle möglichen Stuten. "Nun scheint es mir", silgt Romanes, "liss, wäre das Gewebe, durch relches diese Contractionswellen ziehen, lomogener Natur, ein Grund für so grosse individuelle Verschiedenheit nicht gegehen sein würde. 1)agegen ergibt sich keine Schwierigkeit, irenn wir annelmen. dass die Wege für dieselben mehr oder weniger monshriebene Linien seien; denn es darf wohl erwartet werden, diss bei so niedrigen Lebeusformen diese Liniên keine constante Lage haben. Es könnten desshalb in einem Falle wichtige Leitungslinien bald durchschnitten werden. während sie im anderen anf lange Strecken dem Messer entgehen. Es ist indessen kaum anzunebmen, dass irgend eine Leitungslinie einen spiralförmigen Lanf in zwei oder. drei Windungen um das Thier herum machen und zugleich zufällig in den Bereich des künstlich geschnittenen Gewebsstreifens hinein fallen sollte. Wir müssen daher wolıl annelımen, dass ein mehr oder weniger hoch ansgebildeter (intimate) Plexus von Leitungslinien vorhanden sei, deren Elemente mit der Fähigkeit begabt sind, für einander zu vicariiren und dass der Schnitt zuweilen zufällig eine Anzahl seiner Anastomosen unverletzt lässt. Es ist also die Uebereinstimmung der Auffissung des englischen For'schers in dieser wichtigen Frage mit meiner vor 5 Jahren ausgesprochenen nicht nur dem Inhalt nach eine absolute, sondern sie ist auch der Form nach merkwürdigerweise eine so zu sagen wörtliche.

Der beste Beweis dafür, dass bestimnte Leitungshinien vorlanden sind, liege übrigens, fährt Romanes fort, in der unveränderich sicheren Thatsache, dass, wo inmer in einem Gewebsstreifen die Contractionswelle stockt, die Stockung stets vollständig und durchaus genau an einem bestimnten Punkte stattfindet. Wie es komme, dass zuweilen solche feine Leitungshinien erst so spät vom Schnitt getroffen werden oder bis eine zur Zerstörung der physiologisehen Contimnität genügende Anzahl derselben getroffen werde, mag Verwunderung erregen. Allein trotzdem hat Romanes die Ueberzengung erlangt, dass solche Leitungslinien wohl bei allen Medusen vorhanden sind, dass durch ihre Verwittelung die in den Randkörpern entstandenen Willensimpulse dem contractilen Gewebe des Schwimmorgans mitgetheilt werden und dass dieselben der Funktion, wemn nicht auch dem Ban nach Nerven sind. Die Leitungslinien morphologisch nachzuweisen ist er nicht im Stande gewesen. Ferner hebt er als wichtig hervor, dass die physiologische Verbindung, nachdem sie in dem Gewebsstreifen zum Stocken gekommen war, nach einiger Zeit plötzlich wieder hergestellt erschien - was durchans mit meinen eigenen Beobachtungen übereinstimmt. 
Die Zeit, welche zur Wiederherstellung der Leitung nöthig war, war sehr verschieden: wenige Sekunden bis eine Stunde und mehr; gewöhnlich aber betrug sie zwei bis vier Minnten. Obschon dieser Process der Erholung rasch erfolgte, so geschah er doch nicht so plötzlich wie jener der Störung der Leitung, sundern so, dass zuerst eine Contractionswelle sich nur andentungsweise über die ursprüngliche Haltstelle hinaus fortsetzte, damn eine zweite kräftiger, bis znletzt keine spur von Hemmung mehr vorhanden war. Zuweilen stockte die Welle dann an einer zweiten Stelle und wurde anch hier das Hemmniss nach einiger Zeit überwunden. Weiterhin schnitt nun Rom anes in einen spiralstreifen, in welchem die Leitung frei war, anch quer in verschiedenen Abständen ein: die leitung blieb anch jetzt nnunterbrochen. Wurden nmu aber alternirend mit den ersten Qnerschnitten solche anch von der anderen Seite her geführt, so musste vorausgesehen werden, dass die physiologische Verbindung anfhören werde, nachdem die Zahl der schnitte (,interdigitating cuts") eine grössere geworden. Indessen war der Grad, bis zu welchem die Zerschneidung getrieben werden konnte, zuweilen ein äberraschender. Romanes sah, dass an einem Streifen von 20 Zoll Länge und $1^{\mathrm{t}}{ }_{22}$ Zoll Breite 10 solcher Schnitte an jeder Seite geführt waren, ohne dass die freie Leitung anfgehört hätte. - Es ist dieser Versuch im Wesentlichen ganz derselbe, welchen ich ansgeführt habe, indem ich in den abgeschnittenen Schirmrand von innen und von aussen ahwechselnd Einschnitte machte, wobei ich jedoch viel weiter gegangen bin als fiomanes, indem ich fand, dass Verbindungsbrücken von der Breite weniger Millimeter himreichten, nm die Leitung zn rermitteln, während dieselbe doch einen direkten Weg nur in der Diagonale dieser Brücken finden konnte'). Mit zunehmender Entfernmg vom Rande wird sich allerdings, wie einige meiner Versnche zeigen, die Verhindung mm durch breitere Gewebsbrücken erhalten. - Endlich wird noch bemerkt, dass anch Druck oder selbst die Spannung, welche in einem Gewebsstreifen hervorgernfen wird, dadmeh, dass man ihn an einem Ende frei in der Luft hält, vorübergehend, event. danernd, Stockung der Leitung herbeiführen liönne.

Auch den Einfluss vou Giften auf die Lebensiusserungen von Medusen bat Romanes untersucht. Schon Agassiz hatte die anästhesirende Wiktung ron A ther und Chloroform anf Sarsia beobachtet und bemerkt, dass diese Wirkung allein auf die Anwesenheit von Nerven in ihrem Körper hinweise. Dagegen glaube ich, müchte freilich zu bemerken sein, dass damit für morpholog ische Ausbildung eines Nervensystens nichts bewiesen sein dürfte. Die Wirkung ist allerdings ähnlich derjenigen der genanuten Stofle auf höhere Thiere. Bald nachdem wenige Tropfen von Chloroform dem Wasser zugefügt worden waren, in welehem sich eine Sarsia befand, wurden deren Contractionen langsamer und schwächer, bald hörten sie auf und die Thiere waren nieht mehr erregbar selbst nicht dnreh die stärksten Reize. Sehr raseh aber kehrte

1) vergl. Seite 31 , Holzschnitt 4 . 
das normale Verhalten allmälig zurück, nachdem dieselben in unvermischtes Wasser zurïckgebracht worden waren. Dasselbe zeigte Aurelia. Ganz ähnliche Wirkungen ergab der Einfluss von Morphium. An Cyanea capillata wurde Strychnin versucht; es ist dieses Thier, wie Romanes hervorhebt, für solehe Untersuchung desshalb hervorragend geeignet, weil seine Contractionen in Wasser von gleichmässiger Temperatur so regelmïssig sind wie die eines Herzens. Bald nach Zusatz einer schwachen Lösung von Strychnin in Seewasser' zu dem Wasser, in welchem die Thiere sich befanden, erschienen unzweifelhafte Anzeichen von Unregelmiissigkeit in den Bewegungen. Die Unregelnn̈issigkeiten steigerten sich schliesslich zu Convulsionen, die sich änsserten in extremen Ahweichungen von dem Rhythmus der Contractionen: es entstanden Perioden von heftiger und verlängerter Systole, ähnlich tonischen Krämpfen, und wenn die Stärle dieser Krämpfe sich für einen Augenblick abgeschwächt batte, begannen sie von Neuem, bevor der Schirm Zeit gehabt hatte, sich auszubreiten. Die hrämpfe sind übrigens paroxysmischer Natur: es folgen zwischenhinein Perioden absoluter Lulıe, wälırend welcher das Thier den Schirm voll ausgebreitet erbält. Der Tod erfolgt wäbrend solcher Ausbreitung. Sehr bemerkenswerthe Versuche wurden endlich mit Curare angestelit. Die eine Halfte einer Staurophora laciniata, welche so getheilt war, dass sie mit der anderen nur noch durch eine schmale Bräcke verbunden war, wurde vergiftet, die andere nicht. Reizte man jene durch Einschneiden mit der Scheere, so blieb sie hewegungslos. In frischem Wasser kehrten auch hier die normalen Verhältnisse zurück. Aehnliche Wirkung wurde an Toponeuren beobachtet. Romanes sagt weiter wörtlich: "It is also to be observed that a very shight degree of over-poisoning paralyzes the transmitting system as well as the responding one; .... I I think it would be difficult to overrate the importance of these results: to my mind they are perhaps the most interesting which are contained in this paper. They not only prove that curare poison is consistent in manifesting its remarkable property when applied to these the lowest forms of life that present the hegimings of a nervous system; but they prove what is far more important, that in animals which, as we have seen from other evidence, present us with the first indications of a nervous system, the latter appears to have already undergone a differentiation in its functions, such that it is capable not only of influencing contiguous contractile parts, but also of being influenced by distinct excitable parts." Endlich machte Romanes auf Anregung von Burdon Sanderson noch den folgenden Versuch: ein Streifen Körpersubstanz von Aurelia aurita wurde an einer beschränkten Stelle seines Verlaufs mit narkotischen oder anästhesirenden Mitteln behandelt, worauf die Contractionswellen an dieser Stelle zuerst schwächer wurden und dann stockten. Dieselbe Wirkung luatten Injectionen in die Gefässe eines bestimmten Bezirks.

In der schon in der Einleitung erwähnten, meiner Arbeit gewidmeten Nachschrift helst Romanes als hauptsächlichste Differenz zwischen ums die beiderseitigen Ansichten über den Sitz der contractilen Thätigkeit hervor, eine Differenz, welche ich schon berübrt habe, auf relche ich indessen noch zurückkommen wercle. Meiner Anffassung, dass die Contractionen von Amrelia aurita gewöhnlich unwilkn̈rliche seien, jedoch dem Einfluss des Willens unterworfen werden könnten, stimmt er bei, bemerkt jedoch, dass der Grad unwillkürlichen Vermögens bei verschiedenen Arten ein verschiedener sei; so sei er geringer bei Cyanea als bei Anrelia: die Contractionen der letzteren seien nicht so rein rhythmisch wie die der ersteren. Meine Bemerkungen über die Bewegung von Carmarina hastata zeigen, in wie hohem Maasse auch ich solche Verschiedenheit als bestehend erkenne. Damit ist schon ausgesprochen, dass anch die von mir für Aurelia und Cyanea festgestellte Regel der Bezichungen zwischen Zahl und Daner der Contractionen einerseits und der Pausen andererseits einen allgemeinen Werth nicht beanspruchen kamn - je mehr die 
willkürliche 'Thätigkeit bei einer Art in den Vordergrund tritt, um so weniger wird jene Regel ausgesprochen sein. Die Vergleichung aber, welche Romanes zwischen beiden Thieren in dieser Beziehung anstellt, stimnt in hohem Grade mit den von mir gewonnenen anatomischen Resnltaten ïberein.

Die Uebertragung der Thätigkeit einzelner contractilen Zonen bezw. „lithocysts“ anf andere in der von mis beschriebenen manchfaltigen Weise wird bestätigt und als merkwürdige Thatsache hinzugefügt, dass sehr häufig einer oder mehrere der acht „lithocysts" zeitweilig oder danerud über die anderen das Uebergewicht zu haben scheinen, indem während einer längelen Zeit die Contractionen beständig von ihnen ausgehen. Es wird meine Angabe bestätigt, dass niemals eine Zone sich contrahiren kann, ohne dass alle übrigen gleichzeitig oder nahezu gleichzeitig sich nit ihr contrahiren. Versuche mit Einschnitten, welche Romanes zmm Zweck der genaneren Feststellung 'dieser 'Thatsache gemacht hat, zeigten, dass die von einem Contractionscentrum ausgehende Contractionswelle, sobald sie an einem zweiten angekommen ist. dieses unmittelbar erregt, eine kräftige Entladung bewirkt und so zur Entstehmug einer nenen Contractionswelle Veranlassmug gibt. Die nen entstandene Contractionswelle erregt das nächste Contractionscentrum u. s. w.

Es wird hervorgehoben, dass nicht nur schwache und unregehmässige, bald vorïbergehende Contractionen nach dem Ausschneiden der contractilen Zonen entstehen können - obrrohl dies zuweilen ausschliesslich der Fall ist — sondern sie kömnen ebenso rhythmisch und nicht minder kräftig auftreten wie am muverletzten Thiere und danern gewöhnlich einige lage - Thatsachen, welche im Vorstebenden nach schon 1874 gemithten Beobachtungen vou mir ausführlich geschildert und im Auszug schon in meinem Münchener Vortrag mitgetheilt sind. Meine Schilderung des Terhaltens zerschnittener Aurelien wird bestätigt und die Uebereinstimmung der beiderseitigen Ergebnisse ler Versuche über Einschneiden herrorgehoben.

III. Die der Loyal Society im Jahre 1576 eingereichte mul 1877 (Tol. 167) erschienene neneste Abhandhng Romanes' heschäftigt sich zunächst wienterm eingehend mit meiner Arbeit, bezw. mit den zwischen meinen Angaben und seinen Ergebnissen bestehenden Differenzpmukten, anf Grund neuer von ihm angestellter Untersuchungen. Der erste und wesentlichste dieser Punkte betrifft den Sitz der lokomotorischen Centren, der zweite, gleich dem ersten schon in der vorigen Abhandlung besprochene, betrifft die Art der Erholung der Toponeuren nach bewirkter Lähmmig; der dritte endlich bezieht sich auf die von mir aufgestellte Regel über die relative Kahl der Coutractionen, welche ganze Nednsen und deren Theilstücke ansführen. Ueber den letzteren Punkt hat Romanes sich inzwischen erst orientirt; in Betreff der zwei übrigen 
hat er nene Untersuchnngen angestellt. Ueber die zwei ersten muss ich mich in Iincksicht auf seine Bemerkungen hier äussern; der dritte ist im XlV. Abschnitt erledigt.

1) Der erste Differenzpunkt, betreffend den Sitz der lokomotorischen Centreu, bedarf, trotzdem er einer Ausgleichung nahe geführt ist, noch einer Erläuterung. Romanes wiederholt den im letzten Jahre ron ihm ansgesprochenen, auf Seite 33 von nir citirten Satz, wonach die Otolithensäckchen der Sitz der Contractionsthätigkeit sein sollen mud erklärt dann, dass eine grosse Anzahl ron nenen Experimenten diese seine vorjährigen durchaus bestätigt haben ${ }^{1}$ ). Dass jetzt in "I was able to satisfy myself that the whole spontaneity of the lithocyst appeared to be exclusivly lodged in the mimute sac of crystals" hinter "lodged in " die Wörter "or about" eingefügt sind, ist für die Frage nicht wesentlich. Romanes sagt: "In no one instance have I been able to detect any physiological evidence of the presence of ganglionic matter in the "contractile zones." In most instances, of course, occasional contractions were given after removal of the lithocysts alone; but I was never able to observe that the spontaneity in these instances proceeded more exclusively, or more frequently, from the contractile zones than from any other part of the general contractile tissue. For after allowing the animal to recover from the shock consequent upon removal of its lithocysts alone, and then observing the degree of spontaneity it manifested, I was in no case able to perceive that by now removing all the contractile zones. this degree of spontaneity was in the smallest degree diminished." In der Nachschrift ${ }^{2}$ ) bemerkt er dagegen: "Lastly. the difference of opinion which existed between us with regard to the exact seat of spontaneity in the covered eyed Mednsae has also been happily removed. It appears that I have hitherto been under some misapprehension as to the precise area of tissue which Dr. Eimer intended to denote by his term "contractile zone" for while I have hitherto supposed that by the term "contractile zone" Dr. Eimer" intended to denote ,the crescent-shaped interruption of the margin in which the lithocyst, together with its gelatinous hool, is situated", I now learn that I was incorrect in this supposition. From Prof. Eimer's letter I do not quite recognize the precise tissne-area which he endeavours to describe as the area to which his term "contractile zone" is applicable; but this is a matter of no moment, as he leaves no doubt that the area in question is confined to what I may call the micros- 
copical vicinity of the lithocyst. No dombt, therefore, the difference between our experimental results is to be attributed merely to the different manner in which we performed the operation of excising the lithocysts: for while conducting my experiments 1 supposed that the question which had to be settled was whether the spontaneity of the animal proceeded from the large ,crescent-shaped interruptions" or from the very minute lithocysts; and, accordingly, in removing the latter alone, I was careful to remove them well from their roots - thus, no donbt, disturbing the „nerve-epithelium“, which Mr. Schäfer has figured as occupying the microseopical vicinity of the lithocysts. On the other hand, Dr. Eimer, in conducting his experiments, must have had a completely different question in view, and therefore, in excising the lithocysts, he no doubt took scrupulous care to remove them well above their roots, so leaving the „nerve-epithelium “ intact. Thus our apparent want of agreement on this point is shown to have arisen merely from a want of understanding with regard to the term "contractile zone."

Es ist somit klar, dass Romanes die „flügelähnlichen Anhänge“ des Schirmrandes, zwischen welchen die Randkörper von Aurelia aurita liegen, als „contractile Zonen“ anfgefasst hat und ich kann nur bedanern, dass meine erste Beschreibung zu diesem Missverständniss Veranlassıng gegeben hat, obschon z. B. bei Cyanea capillata solche Anhänge nicht in entsprechender Weise vorhanden sind. Nachdem formanes schon Jei der von ilm als Entternen des Randkörpers bezeichneten Operation ein Stäckchen des Umbrellagewebes, welchem derselbe ansitzt, mit entfernt hatte, konnte er von dem Wegschneiden der von ihm als contractile Zonen aufgefassten Theile eine besondere Wirkung nicht mehr verspüren. Wenn nun durch diese Aufklärung unsere beiderseitigen Ergebnisse sich zusammenstellen lassen, so ist doch, wie ich schon in der Einleitung bemerkte, die Uebereinstimmung nur daun eine vollkommene, wenn Romanes darauf verzichtet, dem Krystallsäckchen, also dem unteren Theile des Randkörpers, die Bedeutung in der Frage zuzuschreiben, welche er demselben in seiner früheren Arbeit zugeschrieben hat. Indessen glanbe ich dies, wie gesagt, voraussetzen zu dürfen und freue mich somit der Erledigung dieser Differenz.

2) Was den zweiten Punkt angeht, in welchem wir uns in verschiedener Weise geäussert haben, die Erholung der Toponeuren nach eingetretener Lähmung, das Anftreten sekundärer Contractionen, wie es Rom anes nennt, so kommen sich darin unsere neneren Resultate durchans entgegen. Wenn Romanes in seiner früheren Arbeit in Beziehung anf meine schilderung unregelmässiger, schwacher Contractionen, welche nach dem linicken auftreten, gesagt hatte: "I have frequently seen these after-contractions as rhythmical (though this is rare), 
as effectual, and as powerful as those which had been previously supplied by the single remaining lithoeyst“, so sagt er jetzt in Beziehung anf Aurelia aurita: „The word "rare" here, as applied to the rhythmical nature of these after-contractions, is not sufficiently strong. If I had said "very" or "exceedingly rare", the statement would have been more accurate“"). Dagegen sei das einfache "selten " für Cyanea eapillata richtig. Aus meinen vorstehenden Angaben ergibt sich, dass ich auf Grund schon $157 t$ und später angestellter neuer Versuche Erfahrungen gemacht habe, welche mit denjenigen von $k$ om a nes durchans äbereinstimmen und bekenne ich mich demselben anfrichtig dankbar für das sorgfältige Abwägen des Ansdrucks, um welchen er sich, wie ich vermuthe, zugleich in Rücksicht anf meine früheren Angaben, bemüht hat. Wenn mir auch bei meinen ersten spärlichen Experimenten vollkommene zeitweise Erholung gelähmter Medusen nicht begegnet war, so legegnete sie mir, wie beschrieben, späterhin häufig und mehr und mehr, unter je natürlicheren Verhältnissen die Thiere zu halten ich Bedacht genommen hatte. Nach meinen Beobachtungen würde ich an tem "rare" vou Romanes nichts anszusetzen haben und möchte ich fast annehmen, dass er damit anch für Aurelia aurita ganz ebenso Reeht gehaht hat, wie mit dem späteren "very" oder "exceedingly rare“ - mir wenigstens ist es, wie meine Darstellung zeigt, bei Beobachtung aller Vorsiehtsmassregeln je länger desto weniger selten vorgekommen, dass eine auf bestimmte Zeit begrenzte vollkommene Erholung nicht eingetreten ist. Unter irgend weniger günstigen äusseren oder anch unter unlerechenbaren individuellen Verhältnissen wird dies dagegen "sehr selten“ der Fall sein können. Meine letzten Kieler Versuche, welche eine ganz ansserordentliche Widerstandsfähigkeit der Thiere zeigten, so dass sogar eine Lähmung derselben selbst durch das Ausschneiden der contractilen Zoneu fast gar nicht zu erreichen war, ohne dass ich im Stancle wäre, mit absoluter Sicherheit die Ursachen dieses Verhaltens zu bezeichnen, beweisen am besten, welche Verschiedenheiten des Verhaltens in verschiedenen Versnchsreihen vorkommen können. - Dasselbe, was für das Anftreten der Erholung an sich gilt, gilt selbstverständlich auch für die Daner derselben. Ich sah die schwachen Contractionen zuierst nur wenige Angenblicke danern, später tand ich, dass rhythmisch gewordene Bewegungen Tage lang anhalten, in Uebereinstimmung mit Romanes, welcher sagt, dass sie gewöhnlich einige 'lage forthestehen. Die Daner hängt auch hier von änsseren, sowie von inneren nicht näher gekannten Ursachen ab. Wollten wir unsere Angaben über die erstere ganz genan vergleichen nnd in ihrem Werthe ab-

1) Seite 662 . 
wägen können, so müssten unsere Versuche nnter ganz denselhen Verhältnissen angestellt sein. Wichtiger als dies ist mir die Bestätigung meiner Angabe, dass die gelähmten Thiere, unter gleichen Verhultnissen mit nicht gelähmten gehalten, früher als die letzteren zu Grunde gehen, dass die Erholung nicht von Daner ist. "Lastly, with regard to the greater vitality of mmutilated covered-eyed Mednsate with their lithocysts in sit $n$ than those which have hod these bodies removed, I have found my previous statement (Bestätigung meiner Angaben) substantially correct." Wenn er aber beifügt: "There are wonderful individual variations, however, in this respect: for sometimes the irritability of the paralyzed specimens will remain after that of ummutilated specimens which are exposed to exactly the same conditions has been destroyed by decomposition" ${ }^{1}$ ), so stimmt solche Auffassung nur mit meinen übrigen Erfahrungen überein. Um möglichst gleiche Verhältnisse für verschiedene Objekte herzustellen ist Romanes schliesshich ebenso verfahren wie ich, indem er eine Meduse in Antimere getheilt and num die einen Antimere geknickt hat, die anderen nicht. Aber, wie wir wissen, haben sogar die Antimere ansgesprochene Eigenart.

Nachdem so die drei wichtigsten Differenzpunle zwischen Romanes und mir in einer befriedigenden Weise erledigt sein dürften, luabe ich noch einige Fragen zn bern̈luren, in Beziehung anf welche der englische Forscher meine ersten Angaben geprüft hat.

Zunächst die Beziehung zwischen der Zahl der in der Zeiteinheit ausgeführten Contractionen nud der Grösse der Thiere. Es frent mich, zu sehen, dass Romanes entsprechend dem von mir aufgestellten satze findet, dass "the rate of the rhythm has a tendency to bear an inverse proportion to the size of the individual" ${ }^{2}$ ). Die Wahl seines Ansdruckes wird erlantert durch die Bemerkung, dass die individuellen Variationen eine grosse Rolle spielen, eine 'Thatsache, auf welche ich im XlV. Abschnitte selbst hingewiesen habe. Trotzdem möchte ich auf Grund meiner zallieichen Erfahrungen und mit Beziehung anf das in jenem Abschnitte Mitgetheilte bemerken, dass mit der von liomanes gewählten Fassung "the rate of the rhythm has a tendency etc." in Aubetracht des Thatsächlichen viel zu wenig gesagt sei. Ich bin vielmehr der Ansicht, dass man sogar im Stande sein wird, empirische Formeln herzustellen, die mit amnähernder Genanigkeit vorausbestimmen, welche Auzahl un willkürlicher Contractionen die verschiedenen Medusen-

1) Seite 663.

2) Seite 665 . 
arten - selbstverständlich jede Art für sich betrachtet - bei gegebenem burchmesser in der Zeiteinheit machen werden und ich glaube, dass dafür schon die Zahlen sprechen, welche ich mitgetheilt habe.

Was ferner meine Angaben über das Verhälniss der 1)auer der Pausenzu der Zahl der voraufgegangenen Contractionen angeht, so habe ich in liücksicht anf dieselben neue Beobachtungen nicht mitgetheilt. Die früheren lauteten wörtlich ${ }^{1}$ ): „Die Contractionen der Scheibe der nnverletzten Aurelia amita finden bei Tag beständig statt und, wie es scheint, ebenso bei Nacht. So . oft ich wenigstens zur Nachtzeit meine Thiere besuchte, traf ich ihren Schirm in Thätigkeit. Auch wemn die Thiere sich nicht von der Stelle bewegen, danert diese Thätigkeit fort.... Die Contractionen treten unter übrigens gleichen Verlualtnissen beim ruhig im Wasser schwebenden Thiere in gleichmässigem Rhythmus nacheinander auf, oft so regelmässig, dass man im Stande ist, ihmen während längerer Zeit zählend zu folgen, ohne dass man das Thier ausieht, nachdem man sich einmal die Grösse des zwischen je zweien derselben gelegenen Zeitintervalls gemerkt hat. Nur von Zeit zu Zeit tindet eine Beschleunigung oder eine Verlangsamung ler' Zusammenziehungen statt und immer setzen dieselben von Zeit zu Zeit einen Augenblick aus, so dass Pausen in der Bewegung entstehen. - Die Pausen treten nicht regellos ein mud auch ihre Dauer ist einer gewissen Ordnung unterworfen. Je einer bestimmten Anzahl gleich rascher und gleich starker Contractionen nämlich folgt gewöhnlich eine Pause vou aunähernd derselben Damer.

Genauer lässt sich diese Regel wegen der Unbestimmbarkeit des einen der in Betracht kommenden Falitoren, der Stärke der Contractionen, einstweilen nicht formuliren. Vielleicht müsste bei genauer Kenntniss aller Thatsachen an ihre Stelle das Gesetz gestellt werden: die Dauer der Pausen steht in direktem Verhältniss zu der Zahl und Stärke der ihnen vorausgegangenen Contractionen. - Reizt man das Thier, sticht man z. B. mit einer Nadel in irgend einen 'Theil der Gallertscheibe ein, so nehmen die in der Zeiteinheit stattfindenden Contractionen plötzlich an Zahl zu; es sucht dasselbe durch Ortsveränderung der Verfolgung zu entrinnen. So oft die Zusammenziehungen des Schirmes zur Fortbewegung im Wasser benützt werden, tritt diese Beschleunigung ein und je schneller die Bewegung, desto grösser ist sie selbstverständlich. Aber auch daun lässt sich oft feststellen, dass anf eine grössere Anzahl von in der Zeiteinheit stattfindenden Contractionen Pausen von längerer Daner folgen, so dass auch dann zuweilen eine gewisse Compensation zwischen Be-

1) Ueber künstliche Theilbarkeit etc. Würzb. Verh. a. a. O. S. 139. Zoolog. Unters. S. 47. 
wegnng und Rulıe durchsichtig wird. lndessen wird hier die Regel noch mehr wie beim ruhig schwebenden 'Thiere dureh jenen nicht genau bestimmbaren Faktor, die Stärke der Contractioneu, hauptsächlich aber dadurch, dass diese jetzt vom Willen beeinflusst werden, während sie vorhin unwillkürlich waren, verwischt oder gänzlich eliminirt. Die folgenden Beobachtungsreihen mögen das Mitgetheilte in etwas erläntern.

Ein frisch eingefangenes, ruhig anf derselben Stelle schwebendes Thier von $13^{1}{ }_{2} \mathrm{~cm}$ Durchmesser contrahirt sich

$\begin{array}{ccc}\text { in der } 1 \text { ten } & \text { Minute } & 20 \\ 2 & " & 20 \\ 3 & " & 20 \\ 4 & , & 20 \mathrm{mal}\end{array}$

und zwar änsserst genau. Je drei Mal nach der zwölften und ein Mal nach der sechszehnten Contraction trat in jeder Minnte eine kleine, einige Sekunden danernde, jedoch nicht jedesmal gleich grosse Panse ein. Die Dauer der Pansen muss in diesem Falle sehr genan in direktem Verhältniss zu der Geschwindigkeit der ihr voransgegangenen Contractionen gestanden haben, denn nur so erklärt es sich, dass trotz ihrer Ungleichheit anf jede Minute genau zwanzig der letzteren fielen. Der grossen Regelmässigkeit wegen muss in diesem Falle wohl voransgesetzt werden, dass auch die Stärke aller Contractionen eine nahezu gleiche war. - In der fünften Minute stellte die Meduse die Contractionen ein und stieg langsam nach oben. Nach längerer Rube traten ungemein rasche und heftige Contractionen ein, die aber bald wieder zur Norm von ungefähr zwanzig zurüekkehrten.

Ein Thier von $4^{1}{ }_{2} \mathrm{~cm}$ Durchmesser machte:

in der 1 ten Minute 36 Contractionen|jedesmal nach der $33^{\text {ten }}$ Contraction

$\begin{array}{llll}2 & \Rightarrow & 36 & " \\ 3 & " & 36 & " \\ 4 & " & 42 & " \\ 5 & " & 45 & " \\ 6 & " & 45 & " \\ 7 & " & 45 & " \\ 5 & " & 35 & " \\ 9 & " & 47 & " \\ 10 & " & 45 & "\end{array}$

trat eine Pause von 1-2 Sekunden auf.
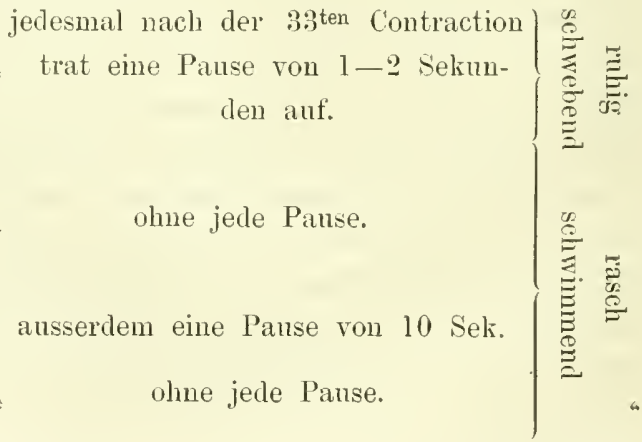

Aus diesem Wortlaut geht vor allem hervor, dass ich proportionale Beziehungen zwischen Zahl und Stäke der Contractionen einerseits und der Daner der 
darauf folgenden Pausen andererseits überhaupt nur für das ruhig schwebende Thier angenommen habe, d. i. für der Mehrzahl nach unwillkürliche Contractionen, für Atlombewegungen; und anch hier sprach ich mich sehr bedingt aus mit den Worten: „Je einer bestimmten Anzahl gleich rascher und gleich starker Contractionen nämlich folgt gewöhnlich eine Pause von annähernd derselben Daner. Genaner lässt sich die Regel . . . e einstweilen nicht formuliren. Vielleicht müsste bei genaner Kenntniss aller Thatsachen an ihre Stelle das Gesetz gestellt werden: die Diner der Pansen steht in direktem Verhältniss zu der Zahl mod Ståke der ihnen voransgegangenen Contractionen." In Beziehung auf die Bewegungen des schwimmenden, den Ort verändernden Thieres aber, bei welchem vorzüglich mit willkürlichen Contractionen zu rechnen ist, habe ich von einer Proportion gar nicht gesprochen, habe nur gesagt, auch bei ilınen lasse sich oft feststellen, dass auf eine grössere Anzahl von in der Zeiteinheit stattfindenden Contractionen Pausen von längerer Daner folgen."

Romanes hat nun, wie er sagt und wie sicherlich richtig sein wird, genane Untersuchungen über die Frage gemacht mit Resultaten, welche meinen Angaben sehr wenig nahe zu stehen scheinen: dies rührt daher, dass er offenbar übersehen hat, dass ich eine proportionale Regel überhaupt nur für die der Mehrzahl nach unwillkürlichen Contractionen des ruhig schwebenden Thieres in Anspruch genommen habe und anch dies nur in der hervorgehobenen bedingten Weise. Er setzt, ganz im Widerspruch zu meiner Aensserung, voraus, ich häte direkt proportionale Beziehungen zwischen Contractionszahl und Pausen angenommen und dies bei beliebig: sich bewegenden Thieren, denn er sagt ohne weitere Einschränkung ${ }^{1}$ ): „Dr. Eimer affirms that the duration of the natural panses, which in Aurelia sometimes alternate with bouts of swimming, bears a direct proportion to the number and strength of the contractions that occured in the previons bont of swimming." Dass er anf Grund solcher Voraussetzung bezüglich meiner Ansicht zu dem Schlusse kommt, dass Beziehungen so genaner Art wie ich annehme zwischen den beiden in Frage stehenden Faktoren nicht existiren ${ }^{2}$ ), ist natürlich. Un so erfreulicher ist es, dass er durch seine Untersuchungen, welche offenbar an durchaus unregelmässig, willkürlich sich contrahirenden Thieren angestellt sind, ganz zu denselben Ergebnissen gekommen ist, wie die sind, welche meine Worte eben in Beziehmng anf diese unregelmässigen, willkürlichen Bewegungen als meine Erfahrung bezeichnet haben. Durch ein sehr

1) 8.665 .

2) Seite 666 und 746. 
schönes, Sarsia entnommenes Beispiel, welches Thier für die Beobachtung günstiger sei als Aurelia, illustrirt er diese Beziehungen und kommt zu dem Schlusse: „as it will be seen that there is no precise relation between the number of the pulsations and the duration of the pauses. Nevertheless, that there is a general relation." Das Beispiel lautet:

Zahl der Contractionen.

38

22

49

30

46

2

24

112

45

s94

(6)

4

2

30

200
Sekunden Ruhe.

30

35

40

45

20

15

350

20

185

30

45

140

185

240

60.

Diese Zahlen in meinem Sinne erklärend, sagt $k$ omanes mit Recht, dass darunter die Beziehung der langen Panse vou 350 Sekunden zu den 112 darauf folgenden Contractionen augenscheinlich sei. „Den letzteren folgte eine kurze Pause von 20 Sekunden und eine andere verhältnissmässig kleine lieihe von 45 Contractionen; der erfrischende Einfluss der voranfgegaugenen 350 sekmnden Ruhe war vermuthlich durch die 112 Contractionen nicht völlig erschöplt. Als daranf weitere 185 Sekunden Ruhe folgten, war eine bedentende lieservekraft angesammelt, so dass die unmittelbar nachher auftretende ungehenre Anzahl von 594 Contractionen erklärlich wird" u. s. w. - Weun man in Betracht zieht, was ich hervorgehoben habe, dass ein wesentlicher Faktor, die Stärke der Contractionen nicht gemessen werden kann und nicht berücksichtigt ist, so wird man für willkürliche Bewegungen in den ans dem Romanes'schen Beispiele sich ergebenden Beziehnngen in kücksicht auf meine Anordnungen Genüge finden. Die eigentliche Bedeutung der von mir aufgestellten Regel aber bezieht sich auf die Athembewegungen und sie besagt im Grunde nur, dass es absolut, mathematisch-regelmässige Athembewe- 
gungen nicht giebt, dass ein gewisses Maass vou Unregelmaissigkeit nach Gescliwindigkeit oder Stärke dahei immer mit unterläuft, sei es in Folge willkürlicher Alition oder von durch irgend welchen änsereu Reiz hervorgerufener Reflexaktion, dass aber solche Unregelmässigkeit so lange als die Bewegungen eben vorzngsweise Athembewegungen sind, gewöhnlich compensirt wird durch Pausen, welche zn der Unregelmässigkeit in Zahl und Stärke der voraufgegangenen Contractionen in einem gewissen proportionalen Verhältnisse stehen. Und dies ist ganz natürlich, denn mag die Contraction durch was für andere, mit der Athmung nicht zusammenhängende Ursachen verstärkt oder beschlemnigt werden, beide, Verstärkung und Beschleunigung, werden ihr zu Gute kommen und eine nachfolgende Pause wird der Ansdruck sein angenblicklich geringeren Athembedürfnisses. Je mehr aber die willkürlichen Contractionen in den Vordergrund treten, nm so weniger dentlich wird die Regel ansgesprochen und um so mehr wird ein auf sie bezügliches Verhältniss überhanpt nur ans der Znsammenfassung zahlreicher Reihen von durch Pansen unterbrochenen Contractionen zu erkennen sein - jetzt kommt zu Allem noch der Faktor der Ermüdung, der Erholungsbedürftigkeit in Betracht, welcher bei den Athembewegrungen wegfült. So wird es deun auch selbstverständlich sein, dass proportionale Beziehnngen in dem von mir hervorgehobenen simne nicht bei allen Medusenarten im Mittel in gleich ausgesprochenem Maasse vorhanden sein werden - viel weniger bei den höher stehenden, bei welchen die Willensthätigkeit in höherem Grade in den Vordergrund tritt, viel melı bei den tiefer stehenden mit melı reflectorischer Existenz. So wird wohl Cyanea capillata in ihren Bewegungen viel mehr Beispiele für unsere Regel darbieten als Aurelia aurita - und dies stimmnt anch mit früher erwähnten Aensseserungen von Romanes überein - Amelia dagegen wird voranssichtlich deren wierler mehr darbieten, als die so hoch entwickelte Carmarina hastata. Eine interessante Stufenleiter würde sich somit ans der Beohachtung der Art der Bewegungen wohl für die geistige Entwicklung nuserer Thiere aufstellen lassen. Die meiner Regel zu Grunde liegenden Zählungen beziehen sich nur anf Aurelia aurita und nur au Cyanea capillata habe ich ausserdem gelegentliche Beobachtungen gemacht.

Abgesehen von den behandelten, mit Bezug auf meine Angaben angestellten Versuchen, hat Romanes nun noch eine Reihe anderer gemacht, welche theilweise insbesondere für die Dentung des Nervensystems von nicht geringerer Tragweite sind als viele der erwähnten, und deren Resultate zum grössten Theile gleichfalls nahe Beziehungen zn den von mir beobachteten Thatsachen haben. Rom a nes findet, dass Abschneiden des Magenrohres (polypite) oder eines Theils der Schwimmglocke von Aurelia oder einer anderen Toponeure zuerst Vermehrung der rhyth- 
mischen Contractioneu, dann aber eine lrogressive Abnahme derselben herror'uft, his ilne Zahl schliesslich, nachdem sie kleiner gevorden ist, als sie im unverletzten 'Thiere war, stationär bleibt. Ummittelbar nach der Operation ist zugleich der Rhythmus ein unregelmässiger. (F.s ist diese letztere Thatsache nach ähmlichen Operationen schon in meiner ersten Mltheilung von mir bemerkt worden - man vergleiche z. B. den T. Abschuitt - zugleich aber, dass stets unmittelbar nach der Verwundung zuerst die oft erwähnte liurze Lähmungsperiode eintritt - erst später erfolgen die von Romanes beschriebenen Erscheinungen.) Wegnahme weiterer Stücke der Sclnwimmglocke hat num dieselben Folgen wie die des ersten: die Zahl der in der Zeiteinheit bleibenden Contractionen sinkt jetzt noch tiefer. Wegschneiden des Gewebes rings um einen liandkörper - aber erst in der Breite von einem bis zwei Zoll - veranlasst ungehener lange Perioden von Unthätigkeit. Während derselben kann auf Reiz eine Reihe von rhythmischen Contractionen auftreten, gefolgt von einer weiteren langen Pause. Diese Thatsachen scheinen zu zeigen, dass die augenscheinlich antomatische 'Thätigkeit der Randkörper verursacht sei durch eine constante Reizung, welche von ancleren Theilen des Organismus hel verstärlit wird.

Ich möchte die von Romanes gegebene Erklärung in Rücksicht auf' meine eigenen Beobachtungen und in Rücksicht anf anderweitige aus Thatsachen von mir gezogenen Schlüsse in etwas anderen Worten ansdrücken. Jch hatte schon nach meinen ersten Tersuchen angegeben, dass das Ausschneiden nur einer contractilen Zone oder selbst das Ansschneiden von sieben derselben so lange als die achte intakt sei, geschehen könne ohne dass - von der Bestürzungsperiode abgesehen - Lähmung auftrete, wie sie and das Entfemen der letzten Zone sofort folgt. Ich hatte nicht mntersncht, ob nicht schon das Ausschneiden einer einzigen contractilen Zone etwa eine längere Lähmungsperiode hervorrufen werde, als sie sonst, nach irgend welcher belieligen anderen Operation sich zeigt. Die Ergebnisse von liomanes weisen auf Delartiges hin. Er findet, dass Wegnehmen irgend eines Körpertheils die Contractionsfăhigkeit des Ganzen herabsetzt, lass aber. Wegschneiden eines der in der Umgebung rer Randkörper gelegenen Bezirlse viel mehr eingreifend ist als Wegnehmen eines anderen, inden es „ungehener lange Pausen von Unthätigkeit veranlasst." Jener Bezirk enthält num eine contractile Zone: wenn $R$ om a n es sagt, dass, um die Wirkung zu erzielen, das Gewebe in der Breite von I bis 2 Zoll weggenommen werden musste, so ist vorauszusetzen, dass sie schon vorher in geringerem Grade bemerkbar gewesen, aber erst successive bis zu dem beschriebenen Grade gewachsen sein wird. Involvirt somit der Tersuch von $R$ o m a $n$ e die Wirkung des 
Ansschneidens einer einzigen contractilen Zone im Gegensatz zu der Operation des Wegnehmens irgend eines anderen hörpertheils von deın übrigens nnverletzten 'Thier*, so muss er veranlassen zu untersuchen, ob die Wirknng nicht jedesmal frülıer, nach Wegschneiden eines kleineren Randstückes eingetreten sein würde, wenn er den zweiten, dritten и. s. w. nud besonders, wenn er den letzten Randbezirk ansgeschnitten hätte - vielleicht würde in diesem letzteren Falle das Entfernen eines ganz kleinen Gewebsstïckchens sammt liandkörper schon genügt haben, nm die Wirkmng - d. i. mehr oder weniger volliommene Lähmmig - hervorzuruten. Entsprechende Versnche würclen noch anzustellen sein. Vielleicht aber dürfte eine grössere lieihe von Experimenten Fälle aufweisen, in welchen anch schon das Ansschneiden eines einzigen ganz kleinen Randkörperbezirks die vou Romanes geschilderten Erscheinnngen bewirkt, wie mir umgekehrt deren begegnet sind, in welchen erst nach Ansschueiden sehr mmfangreicher Raudkörperstücke Lälmmng eingetreten ist. Ich würde die Wirkung des in Frage steheuden Versuchs Hand in Hand mit auderen Erfahrungen nm folgendermassen erklären: es sind über den ganzen Körper der Meduse centrale Nervenzellen verbreitet, besonders angehänft sind sie in der Ungebung der Randkörper. Wegnehmen irgend eines Körperstückes muss demnach nothwendig die Contractionsenergie vermindern, in ganz besonderem Grade aber wird sie vermindert durch Entfernen eines Stückes Gewebe in der Umgebung eines Randkörpers. Wenn also Romanes folgert, dass die antomatische Thätigkeit der liandkörper verursacht sei durch eine constante Reizung, welche von anderen 'Theilen des Organismus her verstärkt wird, so würde ich sagen, sie wird zwar wesentlich verursacht durch die anf den Randkörper'n und in deren Ungebung gelegenen Nervenzellen, aber in den übrigen Theilen des Körpers gelegene Centralapparate haben an ihr gleichfalls einen, wenn auch geringeren Antheil. Das Entfernen irgend eines Stückes des Körpers wird demmach allerdings einen 'Theil des die Berregungsthätigkeit vermittelnden Reizes wegnehmen, weil es einen Theil der centralen Nervenkraft wegnimmr. Unverhältnissmässig viel von dieser Nervenkraft wird aber eliminirt durch die Wegnahme eines liandkörpers sammt Umgebung, weil hier der rorzugsweise Sitz der centralen Apparate ist.

Weiterhin kommt num Romanes zu dem bemerkenswerthen, aber schon früher von mir verwertheten Schluss, dass ein gewisses proportionales Verhältniss bestehe zwischen der Grösse des weggenommenen Gewebsstückes und dem Grade der Verminderuug der Contractionsfähigkeit.

Es clarf wohl hier noch daranf autmerksam gemacht werden, dass die früher von mir ansgesprochene Beobachtnng, wonach eine abnorme Vermehrung der liand- 
körper einer Meduse eine Erhöhung der Contractionsthätigkeit derselben zur Folge hat, anch in den Angaben von Rom anes eine erklärende Stütze findet.

Es sei hier noch angetügt, dass Romanes die unmittelbar nach dem Ahschneiden eines Körnerstückes auftretemiten Erscheinungen (Beschleunigung und Unregelmässigkeit des Rhythmus) als eine Folge der Verletzung der Nerven (1)urchschneiden) lezeichnet. Ebenso erklät er es, dass er einmal sogar nach Wegnahme des Jagenrohrs einen heftigen und lang andauernden Krampf beobachtet hat. Ich sellsst habe die nach einer Verwundung eintretende knrze Lihmungsperiode als Folge des Eingriffes in das Nervensystem lezeichuet (vergl. IV. Aischnitt); zur Erklarung der darauffolgenden Erscheinungen wird aber auch der Einflus des Willens (bezw. autumatisches Handeln) in Betracht zu ziehen sein. Es sei daran erinnert, wie schon Forbes (vergl. den X. Absehnitt) das Verhalten der Rhizostoma Aldrovandi nach Entfernen der einen Hälite der Subumbrella schildert: die nicht rerletzte Hälfte contrahirte sich nach der Operation mit grösserer Geselwwindigkeit: nas it the animal was alarmed or suffering" und weiter sagt er: "All the Medusae when irritated become much more rapid in their novements, and contract and expand their disks or hodies in a hurried and irregular mamner, as if endeavouring to escape from their persecutor" ". Es ist natürlich, dass das Thier die Contractionen beschleunigt, um seinen Peinigeru zu entrinnen; aber auch ahgesehen lievon mag es seinen Körper nach der Verwundung lebhaft contrahiren aus denselben Grimden, aus welchen etwa ein Mensch die Hand, in deren Finger er sich stark geschnitien hat, lehhaft schüttelt - wie viel aber ron den Exscheinungen auf willkürliche, wie viel auf Reflexbewegung zu schieben ist, lässt sich selbstverständlich nicht sagen.

Die T'emperatur übt einen grossen Einfluss anf die rhythmische Contractionsthätigkeit ans ${ }^{1}$ ). Wasser unter $20^{\circ}$ hebt dieselbe ebenso wie auch die Reizbarkeit auf; Wasser über $70^{\circ}$ bewirkt eine andanernde Verlangsamung des Rhythmus, nuchdem es ihn zeitweise beschleunigt hat. Wasser zwischen $50^{\circ}$ und $60^{\circ}$ beschleunigt den Rhythmus andauernd, so lange als Medusen, welche aus kälterem Wasser genommen worden sind, seinem Einfluss ausgesetzt bleibeu. In sehr kaltem Wasser ist der Terlust der rhythmischen Contractionsfühiglieit ein schrittweiser, obschon sehr rascher und ebenso sein Wiederanftreten nach dem Zurückbringen des Thieres in warnes. Anrelien, welche man hat gefrieren lassen, leben nach dem Aufthauen wieder anf, allein eine vollständige Rückikehr des ursprünglichen Rhythmus der Bewegung wurde nicht beobachtet.

Es sind in den angegebenen Zahlen watürlich Grade Fahrenheit gemeint $\left(20^{\circ} \mathrm{F} \doteq-6,66^{\circ} \mathrm{C}, 70^{\circ} \mathrm{F}=+21,11^{\circ} \mathrm{C}, 50-60^{\circ} \mathrm{F}=+10-15,55^{\circ} \mathrm{C}\right) . \mathrm{Am}$ wichtigsten ist für mich die Thatsache. dass schon Wasser über $21^{\circ} \mathrm{C}$ eine andauernde Verlangsammug des Rhythmus der Bewegungen bewirkt; sie erklärt auf das Wünschenwertheste den im Verlunf meiner Larstellung wiederholt hervorgehobenen Einfluss der Temperaturschwankungen, wie sie innerhalb des Rahmens der Jahreszeit auftreten und wie sie geltend werden, je nachdem man die Untersuchung in der See selhst oder ausserhalb derselben anstellt, für die Widerstandsfähigkeit der 'Thiere,

1) Die Versuche sind vorzüglich an Aurelia angestellt. 
insbesondere für deren Erholung ans der Lähmung. Denn es lenchtet ein, dass ein gelähmtes Thier, welches in Folge hoher Temperatur des Wassers nicht zn einer bestimmten Anzahl von Contractionen in gegebener Zeit gelangen kann, sich gar nicht erholen wird oder doch viel schwerer und nnvollkommener, als ein solches, bei welchem in dieser Beziehnng gäustigere Verhältnisse obwalten. Es ist desshalb klar, dass es, um die Wirkungen verschiedener Versuche nmmittelbar genan vergleichen zn können, in Zukuntt nöthig sein wird, bei jedem einzelnen derselben die T'emperatn des Wassers nnd der Lult anzugeben, wie ich schon früher - und bevor ich die Zahlen von Romanes kannte - voransgesetzt hatte (vgl. u. A, besonders Seite 47$)$.

San ers of f beschlennigt den Rhythmns, Kohlensämre verlangsamt ihn; wenn letztere in grossen Dosen angewentet wird, zerstört sie die willkürliche Contractionsfähigkeit md die lieizbarkeit. Der erste T'heil dieses Satzes ist schon enthalten in meiner Schildermng des Einflusses von Sanerstoffmangel anf die Bewegungen (III. Absehnitt). Romanes bestätigt die vou mir anch schon in meiner ersten Abhandlung ${ }^{1}$ ) geschilderte Wirkung verdorbenen Wassers auf den Rhythmus der Contractionen und auf die Daner der Pansen, sowie die Erholung nnter dem Einfluss frischen Wassers; dort ist gesagt, dass die Zahl der Contractionen, welche in dureh die Athmung verbranchtem Wasser in der Zeiteinheit gemacht wird, bald grösser, als beim frischen Thiere ist, ball viel kleiner; es wird somit der Finfluss von Kohlensäure wohl nnter bestimmten Verhältuissen die Contractionsthätigkeit verlangsamen, insofer'n als sie lähmend, vergiftend, anf das Thier wirkt, die zugleich entstehende Athemnoth aber wird ron Zeit zu Zeit eine Beschleunigung derselhen hervorrufen können. Ein sehr schönes Bèispiel für die Terlangsamung des Rhythmus durch hohlensätre bietet das auf Seite 5.j von mir gegebene Beispiel in den Fallen 1-.j gegeü̈ber den Fällen 6 -9 dar.

Die Einwirkung eines einfachen mechanischen oder chemischen Reizes auf den gelähmten Schirm einer toponenren Meduse ruft - wie für ersteren von mir bemerkt - hänfig eine kurze Reihe von rhythmischen Contractionen hervor. Licht wirkt bei einigen Arten als kräftiger lieiz, verursacht Contractionen, und zwar das Licht an sich, nicht der Wechsel von Dunkel und Licht: denn Dunkelheit nach Linwirkung des Lichts reizt nicht (Sarsia). Nach Wegnahme der Randanschwellungen reizt das Licht nicht mehr (Sarsia). Für Aurelia konnte Aehnliches u. S. 61,65 .

1) Ueber künstl. Theilbarkeit etc. Würzb. Verh. a. a. O. S. 148 u. S. 156 , 157. Zoolog. Unters. S. 56 
nicht festgestellt werden. Berreise für Reflexthätigkeit werden nach Untersuchungen an Sarsia beigebracht. Ich mache darauf aufmerksam, welch schönes Beispiel für Reflexthätigkeit bei Aurelia unter meinen Versuchen der in XII. Abschnitt anf Seite S2 geschilderte Versuch D am IV. Tage darbietet: das der contractilen Konen beraubte 'T'hier' ist noch an diesem Tage gelähmt mit Ansnahme zweier Afterlappen, welche sich rhythmisch contrahiren, und in welchen sich also Ersatz-contractionscentren gebildet haben. Sticht man nun mit einer Nadel in den vollkommen gelähmten Mitteltheil der Mednse hinein, so antworten diese Lappen mit einer kräftigen Contraction, und sehwach antworten auch einige der übrigen Afterlappen, welche selbstständiger Contraction noch nicht wieder fähis sind.

Durch Zelschneidungsversuche kommt Romanes u. A. zu dem Schlusse, dass der Magenstiel son Sarsia in sehr inniger Verbindung steht mit dem Schirme und insbesondere mit den laandkörpern durch einen Nervenplexus, welcher das Gewebe durchziehe, aber die Hamptzüge der Nervenfasern seien bei den rerschiedenen Individuen nicht constante und es seien dieselben in keiner Weise an den Verlauf der Radiärgetässe gebunden. - In der Voranssetzung, lass die convexe Oberfläche des Thieres, weil dieselbe am leichtesten in Bertürung mit firemden Körperu kommt, von den Randganglien aus mit Nerven versorgt werke, wurke sie bei Sarsia elektrisch gereizt, allein es ergab sich die auffallende Thatsache. lass selbst starke Reize keinerlei Wirkung haben ${ }^{2}$ ). Bei allen Iedusen, welche darauf untersucht wurden, war die Erregbarkeit des Schirmes beschränkt auf die denselben von unten deckende dünne Lage von contractilem Gewebe ${ }^{2}$. Sehr interessante Versuche an Tiaropsis indicaus (I o m.) zeigen, dass hier jeder Bezirk des Magenschlauches im Stande ist, einen Reiz zu lokalisiren (d. i. die Ștelle zu erkennen, an welcher er ausgeäbt ist): reizt man die Schwimmglocke an gleichviel welcher stelle, jedesmal neigt sich der Magenschlauch gegen die gereizte Stelle hin. Ehenso neigt sich aber irgend ein beliebiges ansgeschnittenes stück des Magenrohres nach der Stelle hin, an welcher es selbst gereizt worden ist: "Hence there can be no doubt that every portion of the polypite... is independently endowed with the capacity of rery precisely localizing a point of irritation which is seated either in its own substance or in that of the bell." Aehnliche Erscheinungen zeigen sich an abgeschnittenen Stücken des Schirmes, sind aber nicht mit derselben Sicherheit zu deuten. Es wird hervorgehoben, dass diese Funktion zu lokalisiren, welche, wenn sie irgendwo bei höheren Thieren sich fünde, sicher umsehriebene Gangliencentren voraussetzen liesse, bei der'

1) S. 699 .

2) Hier und im folgenden ist der Ausdrack contractiles Gewebes richtig für Muskelgewebe gebraucht. 
Meduse über las ganze Lager von contractilem Gewebe zerstrent ist, welches die Obertläche des Magenrohres überkleidet. Es sei ihm nicht bekamnt, dass Aehnliches irgendwo bis jetzt im Thierreiche beschrieben worden, aber er zweitle nicht daran, dass zukünftige Untersuchnngen ein entsprechendes Verhalten als gewöhnliche Einrichtung bei den niederen Thieren erkennen lassen werden. - Ich brauche kaum daran zu erinneru, in wie hohem Grade diese physiologischen Untersuchungen an Tiaropsis indicans eine Parallele bieten zu der Dentung, welche ich den morphologischen Eimrichtungen des Nervensystems bei Beroë ovatus gegeben habe, um so weniger, als ich nothwendig späterhin auf diese Parallele zuräckkommen muss. — Um die Art der Nervenverbindung zwischen Schwimmglocke und Magenrohr festzustellen, ward nun an der Stelle des Uebergangs des letzteren in die erstere ein Einschnitt gemacht: es rermochte jener jetzt auf diese ausgeübte Reize nicht mehr zu lokalisiren - aber er löste den Reiz noch ans und der Magenschlanch suchte jetzt gewissermassen von einer Stelle zur anderen, indem er sein Ende da und dorthin wendete. Je näher dem Schnitt übrigens der Reiz ausgeübt wird, um so sicherer ist noch die Lokalisirung. Ans den Versuchen geht hervor, dass die Verbindung rorzugsweise eine radiale ist, dass aber anch nicht radiale Verbindungen vorhanden sind. Die letzteren müssen nach Zerstören (Durchschneiden) der ersteren für diese vicariiren. Somit kommt Romanes durch seine Versuche im Wesentliehen ganz auf dieselben Schlüsse, welche ich durch Durchschneiden der Muskelschichte verscliedener Medusen erlangt habe, denn er folgert wie ich, dass das Nervenlager, durch dessen Durchschneiden die Coorchination gestört worden ist, unter der Muskelschichte liegen müsse. Von den nicht radialen (überall gelegenen) Nervenzügen, die er als Plexus bezeichnet, bemerkt er noch, dass sie Durchschneiden bis zu bedeutender Tiefe ertragen, insbesondere in ıler Gegend der radialen Ernährungskanäle.

Versnche an Amelia amita mit elektrischer Reizung zeigen die Berechtigung der Auffassung, dass die Erregung durch Nerven vermittelt werde. Die Schirmunterfläche ist nicht überall in gleicher Weise erregbar und der Reiz pflanzt sich nicht überall hin mit gleicher stärke fort, sondern es gibt Bezirke von geringerer und solche von grösserer Erregbarkeit, mit umregelmässigen Grenzen, welche von sehr schwachen Reizen nicht überschritten werclen (an ausgeschnittenen Stücken von Aurelia).

Sebr bemerkenswerth ist die Thatsache, dass ein Nervenreiz in Amelia nicht schneller fortgepflanzt wird als eine Contractionswelle ${ }^{2}$ ). Desshalb können wir nicht annehmen, dass die Aktion der lokomotorischen Ganglien bei diesem Thiere im eigent- 
lichen Simue des Wortes eine coordinirte sei: „for if a stimulus-wave camot ontrun a contractile wave, one ganglion cannot know that another ganglion has discharged its influence till the contractile wave which results from a discharge of the active ganglion has reached the passive one" 1). Die von mir beschriebene T'hatsache, dass sich die Contractionen des unverletaten Schirmes bei der Bewegung desselben dentlich von einer contractilen Zone anf die andere fortpthmzen ${ }^{2}$ ), ohne dass irgend Zeichen von Coordination zwischen den einzelnen Contractionscentren vorhanden sind, erklät sich auf diese IVeise ${ }^{3}$ ), anch wenn Nervenverbindung im Rande wie sonst in der Umbrella vorhanden ist $\left.{ }^{4}\right)$. Romanes gibt dafür eigene Beobachtungen an und ebenso dafür, dass nach Einschneiden zwischen zwei Centren auch dawn wem vorher gleichzeitige Contraction aller Antimere statt hatte, die Synchronie gestört ist und diss jetzt bald dieses Segment, bald jenes den Anstoss zur Erregung gibt, welche daun anf die anderen fortgeptlanzt wird ${ }^{5}$ ),

Da num ausserdem die Meduse in ausserordentlichem Grade zerschmitten werden kann, ohne lass Leitungs- und Contractionsfäligkeit leiden, da Leitungs- und Contractionsfähigkeit gleich schwierig zu zerstören sind, so sind wir, schliesst Romanes, veraulasst anzunehmen, dass diese beiden Funktionen wahrscheiulich an dieselben Gewebselemente gebunden sind ("For excitational continuity beeing thus shown as difficult to destroy, in the case of this Medusa, as is contractional continuity, we are led to conchde .... that both these functious are probably dependent on the same tissue-elements" $)^{6}$ ). Die Thatsache, dass selbst nach ausserordentlich hochgradiger Zerschneidung die Leitungstähigkeit bleibt, kann indessen durch Kleinenbergs Theorie von zweifach funktionirenden Zellen nicht erklart werden, denn es werden zuweilen Coutractionswellen durch Zerschneidung autgehalten. wähend ein Iieiz doch noch Zusammenziehung der Tentakel hervorrnten kann. Oiler: reizt man die Schirmunterfläche so leicht, dass gar keine Contractionswelle hervorgeruten wird. so kann man doch beobachten, dass dieser Reiz Contraction der Teutakel hervorruft. Wir sind somit zu der Annahme eines Nervenplexus mit der Fähigheit des Vicariirens veranlasst. Bei den bedecktängigen Medusen scheint eine andere Coordination zwischen den einzelnen Randkörpern nicht zu bestehen, ansgenommen die, dass contractionswellen schnell von dem einen zum anderen ziehen und, während sie die-

\footnotetext{
1) S. 726.

2) Vergl. s. 21 und seber küustl. Theilbarkeit. etc. Würzb. Verb. a. a. O S. 111. Zoolog. Znter. s. 4!.

3) S. 727 .

4) Man vergleiche das Folgende.

5) Vergl, den VI. Abschnitt und Würzb. Verh. a. a. U. s. 15̄1. Zoolog. Unters. S. 59.

6) S. 749 .
} 
selben durchziehen, Entladnng hervorrufen, während bei den Nacktäugigen eine Verbindung durch Nerven stattfindet. - Ich werde auf diese Fragen und anf die Romanes'sche Fassmng der ans den Thatsachen zu ziehenden Folgernngen am Schlusse meiner Arbeit zurückkommen.

Endlich wird der Einfluss noch einiger Gitte aufgeführt und bemerkt, dass süsses Wasser für die Medusen tödtlich ist.

(lans ${ }^{1}$ ) vermochte ,durch Wiederholung der Eimer'schen Experimente an Aurelia und Chrysaora die líchtigkeit der wichtigsten liesultate derselben zu bestätigen“, macht weiterhin einige Arsstande an denselben, die dnrch das Vorstehende erledigt sein möchten, vor allem derjenige, dass nich der Lähmung nicht nur schwache, sonderu ganz kräftige Contractionen des ganzen Schirmes anftreten, „welche freilich nicht regelnässig und rhythmisch, sondern vereinzelt, nach langen Pansen " er'scheinen. Meine Untersnchungen hatten mich, wie bekannt, schon vorher gelehrt, dass diese Contractionen sogar vollkommen rhythmisch wieder anftreten können.

Erst nachdem ich die wesentlichsten meiner Beobachtungen gemacht hatte, bekam ich mehr und mehr Kenntniss von Versuchen über Zertheilen von Medusen, welche im Gegensatz zu den bisher behandelten vor meinen ersten bezüglichen Experimenten gemacht worden sind, Angaben, welche in der Literatur zerstreut, theilweise in der Zeit ziemlich weit zurückreichen. Zwar sind diese Versuche meist nur gelegentlich erwälint und nirgends planvoll, mit bewusstem Zwecke behandelt und durchgefülurt. Aber trotzdem ist die Thatsache, dass dieselben so spurlos begraben bleiben konnten, ein kaum erfrenliches Erinuerungszeichen einerseits daran, wie ferne die hentige Physiologie der Benützung des fruchtbringenden Bodens der niederen Thierwelt steht und andererseits darin, wie die Zoologie, von der Her'schaft trockener Systematik kaum erlöst, fast ausschliesslich morphologischer Behandlung anheimgefallen und von der berechtigten biologischen Gestaltung mehr als je entfernt ist, so dass allgemein biologische und speciell physiologische Fragen in der zoologischen Sammelliteratur heute auch nicht das bescheidenste Maass ron beachtung finden.

Macri. Vor einem Jahrhundert veröffentlichte der Neapolitaner Saverio Macri eine Abhandlung über den "Polmone marino degli antichi“ ${ }^{2}$ ), d. i. RhizoI. Abth. 1877 .

1) Studien über Polypen u. Quallen der Ad̆ria. Denkschr. d. k. k. Akad. d. W. math. naturw. Cl. XXXVII. Bd.

2) Nuove osservazioni intorno la storia naturale del Polmone marino degli antichi, Napoli 1778. 8. 1 Taf. 
stoma Cuvieri, welche 1532 in den Atti della Reale Accademia Borbonica neu abgedrnckt wrude, weil sie selten geworden war'). Das Original der ersten Auflage muss Eysenhardt vorgelegen haben. welcher den Inhalt der Schritt im Jahre 1521 ziemlich eingehend behandelt ${ }^{2}$ ). Er sagt. er sei auf dieselbe durch hulolphi anfmerksam gemacht worden. Mir liegt der Abdruck ror, der aber gleichfalls wenig bekannt zu sein scheint. Es fehlt die Schrift z. B. in dem Literaturverzeichniss von Bronn's Krlassen und Ordunngen des Thierreichs, obschon sie 50 Seiten in Quart stark und wenn anch dem lnhalte nach nicht vou besonderer wissenschattlicher, so doch jedenfalls von hervorragender historischer Bedentung ist. Ich finde in ihr die ersten Bemerkungen darüber, dass Theile des Medusenschirmes nach ihrer Loslösung vom Gesammtorganismus noch fortleben. M i eri sagt nämlich in dieser Beziehung von dem Polmone matino: "Se si taglia a traverso l'intero gambo, o lombrella, o se tagliasi in piu parti questa Medusa. appena tratta d'al mare, l'animale anche vive per molte ore, palpitando sempre col cappello“ ${ }^{3}$ ). Er behauptet anch. dass nach Verstämmelung des Hntstiels und seiner Theile eine Reprodulition stattfinde. Ans seinen Worten scheint jedoch hervorzugehen, dass er sich im Wesentlichen nur auf die Aussagen der Fischer stützt, während er selbst nur Narbenbildung oder die Entstehnng von kleinen Auswüchsen beobachtet hat, ron relchen letzteren er nun annimmt, dass sie zu dem „Hutstiel“, zu den Armen und deren Anhïngen heranvachsen ${ }^{4}$ ). Thatsächlich berichtet Nienand später über eine heprodnktion verstummelter Theile bei Rhizostoma oder bei anderen toponemen Medusen, wie ich selbst niemals eine solche wahmehmen konnte. Dass sie in der That jedentalls bei Amelia in keiner Weise stattfindet, las beweist die Thatsache, dass an den von mir beobachteten Krrüppeln nie irgend spuren derselben zn beobachten waren.

Gäde spricht sich gegen die Regeneration ron Aurelia aurita in meinem Sinne schon im Jahre 1 sl(6 aus $\left.{ }^{5}\right)$. In seiner Abhandlung sind anch schon Bemerkungen über das Fortleben vou Theilen enthalten, welche von diesem 'Thiere losgetrennt

1) Atti della Reale Accademia delle scienze, sezione della Societa Reale Borbonica, Vol. IlI. 1832, Classe di Fisica e di Storia Naturale \$. 3.

2) F. W. Eysen hardt, zur Anatomie und Naturgeschichte der Quallen. I. Von dem Rhizostoma Cuvierii Lam. N. A. A. C. L. C. T. X. 1821.

3) a. a. O. (Accaul. Borb. s. 40.)

4) Die Worte, welche ich diesem Sinne glaube deuten zu müssen, lanten: »nutilati i rami, le otto braccia o le ultime alpendici le riproduce di bel nuovo come prima. Questa e un opinione ricevutissima da." nostrali pescatori, e confermata dalla lunga osservatione: la quale c'insegna, che nelle parti nutilate prossime a riprodursi. or veggonsi delle manifeste cicatrice ramuarginate, come quelle delle ferite; ed or talune piccole escrescenze irregolari a guisa di bottoni, formanti il gambo, le braccia, i rami." Berlin 1816.

5) Man vergl. die kleine Sclurift von H. M. Gä de, „Beiträge zur Anatomie u. Physiologie der Medusenء, 
waren. Gäde findet, dass die Reproduktionskraft der Aurelia selır gering sei. "Wenn ich", sagt er, ,einen Theil ihres Körpers absehnitt, so bemerkte ich anch nach langer Zeit nicht den geringsten Schein von IViederherstellung des verlorenen Theils, sondern nur eine völlige Abrundung der Durchschnittsstelle, die wenig Stunden nach dem Abschneiden erfolgte. Das 'Thier selbst schien indess, selbst wemn ich ihm viele und grosse Stücke raubte, ebenso munter zu sein, als es vor der Verstümmelung gewesen war. Zerschnitt ich eine Meduse in mehrere Stücke, so lebten diejenigen, an denen anch nur ein Magensack geblieben war, fort; diejenigen hingegen, bei denen das nicht der Fall war, führten höchstens ein zweitägiges Leben. Anch müssen die Gläser, in welchen man diese Thiere beobachtet, täglich mit frischem Meerwasser gefüllt werden; wird diese Ernenerung des Wassers nur für einen 'Tag' ausgesetzt, so sterben sie sehr bald." - Da bei Gäde die des Magensackes belaubten Thiere nicht länger als zwei Tage lebten, so muss er die von ilmm zuletat erwälnute Vorsichtsmassregel selbst sehr wenig sorgfältig gehandhabt haben. Auch

Eysenhardt erwähnt von Rhizostoma im Jahre 1821 die Thatsache, dass abgeschnittene Stücke des "Hutes“ noch nach melıreren Stunden "Klappenversuche" machen ${ }^{1}$ ). Musste ihm dies von Maeri her bekannt sein, so lässt auf eigene Beobachtungen die neue Nachricht schliessen, dass die Klappenversuche, „welche zwvar zuletzt immer schwächer werden, sich erneuern, weun mau die Stücke stark berührt oder hineinsticht" ${ }^{2}$ ).

Spallanzani veröffentlicht, wie es scheint olıne die Mittheilungen der bisher genannten Forscher zı kennen, wenige Jahre später Beobachtungen über die Bewegmngen der Medusen und über das Fortleben von Theilstücken derselben ${ }^{3}$ ). Und zwar verfuhr er zuerst consequent experimentell, in der Absicht, den Sitz der Contractionsursache aufzufiuden. Er beschreibt zunächst die Bewegungen der Medusen ${ }^{4}$ ). Dieselben geschehen, sagt er, durch abwechsehnde Verengerung und Erweiterung des Schirmes in Folge des durch erstere bedingten Rückstosses des Wassers. Hören sie anf, so sinkt das Thier zu Boden, weil es specifisch schwerer ist als das Wasser des

1) a. a.. 0. S. 408 .

2) Claus sagt in seinem Lehrbueh der Zoologie (III. Aufl. S. 241) bei Gelegenheit des Erwähnens einiger Ergebnisse meiner bezüglichen Untersuehungen über Aurelia: „Schon älteren Beobachtern (E ysenhardt) war bekannt, dass der getrennte Sehirmrand automatische Contractionen ausführt. \& Es ist wesentlich, ob Eysen hardt, wie aus den Worten von Claus hervorgehen möchte, schon aufgefallen ist, dass der Schirmran d oder Theile desselben losgelöst sich contrahiren, andere Theile nicht. Aus den oben eitirten Worten dieses Forschers, mit Ausnahme welcher ich bei ihm keine den Gegenstand betreffende Remerkung finde, geht jedoch solche Unterscheidung keineswegs hervor.

3) Lazzaro Spallanzani, Viaggi alle due Sieilie T. III. Milano 1826.

4) a. a. O. S. 15. 
Meeres. Dies hatte übrigens schon mehr denu hundert Jahre früher Rea $\mathrm{um} \mathrm{u} \mathrm{r}^{1}$ ) behauptet. indem er in seiner Abhandhung über die Ortsberegung der Thiere sagt, dass die an's Land geworfenen todten Quallen untersinken, wenn man sie wieder in's Wasser wirft: sie seien schwerer als das Wasser und hielten sich während des Lebens darin durch die Bewegungen des Schimes ${ }^{2}$ ).

Ganz im Gegensatze zu Spallanzanis Aeusserung hatte ich bei meinen ersten Lähmungsversuchen beobachtet, dass Aurelia nach der Lähmung an die Oberfläche des Wassers mit ausgebreitetem Schirme emporgetragen wurde, während Cyanea sank $\mathrm{k}^{3}$ ). Neine neneren Versuche haben mir, wie anf Seite 26 gesagt ist, gezeigt, dass die gelähmte Aurelia bald sinkt, bald steigt; die gelähnite Cyanea mit Fangfäden sank, ohne Fangfäden stieg sie in wiederholten Fällen. Ebenso können lebende Aurelien, wenn sie ihre Bewegungen einstellen, unter die Oberfläche des Wassers emporsteigen und auch bei auderen Nedusen ist dies zu beobachten. Ausgeschnittene Einzelantimere sinken ${ }^{4}$ ). - Ich wercle an einem anderen Orte auf diese Verhältnisse näher eingehen und zugleich äber die Locomotion von Beroë Neues berichten.

Um den Sitz der Contractionsursache zu finden, schnitt Spallanzani zunächst ein kreisförmiges Stück, einen Zoll im Durchmesser haltend, aus dem oberen Theile einer Meduse aus. Dieses ansgeschnittene Stück contrahirte sich nicht mehr, auch nicht auf Reiz. Der ringförmige Rest des 'I'hieres dagegen contrahirte sich noch. Der Ring wurde dariuf ladurch verschmälert, dass eine innere Zone von ihm weggeschuitten wurde. Anch diese letztere contrahirte sich, im Gegensatz zum äusseren Ringtheile nicht. .Con novelle recisioni venni in fine a scoprire la sede e l'origine dell' ascillatione (so nennt er das abwechselnde sich Verengern und Erweitern des Schirmes) nelle meduse" - es ist offenbar das Muskelgewebe der Subumbrella, ron welchem die Contractionen ausgehen ${ }^{5}$ ).

Dieses Muskelgewele beschreibt spallanzani kmrz vorher ${ }^{6}$ ), und wie er sagt, zuerst als solches. Schon M a cri leitete die Zusammenziehungen des Schirmes von den "concentrischen Fibern" auf der unteren

1) Reaumur w Du mouvement progressif et de quelques autres mouvemens de direrses especes de Coquillages, Orties et Etoiles de mer«. Hist. de l'Acad. royale des sciences, Année 1710, S. 434 tt. Paris 1732.

2) a. a. O. S. 484.

3) Ueber künstliche Theilbarkeit etc. Würzb. Verh. a. a. O. S. 143 u. 160. Zoolog. Unters. \$. 51 ๓. 68.

4) a. a. O. S. 145 bezw. S. 53.

5) Di sopra ho ragionato di nin tessuto sottilmente uusculoso, ehe dei lembi dell' ombrello s'inoltra per un dato spazio su l'interuo delle sne pareti. Espiato alla lente si trova composto di un immenso numero di sottilissime fibre carnose trastersali, fra se parallele e sommamente aderenti alla sostanza gelatinosa dell' ombrello d'all agire di cotai fibre trasversali e dal loro rilassarsi dipende tutto il ginoco delle oscillazione. Ogni qualrolta dunque ellene si accorciano la porzione dell' ombrello alla quale sono attacate i stretta a restrignersi il che non puo accadere senza che il restante dell' ombrello vada sogetto a restiguimento. Quindi si ha la sistole nella medusa. a a. a. O. S. 17.

6) ล. а. 0. S. 11 . 
Fläche der Medusen her, zugleich freilich vom Ringkanal, während dagegen die Radiärkanäle die Erweiterungen besorgen sollten (Rhizostoma) ${ }^{\mathbf{1}}$ ). Allein andererseits spricht II acri dem von ihm behandelten Thiere ausdrücklich alle Muskeln $a b^{2}$ ). Dagegen vermuthete Eysenhardt in jenen Streifen nicht nur die Ursache der Contractionsthätigkeit, sondern auch Muskelsubstanz: „die genannten Leisten oder erhabenen Ringe des Rhizostoma“, sagt er auf S. 390 seiner Abhandlung, "schienen nir immer eine Andentung von Muskelwesen, und vielleicht sind sie es, mittelst deren das Thier die Bewegung des Klappens macht, die freilich wolll allen Medusen eigen ist, obne dass man desshalb dergleichen erhabene Streifung fände."

Wemn anch śpallanzani nicht der Erste ist, der dis Muskelgewebe beschreibt, so hat er doch znerst mit Bestimmtheit der Snbumbrella die Eigenschaft als Mnskelsubstanz zngeschrieben und hat auch experimentell nachgewiesen, dass sie es sei, welche den Schirm contrahire. „Entfernt man, sagt er, irgend ein Stück vom Schirme, welches mit diesem Muskelgewebe nicht in Zusammenhang steht, so hört die Bewegung auf. Dagegen war es eigenthümlich anzusehen, wie der von der Meduse abgetrennte untere, mit Muskelbelag versehene Theil, welcher bei grossen 'Thieren mehr denn einen Zoll Breite hat, anf den 'Tisch gelegt bei jeder Systole enger wurde" ${ }^{3}$ ). Spallanzani meint mit dem Theil des Schirmes, den er als muskelfrei bezeichnet und der sich nach dem Ansschneiden nicht contrahirt, den oberen, geschlossenen Abschnitt desselben, mit dem sich contrahirenden Ring dagegen meint er offenbar bei allen seinen Versuchen die ganze Röhre, welche der, seiner Schildernug nach allein mit Mnskelgewebe belegte nutere Theil des Sichirmes nach Entfernen des ersteren darstellt. Inen Muskelbelag beschreibt er nümlich folgendermassen: „osservai ai lembi interui del medesimo (des Schirmes) mn altra organizzata struttura, consistente in un sottilissimo tessuto musculoso, che dall imo fondo ascende per lo spazio di mezzo pollice, ed anche d'un intiero pollice, secondo la grossezza delle meduse; e dove esiste cotal tessuto. la somma trasparenza dell ombrello rimane alquanto oscurata“ ${ }^{4}$ ). Anch da, wo der Forscher davon spricht, dass er den "Ring durch Abschneiden einer oberen Zone verkürzt labe, meint er mit dem letzteren, welcher sich nach dem Abschneiden nicht mehr contrahirte, noch einen muskellosen Abschnitt. Jass ein solches ringförmiges Stück sich nur desshalb nicht contrahirt, weil es vom natürlichen schirmrande losgelöst ist, das war ihm entgangen. Anch seine weiteren Versnche führten ihn nicht daranf. Er schnitt nämlich weiter-

1) I a cri a. a. O. S. 27.

2) Auch nach anderer Seite interessant ist eine bezügliche Aeusserung bei ihm (S. 4S u. 4!!): \Se vi e opera in natura, in cui maggiormente risplende l'onvipotenza, e la saviezza dell' Autor dell' Cniverso, e appunto la considerazione della struttura del nostro animale. Senza testa, senza occhi, senza cervello, privo di midollo spinale, e di nervi (se pur non voglia dirsi, che le strie del cappello, el i canali (Radiärkanäle) siano destinati per questo uso), privo di muscoli, e di vasi grandi, senza bocea, senza cuore, e senz' altri organi, che si stinsan necessari alla vita: pure egli vive, sente, si muove, cresce, si nodrisce, si moltiplica ed esercita tutte le sue funzioni.

3) a. a. $0 . \mathrm{S}, 17$.

4) a. a. O. S. 11 u, 12 . 
hin den durch die beschriebene Operation erhaltenen contractilen Ring yner durch in einzelne Stücke. Diese Strucke contrahirten sich weiter. Mit jeder Znsammenziehung wm de jedes derselben kürzer mul daranf wieder länger und zugleich mit dem Längerwerden verdünnte es sich, wie ein Wurm sich mit dem Kürzerwerden verdickt und umgekelnt. Hob Spallanzani mit feinsten Zängchen das Muskelgewebe an einer Stelle von der Gallertmasse cles Schirmes (eines contractilen Ringes) weg, so hörte dort die Contraction anf. Ungefäln dasselbe erfolgte, wenn er nur die Muskelfasern an mehreren Stellen entzweischnitt. Also ist, folgert er, der Sitz der Contractionsursache im Muskelgewebe zu suchen. Wie schon ans dem Mitgetheilten hervorgeht, beobachtete er aber ferner, dass Contraction auch an Medusen stattfindet, welche auf"s Trockene gebracht worden waren. Grössere Thiere zeigten damn noch nach 2t Stunden Contractionen, trotzdem sie schon ein Drittel ihres Volumens verloren hatten. Nur wurlen gegen den Ablauf dieser Zeit die Contractionen kurz, lingsam, muterbrochen. Und oft, wenn man glauben mochte, dass sie aufgehört hätten, erwachten sie wieder in Folge von Anstreifen (stropiccio) des Muskelgewebes oder anf Stechen in dasselbe. Aehnliches wurde an Theilstücken beobachtet. Diese Ausdaner der Contractionen an sterbenden Mednsen und an abgeschnittenen Theilen derselben möchte, so fahrt Spallanzani fort, einen unviderleglichen Beweis dafür abgeben, dass dieselben mubhängig rom Willen der Thiere seien, in gleicher Weise wie die Contractionen des Froschherzens, des Herzens einer Schildkröte oder einer Schlange, nachdem dasselbe vom 'Thierkörper losgelöst ist. Demmoch wagt er nicht dies bestimmt zu behampten, weil er beobachtete, wie Medusen sich in die Tiefe des Meeres niederliessen, indem sie die Contractionen einstellten und so durch das eigene Gewicht niedersanken. Dort blieben sie eine viertel, eine halbe Stunde und länger, um nach Wiederbeginn der Contractionen wieder aufzusteigen. "La cessazione di questo moto", schliesst er, „e la repristinazione di esso nelle addotte circostanze non par che dipendano dall' arbitrio delle meduse? Lascio tuttavia all illuminato Lettore il farue giudizio, a me bastando su tal proposito la schietta e fedele narrazione dei fatti." Spallanzani schwankt somit, ob er die Contrationen der Mednsen als willkürliche oder als mwillkürliche auffassen soll, ohme einen Versuch zu machen, dieselben bestimmt theils als unwillkürliche, theils als willkürliche zu denten, wenn er nicht aus politischen Gründen sein wahres Urtheil zurtickhält. Für meine Auffassung ist es sehr bemerkenswerth, dass er überhaupt die Frage aufwirft.

Nettenheimer hat in der trüher erwähnten Arbeit '), anf welche ich erst

1) Mettenheimer, Ceber die Gesichtsorgane des violetten Seesterns der Ostsee nebst Beobachtungen aber die Ohrenqualle und Versuchen ïber die Motilität derselben. Arch. f. Anat. u. Physik 1862. 
kürzlich aufmerksam gemacht worden bin, einige bemerkenswerthe Beobaehtungen über die Bewegungen von Aurelia aurita und auf dieselben bezügliche Versuche mitgetheilt. „Ob die Zusammenziehungen des Schirmes für willkürlich grehalten werden müssen“, sagt el, ,darüber kiun ich nach längerer Beobachtung nicht mehr im Zweifel sein. Ich halte sie für mehr willkürlich als die Athembewegungen des Menschen, insoferne es gestattet sein würde, einen höheren Grad von Abhängigkeit von dem Willen in dem Unstande zu erkennen, dass die Quallen die Zusammenziehıngen der Glocke viel länger unterbrechen können als der Mensch seine Athembewegungen." Er habe wiederholt gesehen, dass Quallen sich stundenlang an den Wänden des Glases, in dem er sie hielt, festsangten. Und eine andere Beobachtung, welche beweise, wie vollständig die Contractionen des Schirmes dem Willen unterworfen sind, sei die, dass sich gesunde, lebenskräftige Medusen lıänfig ganz flach machen und eine Zeitlang regungslos auf dem Rücken liegen bleiben. Auch die manchfachen Formen, welche sie den Schirm geben können, sprechen für diese Ansicht. Kíleine Individuen klappen nicht selten ilue Glocke so zusammen, dass sie wie eine Muschel aussehen nnd umfassen dann etwas, z. B. den Stiel eines Tanges, anderer partieller und allgemeiner Zusammenfaltungen des Schirmes nicht zu gedenken. "Sieht man dem Schwimmen der Quallen längere Zeit zu, so wird man sich des Eindıucks nicht erwehren können, dass diese Bewegung eine willkürliche ist. Die Contractionen des Schirmes können stärker und schwächer sein und dadurch die Geschwindigkeit der Lokomotion reguliren. In Gefässen, wo weder Wind noch Wellen einen Einfluss auf die Ortsbewegung der Quallen üben können, ist es nichts Seltenes, sie längere Zeit in einer und derselben Richtıng schwimmen zu sehen, als wenu sie anf einèu bestimmten Gegenstand losstemerten." - Was über die Verengermug der Gefässe gesagt wird, ist schon fiüher erwähnt worden. - Schliesslich theilt der Verfasser "einige einfache Versuche" mit, ,die in der Absicht angestellt worden sind, Fingerzeige zu erhalten, wo man eigentlich bei der Ohrenqualle die nervösen Centra, von denen die willkürlichen Bewegungen abhängig gedacht werden müssen, zu suchen hat." Tha die bisherigen Versuche, anf anatomischem nud histologischem Wege die Nervencentra zu entdecken nur zu unsicheren Riesultaten geführt haben, so scheint es wohl gerechtfertigt, der Lösung der Frage durch den Versuch den IVeg zu bahnen. Ietten heimer schnitt einer $1^{1}{ }_{2}$ Zoll im Durchmesser haltenden Meduse den Mund mit Armen nud Magen ab. Die Contractionen verloren ihren rhythmischen Charakter, ergriffen blitzähnlich einzelne Stellen des Randes, gingen gleithsam ringförmig um den Rand herum. - Schnitt er das ganze Centrum der Glocke, Eierstöcke, Magen und was dazu gehört heraus, so trat die geschilderte Erscheinung sehr deutlich 'auf. 
Das verwundete 'Thier znckte übrigens noch Stunden lang. Mit grösseren Exemplaren gab der Versuch dasselbe Resultat, jedoch nicht so schlagend. - Tiefe Einschnitte in den Rand, die ihn in eine Anzahl Lappen theilten, hatten keinen Einfluss anf deu Charakter und den Rhythmus der Bewegnugen. Erst wenn gleichzeitig Magen und Eierstöcke entfernt wurden, nahmen die Contractionen den blitzähnlich zuckenden, unregelmässigen Charakter an. Reizt man mit einer Nadel die Lippen des intakten Thieres, so erweitert sich der Mund und schickt sich zur Aufnahme der erwarteten Bente an. Der heransgeschnittene Magen aber zeigt sammt den Lippen und Armen sehr geringe Empfänglichkeit für mechanische lieize; jedenfalls ist diese Empfänglichkeit bei ihm viel geringer als bei abgeschnittenen Stücken les liandes. Von selbst aber zuckt das herausgeschmittene centrale Stück gar nicht meln. Der äusserste liand der Glocke zeigt, soweit er lilafarbig ist und die Fühlfäden trägt, nach dem Abschneiden gar keine rhythmische Contraction mehr; allein die wurmförmigen Zusammenziehnngen der Fühlfäden sind noch zu bemerken. Nur wenn eiu Struckchen von der Scheibe mit entfernt ist, danern die rhythmischen Contractionen fort. Je kleiner die Meduse, desto lebhafter contrahiren sich die abgeschnittenen Stücke. Dieselben komnten unter Seewasser noch nach vielen Stunden in lebhafter Contraction beobachtet werden. Man darf sie aber nicht zu klein machen. sonst erlischt die Reizbarkeit sehr schnell. Mettenheimer schliesst: "Es scheinen nach diesen Versnchen im Riandtheil des Discus Ganglien zu liegen, welche die Contractionen hervorrufen; im mittleren 'Theil der scheibe müssen jedoch andere Nervencentra liegen, die diese Bewegnngen beherrschen, coordiniren, zn rhy thmischen machen, eineu Ganzen unterorduen. Meine Versuche, diese supponirten tanglien zu finden, sind bis jetzt ganz missglückt.“

Brïcke bemerkt gelegentlich der Beschreibung der Mnskelelemente von Aurelia aurita') er habe sowohl an ganzen als an zerschnittenen Exemplaren der Medusa aurita beobachtet, dass jede Contraction nach einem bestimmten Typus erfolgte, indem sie sich stets vom Centrum nach der Peripherie ansbreite. Desgleichen sehe man dentlich an der Bewegung einzehner ansgeschnittener Stücke, dass dieselbe, wie dies anch schon die früheren Beobachter angegeben haben, nur von den Inskelelementen ansgehe, die eigentliche (iallertscheibe aber sich dabei passiv verhalte. Der Thatsache, dass 'Theilstücke deș Thieres noch Contractionen anslühren. wird also hier nur ganz kurz beilänfig Erwähnung gethan.

1) Bräcke, Ceber die mikroskopischen Elemente, welche Jen śchirmmuskel der Medusa aurita bilden. Sitzungsber. d. kais. Akad. d. W. math. natw. Classe. XlVIII. Bd. 1. Abth. Wien 1863. S. 155. 
Iläckel berichtet in seinen Studien über Moneren und andere Protisten " 1), über Versuche künstlicher 'Theilbarkeit an cyclonenren Medusen und, was sehr bemerkenswerth ist, über beobachtete Reproduktion. Die auf Lanzarote angestellten Versuchen ergaben, dass die künstliche Theilbarkeit hei manchen Medusen, namentlich aus der Familie der Thamantiaden (Gegenbaur), einen erstanulichen Grad erreicht. „Bei mehreren Arten dieser Familie“, sagt Häckel, konnte ich den Medusenschirm in mehr als hundert Stücke zertheilen und aus jedem Stück, sobald es nur einen Theil des Schirmrandes enthielt, erwuchs in wenigen (2-4) Tagen eine vollständige kleine Meduse. Selbst ein einziger losgelöster Randtentakel, an welchem die Basis, das ansitzende Stück des Schirmrandes, erhalten war, bildete in wenigen Tagen eine Meduse. Noch überraschender war mir das Resultat, das ich bei anderen Hydromedusen erhielt. Hier konute ich deu lingeligen nicht differenzirten Zellenhaufen (oder die wimpernde kugelige Larve), welche ans der Eifurchung hervorgegangen war, in mehrere Stücke zerschneiden und ans jedem Stück entwickelte sich eine selbständige Larve.“

Schliesslich möchte es für die vorliegenden Fragen von Interesse sein, an die Beobachtungen zu erinnern, welche

Kölliker an einer zu den Cycloneuren gehörigen Art, an Stomobrachium mirabile, über Vermehrung durch Theilung gemacht hat ${ }^{2}$ ). Es theilt sich diese Nleduse so, dass sich znerst der Magen spaltet. Man trifft daher im Uebrigen noch einfache Thiere mit zwei mehr oder weniger eingeschnürten und mit vollstündig getheilten, aber noch dicht beisammenstehenden Mägen. Daranf beginnt zwischen den beiden Mägen, jedoch äusserlich an der Scheibe, die Bildung einer Meridianfurche, die, tiefer und tiefer schreitend, die Qualle immer mehr senkrecht halbirt, bis endlich die zwei nenen 'Thiere nur noch durch eine schmale Brücke znsammenhalten, welche endlich anch noch sich theilt. In S-12 Stunden verlänft der ganze Process. Es können nun aber getheilte Medusen sich nochmals theilen. Die nene Theilungslinie steht zu der alten in rechtem Winkel. Dabei schnürt sich jedoch der Magen nicht immer vor der Scheibe ein. Ans den Grössen, in welchen in der Theilung begriffene Thiere rorkommen, lässt sich schliessen, dass die merkwürdige Vernehrung auch mit zweimaliger Theilnng noch nicht abgeschlossen ist.

Es ist sehr zu bedanern, dass Kölliker keinerlei Angaben darüber macht,

1) Häckel, Biolog. Studien I. Heft, 1870. S. 22.

2) C. Gegen baur, A. Kölliker u. H. Müller, Bericht über einige im Herbste 1852 in Messina angestellte vergleichend-anatomische Untersuchungeu. Zeitschr. f. w. Zool. 1V. Bd. 1853. rgl. S. 325. 
in welcher Beziehung die Theilungslinien zu den Randganglien standen, weil daran zu denken ist, dass es sich bei der Theilnng um eine Auflösung in die Antimere gehandelt bat.

\section{Hauptsächlichste Ergebnisse.}

Ans den mitgetheilten Untersuchungen geht hervor, dass das centrale Nervensystem der "Acraspedoten" seine Hanptansbildung in den acht Randlappen haben muss, ohne dass diese Centren durch einen im Schirmrande verlanfenden Nervenring untereinander verbunden wären. Ich bezeichnete die Acraspedoten aus diesem Grunde als toponeure Medusen.

Die .Craspedoten“ dagegen müssen ein centrales Nervensystem haben, welches deu ganzen Schirmrand einnimmt, jedoch so dass sich eine grössere Anzahl von Nervenzellen angehäuft findet in des, anch früher als "Ganglien" bezeichneten Anschwellungen des Schirmrandes, als zwischen denselben. Ich nannte die craspedoten Medusen desshalb cycloneure.

Das centrale Nervensystem der Toponeuren kamn nicht anf die Randlappen beschränkt sein, sondern es müssen sich Nervencentren auch sonst über den Schirm verbreitet, wenngleich in spärlicher Anzahl, finden. Dies wird bewiesen dadurch, dass durch Ausschneiden der Randcentren gelähmte Thiere sich wieder erholen können und zwar soweit, dass sie von Neuem rhythmische Contractionen ausführen und dadurch, dass selbst einzelne beliebig ans dem Schirme ausgeschnittene, eines Randcentrums entbehrende stücke, welche nach dem Ausschneiden stets durchans regungslos sind, sich einer solchen Erholung unter besonders günstigen Verhältnissen als tühig erweisen; endlich dadurch, dass eimzelne Medusen durch das Ansschneiden der Randcentren sogar nur in geringem Grade in ilner rhythmischen Contractionsthätigkeit gestört werden. Am Dentlichsten aber zeigt sich die Verbreitung ron Nervencentren über den ganzen Schirm in der Art und Weise, wie jene Erholung eingeleitet wird, indem dieselbe sichtbar von einzelnen lokalisirten Punkten ausgeht, welche nene Centren tür die Contractionsthätigkeit bilden: Ersatz-Contractionscentren ${ }^{1}$ ). Diese Thatsache erklärt es, dass sich zuweilen einzelne Theile eines

1) lch verweise in dieser Bexiehung nachträglich besonders noch auf Versuch A (XIII. Abschnitt, Seite 76 u. 77), wo sich am 5. Tage in zwei Lappenstïcken, welche Aftertheilen entsprachen, Ersatzcentren gebildet haben müssen. 
waren. Gä de findet, dass die lieproduktionskraft der Aurelia sehr gering sei. „Wenn ich“, sagt er, „einen Theil ihres Körpers abschnitt, so bemerkte ich anch nach langer Zeit nicht den geringsten Schein von Wiederherstellung des verlorenen Theils, sondern nur eine völlige Abrundung der Durchschnittsstelle, die wenig Stumden nach dem Abschneiden erfolgte. Das 'l'bier selbst schien indess, selbst wemn ich ihm viele und grosse Stücke raubte, ebenso munter zu sein, als es vor der Verstümmelung gewesen war. Zerschnitt ich eine Meduse in mehrere Stücke, so lebten diejenigen, an denen auch nur ein Magensack geblieben war, fort; diejenigen hingegen, bei denen das nicht der Fall war, führten höchstens ein zweitägiges Leben. Auch müssen die Gläser, in welchen man diese Thiere beobachtet, täglich mit frischem Meerwasser gefüllt werden; wird diese Emenerung des Wassers nur für einen Tag ausgesetzt, so sterben sie sehr bald." - Da bei Gäde die des Magensackes beraubten Thiere nicht länger als zwei T'age lebten, so muss er die von ihm zuletzt erwähnte Vorsichtsmassregel selbst sehr wenig sorgfältig gehandhabt haben. Auch

Eysenhardt erwähnt von Rhizostoma im Jahre 1821 die Thatsache, dass abgeschnittene Stücke des „Hntes“ noch nach mehreren Stunden „Klappenversuche“ machen $\left.{ }^{1}\right)$. Mnsste ihm dies von Macri her bekannt sein, so lässt anf eigene Beobachtungen die neue Nachricht schliessen, dass die Klappenversuche, „welche zwar zuletzt immer schwächer werden, sich ernenern, wenn man die Stricke stark berührt oder hineinsticht“" ${ }^{2}$ ).

Spallanzani veröffentlicht, wie es scheint ohne die Mittheilungen der bisher genannten Forscher zu kennen, wenige Jahre später Beobachtungen über die Bewegungen der Medusen nnd über das Fortleben von Theilstücken derselben ${ }^{3}$ ). Und zwar verfuhr er zuerst consequent experimentell, in der Absicht, den Sitz der Contractionsursache aufzufinden. Er beschreibt zunächst die Bewegungen der Medusen ${ }^{4}$ ). Dieselben geschehen, sagt er, durch abwechselnde Verengerung und Erweiterung des Schirmes in Folge des durch erstere bedingten Rückstosses des Wassers. Hören sie auf, so sinkt das Thier zu Boden, weil es specifisch schwerer ist als das Wasser des

1) a. a. O. S. 408 .

2) Claus sagt in seinem Lehrbuch der Zoologie (III. Anf, S. 241) bei Gelegenheit des Erwähnens einiger Ergebnisse meiner beziiglichen Untersuchungen über Aurelia: „Schon älteren Beobachtern (E y senhardt) war bekannt, dass der getrennte Schirmrand automatische Contractionen ausführt. Es ist wesentlich, ob Eysenhardt, wie aus den Worten von $\mathrm{Cl}$ a $\mathrm{n}$ s hervorgehen möchte, schon aufgefallen ist, dass der Schirmrand oder Theile desselluen losgelöst sich contrahiren, andere Theile nicht. Ans den oben eitirten Worten dieses Forschers, mit Ausnahme welcher ich bei ihm keine den Gegenstand betreffende Remerkung finde, geht jedoch solche Unterscheidung keineswegs hervor.

3) Lazzaro Spallanzani, Viaggi alle due Sicilie T. 1II. Milano 1826.

4) a. a. O. S. 15 . 
Meeres. Dies hatte übrigens schon mehr denn hundert Jahre früher R e a u m u r 1 ) behauptet, indem er in seiner Abhandlung über lie Ortsbewegung der Thiere sagt, dass die an's Land geworfenen todten Quallen untersinken, wenn man sie wieder in's Wasser wirft: sie seien schwerer als das Wasser und hielten sich während des Lebens darin durch die Bewegungen des Suhrmes").

Ganz im Gegensatze zu Spallanzani's denssermg hatte ich bei meinen ersten Lähmungsversuchen heobachtet, dass Aurelia nach der Lähmung an die OberHäche des Wassers mit ansgebreitetem Schirme enporgetragen wurde, während Cyanea sank ${ }^{3}$ ). Heine neueren Tersuche haben mir, wie auf Seite 26 gesagt ist, gezeigt, dass die gelähmte Anrelia bald sinkt, bald steigt; die gelähnute Cyanea mit Fangfäden sank, olne Fangtäden stieg sie in wiederholten Fällen. Ebenso können lebende Aurelien, wem sie ihre Bewegungen einstellen, mnter die Oberfläche des Wassers emporsteigen und anch bei anderen Nedusen ist dies zu beobachten. Ausgeschnittene Einzelantimere sinken ${ }^{4}$ ). - Ich werde an einem anderen Orte auf diese Verhältnisse näher eingehen und zugleich ïber die Locomotion von Beroë Nenes berichten.

Um den Sitz der Contractionsursache zu finden, schnitt Spallanzani zunächst ein kreisförmiges Stück, einen Zoll im Durchmesser haltend, aus dem oberen Theile einer IJednse ans. Dieses ausgeschnittene Stück contrahirte sich nicht mehr, auch nicht anf Reiz. Der ringförmige Rest des Thieres dagegen contrahirte sich noch. Der Ring wurde daranf dadurch verschmälert, dass eine imnere Zone von ihm weggeschnitten wurde. Anch diese letztere contrahirte sich, im Gegensatz zum ausseren Ringtheile nicht. „Con novelle recisioni venni in fine a scoprire la sede e l'origine dell oscillatione (so nennt er das abwechselnde sich Verengern und Erweitern des Schirmes) nelle meduse" - es ist offenbar das Muskelgewebe der Subnmbrella, von welchem die Contractionen ansgehen ${ }^{5}$ ).

Dieses Muskclgewelye beschreibt $\mathrm{S}$ pallanzani liurz vorher ${ }^{\circ}$ ), und wie er sagt, zuerst als solches. Schon I a eri leitete die Zusammenziehungen des Schirmes von den ,concentrischen Fibern" auf der unteren

1) Reanmur "Dn mouvement progressif et de quelques autres motrvemens de direrses especes de Coquillages, Orties et Etoiles de mer\%. Hist. de l'Acad. royale des sciences, Année 1710, S. 434 ff. Paris 1732.

2) a. a. 0. S. 484 .

3) Ueber kïnstliche Theilbarkeit etc. Würzb. Verb. a. a. 0. \$. 143 u. 160. Zoolog. Unters. S. 51 u, 63.

4) a. a. 0. S. 145 bezw. S. 58

5) Di sopra ho ragionato di tin tessuto sottilmente unsculoso, che dei lembi dell' ombrello s'inoltra per un dato spazio su l'interuo delle sue pareti. Espiato alla lente si trova composto di un immenso unmero di sottilissime fibre carnose trasversali, fra se parallele e sommamente aderenti alla sostanza gelatinosa dell' ombrello d'all agire di cotai fibre trasversali e dal loro rilassarsi dipende tutto il ginoco delle oscillazione. Ogni qualvolta dunque ellene si accorciano la porzione dell' ombrello alla quale sono attacate $\mathrm{i}$ stretta a restriguersi il che non puo accadere senza che il restante dell' ombrello vada sogetto a restignimento. Quindi si ha la sistole nella medusa.« a. a. 0. S. 17.

6) a. a. 0. S. 11 . 
Fliche der Medusen her, zugleich freilicb vom Ringkanal, während dagegen die Radiärkanaile die Erweiterungen besorgen sollten (Rhizostona) ${ }^{1}$ ). Allein andererseits spricht Macri dem von ilım behandelten Thiere ausdrüicklich alle Muskeln $a b^{2}$ ). Dagegen vermuthete Eysenhardt in jenen Streifen nicht nur die $\mathrm{U}_{1}-$ sache der Contractionsthätigkeit. sondern auch Muskelsubstanz: "die genannten Leisten oder erhalenen Ringe des Rhizostoma“, sagt er auf S. 390 seiner Abhandlung, "schienen mir immer eine Andeutung von Muskelwesen, und vielleicht sind sie es, mittelst deren das Thier die Bewegung des Klappens macht, die freilich wohl alleu Medusen eigen ist, ohne dass man desshalb dergleichen erhabene Streifung fünde."

Wenn auch Spallanzani vicht der Erste ist, der dis Muskelgewebe beschreibt, so hat er doch zuer'st mit Bestimmtheit der Subumbrella die Eigenschaft als Muskelsubstanz zugeschrieben und hat auch experimentell nachgewiesen, dass sic es sei, welche den Schirm contrahire. „Entfernt man, sigt er, irgend ein Stück vom Schirme, welches mit diesem Muskelgewebe nicht in Zusammenhang steht, so hört die Bewegung auf. Dagegen war es eigenthümlich anzusehen, wie der von der Meduse abgetrennte untere, mit Muskelbelag versehene Theil, welcher bei grossen Thieren mehr denn einen Zoll Breite hat, auf den Tisch gelegt bei jeder systole enger wurde“ ${ }^{3}$ ). Spallanzani meint mit dem Theil des Schirmes, den er als muskelfrei bezeichnet und der sich nach dem Ansschneiden nicht contrahirt, den oberen, geschlossenen Abschnitt desselben, mit dem sich contrahirenden Ring dagegen meint er offenbar bei allen seinen Versuchen die ganze Röhre, welche der, seiner Schilderung nach allein mit Inskelgewebe belegte untere Theil des Schirmes nach Entfernen des ersteren darstellt. Tten Mluskelbelag beschreibt er nämlich folgendermassen: „osservai ai lembi interni del medesimo (les Schirmes) un altra organizzata struttura, consistente in un sottilissimo tessuto musculoso, che dall' imo fondo ascende per lo spazio di mezzo pollice, ed anche d'un intiero pollice, secondo la grossezza delle meduse; e dove esiste cotal tessuto, la somma traspareuza dell' ombrello rimane alquanto oscurata" ${ }^{4}$. Auch da, wo der Forscher davon spricht, dass er den „Ring durch Abschneiden einer oberen Zone verktirzt habe, meint er mit dem letzteren, welcher sich nach dem Abschneiden nicht nehr contrahirte, noch einen muskellosen Abschnitt. Uass ein solches ringförmiges Stïck sich nur desshalb nicht contrahirt, weil es vom natürlichen schirmrande losgelöst ist, das war ilım entgangen. Auch seine weiteren Versnche führten ihn nicht darant. Er schnitt nämlich weiter-

1) Macria. a. O. S. 27.

2) Auch nach anderer Seite interessant ist eine bezägliche Aeusserung bei ihm (S. 48 u. 49): „Se vi e opera in natura, in cui maggiormente risplende l'ounipotenza, e la saviezza dell' Autor dell' Universo, e appunto la considerazione della struttura del nostro animale. Senza testa, senza occhi, senza cervello, privo di midollo spinale, e di nervi (se pur non voglia dirsi, che le strie del cappello, ed i canali (Radiürkanäle) siano destinati per questo uso), privo di muscoli, e di vasi grandi. senza bocca, senza cuore, e senz' altri organi, che si stinsan necessari alla vita: pure egli vive, sente, si muove, cresce, si nodrisce, si moltiplica ed esercita tutte le sue funzioni.«

3) a. a. $0 . \mathrm{S}, 17$.

4) a. a. O. S. 11 บ. 12 . 
hin den durch die beschriebene operation erhaltenen contractilen Ring quer durch in einzehne Stücke. Diese Stücke contrahirten sich weiter. Mit jeder Znsammenziehmo wurde jedes derselben kürzer und darauf wieder länger mol zugleich mit dem Längerwerden verdünnte es sich, wie ein Wurm sich mit dem híurzerwerden verdickt und umgekehrt. Hol Spallanzani mit feinsten Zängchen das Mnskelgewebe an einer Stelle ron der Gallertmasse des Schirmes (eines contractilen Ringes) weg, so hörte dort die Contraction anl. Ungelähr dasselbe erfolgte, wenn er nur die Mnskelfasem an mehreren Stellen entzweischnitt. Also ist, folgert er, der Sitz der Contractionsursache im Muskelgewebe zu suchen. Wie schon aus dem Iitgetheilten hervorgeht, beobachtete er aber ferner, dass Contraction anch an Medusen stattfindet, welche auf"s Trockene gebracht worden waren. Grössere Thiere zeigten daun noch nach 2t Stmuden Contractionen, trotzlem sie schon ein Drittel ihres Volumens verloren hatten. Nur wurden gegen den Ablanf dieser Zeit die Contractionen kur, langsam. unterbrochen. Und oft, wemn man glauben mochte, dass sie aufgehört hätten, erwachten sie wieder in Folge von Anstreifen (stropiccio) des Muskelgewebes oder auf Stechen in dasselbe. Aehnliches wmde an Theilstücken beobachtet. Diese Ansdaner der Contractionen an sterbenden Medusen und an abgeschnittenen Theilen derselben möchte, so führt Spallanzani fort, einen mnwiderleglichen Beweis dafür abgeben, dass dieselben nuabhängig rom Willen der Thiere seien, in gleicher Weise wie die Contractionen des Froschherzens, des Ilerzens einer Schildkröte oder einer Schlange, nachdem dasselbe rom Thierkörper losgelöst ist. Dennoch wagt er nicht dies bestimmt zu behaupten, weil er heobachtete, wie Medusen sich in die Tiefe des Meeres niederliessen, indem sie die Contractionen einstellten und so durch das eigene Gewicht niedersanken. Dort blieben sie eine viertel, eine halbe Stunde und länger, um nach Wiederhegimn der Contractionen wieder aufzusteigen. „La cessazione di questo moto", schliesst er, „e la repristinazione di esso nelle addotte circostanze non par che dipendano dall arbitrio delle mednse? Lascio tuttavia all illuminato Lettore il farne gindizio, a me bastando su tal proposito la schietta e fedele narrazioue dei fatti." Spallanzani schwankt somit, ob er die Contrationen der Medusen als willkürliche oder als unwillkürliche auffassen soll, ohne einen Versnch zn machen, dieselben bestimmt theils als mwillkürliche. theils als willkürliche zu denten, wemn er nicht ans politischen Gründen sein wahres Urtheil zurückhält. Für meine Anffassung ist es sehr bemerkenswerth, dass er überhaupt die Frage anfwirft.

Nettenheimer hat in der früher erwälnten Arbeit ${ }^{1}$ ), auf welche ich erst

1) Nettenheimer, Ueber die Gesichtsorgane des violetten Seesterns der Ostsee nebst Beobachtungen iiber die Ohrenqualle und Versuehen über die Motilität derselben. Areh. f. Anat. u. Physik 1862. 
kürzlich aufmerksam gemacht worden bin, einige bemerkenswerthe Beobachtungen über die Bewegungen von Aurelia anrita und anf dieschben bezügliche Versuche mitgetheilt. „01, die Zusammenziehungen des Schirmes für willsïrlich gehalten werden müssen“, sagt er, „darüber kann ich nach längerer Beobachtung nicht mehr im Zweifel sein. Ich halte sie für mehr willkürlich als die Athembewegungen des Menschen, insoferne es gestattet sein würde, einen höheren Grad von Abhüngigkeit von dem Willen in dem Unstande zu erkennen, dass die Quallen die Zusammenziehungen der Glocke viel länger unterbrechen können als der Mensch seine Athemberegnngen." Er habe wiederholt gesehen, dass Quallen sich stundenlang an den Wänden des Glases, in dem er sie hielt, festsaugten. Und eine andere Beobachtung, welche beweise, wie vollständig die Contractionen des Schirmes dem Willen unterworfen sind, sei die, dass sich gesunde, lebenskräftige Medusen luäufig ganz tlach machen und eine Zeitlang regungslos auf dem Rücken liegen bleiben. Auch die manchfachen Formen, welche sie den Schirm geben können, sprechen für diese Ansicht. Kileine Individuen klappen nicht selten ihre Glocke so zusammen, dass sie wie eine Muschel aussehen und umfassen dann etwas, z. B. den Stiel eines Tanges, anderer partieller und allgemeiner Zusammenfaltungen des Sehirmes nicht zn gedenken. „Sieht man dem Sehwimmen der Quallen längere Zeit zu, so wird man sich des Eindrucks nicht erwehren können, dass diese Bewegung eine willkürliche ist. Die Contractionen des Schirmes kömnen stärker mnd schwächer sein md dadurch die Geschwindigkeit der Lokomotion reguliren. In Gefässen, wo weder Wind noch Wellen einen Einfluss auf die Ortsbewegung der Quallen üben können, ist es nichts Seltenes, sie längere Zeit in einer und derselben Richtung schwimmen zu sehen, als wenn sie auf einen bestimmten Gegenstand lossteuerten." - Was über die Verengerung der Gefässe gesagt wird, ist schon früher erwähnt worden. - Schliesslich theilt der Verfasser „einige einfache Versuche" mit, „die in der Absicht angestellt worden sind, Fingerzeige zu erhalten, wo man eigentlich bei der Ohrenqualle die nervösen Centra, von denen die willkürlichen Bewegungen abhängig gedacht werden müssen, zı suchen hat." Da die bisherigen Versuche, auf anatomischem und histologischem Wege die Nervencentra zu entdecken nm zu unsicheren Resultaten gefüht haben, so scheint es wohl gerechtfertigt, der Lösung der Frage durch den Versuch den Weg zu bahnen. Metten heimer sehnitt einer $\left.1^{1}\right|_{2}$ Zoll im Durchmesser haltenden Meduse den Mund mit Armen und Magen ab. Die Contractionen verloren ihren rhythmischen Charakter, ergriffen blitzähnlich einzelne Stellen des Randes, gingen gleichsam ringförmig um den Rand herum. - Schnitt er clas ganze Centrum der Glocke, Eierstöcke, Magen und was dazı gehört heraus, so trat die geschilderte Erscheinung sehr dentlich auf. 
Das verwundete Thier zuckte übrigens noch Stunden lang. Mit grösseren Exemplaren gab der Versuch dasselbe Resultat, jedoch nicht so schlagencl. - Tiefe Einschnitte in den liand, die ihn in eine Anzahl Lappen theilten, hatten keinen Einfluss auf den Charakter und den Rhythmus der Bewegungen. Erst wenn gleichzeitig Magen und Eierstöcke entfernt wurden, nahmen die Contractionen den blitzähnlich zuckenden, nnregelmässigen Charakter an. Reizt man mit einer Nadel die Lippen des intakten Thieres, so erweitert sich der Mnnd und schickt sich zur Aufnahme der erwarteten Bente an. Der heransgesehnittene Magen aber zeigt sammt den Lippen und Armen sehr geringe Emptänglichkeit für mechanische Reize; jedenfalls ist diese Empfünglichkeit bei ihm viel geringer als bei abgeschnittenen Stäcken des Randes. Von selbst aber znckt das heransgeschnittene centrale stück gar nicht mehr. Der äusserste Rand der Glocke zeigt, soweit er lilatarbig ist und die Fühlfäden trägt, nach dem Abschneiden gar keine rhythmische Contraction mehr; allein die wurmtörmigen Zusammenziehungen der Fühlfäclen sind noch zu bemerken. Nm wenn ein Stückchen von der Scheibe mit entfernt ist, damem die rhythmischen Contractionen fort. Je kleiner die Meduse, desto lebhafter contrahiren sich die abgeschnittenen Stücke. Dieselben komnten unter Seewasser noch nach vielen Stunden in lebhafter Contraction beobachtet werden. Man darf sie aber nicht zu klein machen, sonst erlischt die Reizbarkeit sehr schnell. Mettenheimer schliesst: "Es scheinen nach diesen Versnchen im Randtheil des Uiscns Ganglien zu liegen, welche die Contractionen hervorruten; im mittleren Theil der scheibe müssen jedoch andere Nervencentra liegen, die diese bewegungen beherrschen, coordiniren, zu rhythmischen machen, einem Gamzen unterordnen. Meine Versuche, diese supponirten Ganglien zu finden, sind bis jetzt ganz missglückt."

Brïcke bemerkt gelegentlich der Beschreibung der Muskelelemente von Aurelia aurita ${ }^{1}$ ) er habe sowohl an ganzen als an zerschnittenen Exemplaren der Medusa anrita beobachtet, dass jede Contraction nach einem bestimmten 'Typus erfolgte, indem sie sich stets vom Centrum nach der Peripherie ausbreite. Desgleichen sehe man dentlich an der Bewegmng einzelner ansgeschnittener Stücke, dass dieselbe, wie dies auch schon die früheren Beobachter angegeben haben, nur von den Mnskelelementen ausgehe, die eigentliche Gallertscheibe aber sich dabei passiv verhalte. Der Thatsache, dass Theilstüclie des Thieres noch Contractionen ansführen, wircl also hier nur ganz kurz beilïutig Erwähnng gethan.

1) Brücke, Ceher die mikroskopischen Elemente, welche den schirmmuskel der Medusa aurita bilden. Sitzungsber. d. kais. Akad. d. W. math. natw. Classe. XLVIII. Bu. I. Abth. Wien 1863. S. 158. 
Häckel berichtet in seinen Studien über Moneren und andere Protisten " '), über Versuche künstlicher Theilbarkeit an cyclonemren Medusen und, was sehr bemerkenswerth ist, über beobachtete Reproduktion. Die anf Lanzarote angestellten Versnchen ergaben, dass die künstliche Theilbarkeit bei manchen Medusen, namentlich aus der Fannilie der Thammantiaden (Gegenbanr), einen erstannlichen Grad erreicht. „Bei mehreren Arten dieser Familie“, sagt Häekel, konnte ich den Medusenschirm in mehr als hundert Stücke zertheilen und ans jedem Stück, sobald es um einen Theil des Schirmrandes enthielt, erwuchs in wenigen (2-4) Tagen eine vollständige kleme Meduse. Selbst ein einziger losgelöster Randtentakel, an welchem die Basis, das ansitzende Stn̈ck des Schirmrandes, erhalten war, bildete in wenigen 'Tagen eine Mleduse. Noch üherraschender war mir das Resultat, das ich bei anderen Hydromednsen erhielt. Hier konnte ich den kngeligen nicht differenzirten Zellenhanfen (oder die wimpernde kugelige Larve), welche ans der Eifurchung hervorgegangen war, in mehrere Stücke zerschneiden und aus jedem Strick entwickelte sich eine selbständige Larve."

Schliesslich möchte es für die vorliegenden Fragen von Interesse sein, an die Beobachtungen zu eriunern, welche

Kölliker an einer zn den Cyclonenren gehörigen Art, an Stomobrachinm mirabile, über Vermehrung durch Theilung gemacht hat ${ }^{2}$ ). Es theilt sich diese Meduse so, dass sich znerst der Magen spaltet. Man trifft daher im Uebrigen noch einfache Thiere mit zwei mehr oder weniger eingeschnürten mond wit vollständig getheilten, aber noch dicht beisammenstehenden Mägen. Daranf beginnt zwischen den beiden Mägen, jedoch äusserlich an der Scheibe, die Bildmng einer Meridianfurche, die, tiefer und tiefer schreitend, die Qualle immer mehr senkrecht halbirt, bis endlich die zwei neven Thiere nur noch durch eine schmale Brücke zusammenhalten, welche endlich anch noch sich theilt. In S-12 Stunden verlänft der ganze Process. Es können nun aber getheilte Medusen sich nochmals theilen. Die nene Theilungslinie steht zn der alten in rechtem Winkel. Dabei schnürt sich jedoch der Magen nicht immer vor der Scheibe ein. Ans den Grössen, in welchen in der Theilung begriftene Thiere vorkommen, lässt sich schliessen, dass die merkwürdige Vermehrung anch mit zweimaliger Theilung noch nicht abgeschlossen ist.

Es ist sehr zu bedanern, dass Kölliker keinerlei Angaben darüber macht,

1) Häckel, Biolog. Studien I. Heft, 1870. S. 22.

2) C. Gegen baur, A. Kölliker u. H. Müller, Bericht über einige im Herbste 1852 in Messina angestellte vergleichend-anatomische Untersuchungen. Zeitschr. f. w. Zool. IV. Bd. 1853. vgl. S. 325. 
in welcher Beziehung die Theilungslinien zu den Randganglien standen, weil daran zu denken ist, dass es sich bei der Theilung um eine Anflösung in die Antimere gehandelt hat.

\section{Hauptsächlichste Ergebnisse.}

Aus den mitgetheilten Untersuchungen geht herror, dass das centrale Nervensystem der "Acraspedoten“ seine Hauptausbildung in den acht Randlappen haben muss, ohne dass diese Centren durch einen im Schirmrande verlaufenden Nervenring untereinander verbunden wären. Ich bezeichnete die Acraspedoten ans diesem Groude als toponeure Medusen.

Die „Craspedoten“ dagegen müssen ein centrales Nervensystem haben, welches den ganzen Schirmrand eimimmt, jedoch so dass sich eine grössere Anzahl von Nervenzellen angehäuft findet in den, anch früher als "Ganglien" bezeichneten Anschwelhungen des Schirmrandes, als zwischen denselben. Ich nannte die craspedoten Medusen desshalb cycloneure.

Jas centrale Nervensystem der Toponeuren kann nicht auf die Randlappen beschränlit sein, sonderu es müssen sich Nervencentren anch sonst über den Śchirm verbreitet. wenngleich in spärlicher Anzahl, finden. Dies wird bewiesen dadurch, dass durch Ausschneiden der Randcentren gelähmte Thiere sich wieder erholen kömnen und zwar soweit, dass sie von Nenem rhythmische Contractionen ansführen und dadurch, dass selbst einzelne beliebig ans dem schirme ausgeschnittene, eines Randcentrums entbehrende Stücke, welche nach dem Ausschneiden stets durchans regungslos sind, sich einer solchen Erholung unter besonders günstigen Verhältnissen als fähig erweisen; endlich dadurch, dass einzelne Medusen durch das Ansschneiden der Randcentren sogar nur in geringem Grade in ihrer rhythmischen Contractionsthätigkeit gestört werden. Am Dentlichsten aber zeigt sich die Verbreitung ron Nervencentren über den ganzen Schirm in der Art und Weise, wie jene Erholung eingeleitet wird, indem dieselbe sichtbar von einzehen lokalisirten Punkten ausgeht, welche nene Centren für die Contractionsthätigkeit bilden: Ersatz-Contractionscentren ${ }^{2}$ ). Diese Thatsache erklärt es, dass sich zuweilen einzelne Theile eines

1) lch verweise in dieser Beziehung vachträglich besonders noch auf Versuch A (XIII. Absehnitt, Seite 76 u. 77), wo sich am.5. Tage in zwei Lappeustiucken, welche Aftertheilen entsprachen, Ersatzcentren gebildet haben müssen. 
geknickten Thieres erholen können, während dasselbe im Uebrigen noch gelähmt ist. Ein sehr schönes Beispiel hiefür bietet der Versuch D. Seite S2, nuch welchem eine Aurelia sich am vierten Tage nur in einzelnen ihrer Lappen erholt hatte, wähend die übrigen Lappen und der centrale Theil noch gelähmt waren. Terfolgt man solche Erholung in ihrem Verlaufe, so bekommt man durchaus den Eindruck, dass sie geschehe durch allmäliges Ansammeln von centraler Nervenkruft, durch Stärkung des Vermögens centraler Zellen und durch allmälige Stärkung und Fixirung der von diesen ausgehenden Leitmng. Denn die ersten Anzeichen von Contructionen treten als lokale Zuckungen auf, welche schwach sind und unwirksam bleiben. Ungeregelt, uncoordinirt, olne bestimmtes Ziel und olune sichere Beziehung laufen sie zuweilen linienartig am Schirme, hänfig rings um denselben hin. Sichtbar stärkt und regelt sich mehr und mehr die centrale Kraft, bis sie sich in ansgiebigen rhythmischen Contractionen zu änssern vermag.

Aus der lethalen Wirkung, welche das Entfernen bezw. Fehlen der Randcentren doch schliesslich hat mond noch mehr ans der mverhältnissmässig bedentenden unmittelbaren Wirkıng, welche dieses Entfernen gegenüber dem Wegnehmen irgend eines anderen Theiles des Körper's ausübt, geht übrigens hervor, dass entweder unverhältnissmässig viel weniger Nervencentren in den übrigen Theilen tes Körper's vorhanden sind, als in den Randlappen, oder wenn sie in gleicher Anzahl hier und dort vorhanden sind, kann nur vielen der über den übrigen Körper verbreiteten zusam men dieselbe Kraft zukommen wie einer einzelnen der im liandlappen befindlichen. Ihre grösste Ansammlung muss liegen in denı Theile des Schirmrandes, welchem der Randliörper ansitzt. Wird dort nur ein Stückchen von wenigen Millimetern Breite an jeclem der acht Antimere ausgeschnitten, so erfolgt häutig schon lange andanernde Lähmnng. In vielen Fällen aber erträgt der Organismus diesen Eingriff ohne zu bedeutende Folgen, und die Nervencentren des übrigen sehirmtheiles führen die Aufgabe der rhythmischen Contractionsthätigkeit nach geringer störung weiter fort. Nun müssen zu den Randcentren noch Nervenzellen des übrigen Schirmes entfernt werden und um die gesuchte Wirkung zu erzielen, muss man jetzt grössere und grössere, oft umfangreiche Stïcke des Schirmes mit ausschneiden. — Lässt sich auch durch das physiologische Experiment nicht genau die Grenze nachweisen, in welcher jene berlentende Anlünfung von Nervenzellen anfhört, so zeigt dasselbe doch, dass sie auf einen kleinen Bezirk beschränkt sein muss ${ }^{2}$ ). Genaner als Ein-

1) Ich mache darauf aufmerksam, dass ich nur bei Aurelia und bei derselben in der histologisehen Struktur unmittelbar verwandten Medusen genaue Untersuchungen äber deu Erfolg des Ausschneidens verschieden grosser 
griffe mit dem Messer dentè̀ auf diesen Bezirk hin die Art des Absterbens der Aurelia aurita, indem nach Auflösung des ganzen Schirmes nnverhältnissmässig lange Zeit noch acht kleine Gewebsstückchen in Verbindung mit dem Randkörper am Leben bleiben, welche jene Tasche einschliessen, in der der Randkörper geborgen ist und deren änssere Fläche somit jenes Polster bildet, welches bei den meisten toponeuren Medusen den Randkörper deckt.

Es scheint nun Dem die Amnahme nicht zu wiedersprechen, dass die eigentlichen Nervencentren in den Randkörpern selbst gelegen seien und würde sich das Ueberleben jener Gewebsstückchen dadurch leicht erklären, dass es diesen C'entren am nächsten gelegen und dass es unter dem Einfluss derselben noch zuletzt fähig ist durch einen kleinen etwa an ihm befindlichen Muskelrest sich zu contrahiren und so für die Ernährmng, speciell für das Athembedürfniss des Nerrencentrums ebenso zu sorgen, wie es von diesem die Anregung zu seiner Thätigkeit erhält. Dass ein solches reciprokes Verhältniss in der. That besteht, abgesehen davon, dass auch sonst niedere Thiere, wie z. B. Beroë, in den Theilen znerst absterben, welche vom Hauptnervencentrum am meisten entfernt sind, ist unzweifelhaft, indessen nicht allein zwisehen Randkörper und jenem als contractile Zone bezeichneten Bezirk. sondern wesentlich zwischen den Nervenzellen dieses Bezirks selbst und seiner Muskulatur. Denn es zeigt sich, dass alleiniges Abschneiden der Randkörper von einer Heduse sehr häufig gar keine erheblichen Lähmungserscheinungen hervorruft, fast immer nur ganz kurz vorübergehende. In noch geringerem Grade stört das alleinige Entfernen der Otolithensäckchen. Demnach möchte angenommen werden können, dass die Nervenzellen des ganzen Randkörpers sammt jenen der contractilen Zone dem Haupttheile des Centralnervensystems entspreche. Dabei ist jedoch die naheliegende F'rage nicht erörtert, ob nicht die zeitweilige Wirkung, wetche das Entfernen der Randkörper anf die Contractionsfähigkeit haben kamn, einem einfachen „Nervenschlag“ (Nervenchoc) entspreche, jener vorübergehenden Lähmung, wie sie auch nach der Durchschneidung ron Nerven bei höheren Thieren vorkommt, dass also die Nervenzellen der Randkörper einfach als Sinnesganglienzellen aufzufassen seien. Wir werden später, nach Erörterung der anatomischen Verhältnisse, noch auf diese Frage zurückkommen. Einstweilen wurden die bezüglichen Erscheinungen so gedentet, dass den Randkörpern allerdings eine Rolle bei der Anregung der rhythmischen Contractionsthätigkeit zugeschrieben werden möchte, wenngleich eine untergeordnete. In der

Randstïcke gemacht babe. Die anatomischen Verbältnisse bei Cyanea lassen annehmen, dass dort eine riel weniger ausgesprochene Concentration der Nervencentren auch physiologisch sich ergeben werde. 
That tritt die Bedentung, welche ihnen in dieser Beziehung zukommen kann und ebenso diejenige, welche die Nervencentren der Umbrella nnter normalen Verhältnissen in gleicher Beziehung haben können, ganz nnverluältnissmässig in den Hintergrund gegenüber jener der Centren der contractilen Zonen, deren Gebiete als der wesentlichste Theil des Centralapparates antgefasst werden müssen. Allein ein streng lokalisirtes nnd körperlich nmschriebenes Nervensystem kinn somit nach den physiologischen Versuchen bei den toponeuren Medusen nicht vorhanden sein und es sind also bei ihnen in dieser Beziehung ganz dieselben Verhältnisse voranszusetzen, wie ich sie bei Beroë ovatus beschrieben habe.

Was das peripherische Nervensystem, speciell die leitendenden Elemente angeht, so ergibt sich gleichfalls ein Resultat, welches mit den von mir morphologisch bei Beroë nachgewiesenen Thatsachen vollkommen in Uebereinstimnung steht: es können bei den toponeuren Medusen keine Nervenstränge im sinne der „Nerven“ der höhern Thiere vorhanden sein, sondern es müssen Nervenfäden das Gallertgewebe nach den verschiedeusten Richtungen durchziehen, welche in hohem Grade befähigt sind, für einander zu vicariuren '). Die Beweise hiefür sind zu deutlich in dem Erfolg der angestellten Zerschmeidungsversuche ausgesprochen, als dass es nöthig wäre, auf dieselben noch näher einzugehen: die physiologische Verbindung der einzelnen Theile bleibt erhalten, so lange als dieselben nur duch eine schmale Gewebsbrücke mit einander verbunden sind, gleichviel in welchem Theile des Schimes man die Trennung vornimmt. Aber in der Gegend des Randes, speciell der Randlappen, brancht die Verbindungsbrücke nicht so gross zu sein als in jener der Kuppe und so muss dort die Verbindung dureh Nerven eine reichlichere sein als hier. Ebenso muss sie reichlicher sein in der Nähe der oralen Schirmoberfläche, als in der Nähe der aboralen. Der grösste Nervenreichthum nuss vorhanden seiu umittelbar minter der Muskelschichte, sofern man den Erfolg des Einschneidens in die Subumbrella auf' unter derselben gelegene Nerven ausschliesslich beziehen darf. Indessen ist eine Betheiligung der Muskelschichte an der Leitung nicht ansgeschlossen. Die Thatsache des Vicariirens von Nervenfäden wird bewiesen durch die Wiederherstellung der Leitung, nachden dieselbe — oft nur kurze Zeit - anfgehört hatte und darin ist

1) Ich habe auf seite 32 die Möglichkeit herïhrt, dass das Gallertgewebe als solches die Leitung besorgen könnte, habe aber im Weiteren - und schon in der Ueberschrift des betretfenden Abschnittes - diese Möglichkeit ausser Betracht gelassen, weil sie sich mit den physiologischen Thatsachen nicht vereinigen lïsst. wie ich denn schon nach meinen ersten Versuchen eine Verbindung der Theile des Nedusenkörpers durch Nervenfasern, welche für einander zu vicariiren im Stande seien, als thatsächlich angenommen hatte. (Ueber künstl. Theilbarkeit, Würzb. Verh. a. a. O. 154. Zoolog. Unters. S. 62.) 
eben zugleich ein Hauptbeweis dafür enthalten, dass die Verbindung durch Nervenfäden, nicht etwa durch das Gallertgewebe, vermittelt werde.

Die Beherrschung der Contractionen des Schirmes und damit die Beherrschung der Ortsveränderung und sämmtlicher vegetativer Thätigkeit geht wesentlich von den Nervencentren des Randes ans. Diese Centren müssen mit den zunächst gelegenen contractilen Elementen in ausgiebigster Verbindung stehen und dieselben unter normalen Verhältnissen vorzüglich zur Contraction md damit die Zusammenziehungen des ganzen Schirmes amregen. Wie weit ausserdem eine Verbindung der Rindcentren mit dem übrigen Theile der Umbrella-Muskulatur unter normalen Verhätnissen thätig ist, inwieweit die Fortpflanzung der Contractionen von den contractilen Zonen aus wesentlich durch die Muskulatur oder durch Nerven geschieht und welchen Antheil an der Anregung gewöhnlich die übrigen im Schirme zerstrenten Nervencentren an der Contractionsthätigkeit haben, lässt sich nicht bestimmen genug, dass die letztereu nach Entfernen der Hauptcentren deutlich wirksam auftreten.

Eine Thatsache von höchster Wichtigkeit für die Bedeutung der Randcentren, bezw. der contractilen Zonen, ist die, dass jedes derselben bei den normalen Bewegungen des Thieres die Amregung zur Contraction des Schirmes übernehmen, die übrigen zur Thatigkeit reranlassen kann. Da nur durch eine Regelung der Thätigkeit aller Centren die Ortsveränderung des ganzen Thieres bestimmt, ein rorgesetzter Zweck erreicht werden kann, so scheint es nöthig, dass eine gemeinsame Kraft die acht Centren wiederum zu dirigiren, sie zu coordiniren oder sich gegenseitig zu subordiniren im Stande sei, ohne dass bestimmte Anhaltspunkte für die Feststellung des Sitzes einer solchen Kraft zu geben wären, es sei denn, sie resultire aus der Gesammtheit der centralen Herde des ganzen Körpers. Dagegen ergibt sich die relativ hochgradige selbständigkeit der einzelnen Randnervencentren vorzüglich aus der Fähigkeit eines einzelnen derselben, für die übrigen zu vicariiren, nachdem liese entfernt sind und das Vermögen eines Strahlstückes des Thieres, ungestört fortzuleben, so lange es nur sein Randcentrum besitzt. Suriel scheint sich ans allen Beobachtungen und Versuchen zu ergeben, dass dieses Vermögen an sich wohl ein absolutes ist und dass es nur eingesehränkt wird durch die Schrierigkeit der Ernährung und überhaupt des Kampfes um's Dasein.

Sonach ist die Frage. in welcher Weise der Begriff Individum auf unsere Thiere anzuwenden sei, eine nicht kurz zu beantwortende. Dabei ist rorauszusetzen, dass dieser Begriff auf organische Körper angewendet, in morphologischem Sinne üherhaupt nur conventionell herechtigt ist. Wenn ich ihn etwa so definire: „ein 
organisches Individumm ist ein als solches entwickeltes Ganzes", so muss hervorgehoben werden, dass die Definition nur für einen gegebenen Augeublick gilt, indem das organische Wesen fortwährend durch den Stoffwechsel sich verändert, einnimmt und abgibt und weil es sogar die Anlage in sich hat, zum Zwecke der Vermehrung Theile von sich abzuschnüren, wemn nicht sich geradezu zu theilen und dass es dies oder jenes im Verlanfe seines Lebens auch wirklich thnt. Hievon abgesehen, in einem gegebenen Augenblicke also, ist die ganze Meduse in morphologischem Sinne ein Individumm. Sie ist es aber nicht in physiologischem Sinne: sie lässt sich theilen in die acht Strahlstücke, ohne dass diese, so isolirt, der Fähigkeit entbehrten selbständig zu leben und sie würde demmach als zusammengesetzt zu betrachten sein aus acht Individuen. Aber auch wieder das Strahlstück ist streng genommen keiu Individum: die contractile Zone scheint an sich ein lebensfähiges Ganzes zu sein, welches erst durch Zerstören des Nervencentrums raschem Untergang anheimgegeben sein wird. Es würde somit in letzter Linie jedes Stückchen Gewebes, welches ein Randcentrum und soviel hest der Organe des ganzen Thieres enthält, dass es selbständigen Lebens fähig ist, aber so wenig, dass ohne dieses Leben alsbald zu gefährden nichts mehr von ihm weggenommen werden darf, ein physiologisches Individum sein. Eine bestimmte Grenze hier zu ziehen ist aber nicht möglich und es schwindet uns bei unseren Thieren der Begriff des Individunms in diesem Sinne unter den Händen.

Nimmt man einem solchen physiologischen Individum das Nervencentrum, so ist es nicht todt, so wenig wie das durch Ausschneiden aller Randnervencentren gelähmte ganze Thier todt ist: beide sind zunächst nur willenlos, bewegungslos sie sterben erst ganz allmälig, in Folge mangelnder Athmung ab, nicht wie ein höheres Thier durch den Stich in eine bestimmte Stelle der Medulla oblongata plötzlich, sondern langsam, wie eine Pflanze stirbt, der man den Erdhoden entzogen hat. Dabei darf allerdings nicht aus dem Auge verloren werden, dass in letzter Linie die Ursache der Folgen ,des Knickens“ eines Wirbelthieres wohl ganz dieselbe ist wie diejenige der Lähmung, des „Knickens“, der Meduse und dass der Unterschied nu in der rascheren Wirkung des Eingriffes im ersteren Falle liegt: denn es ist wohl das durch den Stich beim Wirbelthier verursachte Aufhören des Stoffwechsels, welches von ihm keinen Angenblick ertragen werden kann und daher sofortigen T'od herbeiführt.

Aus der Bedeutung der Raudnervencentren fïr den Organismus unter Zugrundlegen der geltend gemachten Gesichtspunkte erklärt es sich denn anch, dass derselbeu beraubte Medusen nicht dauernd leben kömnen, an sich, nicht etwa aus Grün- 
den, welche im unmittelbaren Kampf um's Dasein zu suchen sind. Sei es auch, dass sie sich zu rhythmischer Contractionsthätigkeit wieder erholt haben: dieselbe wird anf die Daner nicht kraftig, nicht ansgiebig genug sein, um bleibend das Leben des Organismus zu stützen. 


\section{THEIL.}

\section{MORPHOLOGISCHE UNTERSUCHUNGEN.}




\section{Toponemre Medusen.}

Bevor ich zur Darstellung der eigenen Befunde übergehe, wird es meine Aufgabe sein, die Ansichten zu erwähnen, welche über ein Nervensystem der toponeuren Medusen lant geworden sind und ferner mit einigen Worten der von mir angewendeten Untersuchungsmethoden zu gedenken.

Literatur. Ehrenberg beschreibt bei Amrelia aurita ansgebildete Nervenmassen $\left.{ }^{1}\right)$. Unter jedem der "Augenstiele“ liegen nach ihm drüsige Knötchen, welche zur Pigmentstelle verlanfende Schenkel haben und welche seiner Meinung nach Nervensubstanz sein dürften. Die Abbildungen 2) zeigen, dass die "Knötchen“ dasselbe sind, was auch Claus jüngst für Ganglien erklärt hat - zwei blindsackartige Gruben der hinteren Abtheilung der Tasche, in welcher der Randkörper gelegen ist ${ }^{3}$ ). Indem diese Gruben durch die Körpersubstanz durchschimmern, mögen sie den Gedanken an Nervenknoten erregen. Eine genanere anatomische Untersuchung hat Ehrenberg nicht vorgenommen und so sind seine Angaben üherhaupt mehr aus historischen Rücksichten zu erwähnen. Die Nervenschenkel, welche von dem Nervenknötchen ansgehen sollen und die als Augennerven bezeichnet werden, können der Abbildung nach nichts Anderes sein, als die optischen Längsdurchschnitte der Wandungen der äusseren Epithelialhülle des Randkörpers. Ausserdem soll nach

- Ehrenberg längs des ganzen Scheibemrandes zwischen je zwei der feinen Fühlfäden ein bei auffallendem Lichte weisslicher, bei durchgehendem gelblicher, markiger, zweischenkliger Nervenknoten liegen, der mit seinen zwei Schenkeln zu zwei ver-

1) a. a. O. S. 203 .

2) a. a. O. Taf. IV. Fig. 1. r, q.

3) Von mir schon auf Seite 62 als sinnere Riechgruben«, im Folgenden auch als » Fiechkappen 
schiedenen Fühlfäden gehe. Endlich sollen in den Geschlechtshöhlen neben den Eierstöcken zunächst dem Schlunde vier Gruppen ron Markknötchen kranzartig gelegen sein und mit ebensoviel Gruppen von Fühlfäden in Beziehung stehen. - L. A gassiz, der einen oberen und einen unteren Nerveming, beide durch radiäre Nerrenfäden verbunden, bei den Cycloneuren gefunden zu haben glanbte, spricht bei seiner Darstellung wiederholt allgemein vom Nerrensystem der Mednsen überhanpt und ist demnach der Neinung, die dort von ihm erlangten Ergebnisse mmittellar anch auf die Toponemren ausdehnen zn dürfen ${ }^{1}$ ). - I I h selbst habe in der ersten Abhandlung, welche über meine physiologischen Versuche handelte, bemerkt: „die mitgetheilten Experimente möchten vermuthen lassen, dass die leitenden Nervenfäclen sich in acht Ganglien simmeln, welche die contractilen Zonen beherrschen, deren Znsammenziehnngen vorstehen. Ich habe körperliche Ganglien bis jetzt wenigstens nicht auffinden können. Dagegen treffe ich ungewöhnlich zahlreiche Nervenelemente (Fasern und Zellen) in der Umgebung der Randkörper, Elemente, welchen ohne Zweifel zum Theil die Aufgabe zufällt, die contractilen Zonen zu beherrschen, wăhrend sie zum anderen Theile zu den Randkörpern selbst treten." Anch in Beziehung anf das peripherische Nervensystem kam ich schon dort zu den im physiologischen Theile ausgesprochenen Schlüssen ${ }^{2}$ ). Damals in Aussicht gestellte weitere Resultate der Untersuchung sind im Auszug in meinem Münchener Vortrage enthalten. Inzwischen hatte Claus, zum Ergreifen des Themas offenbar reranlasst durch meine Vorarbeiten, welche genau zeigten, wo zu suchen sei, ein körperlich differenzirtes centrales Nerrensystem, die "Ganglien“, welche ich vermisste, bei Aurelia zu finden geglanbt. Dieselben sollen in der Zahl ron zweien an der Basis des Randkörpers liegen und werden ,als sensible Centren und als Ausgangspunkt für die spontanen Bewegungen des Schirmmuskels" anfgefasst. Er sagt wörtlich ${ }^{3}$ ), es "findet sich an der Basis des Randkörpers in der Augenbncht eine paarige, in Form zweier Zapten angeschwollene Verdickung des Ektoderms, die unterhalb des Epithels eine tiefere Schicht von Ganglienzellen und Nervenfibrillen einschliesst. Wie sich dieselben freilich in ihrem weiteren Verlaufe und in ihrer Beziehung zu dem erwähnten Sinnesorgane, eventuell zu der quergestreiften Muskulatnr verhalten, ist mir bislang nicht gelungen. röllig klar zu stellen." Es ist schon bemerkt worden, dass die vou Cla us erwăhnten und

1) Man vergleiche den Abschnitt über die Cycloneuren und: L. Agassiz son the Naked-eyed Medusae of the shores of Massachussets in their perfect state of Developmenta in: Memoirs of the American Academy of Arts and sciences, new series Vol. IV. part. II. p. 232 u. 233 (Cambridge and Boston, 1850).

2) = Ceber künstl. Theilbarkeit« etc., Würzb. Verh. a. a. O. S. 155. Zoolog. Unters. S. 68.

3) a. a. 0. s. 26. 
für Ganglien erklårten, als "Zapten“ beschriebenen Bildnngen nichts auderes sind als Gruben, zipfelartige, vom Ektoderm ausgekleidete Einbuchtungen der lïrpperoberfläche, welche wohl dem Geruchsinne dienen werden. Ferner spricht Cla us von einer tiefen Lage von Ganglienzellen und Nervenfibrillen, welche ,in dem verdickten und Wimpern tragenden Ektodermepithel des Randkörperstiels" (das Sinnesorgan, auf welches er hinweist), enthalten sei. Da er die so bemerkenswerthe Eigenschaft der Ganglienzellen, welche ich über den Randkörper verbreitet finde, nicht erwähnt, die nämlich, dass sie sich nur wenig von Bindegewebszellen unterscheiden und insbesondere weil er sagt, dass die Zellen in dem Epithel liegen, während die von mir gefundenen unter dem Epithel liegen, so bin ich nicht im Stande, die Clans'schen Angaben mit meinen Beobachtungen zu vereinen. Dass die Nervenfibrillen, wie ich fand, Fortsätze des Epithels seien, erwähnt Cla us gleichfalls mit keinem Wort und wenn er endlich sagt, dass er es nach an Chrysaora gemachten Beobachtungen für "sehr wahrscheinlich“ halte, dass noch eine Menge grösserer Ganglienzellen unter dem Epithel der Ringmuskulatur zerstrent liegen und als motorische, bezw. reflectorische Centren dieser Muskellage zu deuten sind, so muss ich dagegen bemerken, dass ich an keiner der von mir untersuchten toponeuren Medusen andere Nervenzellen als solche gefunden habe, welche sich durch ihre Kleinheit auszeichnen und welche morphologisch auch sonst auf einer sehr tiefen Stufe der Ausbildung stehen bleiben ${ }^{1}$ ). Die Claus'sche Schilderung einer Riechgrube (die von mir sogenannte änssere Riechgrube) stimmt dagegen mit meinen Beobachtungen überein.

Was im Uebrigen die Sinnesorgane der Toponeuren, die znerst von Eschscholz ${ }^{2}$ ) sogenannten Randkörper angeht, so haben dieselben früher sehr verschiedenartige Deutung erfahren. Der grösste Theil der bezïglichen älteren Literatur findet sich bei Ehrenberg ${ }^{3}$ ) and bei 0 ken ${ }^{4}$ ) verzeichnet. Schon Gade ${ }^{5}$ ) spricht sich in Beziehung anf Aurelia aurita gegen die Ansicht O. Fr. Müller's aus, dass die in den Randkörpern befindlichen kleinen, wie sie Gäde beschreibt. mehr oder weniger sechseckigen Kö̈rperchen Excremente (und zwar von Meeressant)

1) Es ist mir nicht möglich, eine andere Erklärung der Cla ıs'schen Angaben, insbesondere ïber den Bau der Randkörper, zu finden, als die, dass Claus zwar einige der von mir beschriebenen Dinge vor sich gehabt, aber zur Zeit als er darüber Mittheilung machte, noch nicht mit Musse untersucht hatte. Die wiederholten eilfertigen Veröffentlichungen, durch welche dieser Autor bevorstehenden Publikationen Anderer zuvorzukommen weiss, seheinen durch dip Gelegenheit veranlasst zu sein, neuere Entdeckungen in seinem Lehrbuch auf seinen Namen eintragen zu können.

2) Eschscholz, System der Akalephen, Berlin 1829.

3) Ehrenberg, a. a. O. S. 191.

4) $0 \mathrm{ken}$, a. a. 0 .

5) Gäde, a. a. O. S. 18. 
seien ${ }^{1}$ ), da ja diese Körperchen (die Krystalle) in einer feinen Hant eingeschlossen seien und also nur mittelst Zerreissung derselben fortgeschafft werden könnten. Anch habe er, ungeachtet er sich einer starken Lupe bediente, niemals die Bemerkung machen können, die Müller gemacht hat, dass nämlich diese kleinen Körper oft in's Wasser gestreut würden. Rosenthal²) hielt die liandkörper für Drüsen. Weil er die Krystalle in Schwefelsäure nicht anfzulösen vermochte, erklärte er sie gleichfalls für Sandkörner (abgelagerte Tiieselerde). Die Ansicht, dass unsere Organe Drüsen seien, ist bei 0 ken entweder einfach angenommen ${ }^{3}$ ) oder sie werden mit Drüsen verglichen ${ }^{4}$ ). Einmal aber wird zu der Vergleichung hinzugefügt: „Da es gerade ihrer 8 sind, sind sie vielleicht Ansïtze zu Rippen wie bei den Rippenquallen“5). Eschsehol\% fasste sie als der Leber entsprechende Organen auf. Tilesins ${ }^{6}$ ) erzählt, dass die Randbläschen Nachts leuchtendes Gas aushanchen: „Durch dieselbe allgemeine Respirations- oder Lebensbewegung des ganzen Körpers, deren Systole alle röhrigen Strahlund Cireularmuskeln gewaltsam zurückzieht, wird auch das Wasser aus den 8 Respirationsventrikehn wieder ausgespritzt, wodurch die Meduse ihren Fortstoss im Meere erhält oder sich von einer Stelle zur andern fortbewegt, und zugleich wird auch das lenchtende Gas aus dem zersetzten Meerwasser durch die S Bronchialröhren und Randbläschen ausgehaucht" (Cassiopea Andromeda). Erst Ehrenberg fand den an der aboralen ${ }^{7}$ ) Seite der Randkörper gelegenen Pigmentfleck und erklärte ihn für ein Ange. Die Krystalle, welche er zuerst als solche bezeichnet, vermochte auch er anfangs nicht in Schwefelsäure anfzulösen. „Bei Wiederholung des Versuches“, sagt er, „fiel mir ein, dass die organische Hölle, worin die kleinen Krystalle liegen, vielleicht die Einwirkung der Säure hindern möge und so zerdrückte ich denn erst die beutelchen mit einem Messer so, dass ich die Krystalle frei zn legen glaubte, was ich unter dem Mikroskope anch erreicht fand." Nun lösten sich dieselben auf Zusatz von Schwefelsänre auf ${ }^{8}$ ). Ehrenberg hält sie demnach „mit Wahrscheinlichkeit" für liohlensanren Kalk und glanbt in ihnen eine Kalkansanmlung sehen zu dürfen, wie sie ähnlich anch sonst bei Thieren in der Nähe der Nervensubstanz angehäuft vorkonme. Kölliker stimmte der Dentung des Pigment-

1) O. Er. Míller, Zoologia Danica 1779. Vol. 11. p. 111 und neue Ausgabe ron seinem Bruder besorgt, mit Tafeln. 1788. Vol. II. p. 51. (Medusa aurita.)

2) Rosentlıal, Beitrag zur Anatomie der Quallen. Zeitschr. f Physiol. v. Treviranus, 1825.

3) $0 \mathrm{ken}$, a. a. O. Seite 184 , wo von Quallen überhaupt die Rede ist.

4) ebenda, Seite 216 ( Hutquallen* üherhaupt) 235 (Aurelia aurita).

5) Tilesius, N. Acta L. C. XV. 1831.

6) Seite 216 .

7) Man vergleiche hinten das ïber die Pigmentflecke Mitgctbeilte.

8) Ehrenberg a. a. 0. S. 191. 
fleckes durch Ehrenberg bei, vermuthete aber weiter, dass die die Krystalle umschliessenden Bläschen Hörorgane sein möchten $\left.{ }^{1}\right)$. Gegenbanr ${ }^{2}$ ) macht gegen solche Dentung Bedenken geltend, insbesondere den Mangel von Hörhaaren und die beträchtlichen Schwankmingen in der Menge der unorganischen Einschlüsse und erklärt die Annahme, die clarauf zielt, die Randkörper als Excretionsorgane aufzufassen für nicht gerade verwerflich. Clark ${ }^{3}$ ) beschreibt das Krystallsäckehen genan als zusammengesetztes Auge: 1. A. erklärt er die Kirystalle für Linsen, das Plattenepithel für eine Cornea. (Aurelia flavidula, Cyanea arctica.) Auf die nähere Schilderung dieser lichtbrechenden Körper und ihre Beziehung zo den Zellen, in welche sie eingeschlossen sein sollen, gehe ich nicht ein, da Clark's Darstellung mit dem Thatsächlichen nichts gemein hat. Nur sei noch bemerkt, dass jede dieser Zellen ein vollständiges Ange für sich sein soll, mit vorderer und hinterer Angenkammer, beide mit humor aqueus und gesehieden durch eine undurehbohrte Membrana pupillaris.

Diese Clark'sche Untersuchung der Sinnesorgane der Toponeuren ist bis zu der Zeit, in welcher ich die nachfolgend geschilderten Ergebnisse über dieselben erlangte und bis ich sie in Auszuge veröffentlichte ${ }^{4}$ ), die einzige histologische gewesen, welche, von den Clans'schen Bemerkungen abgesehen, bekannt gegeben war, eine Thatsache, welche für die so verschiedenen Deutnngen dieser Organe eine hinreichende Erklärung abgibt. Die seitdem mitgetheilten Beobachtungen 0 . und $\mathrm{R}$. Hertwig's ${ }^{5}$ ) bestätigen meine Befunde über die Nervenepithelzellen der Randkörper, welehe sie aber fälschlich und sogar ausschliesslich für das centrale Nervensystem der 'Toponeuren halten, indem sie hier wie anch sonst in diesen Thieren Ganglienzellen vermisst zu haben scheinen.

Methoden der Untersuchnng. Nirgends im Thierreiche wird man verhältnissmåssig so wenig Entscheidendes durch die Untersuchung frischen Gewebes erreichen können, als bei den Quallen, fast weniger aber noch als bei den Rippenquallen bei den Medusen. Es versteht sich, dass man trotzdem immer wieder zur Vergleichung auf die Beobachtung olne Reagentien zurückzugreifen versuchen wird, allein bei gewissen Theilen, z. B. den Epithelzellen, sieht man sich zuletzt fast ansschliesslich auf conservirte Präparate angewiesen. Zur Untersuchung und Conservirung von Beroë hob

1) Kölliker, "Uober die Randkörper der Quallen, Polypen und Strahlthiere". Frorieps Notizen, 1843. S. $82 \mathrm{ff}$.

2) G eg e n ba u r, Bemerkungen übel die Randkörper der Nedusen. Müllers Arehiv 1856.

S. $41 \mathrm{ff}$.

3) In L. Agasiz, Contributions to the Natural History of the United States of Amerika. Vol. IV.

4) Vergleiche meinen Münchener Vortrag.

5 a. a. 0. 
ich vorzüglich das doppelt-chromsaure kali als geeignet hervor und ich gebrauchte dieses Salz mit demselben Tortheil bei den Medusen. Die Thiere werden in eine weingelbe Lösung desselben in Seewasser eingelegt, nach einiger Zeit heransgenommen, in destillirtem Wasser so lange ausgewaschen, bis sich dasselbe nicht mehr färbt, sodann werden sie in Carminlösung gebracht. Nachdem sie sich gleichmässig roth gefürbt haben, werden sie in Wasser vollständig wiederum ausgewaschen und daun in eine Mischung ron Glycerin und Wasser zu gleichen Theilen versetzt. Hier bleiben sie, je nach lem Gegenstand der Untersuchung, einige Tage bis Wochen oder länger liegen. Was nach der Färbung in Carmin zuerst undurchsichtige Gewebe - insbesondere das Epithelialgewebe, hellt sich durch die Einwirkung des Glycerins mehr und mehr anf und wird durehsichtig. Auf diese Weise war ich z. B. im Stande, die Ganglienzellen ron Carnarina hastata ${ }^{1}$ ) durch das Epithel hindurch in schöner rother Färbung deutlich zu machen und ebenso den Ringnerven ohne weitere Präparation zu sehen. Erst nach der Erhärtung in Chromkali lassen sich die Epithelzellen, z. B. der Randkörper der T'oponeuren, isoliren und in ihren Einzelheiten studiren. Die Nerrenfortsätze dieser und der Nervenepithelien der C'ycloneuren und die Nerrenfüden der letzteren werden dann varikös und lassen sich anf solche Weise sofort in ihrer Eigenscbatt erkennen und von Bindegewebs- oder Muskeltäden unterscheiden. Es bietet dieses Reagens dadurch einen grossen Tortheil dar ror der Anwendung der Osminmsäure in stärliren oder ganz schwachen Lösungen, welche letztere übrigens als lsolationsmittel gute Dienste leisten. Stärkere Osmiumsäure bindet in Gegentheil die Gerrebselemente, besonders die Epithelzellen und schwärzt diese zu sehr. Zu Durchschnitten durch das Gewebe eignet sie sich besser und habe ich sie abwechsehnd mit Chromkali zur Herstellung von solchen angewendet. - In doppelt-chromsanrem Kali eingelegt halten sich Quallen histologisch verwerthbar wohl nahezu ein Jahr lang. Damn aber wird das Gewebe brüchig und unhranchbar. Hat man dasselle dagegen früher in der beschriebenen Weise mit Carmin behandelt und in Glycerin und Wasser eingelegt, so lässt es sich viel länger erhalten. Meine eingelegten mikroskopischen Präparate haben sich Jahre lang conservirt, ohne spuren des Verderbens zu zeigen.

Ja wir, wie sich aus den physiologischen Untersuchungen ergil,t, den wesentlichsten Theil des Nervensystems in der Umgebung der Ranikörper und an diesen

1) Die Untersuchungsmethoden gelten sowohl für Cycloneure als auch für Toponeure. 
selbst suchen müssen, so beginne ich, nach voransgeschickter topographischer Orientirung, mit der Beschreibung der letzteren, um von da auf die contractilen Zonen überzugehen, welche uns von selbst anf den Ban des übrigen Schirmes, besonders der Subumbrella und des die aborale Fläche deckenden Epithels führen werden. - Um mnöthige Wiederholungen zu vermeiden, werde ich gewöbnlich Anrelia aurita und Cyanea capillata, als typische Repräsentanten bei der Beschreibung voranstellen und brauche im Uebrigen nur auf die Unterschiede anfmerksam zu machen, welche sich diesen gegenüber bei anderen von mir untersuchten Formen finden.

\section{Gröbere Bauverhältnisse der Randlappen.}

Der Schirmrand der Toponeuren ist bekanntlich nicht wie jener der Cycloneuren geschlossen, sondern vielmehr durch Einschnitte in Lappen abgetheilt, deren jeder einen Randkörper trägt. Da die Grundmembran des Randkörpers nichts Anderes ist als eine dünnhäntige Fortsetzung des Gallertgewebes der Umbrella, seine Höhle aber die blindsackartige Endigung je eines Gastrovaskulargefässes, wie dies zuerst Gegenbaur bei Pelagia nachgewiesen hat ${ }^{1}$ ), so müssen wir uns, um eine Grundlage für das Verständniss der Randkörper zu gewinnen, zmächst über die gröberen anatomischen Verhältnisse der Umgebming derselben d. i. eben der Randlappen, orientiren, Als Ansgangspment der Schilderung für dieselben nehme ich:

\section{Aurelia aurita.}

In der Richtnng von den acht Randkörpern zum Magensack verlanfen bei Aurelia aurita ebensoviele Radiärgefässe. Wir können dieselben als $\mathrm{H}$ a u p tradiürgefässe bezeichuen, im Gegensatze zu den acht in den Interradien gelegenen Gefässeu, welche von je einer Afteröffunng zum Magen ziehen, den Afterradiärgefässen. Die Hauptradiärgefïsse allein geben, wie Ehren berg richtig abgebildet hat ${ }^{2}$ ), schon im oberen Theile ihres Verlaufes starke Seitenäste ab. Diese Seitenäste spalten sich, indem sie, gleich den Haupt- md Afterradiärgefässen, gegen den Schirmrand hinziehen, mehr und mehr auf ihrem Wege in Zweige, welche schliesslich gleich jenen beiden und zwischen denselben in das Ringgefäss einmünden ( $Z$ wischen radiürgefässe). Betrachten wir nun die Beziehnng der

1) Gegen ba u r, Müllers Arebiv 1856.

2) a. a. O. Taf. 1. Fig. 1 und Taf. 3. Fig. 5. 


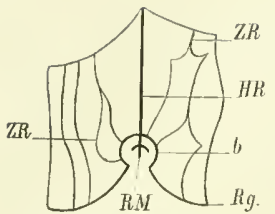

Holzschnitt 19.

Hauptradiärgefässe zum Ringgefäss genaner, so finden wir, dass jedes derselben (HR, Holzschnitt 19, H, Holzschnitt 20) in den obersten Theil der convexen Seite einer bogenförmigen Biegung (b) einmündet, welche das Ringgefüss (Rg) $1 \mathrm{~m}$ jeden Randkörper (RM) hermm beschreibt. In die Seitentheile des Bogens münden einige Zwischenradiärgefässe (ZR. Holzschnitt 19, Z Holzschnitt 20) ein, welche theilweise durch Anastomosen nntereinander in Verbindung stehen. Gegenüber der Einmündungsstelle des Hauptradiärgefässes in das Ringgefäss, also aus dem obersten Theile der Concavitat

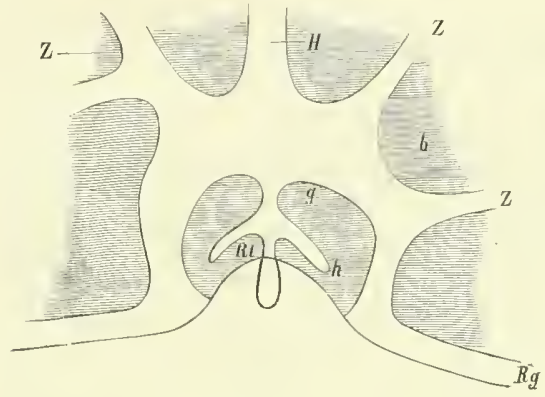

Holzsehnitt 20.

Orale Ansicht der unteren Flïche des Schirmes in der Randkörpergegend, bei einer Einstellung, welche am Deutlichsten die Gefässe zeigt.

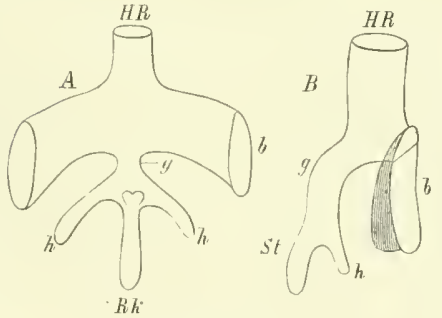

Holzschnitt 21. des an der betreffenden Stelle von diesem gebildeten Bogens, entspringt nnn, in der Richtung der Fortsetzmng des Hanptradiärgefïsses, aber erheblich enger als dieses, ein Gefäss, (Holzschnitt 21 A bei g) welches, wie die Seitenansicht lehrt (ebenda B bei g) im Bogen nach auswärts — vom Centrum des Schirmes aus gedacht - und damn nach abwärts länft, um sich darauf nach Art einer dreizinkigen Gabel in drei Zweige zu theilen, welche am Ende blind geschlossene Schlänche darstellen. Die seitlichen Zinken (h) der Gabel sind etwas kürzer als der mittlere (Rk, Holzschnitt 21 A, St ebenda B); sie biegen sich gegen ihr Ende etwas nach imnen, gegen die Höhle des Schirmes zu und verengern sich hier zngleich ein wenig, so dass sie bei der Ansicht von anssen - von der aboralen Fläche des Schirmes her - wie zwei nach abwärts gerjchtete Kuhhörner aussehen. Wir werden sie desshalb in Zukunft kurzweg als die „Hörner”, itus anderen Gründen anch als Hörgefä s se oder A mpullen bezeichnen ${ }^{1}$ ). Das mittlere oder liandkörperrohr, dessen Anfangstheil wir Randkörperstiel (Holzschnitt 22 St) nemnen, 
Wii $11 . .$. sein blindsackartig geschlossenes nuteres Ende das Kr., - .lsäckelen (Rk) herstellt, biegt sich numittelbar. nach einem Ursprung ans der Dreitheilnng, also an seiner Wur/l (W) nach anssen gegen die aborale Körperoberfläche hin un wieder zurtick und ferner macht es in seinem weiteren Verlauf eine, wenngleich schwache, Biegnng in entgegengesetzter lichtung mit dem Erfolg, dass sein unteres, blind geschlossenes Ende, das Kirystallsäckichen, etwas nach anf- nnd answärts (aboralwärts) sieht; indessen trifft man anch die umgekehrte Biegung oder gar keine.

Wie auf Querschnitten leicht zu sehen ist, sind die soeben beschriebenen Hörner in das Gallertgewebe des Körpers eingebettete, ron diesem rings umgebene Röhren. Der mittlere

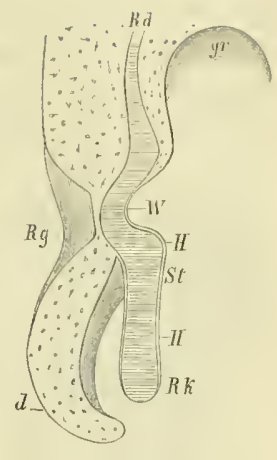

Holzschnitt 22.

Radialer Iängsdırchschnitt des Schirimrandes. der drei Zinken. das Randkörperrohr dagegen ragt, nachdem er lie beschriebene erste Biegung gemacht hat, frei über den Körperrand hervor, ist jedoeh in einer Tasche geborgen, welche, wie alsbald näher beschrieben werden soll, von der Wand des Schirmrandes gebildet wird (Holzschnitt 23 und 26 und Taf. $T$, Fig. 1). Das Rohr selbst wird zunäehst hergestellt von einer dünnen Hant von Gallertgewebe (Holzschnitt 22, vergl. anch die Tafeln), welche nichts anderes ist als eine unmittelbare Fortsetzung des Gallertgewebes der Umbrella: man wird sich die Verhältnisse richtig vorstellen, wenn man sich denkt, ein blindsackartiger Fortsatz des Radiärgefïsses habe dieses Gallertgewebe vor sich hergetrieben und zu einer dünnen Wand für sich ausgebanscht. Diese dinne Wand ist anssen überzogen von einer Fortsetzung des auch die übrige Körperobertläche bedeckenden, aber auf dem Randkörper zum Zweck der Simnesempfindnng modificirten Epithels; innen ist das Rohr, wie die Gastrovaskularräume überhanpt, ausgekleidet von Geisselzellen, die sich indessen vor den äbrigen Elementen des Entoderms dadurch anszeichnen, dass sie hoch eylindrisch sind; in seinem blindsackartig erweiterten Ende, dem Krystallsäckehen, abęr sind die Entodermzellen modificirt zu den otolithenführenden Zellen des Organs. Auf senkrechten Durchschnitten jener Gegend erkennt man noch weitere Eigenthümlichleiten des Raudkörperrohres: an seiner Wurzel (W Holzschnitt 22) ist lissslbe bedentend rerengert und kommt dadurch, dass es an dieser Stelle die erwähnte starke Biegung nach answärts macht, mit der änsseren Wand numittelbar nnter den Bollen einer dort in die Oberfläche des Schirmes eingedrückten Grube, der äusseren Riechgrube ( $\mathrm{Rg}$ ) zu liegen. Darauf erst tritt es, indem es zugleich sich erweitert, ringsum vollkommen frei ans dem Schirmrande herans, während die 
Wurzel wenigstens seitlich und, abgesehen von den Beziehungen zm Riechgrube, nich aussen noch von dicker Gallertmasse umgeben und nur hinten durch eine sehr dünne Gallertwand (W) begrenzt ist. Wie schou angedentet, liegt nun aber das handkörperrohr nicht unbedeckt da, sondern es liegt in einer Art Tasche. Der Rand-

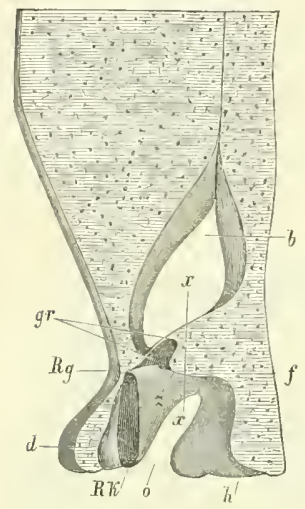

Holzsehnitt 23.

Radialer Durchschnitt des Schirmrandes nach einem Osmiumsäurepräparat: Rk Ranillörper; gr eine der zwei Riechkappen (innere Biechgruben); d Decklappen; Rg änssere Riechgrube; o Riechtasche; b durchschnittenes Gefäss; f Gallertgewebe; $h$ unterer. hinterer Rand der Riechtasche. Der Schnitt ist neben dem Randkörper vorbei seitlich ron dem auf 'Tafel V. Eig. 1, abgebildeten gefiurt. körper hat bekammtlich schon ladurch eine geschützte Lage, dass er in einem Ausschnitte des Schirmrandes geborgen ist (Holzschnitt 20). Indem nun je ein Fortsatz der Körperwand diesen Ausschnitt aussen und innen überdeckt, entsteht um ihn eine Art Tasche mit unterer Oeffnnng. Die änssere (aborale) Wand der Tasche liegt dem Randkörperrohr viel näher als die innere. Sie wird gebildet von einem ziemlich dicken, vorhangartig über letzteres herabfallenden Lappen (d, Holzschnitt 22. und 23, man vergleiche hiezu überall Tafel V, Fig. 1), der jederseits in einen mehr oder weniger langen Fortsatz ausgezogen ist, ähnlich einem Ohrlïppchen (Taf. I, Fig. 2, L), Theile, welche in Verbindung mit der Gestaltung der ganzen Randkörpergegend bei der Ansicht von aussen unserer Qualfe den Nameu gegeben haben mögen.

Die hintere Wand der Tasche liegt nicht wie die vordere dem Randkörperrohr nahe an, sondern es bleibt, rie Durchschnitte durch erhärtete Präparate zeigen. zwischen beiden ein ziemlich weiter Ranm (Holzschnitt 2:3, die hintere Wand ist mit h luezeichnet). Auch diese hintere Wand schliesst nicht vollständig ab, sie besteht, einem Fenster-

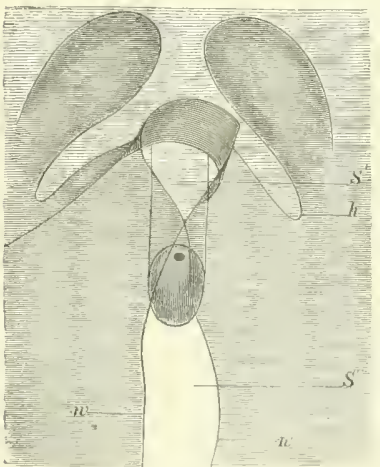

Holzsehnitt 24. vorhang ähnlich, aus zwei von der Seite hertretenden Lappen, welche sich je nach der Wirkung der Zusammenziehnugen des Schirmrandes in verschiedener Weise übereinanderschlagen oder von eimaniler zurückziehen, und dabei eine verschieden grosse Spalte zwischen sich lassen können, durch welche der Randkörper theilweise oder ganz frei nach innen durchblickt. (In Holzschnitt 24 und 26 bezeichnet w die Ränder der hinteren Wandtheile, $S^{\prime \prime}$ und $S^{\prime \prime}$ den dazwischen liegenden freien liaum: in Holzschnitt 25 bezeichnet sw die hier zurückgezogenen linteren Wände, die Linie Z aber entspricht z 
in Holzschnitt 23). Der Raum, welcher zwischen der hinteren Taschenwand und dem Randkörper übrig bleibt, ist unten offen (Holzschnitt 23, o), oben aber durch eine Wand geschlossen, welche im inneren 'Theile des Raumes zwar horizontal verläuft (bei f), nach aussen dagegen unmittelbar über der Wurzel des Randkörperstiels zwei Gruben von der Form phrygischer Mützen bildet, welche so nebeneinandergestellt sind, dass die Zipfel der Mützen nach hinten schanen. Ich bezeichne diese Gruben als "Riechkappen“ oder innere Riechgruben. Anf dem Längsdurchschnitt, welcher in Holzschnitt 22 dargestellt ist, sieht man von der Seite nur eine der Kiappen (bei gr); dagegen zeigt Holzschnitt 25 beide von hinten (oral) gesehen, bei einer Einstellung, deren Ebene der Linie xx Holzschnitt 23 entspricht. (Die Bogenlinie Z in Holzschnitt 25 entspricht, wie schon bemerkt, der Stelle $z$ in Holzschnitt 23.) In Holzschnitt 23 ist bei gr unmittelbar ausserhalb einer der Kappen durchgeschnitten und in Holzschnitt 21 A sieht man beide Kappen bei schwächerer Vergrösserung in der Flächenansicht von anssen durch die Wand des Randkörpergefässes durch-

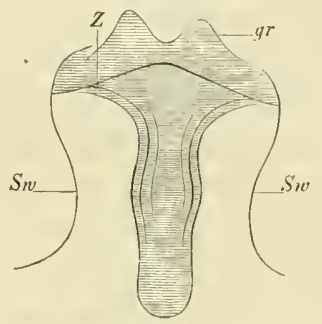

Holzschnitt 25.

schimmern, da wo dasselbe in die Hörner und das Randkörperrohr sich theilt ${ }^{1}$ ). Die Flächenansichten der Kappen, sei es die von aussen oder die von jnnen, sind es, welche vor bald 50 Jahren Ehrenberg und nenestens Claus zur Annahme von „Ganglien" verführt haben. In seiner Figm 1, Tafel IV und V bildet Ehrenberg die Kappen unter der Bezeichnung r ab und nennt sie "Nervenknötchen“ oder „Markknoten“. Claus bildet sie in Figur $40^{\prime}$ seiner IX. Tafel unter der Bezeichnung G ab als "Ganglien" ${ }^{2}$ ). Sehon die bildliche Darstellnng des Objekts an sich zeigt dies unzweifelhaft; wenn aber weitere Beweise für die Richtigkeit dieser meiner Behauptung nöthig wären, so würden sie in den Beziehungen der Psendoganglien von Claus zu deren Umgebung auf dessen Abbildung leicht zu liefern sein. Wie meine Holzschnitte 2.2 und 23 zeigen, liegen die Kappen etwas oberhalb und zugleich nach innen von der schon früher von mir erwähnten änsseren Riechgrube. In der Flächenansicht ergeben sich die Lagerungsverhältnisse ganz so, wie sie Claus in seiner Figur $40^{\prime}$ für seine Ganglien und die änssere Riechgrube darstellt. Ebeuso stimmen vollkommen die Lagerungsbeziehungen von Kappen, bezw.

1) Zum besseren Verständniss ist die Figur umrandet zu denken als ein Stück des Schimrandes, durch dessen Gallertgewebe die Kappen durch die Gefässe sichtbar sind.

2) Man rergleiche die Erklärung der Abbildungen bei $\mathrm{Cl}$ a us auf Seite 63 seiner Abhandlung. 
"Ganglien“, und den von mir sogenannten Hörnern (Hörgefässen oder Ampullen), welche Claus als Augenlappengefässe bezeichnet. Mein Holzschnitt 21 zeigt, wie früher bemerkt, dass die Kappen in der Höhe der Vereinigungsstelle der Hörner mit dem Randkörperrohr liegen (und zwar liegen sie hinter den Gefässen und schimmern bei der aboralen Flächenansicht durch dieselben hindurch) ebenso rerhalten sich die "Ganglien" und die Augenlappengefüsse von Claus in ihren Lagerverhältnissen.

Die Kappen, in welchen der Randkörper in der beschriebenen Weise liegt, sind nun mit Geisselzellen ausgekleidet. Diese Thatsache an sich und lie später näher zu berührenden Verhältnisse les Epithels veranlassen mich, lie Kappen für Sinnesorgane zu halten, und ich bezeichne laher die Tasche auch als lituch tasehe. die Kappen selhst als Riechkappen oder in nere Riechyruben. Tene andere Grube, die Einziehung der aboralen Schirmfläche, deren Grund gegenüber der Randkörperwurzel liegt' ${ }^{1}$, habe ich desshalb schon im Vorstehenden als ä ussere Riechgrube bezeichnet.

Um die Topographie der Randkörperumgebung zu vollenden, erübrigt mir nun noch, die Lage der änsseren Riechgrube in Beziehung auf ihre Umgebung in der aboralen Flächenansicht zn schildern. Betrachtet man in dieser Ansicht den Rand einer Aurelia in der Randkörpergegend, so zeigt sich zunächst der Ramulkörper nach aussen bedeckt durch eine beutel- oder ärmelpufferartige Erhebung der schirmoberfläche, sich ausnehmend wie ein kleines Säckchen, dessen Grenze nach oben ganz allmalig in letzterer vershwindet, während sie nach den Seiten mit scharter Linie

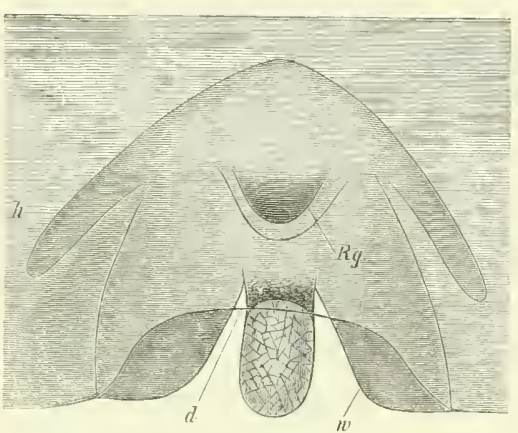

Holzschnitt 26 . wie eingeschnürt von derselben abgesetzt ist (Tafel I, Fig. 2). Der Beutel erscheint auf dem nnteren Theil seiner Uberflïche tief eingezogen. Die Wände der Einziehnng sind zuweilen so gefaltet wie die der Einziehungen eines Polsters. Die so beschaffene Grube ist die änssere líechgrube (Holzschnitt $26 \mathrm{Rg}$, Tafel 1, Fig. 2 und 10, Taf. I, Fig. 1 Rig). Der senkrechte Durchschnitt zeigt, dass der untere Theil des Säckchens gebildet wird durch den in Holzschnitt 22 und 23 dargestellten Lappen d, dass sein unterer liand

1) Holzschnitt 20 , Rg. 
somit ein freier ist. Dieser untere Theil des Süickchens entspricht somit der äusseren (aboralen) Wand der liandkörpertasche und überdeckt, bei der Ansicht von aussen, den Schirmandansschnitt, in welchem der Randkörper liegt, und welcher ringsum von dem Ringgefäss umgrenzt wird. (Fn Holzschnitt 2:3 bei b ist der Durehschnitt der Vereinigung von Ringgefäss und laandkörperohr (g Holzschnitt 21 ) zu sehen vergl. Erkläıung von Holzschnitt 23.)

Zur weiteren Erlänterung dieser Verbältnisse mögen noch einige Abhildungen dienen: Holzschnitt 26 stellt eine Ansicht der Randkörpergegend von der aboralen Schirmfläche dar, bei einer solehen Stellung des Schirmrandes, in welcher dessen Kante dem Beschaner etwas zugekehrt ist, so dass man in den unteren 'Theil der Randkörpertasche himeinblicken kann, zu welchem Zwecke zugleich die seitlichen Fortsatze der vorderen Taschenwand, die Ohrlappen, entfernt gedacht sind. Die Einstellung ist nicht ant die Oberflïche der aboralen schirmseite, sondern etwas tiefer genommen. Man sieht in die äussere Riechgrube (Rg) hinein und oberhalb mu zur Seite derselben sieht man die Hörner (h) durchschimmern. Ferner ist die vordere Taschenwand zu sehen (d) und ebenso die Ränder der beiden die hintere Taschenwand bildenden Vorbänge, welche einen Spalt zwischen sich lassen. Die säckchenartige Erhebung des die äussere Riechgrube tragenden Theils der Schirmaussenfläche tritt in der Zeichnung desshalb nicht hervor, weil ja die Einstelhung nicht auf die Oberfläche, sonder'n etwas tiefer genommen ist. Man sieht iudessen die Seitenränder des Sïckchens.

Erst die durch erhärtete Präparate nach verschiedenen. Richtungen geführten Durchschnitte klären die Bauverhältnisse der Randlappen in der geschilderten Weise aul und machen auch die Bilder verständlich, welche die aborale Flächenansicht am frischen Thiere darbietet. Fig. 2, Tafel I gibt diese Ansicht wieder. Znnächst fällt das Polster $(P)$ in die Angen und ist deutlich zu erkennen, wie es besonders nach rechts und links hin scharf ron der Ungebung abgesetzt ist. An diesen seitlichen Grenzen sind im Profil einzelne jener Häufchen Nesselzellen sichtbar, wie sie die ganze Oberfläche der Aurelia zerstreut bedecken. Diese Häufchen von Nesselzellen fehlen anf der Oberfläche des Polsters fast ganz - nur gegen die obere Grenze derselben hin, welche in schiefer Ebene ganz allmälig in die Umgebung übergeht, kommen sie vereinzelt vor. Der mittlere Theil des unteren liandes biegt in starker Wölbung nach innen (oralwärts) um, so dass er bei der gegebenen Ansicht als scharfe Querlinie (Q) erscheint; die Seitentheile. dagegen gehen in jene zwei zipfelartigen, über den schirmrand herabhängenden Lappen (L) n̈ber, welche schon als ,Ohrlappen" erwähnt sind. Bei hoher Einstellung, bei welcher die Ab- 
bildung aufgenommen ist, erkennt man den Eingang zur Riechgrube (lig): werhalb der Riechgrube sieht man die Hörner (H) hindurch, durch ihren Borlen n.. 1 unter ihr den Randkörper. Während der Contractionen zieht sich die Oeffnung der Riechgrube gewöhnlich etwas nach unten, schirmrandwärts und inden ihr Bołlen annähernd die frühere Lage beibehält, erscheint sie als ein nach unten geoffneter Trichter, durch dessen hintere Wand ein Theil des Randkörpers hell durchscheint ('laf. I, Figur 10 lig). - Bei tieferer Einstellung (Taf. I, Fig. 1) treten Hörner und Randkörper schärter hervor. Nan sieht den Ursprung der Hörner (H) aus dem von oben kommenden Radiärgefässe $(g)$ und an der Stelle, an welcher dieser Ursprung statt hat, sieht man zwei zipfelartige Bildungen (gr) hinter dem Gefäss durchscheinen, die Riechkappen. Der Randkörper selbst scheint nach oben abgerundet aufzuhören (Fig. 1 bei $x$ ): es berụt dieses Bild auf einer Täuschung, hervorgerufen durch die Biegung, welche der Randkürper an seiner Wurzel macht. Auf dem nach oben convexen Bogen, welcher auf diese Weise im optischen Durchschnitt entsteht, sieht man jederseits zwei Linien weglaufen (Taf. I Fig. 1, l), welche, je nachdem die Einstellnng eine etwas höhere oder tiefere ist, entweder nach unten in Bogen sich vereinigen oder aber durch den doppelt begrenzten Rand eines ovalen Loches verdeckt werden (Fig. 1, L). Es handelt sich in diesen Linien $n$ m die Grenzen des in jener Gegend auf kurzer strecke zureilen fast horizontal verlaufenden Randkörperrohres (Z, Fig. 4). Das Loch stellt den reinen Querschnitt dieses liohres dar (Fig. 1): durch dasselbe sieht man die Chyluskürperchen lebhaft in das Randkörperrohr herein- und wieder hinauswirbeln. Alle diese Verhältnisse, welche wesentlich dureh die Biegungen des Randkörperrohres complicirt sind, werden noch dentlicher in dem vertretenen Simne erklärt, wenn man die hintere (orale) Flächenansicht zu Hülfe nimmt: in ligur 9, Taf. I stellt o den oberen Theil des absteigenden Fandkörperrohres dar, hei L sieht man in die wagrecht gerichtete Abtheilung desselben von innen hinein. Fig. 6 gibt diesen Einblick in etwas rergrössertem Massstabe. Bei $\mathrm{r}$ sieht man einen Theil der Fläche der unteren Wand des wagrecht gestellten Rohres und diese Ansicht zeigt anch, dass die doppelt begrenzte Linie 1 nichts Anderes ist als der optische Querschnitt jener Wami. - In Fignr 3 ist eine orale Ansicht gegeben, in welcher das wagrecht gerichtete hohr sehr verkürzt erseheint, so dass die Höhle des Ramlkörpers unmittelbar in den haum übergeht, welcher durch den Zusammentritt der Hörner gebildet wird; gr dieser Figur ist ein Theil der Auskleidung der hinteren Riechgrube (vergleiche damit Holzschnitt 23 bei $\mathrm{gr}^{\mathrm{r}}$ ) in Fig. 1 ist die Ansicht so, dass diese Aukkleidung scharf im optischen Quersehnitte gesehen wird (gr), so dass statt der zwischen $\mathrm{x}$ und $\mathrm{x}^{1}$ gelegenen Flache 
der Figur 3 dort nur eine doppettbegrenzte linie zu bemerken ist. - In Fign 4 auf Tafel Il ist endlich ein Querdurchschnitt durch den Randlapren gezeichnet, welcher die Orientirung sehr erleichtert: D ist das Säckchen, die polsterartige Erhebung der Aussenflïche, Rg die äussere Riechgrube, O die Randkörpertasche, Rk der Randkörper, H sind die Durchschnitte der als Hörner bezeichneten (iefässe, b diejenigen der zwei schenkel des in jener Gegend bogenförmig über den Schirmrand sich erhebenden Ringgefässes (vergleiche Holzschnitt 20). —. Figur 6 derselben Tafel stellt einen ähnlichen Querdurchschnitt dar. (Man vergleiche dazu die Querdurehschnitte durch dieselbe Gegend von Rhizostoma und Cassiopea auf Tafel V1.)

Als eine Variation der beschriebenen Verhältnisse sei erwähnt, dass zuweilen statt eines einfachen Randkörpers Zwillingsranđäörper vorkommen: es laängen zwei derselben in der Weise zusammen, dass die liandkörperwurzel gemeinsam ist; dieselbe geht in zwei Randkörperohre aus, welehe in spitzem Winkel divergiren. Dass auch die 'Zahl der einzeln ansgebildeten Randkörper stark variirt, ist dnreh die Darstellung Ehrenberg's hinreichend bekannt. Sie kann dadurch vermehrt werden, dass zwei Randkörper an einem Antimer sitzen oder es sind mehr Antinere als die gewöhnlichen acht vorhanden und jeder Antimer hat seinen Randkörper. Damit kann dann anch die Zahl der Geschlechtsorgane vermehrt sein. Umgekehrt kommt eine Verminderung der Zahl der Antimere vor. Auf seiner Tafel II hat Ehrenberg solche Varietäten abgebildet: unter Anderem stellt dort Figur I ein Thier mit 6 Antimeren (Randkörpern) und 3 Geschlechtsorganen vor, Fig. 1] ein solehes mit 12 Antimeren und 6 Geschlechtsorganen u. s. w. Eine derartige Vermehrung oder Verminderung der Antimerenzahl muss selbstverständlich in Anstössen auf die Entwicklnng liegen, welche wir auch! nieht entfernt festzustellen im stande sind. Dem Verständniss einer einfachen Vermehrung, sowie der phylogenetisehen Entstehung der Randkörper an sich aber rüeken wir dadurch näher, dass wir sie morphologisch mit den Randtentakeln vergleichen. Diese Vergleichung ergibt nümlich die Thatsache, dass der Bau der Randkörper nur eine Modification desjenigen der. Tentakel darstellt. Ganz ebenso wie die ersteren, sind die letzteren röhrentörmige Ausstülpungen der Gastrovasknlargefïsse, speciell des lingkanals. Ganz ebenso wie das Randkörperrohr ist das Tentakelrohr gebildet ans einer Stützlanelle, welche eine Fortsetzung der Körpergallerte ist, ans einer Auskleidung von Entoderm und einer Umhüllıng von geisselnden Ektodermzellen. Es bedarf nur geringer Umänderungen, um aus einem Tentakel einen Randkörper zn bilden und es ist angenscheinlich, dass die letzteren mrsprünglich aus der einfacheren Anlage der ersteren hervorgegangen sind. 
Bekanntlich ist die Vertheilung der Gefässe bei Aurelia in früheren Stadien des Lebens eine viel einfachere als später. Es sind zmächst nur acht e in f a e he Radiärgefüsse vorhanden, welche an den bleibenden Znstand, z. B. bei Cyanea capillata in dieser Beziehung erinnern, indem hier acht taschenartige Ansbuchtungen der Magenhöhle zeitlebens bestehen. Erst während die junge Aureliạ im selbständigen Leben heranwächst, beginnen ihre Radiärgefässe sich zn verzweigen. Anch die Bildung der Randlappen der jungen, erst kürzlich abgelösten Aurelia erimert sehr an die bleibenden Verhältnisse der Cyanea. Lie 'Taschen, in welchen nach meiner Schilderung die Randkörper der ansgebildeten Amelia amita gelegen sind, ebenso die zwei zipfelartigen Ausbuchtungen der oberen Wand derselben, die Riechkappen. entstehen erst allmälig während des freien Lebens, an Thieren ron einigen Centimetern in Dnchmesser sind sie nur in der Anlage ansgebildet oder fehlen vollkommen. Ebenso entwickeln sich anch die Ohrlappen erst später.

Die wesentlichsten Banverhältnisse der Randkörper: und ihrer Umgebung verhalten sich ähnlich oder ebenso wie bei Aurelia auritit anch bei

\section{Rhizostoma Cuvieri, Pelagia noctiluea und Cassiopea borbonica.}

Ueberall stellt das Randkörperrohr eine Ansstülpung des Gastrovasknlarsystems dar, überall besteht es ans der Stützlamelle, der Ektodermumhüllung und der Entodermauskleidung und diese drei Lagen zeigen dieselben Beziehungen zu dem übrigen Körper hier wie dort. Die Entodermanskleidung ist überall cylindrisch und rerhält sich zn der Otolithenansammlnng in der bei Amelia geschilderten Weise. Ueberall ist eine äussere Riechgrube vorhanden, welche in ähnlichen Beziehungen zum Randkörperrohre steht und in derselben Art in eine polsterartige Erhebung anf dem Randlappen eingesenkt ist. wie ich das von Aurelia beschrieben habe. Ueberall ist der Randkürper son einer Deckplatte bedeckt und liegt in einer Tasche. welche hinter seiner Wurzel eine Grube bildet, die wohl als Riechorgan wirksam sein mag und die wenigstens bei Cassioprea in dieselben zwei Ausstülpungen, die Riechkappen. sich mach oben fortsetzt wie sie bei Amelia rorhanden sind. Stets zeigt das Rindkörperrohr mehr oder weniger schön geformte Biegungen md ist wenigstens bei Ihizostoma an der ron mir als Wrurzel bezeichneten Stelle rerengert wie bei Aurelia. Auf Tafel II und III habe ich einige Abbildungen von Flächenansichten und Dnrchschmitten der betreffenden 'T'heile von Rihizostoma Curieri und Pelagia noctiluea gegeben. Figm 3, Tafel II zeigt die Flächenansicht eines Ausschnittes des Schirmrandes von Rhizostoma mit dem Polster (x), welches wie bei Amelia nach unten in 
zwei Zipfel') ansgeht, die jedoch hier kürzer sind als dort. Man sieht auch hier die als Hörner bezeichneten Gefässausstülpungen (H), die sich ziemlich weit beiderseits vom Randkörper herabziehen, unter der Oberfläche durchschimmerw. Der Randkörper (Rk) ist bedeckt von der Deckplatte $d$, durch welche hindurch sein Pigment dentlich sichtbar ist. Die Deckplatte hat hier wie bei den übrigen genannten 'Toponeuren von aussen gesehen eine von rechts nach links gewölbte Oberfläche und stellt ein hohlziegelähnliches Schntzdach für den Randkörper dar. In Figur l und ? derselben Tafel sind senkrechte Durchschnitte durch Randkörper und Umgebung von Rhizostoma geführt. Man sieht deutlich den Uebergang des Stützblattes (3) in das Gallertgewebe der Umbrella, die Verengerung des Randkörperrohres an seiner Wurzel, die Deckplatte (D), die änssere Riechgrube (lig) und in Figur @ anch den hinter dem Randkörper gelegenen Theil der T'asche $\left(\mathrm{Rg}^{\prime}\right)$, in welchem derselbe geborgen ist. Das Randkörperrohr macht mit seinem geschlossenen Ende wie bei Aurelia anrita eine leichte Biegung nach aus- bezw. anfwärts, nachdem es unmittelbar vorher eine solche in entgegengesetzter Richtung ansgeführt hatte. Anf Tafel III sind Abbildungen des Randkörpers von Pelagia noctiluca gegeben. Die Gestalt des Randkörperrolnes schliesst sich hier insofern an die bei Cyanea capillata zn beschreibenden Einrichtungen an, als dasselbe von einem Gastrovaskularrohr abgeht, welches sich hinter ihm herab noch etwas verlängert (Fig. 1, 4 und S, y) und so zu ihm in demselben Verluältniss steht wie der Wassersack zur Tabakspfeife. Figur 1 und 4 zeigen die Ansicht von der Seite, Fig. ? von anssen (ahoral), Fig. S von innen (oral). Der Randkörper macht anch hier zuerst eine Biegung nach auswärts, hängt dann schief nach aus- und abwärts, und zuletzt ist das Hörsäckchen wiederum stärker nach auswärts gerichtet (Fig. 4). - In Figur l ist das Ektoderın weggenommen, die Stn̈tzlamelle liegt frei, in Figur 4 hängt $n$ m noch ein Fetzen desselben $(x)$ der Wand hinter ihm theilweise abgelöst an, in Figur \& aber (Ek) hat es sich in Folge der Präparation schalenartig halb abgehoben.

\section{Cyanea capillata.}

Die Banverhältnisse der Randlappen sind bei Cyanea capillata gegenüber jenen der bisher besprochenen Thiere so eigenthümliche, dass sie eine besondere Behandlung benöthigen, und dasselbe gilt anch für viele andere Organisationsverhältnisse. Cyanea scheint, wie schon angedentet, nach verschiedenen Richtungen

1) Der Buchstabe i bezeichnet den Zwischenraum zwischen beiden Zipfeln. 
hin, bleibend Zustände sich erhalten zu haben, welche für andere Formen im Laufe der Entwicklung vorübergehend geltend waren. Sie ist auf einer tieferen Stufe der Ansbildung stehen geblieben. Betrachtet man einen liandlappen von Cyanea capillata in der Flächeninsicht von aussen, so sieht man ihn durch einen tiefgehenden radiären Einschnitt in zwei Flügel getrennt, welche den zipfelartigen Fortsätzen des Polsters von Amelia und Rhizostoma entsprechen, aber viel länger und breiter als diese und unten breit abgeschnitten, nicht zugespitzt sind (Taf. 1, Fig. 5, L). Wie bei den letztgenannten Medusen liegt der Einschnitt in seinem unteren Theile frei, oben aber ist er von einem hohlziegelartigen Dächlein (d) überbrüekt, rrelches nur viel länger unt anch breiter ist als bei jenen. Indem sich die getrennten Lappen unter dem Däehlein nach aufwärts fortsetzen, bilden sie mit diesem eine Art Tasche, welche bei der oralen Ansicht durch sie wie durch die zwei Flägel einer Thäre geschlossen wird (Taf. T, Fig. 6 u, 7 F). Diese Flügel entsprechen den als rorhangartig bezeichneten Lappen, die die Hinterwand der Tasche bikden helfen, in welcher der liandkörper bei Aurelia liegt (Holzschnitt $2 t$ bei w). Bei Cyanea sind diese Bildungen im Gegensatz zu dort starr, sie können sich bei der Contraction nicht wie dort falten und in der Lage verschieben; daher hier der Vergleich mit Thürflügeln passend erscheint. Oben bildet die hintere Wand, ähnlich wie bei Aurelia, mit der vorderen eine geschlossene Tasche, welche wie dort in zwei fiechkappen (gr, Fig. 5, Taf. I) verlängert ist. Die ganze Tasche mag auch hier ein Riechorgan sein. In iln liegt der Randlörper, welcher durch die Gallertwand von aussen sichtbar ist. Er liegt unverhältnissmässig weit vom hande des Schirmes und auch vom freien liande des hohlziegelartigen Dïchleins entfernt (vergl. anch Tat. V. Fig. 6, 7 n. S). l)urch das Düchlein sieht man ein langes Röhrchen (R) durchschimmern, eine stielartige Fortsetzung des taschenartigen weiten Gastrovaskularraumes (fit), welcher einem Radiärgefässe entspricht. Jede der s Gistrovasknlartaschen erstreckt sich zur Seite des Randkörpers, die eine in der rechten, die andere in der linken Hälfte des liandlappens, in Gestalt eines Sackes nach abwärts. Die beiden Säcke (H) scheinen, wenigstens physiologisch, den bei Rhizostoma und Anrelia beschriebenen Hörnern - Hörgefässen zu entsprechen. Unten und an ihrem inneren Rande haben die Säcke fjordähnliche Einbuchtungen.

Das zwischen den Säcken nach abwärts gerichtete Röhrchen ( $\mathrm{R}$ ) liegt noch in der Gallertwand der Umbrella, je weiter nach unten um so mehr nahe der Oberfläche derselben (Taf. II, Fig. 7 li). Es endigt unten in eine Spitze (ebenda s), aber vorher geht von ihm nach aussen ein nach abwärts hängendes Bentelchen ab, der Raudkörper (kk). Dieses Beutelchen verhält sich zu der unteren stumpfen spitze 
des im Gallertgewebe verlaufenden Röhrchens und zu diesem selbst wiederum wie der in der Wassersackmündung umgedrehte Pfeifenkopf zum Wassersack, bezw. zum Pfeifenrohr. Es sind also in dieser Beziehung hier dieselben Verhältnisse vorhanden wie bei Pelagia noctiluca. Ein schlankes Raudkörperrohr wie bei den übrigen behandelten Toponeuren ist nun bei Cyanea capillata nicht ansgebildet. liandkörperrohx und krystallsäckchen bilden vielmehr zusammen ein kurzes, länglich ovales Beutelchen, welches sich durch ein ovales Loch (o) in das beschriebene Gefässiöhrchen öffnet und davon in spitzem Winkel nach anssen absteht. Lie Abbildungen (Taf. II, Fig. 7 und Holzschnitt 27) geben von dieser Eimrichtung einen deutlicheren Begriff als alle Beschreibung. Im Uebrigen verhalten sich die Wände des Randkörpers ganz ebenso wie bei den übrigen Arten. Eine polsterartige Erhebung der Aussenfläche der

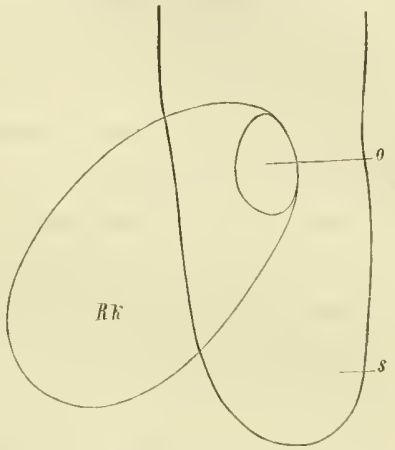

Holzschnitt 27.

Randlappen und eine die äussere Riechgrube darstellende Einziehung dieses Polsters ist bei Cyanea capillata nicht vorhanden. Allein die Mitte des Randlappens ist wenigstens bei älteren Thieren zn einer Furche eingezogen, welche etwas oberhalb des Randkörper's beginnt, diesen sammt einem 'Theil des zu ihm hintretenden Röhrchens deckt und sich bis zum Schirmrande hinzielıt, den Boden dieser Furche bildet sonach das geschilderte Dächlein. Die Furche nimmt in ihrem oberen Abschnitt die Stelle der äusseren Riechgrube der anderen Toponeuren ein und sie ist von demselben Sinnesepithel ausgekleidet, wie diese: sie wird somit gleich ihr als Riechorgan aufzufassen sein. (Vgl. Tafel V, Fig. 6 lig; die in Taf. I, Fig. 5 gegebene Ansicht ist bei tieferer Einstellung - bei Einstellung auf den Boden der Riechgrube, gezeichnet. Die hier in Betracht kommende Ansicht dagegen berücksichtigt die Oberfläche des Randlappens.)

\section{Feinerer Bau der Randkörper.}

\section{Aurelia aurita.}

Wir haben am Randkörper unterschieden einen oberen Theil, den Stiel und das untere blindsackartige Ende, den Krystallsack. Der Krystallsack findet seine Stütze in einer sehr dümmen Gallerthant, ist bedeckt von einem niedrigen Epithel 
und enthält die Otolithen. Zwar ist seine Wand nur eine Fortsetzung derjengen des stiels, aber die Gallerthaut des letzteren ist dicker und ist aussen und innen von cylindrischem teisselepithel belegt. Wir behandeln zuerst den kandkörperstiel, sodann den Krystallsack.

Der Randkörperstiel ist hohl. In seiner Höhle circuliren oder besser wirbehn, wie schon angedentet, die Chyluskörperchen; die das Rohr auskleidenden Geisselzellen treiben sie nach abwärts bis gegen die Otolithenansammhng hin nud von da wirbehn sie wieder zuräck. Die Wandung des handkörperstiels zeigt bei schwacher Vergrösserung vier Schichten:

1) eine innere, trübe (Taf. I Fig. I, 3, 4, 6, 7, S, 9 En):

2) daranf folgend eine glashell aussehende (ebenda bei $\mathbf{s}$ );

3) nach aussen von ler vorigen eine träbe, bei starker Vergrösserung feinkörnig aussehende (Fig. 1, 3, 7, $\mathrm{S}$ bei $\mathrm{N}$ );

4) zu äusserst eine radiär gestreifte. auf der ganzen Oberfläche flimmernde (Fig. 1, $3,4,6,7,5,9$ hei Ek).

Die erste dieser Schichten gehört dem die Gastrovaskularrămme auskleidenden Entodermepithel an. Die zweite ist, wie schon fräher bemerkt wurde, die Fortsetzung der Gallertwand der Umbrella, das stützblatt, wie ich sie nemnen will. Die dritte besteht ans einem Filz von Nervenfüserchen, welehe zngleich nichts anderes sind, als die Fortsätze der Zellen der vierten, äussersten Schichte. Diese ist die Ektodermzellenlage; ihre radiäre Streifnng rührt her von den Grenzen der webeneinander grelegenen Epithelzellen.

Auf dem Stützblatt unter der Nervenfilzschicht liegen Nervenzellen, welche anf dem Durchsehnitt als hesondere Lage nicht gesehen werden, sondern erst nach Abheben der letzteren vom ersteren zu erkemen sind. Wir besprechen zunächst

1) Die äusserste Schicht. Während die Elitodermzellen des grössten Theils der aboralen Schirmfläche von Anrelia durchans platt sind, ist die Elitodermschicht des Randkörperstiels ans hohen cylindrischen (teisselzellen und zwischen denselben gelagerten, eigenthümlichen, spindeltörmigen, an die Zapfen der Retina der höheren Thiere erinnernden klementen zusammengesetzt. Beide sind ansserordentlich klein und zart und sind zu ilnem genanen Studium die stäksten Tergrösserungen (ich benützte etwa 1000: 1, nämlich Immersion VIll von Seibert und Krafft nnd Oknlar 3 von Hartnack) und beste Belenchtung nothwendig.

a) Die Geisselzellen sind schmale hohe Cylinderzellen, welche sich (Taf. 1V, Fig. 2, 3, Fig. 4 d, Fig. 6 b, f, Fig. 7 a-d. Fig. 16) nach unten meist ganz allmälig in einen dünnen Faden versehmäthtigen. Ton diesem Fateu abgesehen, sind 
dieselben etwa 0,012 $\mathrm{mm}$ lang oder länger und an der 13 sis höchsteus $0,004 \mathrm{~mm}$ breit. Der Kiern liegt entweder in äusseren Drittel der Zelliörpers oder tief unten mnd treibt in letzterem Falle die an der betreffenden stell schon farlenartig gewordene Zelle spindelförmig auf. Andere Male eudigt der Zellkörper stmmp mit dem Kerne und geht nun plötzlich in den feinen Anslätfer über. Es sind dies wohl die Zellen, welche mit ihrem grössten Dickendurchmesser der Nervenfilzschicht unmittelbar nalie und tiefer als die Sehspindeln liegen (vergl. Fig. 2); sie keilen sich nach oben zwischen die letzteren und zwischen die übrigen Geisselzellen ein und müssen, wenn sie die Oberfläche des Epithels erreichen wollen, die Höhe der ganzen Ektodermzellenlage haben. Mas Protoplasma der Zellen ist feinkörnig. Nach oben tritt aus jerler der letzteren ein feiner Geisselfaden heraus, welcher bei Anwendung sehr starker Vergrösserungen zuweilen dentlich in die Zelle hinein zu verfolgen ist und zwar in gerader Linie bis zum Kerin hin verlaufend (Taf. IV Fig. 7, b, d, Fig. 16, a). Jede Geisselzelle geht also nach unterì in einen Faden über, welcher meist rarikös und von muendlicher Feinheit - Auslänfer erster Ordnung, wie ich ihn nemen will ist. Der Faden kann sehr langen mrerzweigten Verlanf nehmen oder er beginnt bald häıfig von einer protoplasmatischen Anschwellung oder von knöpfchenartiger Endigung aus ${ }^{1}$ ) sich dichotomisch zu verzweigen, in jener eigenthümlich starren, spitzwinkligen Art, wie ich sie von den Nervenfädchen ans den Gallertgewebe von Beroë beschrieben habe, in die Auslänfer zweiter Ordumng. Zuweilen entstehen zugleich miteinander mehrere solcher Fädchen aus dem. unteren Ende einer Geisselzelle, Iäufig ans dem Protoplasma, welches den weit nach abwärts gerückten Kern unmittelbar noch nach unten mmgibt. Liegt der Kern weit oben, so sieht man oft unterhalb desselben - im Zellkörper — ein Fädchen auftreten, welches dem in den oberen Theil der Zelle eingetretenen Gieisselfaden durchaus gleicht, anch in der direkten Fortsetzung desselben, nämlich senkrecht nach abwärts verläuft und welches in das variköse den Auslänfer der Zelle bildende Fädchen wiederum ummittelbar übergeht. Zuweilen hatte ich Bilder vor mir, welche ich dahin denten musste, dass der Geisselfaden durch die Axe der ganzen Zelle und des Kerms, das Kernkörperchen durchziehend, in den varikösen Anslänfer am unteren Ende direkt sich fortsetzt (Taf. IV Fig. 7 d). Indessen handelt es sich hier um Verhältuisse von äusserster Feinheit. Leichter ist der Geisselfaden einerseits und der variköse Faden anderer-

1) Es wird ausdrücklich hervorgehoben, dass die ganze Beschreibung nach Präparaten ge macht ist, welche mit doppeltchromsaurem Kali isolirt worden sind und nach solchen Präparaten sind auch die meisten Zeichnungen ausgefübrt. Am frischen Objekt ist die Isolirung einer intakten Zelle unmöglich. 
seits hãufig bis genan an den Kíeln hin zu verfolgen; ebenso sicher und scharf sieht man zuweilen das hernkörperchen von einem fadthen durchzogen, welches die Richtung beider genanten Fäden verbindet — aber im oberen und im unteren Grenzgebiete des Kierns wind die Fortsetzung des Füdchens meist undentlich ${ }^{1}$ ).

Der obere 'Theil der varikösen Anshäuler der zellen gehört noch der äussersten der vier aufgezihlten Schichten an. Ihr unterer Theil und alle ihre Verzwei-

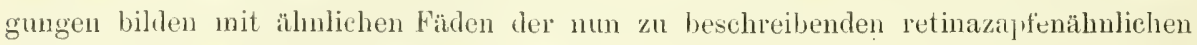
Elemente die zweite, die Nervenfilzschicht.

b) Die Sehspindeln. (Tat. IV, Fig. 1, 2, 3, Fig. 4, a-c, e, f, Fig. 7, e, f, ğ, Fig. 13, 18.) Mit diesem Namen bezeichne ich die spindelförmigen, retinazapfenähnlichen Bildungen, welche, wie früher bemerkt wurde, zwisehen den Geisselzellen des Randkör|erstiels gelegen siud. Es bestehen diese Elemente aus einem mittleren spincleltörmigen Körıer, aus einem starlen, stäbchenatigen 'Theil, in welchen sich dieser nach oben tortsetzt nud aus einem oder mehreren dichotomisch sich verzweigenden Fïdchen, in welche er nach unten übergeht. Der hörper misst in der Höhe etwa 0,01 mm, in der grössten Breite 0,003-0,004, das Stübchen ist gewöhulich nahezu so liug wie der Körper $(0,005$-0,009) und etwa zwischen 0,0005 und 0,0007 mm dick. (lsolirte Spindeln, sowie isolirte Geisselzellen massen, jene vom oberen Ende des Stäbchens, diese von der Basis, beide simmt varikösem fortsatz bis zum Beginn der Verzweigung desselben 0,02 bis $0.025 \mathrm{~mm}$.)

Der İ̈rper der Sehspindel hat, wie mir scheint nach dem Grade seiner Ausbilkung, ein verschiedenes Aussehen. Er sielıt zuweilen so aus als ob er ans feinkörnigem P'rotoplasma durehaus bestehe nnd ist ein Kern ohne Zuhülfenahme von Reagentien in ihm nieht wahrunehuen. In anderen Fällen ist das Protoplasma ebenso beschaffen, aber ein liern scheint hindurch und liegt meist im unteren oder anch im oberen 'Theil der spindel oder in der llitte. In Fällen, in welehen ich den Auschruck höherer Ansbildung selıen möchte, ist das körnige Protoplasma ganz oder theilweise geschwunden. In letzteren Falle umgibt es noch den im Grunde des Spindelkörpers gelegenen Kern, während der lianm über diesem homogen, körnchen-

1) Ich muss gestehen, dass mir sellyst ein Tehergehen der Fortsetzung des Geisselfadens in das Fadenuetz des Kerns und ein Wiederanstritt desselben am unteren Kernonde Anfangs wahrscheinlieher erschien als die beschriebene direkte Verbindung (man vergleiche die bezïglichen Aeusserungen in meinem Anfsatze: „IVeitere Naelirichten über den Bau des Zellkerns, nebst Bemerkungen über Wimperepithelien. Arehiv f. mikrosk. Auatomie XlV. Band). Allein immer und immer wieder drängten sich mir Bilder auf, welche die Existenz dieser direkten Verbindung bejahen liessen. Ausdriaklich ist allerdings zu bemerken, dass die besten Instrumente, die beste Beleuchtung und ebenso gute Geduld zur Beobaehtung nothwendig sind. Bezïglich des Eintretens des Geisselfadens in Sinneszellen vergleiche man auch die Hörzellen von Carmarina hastata (Tafel XlII). 
los ist (Fig. 6, d). Nach Isoliren in Jodsermm traf ich anch Spindeln wie deren eine in Fig. $6 \mathrm{~h}$ abgebildet ist: der Spindelkürper ist in einem oberen hellen, homogenen und in einem nnteren körnchenführenden Abschnitt durch eine horizontale Grenze geschieden; ob es sich hier nm normale Verhältnisse handelt, ist zweifelhaft. Hänfig füllt nun aber der Kerm den ganzen Spindelkörper ans oder es bleibt nur ein ganz. kleiner Raum über ihm (Fig. 1, a, 7, e und g). Auch der Kerm kann mehr und mehr homogen werden, so dass der Spindelkörper jetzt als ein durchans gleichförmiges Gebilde erscheint. - Nicht immer ist der Spindelkörper spindelförmig. Znweilen weist er Gestalten anf, wie sie in Fig. 1, e, 4, e, 15, b abgebildet sind, nnd zeigt schon dadureh deutlich, dass die Sehspindel überhant der Umwandlung einer gewöhnlichen cylindrischen Ektodermzelle ihren Ursprung verdankt. - Der Kern der Spindeln ist, gleich jenem der Geisselzellen, meist eiförınig. In den Stadien trüherer Ansbilang der Spindel ist er, wie aus dem Geschilderten schon hervorgeht, mehr körnig, später erscheint er mehr homogen. Ich möchte vermuthen, ‘lass das körnige Anssehen herrührt ron einem feinen Protoplasmanetz in seinem Innern, einem Netze, welches späterhin feiner wird, beim Untergang der Spindel vielleicht schwindet und so das mehr homogene Aussehen hervorruft. Für diese Auffassung spricht in meinen Augen schon die 'Thatsache, dass ich den Körnchenkreis in den Spindehn vielfach dentlich ansgeprägt gefunden habe, die Körnchen dureh Radiürfäden verbunden mit dem Kernkörperchen oder doch auf dasselbe zustrebend (Fig. 4, a). Andererseits sah ich hänfig genng, ganz so wie im Kern der Geisselzellen, einen Faden senkrecht den Kern durchziehen, das Kernkörperchen schneidend (Fig. 1, c, Fig. 6, d, Fig. 7, e, Fig. 1S), wie dort war aber die Fortsetzung desselben von der oberen und unteren Grenze des Kerns an, also innerhalb des letzteren meist verwischt, und trat erst ansserhalb dieser Grenze und zwar uben und unten wieder hervor, hier wie dort die Längsaxe des Spindelkörpers durchziehend and einerseits weiterhin die Axe des arsbald zи beschreibenden stabehens bildend, andererseits in den nach unten gerichteten Anslänfer der spindel äbergehend. In vielen Fälen - und vielleicht sind dies die späteren Stadien der Ausbiłlung der Spindel - scheint das Kiernkörperchen völlig geschwunden zn sein. In Fig. 7,g ist ein solcher Fall abgebildet. Der Spindelkörper ist feinkörnigg und scheint durehans nur ans dem Kém hervorgegangen zu sein. Im Centrum ist er vou oben nach unten - und dies sah ieh hier durchaus dentlich - von einem feineu Faden durchzogen. Diese Spindel und die in Figur 1, a gezeichnete möchten nach allen Beziehnngen dás normale, ausgebildete Objekt am besten wiedergeben, nur dass das feinkörnige Aussehen (das übrigens einem Chromkalipräparat sngehört) noch mehr zurücktreten, kann. Das 
Stäbchen der Spindel zeigt gleich dem Förper verschiedene Beschaffenheit, was hier ebenso wie dort anf verschiedene Grade der Ansbildung zu beziehen ist. Häufig besteht es ans dem rorhin erwähnten Centralfuden, erinnernd an den litter'schen Faden der. Wirbelthiersehstäbchen, und einem um denselben herum gelagerten feinkörnigen, äusserst zarten Protoplasmamantel, welcher von der Fortsetzung des Protoplasma des spindelkörpers gebildet wird. Znweilen sah ich (dies ïbrigens bei Rhizostoma Cuvieri) den Axenfaden in einen Geisselfaden sich fortsetzen. Wie weit diese Einrichtung verbreitet ist, kann ich nicht sagen, vielleicht dass sie die jugendlichste Bildung darstellt, vielleicht dass sie auch später noch angetrotfen werden mag, denn der Geisselfaden ist ausserordentlich fein und schwer zu sehen. In anderen Fällen ist von körnigem Protoplasma nichts mehr zu bemerken, der Axenfuden wird undentlich oder nnsichtbar und es besteht das stäbchen jetzt aus einem gleichartig, blass aussehenden, starren Faden, welcher sofort den Vergleich mit dem Anssenglied eines Retinaelementes bei höheren Thielen heransfordert. Diese Zusammenstellnng möchte noch um Tieles gerechtfertigter erscheinen durch andere 'Thatsachen, zunächst dmech die folgende: ich habe an solchen blassen, übrigens homogenen Stäbcheu der Aurelia aurita, allerdings nur mnter Anwendung der stärksten Vergrössermgen und unter Anfbietung aller Anfmerksamkeit an in Chromkali behandelten Präparaten deutlich eine Qnerstreifung beobachten können, welche an Verhältnisse erimnert, wie sie ron den Anssengliedern der Retinaelemente der höheren Thiere bekannt sind. (Fig. 1, a.) Ich sah diese Querstreifung deutlich nur in seltenen Fällen, aber ich war auch - abgesehen davon, dass sie an der Grenze des mit meinen Linsen Sichtbaren, steht - nicht in der Lage, auf diesen Punkt unter Anwendung verschiedener. Untersuchungsmethoden die Sorgfalt speciell zu verwenden, welcher er von physiologischem Gesichtspunkte aus würdig sein möchte.

Die nnteren Fortsätze des spindelkörpers. Esist der gewöhnlichere Fall, dass die untere Spitze des spindelkörpers sich zunächst in einen protoplasmatischen Faden fortsetzt, den Auslänfer erster Ordnung, in dessen Innerem zuweilen der Axenfaden noch zu erkennen ist oder in einem ummessbar feinen Faden, welcher mit dem Axenfaden identisch zu sein scheint. Der Protoplasmatortsatz rerdickt sich am Ende etwas, der feine Faden, wo er vorhanden ist, endigt in ein Knötchen augenscheinlich eine Varikositä — und ron diesem Knötchen oder von jener Verdickung, welche sogar eine mehr orler weniger sternförmige, grössere Protoplasmaansammlıng darstellen kann, treten nun spitzwinklig variköse und reichlich gabelig sich verzweigende Fortsätze ab, (Fig. 1, 6, 14) Anslänfer zweiter Ordnung - ein halbes Dutzend nud mehr derselben sah ich oft zugleich von dem Ende des Ans- 
läufers erster Ordnung abgehen. In anderen Fällen fehlen, wie bei den Geisselzellen, die letzteren und es entspringen jetzt die varikösen Füdehen unmittelbar vom Spindelliörper. Uebrigens kann anch der Ausläufer erster Ordnung ein variköser Faden sein. Es sind somit hierin dieselben Verhältnisse vorhanden wie bei den Geisselzellen, nur mit dem Unterschiede, dass die Auslänfer erster Ordnung bei den Spindeln viel kürzer, hänfig dicker und protoplasmaführend, desshalb seltener varikös sind, ferner aber, was noch ausdrücklich bemerkt werden muss, dadurch, dass ihre Terzweigung in Auslänfer zweiter Ordnung gewöhnlich eine viel reichlichere ist.

Lage - nnd Mengenverhältnisse zwischen sehspindeln n nd Ge is selzellen. Die Abbildungen (T'af. 1V, Fig. 2, 3, 13) zeigen am besten und machen weitere Beschreibung der Art und Weise äberfln̈ssig, wie die Spindeln auf Durchschnitten durch das Ektoderm, senkrecht zu dessen Fläche zwischen den Geisselzellen gelagert, sich darstellen, insoweit zmmächst gefragt wird nach der relativen Lagebeziehung der einzelnen Theile der Sehspindeln zu jenen der Geisselzellen bei gegebener Ansicht. Es sind demnach die grössten Querdurchmesser der Spindelkörper meist zu suchen etwa in der Mitte der Ektodermzellenlage, wenn man diese der Schicht des Nervenfilzes, d. i. der zweitänssersten, durch Verästelung der Ansläufer jener entstehenden Schichte des Randkörperrohres gegenüberstellt. Es füllen die Spindelkörper die Ränme ans, welche zwischen den nach unten, bezw. nach oben, sich verschmälernden Geisselzellen übrig bleiben. Die Spindelstäbchen schieben sich zwischen die Basalenden der letzteren ein. Zuweilen habe ich notirt, dass ilır oberster Theil über die Basis derselben etwas hervorragt. Bezügliche Präparate waren dem äusseren Pigmentfleck entnommen. Ob das Verhalten ein weiter verbreitetes oder wie es in den beobachteten Fällen zı denten sei, darüber zı urtheilen fehlen mir nähere Untersuchungen (vergl. Taf. 1V, Fig. 6, f). In der Flächenansicht des von seiner Unterlage losgelösten Epithels, bei Einstellung etra anf die Mitte des Höhendurchmessers der Epithellage, ergeben sich die Spindeln natürlich als kleinere oder grössere helle Kreise und fielen sie mir dann besonders nach Goldbehandlung schön in die Angen, wo sie wie runde Löcher sich ansnehmen. Anf solchen Flächenansichten bezw. anf optischen Querschnitten sieht man nun auch, dass gewöhnlich je ein Zapfen - eine Spindel - von einem Ring von Geisselzellen nmgeben ist, so dass er von diesen ringsum eingeschlossen erscheint. Und zwar fand ich dieses Verhälniss sowohl in dem alsbald zu behandelnden äussern Pigmentfleck als auch im oberen und im unteren Theil der Randkörperstiele. Dabei ist die Vertheilung der Zapfen eine ziemlich regelmässige. Ich fand indessen sowohl bei Aurelia wie bei Cyanea wiederholt eine Stelle am Randkörperstiele, welche lauter Spindeln aufzuweisen 
schien und bedame nur, genamere Angaben über die Lage derselben nochmaliger Untersuchung rorbehalten zu müssen.

Zusammenfassung. Die Geisselzellen und die Spindeln des Randkörperstiels haben somit das Gemeinsame, dass sie Epithelialbildungen sind, welche sich in Nervenfädchen fortsetzen. Das Nervenfädchen durchsetzt beide, um in den Geisselzellen in den Geisselfaden überzugehen, in den Spindeln aber einen Centralfaden in dem Stäbchen zu bilden, in welches der Spindelkörper sich nach oben rerlängert. Die spindeln sind umgewandelte Geisselzellen, deren Körper im rollendeten Zustande wesentlich aus dem mehr oder weniger homogen gewordenen Zellkern besteht, wïhrend das demselhen aufsitzende Stäbchen augenscheinhich aus dem Zellprotoplasma hervorgegangen ist; ursprünglich, gleich diesem, feinkörnig, erscbeint es später homogen, glashell, lässt den Centralfaden im Inneru erkennen und ist zureilen dentlich quergestreift.

Die Pigmentflecke. Ehrenberg beschrieb, wie schon erwähnt, bei Amrelia aurita zuerst einen Pigmentfleck und erklärte denselben als Auge. In Beziehung auf die Lage dieses Auges sagt er: "Ich bemerkte schon mit blossem Auge einen rothen Punkt auf der Oberseite der bramen Körperchen und mit der Lupe erkannte ich alsbald, dass dieser Pigmentpunkt auf der Unterseite fehle“ 1), und später: „acht schön rothe, augenartige Punkte stehen ... a auf sehr kleinen, dem blossen Ange brämlichen Körpern am fiande nnd die rothen Augeupunkte sind dem Rücken zugewendet“2). Ich finde nun aber zwei Pigmentflecke an jedem liandkörper, einen an der äusseren, aboralen und einen an der oralen Seite, da wo Ehrenberg nach seiner ausdrücklichen Bemerkung einen solchen vermisste und zwar hat dieser letztere auffallender Teise gewöhnlich die scharf umgrenzte münzenförmige Gestalt, in welcher Ehrenberg sein nach oben sehendes Auge abbildet, während der erstere vou weniger typischer Form ist. Dieser äussere Fleck ist es, welcher dem liandkörper das con Ehrenberg erwähnte brämuliche Aussehen rerleiht, er gehört dem Elitoderm an und ist durch die histologische Untersuchung als Augenfleck zu bestimmen. Der innere dagegen ist Bestandtheil des Eutoderms. Wemn ich trotzdem auch den letzteren hier abhandle, so geschieht dies aus praktischen, auf die Darstellung bezüglichen Gründen.

Der äussere Pigmentfleck (Tafel I, Fig. 1, 4, 7, S, 10 P) ist der bei weitem grössere. Betrachtet man den Randkörper direkt ron aussen, ron der aboralen

1) a. a. O. Seite 192.

2) Seite 207. 
Schirmfläche her (Fig. 1), so sieht man den untersten Abschnitt des Randkörperstiels und den obersten des Otolithensäckchens, soweit ihr Unfang zu übersehon ist, jigmentirt. lie Grenzen dies Pigmentflecks nach oben und nach mnten soheinen gewöhnlich auf den ersten Blick scharf zu sein. Die obere Grenze sah ich wiederholt in der Mitte nach Art des oberen Randes eines Wappenschildes in zwei mit der Concavität nach anfwärts gerichteten Bogen und mit mittlerer Spitze sich erhebeu, während die untere abgermotet endete. Aber Form und Grenzen variren sehr. Auch zeigt genanere Untersnchung, stärkere Vergrösserung, dass das Pigment in feiner Vertheilung sich noch über jene Marken nach auf- und nach abwäts erstreckt, um sich ganz allmälig zı verlieren. In der Seitenansicht des Randkörpers, bei hoher' Einstellung, sieht man den Pigmentfleck etwa anf die Hälfte des Umfangs der in dieser Ansicht sichtbaren Fläche des Hörsäckchens und des Randkörperstiels sich ansbreiten (Fig. S). Somit umfasst derselbe die llälfte res Umfangs beider von aussen nach den Seiten hin. Dabei erstreckt er sich etwa über ein Viertel oder n̈ber ein Fünftel der Höhe des Otolithensäckchens herab und über das untere Viertel des Randkörperstiels.

Der innere Pigmentfleck (Taf. I. Fig. 3, 4, 7, 9 bei p) ist kreisrund und liegt an der der Schirmhöhle zugekelurten Fläche des Randkörpers, in der Mittellinie dieser Fläche, am oberen Abschnitte des Otolithensäckchens, gewöhnlich um ein Geringes unterhalb der oberen Grenze desselben. Betrachtet man, um ihn zu sehen, den Randkörper von der oralen Schirmfläche aus, so sieht man den oberen Abschnitt des äusseren Pigmentflecks um ihn herum und nach anfwärts von ihm von der entgegengesetzten Wand her durchscheinen. Ich beobachtete zuweilen auch zwei innere Pigmentflecke, beide kreisrund und symmetrisch jederseits der Mittellinie der nach der Schimhöhle zu schanenden Obertäche des Otolithensäckchens gelegen.

Die listologische Untersuchung des äusseren Pigmentflecks ergibt, dass die cylindrischen Geisselzellen es sind, welche das Pigment in feinen Körnchen enthalten. Zwischen ihnen liegen als helle klare Körper die Sehspindeln (Tat. IV. Fig. 13, 14). Wie oben schon angedentet, erstreckt sich das Epithel in der vom Randkörperstiel beschriebenen Beschaffenheit noch über den oberen Theil desjenigen Bezirks, in welchem das Otolithensäckchen beginnt, über dieses hin. Man sieht im optischen Längsdurchschnitt, wie die drei änsseren Lagen der Wand des Randkörperstieles sich ganz alhmälig verdünnen, und so findet, was die Ektodernzellenlage angeht, ein allnäliger Uebergang der Geisselzellen in die das Otolithensäckchen auf dem grössten Theil seiner Oberflüche bedeckenden kurzen, fast platten Epithelien statt. Der äussere Pigmentfleck fällt noch in das Gebiet des cylindrischen 
Geisselepithels. Die Geisselzellen enthalten in ihrem Bereich das in feinsten und gröberen braunen Körnehen abgelagerte P'igment entweder nur in ihrem oberen Theile oder so, dass der ganze Zellkörper damit ertïllt ist. Anch in jenem Falle liegen die Kö̈nchen sehr dicht, soweit die sie führenden Zellen dem dunkeln Abschnitte des Pigmentfleckes entnommen sint. Untersucht man dagegen die verblassende Zone ansserhalb desselben, so trifft man nur einige oder öfters nur ein einziges Pigmentkörnchen in einer Geisselzelle. Die Spindeln liegen, wie sehon bemerkt worden ist, so zwischen den pigmentirten Geisselzellen, dass jete derselben von letzteren ringsmm völlig umgeben ist.

Der innere P'igmentfleck liegt also, anffallender Weise, im Entoderm (Taf. I, Fig. 4, 7, 1). Man überzengt sich hievon sehr leicht bei Betrachtung des Rimdkörper's ron der Seite. Vollkommen isolirt habe ich die Entodermzellen, in welehen das Pigment liegt, nicht, allein durch leichten Druck anf das frische Präparat verursachte ich ein Anseinanderweichen der Pigmentzellen und erkannte dabei, dass diese von grösserem Breitendurchnesser seieu als die Pigmentzellen des Ektoderms. Von der Basalflïche ans gesehen bieten sie dem Besehaner verhältnissmässig grosse Polygone dar. Das P'igment ist in ihnen in gröberen 'Theilchen enthalten, macht weniger den Eindruck ron Köruern, als den einer diffns in ölartigen 'Tropłen enthaltenen Hasse. Einen Unterschied in der Farbe zwischen äusserem und innerem Pigmentfleck habe ich nicht feststellen können - in beiden ist dieselbe brannroth bis bramgelb in feinerer Vertheilung und bei starker Vergrösserung, dunkelbram, wenn man die ganze Masse ror sich hat, beides bei durthfallendem Licht. Bei auffallendem Lieht ist dieselbe in Ehrenbergs Abbildungen I, II und V. Tatel V, schön roth gegeben.

2) Die Nervenfizschicht (Taf. 1V, Fig. 2, 15 n) wird zusammengesetzt 1) aus den dichotomischen Verästelnngen der Ausläufer der Geisselzelien und Sehspindeln, also ans Anslüufern zweiter Ordnung nud 2) ron den Geisselzellen angehörenden Ausläufern erster Ordnung. Alle diese Ansliufer dokunentiren durch ihre Feinheit, durch ihre variköse Beschaffenheit und endich dureh die Art ihrer Verzweignng unzweifelhaft den Charakter von Nervenelementen. Nan kann jedoch diese Eigenschaften nur nich lsoliren der Zelle erkemnen. Betrachtet man die Nervenfilzschicht im Zusammenhang, selbst mit sehr starken Vergrösserungen, so macht sie gewöhnlich nicht ten Eindruck eines Filzes feiner Fädchen, sieht viehnehr, wie schon früher bemerkt worden ist, aus wie eine ans feinsten Köruchen zusammengesetzte Punktsubstanz. Nur da nnd dort sieht man dann bei genauer Beobachtung in ihr nicht nur dentlich manchfach sich durchkreuzende Fädchen, sondern es treten noch viel 
dentlicher Fadenzüge anf, welche die scheinbare Punktsubstanz theils in der Richtımg von aussen mach innen, theils parallel der oberfliche des liandkörjers durchziehen, anf welchem Zuge sie znweilen auf weite Strecken hin zu verfolgen sind, ohne dass Veræweigungen an ihnen wahrunehmen wären. Jene sind unzweifelhaft die unmittelbaren Ausläufer der Geisselzellen. Die Verbindung her mit der Fläche parallel gerichteten Fäden mit Geisselzellen lässt sich zwar nicht direkt sehen, allein man wird an der Existenz derselben nicht zweifeln dürfen. Es landelt sich in ihnen wohl meist um Fasern, welche ihren Weg nach aulwärts, gegen die Randkörperwurzel hin nehmen, um weiter oben nit Ganglienzellen in Verbindung zu treten oder auch um solche, welche nach demselben Ziele in umgekehrter Richtung streben.

3) Die Schicht der Ganglienzellen. Nachdem man das Epithel sammt dem Nervenfilz von der Gallerthaut des Randkörperstiels sorgfältig da oder dort entfernt hat, kommt man zur Ansicht einer Lage von Formbestandtheilen, welche bei Betrachtung des liandkörpers als Ganzes nicht zn sehen war: es liegen unter dem Nervenfilz und anf dem stützblatte desselben zahlreich zerstreut Nervenzellen (Taf. IV, Fig. $15,17,20,24,25)$. Diese Nervenzellen zeigen allerdings keineswegs die ansgeprägte Differenzirnng, welche wir an solchen bei den höheren Thieren zu sehen gewohnt sind. Sie unterscheiden sich nur durch wenige, aber charakteristische Merkmale von den gewöhnlichen "Bindegewebszelten" des Gallertgewebes. Das Hanptunterseheidungsmerkmal ist, dass sie a uf Einwirkung von lieagentien nicht wie letztere ihre Fortsätze einzieheu und kugelige Gestalt annehmen, dass sie diese Fortsäte vielmehr ausgestreckt und überhaupt i re verzweigte Gestalt beibehalten. Diese Gestalt hat ferner das Charakteristische, dass sie in weitaus den meisten Fällen nicht rein sternförmig, sondern dass sie mehr langgestreckt ist. Die Fortsätze erweisen ihre Zngehörigkeit zum Nervensystem dadurch, disss sie hänfig - wenn anch nicht immer - Varikosităten zeigen. Auch verzweigen sie sich häufig nach Art der Fäden der Nervenfilzschicht dichotomisch und verbinden die einzelnen Nervenzellen untereinander. Sorgfältigen Bemühnngen gelingt es aber anch zureilen, eine Verbindung dieser Ansläufer mit Nervenfädchen der Ejithelschicht nachzuweisen. Solcher Nachweis ist jedoch desshalb sehr schwer und nur nach vielen vergeblichen darauf gerithteten Versuchen da oder dort zn liefern, weil die Epithelschieht in Zusammenhang mit dem Nervenfilz beim Al,heben stets so abreisst, dass die Ganglienzellen auf der Stützhaut liegen bleiben, so dass man nur selten eine Verbindung constatiren kann. In sehr seltenen Fällen glaubte ich anch den Ausläufer einer isolirten Geisselzelle 
oder Sehspindel in ummittelbarer Verbindung mit einer Nervenzelle anzutreffen (Fig. $16, \mathrm{~b}, 18, \mathrm{a})$.

Im Stützblatte des Randkörperstiels selbst sieht man nun eine ausserordentlich grosse Masse feinster Fäden ziehen, vorzüglich in einer Richtung entsprechend der Längenausdehnung des liandkörperstiels, vielfach aber auch sich durchkrenzend. Man triftt einzelne dieser Fäden in Verbindung mit den Ansläufern der Nervenzellen, deren unmittelbare Fortsetzung sie bilden. Ich halte sie für Nervenfäden, welche hauptsächlich nach aufwärts, gegen die Randkörperwurzel, gegen die contractilen Zonen hinziehen.

Die Zellsubstanz der Nervenzellen hat ein feinkörniges Aussehen, wie diejenige gewöhnlicher amöboider Bindegewebszellen. Auch ihr liern ist nicht ansgezeichnet. Ausser ihm liegt im Zellinhalt gewöhnlich ein eigenthümlicher, kugeliger, gelblich glänzender Körper (Fig. 25), über dessen Natur und Bedentung ich mich nicht näher orientirt habe. Alle Eigenschaften dieser Nervenzellen weisen auf die niedere Stufe ihrer Ausbildung hin: sie sind die morphologisch am Tiefsten stehenden unter ihres Gleichen, und sie scheinen nichts als eine geringe Modification der gewöhnlichen sogenaunten Bindegewebszellen aus dem Gallertgewebe unserer Thiere darzustellen. Dass nicht nur auf dem Stützblatte des Randkörperstiels, sondern auch auf jenem des Otolithensäckchens Nervenzellen derselben Art wie dort gelegen sind, sei gleich hier bemerkt.

4) Das Stützblatt des Liandkörperstiels (S der Abhildungen auf Taf. I u. IV) ward in seinen Eigenschaften theilweise schon berührt, indem hervorgehoben worden ist, dass eine ausserordentlich reichliche Anzahl von Nervenfäden in bestimmter Richtung in ilum verlaufe. Anch ward schon bemerkt, disss das Stützblatt sehr viel dünner wird, da wo es das Hörsäckchen zu umschliessen beginnt (Taf. I, Fig. $\&$ u. 7). Jene Fasern wurden bezeichnet als mit den Nervenzellen in Verbindung stehend. Sie sind, wie es scheint, in allen Lagen des Stützblattes ungemein reichlich vorhanden. Von ihren Eigenschaften wird bei Besprechung des Banes der Randlappen gehandelt werden. Wenn man das Stützblatt sammt Nervenzellen in der Flächenansicht vor sich hat, so ist nicht immer leicht zu beurtheilen, ob die letzteren auf oder in den ersteren liegen. Ueber den Zweifel kommt man jedoch alsbald hinweg, wenn man, wie dies in Fig. 15, Taf. IV abgebildet ist den Rand der vom Ektodermepithel entblössten liandkörperröhre betrachtet, um durch die Dicke der Wand derselben hindurchznsehen. Man findet dann im Innern des Stützblattes gewöhnlich keine Zellen, während dieselben auf der Oberfläche zahlreich gelegen sind. Gerade bei Anrelia fand ich aber in einzelnen Fällen autallender Weise zuweilen 
anch in der Stützhant Zellen, welche ich am lebenden Thiere amöboide Bewegungen ausführen sah ('laf. I, Fig. S). Sie schickten Fortsätze nach verschiedenen Richtungen ans, häntig nach beiden Seiten quer durch die Gallertwand hindurch, so dass sie deren Entoderm- und Ektodermzellenoberfläche miteinander verbanden. Diese Eigenschaften, sowie die Unbeständigkeit ihres Vorkommens lassen daranf schliessen, dass sie von durchans sekmndärer Bedentung für unsere Frage und dass sie vielleicht eingewanderte amöhoide Zellen sein werden.

Das Ilörsäckchen. Es ist schon ansgeführt worden, dass die einzelnen Schichten des Randkörperstiels, indem sie an das Hörsäckchen herantreten, sich allmälig verdünnen, so dass dieses abgesehen von seinem oberen Viertel oder Fünftel nur von einer ganz dünnen Hülle umgeben ist (Taf. I, Fig. S, e). Das Ektodermepithel wird - und zwar geschieht der Uebergang ziemlich rasch - zu kurz cylindrischen, nahezu platten, nicht geisselnden Zellen, zwischen welchen Sehspindeln nicht mehr vorkommen (vergl. Taf. IIl, Fig. 11, a und b, wo der Ejuthelialbelag vom obersten Theile des Hörsäckchens von Pelagia noctilnca gezeichnet ist). Eine Nervenfilzschicht lässt sich unter diesen Zellen bei Betrachtıng des Randkörpers als Ganzes nicht wie am Randkörperstiele erkennen. Macerationspräparate lehren indessen, dass jede der Zellen nach unten in einen varikösen Faden sich fortsetzt, der gröber ist als die varikösen Auslänfer der Geisselzellen und, soweit er in Zusammenhang mit der Zelle zu beobachten ist - und das ist gewöhnlich in ansnehmender Länge möglich - keine Verzweigung zeigt (vergl. ebenda). Es möchte scheinen, dass die Fäden sämmtlich ihren Verlanf über das Hörsäckchen nach anfwärts gegen den Randkörperstiel hin nehmen, ohne sich auf dem otolithensäckchen selbst an Nervenzellen zu begeben. Dem widerspricht indessen die schon erwähnte Thatsache, dass auch unter dem Ektodermepithel des Otolithensäckchens zahlreiche Nervenzellen liegen.

Las Hörsäckchen enthält die Hörkrystalke in verschiedener Grösse und Ausbildung. Es ist indessen nicht, wie man etwa früher angenommen hatte, ein eiförmiges, nach allen Richtungen ron einer Stützhant geschlossenes Säckchen mit den Hörkrystallen als lnhilt. Denn, obwohl die letzteren eine Umhüllnug anch nach oben, gegen den Randkörperstiel hin, haben, so wird dieselbe hier doch nicht ebenso wie im übrigen Umfange des Säckehens mit durch eine solche Stützhant gebildet, sondern sie sind von der Höhle des Randkörperstiels nur geschieden durch die cylindrischen Entodermzellen, welche sich in einem leicht concaven, nach oben offenen Bogen nuber sie heräberziehen ('l'af. I, Fig. 7 и. 5, x).

Die Hörkrystalle (Taf. I. Fig. 7 n. S) können sich nach Zusatz von Säuren 
auflösen. Die grösseren derselben lassen dann eine meist bräunlich oder gelblich gefärbte Membran als Rückstand. Die Auflösung geschieht unter eigenthümlicher, der Lünge des Krystalls nach gerichteter Zerklüftung (Taf. III, Fig. 20, 22); dabei schwinden zuerst die beiden ïussersten Enden desselben, von beiden her rïckt die Auflösung der Mitte näher, bis alles zerstört ist (Fig. 22 c). liosenthal gab an, dass Schwefelsäure die Krystalle nicht löse, und er erklärte sie daher für Sandkörnchen ${ }^{1}$ ). Dagegen fand Ehrenberg, dass sie in Sären löslich seien und schloss, dass sie aus kohlensaurem Kalk bestehen. Ich habe bei einer grossen Anzahl von Aurehien anf Einwirkung von Essigsäure regelmässig eine Auflösung der Krystalle beobachtet. Um so mehr war ich erstaunt, zu sehen, dass an kleinen, nu wenige Cm. im Durchmesser haltenden T'hieren (die ich zu einer anderen Zeit, im Frühjahr, untersucht habe) die Essigsäure bei zahlreichen Versuchen niemals eine Autlösung herbeiführte. Erst nachträglich fiel mir die oben citirte Stelle bei Ehrenberg auf, wonach dieser Forscher gleichfalls zuerst eine Autlösung (in Schwefelsäure) nicht erzielte und dieselbe erst erreicht haben will, nachdem er die Wand des Krystallsäckchens zerstört und die Krystalle befreit hatte. Ob diese Erklärung wirklich massgebend ist oder ob andere Ursachen für die Verschiedenheit des Verhaltens anzunehmen sind, vermag ich heute, fern von der See, nicht mehr zu entscheiden ${ }^{2}$ ).

Die Krystalle entstehen, wie ich finde, in amöbiden Zellen (Taf. III, Fig. 21) und lässt sich diese Entstehung ron Kleinem an verfolgen, indem sich im Hörsäckchen zwischen ausgebildeten Krystallen anch solche finclen, welche eben erst als kleinste glänzende Körperchen in der amöboizlen Zelle sichtbar werden. Diese amöboide Zelle zeigt in Anssehen und Lebenserscheinungen eine grössere Aehnlichkeit mit freilebenden Amöben als irgend andere, mir aus dem Körper der Metazoen bekannte. Sie enthält - abgesehen ron feinkörnigem, wohl auf die Struktur des Protoplasma zurückzuführendem Aussehen - meist noch einzehe braune Pigmentköruchen. Das Kryställchen liegt gewöhnlich nahe der Iitte; einen Fern sah ich nach Zusatz von Essigsänle wenigstens in solchen Zellen, deren Krystall schon bedeutendere Entwickhmg erreicht hatte (Fig. 21). Die Bewegungen der krystallbildenden Zellen sind sehr lebhafte. Fig. 22l zeigt die Formveränderung an, welche eine derselben unter meinen Augen in wenigen Angenblicken

1) Rosentha1, Beitrag zur Anatomio der Quallen, Zeitschr. für Physiologie von Treriranus. Bd. 1. 1825 .

2) Vielleicht liegt die Ursache der Versehiedenheit dor Wirkung in der Verschiedenheit der Concentration der angewendeten Sïuren: gerade wasserfreie Säuren greifen bekanntlich vielfach gar nicht an und rerwenden Botaniker z. B. sogar concentrirte schwefelsäure zum Conserviren. 
ansgeführt hat. Dabei geht immer, wie bei den Amöben, ein durchaus hyaliner, köruchenloser Theil in der Bewegung dem Uelrigen voran. Aber auch die grössten, vollkommen ausgebildeten Kirystalle sah ich zuweilen in Protoplasma eingeschlossen, welches bald da, bald dort im Umfang des Krystalls sich anhäufte und amöboide Bewegungen ansführte. Nach Znsatz von Essigsaure zeigte sich anch hier cin Kern: es liegen also inch ansgebildete Krystalle noch in einer amöboiden Zelle. Die Berregungen beobachtete ich sehr lebhaft in Jodserum. Dabei sah ich zuweilen im Protoplasma ein Gebilde wie eine Vaknole anftreten, ohne disss ich entschieden hätte, ob ich nicht eine Wirkung des Ënflusses der Zusatzflüssigkeit darin vor mir gehabt habe. Augenscheinlich mit der hespirationsthätigkeit in Bezielnung stehende Vaknolen scheinen nämlich nach meinen gelegentlichen Beobachtungen viel hänfiger in Zellen vorhanden zu sein, als man bis jetzt, da nur ganz vereinzelte derartige Fülle bekannt sind, annimmt. - Die Bildung der Hörkrystalle von Aurelia anrita geschieht somit ganz ebenso wie diejenige der Kiesel- nul Kalknadehn und der Kiesel- und Kalkkörperchen bei den Spongien. Ich bemerkte, dass ich selbst um ausgebildete Hörkrystalle noch Protoplasma mit einem liern getroffen habe: damit soll aber nicht gesagt sein, dass beides immer an ihnen vorhanden ist. Vielmehr diurfte angenommen werden, dass, wie bei den Spongienzellen, so auch hier das Protoplasma schliesslich vollkommen anfgebraucht wird, der Kern nicht mehr nacliznweisen ist, so dass nur ein Krystall zurückbleibt. - Dass die krystallführenden Zellen des Hörsäckchens Entodermzellen, sein müssen, braucht schliesslich nicht besonders hervorgehoben zu werden.

\section{Rhizosioma Cuvieri, Peligia noctilnea, Cassiopea horhonica}

zeigen in Beziehung auf den feineren Bau der Randkörper im Wesentlichen dieselben Verhältnisse wie Aurelia aurita (Taf. II, Fig. 1 und 2 Rhizostoma, Taf. III, Fig. 1-3 Pelagia). Ueberall findet sich anf dem Randkörperstiel eine dicke Nervenfilzschicht, welche von den Ausläufern der geisselnden Ektodermzellen nnd der Sehspindeln zusammengesetzt wird. Bei Rhizostoma und anch bei Pelagia (T'af. III, Fig. 10) sind die Epithelzellen mit ihren Auslänfern sehr hoch und schlank. Bei beiden finde ich theilweise Spindeh mit ausserordentlich langen Stäbchen (T'af. Ill, Fig. 10) and den Körper der Spindeln traf ich bei Pelagia (an (hromkalipräparaten) zuweilen von auffallend grossem Durchmesser. Ueberall ist dis liohr des Randkörperstiels von geissehndem Cylinderepithel umkleidet; überall wandelt sich auf dem krystallsäckchen das hoch- 
cylindrische Ektoderm in ein niedriges $n m^{1}$ ); die Nervenfilzschicht ist im optischeu Durchschnitt nicht mehr als besondere Lage zu erkennen, aber jede Ektodermzelle sendet, wie auf tem Stiel, ein Nervenfüdehen als Ausläufer aus. Diese Ansläufer sind überatl staiker als anf dem Stiel und kommen isolirt nur unverzweigt zu Gesicht. Auf den Stützblatte von Stiel und Hörsäckchen finde ich Nervenzellen, welche durchaus die Beschaffenheit jener von Aurelia haben: anch das glänzende Körperehen wird in denselben angetroffen (Rhizostoma). Zuweilen isolirt man sehr lange, variköse Nervenfäden, in welche eine spindelfömige Nervenzelle eingeschaltet ist. In Fig. ऽ. Taf. IlI ist Derartiges von Pelagia noetiluea abgebildet. Im Stützblatte selbst habe ich bei keinem der genannten Thiere Zellen gefundeu, wie sie ausnahmsweise bei Anrelia vorkanen, im Uelnrigen bietet es bei allen Arten dieselben Verhältnisse dar.

Rhizostoma Cuvieri zeigt in Beziehnng auf die Ektodermschicht des Stiels ein besonderes und bemerkenswerthes Verhalten, indem diese Schicht im änsseren, aboraleu Unfange des letzteren sich an einer Stelle stark verdickt. In Figur 1 und a der Tafel II ist dieses Verhalten auf dem sagittalen Durchsehnitte des Randkörpers deutlich zu sehen: an der Wurzel des Randkörperstiels beginut die Verdickung, nimmt allmälig zu nud nuchdem sie deu höchsten Grad erreicht hat, ebenso allmälig wieder ab, so dass ein kleiner Hügel durch dieselbe gebildet wird. Auf dem Durchschnitte sieht man, diss diese Verdickung hervorgerufen wird einmal von einer Vergrösserung des Höhendurchmessers des Körpers der dort gelegenen Epithelzellen (1), zugleich aber anch von einer Znnahme des Höhendurchmessers der Nervenfilzschicht (2); die Zellen erscheinen anf dem Durchmesser neheneinander gestellt wie die Steine eines Brückengewölbes: die in der Mitte gelegenen senkirecht, die beiderseits von der Mitte gelegenen mit dem nnteren Ende gegen diese Mitte geneigt. Genanere Untersuchung möchte zeigen, dass an dieser Stelle bei unserem Thiere eine besondere Ansbildung und Anhäufung der Ganglienzellen statt hat und somit vielleicht, dass dort der erste Ausatz zu einer grösseren Centralisation des Nervensystems gegeben ist. Rhizostoma Cuvieri würde in dieser Beziehnng unter allen von mir untersuchten Formen am liöchsten stehen. - Speciell darant gerichtete Beobachtung dürfte anch bei anderen Arteu Andentmigen dieses Verhaltens anffinden.

\section{Cyanea capillata}

zeigt dieselben Verhältnisse wie die übrigen genamnten Formen. Wie bei jenen finden sich anch hier Sehspindeln auf dem ganzen Randliörperstiel zwischen deu Geissel-

1) Taf. III, Fig. 11 a und b und Fig. 6 stellt das schon erwähnte Ektodermepithel der Pelagia rom obersten Theile des Hörsäckchens dar. 
zellen zerstreut. Und wie bei Aurelia trat ich anch hier eine Stelle, an welcher nur Sehspindeln vorhanden waren. Besondere Pigmentflecke hat Cyanea nicht, aber nach Isoliren findet man in den Geisselzellen des Ektoderms vielfich, wenngleich spärlich, Pigmentkörnchen. Anf dem Krystallsäckchen fand ich auch hier Nervenzellen.

\section{Feinerer Bau der Randlappen.}

\section{Anrelia anrita, Rhizostona Cuvieri, Cassiopea borbonica.}

Ueber diese physiologisch hochwichtigen Bezirke des hörpers der toponeuren Medusen kam ich mich nach der genanen Schilderung der Bauverhältnisse der Randkörper selbst, wenigstens in Beziehung ant vorstehend genannte Formen, verhältnissmässig kurz fassen, weil diese Bezirke hier Einrichtungen zeigen, welche sich an jene der Randkörper unmittelbar amreihen und welche gewissermassen nur anf einer massigeren Ausbildung derselben beruleu.

Die ganze, bisher als "Polster" bezeichnete, sïckchenartige Erhebung des Schirmrandes, unter welcher der Randkörper sammt seiner „Wurzel“, zirsammt den als „Hörner“ bezeichneten Gefässansstülpungen nnd mit dem „Randkörperrohr“ genannten, vom Ringgefäss znm Randliörper radial verlanfenden Gefässabschnitte liegt, . das Polster, welches in seiner Mitte zn der „äusseren Riechgrube" eingezogen ist, und welches mit seinem unteren Abschnitte, dem „Decklappen“, die äussere Wand der Randkörpertasche bildet, ist hei Aurelia, Rhizostoma und Cassiopea mit Nervenepithelium überkleidet. Ich bezeichne die acht Polster fortan als Sinnespolster, und die im Folgenden zu schildernden Thatsachen werden es rechtfertigen, wenn ich diese Simespolster. diese die Randkörper nnmittelbar umgebenden Bezirke des schirmrandes, als den wesentliclsten Theil des Centranervenapparates derselben, als ilre Gehirne in jenem eingeschränkten Sinne erkläre, in welchem sie schon im physiologischen Abschnitte dieser Arbeit als solche angekündigt sind. Das Nervenepithelium erstreckt sich über das ganze sinnespolster ${ }^{1}$ ), soweit anf demselben die

1) Nach der auf Seite 104 citirten Bemerkung von Rom anes zu schliessen, wärde ein Nervenepithelium in dieser Gegend anch von anderer Seite beobachtet sein. Ob aber die Arbeit des Herm Scbäfer schon elschienen ist, oder ob sich die Worte von $R$ o m a n s auf das ilsm bekannte, etwa an eine Zeitschrift eingesendete Manuscript beziehen, weiss ich nicht. Ebenso spricht Romanes auf Seite 719 (Philos. Transact. Vol. 167) von einem Nervenplexus, welcher von Schäfer im veontractile tissues von Aurelia aurita aufgefunden worden sei. 
Häufchen von Nesselzellen - ich gehe bei der Beschreibung von Aurelia aurita ans -. welche sonst über die convexe Obertläche des Körpers zerstrent sind, fehleu (vergl. T'af. 1, Fig. 2). An den seitlichen Grenzen des Polsters (P) geht es mit dem Auftreten dieser Nesselbatterien rasch in das gewöhnliche Epithel der KörperoberHä̈che äber, nach oben dagegen mehr allmälig. Nach unten wird es niedriger, während Nesselzellen zwischen ihm anftreten und modificirt sich (über Q hiuaus) nach und nach zu der alsbald näher zu schilternden Anskleidung der Randkörpertasche. Es hat dieses Nervenepithel der Aussenfläche des Sinnespolsters auf dem grössten Theile dieses Polsters, la wo es am besten ansgebildet ist, durchaus die Eigenschatten des den Randkörperstiel deckenden: es besteht ans Geisselzellen und dazwischen gelagerten Spindeln und ans einer Nervenfilzsehicht von ansehnlicher Mächtigkeit. Die Höhe der Zellenlage beträgt dort $0,024 \mathrm{~mm}$, ist ungefähr dieselbe wie auf dem Randkörper. Die Nervenfilzschicht, welche auf dem Randkörper nahezu die gleiche Höhe hat wie die Zellenlage, ist anf dem Simnespolster niedriger (vergl. Tat. IV, Fig. S aus der äusseren Riechgrube von Rhizostoma); nach unten hin nimmt, wie bemerkt, anf letzterem die Höhe beider Schichten ab. - In der Nervenfilzschicht sieht man sehr deutlich zahhreiche Faser'n parallel der Körperoberfläche ziehen, wie ich clies in der soeben erwähnten, Rhizostoma Guvieri entnommenen Figur abgebildet habe. Diese Figur zeigt, dass die Riechgrube von demselluen Epithel ausgekleidet ist, welches den übrigen Theil der Oberfläche des Simnespolsters deckt, allein ich habe darin, wenigstens bei Rhizostoma, keine Spindeln gesehen - In der Randkörper (Riech-) tasche finde ich bei Aurelia aurita im unteren 'T'heile ein niedriges, fast plattes Epithel, zu welehem sich das Nervenepithel des Simnespolsters allmälig ungewandelt hat, dazwischen einzelne Nesselzellen, darunter glaubte ich wiederholt - ich hahe diesen Punkt nicht erschöpfend untersucht - feine Nervenfädehen zи sehen. Jedenfalls findet sich vine mächtige Nervenfilzschicht mit Geisselepithel und mit dazwischen gelegenen Spindeln, also wieder ein ausgebildetes cylindrisehes Nervenepithel, ähnlich jenem des lianlkörperstiels, in den Riechkappen und schon an der oberen Wand der Randkörpertische, noch ansserhalb der Riechkappen, beginnt dasselbe anfzutreten. Ueberall da wo das Nervenepithel am vollkommensten entwiekelt ist, fehlen die Nesselzellen durchaus, wo es in seiner Ausbildung zurückzutreten heginnt, zeigen sich einzelne derselben, aber erst da treten sie in Batterien auf, wo das Ektodermepithel den Charaliter der gewöhnlichen platten Ektodermzellen angenommen hat. - So viel ich mich erinnere, ist bei anderen Formen, so bei Cassiopea und bei Rhizostoma, ein grösserer Theil der Randkörpertasche von eylindrischem Nervenepithel ansgekleiilet, indessen bedarf die nähere Feststeliung des 
Verbreitungsbezirkes nener Untersuchung. - Entfernt man nun das Nervenepithel von der Oberfläche des Sinnespolsters, so sieht man dieselben Zelleu, welche man nach der gleichen Behandlung auf dem Stützblatte des Randkörpers findet, in grosser Anzahl äber diese Oberflüche zerstreut. Aber nicht nur hier trifft man sie, einschliesslich selbstverständlich des lBodens der änsseren Riechgrube, sondern anch überall unter der Epithelunskleirlung der Riechtasche und der Riechkappen. Durehschnitte durch das Gallertgewebe der Gegend zeigen, dass es im grössten Theile des Sinnespolstergebietes von diesen Nervenzellen durchsetzt ist. Einmal anf die nun näher zu beschreibenden Verhältnisse aufmerlisam gemacht, werden sie einem Jeclen leicht in die Augen fallen: anf solchen Durchschnitten, gleichviel in welcher Richtung an erhärteten Präparaten z. B. von Anrelia aurita oder von Rhizostoma Cuvieri ansgeführt, wird man alsbald finden, dass eine Anzahl der im Bereiche des Sinnespolster's und speciell die in der UTmgebung der Randkörper, bezw. der Randkörpertasche, gelegenen Zellen des Gallertgewebes - also gewöhnlich sogenannte Bindegewebszellen - ein ganz anderes Aussehen zeigen, als die übrigen Bindegewebszellen der Gallerte. Ein Ueberblick über einen grösseren Theil der Oberfläche eines solchen Durchschnittes, z. B. mit System V. von Hartnack, zeigt diese überraschende Thatsache auf das Dentlichste: die ersteren erscheinen bei solch schwacher oder selbst bei noch schwächerer Vergrösserung vielfach verzweigt, mit Fortsätzen versehen, ihr liörper sehr verschieden gestaltet, meist aber mit einer Neigung zur Ausdehnung nach einer lichtung oder ansgesprochen langgestreckt, dann wieder zugleich im Winkel gekniclit, andere Male spindelförmig oder sternförmig. Die Zelleu des übrigen Gallertgewebes dagegen haben sich unter dem Einfluss der Reagentien mehr oder weniger vollkommen kugelig zusammengezogen, nur einzelne kmze Fortsätze lassen sich an ihnen bei stärkerer Vergrösserung wahrnehmen, insbesondere an Osmiumsänrepräparaten, indem die Osminmsäure die amöboideu Zellen theilweise getödtet hat, bevor sie im Stande waren, ihre Fortsătze einzuziehen. Ich unterscheide die zweierlei Arten von Zellen in Zukunft als amöboide und als Nervenzellen.

Sehen wir uns nun zunächst die Verbreitung der letzteren an der Hand einiger Durchschnitte genaner an: in Figur 1 anf Tafel $V$ ist ein radialer Durchschnitt durch den Randkörper und Umgebung von Aurelia aurita gezeichnet. In Fig. 2 und 3 derselben Tafel ist ein Theil des Decklappens (D) der Figur 1 nud der unmittelbar oberhalb der Riechgrube gelegene vom Schnitte getroffene Bezirk der Gallerte des Sịnespolster's, etwa bis zu der Gegend $\mathrm{x}$, vergrössert wiedergegeben. Im Decklappen (Fig. 3) sieht] man lauter verzweigte Zelleu, in Fig. 2 sieht man nur 
solche im unteren Theile, nach oben beginnen sie dagegen kugelig zu werden. In Fig. 2, Taf: Tl ist eine Ansicht der (iallertzellen ans dem Schimrande, also entfernt vom Centralapparat, dargestellt (von der Stelle y, Taf. T. Fig. 10), in Fig. 3, Taf. VI dagegen eine Ansicht der Zellen, welche unterhalb der Auskleidung der Riechtasche gelegen sind (ans der Gegend von x Fig. 4, Taf. V), beide Ansichten aus demselben Exemplar ron Cassiopea borbonica. In Tat. V1, Fig. 4, 5, 6 and 7 sind Querdmrehschnitte durch den schimmand von Rhizostoma cuvieri gezeichnet, in welchen die Verbreitung der Nervenzellen dureh Punkte angedentet ist, während die amöboiden Zellen weggelassen sind. Es sind dieselben ans einer Anzahl von 14 successiven Schnitten, welche ich in jeuer Gegend gemacht hatte, als hepräsentanten ansgewählt (vergl. die Erklärung der Tafeln). Man sieht, dass die Nervenzellen überall in dem als sinnespolster bezeichneten Abschnitte und in der Nahe des Randkörpers, bezw. in der Umgebnng der Randkörpertasche angehänft sind. In Tat. V, Fig. 10 ist ein Durchschnitt durch den untersten Theil des Schirmrandes (y) sammt dem unteren Ende eines der den Ohrlappen entsprechenden Bezirke des Simespolsters (p) von Cassiopea gezeichnet. Die in dieser Abbildung sichtbaren Punkte denten nicht Nervenzellen allein, sondern die Zellen des Gallertgewebes überhanpt an; in der Gegend ron $P$ sind aber anch hier die Nervenzellen überwiegend, während ans der Gegend ron y dagegen die Ansicht Fig. 2, Taf. Vl genommen ist, worans zn ersehen, dass dort nur amöboide Zellen augetrotfen werden (man vergleiche hierzu die 'l'afelerklärumg). Ueberall liegen in den Bezirken, welehe die höchste Bedentung für das Nervenleben haben müssen, ansschliesstich Nervenzellen, so insbesondere zwischen änsserer Riechgrube und Randkörpertasche. Es sind diese stellen in den Jurchschnitten durch stärkere P'unktirung ansgezeichnet. Je mehr entfernt vom Mittelpunkte dieser Stellen, m so mehr mischen sich mit den Nerrenzellen amöboide. bis diese überwiegen und schliesslich allein übrig sind (an den nicht pruktirten stellen der Durchschnitte). Bei Cassiopea burbonica geht die Mischmg sehr weit gegen die Centren der Herde von Nervenzellen vor. ja es scheinen sogar die amöboiden in der Nähe der für das Nerrensystem wichtigen Bezirke grösser und reichlicher zu sein als anderwärts. - Bei Cassiopea wie bei anderen Formen finden sich nun in den Grenzgebieten ron beiderlei Zellenarten solche Zelleu. Welche zwischen amöboiden und Nervenzellen mitten inne stehen. Bei Rhizostoma ist mir anfgetillen, dass dort in diesen Grenzgebieten znerst amöboide Zellen inftreten, welche in eigenthümlicher Weise zu mehreren in Hänfchen zusammen liegen. Erst mehr peripherisch bekommen die einzehn gelegenen amöboiden die oberhand. Es sind somit angenseheinlich die Nervenzellen nichts anderes als eine Modification der amoboiden. 
Bei Cassiopea borbonica findet sich num ansser den angegebenen Ansammlnngen von Nervenzellen noch eine solche an der aboralen Schirmfläche in dem früher schon als "Knöpfchen“ bezeichneten Gebilde (Taf. V, Fig. 9, k), von welchem ans die Muskelelemente der Subumbrella radiär nach den Seiten und abwärts ansstrahlen, wie dirs in der Abbildung angedentet ist, allerdings nach einem erhärteten Präparate, an welchem diese Verhältnisse nicht mehr so dentlich waren wie am frischen Objekt. Von der oralen Schirntläche aus gesehen bietet sich dieses Küüpfehen als eine kleine Erhabenheit dir, welche muskelfrei ist und ummittelbar über der Einziehnng: des Schirmrandes liegt, die in die aborale Wand der Randkörpertasche einschneidet. Auf dem in Fig. 4, Taf. $\mathrm{V}$ dargestellten Durchschnitt erkennt man die Lage des linöpfchens (k) etwa gegenüber der Randkörperwurzel. In Fig. j derselben Tafel ist es vergrössert dargestellt. Es ist anssen (oral) überzogen von einem niedrigen Epithel, welches aber in dem abgebildeten Präparate bis auf einen kleinen Theil (oben) entfernt ist. Die Durchschnitte lehren, dass das Kinöpfchen ein linsenförmiger Körper ist. Derselbe besteht aus Gallertgewebe, gleich dem übrigen Schirm, enthält aber nur Nervenzellen und Nervenfäden. Züge solcher Fäden strahlen gegen seine freie Oberfläche hin aus und ungrenzen den Körper gegen die übrige Umbrella hin. In rlen nach anssen strebenden Fäden trifft man von Stelle zu Stelle Nervenzellen eingeschaltet und sie treten mit den Epithelzellen der Oberfläche in Verbindung. Es ist dieser Körper, welcher übrigens insbesondere in Rücksicht anf seine Beziehungen zu der umgebenden Muskulatur eine genauere Untersuchung verdient, geradezu ein Ganglion, relativ scharf ungrenzt, wie es an keiner anderen Stelle des Körpers unserer Medusen von mir beobachtet worden ist. Dabei darf man allerdings an ein Ganglion im Sinne jener der höheren Thiere oder anch nur der cycloneuren Medusen, bestehend aus eng aufgehünften Zellen, nicht denken: die Nervenzellen liegen zerstreut durch die homogene Gallerte und die Bezeichnung Ganglion ist nur desshalb zulässig, weił der Körper nach anssen abgegrenzt, was bei den äbrigen Nervencentreu der Toponeuren nicht der Fall ist. Es erhalt durch die Existenz dieses Ganglions der auf Seite 59 von mir mitgetheilte Versnch, bei welchem dasselbe verletzt worden ist, eine nähere Erklärung, anch scheint nmgekehrt jener Versuch dafür zu sprechen, dass das Ganglion wesentlich als ein motorisches anfzufassen sei. Unzweifelhaft werden ferner darauf gerichtete Untersuchungen ähnliche Eimrichtungen, weun auch da und dort in geringerer Ausbildnng, auffinden. Bei den übrigen von mir studirten Formen habe ich Aehnliches nicht beachtet, kaunte aber allerdings zu der Zeit als ich sie untersuchte, das Ganglion bei Cassiopea noch nicht. Indessen liegen dort, was übrigens auch bei Cassiopea der Fall ist, im Gebiete der contrac- 
tilen Zoner, also in der Gegend und in der Umgebung des Ganglions der Cassiopea, zahlreiche Nervenzellen ummittelbar nnter der Muskulatur. Anf den Durchschnitten der Tafel VI sind sie nicht zu sehen, man muss stärkere Vergrösserung und Flächenansichten zu Hülfe nehmen, um sie zu Gesicht zu bekommen. Sie sind ebenso unscheinbar wie die übrigen Nervenzellen und werden wie diese ohne gentuere Untersuchung für "gewöhnliche "Bindegewebszellen" erklärt werden. Hat man die Muskulatur abgelöst, so sieht man unter derselben zugleich sehr zahlreiche, mehr oder weniger parallel verlanfende Fäden, welche ich anf Grund meiner physiologischen Versuche und in Zusammenhalt mit sogleich zu schildernden Thatsachen glaube für Nervenfäden ansprechen zu dürfen.

Man sieht die Nervenzellen oft anf weite Strecken hin Fortsätze anssenden, welche dieselben mit anderen ihres Gleichen in Verbindung setzen oder welche gegen das Epithel hinstreben. Die Fortsaitze verzweigen sich vorher vielfach dichotomisch zu ansserordentlich feinen Fädchen. Das von mir zur Untersuchung angewendete doppelt-chromsaure Kali reicht übrigens zu erschöptenden Erkenntniss dieser feinen Verhältnisse nicht ans und die Goldreaktion, von welcher ich mir die besten Antschlüsse verspreche, ist mir bei wiederholten Versuchen einstweilen nicht gelungen. Inclessen lässt sich schon an Chromkali oder an Osminmsäurepräparaten unschwer ferner so viel erkennen, dass die Nervenzellen an bestimmten Stellen in bestimmter Richtung gelagert sind: so sind sie z. B. am Boden der äusseren Riechgrube mit ihrer längsten Axe meistens senkrecht zn der Epitheliallage gestellt, strahlen auf Querdurchschnitten radiär gegen diesen Boden ans; anch an anderen stellen streben sie in dieser Weise dem Ektolermepithel zn nud senden ihre Fortsätze nach demselben hin. - Ebenso sieht man nun im Gebiete des Centralapparates ansserordentlich zahlreiche, feinste Fäden in entsprechender Richtung oder sunst in bestimmten constanten Zügen das Gallertgewebe durchziehen (Fig. ״ und 3, Taf. V). Auf Qnerdurchschnitten, durch dis Simespolster in der Nähe der liechgrube ausgeführt, erscheint die Fichtung der Fasern überall ähnlich wie in Fig. 1, Taf. VI ron Cyanea capillata angegeben ist. Sie sind stets da am zahlreichsten, wo man den wesentlichsten Theilen des Sinnesapparates am nächsten ist. So ziehen sie in ungehemrer Menge vom Boden der Riechgrube gegen die Randkörperwurzel hin ans ${ }^{1}$ ), und so werden sie auf Durchschnitten wie die in der. VI. Tafel abgebildeten in grosser An-

1) Die Fig. 1 aul Taf. VI ist der entsprechenden Gegend ron Cyanea entnommen: die Zahl der Faseru ist in der Abbildung aber viel zu gering angegeben, weil die meisten derselben wegen ihrer ausserordentlichen Feinheit erst bei starker Vergrösserung sichtbar werden. 
zahl anch quer durehsehnitten insbesondere in der Gegend des Randkörperrohrs angetroffen - als die Fortsetzung der Fasern, welche ich aus dem Stützblatte des Randkörpers schon beschrieben liabe. Es zeichnen sich diese Füden morphologisch nicht allein durch ihre ansserordentliche Feinheit, sondern auch dadurch ans, dass sie überall von gleicher Dicke sind, und dass sie sich nirgends zu Maschennetzen verbinden, wie dies die Bindegewebsfäden ans anderen Theilen des Gallertschirmes thun. Anch finclet man an denselben niemals jene platten, flügelartigen Verbreiterungen, welche die Bindegewebsfasem der Medusen vielfach gegenseitig ineinanderheften ${ }^{1}$ ). So kommit es, dass man auf Durelischnitten im Gebiete der contractilen Zonen ganz andere Bilder erbält, als auf Durchschnitten anderer Umbrellatheile, wo unzweifelhafte Bindegewebsfasern vorherrschen (vergl. Taf. VI, Fig. 2 und Taf. V, Fig. 10). Demnoch machen die Fasern des Sinnespolsters im Algemeinen viel eher den Eindruck von feinsten Bindegewebsfäden als den von Nervenfasern. Nun kann man aber an vielen derselben einen Inlualt und eine Hülle unterscheiden: der erstere bestelıt aus einer Masse, welche die Beschaffenheit eines sehr feinkörnigen Plasma hat. Nach längerem Einlegen von Clromkalipräparaten in Glycerin und Wasser bekommt dieser Inhalt ein wie geronnenes Aussehen, zieht sich auf einzelne kleine Portionen innerhalb der Fasern zusammen und schwindet schliesslich, so dass jetzt alle Fäden ähnlich Bindegewebsfasern aussehen. Stücke solcher plasmatischer Fïden sind in Fig. 3, Taf. $V$ bei a angedentet. Es kömnen nun fermer diese Fäden zwar in weiten Strecken durch das Gewebe zielsen, ohne mit Nervenzellen in Verbindung zu treten; in andern sind dagegen von Stelle zu Stelle Zellen in sie eingeschaltet, so dass der Nervenfaden eine Zellkette darstellt, ähnlich, wie sie die Nervenfasern von Beroë bilden. In Gegensatze hiezı finde ich in nuzweilelhaften Bindegewebsfäden niemals Zellen eingeschaltet: die amöboiden Zellen líegen stets zwischen ihnen oder hängen ihnen nur zufällig an.

Die beschriebenen Fasern, seien sie plasmahaltig oder nicht, streben nun, wie gesagt, vorzüglich zum Ektoderm hin und scheinen überall mit dessen Epithelzellen in Verbindung zu treten. Denselben Verlanf' nehmen aber auch Fäden, welche entschieden bindegewebiger Natur sein müssen. So trifft man überall in der Gegend z, Taf. VI, Fig. 4, entsprechend z Fig. 1 derselben Tafel, also von der tiefsten Umgrenzung des Simnespolsters ausgehend, Fäden, welche, gleichlaufend mit den Nerven, Bindegewebsfasern sind oder sogar querdurchschnittene bindegewebige

1) Vergl. 'Taf. XII, Fig. 9, a, wo solche flügelartige Verbreiterungen an der Hülle von Fasern des Hörnerven abgebildet sind und: M. Schultze, über den Bau der Gallertscheibe der Medusen, Müller's Arch. 1856, Taf. XI, Fig. 7 und Taf. XII. 
Scheidewände, Blätter, welche der Gallertwand hier hesonderen Halt zu geben scheinen. Jene Fasern zeichnen sich von Nerventäden gewöhnlich durch grössere Dicke und durch eimen welligen Verlauf, ähnlich elastischen Fasern aus. Aber genau zu unterscheiden, wo die Grenze sei zwischen Fäden, welche dem Nervensystem und solchen, welche dem Stützsystem zngehören, bin ich nicht im Stande, wie ich denn der Ansicht bin, dass eine solche Grenze morphologisch scharf bei unseren Thieren gar nicht nothwendig existiren muss.

Für Anrelia aurita ist nun endlich noch über eine dort häufige Erscheinung zu berichten, welche an dieser Stelle zu erörtern ist und welcher zugleich für die Frage nach den Beziehungen zwischen amöboiden und Nervenzellen Bedeutung zukommt: anscheinend gewöhnliche, amöboide Zellen durchziehen hier häutig kettenartig aneinander gereilut in einer bestimmten Richtung, und zwar oft in einer den Nervenfasern entsprechenden, von Ektoderm zu Ektodem, das Gallertgewebe (vergl. Taf. Il, Fig. 6, wo solche Züge von Zellen bei schwacher Vergrösserung angedentet sind). Es können nun diese Zellen unmittelbar aneinanderliegen, oder sie sind durch zwischengelagerte längere oder kürzere Fäden von einander getrennt, und scheint auf diese Weise der Uebergang zu den vorhin beschriebenen Nervenfasern mit eingeschobenen Nervenzellen gegeben zu sein. Man ist versucht, derartigen Zellketten gleichfalls eine Bedentung für die Leitung des Nervenstromes zuzuschreiben: sie könnten sich nach Bedürtniss bilden und in Folge wiederholten und langen Gebranchs würden aus ihnen allmälig constante Nerven hervorgehen ${ }^{1}$ ).

\section{Cyanea capillata.}

Die Einrichtungen des Nervensystems müssen bei diesem Thiere schon desshalb nach verschiedener Richtnng andere sein, als bei den bisher abgehandelten Formen, weil bei ihm Zellen im Gallertgewebe bis jetzt gar nicht beobachtet worden sind. Allein auch in Beziehung auf das Nervenepithel zeigen beide nach Form und Verbreitung grosse Verschiedenheiten. Zugleich mag ausserdem hier schon hervorgehoben werden, dass bei Cyanea capillata die ganze Körperoberfläche von cylindrischem Geisselepithel bedeckt ist, dessen Elemente ganz allmälige Uebergänge zu dem ausgebildeten Nervenepithel der Kandlappen darbieten, so dass ein

1) leh glaube mich bestimmt zn erinneru, dass Gegen ba ur solchen kettenartig aneinander gereihten Zellen schon die Bedeutung von leitenden Nervenelementen zugesehrieben hat — vielleicht in der mir a ugenblieklieh nicht zugänglichen ersten Auflage seiner Grundzüge der vergleichenden Anatomie. 
scharfer Gegensatz zwischen beiden wie bei den bisher abgehandelten Arten nicht besteht. Es enthalten diese Geisselzellen der Schirmoterfläche meist in ihrem oberen Abschnitte feine Pigmentköruchen. Ihre Geissel ist von so ansserordentlicher Feinheit, dass sie nur mit den stärksten Vergrösserungen gesehen werden kam - dies wohl die Ursache davon, dass die Art der Bekleidung der Cyanea der Beobachtung bisher entgangen ist. Oh die geisselnde Epithelialdecke sich auch bei den grösster, völlig ausgewachsenen Thieren oder bis zu welcher Grösse derselben sie sich eventuell erhält, bleibt noch zu entscheiden: ich habe aut diesen Pnnkt nicht besonders geachtet, jedentalls aber traf ich sie bei Thieren von einigen C'entimetern im Durchmesser. Bis jetzt ist meines Wissens nur in der Aeginopsis mediterranea J. Müller eine Meduse bekaunt, welche, wie dieser Forscher nachgewiesen hat, noch einige Zeit nach der vollendeten Entwicklung, freilich nur in den jüngsten Exemplaren, Wimperbewegnng anf der Obertläche des Körper's zeigt ${ }^{1}$ ). Bei dem von G egenb a $u r$ beschriebenen T'rachynema ciliatum erhät sich das Wimperkleid bis zur vollkommenen Ausbildung der Medusenform und schwindet dann ${ }^{2}$ ). Der grösste Theil dieser cylindrischen, die aborale Oberfläche von Cyanea capillata deckenden Epithelzellen ${ }^{3}$ ) ist durch besondere Eigenschaften, die Gestalt betreffend, ausgezeichnet: die Zellen spitzen sich nämlich nach unten nicht $z u$, sondern sie sitzen mit einer breiten Endfläche, welche gewöhnlich noch nach zwej entgegengesetzten Seiten oder einseitig in einen langen Faden, den ich als "Fuss“ bezeichne, ausgezogen ist, dem Gallertgewebe auf (Holzschnitt 2s). Solchen Fuss hat nun auch ein 'Theil des die Randlappen deckenden Ejpithels, während ein anderer Theil desselben sich nach unten zaspitzt, ähn-

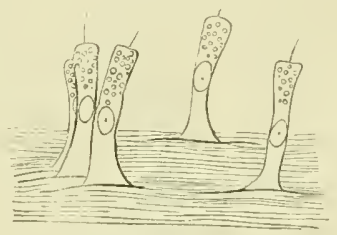

Holzschnitt 28.

lich den Ektodermzellen des liandkörperstiels von Anrelia und Vervandten ${ }^{4}$ ): in beiden Fällen ist es, wie dieses, fast a ul dem ganzen Randlappen und zwar nicht nur a te desen aboraler, sondern auch a f seiner oralen Fläche als Nervenepithel zu erkennen. Wir gehen bei der Schilderung von der Furche aus, welche bei Cyanea capillata statt der äusseren Riechgrube vorhanden ist, weil dort die bezüglichen Verhältnisse besonders ansgeprägt sind. Ent-

1) Joh. Il ïller, Ceber eine eigenthümliche Meduse des Mittelmeeres und ihren Jugendzustaud, Arch. f. Anat. u. Physiol. 1851. S. $272 \mathrm{ff}$.

2) Vergl. Gegenbaur, zur Lehre vom Generationswechsel und der Fortpflanzung der Medusen und Polypen, Würzb. 1854. S. 50 ft:

3) Aut der Kuppe des Schirmes sind die Epithelzellen sehr hoch cyliudrisch (Taf. II, Fig. 5), aber ohne Fuss.

4) Ich bezeichne in Zukunft die toponeuren Medusen, deren Gallertgewebe von Zellen durchsetzt ist als cy toph ore, die übrigen als a c y tophore. 
fernt man in dieser Furche das Epithel von seiner Unterlage, so bemerkt mau unter ihnn und mit ihm zusammenhängend, ein Lager von varikösen Nervenfädchen. Sorgfältige Beobachtung nnter Anwendung starker Vergrösserungen und Isoliren der Epithelzellen lehrt nun das Folgende: die breit abgeschnittene Basis jeder Zelle geht (z. B. im oberen Theił der Furche, über dem Randkörperröhrchen) nach einer Seite in einen langen Fortsatz - entsprechend dem Fuss der gewöhnlichen Deckzellen der Oberfläche, über (Tar. IV, Fig. 21, a, b). An diesem Fortsatz kann man unterscheiden: 1) eine Hülle, welche die unmittelbare Fortsetzung der Zellhülle ist, 2) ein äusserst feines, von dieser Hülle umschlossenes Fïlehen - ein Nervenfüdchen. Das Nervenfädehen setzt sich einerseits fort in einen jener varikösen Fäden, welche soeben, als ein besonderes Lager bildend, erwähnt worden sind, ohne dass in der Regel eine Umhüllung weiterhin an ihm noch dentlich zu erkennen wäre. Andererseits aber kann dasselbe zuweilen auf das Dentlichste in das Innere der Zelle hinein verfolgt werden. Es strebt direkt anf den Kern zu, seheint in denselben einzutreten und ihn zu durchziehen, dem es wird anf der seiner Eintrittsstelle entgegengesetzten Seite des Kerns, im oberen Abschnitt der Zelle wieder siehtbar und setzt sich in das Geisselhaar fort. Das letzterwähnte Verhalten ist äusserst schwer zu erkenmen, und anch der übrige Verlaut des Nervenfätchens, ebenso wie die Unterscheidung einer besonderen Umhüllung an der Stelle seines Austritts ans der Zelle, bedarf zur Feststellung ausgezeichneter Linsen unl bester Belenchtung. Nur selten wird eine Zelle isolirt werden kömnen, welche alle Einzelheiten zugleich zeigt und ist man meist genöthigt, die bald da, bald dort sich lenthich ergebenden Thatsachen zu combiniren. - Aehnliche Verhältnisse kommen num anch ansserhalb der Furche fast auf der ganzen Aussenfläche des Randlappens vor. Oberhalb und zu den Seiten jener traf ich die Epithelzellen gleichfalls mit breiter Basis, übergehend in je ein Nerventädchen und dieses zuweilen anch innerhalb der Zelle sogar varikös! Etwa in der Mitte der beiden Hälften des Lappens - beiderseits von der Furche - waren solche Zellen von grösserem Breitendurchmesser und niedriger als in derselben (Tat. IV, Fig. 21, c). Etwas mehr nach aussen fand ich nach unten zugespitzte Zellen, je in ein langes variköses Nervenfüdchen ausgehend, mit excentrisch grelagertem Kiern. Diese varikösen Zellfortsätze billen auf der Aussenfläche der Randlappen eine Nervenfilzschicht, welche jedoch dünn und nur in der Riechturche von bedeutenderem I)urchmesser ist; mur ganz am Raude der Lappen vermisste ich an den hier wieder mit einem Fusse versehenen Zellen einen längeren Faden. Die Zellen sind hier höhere oder niedrigere polygonale Säulen mit kn1z ausgezogenem Fusse (Taf. IV, Fig. 5 u. 11), welchen ich nicht positiv für cinen Nervenfaden erklitren komnte. 
Nicht nur an der Aussenfläche der Randlappen trifft man nun die geschilderten Verhältnisse: die orale Fläche dieser Lappen ist zum grössten Theile nicht mit Muskulatur belegt und dieser muskelfreie Bezirk führt an verschiedenen Stellen ein Epithel, welches gleichfalls dentlich mit Nervenfïdchen in Verbindung steht. So finde ich an der unteren, gegen die Concavitat des Schirmes zu gerichteten Fläche der oben erwähnten, Riundkörper und Randkörperrölırchen von unten deckenden Flügel ein kurzes, breites Geisselepithel, mit seitlich, an der Zellwand gelagertem Kern, mit wenig körnigem Inhalt und wenig Pigment, mit breiter Basis aufsitzend und diese Basis ausgehend in ein ziemlich grobes Nervenfädchen (Taf. IV, Fig. 19 und 23$)^{1}$ ). Die Masse solcher Fädchen macht in tieferer Lage den Eindruck von Punktsubstanz. Anch seitlich von den Fallthüren steht das die Unterseite der Randlappen bedeckende Epithel mit Nervenfädchen in Verbindung. Die Zellen enthalten hier besonders in ihrem oberen Theile reichlich Pigment, dazwischen häufig gelblich glänzende Kugeln als Inhalt, welche oft wie Zellen aussehen (Holzschnitt 29). Im unteren Abschnitte sind sie dagegen vielfach ganz leer und bauschen sich hier zugleich oft becherzellenartig aus. Sie laufen nach unten spitz zu (oder verzweigen sich auch) und gehen in ein variköses Nervenfädchen, zuweilen von ziemlicher Stärlie über. Bei grösseren Thieren traf ich ein Nervenepithel an der Unterfläche der Randlappen sogar noch in einer Entfernung von mehreren em oberhalb der Randkörpertasche. An der oberen Grenze des muskelfreien Bezirks aber bildet sich die fadenförmig auslaufende Basis der Epithelien, welche kurz vorher in ein Nervenfüdchen überging, zu einer Substanz um, welche sich zunächst durch stärkeres Lichtbrechungsvermögen vor dem übrigen Theil Holzschnitt 29. der Zelle auszeichnet und welche sich mehr und mehr als Anfangsstufe zur Bildung eines contractilen Fadens, des contractilen Theils einer Neuromskelzelle erweist, wie sie s päterhin von der Unterfläche unserer Medusen beschrieben werden sollen. - Nerrenepithel findet sich nun ferner noch reichlich in der landkörpertasche, theils mit Fuss (Taf. IV, Fig. 12), theils nach unten zugespitzt (Unterfläche des Randkörperröhrehens). Gegen den Rand des Lappens hin endlich wird anch unten das Epithel niedrig, und seine Auslänfer lassen sich nicht mehr direkt als Nervenfädchen erkennen.

Bei Gelegenheit des Wegnehmens der Nervenepithelien vom Schirme traf ich zuweilen sehr lange Nervenfüden mit stark ausgebildeten Varikositäten, welche oft nicht

1) Die Fäden sind in der Abbildung (ebenso auch die der Fig. 12) sehr kurz gezeichnet - sie können auf viel lïngere Strecken isolirt werden, und bilden zusammen eine dünne Faserlage. 
mehr wie an den Auslăufern der Epithelien punktförmig, sondern spindelartig anfgetrieben waren: es schienen diese Varikositäten Erweiterungen einer Hülle darzustellen, welche erst das Nervenfädchen einschliesst. Dieses letztere nahm als feinster Faden die längste Axe der Spindeln ein, durchzog dieselben somit central (T'af. IV, Fig. 22), Eigenschatten, welche ich ganz ebenso von den Nervenfasem von beroë beschrieben habe. Aus diesen Thatsachen und den vorhin von len Nerven des Gallertgewebes, sowie von den Ausläufern der Ej,ithelzellen beschriebenen Verhältnissen möchte zu schliessen sein, es sei eine allgemeine Eigenschatt der Nerventäden, auch der feinsten unserer 'Thiere, dass sie aus Hülle und Inhalt bestehen.

Das Gallertgewebe von Cyanea capillata wird als zellenlos beschrieben. In der That sieht man auf Durclischnitten, z. B. durch die Randkörpergegend, von gewissen Zellen, aut welche ich später zo reden komme, abgesehen, nur klare Gallerte, von Fasern durchzogen. Solche Schnitte z. B. ummittelbar oberhalb des Randkörpers geführt, zeigen ansserordentlich reichliche Fasern von der Umgebung des Randkörpers aus radiär nach dem gegenüberliegenden Ektuderm strebend (Taf. VI, Fig. 1), ganz ebenso wie die entsprechenden Schnitte durch Cytophore. Nicht minder zahlreiche Fasern sind hier wieder im Querschnitt getrotten und sind diese angenscheinlich wiedermm die Fortsetzung jener Fäden, welche aus der Stützlamelle der kandkörper erwähnt worden sind. Quere Fasern ziehen mu aher nicht allein vom Raudkörper zum Ektoderm, sondern auch vom aboralen Ektoderm zum oralen. Die Eigenschaften der Fasern sind ganz dieselben wie bei den Cytophoren, von den Verhältnissen abgesehen, die eben dureh die Zellen bedingt werlen, welehe das Gallertgerrebe der letzteren führt. Wir unterscheiden wiederum zweierlei Fasern, solche mit plasmatischem Inhalt und solche ohne Inhalt. Jene haben ein feinkörniges Aussehen, wurden hier nicht immer ganz scharf begrenzt, nicht immer überall gleich dick angetroffen und machen den Eindruck von Plasmafïden, wie sie etwa entstehen würden, wenn man eine Zelle nach zwei entgegengesetzten Richtungen sehr lang anseinandergezogen hätte. Die zweite Art von Fasern macht den Eindruck von Bindegewebsfasern, unterscheidet sich aber von den bindegewehsfasern des übrigen Körpers in der bei den Cytophoren beschriebenen Weise (vergl. für Cyanea gegen Taf. VI, Fig. 1, die Fig. 5 auf Taf. II, welche dem Gallertgewebe ans der Gegend der Kuppe entnommen ist). Allein desshalb, weil sie mit den plasmaführenden gemischt und Uebergänge zu ihnen zeigend, überall an den für das Nervenleben wichtigsten bezirken in ausserordentlicher Menge und in ganz typischen Zügen rorkommen und weil sie derselben Art sind wie die aus den Randkörpern beschriebenen. stellt sich die Frage, ob sie nicht gleichfalls als leitende Elemente anzus]reehen 
seien, obschon sie anch hier, wie bei den Cytophoren an bestimmten Stellen übergehen in stark lichtbrechende, geschlängelte, elastischen ähnliche Fasern (Taf. VI, Fig. 1, z). Da diese letzteren den gleichen Verlauf wie die übrigen nehmen und sich in gleicher Weise wie sie mit dem Epithel verbinden, so sind beide mit den Plasmafäden angenscheinlich derselben Anlage entsprungen und mögen nur funktionell verschiedene Aufgaben haben.

Sämmtliche Fäden sind also als Fortsätze des Ektoderms zu erkennen. Es wuchert dieses insbesondere an bestimmten Stellen, so im Grunde der nach hinten von den „Flügeln“ begrenzten Taschen, in förmlichen Zapfen in das Stützgewebe hinein; von solchen Zapfen treten, oft geradezn büschelförmig, in grösster Zahl die Fäden ab, nm quer oder nach anderer Richtung die Galleste zu durchziehen (Taf. VI, Fig. 1, x) und sich gegenüber wieder an das Epithel anzusetzen. Die zapfenartige Einwucherung des Fktoderms, welche also an der oralen Schirmoberfläche statt hat, geht so weit, dass zuweilen einzelne unförmlich gestaltete Protoplasmamassen (Zellparthien) von dem Oberflächenepithel getrennt, nu durch Anslänfer mit ihm verbunden, im Stützgewebe gelegeu sind und nun erst die Fasern abgeben. Inwieweit ansserdem subepitheliale Nervenzellen hier eingelagert sind, bleibt noch zu untersuchen: auf dem übrigen Theil der Körperoberfläche kommen, wie wir sehen werden, Zellen, obgleich sehr spärlich und unscheinbar zwar vor und ebenso finden sich solche im Gebiete der Subumbrella, es scheint mir aber der Gedanke nicht von der Hand zn weisen zu sein, dass jene Wncherung der Epithelien an der oralen Schirmfläche an Stelle von Nervenzellen tritt, so dass hier der primitive Zustand gegeben sein würde, in welchem noch das Urektoderm, das Deckenepithel, die Funktion von Nervenzellen mit übernimmt, oder gerade erst im Begriffe steht, besondere Nerveuzellen nach innen abzusondern - ein Znstand, welcher anf den ganzen mit Muskelelementen belegten 'Theil der oralen Schirmfläche bei allen von mir untersuchten Medusen gleichfalls besteht, insofern als hier der nicht contractile Theil der Nenromuskelzellen als nervöser Theil gegenüber dem contractilen aufgefasst werden muss, während ausserdem eine Bildung meist spärlicher und wenig entwickelter gesonderter Nervenzellen begounen hat.

Nach dem Mitgetheilten würden wir bei den Toponeuren als Wege für die Nervenleitung ansehen dürfen: constante Bahnen, hergestellt 1) entweder durch mittelst Fäden verbundene Zellen, 2) durch feinste Protoplasmafäden; dazn kommen 
vielleicht 3) inconstante Bahnen, Ketten von Zellen, welche möglicherweise nach Bedürfniss, im Augenblicke der Aktion sich bilden und die sich wieder lösen lïnnen. Die zweite Form, welche man bei Cyanea ansschliesslich antrifft, ist wohl als die primitivste von allen zu betrachten: sie konnte entstehen, noch bevor Zellen in die Gallerte aufgenommen worden waren, wie wir voraussetzen dürfen, durch gegenseitige Entfernung zweier ursprünglich ans einer und derselben Anlage hervorgegangener Lager von Ektodermzellen, somit durch fadenartiges Ausziehen von Zellinllalt. Derartige Plasmafäden als leitende Nervenfäden muserer Thiere anfunfassen, dazu ist man sicherlich vollkommen berechtigt. Ich hege nach dem Mitgetheilten die Hoffnung, dass speciell anf den Gegenstand gerichtete Untersuchung einen Inhalt anch in vielen der feinen Fäden noch nachweisen wird, welche mit den ron mir angewendeten Nitteln einen solchen nicht erkemnen liessen. Allein es wird wohi immer eine Grenze bleiben, in welcher Nerven- und Bindegewebsfäden sich nicht von einander unterscheiden lassen und dies ist in Anbetracht der tiefen Stufe der Entwicklung, anf welcher unsere Thiere stehen, sehon begründet in der Thatsache, dass beide, nach Allem, was über die Embryologie der Quallen bekannt ist, aus einer und derselben Anlage hervorgegangen sein müssen. Ganz dasselbe ist der Fall mit den Nervenzellen und den amöboiden. Es ist die ausschliesslich herrschende Vorstellung, dass die Zellen des Gallertgewebes der Cytophoren "Bindegewebszellen" seien. Da sic aber aller Erfahrung nach ans dem Ektoderm stammen, so ist gar nicht abzusehen, warum ihnen nicht von vornherein eine auf das Nervenleben bezügliche Fähigkeit zu funktioniren. zngeschrieben werden sollte. In den für das Nervenleben wichtigsten Bezirken des Körpers, in der Umgebung der Randkörper, tritt diese Fahigkeit in potenzirtem Maasse hervor oder kommt zu ausschliesslicher Geltung und prägt den Zellen bestimmte morphologische Eigenschaften auf, welche sie von den übrigen unterscheiden. Die Thatsachen, auf welche sich diese meine Auffassung stützt, stimmen im höchsten Grade mit den von mir bei Beroë ovatus geschilderten Verhältwissen überein, nur ist dort die morphologische Differenzirung der Nervenelemente, der Fasern wie der Zellen, wenigstens theilweise eine viel mehr ansgesprochene als hier. - Ist es geradezu ein Postulit, dass Thiere existiren müssen, in deren Körper Elemente vorkommen, welche morphologisch ihre Zugehörigheit zum Nervensystem erst andenten und andere mit Elementen, welche im Dienste des Nervenlebens steheu, ohne dass sie dies durch ihre morphologischen Eigenschaften kund geben, so ist dieses Postulat nach beiden Richtungen hin bei unseren cytophoren Toponenren in einer und derselben Person erfüllt. Die erschöpfende Untersuchung der so auf der Grenze stehenden Gewebselemente gebört zu den schwierigsten, aber 
auch sicherlich zu den interessantesten Aufgaben der Histologie. Meine in dieser Beziehung hente mitgetheilten Beobachtungen können und sollen nu die Grundlage für die weitere Verfolgung dieser Aufgabe geben: niemals aber wird die morphologische Untersuchung bei der Bentheilung so wenig differenzirter Gewebselemente wie der in Frage stehenden vergessen dürfen, dass sie ihr Urtheil eben von einer gewissen Grenze an dem physiologischen Experiment unterordnen muss.

\section{Zellen und Fasern des übrigen Körpers.}

Das Epithel der aboralen Körperoberfläehe verliert bei Cyanea capillata je weiter von den landlappen entfernt um so mehr die ansgesprochenen molphologischen Eigenschaften eines Nervenepithels. Allein es ist bemerkenswerth genug, dass diese Umänderung eine ganz allmälige ist. Im Gebiete einer mittleren Zone der Körperobertläche haben die cylindrischen Epithelzellen zwar einen ansgesprochen fadenartigen Fuss, aber Varikositäten lassen sich an denselben nicht mehr erkennen (vergl. Holzschnitt 2S). Entfernt man die Epithelzellen von der Umbrella, so sieht man diese ansserordentlich fein gestreift: ob die Streifen nur anf Eindrücke zurẗckzuführen sincl, welche die "Füsse“ auf der Oherfläche der Umbrella hervorrufen, orler auf feinste Fäden, welche. als die Fortsetzung der Zellenfüsse, vielleicht anch in das Gallertgewebe eintreten und dassellue durchziehen, das habe ich nicht entschieden. Nach der Kuppe zu verlieren die Epithelzellen den Fuss allmälig und werden mehr und mehr sthlank und hoch. Aber wiederholt gliubte ich selbst hier in der Zelle noch ein Füdchen zu erl,licken, wie es von den Randlappen als Nervenfädchen beschrieben worden ist, treilich ohne dass ich dazu gelangt wäre, nach dieser Richtung hin erschöpfend zu untersuchen. - Zwischen den cylindrischen Epithelzellen. welche, wie schon trüher erwähnt, in ihrem oberen Abschnitte braunes Pigment führen, liegen eigenthümliche spindelförmigé Körper, ähnlich an Gestalt den Sehspindeln, aber von viel bedeutenderem 1)urchmesser. welche theils feinkörnigen Inhalt führen, theils hohl erscheinen und welche im letzteren Falle im oberen Schluss der Spinrlel ein kleines glänzendes, durch Carmin sich rothfärbendes Körperchen zeigen, und in dessen Fortsetzung in ein feines, starres Stäbchen ïbergehen. Es stecken diese Spindeln ähnlich den Sehspindeln zwischen den Geisselzellen, sitzen der Umbrella aber gewöhnlich mit fadenartigem Fusse anf, nachden sie sich hänfig ninterhalb der Spindel noch einmal blasenartig erweitert haben. Ausser diesen Spindeln liegen (und 
dies ist bei allen von mir untersuehten Toponeuren der Fall) auf der aboraten Körperoberfläche Becherzellen, welche den Schleim erzengen. den die Thiere in so reichlichem Maasse z. B. beim Anfassen (Amelia) absonderu.

Nach dem früher Mitgetheilten ist bei Aurelia aurita und ebenso bei den übrigen Cytophoren ein viel schärferer Gegensatz zwisehen dem gewöhnlichen, die ahorale Körperoberfläche deckenden Epithel und ausgesprochenem Nervenepithel gegeben als bei Cyanea. Die Verhältnisse bei letzterem 'Thiere, welche amnehmen lassen, dass die Bedentung der Deckephthelien für las Nervensystem sich in der Richtung nach der kuppe des Körpers zu alluälig verliere, liessen mich auch bei Amrelia damach smchen, ol sich an den platten Deckepithelien derselben nicht. Einrichtungen finden wärden, welche anf entsprechende Beziehnngen hindenteten. Verschiedene Untersuchmngsmethoden tührten zu negativem Ergebuiss, und nu wenn ich auf Stückchen des frischen Thieres sehr schwache Goldlösungen einwirken liess, ein Verfahren, welches mir bei Berö̈ sehr gute bienste geleistet hatte, sah ich zuweilen variköse Fädchen muter dem Epithel anftreten, welche mit demselben in Verbindung zu stehen schienen (Taf. III, Fig. 10), allein ich habe keinerlei Entscheidung darüber erlangen können, ob es sich in diesen Dingen nm normale Verhältnisse handle. Für die Wiederholung iler Untersuehung werden die dem Nervenepithelium am nächsten gelegenen Bezirke des Schirmrandes auszuwählen sein, und ist anzunehmen, dass, wenn überhaupt irgendwo, hier positive Resultate erwartet werden dürften.

Die Śbumbrella. Die Epithelzellen der Subumbrella stehen bei allen ron mir untersuchten Toponeuren in derselben Weise mit spindelförmigen Muskelfädlen in Verbindung, wie die von Kleinenberg für contractil erklärten Fortsätze der Ektodermzellen von Hydra zu deren plasmaführendem Theile. Nur haben wir bei den Toponeuren morphologisch durchaus als solche ansgeprägte quergestreifte. nach beiden Enden spitz zulaufende Inskeltäden vor uns (Taf. III, Fig. j. u. 12). Der Muskelfaden entspricht in semem Verhalten zum plasmatischen. Kernführenden Abschnitte der Zelleu denı „Fusse“ der von C'yanea capillata beschriebenen Deckzellen der aboralen Oberfläche des Körpers und der oralen der Randlappen. Ihm, dem contractilen Organ der Senronuskelzelle, sitzt der Plasmacylinder oralwärts anf. Wer letztere spitzt sich nach ersterem hin entweder zu, um, in seiner Nähe angelangt, in ein Lager von Plasma sich fortzusetzen, welches seine orale Seite gewissermassen überfliesst (T'af. III, Fig. 12: das Plasma ist hier durch die Wirkung des Chromkali vom Muskeltaden theilweise abgehoben) oder es kann sich die 'Zelle gegen den Muskelfaden hin mehr und mehr verbreitern und anf diese Weise dassellue Plasmalager an ihm bilden (Taf. III, Fig. j). Bei der ersteren Art 
des Terhaltens kann der sich verclünnende Theil des plasmatischen Absclmittes der Zelle zu einem gleichmässig dünmen Faden werlen, welcher sich zuveilen sogar gabelt und varikös erscheint, bevor er an den contriutilen lrerantritt, wie ich öfters bei Cyanea beobachtet habe, und macht damn dieser Faden durchans den Eindruck eines Nervenfadens. Es rechtfertigen diese Thatsuchen durchaus die Deutung, welche E. van Beneden der von ihm bei Hydractinia echinata beobachteten Form von Neuronuskelzellen gegeben hat, indem er einen dort Zelle und Muskeltaden verbindenden Plasmatiden als motorischen Nerven anspricht ${ }^{2}$ ). - ler plismatische 'Theil der Nemromuskelzellen enthält vieltach, vorzüglich oberhalb des kerus, P'igment (besonder's schön bei Rihizostoma).

Bei Aurelia traf ich, wie hier angefügt werden mag, in einem eine strecke weit oberhall, des Randes gelegenen Gehiete eiren Theil der Zellen zu einer Substan umgewandelt, welehe äusserlich den Eindruck einer elastischen machte: ich isolirte dort Deckzellen, welehe zu mehreren vereinigt und zu mehr niedrigen, nicht mehr cylindrischen Zell-n gestaltet, eine stark lichtbrechende l'litte aufsitzen hatten, die von gröberen, auf Verlickung zurikczuführenden Balken und Füden durchzogen war, ähnlich einer elastischen Membran, oder die durch solche, parallel gestellte, Verdickungen gestreift war (Taf. III, Fig. 14 bis 18). Es ist diese Platte angenscheinlich als Cuticularbildang aufzufassen, welche als zusammenhïgendes Lager Reihen von Deckzellen verbindet, Reihen, von welchen bei der Isolirung nur Bruclistilcke zu Ansicht kommen. E; erinnern diese Verhältnisse sehr an die von mir näher beschriebene Auskleidung des unteren Theils des Magensackes von Beroë, wo die Cuticularbildıng in Reihen stehende, nach bestimmter Riclitung gebogene, lüikelienartige Bildungen herstellt. Vom einen Muskeltaden war an den geschilderten Zellen nichts zu benerken.

Werten wir einen Blick aut die Gesammtheit der Ektodermzellen, mm dieselben zn vergleichen, so gehen wir billig von Dem aus, was uns Cyanea capillata bietet, denn es ist augenscheinlich, dass hier die primitivsten Verhältuisse vorliegen. Dabei ergibt sich die bemerkenswerthe Thatsache, dass zwar die an höchsten entwickelten Nervenepithelien auch clieser Meduse, gleich jenen der cytophoren, nach dem einen Ende hin, sich zuspitzen, allmälig zu einem Firlen verfeinem (einige Bezirke der Randlappen), dass aber sonst das aborale wie das orale Deckepithel in gleicher IVeise ebendort in einen "Fuss" sich umbildet, und dass dieser Fuss aut" der aborilen Fläche der Randlappen sich in ein Nerventädchen fortsetzt, während er auf der oralen theils ebenso beschaflen, theils zum Muskeltaden geworden ist. Auf der aboralen Körperobertläche, von den Randlappen abgesehen, ist zwar die Zugehörigkeit des Fusses zum Nervensystem morphologisch nicht sicher nachgewiesen, indessen ist eine gemeinsame Anlage mit dem Nervenfuss mmzweifelhaft und die Annahme einer und derselben, nur den Grade nach verschiedenen physiologischen Bedeutung beider sicherlich nicht ohne Weiteres von der Hand zu weisen. An der

1) E. van Beneden, De la distinction originelle du testicule et de l'ovaire. Bulletins de l'Académie royale de Belgique 2ue sér. T. 37, 1874. 
Grenze zwischen dem Nervenepithel der oralen Fläche der Randlappen und deren muskelführendem Gebiete endlich verliert. wie ich schon früher gelegentlich erwähnt habe, der Nervenfuss die morphologischen Eigenschaften. Welthe er vorher hatte, erhält zunäehst ein homogenes, stark lichtbrechendes Aussehen und wandelt sich weiterhin in einen contractilen Faden, den Muskelfuss nm. Wenn Huxley den von Kleinenlserg für contrictil erkläten Fiss der Ektodermzellen von Iydra für einen Nervenfaden anspricht ${ }^{1}$ ), so ist, diese entgegengesetzten $\Lambda$ uffassungen verbindend, die thatsache $z u$ betonen, dass es nach dem Mitgetheilten hei mserem Thiere Bezirke gibt, in welthen der Fuss der Ekitodermzellen ebensogut oder ebensowenig Muskel- wie Nervenelement ist, und gibt diese interessante Thatsache einen nenen und schlagenden Beweis für die Gemeinsamkeit der Anlage und der genetischen Continuität von Inskel- und Nervensubstanz bei den Quallen, ein Beweis. Welchem ich bei Gelegenheit der Behaurlung der Cyclonemen noch andere, nicht minder wichtige werde anzureihen haben.

Nervenzellen und Nervenfasern. Der Erfolg der im ersten Theil geschilclerten Zerschneidungsversuche verlangt, wenn nicht morphologisch als solche erkennbare, so doch als solche funktionirende Nervenelemente nicht nur im Gebiete der contractilen Zunen, bezw. der Rindlappen, sondern auth in jenem des übrigen Körpers und zwar vorzngsweise in der Nähe der oralen Schirmoberfläche. Ich habe die Anfgabe, darnach zu suchen, nicht melu mit der Musse nnd Sorgfalt austühren können, welche die Schwierigkeit derselben erfordert. Es ist nicht unwahrseheinlich, dass sich bei den Cytophoren morphologisch als solche erkenubare Nervenzellen und Nervenfasern in den für das Nervenleben wichtigsten Theilen des Körpers auch ausserhalb der Submmbrella auffinden lassen, allein wegen der Unmasse von dort gelegenen amöboiden Zellen lässt sich ron vol'n herein erwarten, lass bei ihnen die Lntersuchung sehwieriger sei als bei den Acytophoren. Andererseits ist es nach den über das Gallertgewebe der simnespolster mitgetheilten 'Thatsachen möglich, dass amöboide Zellen in übrigen Körper die Anfgabe von Nervenzellen übernehmen. Ans diesen Gründen habe ich mich an Cyanea eapillata gewendet. Hier fand ich nun in der That unter den Epithelien der aboralen Körperoberfäche weitah vom Schirmrande noch Zellen: es ward mir schwer, zu entscheiden, ob ausschliesslich in der äussersten Schicht der Gallerte oder ob auch auf derselben gelegen, einmal wegen der Durchsichtigkeit der letzteren und damn wegen der ausserordentlichen Kleinheit und Unsehein-

1) Huxley, A Manual of the Anatomy of Invertebrated Animals, 1877. 
barkeit jener. Dieselhen haben das Anssehen amöboider Zellen, sind kaum so gross wie solche z. B. bei Aurelia aurita angetroffen werden, sind alser durch Anslänfer untereinander verbunden, welche wiedermm mit einem die Gallerte durchziehenden Fadennetz in Zusammenhang stehen. Ihr Vorkommen ist ein äusserst spärliches, so dass man oft lange suchen muss, bis man ihrer eine oder einige habhaft wirl. Nichts als ihre Lage und ihre Einschaltung in Fasern liesse die Annahme stützen, diss wir in ihnen die Anfinge einer Abtrenunng von Zellen aus dem Epithel vor uns haben, ähnlich wie ich solche ron den Randlappen beschrieben und dass sie demnach dem Nervensystem zugerechnet werden dürften. Der Nachweis einer Verbindung derselben mit den Epithelien würde weiter für diese Annahme sprechen, allein, diese Verbindnng anch vorausgesetzt, würde doch nur das physiologische Experiment der Dentung Berechtigung geben können und dieses spricht nach den neuesten Beobachtungen von Romanes für Unempfindlichkeit der aboralen Körperoberfläche der Medusen. Ich bin nun allerdings der Ansicht, dass dieses auffallende Ergebniss ernenter Prüfung bedarf, schon desshalb, weil ich annehmen muss, dass jene mscheinbaren Zellen, anch wenn sie Nervenzellen sind, jedenfalls mur sehr geringe Funktionsänsserungen werden zeigen kömnen, dass also das Experiment sehr sorgfültig wird ansgeführt werden müssen, falls dieselben erkannt werden sollen. Ferner sehe ich es als selbstverständlich an, dass die Annahme der Unempfindlichkeit für das Gebiet der Randlappen nicht zntrifft und endlich, dass sie von diesen weg centralwärts wenigstens bei Cyanea jedenfalls nur als eine ganz allmälig anttretende sich heransstellen werde. Indesseu fehlen bis zur Erledigung dieser F'agen die positiven Beweise dafür, irgend Zellen der von den Randlappen entfernten Bezirke der aboralen Körperoberfläche für Nervenzellen zu erklären oder eive Verbindung der Epithelien derselben mit tiefer gelegenen Theilen durch Nervenfïden vorauszusetzen.

Schon bei Gelegenheit der Besprechung der Randlappen wurde erwähnt, dass dort der Subumbrella bei den Cytophoren zahlreiche Nervenzellen anliegen. Ich meinte damit Zellen, welche mnter der Muskulatm gelegen sind, Zellen wie sie überall im Gebiete der contractilen Zonen das Gallertgewebe durchsetzen und so anch bis an die Muskelschichte heranreichen. Lei Cyanea capillata fand ich eine Anhänfung solcher Zellen anch in jenem Gebiete nicht. Dagegen traf ich da und dort, wenngleich selten, an der muteren Schirmfläche in der Flächenansicht rereinzelt theils sternförmige, theils spindelförmige, unscheinbare Zellen, welche mir zwischen Umbrella und Muskulatur oder im änssersten Theile jener zu liegen schienen, durch Fäden verbunden oder Fïden absendend. 'Morphologisch unzweifelhaft als solche erkennbare Nervenelemente traf ich aber bei allen ron mir untersuchten Toponenren beim 
Tersnch, die Neuromuskelzellen der Subnmbrella zn isoliren. Dabei erschienen isolirt oft ziemlich lange zuweilen sich verzweigende Nervenfäde n ähnlich jenen, welche ich auch unter dem Nervenepithel angetrotten habe (Taf. IV. Fig. 22). Theils waren dieselben sehr fein, mit punktförmigen Varikositäten versehen, theils waren sie gröber und die Varikositäten erschienen als Auftreibung einer scheide, welche das centrale in ihr gelegene Nervenfädchen nugab. Oft ging die zweite Form von Fasern in die erste allmälig über. In diese Fasern fand sich nun häntig eine spindelförmige Nervenzelle eingeschaltet (Taf. IV. Fig. 10). Es sei hier erwähnt, dass ich ganz dieselben Terhältnisse bei Cyclonemen, z. B. bei Lizzia Köllikeri, bei Gelegenheit des Isolirens der Subnmbrellatemente angetroften habe: der Nervenfaden mit der Nervenzelle wmele damn wiederholt anch mmittelbar einem Muskelfaden anliegend gefunden und zwar so, dass sie zwischen letzterem und der Deckzelle lagen, also "mnter dem Epithel", wie man sich, wenn anch in Anbetratht der Einlıeit von Deckzellen und contractilen Fäden nicht ganz richtig, ansdrücken kann ${ }^{1}$ ). Die bei Carmarina zu schildernden Verhältnisse werden anch dort eine solche Lage von Nervenzellen erkenuen lassen. Leider ist es mir aber weder hier noch dort bis jetzt gelnngen, die Verbindung der Nerrenfäden mit der Muskulatur und eventuell mit den Deckzellen nachzuweisen.

Bei Gelegenheit der Besprechung der liandlappen wurden anch zahlreiche Fasern erwïhnt, welche in der änssersten Gallertschichte nahe der Mnskulatur liegen. Es ziehen cliese Fasem in anffallender Menge der Unterfläche des Schirmes parallel und finten sich auch ausserhalb des Gebietes der Randlappen. Ihre Achnlichkelt mit den ans der Gallerte des sinnespolsters und speciell mit den ans dem hinulkörperstiel beschriejenen, liess mich vermuthen, dass sie gleichtalls dem Nervensystem znzmechnen seien. Her Forderung meiner physiologischen Versuche aber, auch soust im Inneru der Lmbrella Nervenfäden nachzuweisen, habe ich nicht mehr nachkommen können. Diese Fordernng ist eine so bestimmte, dass man, falls morphologisch sicher auf Nerventäden hinweisende Eigenschaften sich nicht sollten erkemnen lassen, dennoch wird annehmen müssen, dass ein 'Theil der das Umbrellagewebe durehriehenden Fasern den Nervenstrom leite.

Bindegewebstasern. - Verbindnugsblatt. Wie schon früher bemerlit wrode, bieten Durehschnitte durch das (iallertgewebe des ïbrigen sehimes gauz andere Bilder dar, als solche durch die Gegend der liandlappen. Wie weit nach Zugrichtung und sonstigen Eigenschatten etwa für Nervenfäden zn erklärende

1) "Unter der Muskelschichte kann man sagen, wenn man die Ansicht des Schirmes des ganzen Thieres in natürlicher Stellung von der oralen Fläche her voraussetzt. 
Fasem hier vorkommen, bleibt, wie gesagt, noch zu mutersuchen. Abgesehen davon trifft man ausserhalb der Randlippen ein Gevirre fron meist maschenartig untereinander verbundenen, vielfuch durch die erwähnten zipfelartigen Verbreiterungen vereinigten Fasern. Es bildet dieses Maschennetz, in dessen Fäden ich niemals Zellen eingeschlossen sah, in geringer Entfernung von der aboralen Uberfläche in grössten Theil des 'Thieres einen ganz besonders dichten Filz ('Taf. Il, Fig. 5), welchem ich es zuschreibe, lass die Aussenfläche mancher Medusen clem Messer einen auffallenden Widerstand entgegensetzen kamn, wie dies z. B. am ȟppentheile von Cyanea zu beobachten ist. Man möchte diese Zähigkeit hierselbst mit derjenigen von Leder vergleichen. Ansserhalb dieses dichteren Filzes von Fasern, zwischen ihm und dem Epithel, findet sich vielfach eine, mit schwachen Vergrösserungen betrachtet, homogen anssehende Gallertlage, welche von dem faserfilz mit scharfer Grenze sich sondert. Auch nicht maschenartig untereinander verbundene, sondern in bestimmten Richtungen die Gallerte durchziehende Fasern erweisen sich als dem Bindegewebe zugehörig, znweilen schon durch eine eigene Art der Gabelung, wie sie sonst nur bei elastischen Fasern beobachtet wird (Cassiopea), sowie anch durch andere Eigenschatten, durch ihre Dicke, ihren geschlängelten Verlauf, ihr Lichtbrechungsvermögen.

Eine ganz eigenthümliche Einrichtung im Körper der 'T'oponemren muss hier' noch Behandlung finden: auf Querdurchschnitten der Umbrella trifft man eigenthümliche Blätter, welche theils die Gefässe untereinander, theils diese und das Ektoderm (z. B. in der Randkörpertasche) verbinden. Auf den Durchschnitten der 'Tafel V und VI sind diese Blätter, Verbindungsblätter, wie sie in der Erklärung der Abbildungen genamnt sind, zu sehen. Es ziehen die Blätter dort theils oralwärts. von der Randkörpertasche mach den Gefässen, theils von diesen ans horizontal, parallel der unteren Fläche des Schirmes. Die letzteren sind Stücke eines Blattes, welches im ganzen Schirm die Gefässe zu verbinden scheint und also eine etwas oberhalb der Subumbrella gelegene und durch eine Schicht von Gallertgervebe von dieser getremnte Scheidewand in der Umbrella bildet. Durch die in den simnespolstern oralwärts ziehenden Blätterabschnitte steht die Wand mit dem Ektoderm in Verbindung. Sie besteht offenbar ursprünglich aus zwei aus Zellen gebilkten Lamellen, welche, wie in mehreren der Abbildmgen, insbesondere aber in Fig. 9, Taf. II zu sehen ist, dadurch die Entodermauskleidung der Gefässe bilden, dass sie anseinander weichen und sich wieder vereinigen. Man sieht nun aber die Blätter ebenso durch Auseinanderweichen in das Ektoderm übergehen, eine T'hatsache, welche nur die entwicklungsgeschichtliche Untersuchung wird lösen kömmen. Zuweilen aber bemerlit man, dass: die Wand vor dem Ektoderm (Riechgrube) angelangt, wenigstens theil- 
weise frei in der Gallerte endigt, indem ihre Zellen in zapfenartige Answächse anfgelöst, gegen dasselbe hinstreben (vergl. Taf. II, Fig. S, und die Erklärung der Abbildungen). - Senkrecht anf die Wand streben, wie noch bemerkt werden mag, nud wie in Fig. 9, Taf. II) zu sehen ist, von beiden Seiten feine Fasern herzn. Schon Kölliker hat die Verbindungsblatter beachtet, dem er meint offenbar sie, wenn er sagt ${ }^{\prime}$ ): „Es zeigen übrigens anch nach meinen Ertahrungen die höheren Mednsen an einen bestimmten Orte netzförmig vereinte sternförmige Zellen.... Es sind dies meines Wissens noch nirgends erwälnte Bildnngen, die bei Amelia anrita, Rhizostoma Cuvieri, Cassiopea borbonica und anch bei Cyanea capillata, deren Scheibe keine Zellen enthält, an der unteren seite der Scheibe in einer Ebene mit den Eruährungsgefässen sich finden. In der concaven Seite des Schirmes findet sich von aussen nach innen 1) ein zartes Pflasterepithel, 2) eine Muskelage, 3) eine dünue Lage der Gallertsubstanz der scheibe n. t) die Radiärgefässe und in den Maschen derselben das fragliche Zellemetz. Dieses Netz füllt, soweit ich diese Angelegenheit habe verfolgen können, alle Zwischenräume zwischen den Gefässen ans unr erscheint bald wie ein dichtes Netz sternförmiger Zellen (Anrelia, Rhizostoma), bald wie ein System ron Kanälchen mit Kernen an den Verbindnugsstellen, das an Capillaruetze erinnert (Cyanea). Ueberall liegen die Elemente dieses Netzes in einfacher Schicht und stossen somit nur an einen beschränkten Theil der Gefässe an, was den Gedanken in mir rege machte, ob dieselben nicht vielleicht wirklich eine Art capillärer Gefässe für den Nahrungssalt seien. Allein es ist mir in keiner Weise gelungen, eine offene Verbindung der beiderlei Theile nachzuweisen, vielmehr fand ich das Zellemnetz immer nur den Ernährungsgefïssen einfach ron anssen anliegend, und ich bin so schliesslich hei der Termuthmg stehen geblieben, dass dasselbe in der That nur ans einer besonderen f'orm von lindesubstanzzellen besteht. Uebrigens müssen die Elemente diests Netzes, anch wenn sie mit den Radiärgefïssen in keiner offenen Verbindung stehen, doch mit Leichtigkeit die säfte derselben anfnelmen nnd weiter leiten, und wird man vielleicht nicht irren, wem man diese besondere Einrichtung mit der Emährumg der wichtigen Mnskel- und Nervenelemente an der unteren seite der scheibe in Terbindung bringt."

Nach meinen Beobachtungen sind also die Zellen des Verbindungsblattes in zwei Lagen angeordnet, welche allerdings meist nur in der Nähe ilres Ueberganges in die Getässanskleidung dentlich sind, während sie weiterhin zßn einer eintiehen llant verschmolzen zu sein scheinen. Wïren die Zellen des Blattes contractil, so

1) Köll iker, Icones histiologicae S. 109 und Tafel X, Fig. 14, a und Fig. 15. 
würden sie eine einfache Erklärung für eine dem Einflusse der Subumbrella entrückte Verengerung, bezw. Erweiterung der Gefässe wenigstens in einem bestimmten Bezirke abzugeben vermögen; allein von Muskelelementen ist nichts zu bemerken. Möglich, dass sie, wie Kölliker meint, der Ernährung dienen, indem ihre Zellen Ernährungsmaterial aus den Gefässen aufnehmen: die von mir geschilderte Art der Verbindung mit den letzteren und ihre demnach wahrscheinliche Entodermnatur spricht für diese Auffassung, aber die Kenntniss der Entwicklungsgeschichte der eigenartigen Bildung muss zur Entscheidung abgewartet werden. 


\section{Cycloneure Medusen.}

Literatur. Zuerst hat L. Agassiz mit Bestimmtheit das Vorhandensein eines körperlich umschriebenen Nervensystems bei den Medusen behauptet ${ }^{1}$ ). Es existirt, sagt er, indem er von Sarsia handelt ${ }^{2}$ ), unzweifelhaft ein Nervensystem bei den Medusen, allein es bildet dasselbe nicht grosse Centralmassen, von welchen alle Lebenserscheinungen des Körpers ausgehen, sondern es besteht ans einem einfachen Strang eirunder Zellen, welche einen um den nnteren Rand des Thieres herumlaufenden Ring zusammensetzen, einen Ring, der sich von einem Angenfleck zum andern erstreckt, dem Ringkanale folgend. Ebenso ziehen mit den senkrechten Zweigen des Gefässsystems (mit den Radiärkanälen) Nerven und sind um den oberen Theil (um die Kuppe) des Thieres durch einen zweiten Ringuerven rerbunden. Dieses Nervensystem besteht also durchans nur aus Zellen; Fasern sind nirgends zu finden. Weiterhin ${ }^{3}$ ) wird das Nervensystem von Lizzia (Hippocrene) näher beschrieben. Ausser dem an der Einmündungsstelle der vier Radiärkanäle in den Ringkanal zu je einem Ganglion angeschwollenen Ringnerven, der an der inneren Seite des Ringgefässes verlänft, findet man unschwer an der inneren Oberfläche jedes Radiärgefăsses einen oder zwei Fäden. welche der ganzen Länge desselben nach zu rerfolgen

1) Von einer Besprechung der unsicher ausgesprochenen und nicht genau auf bestimmtes Objekt beziehbaren Angaben, welche schon vorher Kölliker: Ceber die Randkörper der Quallen, Polypen und Strahlthiere, Froriep's Notizen 1843 und Will: Horae tergestinae 1S44, p. 72, jener über radiale Nerven, dieser über Ganglien bei Geryoniden gemacht haben, glaube ich abseben zu dürfen; ebenso von den nach der Veröffentlichung ron A gassiz bekanut gegebenen Beobachtungen von Wright: Proceed. Roy. phys. Soc. Edinburg I. 1858.

2) Contrib. etc. a. a. O. (1849) S. 232 в. 233.

3) S. $266 \mathrm{ff}$. 
sind. Unterhalb der Stelle, wo die Radiärgefässe nach abwärts umbiegen, um zum Magen zusammenzutreten, bildet jeder Nervenfaden einen Plexus. Von jedem dieser Plexus geht ein Faden ab, der horizontal zum nächsten verläuft, und wird anf diese Weise ein Ring solcher Faden ,a circle of sueh threads" rings um den oberen Theil des Verdaumgsapparates gebildet, unterhalb des Centrums der Sehwimmglocke. - In der Mitte zwischen je zwei Plexus geht von dem horizontalen, sie verbindenden Faden ein nach abwärts verlaufender Faden ab, der dem Hauptzug der breiten senkrecht'ziehenden Inskelbündel folgt. Bei Sarsia soll dasselbe Nervensystem vorhanden sein, nur fehlen die Plexus. In Beziehung anf die Zugehörigkeit dieser letzteren zum Nervensystem spricht sich Agassiz indessen selbst zögernd aus, und in der That sind oberer „Ringnerv“, davon abgehende „Nervenfäden" nud "Nervenplexus" augenscheinlich nichts anderes als Falten der immeren Schirmglockenwand, wie für Sarsia tubulosa n. A, die Ansicht einer Meduse vom dorsalen Pole aus, welche F. E. Schulze in Fig. 22, Taf. III seiner Abhandlung über diese Meduse ${ }^{1}$ ) gegeben hat, zeigen kann: die Ränder der dort mit den Buchstaben mp als Muskelplatte bezeichneten Haut sind der obere Ringnerv von Agassiz; die nach abwärts ziehenden Anheftungsstellen dieser Haut an den Radiärkanälen mögen A gas siz die an der inneren Wand dieser von ihm beschriebenen Nerven vorgetäuscht haben. Anch die Fig. 23, Taf. III von F. E. S $\mathrm{Chul}$ z e ist in dieser Beziehung lehrreich. Schon Keferstein und Ehlers ${ }^{2}$ ) haben eine ähuliche Erklärung für das Agassiz'sche Nervensystem abgegeben. Diese Erklärung macht es leicht verständlich, dass dieser Forscher von seinen Nervenfäden sagt, sie hätten in jeder Beziehnng etwas Besonderes in ihrem Aussehen. Für die lerechtigung der Agassiz'schen Annahme. des Nervenringes erklärt sieh dagegen Mc $\left(\mathrm{Crady}^{3}\right)$ und auch flensen bemerkt gelegentlich seiner Beschreibung des Hörorgans einer Eucope in der Abhandlung über das Hörorgan der Decapoden ${ }^{4}$ ), dass ex für die Nerven nach Agassiz eintrete. Fritz Müller beschrieb im Jahre 1859 einen Nervenring bei Liriope catharinensis ${ }^{5}$ ). Um das Ringgefäss ziehe sich ein ziemlich undurchsichtiger gelblicher Saum, der namentlich nach aussen conturirte rundliche Zellen von 0,005 bis $0,008 \mathrm{~mm}$ Durch-

1) F. E. Schulze, Ueber den Ban von Syncoryne Sarsii, Lovén und der zugehörigen Meduse Sarsia tnbulosa, Lesson, Leipzig 1877.

2) Ki f e r ste in u. E h lers, Zoolog. Beiträge, Leipzig 1861.

3) $\mathrm{Mc} \mathrm{Crady}$, Proceed. of the Elliot Soc. of Charleston, 1859.

4) Hensen, Studien über das Gehörorgan der Decapoden. Ztschr. f. wissensch. Zool. Bd. XIII. 1863. S. 355 Anmkg.

5) Fritz II üller, Polypen u. Quallen von Santa Catharina, Die Formwandlungen von Liriope catharinensis n. sp. Archiv für Naturgeschichte 1859. S. 314. 
messer zeige und auf dem mehr oder weniger reichliche Nesselzellen liegen. An der Basis der Tentakel und dazwischen habe er längliche Anschwellungen, denen die sogenannten Randbläschen aufsitzen. Mit aller Wahrscheinlichkeit sei er als Nerrenring zu deuten. Es spreche dafür ausser den die Randbläschen tragenden Anschwellungen die Thatsache, dass von jeder dieser Anschwellungen ein zarter aber scharf begrenzter Strang nach oben verfolgt werden könne. Von den acht Strängen gehen vier zur Basis der Tentakel, vier zu Punkten, an denen das jüngere Thier ebenfalls Tentakel getragen hatte. Fritz Müller beschreibt die Randbläschen der Liriope als Bläschen mit doppelter Begrenzung: am oberen Rande entferne sich die innere Contur von der ansseren und bilde eine Art breiten kurzen Stiel, anf dem eine gelbliche Kungel aufsitze und diese, dem Stiele gegenüber leicht ausgehöhlt, umfasse hier eine kleinere, stark lichtbrechende Kugel ${ }^{1}$ ): diese letztere wird als Linse, der erstere als Sehnerv gedeutet. Es ist aber jene offenbar nichts anderes als die ron mir bei Carmarina alsbald zu beschreibende Kapsel von Hörzellen, welche den Hörstein (die untere, glänzende Kugel) umschliesst. Dagegen handelt es sich in den beiden Grenzlinien des Randbläschens, welche sich „oben von einander entfernen und eine Art breiten Stiel bilden" angenscheinlich um die wirklichen Sinnesnerven, d. i. um die Hörnerven. Die zarten aber scharf begrenzten Stränge, welche von den Anschwellungen des Ringnerven nach oben gehen, sind offenbar die später ron Häckel als Mantelspangen beschriebenen Einrichtungen. - Ferner glanbt Fritz M üller anch bei Conina Köllikeri bestimmte Theile clem Nervensystem zurechnen zu dürfen: einen matten, hei dem Randbläschen anschwellenden, aus Zellen bestehenden Streifen am Sanme der Randlappen und ebenfalls aus Zellen bestehende Wülste an der Basis jedes Tentakels ${ }^{2}$ ). - Endlich beschrieb er bei den Charybdeiden an zwei nenen Arten, Tamoya haplonemi und quadrumana, ein Nervensystem, welches im Wesentlichen mit dem bei den genannten Craspedoten geschilderten übereinstimmen würde. Der lingnerv schwelle zu vier Ganglien an, ron welchen bei quadrumana gegeu zwanzig Nerven theils zum Telum, theils zum handförmigen Anhang abgehen; bei hajlonema seien die Nerveu weniger zahlreich. Wenn anch der Ringnerv F. Mäller's ${ }^{3}$ ) nicht überall dem wirklichen ans Fasern zusammengesetzten Ringnerven entsprechen kann, sondern vielmehr der Beschreibung nach theilweise zurückzuführen ist auf zellige Elemente des Schirmrandringes, so zeigt doch schon

1) Man vergl. Mäller's Fig. 9. Bd. I. I 1861 .

2) Fritz M ̈̈ller, Cunina Köllikeri n. sp. Beitrag zur Naturgesch. d. Aeginiden, Archir f. Naturgesch.

3) Fritz Müller, Zwei neue Quallen fon Santa Catharina, Abhdl. d. naturf. Ges. zu Halle, T. Bd. 1860. 
die Uebereinstimmung dieser nnd anderer Verhältnisse zwisehen den Charybdeiden und den Craspedoten, dass F. Müller im Rechte ist, wenn er jene von den Acraspedoten weg und zu diesen stellt und ist anzunehmen, dass bei ihnen in derselben Weise auch ein faseriger Ringnerv in Schirmrande wie bei den Craspedoten vorhanden sei, so dass sie also wie diese Cyclonenren sein werden. Ausser Fritz Müller erwähnt anch Semper einen Nervenring bei zwei von ilm beobachteten Charybdeiden ${ }^{1}$ ); ob er eine histologische Untersuchung desselben vorgenommen hat, geht aus seinen Angaben nicht hervor.

Leuckart ünssert sich, die oben berührten Ansichten von Keferstein und Ehlers besprechend, dass er sich im Gegensatze dazn bei einer in der Nordsee weitverbreiteten Eucope anf das Bestimmteste von der Existenz eines besonderen, neben dem Ringgefăsse hinlaufenden Randfadens überzengt habe ${ }^{2}$ ). $\mathrm{Ob}$ derselbe freilich ein Nervensystem darstelle, sei mit Sicherheit nur schwer zu entscheiden. Als der Erste thut er übrigens einer Längsstreifung Erwähnung, welche die zwischen den Anschwellnngen des Schirmrandes gelegenen Commissuren zeigen. Cla u s sah den von F. M ü $\mathrm{l}$ le r bei Liriope catharinensis beschriebenen Nervenring an Eucopiden, Oceaniden und Geryoniden ${ }^{3}$ ). Er findet zwei Zellenlagen am Ringgefäss; von welchen die untere als eine Verdickung des Zellbelags der Gefässivand anzusehen sei und gleich der oberen, an den Tentakelursprüngen Wülste bilde (also wohl die auf Seite 71 von mir beschriebenen Anschwellungen). Die von der oberen Zellenlage gebildeten Wülste seien nicht etwa Ganglien, sondern das Epithel der Tentakelanlage, welches Nesselzellen einschliesse. Die Deutung des Randsaumes als specifisches Nervensystem sei wegen des Fehlens von Fasern zurückzuweisen. Dagegen weist F. I ü 11 er wiederum darauf hin, dass er auch von zarten radial verlaufenden Strängen gesprochen habe, welche möglicherweise Sinnesnerven sein könnten ${ }^{4}$ ).

Es würde ungerecht sein, nicht hervorzuheben, dass der Hanpttheil des Nervensystems der Cyclonenren in der That in den Gebieten liegt, welche von den meisten der genamnten Autoren dafür in Anspruch genommen sind, nümlich in Form eines Nervenringes am Schirmrande; und class auch die Zellen, welche dort schon

1) Semper, Zeitschr. f. wissensch. Zool. Bd. XIII. S. 562.

2) Le u ckart, Bericht über die Leistungen in der Naturgeschichte der niederen Thiere während der Jabre 186I-1862. Archiv f. Naturgesch. 1868. Il. Th. S. 232.

3) Cla us, Bemerkungen über Ctenophoren u. Medusen, Ztschr. f. wissensch. Zool. Bd. XIV. I864. [Die Beobachtungen sind theilweise schon 1860 gemacht.

4) F. M ï 1 le r, Ueber die Randbläschen der Bydroidquallen. Archiv f. mikı. Anat. Bd. I. 1865. 
ron Agassiz dem Nervensystem zugetheilt worden sind, demselben zugehören, wenn anch nicht in dem von ihm rorausgesetzten sinne, sonderu nur als Nervenepithelien möchte man annehmen, wenn er nicht ansdrücklich seinen lingnerven an die innere seite des Ringgefässes verlegte. Auch Diejenigen, welche einen der Mantelspange $\mathrm{Hackels}$ entsprechenden Radialstrang dem Nervensystem zurechneten (F. M ülle r), hatten nicht ganz Unrecht, und dasselbe scheint für einige der den Ringnerven betreffendeu Angaben der Fall zu sein (F. M M̈ller, Lenckart): aber freilich ist die Uebereinstimmung dieser Angaben mit dem Thatsächlichen eine melı oder wenig̉er zutällige, weil sie nicht anf Grund genaner, feinerer. Untersnchung gemacht worden sind. Erst Häckel hat den wirklichen, ans Faseln znsammengesetzten Ringnerven unzweifelhaft vor sich gehabt und zwar speciell bei den hiüsselquallen ${ }^{1}$ ). Er beschreibt ein Nervensystem bei Glossocodon eurybia und bei Carmarina hastata, indem er bemerkt, dass die Bildungen, welche er als solches "mit sicherheit denten zn dürfen glanbe" nur mit den von Fritz 11 üller bei Tamoya geseheneu, und namentlich mit den von Lenckart als Nerven beschriebenen Theilen unter den früheren Angaben zusammenfalleu. Es ist Häckel der erste nud einzige Forscher, welcher Elemente beschreibt, die Aehnlichkeit mit Nervenzellen und Nerrenfasern haben und der erste. welcher dieselben isolirt zu haben scheint und isolirt abbildet. Der liingnerv liegt zwischen lingeanal und dem sogenamnten Knorpelring und schwillt bei Carmarina an der Basis der zwölf Simnesbläschen zu ebensovielen Ganglien (Ganglien des Ringnerven) an (bei Glossocodon zu deren acht). An der Basis jedes Randbläschens befinde sich ein flaches, wahrscheinlich mit dem Ringnervenganglion in Znsammenhang stehendes Zellenpolster, welches für einen Nervenknoten erklärt mul als basalganglion bezeichnet wird. Rechts und links rerlängert sich dasselbe in die Sinnesnerven, vielmehr entspringen diese je zu zweien ans einem Gauglion des Ringuerven und treten durch das Basalganglion durch. Beide bandförnigen sinnesnerven lanfen an der Wand des Simnesbläschens nach oben, wo sich ihre Fasern zn duchkreuzen scheinen und in ein kugeliges, die dirin gelegene. concentrisch gestreifte Concretion (Otolith oder linse) umgebendes körperchen eintreten, welches tür einen dritten Nervenknoten erklärt mnd als Sinnesganglion bezeichnet wird. Es soll dasselbe bei starker Vergrösscrung als eine Kapsel erscheinen, welche in doppeltbegrenzter Membran eine aus dichtgedrängten kleinen Zellen zusammengesetzte Masse numschliesst. Anssel den Simesnerren schickt jedes Ganglion des lingnerven noch einen spangennerven

1) E. Hï ekel, Die Faruilie der Rüsselquallen, eine Monographie, Leipzig, Engelmann 1 S6j u. Jenaisehe Ztschr. f. Medicin u. Naturw. Bd. I w. II. 
$\mathrm{ab}$, welcher über das Sinnesbläschen weg nach aufwärts verläuft, ferner jedes der sechs radialen einen anderen, welcher das entsprechende Radialgefäss begleite, den Radialnerven und endlich noch einen Tentakelnerven, zu jedem der 6 Haupttentakel. Die sechs stärksten Nervenstränge des Schirmes seien die Radialnerven, welche als platte, breit lineare Bänder, begleitet von den 6 unpaaren radialen Muskelbänder'n der Subumbrella, in der Mittellinie der unteren Wand der Radialkanäle verlaufen, so dass sie hier nur von dem düunen Ringmuskelbelege und dem zarten Epithel der Snbumbrella bedeckt sind. Sie lassen sich bis zum Magen herab verfolgen, wo ihr weiteres Verhalten undentlich wird. - Die Sinnesbläschen liegen eingebettet in die Wand der Mantelgallerte, wie auch bei anderen Geryoniden. Die sehr dünne, doch bei starker Vergrösserung doppelt conturirte Wand des Randbläschens wird von einer homogenen Membran gebildet und ist innen von einem einfachen platten Pflasterepithel ausgekleidet. - Der Knorpelring bildet einen den Schirmrand rings umgebenden Strang von Knorpelzellen, und schickt über jedes Sinnesbläschen ein nach oben sich verschmïlerndes und zuspitzendes, ans ebensolchen Zellen bestehendes Band, die Mantelspangen. Knorpelring und Mantelspangen stützen den Schirmrand. Was F. M üller bei Liriope als Ringnerv beschreibt, sei ohne Zweifel der Knorpelring: der Ringnerv enthalte nicht überall, sondern nur unter den Sinneshläschen Zellen. Die Mantelspangen seien von F. Müller bei Liriope gesehen und als Tentakelnerven gedentet worden. Es entspreche jedoch nicht die ganze Spange dem Nerven, der letztere verlaufe vielmehr in der Mitte über dem breiteren darmerter liegenden Muskelstrange, der sich durch die Querstreifung seiner dunkleren Fasern dentlich von den helleren und blasseren Nervenfaserm unterscheide. Beide seien ansserdem nach aussen von dem Spangenepithel überdeckt, welches zerstreute Nesselzellen enthalte. Bei Glossocodon sind die Verhältnisse im Wesentlichen dieselben wie bei Carmarina, nur in manchen Punkten nicht so deutlich. - Noch schwieriger als bei den Geryoniden sei es bei Cunina rhododactyla sich auch nur von der Existenz des Ringnerven zu überzengen. Was F. M üller bei Cunina Kóölikeri als Ringnerv besclureibt, hält Häckel für den Knorpelring. - Die Elementartheile des Nervensystems der Geryoniden seien Fasern und Zellen, beide sowohl bei Glossocodon wie bei Carmarina, schwer nachizuweisen. „Viele Zeit und Mühe“, sagt der Autor, „habe ich vergeblich aufgewendet, ehe es nir gelungen ist, die nervösen Elementartheile völlig zu isoliren und als solche zu bestimmen. Soweit ich diese sehr schwierigen Verlältuisse mit einiger Sicherheit erforschen komnte, habe ich die Nervenzellen nicht allein auf die unter der Basis der Sinnesbläschen gelegenen Ganglienknoten beschrănkt gefunden, sondern auch im Verlaufe der Fasern mehrfach zu 
erkennen geglaubt" (vergl. dagegen vorhin). Als zum Studium der Nervenfasern besonders günstig werden die Radialnerven hervorgehoben, welche indessen, wie wir sehen werden, Muskelbänder sind. Ueberhaupt wird sich ergeben, dass ich in vielen wichtigen Punkten mit der Darstellung Häckels nicht übereinstimmen kann: jedenfalls aber hat dieser Forscher das grosse Verdienst, den wesentlichsten Theil des Nervensystems der Cycloneuren, den Ringnerven, znerst auf Grund histologischer Untersuchung als solchen dargestellt und damit für weitere Untersuchung Bahn gebrochen zu haben. Wenn die Angaben $\mathrm{Häckel's} \mathrm{vielfach} \mathrm{nicht} \mathrm{als} \mathrm{entscheidend}$ hingenommen worden sind, so erklärt sich dies, wie schon in der Einleitung bemerkt worden ist daraus, dass er selbst sich vielfach zweifelnd und unbestimmt ausspricht, und dass auch seine Abbildungen nicht gerade beweisend sind. Um so mehr bleibt es zu verwundern, dass eine eingehende Untersuchung des Gegenstandes so lange Zeit nachher nicht vorgenommen worden ist, demn vor mir sind von Anderen nur einzelne gelegentliche Beobachtungen in Betreff desselben gemacht worden. Nach F. E. Sehulze soll bei Sarsia tubulosa ${ }^{1}$ ) ein Ringnerv vorhanden sein, vielleicht auch Radiärnerven. In Beziehung auf die letzteren enthält er sich eines bestimmten Urtheils und erklärt, dass sie auch Muskelfasern sein könnten. Sie sind dies, wie mir eigene Untersuchungen zeigen, in der That. „Mit grösserer Sicherheit" sagt Schulze, „kann ich mich für das Vorhandensein eines Nervenstranges in dem unteren Randtheile der Glocke aussprechen. .... Nach unten und etwas nach aussen vom Ringkanal liegt nun jener aus etwa 6 bis $S$ gleichmässig dicken, mässig stark lichtbrechenden Fasern bestehende bandförmige Strang, welchen ich nur für einen Nervenring halten kann. Mit den oben beschriebenen Muskelfasern haben diese völlig parallelrandigen Fasern, an welchen ich niemals freie Enden wahnehmen konnte, durchaus keine Aehnlichkeit. Sie sind gleichmässig hell, schwächer lichtbrechend, ohne Spur von Querstreifung. Während alle Muskelfasem ganz gerade gestreckt verlaufen, zeigen sie an den erhärteten Objekten wellige Biegungen. Auffällig erscheint ferner eine grosse Menge ovaler Kerne, welche, von wenig körniger Masse umgeben, zwischen oder an diesen Fasern bemerkt werden." — Ich bedaure, mit der Deutung, welche Schulze den von ihm beschriebenen Fäden gibt, nicht übereinstimmen zu kömnen: dieselben, wie sie in Figur 16 und 17 von ilm abgebildet sind, können ihrem ganzen Habitus und ihrer geringen Zahl nach und -besonders ihres grossen Dickendurchmessers wegen, unmöglich Nervenfäden sein; es kann sich in denselben 
nur um Muskelelemente handeln und in der 'That finde ich bei Sarsia am Schirmrande ausser einem aus feinsten Fäden zusammengesetzten Ringnerven einen Ringmuskelbelag.

A $11 \mathrm{mann} \mathrm{n}^{1}$ ) stimmt der Darstellung Häckel's bezüglich des Ringnerven bei den Geryoniden bei, vertritt aber die Ansicht, dass dieselbe auf andere Medusen, speciell anf die Encopiden, nicht anwendbar sei, wogegen Ha rting ${ }^{2}$ ) den Nerven bei einer Eucope (?) beschreibt.

Den im Uebrigen von mir selbst über das Nervensystem der Cyclonemren gewonnenen Ergebnissen, wie ich sie vorzüglich für Carmarina hastata in September vorigen Jahres auf der Naturforscherversammlung zu München im Auszug mitgetheilt habe, folgten bald die Veröffentlichungen von $U$. und $R$. Hertwig ${ }^{3}$ ) und anch R. Böhm ${ }^{4}$ ) hat seitdem einige bezügliche Beobachtungen bekannt gegeben.

Unter allen von mir untersuchten cycloneuren Medusen bieten die Geryoniden das günstigste Objekt zum ersten Erkennen des Nervensystems dar: an ihnen gelang es mir alsbald, mzweifelhafte Nervenelemente nachzuweisen, nachdem ich vorher bei anderen Formen mit wenig Erfolg darnach gesucht hatte und erst jetzt fiel es mir leichter, auch an diesen positive Ergebnisse zn erlangen. Da vollends das Nervensystem der Toponeuren in seiner Ausbildung weit hinter dem der Geryoniden zurücksteht, so hat $\mathrm{H}$ äckel mit der Untersuchung gerade der letzteren den denkbar glücklichsten Griff gethan. Wie früher bemerkt, sind meine bezüglichen Untersuchmngen während der Monate März und April 1576 in der zoologisehen Station zn Neapel angestellt, in welcher Zeit mir dort Carmarina hastata und Geryonia exigua in Fülle zur Verfügung standen. Die folgenden Angaben beziehen sich auf Carmarina hastata; auf Geryonia exigua habe ich nur gelegentlich Rücksicht genommen, fand inclessen, soweit dies geschehen ist, nur Verhältnisse, welche mit den bei Carmarina von mir beobachteten übereinstimmen. Bevor ich an die Schilderung des Nervensystems ron Carmarina hastata gehe, ist es nöthig, die allgemeinen Bauverhältnisse des Schirmrandes dieses 'Thieres zu behandeln, deren Kenntniss zu jener Schilderung vorausgesetzt werden muss.

1) A 1 l man, A Monograph of the gymnoblastic or tubularian Hydroids, London 1871.

2) Harting, P., Notices zoologiques. Niederländisches Archiv für Zoologie. Bd. 11. 1873.

3) a. a. 0 .

4) a. a. 0 . 


\section{Allgemeine Bauverhältnisse von Schirmrand und Segel.}

Betrachtet man den Schirmrand einer lebenden Carmarina genau mit blossem Auge von aussen, so sieht man ihn begrenzt von einem wulstartigen Sanme, welcher mehr träbe aussieht als die klare, durehsichtige Masse des übrigen 'I'heils des Schirmes. An dem conservirten, mit Carmin gefärhten Thiere wird dieser Wulst dunkler roth als die Umbrella. An einem Exemplare, dessen Schirm in flach ausgebreitetem Zustande ohne Einrechnung des Segels $6 \mathrm{~cm}$ im Dnrchmesser hielt, war er etwa 3,5 $\mathrm{mm}$ breit. Schneidet man ein Stückchen des Schirmrandes ans und bringt dasselbe in der Lage nnter das Mikroskop, dass die aborale Fläche uach oben schant, so bietet sich der liandwulst als ein zuweilen leicht rosá gefärbter, im unteren, dem Yelum anstossenden Bezirke lebhaft Himmernder Streifen dar, dessen Oberfläche aus Geisselzellen znsammengesetzt ist, während oberhalb dieses Streifens, zwischen nicht geisselndem Epithel zahlreiche Nesselzellen auf ihm in die Augen fallen. Dieser rings den Schirmrand umgebende Wulst, der Schirmrandring, wie ich ihn nennen will, ist es, welcher ganz oder in Theilen seines Inhaltes von versehiedenen Forschern als Ringnerv in Anspruch genommen worden ist, und welcher diesen Nerven in der T'hat enthält. Untersncht man den ganzen Randwulst mit schwachen Vergrösserungen, so sieht man oberhalb desselben, wie ihm aufsitzend, die zwölf, übrigens sehon mit blossem Auge sichtbaren, Sinnesbläschen, Hörbläsehen, wie ich sie nenne, von denen sechs um ein Geringes seitwärts von den sechs nach unten vom Rand abgehenden Tentakehn sitzen (Taf. VII, Fig. 1, Hbl), während von den anderen sechs je eines zwischen zwei der ersteren seine Lage hat, so dass alle zwölf in gleichmässigen Abstand von einander angebracht sind. Ueber jedes Hörbläschen läuft ein nach oben sich verschmälernder Faden an der Anssenfläche des Schirmes nach anfwärts (Taf. VII, Fig. 1 Sp) mit breiter Basis rom Randwulst entspringend das Radialganglion oder spangenganglion, die ron Häckel sogenannte Mantelspange. Eine Ansammlung trüber Ektodermzellen. zwischen welehen nesselnde eingestrent sind, verdeckt diese Verbindung (Taf. VIII, Fig. 3. Gg) bei der gegebenen Ansicht. Zur genaneren Untersuchung des Schirmrandes, besonder's zum Nachweis des Ringnerven, bezeichnet Häckel Querschnitte durch den ersteren oder Zerzupfen als geeignet. An in doppeltehromsaurem Kali conservirten Thieren. welche ich vorzugsweise $z$ mistologischen Studium benützt habe, hat man ein anderes gutes Nittel, um sich von der Anwesenheit, der Lage und der Beschaffenheit des Ringnerven zu überzeugen : begimnt man hier mit der Nadel die änssere Oberflärhe des Schirmrand- 
ringes zu verletzen, so gewahrt man, dass das dieselbe bildende Epithel sich ablöst und dass es sich leicht eutfernen, ja mit einer Lanzette stückweise abheben lässt. Hat man dies in geeignetem Umfange gethan, so erkennt man 1) nach unten, dicht neben dem Ansatze des Velums, einen aus feinsten Fäserchen zusammengesetzten Strang von etwa $0,05 \mathrm{~mm}$ Querdurchmesser - den Ringnexven (Taf. VIII, Fig. 1, N) und 2) eine eigenthïmliche lockere Zellenmasse, welche den vom Nerven freigelassenen Ranm des Schirmrandringes ausfüllt, indem es jenen nach oben und in besonderer Mächtigkeit nach anssen einschliesst - Häckel's sogenannter Knorpehring, die Füllzellen, wie ich diese Zellen nemnen will. Un sich äber dic näheren Verhältnisse des Schimrandringes zn unterrichten, verbinde man die soeben angeweudete Methode mit Querschnitten. Man erkennt anf diese Weise, dass der Sichirmrandring ein Rohr darstellt, welches, wie schon vorausgeschickt wurde, an der Kante des von Schirmwand und Telum gebildeten Winkels gelegen ist, ein Tiohr, ausgefüllt von den von Häckel sogenannten Kinorpelzelleu, den „Füllzellen", und ausserdem enthaltend den Ringnerven, sowie endlich eine grössere Anzahl von Zellen näher zu besprechender Art.

Die Wande des Rohres sind die folgenden: die nach aussen und unten gerichtete, die convexe Wölbung des Wulstes bildende Wand (IV, Holzschnitt 30) wird hergestellt von dem schon erwähnten Epithel, welches nach oben in die platten Deckenepithelien der Aussenfläche der Umbrella, nach unten in diejenigen der aboralen Fläche des Segels (niedrige, einschichtige Zellenlage) übergeht. Es besteht dieses Epithel da, wo es den Ringnerven (N, Holzschnitt 30) überdeckt, und weiter proximalwäts, in der kichtung vom Velum weg, aus näher zu beschreibenden hohen, wie schon erwähnt, theilweise geissehden, Nervenupithelien (vergl. n. A. Taf. XI, Fig. 2, Taf. XII, Fig. S u. 12 u. Taf. VIII, Fig. 1 u. 2 und die Tafelerklärungen), welche mehr und mehr nach aussen einer niedrigeren, von Nessel- und gewöhnlichen Drüsenzellen durchsetzten Bedeckung Platz machen ('laf. VIII, Fig. 2 D, Tat. IX, Fig. 3. d, Fig. 5 Jrüsen, Taf. VIII, Fig. 1, 2, '/ Nesselzellen). Die Irïsen haben theils einen mehr homogenen, theils einen ausgesprochen körnigen Inhalt, welcher sie nach Carminfärbung schön roth von der Umgebung abhelst. Uieselbe Fürbung zeigen die Nesselschläuche derjenigen Nesselzellen, welche noch im jugendlichen Zustande sich befinden, und solche Formen sind von den Drüsen mit homogenem Inhalt oft kaum zu unterscheiden. एaa heiderlei Bildungen ausserdem zwischen einander liegen, so drängt sich der Gedanke anf, dass beide, Nesselzellen und gewölnliche Drüsenzellen verwandtschaftlich unmittelbar zusammeuhängende Bildnngen seien. Gegen die obere Grenze der Epithelialdecke hin traf ich wieder sehr hohe Zellen. - Irgend eine besondere Stützhant hat diese Epithelialwand des Schirmrandringes nicht; sie ist desshalb an er- 
harteten Prifuaraten wenig wirlerstandsfihig, brïchig; im frisehen Zustande dagegen

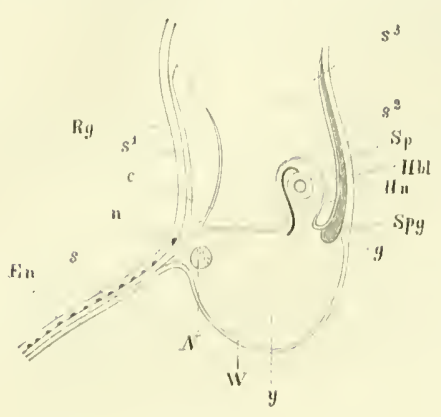

Holaschnitt 30 .

W Epithelwand Jes Schimmrandringes; y von bitllzellen eingenommener Raum; c Cuticularwand desselben; IIbl llörbläschen; Iln Hibnerv; N Nerv; n dessen orale Abtheilung; 8 Stiitzblati des Velums; B $^{1}$ Stützblatt der linteren, $\mathrm{s}^{3}$ St ätzllatt der vorderen Wand des Lingrgefísses; s $^{2}$ Stützblatt der Aussenfläche der ITmbrella; Spg Radialganglion; $S_{1}$ Spangenganglion; or das das Radialganglion deckende Hithel; lin Neuromuskelzellen. (Schematisehe Zcichnung.) mag dureh die unterilır gelegenen Zellen ein mehr oder wenigrer elastisehes J'olster für sie hergestellt werden. Die äbrige Ungrenzung des Schirmrandringes dagegen, der obere Theil der inneren oder hinteren und die obere Wand, weleh letztere denselben vom linggefïss mud von der über ihm gelegenen Umbrella trennt, ist fest, indem sie ans cincr homogenen Stützhant hergestellt wird (e, Holzselunitt 30). Eis ist diese Stützhaut, das St ützb. $l$ a $t \mathrm{t}$, eine l'ortsetzung des Stützblattes des Segels. Querdurehsehnitte durch das Segel zeigen nämlich, diss es zusimmengesetzt ist aus diesem Stützblatt (s), darauf gelagerten Nemromiskelzellen (En) und 3) einer anf seiner unteren (aboralen) Fliche gelegenen niedrigen Epithelschicht. Dats homogene Stritzblatt des Segels ist ziemlich dick, die Muskelfüiden kömen durch ilne Anlagerming anf seiner oberen flitche eine feine Streiting hervorrufen, anf der unteren dagegen werlen leichte warzenatige Erhebmgen bemerkt mo besonders gegen ihren Uelergang in alen schim erseheint sic haintig, parallel dem liande des Telums, gefaltet. Wie Durehsehnitte tehren, geschicht der Ansatz des Segels an den Schirm da, wo die hintere (inmere) Wand (s') des Ring gefitsses (lig) in dessen Boden übergeht.

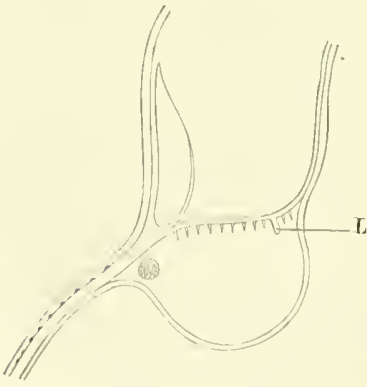

1lolzsehnitt 31 . An dieser Ansatzstelle theilt sieh das Stützblatt desselben in zwei hamellen, von welchen die eine nach oben steigt und das stützhlatt dor linteren Wand des Ringefässes (s) Jildet, während die indere, ungefïhr in horizontaler lichtung nach answitrts strebent, nach ans- mol aufwairts rieht, (e und $\mathrm{s}^{2}$ ) mun, nach anfwärts clümner und dünner werdend, eine Art anf der Lmbrella anfgelagerter C'ntienla zu bilden (Holzschnitt 31), mit woleliem Namen sie auch von Köulliker, der die geschilderten Verhältnisse schom richtig besehrieben hat'), bezeichnet worken ist. Zuweilen schien os mir, als ob sieh anch anf die hintere Oberflache der das ling-

1) Kölliker, Icones histiologicae, Taf. XVIl, Fig. 1. 
gefäss nach aussen mmgebenden Gallertmasse eine sehr zarte Fortsetzung des Stützblattes ausbreite $\left(\mathrm{s}^{3}\right)$. - Es wird somit jedenfalls die obere und der oberste $\mathrm{Ab}$ schnitt der hinteren Wand des Schirmrandringes vou dem Stützblatte gebildet und zwar der letztere vom Stützblatte des Segels. - Der Mnskelbelag des Segels reicht, wie schon Kölliker erwähnt, nicht ganz bis an seinen Ansatz am Schirme, hört vielmehr links von n (Holzschnitt 30) auf, un an der hinteren Wand des Ringgefässes wieder zu beginnen, so dass in der Gegend von n nur Epithelbelag zu suchen ist, nicht aber Nemromuskelzellen. Mit Ansuahme dieser Stelle ragen nun von dem an der Wand des Schirmrandringes sich betheiligenden Abschuitte des Stützblattes in das Lumen des letzteren eigenthümliche kegelförmige Erhebungen zapfenartig hinein (Holzschnitt 31) ${ }^{1}$ ), deren freies Ende theils spitz, theils mehr abgestumpft, stets aber deutlich zerfasert erscheint (Taf. VII, Fig. 6, 7, w): an günstigen Präparaten sieht man, dass diese Faserung den Anfang dünner, starrer Fäden bildet, in welche sich die zapfenartigen Erhebungen auflösen und welche, wie anf Querschnitten theilweise deutlich zu verfolgen, zwischen den den Schirmindring erfüllenden Zellen durchziehend, der gegenüberliegenden Epithelwand zustreben: die Stützfaseru des Schirmrandringes, wie ich sie nennen will. Es sind diese Stützfasern besonders leicht an der oberen Grenze des Schirmrandringes, da wo dessen Epithel in das gewöhnliche Epithel der Körperoberfläche übergeht, zn sehen (Taf. V1I, Fig. S, F), wem man, in der früher beschriehenen Weise das erstere entfernend, die Untersuchung von der Aussenfläche her vornimmt. Man erkennt damn zugleich, dass jene Grenze am Stützblatte durch eine unterbrochene, niedrige, zuweilen wie gezähnte leistenartige Erhebung bezeichnet wird, von welcher, wie von den gewöhnlichen Zapfen, Stützfasern abgehen (Taf. VI, Fig. 2 und 6, Taf. 1X, Fig. 2 y, und Holzschnitt 31 ). Eine zweite Leiste, welche indessen durchaus regelmässig glattrandig, scharf doppelt begrenzt und welche, wie wir sehen werden, von grösserer topographischer Bedeutung ist, erhebt sich etwas einwärts von der eben erwähnten, und durchzieht, ihr parallel, nur unter jedem Hörbläschen im Bogen gegen dasselbe hinauf strebend, den Schirmrandling. Sie fällt in der Flächenansicht nach Wegpinseln des Inhalts des Schirmrandringes sofort in die Augen (Taf. VII, Fig. 2, 6, VIII, Fig. 2, IX, Fig. 2, 8, 9, 11 und Holzschnitt 31 , überall bei L), nach Carminfärbung besonders auch durch das dunklere Roth, welches sie gegenüber den übrigen Theilen des Stützblattes angenommen hat.

Inlialt des Schirmrandringes. Gleich unter der Epithelwand trifft man zerstreut Ganglienzellen (Taf. VI11, Fig. 1, 2, 3, 13, gz), von welchen später ausführ-

1) Holzschnitt 31 stellt einen $\mathrm{z}$ wis chen zwei Hörbläschen geführten schematischen Durchschnitt des Schirmrandes dar. 
licher gehandelt werden soll. Unter demjenigen Theile dieser Wrand, welcher sich der Stützlamelle des Segels nähert, um sich als Epithel der Unterfläche desselben fortzusetzen, liegt parallel mit der Grenze dieses Ansatzes, ein Strang von feinen Fäden, der Ringuerv (Taf. VIII, Fig. 1, 2, 4, N, Holzschnitt 30, N)²). Der übrigbleibeude Ramm des Schirmrandringes ist ausgefüllt von Zellen, welche im Wesentlichen von zweierlei Art sind. Die emen liegen dem von der stützlamelle gebildeten Theile der Wand dicht an - ich dente sie als Nervenzellen und werde sie als solche später näher behandeln (Taf. FIIT, Fig. 12). Die anderen sind die von Häckel sogenannten Knorpelzellen, und sollen nach diesem Antor eineu „Knorpelring“ herstellen, der dem Schimmande Festigkeit verleihe. Ton diesem Kinorpelringe aus soll ein Strang von Kónorpelzellen unter der Anssentläche des Schirmes je über einem Hörbläschen raliär nach aufwärts verlaufen, um muter allmäliger Verschmälerung spitz zu endigen: die Spangenknorpel Häckel's. Ebenso soll sich vom knorpelringe aus ein Strang von Knorpelzellen je in einen T'entakel erstrecken: 'Tentakelknorpel. Ich bedaure, diese Darstellung, welche z. B. in die Lehrbücher der vergleichenden Anatomie von Gegenbaur, selbst durch einen schematischen Uurchschnitt des Thieres erläutert, äbergegangen ist ${ }^{2}$ ), nicht für richtig erkilären zu kömnen: die Zellen des Spangenknorpels sind Nervenzellen und jene des Schirmrandringes sind ebenfalls keine Knorpelzelleu, sondern Zellen gauz eigener Art. Hä ikel sagt, es seien die letzteren vou lntercellularsubstanz znsammengehalten und seine Abbildungen scheinen allerdings ziemlich typischen Knorpel wiederzugeben. Teh kann jedoch eine Intercellnlarsubstanz nicht finden, wie denn auch die Zellen selhst in ihrem Ban mit Knorpelzellen gar nichts gemein haben. Anch das physikalische Erforderniss zum Begriffe des Knoripels fehlt ihnen vollständig: einen Halt können sie dem Sichirnrante in keiner Weise bieten, vielmehr möchten sie die am lockersten zusammengefügten Zellen des ganzen Körpers sein. Sie fallen wenigstens an Chromkaliprälparaten, auch damn, wenn andere Zelienverbindungen eine nur mässige Lockerung erfahren haben, anf die leichteste berälrmng hin anseinander, so wemm man nach Entfernen des Oberfiächenepithels eine Zerstörmug des .Knorpelringes" mit der Präparirnadel versncht, robei es sich zeigt. dass z. B. speciell die Elemente des Epithels riel imniger aneinander haften als sie. Anch wenn man an sulchen Präparaten Querschnitte durch den Schimmandring macht, sind es znerst die fraglichen Elemente, welche eventuell anseinanderfallen und das Misslingen eines feinen schnittes

1) Der Nerv ist im Holzschnitte zu weit vom stützblatte entfernt gezeichnet: er liegt lemselben in Wirklichkeit unmittelbar au.

2) Gegeuba ux, Grundzïge der vergleichenden Anatomie 2te Autlage, S. 152, Grundriss S. 120. 
verursachen können. Da diese Zellen den ginzen Innenraum des Schirmrandringes, abgesehen vom Nervemring und von den der Wand anliegenden Nervenzellen, ausfüllen, so habe ich sie als „Füllzellen“ bezeichnet. Es erscheinen dieselben (Taf. IX, Fig. 10, a bis p) an Chromkalipräparaten als Bildungen von wenig bestimmter Gestalt, meist sind sie länglich eiförmig, dabei bald plattgedrückt, bald becherartig aufgebanscht. Sie bestehen aus einer glashellen, durchsichtigen Hülle, welche zuweilen an einem Ende wie eine Becherzelle geöfnet angetroffen wird und in welcher, ihren Innenraum nur zum Theil ausfüllend, ein durch Carmin sich meist intensiv rothfärbender wurstförmiger, sichelähnlich gebogener Körper neben einem Keru liegt. Ein Inhalt ist in dem freibleibenden Theile der Zelle nicht dentlich zn erkennen, aber eine dort zureilen sichtbare, nach Art der Schichtung der Amylumkörner concentrisch gestreifte Zeichmung dentet auf solchen Inhalt, der durchaus glashell wie die Hülle sein würde, hin. Im Kerne beobachtet man bei starker Vergrösserung zuweilen den Körnchenkreis mit von dessen Elementen radiär nach dem Kernkörperchen verlanfenden feinsten Fühlchen, wie ich das schon anderwärts für diese Füllzellen beschrieben und abgebildet habe ${ }^{1}$ ), oft ansserordentlich schön. Ebenso sieht man, wie ich dort gleichfalls schon hervorhob, häufig in der Peripherie des Kerns in regelmässigen Abständen und in bestimmter Richtung hinziehende feinste Fäden, die ich als Bestandtheile des Kernfademnetzes bezeichnete (Taf. IX, Fig. 10, o und p). Der erwähnte sichelförmige, wurstähnliche, durch Carmin sich meist intensiv rothfärbende Körper ist augenscheinlich ein Nesselschlauch und dürften demnach die Füllzellen nichts anderes sein, als Entwicklungsstadien ron Nesselzellen. Diese Auffassung erklärt auch die Thatsache, dass zwischen den beschriebenen Elementen auch Zellen liegen, in welchen statt des sichelförmigen ein eiförmiger, noch nicht gekrümmter Körper, gedrumgener als jener, liegt oder gar nur ein ganz kleines Gebilde, welches sich als frühere Entwickhungstufe des letzteren und damit des ersteren erkeunen lässt. Und endich findet man zwischen diesen Zellen mit mehr oder weniger ausgebildeten Nesselschläuchen solche, welche noch gar keine Spur eines derartigen Gebildes enthalten (Fig. 10, m).

Lagebeziehungen der Hörbläschen zum Schirmrandring und zur. Umbrella. Dass die "Sinnesbläschen" der Geryoniden in die Gallertwand des Körpers eingebettet sind, hat schon IÏ̈ckel angegeben. Auf Durchschnitten lässt sich diese Angabe bestätigen (Tat. X, Fig. 2, Holzschnitt $30 \mathrm{Hbl}$ ), ebenso aber dadurch, dass es, wie ich finde, möglich ist, die Hörbläschen unversehrt aus der Körperwand herauszuziehen.

1) Weitere Nachrichten über den Bau des Zellkerns etc. Arch. f. mikr. Anat. XIV. Bd. 
Man lege ein Stück des peripherischen Theils des Schirmes unter das Präparirmikroskop, setze mit der Präparirnadel zwischen der oberen Grenze des Schirmrandringes und der unteren der denselben nach oben begrenzenden Wand des Köruers ein, und versuche den ersteren von der letzteren abzuziehen: es wird dies so gelingen, als ob er an ihr nur angeheftet wäre, zugleich aber werden sich mit ihm die benachbarten Hörblïschen in Zusammenluang erhalten, herausgezogen aus der Gallertwand des Körpers, so dass in dieser an ihrer Stelle je eine ihrer Gestalt entsprechende Höhle ïbrig bleibt. Ausserdem lösen sich mit Schirmraudring und Hörbläschen jenem anhaftend, die entsprechenden "Mantelspangen“ los. als nach oben sich verschmälernde und schliesslich spitz znlanfende Bänder, bestehend aus einer gallertartig durchsichtigen, längsgestreiften Hülle und einem Inhalt von reihenähnlich angeordneten Zellen. Figur 9 anf Tafel IX zeigt ein stück des Schirmrandrings sammt Hörbläschen und "Mantelspange", welches anf diese Weise rom unteren liande des Schirmes losgelöst worden ist. Daran ist allerdings die Epithelwand nicht mehr zu sehen, auch die Füllzellen sind entfernt. Der notere Fiand der Umbrella, wie er sich nach solcher Ablösnug des Schirmrandringes darbietet, ist in Figur S, Taf. VII dargestellt. In Figur 1 und 4, Tafel IX ist in einer Ansicht von aussen (Fig. 1) und in einer Ansicht von inven (Fig. 4) stärker vergıössert das Stückehen der Umbrellawand abgebildet, ans welchem das Hörbläschen heransgezogen worden ist, so dass die elwähnte Höhle in derselben zor Anschammg kommt. In Figur $t$ sieht man, dass diese Höhle, die eine amuähernd kugelförmige Gestalt hat, sich unten in ein Loch öffnet, durch relches, wie wir sehen werden, die Hörnerven eintreten. In Fig. 1 bei x ist anf der äusseren Fläche der diese Höhle umschliessenden Umbrellawand eine sich nach oben verlierende Furche angedentet, in welche der untere Theil der "Mantelspange" eingelsettet war. Ans dem Nitgetheilten und ans Tergleichung der Fig. 9, Taf. IX geht hervor, dass das Hörblïschen alś von einer häutigen Hülle nmschlossenes Säckchen aus der. Umbrella herausgezogen wird. Es ist diese Hülle änsserst dünn und halte ich sie für entsprechend der beschriebenen. die obere und den oberen Theil der hinteren Wand des Schirmrandringes bildenden Cuticula, welche sich somit in der in Holzschnitt 30 schematisch angegebenen Weise als Anskleidnng der das Hörbläschen umschliessenden Höhle fortsetzen wärde und in derselben Weise glaube ich, wie schon hier bemerkt werden kann, annehmen zu dürfen, dass die später zu besprechende, das von mir sogenannte Spangenganglion einschliessende Scheide eine Fortsetzung jener Cuticnla sei. Es würde somit die beschriebene Ablösung von Hörbläschen und Spange von der Umbrella durch eine Ablösung der Cuticula vom Gallertgewebe der Umbrella sich erklären. 


\section{Der Ringnerv.}

Dis Anffinden des Ringnerven, wie ihn Häckel beschrieben hat, war mir in Anbetracht des Fehlens desselben bei den 'Tojoneuren zuerst ein sehr unerwartetes. Musste es doch scheinen, als ob die Existenz eines solchen Nerven jede auch sehr entfernte Beziehung zwischen dem Nervensystem der beiden Medusengrupen ausschliessen würde. Allein es stellte sich bald lieraus, dass derartige Beziehungen doch vorhanden seien, indem, wie später näher erörtert werclen soll, auch bei den Cyclonencen ein Zusammenhang zwischen Epithelzellen und Nervenfüden besteht, in der Weise, dass die letzteren als eine Fortsetzung der ersteren zn betrachten sind. Der Ringnerv ist am leichtesten durch die früher angegebene Präparationsmethode Entfernen der Epithelwand des Schirmandringes und der Füllzellen - aufzufinden. Er zeigt sich daun als ein ans feiusten Fäden zusammengesetzter Strang (Taf. VIII, Fig. 2 N, Taf. IX, Fig. 8 n, Fig. 9 N, 'Taf. XI, Fig. 2 N, Fig. 3), welcher seine Lage numittelbar unter der Epithelwand des Schirnrandriuges an der Stelle hat, wo diese in das Epithel der Unterfläche des Segels übergeht. Er nimmt nur einen kleinen Theil des Raumes des Schirmmandringes ein; der Rest dessellen ist ausgefüllt von den Füllzellen, welche somit den Ringnerven an demjenigen Theil seiner Oberfläche umgeben, welcher frei in jenen Raum himeinsieht. Hat man eine Stelle des Randes aus der Nähe eines Hörbläschens, ein Weniges seitlich von diesem, zur Untersuchung gewählt, so wird man leicht bemerken, dass der Ringnerv aus zwei Strängen besteht, einem obereu und einem unteren. Untersucht man deu Rand in der Gegend rles Sitzes eines Hörbläschens selbst, so trifft man den unteren Nervenstrang am Schirmrande und parallel mit ihm verlaufend (Taf. XIl, Fig. 24, N), während aus dem Hörbläschen 2 Nervenstränge austreten, $10 \mathrm{~m}$ in entgegengesetzter Richtung von jenem sich zu entferuen und dem unteren Nervenstrange sich zu nähern, sich ihm schliesslich anzulegen (ebenda Hn). Untersucht man eudlich den Rand etwa in der Mitte zwischen zwei Hörbläschen, so wird man nur noủ zwei unvollkommen getrennte Stränge, oder man wird beide zn einem Ganzen mehr oder weniger dentlich zusammengelagert fiuden. Fassen wir demnach das ganze Ringnerveusystem in's Auge, so haben wir an ihm zu unterscheiclen: 1) einen unteren Nervenstrang, welcher ohne Unterbrechung rings um den Schirmrand herumläuft; 2) einen oberen, der jedoch aus zwölt Abtheilungen besteht, deren jede zwischen je zwei Hörbläschen gelegen ist und dieselben etwa so untereinander verbindet, wie die Aufhängepunkte von Guirlanden durch diese selbst verbunden werden. Da die zwei Enden dieser zwölf Nervenstränge, wie wir sehen werden, an je zwei benachbarten 
Hörbläschen in der Art anfhören, dass ihre Fasern in den Hörstein umgebende percipirende Hörzellen übergehen, so hätten wir statt des oberen Ringnerven zwölf Nervenstränge zn unterscheiden, welche wir als Hörnerven bezeichnen können, während der untere Ringnerv einen einzigen um den Schirmrand herumlaufendeu strang darstellt. Indessen muss noch genaner festgestellt werden, ob und in welchem Grade in den zwischen je 2 Hörbläschen gelegenen Bezirken des Schirmrandes nicht nur eine Verschmelzung, sondern vielleicht auch eine Vermischung der zwölf Hörnerven mit dem hinteren Nervenstrang, welchen ich als Centralnerven bezeichnen will, statt hat. Hä ckel hat, wie aus der Vergleichnng seiner Angaben hervorgeht, die bezüglichen Verhältnisse ganz anders beschrieben. Er nahm nur einen Nerrenstrang am Schirmrande an, welcher je in der Nähe eines Hörbläschens angelangt, mit zwei Schenkeln zu demselben anfsteigen sollte. Diese Nervenschenkel bezeichnete er als Sinnesnerven. Beror der Ringnerv die zwei „Sinnesnerven“ abgibt. soll er je unter einem Hörbläschen zu einem Ganglion anschwellen; aus je einem der (ianglien sollen zwei "Sinnesnerven" hervorgehen. Im Girunde des sinnesbläschens sollen diese noch einmal zu einem Ganglion, dem Basalganglion, anschwellen und jeden Otolithen soll ein drittes Gauglion (Sinnesganglion) nmschliessen. Yon diesen drei angenommenen Ganglien existirt nach meinen Untersuchungen das Basalganglion nicht; das Sinnesganglion ist kein solches, die um den Otolithen gelagerten Zellen sind rielmehr percipirende Hörzellen. Aber auch in den Ringnerven ist nirgends ein Ganglion eingeschaltet: der Centralnerr läuft ohne jede derartige Einschaltung rings um den Schirmsand herum und sorgfältiger Präparation gelingt es, die Hörnerven in ihrem Zuge vom Rande zum Hörblisschen dentlich zu verfolgen und bloszulegen, wobei zu erkennen ist, dass auch sie nirgends durch Einschaltung eines Ganglion unterbrochen oder gesammelt sind. Indessen wird die Amahme eines "Ganglion des Ringnerren" von Seiten Häckels dadurch erklärlich, dass allerdings in der Gegend des Eintritts der Hörnerven in das Hörbläschen eine Anhänfung von Zellen und zwar von Terrenzellen liegt, welche indessen ausschliesslich mit dem spangennerven in Beziehung zu stelen scheint.

Wie bemerlit ist der lingnerv, und zwar gleichartig in beiden seiner Abtheilnngen, dem Hörnerven wie dem Centraluerven, zusammengesetzt aus feinsten Nervenfädchen. Es zeigen nun diese Fädchen an Chromkalipräparaten ein feinkörniges, wie geronnenes (variköses) Aussehen. Allein es sind diese Fasern, wie schon Häckel vermuthet, nicht der einzige Bestandtheil des Nerven. Es sind in dieselben. und zwar insbesondere in jene, welche anf seiner Oberfläche, in seiner Peripherie liegen, häufig von Stelle zu Stelle spindelförmige Zellen eingeschaltet (Tat'. N1, Figg. 
2, 3 k, Fig. 9 a), grosse, kngelige Kerne, welche meist nur an den zwei entgegengesetzten, durch den Ansatz der Nervenfadden bezeichneten Polen etwas weniges Zellplasma zeigen: Nervenzellen. Beginnt man den Ringnerven an seiner Oberflïche mit der Nadel zu misshandeln, so fallen die Zellen leicht herans und der Nervenstrang bekommt nun ein wie zerfressenes Aussehen, indem die Zellen durch ihre Lagernng anf denselben mehr oder weniger tiefe, selbst höhlenartige Eindrücke hinterlassen (Taf. XI, Fig. 2 1). Zerfasert man den Nervenstrang, so findet man, dass auch in seinem Innern da und dort einzelne Zellen in die ilm zusammensetzenden Fädehen eingeschaltet sind. Ess erinnern diese Verhältnisse sehr an jene der von mir bei Beroë ovatus beschriebenen, das Gallertgewebe des Körpers isolirt durchziehenden Nervenfasern, indem in diese gleichfalls überall von stelle zu Stelle von wenig Zellplasma umgebene Kerne eingeschoben sind, so dass jeder Nerv gewissermassen eine Kette von Ganglienzellen darstellt.

Auf der Oberffäche des Ringnerven liegen zwischen den beschriebenen, in die Nervenfäden eingeschalteten Zellen nmm aber auch plasmareichere, welche sich in der Form mehr oder weniger einer Art der bald zu behandelnden Epithelzellen (Tat. XI. Fig. 7 und 10) nähern, Descendenten derselben sind und den Uebergang zwisehen ihnen und den ersteren bilden. Sie gehen nur nach dem einen Ende in einen langen Nervenfaden über, mit dem anderen, mehr oder weniger lang ansgezogenen sehieben sie sich mehr oder minder deutlich zwischen den Epithelzellen ein (Taf. XI, Fig. 9, b, c). Ausserdem finden sich auf der Oberfläche des limgnerven und überhaupt unter der Epitheldecke des Schirmrandes noch Ganglienzellen gelagert, welche die Eigenschaften von solchen in ansgebildetem Maasse besitzen. Zur Beschreibung dieser Elemente gehe ich jetzt über.

Ausser den besehriebenen anf der aboralen Seite der Stützlamelle des Schirmrandringes gelegenen Nervenfasern nehmen an der Bildung des lingnerven noch oral gelagerte Antheil, von welchen später gehandelt werden soll.

\section{Typische Ganglienzellen des Schirmrandringes.}

Die vorhin beschriebenen Kerne und Zellen verrathen ihre Zugehörigkeit zum Nervensystem nur durch ihre Verbindung mit Nervenfäden; ohne diese Verbindung würde ein richtiger Schluss anf ilıre physiologische Bedentung nur schwer zu ziehen sein. Dagegen liegen nun dem liingnerven ansser ihnen noch typische, an ihren morphologischen Eigenschaften sofort als solche zu erkennende Ganglienzellen auf, unmittel- 
bar bedeckt von dem die äussere nnd untere Wand des Schirmrandringes bildenden Epithel. Anch diese Zellen nehmen Theil an der Znsammensetzmng des Ringnerven. indem sich ihre Auslüufer mit dessen l'asern mischen (Taf. XI, Fig. 2 Giz, Taf. VIII, Fig. 13), sofern sie sich nicht nnter der Epithelwand des Schirmrandringes über den Bereich des Ringnerven nach aufwärts und nuter dem Epithel der Anssenfläche des Segels nach abwärts verbreiten (Taf. VIII, Fig. 1, 2, 3 Gz). Es sind diese Ganglienzellen so prachtvoll ansgebildet, dass man sie typischer im Nervensystem selbst der höchsten Thiere nicht wird finden können (Taf. XIII, Fig. 5 bis 11 und Fig. 13). Ihr Körper ist oft von sehr berlentender Grösse $(0,016 \mathrm{~mm})$ und je nach der Zahl der von ihm alrgehenden Fortsätze - einer, zwei oder (neistens) mehrere - von sehr verschiedener Gestalt: keulen-, spindel- oder sternförmig. Ihre Oberfläche ist nicht immer von glatten Flächen begrenzt, sondern znweilen durch Eindrücke kantig, wie geknetet (Fig. 11). Ihre Ansläufer sind hänfig, besonders in ihrem Anfangstheile, ansserordentlich dick und verzweigen sich verschiedentlich, in ihrem Verlaute feiner und feiner werdend und oft in bedentender Länge verfolgbar. Der Kern der (ranglienzellen ist sehr gross, kugelig, selten eiförmig und zeichnet sich insbesondere durch ein gewöhnlich excentrisch gelegenes oder durch zwei anffallend grosse Kernkörperchen aus. Auch der Körnchenkreis und das davon ansgehende System ron Radiärfäden ist in diesen Kermen ungemein deutlich zu sehen (Fig. 7), wie ich dies sehon in meiner letzten Ablandlung äber den Zellkern beschrieben und abgebildet habe. Der übrige Inhalt des Kerns ist stark körnig, was auf bedentende Ansbildung des Fadennetzes in demselben gleichfills hinweist. Das Plasma dieser Ganglienzellen erscheint an mit Carmin behandelten Chromkalipräparaten roth oder bräunlich tingirt und heben sich dieselben daher von anderen Zellen dann deutlich ab. Sind solche Chromkalipräparate längere Zeit in Glycerin anfgehellt worden, so sieht man sie bei der Flächenansicht des Schirmrandes durch das Epithel hindureh zerstrent dem Ringnerven aufliegen. Aber man sieht dann, wie schon angedentet, dass sie in ihrem Vorkommen nicht eben anf die Oberfläche des Ringnerven beschränkt sind. sondern dass sie anch oberhalb desselben unter der Epithelwand des Schirmrandringes und nach unten bis unter das das Segel deckende Epithel zerstrent sich finden ('l'af. VIII, Fig. 1, 2). Behandelt man diese Ganglienzellen frisch mit sehr verdünnter Essigsäure, wie das zum Zweck des Isolirens der Zellen des Thieres mit Vortheil geschehen kann, so zeigt der Zellinhalt, das sogenannte „Protoplasma“, eine sehr bemerkenswerthe Eigenschaft: es tritt eine Streifung in seinem Innern auf, welcher anf's Dentlichste eine fadenartige Differenzirung zu Grunde liegt, wie sie den Ganghienzellen höherer Thiere von Max Sehulze als organische Eigenschaft zuerst zugesehrieben worden ist (Fig. 
S, 10). Ich habe an den Ganglienzellen von höheren 'Thieren dasselbe Verhältniss an ganz frischen Objekten zu oft und mit zı grosser Deutlichkeit beobachtet, als dass ich nicht mit der Schulze'schen Auffassung, wonach es sich in der Faserung um ein normales Strukturverhältniss handelt, vollkommen ïbereinstimmen sollte. Nicht nur an mit Essigsäure behandelten, sondern an der Finwirkung von Chromkali ausgesetzten Zellen ist die Faserung der Ganglienzellen bei Carmarina, wenngleich weniger deutlich ausgesprochen, öfters zu erkennen. Wir werden bald sehen, dass dieselbe Eigenschaft in dem Nervensystem zugehörigen Zellen unserer Medusen eine sehr verbreitete ist. Die auch sonst viel missibranchte Bezeichnung "Protoplasma" passt am wenigsten auf diesen so hoch differenzirten Zellinhalt und ich werde denselben in Zukunft als ne urofibrilläre Substanz oder Neuroplasma bezeichnen. - Die geschilderten, wie beschrieben unter der Epitheldecke des Schirmrandringes gelagerten Ganglienzellen stellen nun aber gegenüber jenen anderen, ausser ilmen noch in die Zusammensetzung des Ringnerven eingehenden, viel geringer als sie entwickelten Zellen nicht etwa eine gänzlich abgeschlossene Form dar, vielmehr lassen sich zwischen beiden vielfach Uebergänge auffinden und beide sind wieder gewissen aus der Epithelialdecke zu isolirenden Elementen unmittelbar verwandt.

\section{Das Nervenepithel der Wand des Schirmrandringes.}

Es ist, wie schon hervorgehoben wurde, die äussere und untere Wand des Schirmrandringes ohne Stützblatt und ausschliesslich aus Epithelzellen zusammengesetzt. Dieses Epithel liegt da, wo es den Ringnerven bedeckt demselben unmittelbar auf. Isolirt man seine Zellen in dieser Gegend nach Behandeln mit verdümnter Essigsäure oder mit schwacher Chromkalilösung, so stellen sich dieselben in zwei sehr bemerkenswerthen Formen dar. Die eine dieser Formen besteht ans cylindrischen Zellen mit breiter Begrenzung nach aussen, nach unten allmälig sich verschmälernd und, was das Bemerkenswertheste ist, hier meist besenartig in feine Fäden sich zerfasernd (Taf. XI, Fig. 2, 6; Taf. XII, Fig. S, 19). Diese Fäden erscheinen an Chromkalipräparaten hänfig durchans varikös und machen so den Eindruck von Nervenfibrillen. An denselben Präparaten ist nun aber weiter vielfach auf das Deutlichste zu sehen, dass die Fäden sich in den Zellkörper linein fortsetzen bis zur Basalfläche desselben hinauf. Es erhält dadurch der Zellkörper ein feingestreiftes Aussehen: es erscheint sein Inhalt wie aus lauter feinsten Fädchen zusanmengesetzt und erinnert die ganze Einrich- 
tung auf das Lebhafteste an die Darstellung und Dentung der Strukturverhältnisse der Zellen der Speicheldrüsen durch Pflüge $r^{1}$ ). Und in der That handelt es sich in den in Rede stehenden Ektodermzellen von Carmarina augenscheinlich um Nervenepithelien, um Zellen, deren Plasma in neurotibrilläre Substanz nmgewandelt ist und welche numittelbar in Nervenfäden sich nach unten zerfasern und durch diese ihre Nervenfortsätze den Ringnerven zum grösten Theile bilden. Wir sahen früher, dass vou der hinteren Wand des Schirnrandringes Fasern ausgehen, welche ich als Stützfasern des Schirmrandringes bezeichnet und in Beziehung auf welche ich die F'rage anfgeworfen habe, ob sie nicht mit Zellen der Epithelwand in Verbindung stehen. Dass es die soeben beschriebenen Elemente nicht sein können, mit welchen eine solche Verbindung statt hat, dass diese also nicht etwa als Stintzzellen zu bezeichnen sind, geht nicht allein aus der varikösen Beschaffenheit ihrer Fortsätze, sondern anch daraus hervor, dass gerade diese Besenzellen es sind, welche beim Versuch, die Elemente der Epithelialdecke mit den Faseru des Ringnerven im Zusammenhange zu isoliren am wenigsten positive Ergebnisse liefern, weil ihre Fäden so ausserordentlich fein und zart sind, dass sie bei diesem Versuche gewölnnlich abreissen, so dass die Zellen abfallen. Von durch diese Besenzellen vermittelter Stn̈tze kann also keine Rede sein. Auch sind die als Stützfaseru von mir bezeichneten Fäden viel gröber als die Fortsätze dieser Zellen und niemals varikös. Einen unmittelbaren Zusammenhang zwischen beiden habe ich nie beobachtet. Zuweilen gelingt es dagegen Besenzellen und Ringnerv so weit in Zusammenhang zu erhalten, dass man die Fortsätze der ersteren mit den Fasern des Ringnerven sich mischen sieht und anch an isolirten Besenzellen bekommt man oft ausserordentlich lange Fortsätze zu sehen. welche mit den Nervenfäden des Ringnerven durchaus identisch sind. Es kann somit keinem Zweifel unterliegen, dass die Zerfaserung des unteren Endes der Besenzellen den Aufbau des wesentlichsteu Theils des Ringuerven bildet, um so weniger, als solches Verhalten durchaus übereinstimmt mit demjenigen, welches, wie wir sehen werden, ein grosser Theil der Ektodermzellen ïberhaupt darbietet. - Zwischen den losen Zellen liegen nun im Ektoderm, im Gebiete des Ringnerven andere Zellen zerstrent, welche aus einem grossen Kern mit wenig Zellsubstanz bestehen, etwa von kurz spiudelförmiger Gestalt, die eine Spitze der Spindel als kurzen, häufig mehr oder weniger stumpf abgerundeten oder anch quer abgestutzten Źapfen nach aussen kehrend, eingeschoben zwischen die breiten

1) Pf $l$ ü ger, die Endigung der Absonderungsnerven in den Speicheldrüsen. Bonn 1866 und Archiv für mikr. Anat. Bd. V. 1869. 
Endflächen der Besenzellen, mit der anderen, unteren übergehend in einen Faden, welcher in den Ringnerven gleichfalls eintritt und mit dessen Fasern sich mischt, in Form und Lage also erinnernd an die „Spindeln“ der Toponeuren (Taf. XI, Fig. 2, a; Taf. XII, Fig. 12, a). Es ist dieser Faden meist gröber als die Fortsätze der Besenzellen und ich hielt ihn anfangs für die Fortsetzung einer Stnitzfaser, die Spindelzellen also für Stützzellen. Es ist möglich, dass sie dies wenigstens theilweise sind, jedenfills aber sind sie es nicht alle, denn man findet unter ihnen solche, deren Anslänfer ansgezeichnet varikös ist (Taf. XI, Fig. 10, a) und diese wiederum sind offenbar nur eine Modification von Zellen, welche sich nach unten gabelig in zwei Ansläufer theilen, die sich in variköse Fäden fortsetzen (Taf. XI, Fig. 7, b, e, Fig. 10, a, c, d, Fig. 2, c). Einen Uebergang zwischen Gabelzellen und Spindelzellen scheint die in Fig. 7, a, Taf. XI abgebildete Form darznstellen. An solchen mit varikösen Fortsätzen versehenen Spindel- und Gabelzellen findet sich nun häufig noch ein anderer Beweis für die Zugehörigkeit zum Nervensystem: ein Geisselfaden (Taf. XI, Fig. 7, b; 10, c). Es sind somit offenbar diese Elemente, welche das Flimmern des Schirmrandringes verursachen. Endlich sind es die nervösen Spindel- bezw. Gabelzellen, welche Uebergänge darbieten zn den in die Fäden des Ringnerven eingeschalteten Nervenzellen: es ist a ugenscheinlich, dass die letzteren a us ersteren allmalig entstanden sind, indem diese in die Tiefe traten. Zuweilen triftt man sie gewissermassen unterwegs an: nit einem langen Auslänfer setzt sich eine Zelle nach oben zwischen die übrigen Epithelien hinein fort, während der Körper schon nnter der Epitheldecke, dem Ringnerven anfgelagert ist und mit dem anderen Ende in einen Nervenfaden übergeht (Taf. XI, Fig. 9, b). Es handelt sich somit hier deutlich $u m$ in der Entstehung aus Ektodermzellen begriffene Nervenzellen, ein Umbildungsprocess, welcher, wie wir sehen werden, in höchst bemerkenswerther Weise auch aus anderen im Ektoderm unserer Thiere zu beobachtenden Thatsachen zu erschliessen ist. — Nicht alle Nervenepithelien mit breiter Basis und nenrofibrillärem Inhalt sind wirkliche Besenzellen: man findet deren auch solche, welche nach unten in einen einzigen, ziemlich starken Fortsatz ansgehen (Taf. X11, Fig. 12) nnd möchten damit Uebergïnge wiederum zu den Eigenschaften der Gabel- bezw. Spindelzellen geboten sein. Es wäre möglich, dass auch solche Elemente es sind, welche, unter Zurücktreten ihrer neurofibrillären Beschaffenheit, d. i. ihrer Thätigkeit im Dienste des Nervensystems oder welche eher umgekehrt bei mangelnder Entwicklıng derselben, als Stützzellen dienen. - Wie schon erwähnt, findet sich Nervenepithel anch in proximaler Richtung über den Umfang des Ringnerven hinaus. Man sieht hier in der Oberflächenansicht im 
Epithel an Chromkalipräparaten sehr häufig eime faserige Differenzirung des Zellinhaltes. Die Streifung erscheint bei dieser Ansicht - und dasselbe ist, wie wir noch sehen werden, der Fall bei in der Seitenansicht gleichfalls längsgestreiften Epithelien der Subumbrella - der Oberfläche parallel gerichtet und wirr durcheinandergezogen (Taf. VIIl, Fig. 4, E). Andererseits schien mir auch distal rom Ringnerven, auf dem dem Schirmrandringe des Segels zunächst gelegenen Bezirke der Stützlamelle, Aehnliches vorzukommen, wie anch dort unter dem Epithel zerstreut noch Ganglienzellen gefunden werden.

\section{Belegzellen des Stützblattes des Schirmrandringes. Ringganglion. Radial- ganglien. Spangenganglien.}

Der ganze Inhalt des Schirmrandringes ist, gleich seiner Epithelialdecke, selbstverständlich als Ablömmling des Ektoderms zu betrachten. Als solchen Inhalt haben wir bis jetzt kennen gelernt: die unter der Epithelialwand gelegenen Ganglienzellen, den Ringnerven, die Füllzellen. Ebenso wie Nervenzellen ummittelbar unter der Epithelwand gelagert sind, trifft man, wie schon beilanfig erwähnt worden ist, anch die obere, die Stützenwand des Schirmrandringes belegt mit Zellen, welche einen grossen kugeligen Keru und wenig Plasma führen, und welche oft an einem oder an zwei entgegengesetzten Enden in einen langen Faden auslanfen, so durchaus ähnlich werdend den spindelförmigen Zellen des Ringnerven. Es pflastern diese Zellen die Hinterwand des Schirmrandringes gewissermassen ans, indem sie sich an dieselbe zwischen und auf deren zapfenartigen Erhebungen anlagern (Taf. VIII und XI. Fig. 12). Die Menge des Plasma dieser Zellen ist oft so gering, dass es im optischen Durchschnitt nur in Form einer ganz schmalen Linie um den fiem herum sichtbar wird. Wegen solcher Eigenschaften können diese Belegzellen des Stützblattes des Schirmrandringes wohl nur als Nervenzellen anfgefasst werden. - Zu beiden Seiten des leistenartigen Vorsprunges, zu dessen Bildung das Stützblatt in geringer Entfermung hinter seiner oberen Verbindung mit der Epithelialwand verdickt ist (Taf. VII, Fig. 2 und 6; Taf. VllI, Fig. 2; Taf. IX, Fig. 2, S, 9, 11, Holzschnitt 31, überall bei L), findet sich nun eine Lage von Zellen, welche sich durch reichliches trübe aussehendes Plasma vou den beschriebeuen Elementen sehr unterscheiden (T'af. VIII. Fig. 2 unter L; Taf. IX, Fig. $S \mathrm{~g}^{1}$ ). Es ist nir nicht unwahrscheinlich. class diese Zellen die ganze Leiste nmgeben, dass aber die anf der Kante derselben gelegenen bei der Präparation leicht abfallen; indessen traf ich sie meist nur vor, zuweilen anch hinter 
der Leiste. In ihrem natürlichen Znsammenhang sind sie schwer genaner zи studiren, weil sie so undurchsichtig sind, dass man gewöhnlich nicht einmal den Kern in ihnen sehen kamn: es scheint damn ihre Gesammtheit einen zusammenhängenden Zellenbelag an der Leiste zu bilden (Taf. VIII, Fig. 2). Sie zu isoliren ist mir nur gelungen in der Nähe der Hörbläschen. Unter jedem Hörbläschen nämlich schwillt der sonst so unscheinbare Zellenbelag, welchen ich als Ringganglion bezeichnen will, zu einer mehr oder weniger ansehnlichen Zellenmasse an (T'af. IX, Fid. 11 Gi), welche die hier zum Hörbläschen aufstrebenden Hörnerven und dieses selbst in seinem unteren Theile deckt (vergl. Holzschnitt 30 , Spg). Dieses Radialganglion setzt sich in ein centripetal verlaufendes Band von Zellen fort, das spangenganglion (Taf. VIl, Fig. 3'), Fig. 4 und $5 \mathrm{Sp}$; Taf. IX, Fig. 2, 7, 8 und 11 g; vergl. anch Holzschnitt 3()$^{2}$ ), dasselbe Band, welches von $\mathrm{Häckel}$ als Spangenknorpel bezeichnet worden ist. Es zielıt dieses Band an der Aussenfläche der Umbrella unter dem Ektodermepithel nach aufwärts, um nach kurzem Verlauf oberhalb des Hörbläschens nach allmäliger Verschmächtigung spitz zu endigen. Bei der Ansicht von aussen deckt es das Hörbläschen. Es besteht nach seinem Ursprunge aus dem Radialganglion gewöhnlich znerst aus mehreren Reihen von Zellen, bald darauf nur noch ans zwei Reihen und zuletzt nur noch aus einer, wobei die Zellen gleichzeitig je weiter nach aufwärts um so kleiner werden, Verhältnisse, durch welche eben die Verschmächtigung desselben hervorgerufen und bewirkt wirel, dass es allmälig spitz zulänft. Es sind diese Bänder dieselben, welche sich im Zusammenhang mit dem Schirmrandringe und mit den Hörbläschen vom übrigen kïrper loslösen lassen (Fig. 9, Taf. IX). Wer sie irgend genauer untersucht, kann mnöglich etwas an ilnen finden, was dazı berechtigte, die sie zusammensetzenden Zellen als Knorpelzellen zu deuten. Es haben nämlich diese Zellen, je nachdem sie mehr zusammengedrängt oder mehr frei, vereinzelt, liegen, eine verschiedene, niemals aber eine bestimnte, charakteristische Gestalt. In ersteren Falle sind ihre Grenzen häufig fast ganz verschwunden und man möchte auf den ersten Blick glauben, in dem Zellenband eine zusammenhängende Plasmamasse mit einzeln darin zerstrenten Kernen vor sich zu haben (Taf. VII, Fig. 4; vergl. anch Taf. IX, Fig. 7). Sind die Grenzen dentlich, so erscheinen die aneinander gelagerten Zellen als Elemente von meist annähernd gleichem Durchmesser, aber von durchaus wechselnder Form. Liegen sie frei (Taf. VIl, Fig. 5), so

1) Iu dieser Figur ist die von $\mathrm{Sp}$ auf den Zellenstrang hingerichtete Linie nicht weit genug geführt.

2) Im Holzschnitte ist das Band, als Fortsetzung des Radialganglion Spg nach oben, der Deutlichkeit wegen verhältnissmässig zu dick gezeichnet. 
trifft man sie häufig in die Länge gestreckt, an verschiedenen Stellen zu Fortsätzen ansgezogen und durch solehe Ausläufer untereinander in Verbindung stehend. Dieselben Fortsätze kann man aber überall anch von den Zellen, seien sie compakt zusammengelagert orler nicht, nach der Peripherie des Stranges ansstrahlen sehen. Genauere Beobachtung lehrt, dass der ganze, übrigens reichliche Inhalt der Zellen eine faserige Differenzirung zeigt, wie aus feinsten Fäden zusammengesetzt ist, aus ueurofibrillärer substanz besteht. Diese Fäden lilden, da und dort in Bündeln von der Zelle ab nach aussen tretend, jene Fortsätze, welche die Zellen theils nntereinander verbinden, theils aber gegen die Peripherie des Zellenlyandes hin gerichtet sind. Besonders das letzterwähnte Verhalten ist bemerkenswerth: mittelst starker Systeme erkeunt man deutlich, dass die peripherisch vom Bande abgehenden Fortsätze sich zuletzt vielfach wiederum in die feinsten Fälchen anfïsen und es unterliegt keinem Zweifel, dass- diese Fibrillen N e rvenfibrillen sind, die Zellen der von Häckel sogenannten knorpeligen Mautelspange aber Nervenzellen. Wieder tritt in diesen Zellen die faserige Differenzirung des Inhalts als eine Eigenschaft iuf, welche auf die Natur derselben als Nervenzellen hiuweist und dass dieser Hinweis ein sicherer ist, werden wir noch dureh weitere Thatsachen belegen können. Es handelt sich somit in den zwölf Zellensträugen der sugenannten Mantelspange nm Stränge von Nervenzellen. welche die unmittelbare Fortsetzung sind der den Hörbläschen an und antliegenden zwölf Ganglien, und diese wiederum sind nichts auderes als Anhäufungen der trüben Zellenlage, welche an der Leiste der oberen Wand des schirmrandringes zu finden, und welche als lingganglion bezeichnet worden ist. Dieses lingganglion liegt anf den zwischen den Hörbläschen gelegenen Strecken des Schirmrandringes in der Tiefe, erhebt sich aber unter jedem Hörbläschen, indem es hier zum Radialganglion anschwillt, bis unter die Oberfläche der äusseren Wand des Schirmrandringes. Jedes Radialganglion sendet somit eine blattartig dünne (wenigstens im proximalen Theile einschichtige) Lage ron Zellen, das Spangenganglion, eentripetal an der Anssenfläche des Thieres und über das Hörbläschen nach olsen, um nach linrzem Verlaufe spitz zu endigen. - An der Verbindungsstelle zwischen Radial- nud Spangenganglion traf ich häufig die Kerne auf eine kurze Strecke fehlend, das nemrofibrilläre Plasma aber zu einem fadenartigen Strange ausgezogen, ähnlich der ausgezogenen Masse „mürben Teigs“, wie das in Taf. IX, Fig. 11 angedeutet ist, - Zerzupft mau das Radialganglion, so erhält man Zellen mit neurofibrillärem Inhalt, ähnlich jenen des Spangenganglion und zwischen den Zellen findet man einen Filz feinster Füdchen, Nervenfädchen, welche der Anffaserung 
des Zellinhalts den Ursprung verdanken. Hie zwischen den Iiadien an der Leiste des Schirmmandringes gelagerten trüben Zellen habe ich, wie bemerkt, nicht isolirt zu Gesicht bekonmen, und ich schliesse nur nach Analogie, dass das trübe Aussehen ihres luhalts gleichfalls auf Zusammensetzung aus Nemoplasma zurückzulühren ınd darius nur aus ihrem Zusammenhang mit den Radialgauglien, dass sie als Strang von Nervenzellen, als Ringganglion aufzufassen seien.

Das Spangengangliou liegt, von seiner alsbald zu besprecheuden Scheide umschlussen, unter dem Ey,hithel der aboralen Körperoberfläche. Dieses Epithel hat aber, soweit es das Ganglion bedeckt, eine von dem gewöhnlichen Epithel der Umbrellaanssenfläche sehr verschiedene Beschaffenheit, indlem es, ähnlich dem Nesselzellen führenden Theile des Schirmrandringes aussehend, wenigstens im distalen Abschnitte mehrschichtig ist und gleichfalls reichlich Nesselzellen enthält, anch sich durch eine trïbe Beschaffenheit auszeichnet. Ueber der Gegend des Hörbläschens augelangt, breitet sich dieses Epithel auf eine grössere, amnäherud kreisförmige Fläche aus (Taf. VII, Fig. 3, Hbl; 'Taf. IX, Fig. S ek: hier ist es theilweise weggenommen) und zngleich deckt es das Kadialganglion, welchem es unmittelbar auHlegt (vergl. Holzschnitt 30, wo Slg Radialganglion, $g$ das in Rede stehende Epithel bedentet), um (larauf in die übrige Decke des Schirmrandringes überzugehen. Diese nach obenin ein ïber dem Spangenganglion gelagertes Band sich fortsetzende Ejithelplatte zeigt in der Flächenansicht eine leicht kmppenartige Wölbung, welche nicht allein dadurch hervorgerufen wird, dass ihr Dickendurchmesser mächtiger ist, als jener des Epithels der Umgebung, sondern vorzüglich durch ilıre Auflagernng anf dem Radialganglion. Diese Verhältuisse sind es, welche Häckel dazı Veranlassung gegeben haben mögen, eine Anschwellung des Ringuerven anzunehmen, welche ein in denselben eingeschaltetes Ganglion lerstelle. Beim Zerzupfen der Epithelialdecke des Ganglion traf ich in der That Zellen mit nenrofibrillärem Inhalt, Zellen, welche sich nach unten un uach der Peripherie hin in ihre Fäden, Nervenfäden, auflösten ('laf. X, Fig. 6), allein ich bin nicht sicher, inwieweit solche Zellen nicht dem unter dem Eyithel gelegenen Radialganglion angehört habeu kounten. wie ich auch nicht festgestellt habe, ob und in welcher Verbiudung beide zusammen stehen. Führt, was allerdings das Wahrscheinlichere ist, auch das Epithel Nervenzellen und steht es durch dieselben mit dem liadialganglion in Verbindnng, so würlen beide als Ganzes, als Radialganglion im weiteren siune aufzufassen seiu. Ferner stellt sich aber die Frage, ob nicht doch eine Verbindung dieses Ganglion mit dem Ringnerven, wem auch nicht in der von Häckel angenommenen Weise, bestehe. Ich habe eine Verbindung zwischen den Nervenzelleu des Radialganglion und den Hörnerven, welche hinter demselben anf- 
steigen, nicht beobachtet. Dem Centrahnerven liegt das Ganglion nicht einmal mnmittelbar an (vergl. den Holzschnitt), ebenso liegt die als Ringganglion bezeichnete Zellenlage vom Centralnerven entfernt. Denuoch möchte die Annahme, dass jedenfalls die von den Zellen der Radialganglien anstretenden Nerreufädchen mit den Fasern des liingnerven und speciell mit der Hörnervenabtheilnng desselben sich mischen, nicht von der Hand zn weisen sein. Anch ist nicht muwahrscheinlich, dass ebenso von den Zellen des Ringganglion feinste Fäserchen abgehen, welche mit dem Centralnerven sich mischen: indessen fehlt mir hierüber jegliche Beobachtung.

Wir müssen nun noch einmal zum spangenganglion zurückkehren, nm schliesslich den Zusammenhang für die complicirt erscheinenden Einrichtungen des bisher behandelten Theils des Nervensystems mserer Meduse zu gewinnen. Wem man die "Mantelspangen" sammt den Hörbläsehen in der früher beschriebenen Weise vom Schirme losgelöst hat, so besteht der losgelöste Theil nicht allein ans dem Zellenstrange, sondern es hängt mit diesem noch ein nach oben sich verschmälerndes und schliesslich, entsprechend dem Verhalten des Zellenstranges selbst, spitz endigendes Band zusammen (Taf. IX, Fig. 9). Auch sonst beobachtet man, besonders an Chromkalipräparaten, dass die Spange sich gerne in dieser Weise, hestehend aus dem Zellenstrang und einem Blatte durchsichtigen Gewebes, von der Körperoberfläche lostremnt. Dieselbe haftet also nur sehr leicht an dieser an. Betrachtet man num das so beschaffene Ganze genaner, so wird dentlich, dass es, vom Epithel abgesehen, aus dem Spangenganglion und riner dieses umhüllenden Scheide znsammengesetzt ist. Es liegen die Nervenzellen somit nicht wie diejenigen des Radialganglion immittelbar nnter dem Epithel, sondern sie sind davon durch eine, weungleich sehr feine Hant getrent. Diese Scheide kann nichts anderes sein als eine schlanchartige Fortsetzung der die Gallertwand des Schirmrandringes deckenden Cuticula, wie sie anch die Anskleidung der Hörsäckchen bildet oder eine Umhällung, hergestellt aus dieser Cuticula und einer dunnen Lage Umbrellagewebes. Dazu, an das Letztere zu denken, kam ich desshalb, weil sich jeweils in Zusammenhang mit dem Zellenstrange ein sehr dünner Theil der Umbrella loslöst ${ }^{1}$ ). Man sieht nun in der aboralen Ansicht bei Anwendung schwächerer Tergrösserungen beiderseits von Spangenganghion eine ihm parallel ziehende Längsstreitung (Taf. VII. Fig. 3; 'Taf. 1X, Fig. S u. 9) und diese Streifung erscheint bei dieser Ansicht häufig in eine innere dichtere (Taf. VII, Fig. 3 n) und in eine äussere weniger dichte Parthie (ebenda bei x) geschieden. Die

1) In Holzschnitt 30 ist von der Bedeckung durch ein äusseres Blatt der Cuticula und ron etwaiger Bedeckung durch Umbrellagewebe keine Andeutung gegeben. 
Streifung ist wohl nur wegen der Undurchsichtigkeit der Zellen nicht anch über dem Ganglion sichtbar. Wendet man sehr starke Vergrösserungen an und stellt tief auf das Spangenganglion ein, so gewabrt man, dass die früher als Nervenfäden bezeichneten Fortsätze der Zellen desselben (f', Taf. VII, Fig. 4 I. 5) unmittelbar in einen zunächst dem Spangenganglion gelegenen Zug von Fasern übergehen. Es liegt am nächsten, diese dem Śpangenganglion anliegenden Fasern fün Nerventäden anzusehen mod somit einen Spangennerven anzumehmen, welcher von ausserhalb der Scheide (Taf. IX, Fig. 2, n) gelagerten Faserı, die Muskelfälen sein könnten, zı unterscheiden wäre. Indessen habe ich beiderlei Fasern nicht isolirt und bin desshalb nicht im Stande, für diese ihre Qualität entschieden einzutreten, dies um so weniger, als ich anch nicht dazu gekommen bin, mir durch Querschnitte vollständige Gewissheit darüber zu versehaffen, ob wirklich zweierlei, in zwei Lagen geschiedene Fadenzüge rorhanden sind. Solches hat $H a ̈ c k e l$ angenommen und abgebildet, und zwar, was meiner Tolaussetzung entgegengesetzt sein würde, einen inneren Muskel- uncl einen äusseren Nervenstrang (Spangennerv). Man darf sich nicht verhehlen, dass Muskelfächen auf der Aussentläche eines Mednsenschirmes oder in der peripherischen Gallertschichte desselben immerhin ein so eigenartiges Vorkommniss wären, dass nur der genaneste histologische Nachweis, auf Grund von Isoliren der fraglichen Elemente, davon würde überzengen können; auch der Ausgangspunkt dieser Muskelfasern würde noch festzustellen sein. Andererseits liesse sich solcher Apparat durch die Annahme erklären, dass er etwa dazu bestimmt sei, die Spannungsverhältnisse von Wand und Inhalt der Hörbläschen zu reguliren und auf diese Weise einen Hülfsapparat des Hörorgans herzustellen.

Fassen wir die geschilderten Thatsachen noch einmal mit wenigen Worten zusammen: entfernt vom Ringnerven liegt, von den gewöhulichen Belegzellen des Stützblattes des Schirmrandringes unterschieden, an der an der letzteren sich erhebenden Leiste eine Lage von plasmareichen, trübe aussehenden Zellen: das Ringganglion. Unter und auf jelem Hörbläschen rerdickt sich diese unscheinbare Zellenlage zn einer mehr oder weniger entwickelten Zellenanhäufung, dem Radialganglion und von jedem Radialganglion zieht ein Band von Zellen radiär an der Aıssenfläche des Schirmes, üher dem Hörbläschen weg, empor, ım bald, spitz zulaufend, zu eudigen: das Spangenganglion. Mit diesen Zellenbändern und wohl anch mit den Radialganglien, stehen Fasern in Verbindung, welche in der Ungebung derselben über den Schirm heraufziehen und welche wals'scheinlich als Spangennerven aufzufassen sind. Während das Ringganglion im Innern des Schirmrandringes verborgen liegt, erheben sich seine Anschwellungen unter das Epithel der 
Aussenfläche, und deren Fortsetzungen, die Spangenganglien endlich liegen zwar gleichfalls unter diesem, aber in eine Scheide eingeschlossen, welche eine Fortsetzung der Wand des Schirmrandringes ist. Da anch die übrigen an der Cnticularwand des Schirmrandriuges gelegenen Zellen wahrscheinlich dem Nervensystem zugehören, da die Epithelwand weit über den Ringnerven hinaus nachweishich Nervenepithel ist, wie sie auch auf den Radialganglien diesen Charakter zu haben scheint, so ergibt sich, dass wir im Schirmrandringe und den von ihm abgehenden spangen ein system von Zellen und Fasern vor uns haben, welche vorzugsweise dem Nervensystem zugehören und tritt der Gedanke nahe. dass die Zellen des ersteren überall mehr oder weniger diesem System dienlich seien, vielleicht auch zwischen den „Füllzelleu“ gelegene. Wie die von diesem ganzen Zellencomplexe abgehenden Nervenfüdchen äberall zusammenhängen, ist zu bestimmen unmöglich; indessen wird ein soleher Zusammenhang als selbstverständlich angenommen werden und voransgesetzt werden dürfen, dass die von mir wegen ihrer relativen sonderung und aus auf die Beschreibung bezüglichen Gründen mit besonderen Namen belegten Nervenzellengruppen des Schirmrandringes und ihre radialen Ausläufer einerseits und die Faserstränge andererseits, nur Differenzirungen eines Ganzen darstellen, welche durchaus in innerer Abluängigkeit stehen, wie sie auch aus gemeinsamer zelliger Grundlage hervorgegangen sein müssen. Dabei ist als besonders bemerkenswerth hervorzuheben, dass die Nervenzellen überall in Strängen oder Bändern, strang-oder bandförmige Ganglien bildend gelagert sind, und dass sich nu' in geringem Grade ein Anlanf zeigt zn knotenartigen Nervencentren, wie sie sich bei den höheren Thieren finden.

\section{Die Hörbläschen.}

Die Hörbläschen, sonst mit dem mehr indifferenten Namen simnesbläschen bezeichnet, gehören eigentlich mit zum Schirmrandringe, sind nur Ausstülpungen desselben in die Umbrella hinein. Die Thatsache, lass sie mit der W and des ersteren aus der letzteren herausgezogen werden können (Taf. LX, Fig. 9), findet, wie schon erwähnt, ihre Erklärung darin, dass jedes Hörbläschen von einer düunen Hant nmschlossen wird, die wohl als eine Fortsetzung der oberen Wand des Schirmrandringes, d. i. der dieselbe nukleidenden Cnticula betrichtet weruen darf. Es wird also die Höhle in der Umbrella, in welchel das Hörbläschen liegt, von einer dümnen Haut ausgekleidet, der Umhüllungshaut des Hörbläschens nud diese Umhüllungs- 
haut wird in Zusammenhang mit dem Schirmrandringe aus jener Höhle herausgezogen. Die Unhüllungshant des Hörbläschens ist von einem zarten Plattenepithel ausgekleidet (angedentet in Fig. 25, w, Taf. XIl), welches seine Entstehung ans dem Ektoderm noch dadnrch anzeigt, dass es dann und wann eine Nesselzelle führt. Die Höhle des Hörbläschens öffnet sich, wie schon beschrieben worden ist, durch eine kreisrunde oder elliptische Oeffnung in die Höhle des Schirmrandringes, und es ist demuach anzmehmen, dass die Epithelialanskleidnng des Hörbläschens die direkte Fortsetzung der Zellen des Schirmrandringes sei, wie dessen Stützmembran die Fortsetzung der Hant der letzteren ist, und wie auch die Zellen des Spangenganghion eine Fortsetzung der Zellen des Schirmrandringes sind. Durch die erwähnte Oeffnung treten die Schenkel von zwei benachbarten Hörnerven ein (Taf. IX, Fig. 9, Taf. XIl, Fig. 24)'). Der Eintritt geschieht, wenn man sich das 'Thier in natürlicher, anfrechter Stellung vor sich denkt, von rechts und von links. Jeder Nervenstrang legt sich an die Wand der Hörbläschenöffnung dicht an, biegt sich in dieses hinein, steigt, an die rechte, bezw. linke Wand desselben dicht angeschmiegt, empor und wendet sich, nahe dem Grund des Bläschens angelangt, in schöngeformtem Bogen nach abwärts zn dem den Otolithen umhüllenden, aus Zellen bestehenden Körper heran (Taf. VII, Fig. 2; IX, 9: X, 2; XII, 1, 5, 24, 25; XIII, 6, S, 11, Hn). Es frägt sich nun, liegen die Hörnerven innerhalb des Hörbläschens zwischen dessen Stïtzlamelle und zwischen dem Epithel, oder liegen sie a nf dem letzteren, frei in die Höhle des Hörbläschens hineinragend? Man kamn diese Frage nicht gerade leicht an durchaus überzengenden Bildern entscheiden. Das Epithel des Hörbläschens ist so zart, dass man es überhaupt nur an günstigen Objekten zu sehen bekommt und dann erscheint es meist zweitelhaft, ob es die Hörmerven überzieht oder nicht. Allein man sieht mit Sicherheit zuweilen Nesselzellen auf den Nerven anfliegen, besonders nach Einwirkung von Essigsäıre (Taf. XII, Fig. 1) und ebenso sieht man dann auch znweilen dentlich (Fig. 25) die Kerne der Epithelzellen in derselben Lage; desshalb, sowie ans andern Gründen, müssen die Hörnerven als unter dem Epithel, zwischen diesem und der stützlamelle gelegen betrachtet werden. Die Nerven, welche znerst richtig beschrieben zu haben das Verdienst $\mathrm{Häckels}$ ist, bestehen ans denselben Fäden wie im Schirmrandring, nur sind diese Fäden, wenigstens im oberen Abschnitte der Nerven, etwas dicker als dort. Auch spindelförmige Nervenzellen trifft man noch innerhalb des Hörbläschens zuweilen in die Hörnerven eingeschaltet (welche, bezw. deren lierne in Fig. 4. Taf. XII unu in Fig. 6, 11, 12. Taf. XIII zu sehen

1) Wir bezeichnen dieselben in Zukunft als Hörnerven. 
sind). Sorgfältige Präparation: Entfernen der Epithelwand und der Zellen des Radialganglion, bezw. der Füllzellen des Schirmrandringes, zeigt auf's Deutlichste den Verlauf der Nerven so wie ich ihn geschildert habe. Ton einem Basalganglion, welches, wie Häckel ammahm, im Grunde des Hörbläschen liegen und durch welches die Wurzeln der Hörnervenschenkel durchtreten sollen, ist nichts zu sehen. - Im Hörbläschen nnd zwar im oberen Drittel von dessen Innenraum findet sich der Otolith, umschlossen von Zellen, welche, wie bekannt, von Häckel ebenfalls für ein Ganglion erklärt und als Sinnesgauglion bezeichnet wurden (Taf. VII, Fig. 2; IX, 9; XII, 24; XIII, $6 \mathrm{~Hz}$ und XIII, 8 und 11). Zu dieser Zellenumhüllung des Otolithen treten von oben und hinten her die zwei Hörnerven: der aus beiden zusammengesetzte Körper ist an ihnen frei aufgehängt. Der durch seinen Zellenmantel durchscheinende Otolith zeigt sich im frischen Zustande als stark lichtbrechende Kingel, deren concentrische Streifung auf eine Schichtung oder doch aut eine ungleichartige, in concentrischer Folge angeordnete Beschaffenheit der ihn herstellenden Substanz hinzuweisen scheint. Er löst sich in Säuren auf, nachdem die concentrische Streifung dentlicher geworden ist und nachdem sich in seinem innersten Theile hänfig eine radiäre Strahlung gezeigt hat (Taf. XII, Fig. 3) und es bleibt zuletzt nur eine zarte I I mbran zurück, die ihn mrsprünglich umhüllt hat nud welcher nach aussen die Zellen anfliegen. Dagegen sind die letzteren nicht wieder, wie Häckel angibt, von einer besonderen, gemeinsamen Hülle umschlossen. An Chromkalipräparaten, an welchen der Otolith sich aufgelöst, seine Membran sich hänfig etwas znsammengezogen hat (Taf. XIII, Fig. 11, w), sind sie mit der Nadel sehr leicht auseinanderzuziehen und zu isoliren. Wie Art der Endigung der Nerven an den Zellen zeigt sich dann mit ansserordentlicher Klarheit (ebenda). Die Zellen umgeben den vtolithen in einer einzigen Lage. Sie sind cylindrische Elemente, welche mit der meist breiteren äusseren Fläche frei in die Höhle des Hörbläschens gerichtet sind und ihrer Aufgabe nach nichts anderes sein können als die percipirenden Hölı l] en.

Jede Hörzelle geht nach unten zuletzt in einen Nerrenfaden u n mittelbar über. Aus ihrer freien äusseren Fläche digegen tritt ein langer, äusserst feiner Geisselfaden hervor (Taf. XIII, Fig. 7, 9, 11, 12, 15). Die Geisselfäden ragen von den Zellen aus in die Hölıle des Hörbläschens hineiu und mögen, frei in einer dieselbe austiüllenden Flüssigkeit schwebend, dessen Wand berähren.

Sehen wir weiter zmnächst zu, wie die Hörnerven sich als Ganzes zu der Lage der Hörzellen verhalten. Nachdem sie im hinteren, oberen Abschnitte der Zellhülle dicht nebeneinander angekommen sind, treten ilıe Fasern zwischen die percipirenden 
Zellen jener Gegend ein und verbreiten sich, indem sie sich theilweise kreuzen, divergirend nach allen Seiten über die ganze Oberfläche der den Otolithen umschliessenden Hant (Fig. 11). Näher an der Stelle des Nerveneintrittes oder weiter von ihr entfernt - denn jede Zelle wird versorgt - biegt sich je eine Faser nach antwärts um und geht in eine der Hörzellen über. So liegt die Ausbreitung der Hörnervenfaseru zwischen der Otolithenkapsel und den Hörzellen, und diese werden von jenen versorgt, indem sie zuerst zwischen ihnen durch und dann von unten an sie lierantreten.

Lie Hörzellen selbst (Taf. XIII, Fig. 7, 9, 11, 12, 15) zeigen weiter folgende Eigenschaften: ihre frei dem Hohlraume des Hörbläschens zugekehrten Endflächeu sind bald von ausehnlicher Breite. bald sehr schmal, fast stabförmig; ebenso ist die Gestalt der ganzen Zelle bald nahezı kubisch, bald kürbistlaschen- oder becherzellenähulich, wobei der in jeder Zelle gelegene grosse, ellipsoidische Kern lıäufig den ansgebauschten Theil derselben vollständig ertïllt, während der plasmatische Zellinhalt als umgekehrte, langgezogene Pyramide oder als đünner, stabförmiger Fortsatz dieser Ausbauschung nach oben aufsitzt, Verschiedenheiten, welche daher rühren, dass die Zellen, sämmtlich mit allen ihren Flächen dicht aneinanderliegend, sich in allseitiger Ausdehnung beschränken, während doch die änssere Endfläche einer jeden frei in den Raun des Hörbläschens hineinsehen will. Sind die Zellen auch unten, am anfsitzenden Ende, nicht spitz, sondern breit, so tritt der Nervenfaden an eine der Kanten der Zellbasis heran (Fig. 7, b, c, d; F'ig. 9, e). Der Zellinhalt erscheint an Chromkalipräparaten feinkörnig. Eine besondere Eigenthümlichkeit zeigt er im Aussentheil der Zellen. Sei dieser breit oder von ganz geringem Durchmesser, stets bietet er eine obere Endfläche von gewisser Ausdehnung dar und die Endflächen aller Hörzellen zusanmen bilden daher die Kungeloberfläche des den Otolithen umhüllenden Zellmantels. Mit starkeu Vergrösserungen lassen sich nun im änssersten Theile einer jeden Zelle gegen deren Endflache hin und zu ihr senkrecht gestellt einige sehr kurze mud feine Strichelehen erkenuen, wie feinste stabförmige Differenzirungen des Zellinhalts (Fig. 7. b, c; 9, c, d u. Fig. 15). Von einem dieser Stäbchen, welches in der Mitte der Zellenendfläche gelegen ist, geht der sehr lange Geisselfaden aus, unmessbar fein schon unmittelbar nach seinem Austritt, aber vollends gegen sein freies Ende hin zu so unendlicher Feinheit sich gestaltend, dass er selbst mit den stärksten Vergrösserungen kaum bis zu seinem Ende hin verfolgt werden kann. Die Fäden sind nicht starr, sondern im Gegentheil äusserst biegsam. Mittelst der stärksten Vergrösserungen gelingt es nun zuweilen weiter, den Geisselfaden in die Zelle hinein zu verfolgen. Das mittlere der Basalstäbchen, dessen Fort- 
setzung el nach aussen bildet, erstreckt sich manchmal zienlich weit in der Zelle nach abwärts und von seinem unteren Ende ab setzt sich der Faden, ebenso fein wie nach aussen, nach innen, bezw. mnten, gegen den liern hin fort. In den meisten Fällen ist das mittlere Stäbehen von den übrigen nicht unterschieden und der feine Faden beginnt jetzt nnmittelbar unter der Endlizche der Zellen (Fig. 9, b, c, d; Fig. 15).

Znweilen glaubte ich den Faden im weiteren Verlaufe in den Kerm hinein verfolgen zu küunen. Dagegen sah ich an Chromkaliprïparaten im Zellinlıalt hïufig dentlich mehrere feinste Fäden auf kürzeren oder liingeren Strecken unả in verschiedenen Richtungen, theilweise sich durchkreuzend, hinziehen, durchaus von derselben Beschaffenheit wie der Geisselfaden (Fig. 9, c). Und ganz dasselhe Verhalten schien mir im Kerne vorzukommen. So kam mir immer wieder der Verdacht, irh könnte bei jener Auffassung dadurch getïuscht worden sein, dass der Faden, welcher die unmittelbare Fortsetzung des Feisselfadens bildet, nicht unmittelbar in den Kern eingetreten war, sondern auf demselhen gelegen hatte; diss er vielleicht zuerst in verschiedenen Richtungen in der Zelle herumzöge, um erst später in den Kern einzutreten und sich hier in derselben Weise wie im Zellinhalt zu verhalten, indem er auch hier complicirt verlaufe. Der naheliegende Gedanke, dass er sich im Zellinhalt wie im Kerne in das gewöhnliche Fadennetz des Protoplasma fortsetze, würde wit der Beobachtung nur damn sich vertragen, wenn man annehmen wollte, dass er sich trotz solcher Verbindung wenigstens streckenweise besonders ausgeprigt und in selbstïndigem Verlauf erbalte. Da ich die bezüglichen Untersuchungen gemacht habe, noch bevor ich meine inzwisehen veröffentlichten nenen, genaneren Beobachtungen äber das Fadennetz im Kerne anderer Zellen angestellt hatte ${ }^{1}$ ) und hevor ähnliche Beobachtungen von Anderen gemacht waren, so habe i.h diese Frage niher zu prüfeu nicht Veranlassung genommen. Allerdings wïrde es eigenthümlich sein, wenn der Geisselfaden einer Hörzelle von Carmarina sich in dieser Bezichnng so ganz anders verhielte als derjenige der'Sinneszellen der Toponeuren. Dies, weil das Verhalten in Beziehnng auf das Austreten des Fadens in beiden Fiillen ganz dasselbe ist.

Man sieht mterhalb des Kerns in den Hörzellen von Carmarina ebenso wie in den Sinneszellen der 'Toponemen hüntig dentlich einen Faden, welcher genau so beschaffen ist, wie der im oberen Theile derselben sichtbare, als Furtsetzung des Geisselfadens beschriebene, vom Kerne an direkt in den fröher als Nervenfaden der Zelle bezeichneten Ausläuter hineintreten (Tat. XII, Fig. 9, c, ß), sei es dass dieser als die Fortsetzung des unteren sich spitz ansziehenden Endes der letzteren erscheint oder dass el von irgend einer Stelle der breiten Zellbasis aus ansgezogen sei. Es zeigt sich nun aber ferner, dass dieser Anslänfer nicht als Ganzes als Nerrenfaden hezeichnet werlen kam: "r besteht aus Hülle und Inhalt. Die Hälle geht unmittelbar üher in die Aussengrenze der Zelle. Den Inhalt bildet eben jener feine Farden, der Nervenfaden. Somit sind in dieser Beziehmng ganz dieselben Verhältnisse vorhanden, wie sie in Vorstehenden von Ekiodermzellen von Cyanea eapillata beschrieben worden sind. An der Hülle beobachtete ich dann und wann, öfters an mehreren Stellen hintereinauder, nach einer Seite hin platte, zipfelartige Fortsätze,

1) Vergrl. die Arbeit: Weitere Nachrichten über den Bau des Zellkerns etc. a. a. 0. 
ähnlich wie an den Bindegewebsfisern \%. B. von Aurelia anrita und von Beroë ovatus, wo sie die gegenseitige Verbindung dieser Fasern vermittehn ${ }^{1}$ ). Ein ähnlicher Zweck mag auch bei unseren Nervenhüllen gegeben sein (Fig. 9, a).

Durch das Vorhandensein einer deutlichen Hülle unı die Füden der Hörnerven ergibt sich nun auch die Erklïrung einer sehon berührten Eigenthümlichkeit, welche beim Isoliren derselben alsbald in die Augen tïllt, wenigstens soferm man ihren peripherischen Abschnitt zur Untersuchung lringt: der Thatsache, dass die Fäden hier nm ein leutliches dicker sind als diejenigen, welche den líingnerven zusammensetzen. Und fermer erklïrt sich wohl dadurch auch die weitere Thatsache, dass sie selust an Chromkaliprälaraten nicht leicht variküs erscheinen wie jene. Die Ursache dieser Verschiedenheiten ist augenscheinlich die, dass den Fibrillen des Ringnerven eine Hülle durchans fellen oder dass sie, wenn vorhanden, doch von ausserordentlicher Zartheit sein muss, wïhrend sie an jenen der Hörnerven viel dicker ist. Daher resultirt, abgesehen von den angegebenen Eigenthümlichkeiten, auch ein stürkeres Lichtbrechungsvernögen der letzteren.

Die wesentlichste der mitgetheilten Thatsachen ist die, dass in jede Hörzelle ein Nervenfaden eintritt, welcher his zum hern hin rerfolgt werden kann und welcher, wahrscheinlich durch diesen hindurchtretend, zuletzt in den Geisselfaden der Hörzelle sich fortsetzt.

Der genetische Zusammenlıang der Hörzellen mit der Zellenanskleidung des Hörbläschens und mit der Zellenbedeckung des Ringnerven, also ihre — übrigens selbstverständliche — Ektodermmatur gibt sich auf sehr hübsche Weise auch dadurch zu erkeunen, dass man zwischen ihnen zuweilen da oder dort eine Nesselzelle antreffen kaun (Taf. XII, Fig. 1, 25; Taf. XIlI, Fig. S). Diese Thatsache stimmt zugleich damit überein, dass das Epithelium des Hörbläschens, in welchem sich, wie erwähnt wurde, gleichfills Nesselzellen finden, die Hörnerven bedeckt: wahrseheinlich bedeckt es sie auch da, wo sie sich gegen den Otolithen herabbiegen vollständig, um zuletzt anf dem letzteren zu Hörzellen zn werden. Sumit würden die letzteren nichts anderes'sein, als eine Modification des das Hörbläschen auskleidenden Epithels. Die Unkleidung auch der zum Otolithen herabsteigenden Fortsetzung der Hörnerven mag die Ursache diwon seim, diass man zuweilen, besonders nach Anwendung von Essigsäure, in jener Gegend eine grössere Anzahl von Kernen sieht, welche leicht die Meiuung erregen könnten, als liege dort ein Hüufchen Zellen, etwa zu einem Ganglion vereinigt, beisammen (Taf. XII, Fig. 5, K). - Eine andere, sehr auffallende Thatsache, die mir nach Einwirkung vou Essigsäure anch an den Hörorganen anderer Cyclonenren begegnet ist, mag hier Erwähnung finden. Nachdem starke Essigsäure die Hörzellen und dereu Kerne vollkommen unsichtbar gemacht hat, beobachtete ich an deren Stelle häufig kleine, glänzende, wie krystallinisch ans-

1) Kan vergleiche meine Abhandlung über Beroë ovatus Taf. V, Fig. 47; Taf. VII, Fig. 69, b' und Taf. VIII, Fig. 78 . 
sehende Körnchen, welche nicht ordnungslos, sondern in der Weise vertheilt waren, dass ich amnehmen musste, sie seien einzeln oder zu mehreren ursprünglich etwa in die Hölzellen eingeschlossen gewesen (Taf. XIl, Fig. 5, p). Bei einer Thaumantias, wo sie einzeh lagen, massen die grössten nahe an $0,002 \mathrm{~mm}$. Bei anderen Formen traf ich ein einziges köruchen an, aber immer an derselben Stelle, oberhalb des Otolithen, offenbar ursprünglich gleichfalls in eine Zelle eingeschlossen (Aegineta, Rhopalonema), und von ihm aus liess sich dann zuweilen wie ein starres, feines Fädchen nach aufwärts verfolgen (Rhopalonema velatum). An derselben Stelle sah ich nun anch einzelne Körnehen bei Cammarina manchmal besonders dentlich, noch bevor die Kerne geschwunden waren, und sie schienen dann. was ich übrigens nicht hinreichend festgestellt habe, in diesen zu liegen (Taf. XII, Fig. 25, k). Es tritt der Gedanke nahe, dass es sich in diesen Körnchen nm eine Art feinsten Hörsandes handeln möchte, welcher etwa die Reizung des die Hörzelle durchziehenden Hörnervenfädchens in Folge von Erschütterung vermehre.

Die Sinnesbläschen der Geryoniden sind bisher in verschiedener Weise ron verschiedenen Forschern gedentet, zuletzt noch von $\mathrm{Häckel}$ eingehender besprochen worden. Häekel stellt die früheren Ansichten zusammen ${ }^{1}$ ). Gegenbaur glaubt sie, bei den Geryoniden wie bei den übrigen Cycloneuren, zwar füı Sinnesorgane, aber nicht bestimmt für Hörorgane erklären zu dürfen, weil den in ihnen eingeschlossenen Concretionen die freie Berveglichkeit abgeht, welche sich sonst bei den analogen Otolithen niederer Thiere allgemein findet ${ }^{2}$ ). Leuckart dagegen erklärt die Simnesbläsehen seiner Geryonia exigua (Liriope ligurina (Hä ckel) für Hörorgane ${ }^{3}$ ). Fritz Mäller endlich hält die Sinnesbläschen der Liriope catharinensis und der Cyeloneuren überhaupt mit A gassiz für Sehorgane. Häckel fügt bei. es stimmen die drei genamnten Forscher in der anatomischen Beschreibung der sinnesbläschen der Geryoniden überein, während sie in rler buntung derselben weit anseinander gehen. Woch seien sowohl diesen Dreien, als auch allen anderen Beobachtern, die noch die Simnesbläschen der Geryoniden untersucht hahen, mehrere höchst wesentliche anatomische Verhältnisse im Innern derselben entgangen, welche ihm für deren Dentung als Sinuesorgane von dem grössten (iewicht zu sein schienen. Er führt als diese von ihm aufgedeckten Verhältnisse an: sein Basalganglion, die sinnesnerven, ein sinnesganglion und bemerkt dazu: was die Dentung der sinnesbläschen (Rand-

1) Häckel, Rüsselquallen, S. $51 \mathrm{ff}$.

2) Gegen b a r r, Bemerkungen über die Pandkörper der Medusen, Müller's Archiv 1856. S. 234.

3) Leuckart, Beiträge zur Kenutniss der Medusenfauna von Nizza. Arch. f. Naturgesch. 1856. 
körperchen, wie er sie nenut) angehe, so werde zunächst durch seine Beobachtungen deren Stellung als Sinnesorgane nur befestigt; was aber die speciellere Feststellung der simnesqualitat betrifft, so scheine ihm diese dadurch nach keiner Richtung bestimmter bezeichnet zu werden. Im Gegentheil glaube er, dass damit nur die wesentliche Differenz dieser Randbläschen von anderen ähnlichen Sinnesorganen niederer Thiere (Würmer, Mollusken) noch mehr bestätigt und ausdrücklich hervorgehoben werde. Da das concentrisch geschichtete Concrement, welches gewöhnlich als Otolith anfgefasst wird, ganz in der zelligen, von ihm als Simnesganglion gedenteten Blase eingeschlossen sei und ausserdem die Nervenfasern rings um dasselbe innerhalb jener Zellenmasse auszustrahlen scheinen, so springe die auffallende Verschiedenheit dieses Organs von den mit frei beweglichen Otolithen versehenen Hörbläschen anderer niederer Thiere sofort in die Angen. Weder die morphologischen, noch die physikalischen Verhältnisse jenes Apparates lassen eine direkte Vergleichung mit letzteren zu. Noch weniger könne die Ansicht befriedigen, dass die Sinnesbläschen Augen seien. "Die Deutung der Sinnesorgane niederer Thiere" fährt Häckel fort, "gehört ohne Zweifel zu den schwierigsten Objekten der vergleichenden Physiologie und ist der grössten Unsicherheit unterworfen. Wir sind gewohnt, die von den Wirbelthieren gewonnenen Anschautungen ohne Weiteres auch auf die wirbellosen Thiere der verschiedenen Kreise zu übertragen und bei diesen analoge Sinnesorgane anzunehmen, als wir selbst besitzen. Und doch ist viel wahrscheinlicher, dass hier wesentlich andere Simnesempfindungen zu Stande kommen, von deren eigentlicher Qnalität wir uns keine bestimmte Vorstellung machen können; wie es z. B. sehr wahrscheinlich ist, dass die Empfindung der Licht- und Schallwellen, für welche bei den höheren Thieren verschiedene Organe differenzirt sind, bei den niederen an ein und dasselbe Simmesorgan, natürlich in unvollkommener Ausbildung, gehunden vorkommen. Als ein solches "gemischtes Sinnesorgan", über dessen eigentliche Funktion wir uns natürlich vorlänfig jerler bestimmteren Vermuthung enthalten müssen, möchte ich anch die Randkörper eines grossen Theils der Medusen und namentlich die sogenannten "Randbläschen“ bei den Geryoniden, Trachynemiden etc. betrachtet wissen." Wie wir gesehen haben, hat Häckel zwar Recht, wenn er sagt, dass allen früheren Beobachtern höchst wesentliche Verhältnisse der Randbläschen, welche für ihre Deutung vom grössten Gewicht sind, entgangen seien und er selbst hat allerdings das Verdienst, die Sinnesnerven nachgewiesen zu haben; allein die für die Dentung der Sinnesbläschen wesentlichsten Verhältnisse sind auch ihm verborgen geblieben: solange als die percipirenden Endzellen der Sinnesnerven nicht bekannt, oder in dieser Eigenschaft nicht erkannt waren, konnte selbstverständlich von einer rich- 
tigen Anffassung der Sinnesorgane keine Rede sein. So ist es anch wohl verständlich, dass Häckel zu der Ansicht kam, es möchte sich in denselben handeln un Organe, in welchen Sinnesempfindungen zu Stande kommen, von deren eigentlicher Qualität wir uns lieine Vorstellung machen können, um ngemisthte Sinnesorgane“, über deren eigentliche Funktion wir uns vorläntig jeder bestimmteren Vermuthung enthalten müssen.

Nach meinen Beobachtungen dagegen kann es nicht mehr zweifelhaft sein, welcher Simnesqualität Vertretung unserem Organ zukommt: es ist ein Hörorgan. Freilich ist dieses Hörorgan sehr eigenartig gebant, nach einem ganz anderen Schema als die Hörorgane anderer niederer Thiere, z. B. der Würmer und Mollusken. Der Hörstein ist unbeweglich in einer Kapsel eingeschlossen. Es ist nicht möglich, dass Erschütterungen desselben die Termittelung der Uebertragung der Schallwellen auf die percipirenden Zellen besorgen. Dagegen ist angenscheinlich, dass die in den mit Fhüssigkeit gefüllten Hörbläschen schwebenden, langen und feinen Geisselfäden der letzteren, die Hörhaare, von den durch Erschütterung von anssen veranlassten Bewegungen dieser Flüssigkeit ergriffen werden und die Erschütterung in die Zellen leiten müssen. Da wegen der Länge der Haare anzunehmen ist, dass sie der Wand des Hörbläschens anliegen, so wird auch unmittelbar die Erschütterung dieser anf jene übertragen werden können. 1)em Hörsteine kann dabei nur die Bedentung zugeschrieben werden, dass er, indem er einen festen Rückhalt für die Zellen bildet, deren Mitbewegung bei der Erschütterung verhindert, einen Anprall der Wellenbewegung an dieselben, heziehungsweise an die Hörhaare ermöglicht und so deren Wirkung verstärkt. Wir haben somit im Princip nier dieselben Einrichtungen, welche, wie noch besprochen werden soll, bei den toponenren Medusen bestehen, nur mit dem Unterschiede, dass dort die Hörhaare fehlen und dass stutt eines Hörsteins zahlreiche Hörkrystalle vorhanden sind.

\section{Untere Schirmoberfläche, deren Epithelien, Muskel- und Nervenelemente.}

Muskulatur. Häckel hat mitgetheilt, dass das contractile Gewebe des Geryonidenkörpers in zwei verschedenen Formen auftrete, als quergestreifte und glatte Huskulatur. Es sollen nach ihm die glatten Muskelfusern ansschliesslich das contractile Gewebe der radialen Haupttentakeln nnd zum Theil anch der Magenwand bilen, während die quergestreiften dasjenige aller übrigen Körpertheile zusammensetzen. Ich 
habe genaner nur die Muskulatur der Unterfläche des Schirmes untersucht, kann aber für diese die Angaben Häckels bestätigen. Nur bin ich nicht überall einverstanden mit der Beschreibung, welche dieser Forscher von den Muskelelementen gibt. Insbesondere sind ihm die Beziehungen entgangen, welche die quergestreifte Mnskulatur zn den Epithelien hat, Verhältnisse, die, wie wir sehen werden, von besonderer morphologischer und physiologischer Bedentung sind. In Betreff des Vorkommens der beiden Arten von Muskelelementen wird man sich am übersichtlichsten äussern. wenn man sagt: es sind an der oralen Fläche des Schirmes von Carmarina nach zweierlei Richtungen angeordnete Muskelelemente vorhanden, radiäre und cirkuläre. Die radiären sind von glatten, die cirkulären fast sämıntlich von quergestreiften Elementen gebildet.

Die cirkuläre, quergestreifte Muskulatur belegt auch die Unterfläche der Stützlamelle des Velum, setzt sich aber nicht unmittelbar anf die Unterflache des Schirmes fort. vielmehr findet sich, wie früher erwähnt worden ist, an der (trenze zwischen Segel und Schirmrand eine muskelfreie Stelle, die sich also $\mathrm{nm}$ den Umfang des Schirmrandes herumziehen muss. Von der Unterfläche des Schirmes bedeckt die cirkuläre Muskulatur nur den Abschnitt, welcher bis zu den Genitalblättern hinreicht, vollkommen. Von da an sind die vorher zwischen ihr und dem Deckepithel eingeschlossenen Radialmuskelstrảnge (T'af. X, Fig. 10) dem Gallertgewebe der Umbrella unmittelbar aufgelagert. Ansser den quergestreiften, alsbald näher zu beschreibenden Muskelelementen von Schirm und Velum traf ich im Schirmrandring, das Ringgefäss begleitend, bei anderen Cycloneuren (Sarsia) einen ans glatten, spindelförmigen Elementen zusammengesetzten Muskelbelag und derartige Muskelelemente habe ich, wenngleich spärlich, in jener Gegend auch bei Carmarina bei Gelegenheit des Isolirens der Theile des Schirmrandringes zuweilen zu Gesicht bekommen, ohne dass ich sie nach Lage und Beschaftenheit näher untersucht hätte.

Die radiären, aus glatten Elementen zusammengesetzten Muskeln der Subumbrella sind in zwölf Zügen angeordnet, sechs in der Fortsetzung der Tentakel in der Mittellinie der Unterseite der Radiärgefässe verlanfenden, welche ich als mediale bezeichnen will (Taf. XI, Fig. 4, m. Fig. 5, x) nnd sechs seitlich davon in derselben Richtung ziehenden, lateralen (ebenda bei 1). Beide zeigen in Beziehung anf die Ausdehnnng ihres Verlanfs ein verschiedenes Verhalten. Nur die ersteren sind bis zum Schirmrande hin zu verfolgen und strahlen dort sogar in die Tentakel hinein ans, wo ich ihrer ferneren Verbreitung nicht nachgegangen bin. Sie liegen dabei dicht unter dem Epithel der Schirmunterfläche, wie schon bemerkt, zwischen diesem und der cirkulären Muskelschichte (Taf. X, Fig. 10, Rm). Thre Fortsetzung im Bereich 
des Magenstiels habe ich gleichfalls histologisch nicht untersucht, an den wie erwähnt behandelten Präparaten lässt sich aber als solche ein Streifen verfolgen, welcher bis gegen das untere Ende desselben ant jedem Radiärgefäss hinzielıt. (Taf. XI, Fig. 5, m.) Es sind mnzweifelhaft diese sechs mittleren Radiärmuskelstränge, welche Häckel als Radialnerven beschrieben und abgebildet hat: dass dem so ist, geht dentlich ans den Abbildungen dieses Forschers hervor ${ }^{1}$ ), obschon derselbe angibt, dass seine Radialnerven nicht auf, sondern unter der cirkulären Muskulatur liegen. Rałlalnerven, wie sie Häckel annimmt, existiren also in Wirklichkeit nicht, dass es sich in den Strängen um Mnskelbündel handelt, kann unschwer durch Isoliren der sie zusammensetzenden Elemente nachgewiesen werden. Nach Behandeln mit Ueberosmiumsäure tritt der mittlere radiäre Muskelstrang in schwarzer Färbung ganz besonders dentlich hervor. Die zwei lateralen bleiben gewöhnlich blasser. Diese letzteren schliessen den mittleren von beiden Seiten ein (Taf. XI, Fig. 4 n. 5 , 1), ziehen parallel mit ihn, haben jedoeh nach oben und nach unten mit ihm nicht dieselbe Ausdehmung. Unten beginnen sie erst eine Strecke weit oberhalb des Schirmrandes in der Höhe der mnteren Grenze der Genitalblätter (Trr. XI, Fig. j, 1). Nach oben werden sie nicht schmäler wie der mittlere Strang, sondern vielmehr breiter und von da an, wo dieser sich verschmälert, nähern sich beide, um sich aneinander zu schliessen, zu vereinigen, und als ein Band je über den Magenstiel bis zu dessen mnterem Ende hin nach abwärts zu ziehen (die longitudinalen Stielmuskeln Häckels).

Bau der M nskelelemente. Die glatten Muskelelemente bestehen überall ans lungen, beiderseits zugespitaten, also spindelförmigen Fasern, deren Dicke diejenige der Nervenfibrillen um ein Bedentendes übertrifft (Taf. XI, Fig. S). Anch zeigen sie ein stärkeres Lichtbrechungsvermögen als diese. Indessen liefert zuweilen doch erst die Isolinng völlige Sicherheit darüber, was man vor sich hat. Bei anderen Cycloneuren, z. B. bei Sarsia, traf ich stets an der einen Seite wenigstens der tiefgelegenen Fäden ein Lager oder eine Anhäufung von Plasma, einen Kern einschliessend. Bei Carmarina habe ich Aehnliches nicht beobachtet, halte jedoch datïr, dass dieselben Einrichtungen an unverletzten Fasern jedenfalls in den jüngeren Lebensstadien hier ebenso ausgebildet vorhanden seien, wie sie denn thatsächlich nichts anderes als eine Modification oder ein Proliferationsprodukt der alsbald zu besprechenden neurofibrillaren Deckzellen darstellen, mit diesen somit gleichen gene-

1) a. a. 0. Taf. I, Fig. 1, $3 \mathrm{a}^{3}$; Taf. VI, Fig. 72 , ar. 
tischen Ursprungs sein müssen. Nur wäre es möglich, dass im höheren Alter da oder dort der plasmatische Theil an den coutractilen Fäden mehr zurïcktritt. Ich komme auf diese Verhälnisse später noch zu sprechen.

Die quergestreiften Maskelelemente zeigen da, wo ich sie genauer nntersuchte, nämlich an der Unterfläche des Schirmes, sehr bemerkenswerthe Eigenschaften, stehen hier ebenso wie bei den T'oponeuren mit den Deckzellen in organischer Verbindung, und lassen sich von diesen daher in der Beschreibung nicht trennen. Indessen sind die Banverhältnisse dieser Neuromuskelzellen gegenüber den den Toponeuren zukommenden sehr eigenartige. Die Zellen erscheinen in der Ansicht von der Unterfläche des Schirmes her anuähernd spindelförmig (Taf. XII, Fig. 6, 9, 20), mit der längsten Auslehnung der spindel radial gelagert ${ }^{1}$ ). Entfernt man einige der deckenden Zellen, so sieht man darunter Muskelelemente senkrecht zur längsten Ausdehuung des Querschnittes derselben verlanfen und zwar so, dass jede Zelle von mehreren Muskelelementen gekrenzt wird (Taf. XII, Fig. 6). Isolirt man die Deckzellen, so bleiben die letzteren an ihnen hängen und bilden mit ihnen in sehr eigenthümlicher Weise ein Ganzes. Zum Zweck der Beschreibung denken wir uns isolirte Deckzellen in der Richtung von m, Taf. XII, Fig. 6 von ihrer breiten Seitenfäche her gesehen. Dieselben erscheinen so in folgender Gestalt: ein im optischen Dnrchschnitt quadratischer oder rechteckiger Zellkörper (Taf. XII, Fig. 2, 7, 13, 17, 32) ist unten, da wo er die freie Oberflüche der Ektodermlage mit bilden hilft, scharf abgeschnitten, oben, an der entgegengesetzten, der Muskelschichte zugekehrten Seite, mehr oder weniger stark ausgebuchtet oder ansgezackt. In den Buchten und anf der Höhe der diese Buchten begrenzenden Fortsïtze sieht man nun in der gegebenen Ansicht eigenthümliche, stum]fe, an der Basis häutig gekrümmte, stabähnliche Bildungen, meist ammähernd von der Höhe der Zelle selbst, und ziemlich dick in grösserer Anzahl - bis 15 und mehr - aufsitzen, so dass ein Bild hervorgebracht wird, welches man ungefähr mit einer Flimmerzelle vergleichen könnte, die statt der feinen Wimperhaare grobe Stäbe tragen wïıde. Erst die Ansicht von einer der schmalen Seitenflächen der Zellen, von z Fig. 6, 'Taf. XII her, znsammengestellt mit dem Geschilderten, gibt Aufschluss über den eigenartigen Bau des Ganzen (Taf. XI1, Fig. 11, 16, 21): die Deckwellen haben etwa die Gestalt kurzer, hoher Wetzsteine; quer über die aborale Fläche jeder derselben ist eine Anzahl von Muskelbändern gestellt, wie sie in Fig. 11, 16, 18, 20, 21 ganz oder

1) Zum richtigen Verständniss ist Fig. 6 in derselben Lage $z u$ denken wie Fig. 20, also um 90 Grad 
in Stücken abgebildet sind. Die Bänder sind an beiden Enden entweder abgerundet oder zugespitzt; sie stehen mit der schmalen hante theils auf den beschriebenen Fortsätzen der aboralen Zellenoherfläche, welcht als quer über diese gezogene Leisten aufgefasst werden ıüssen, theils stehen sie in den limnen zwischen diesen Leisten. Ansichten wie die in Fig. 11, 16, 21 wiedergegebenen zeigen, dass die Zellen und die Muskelbänder miteinander durchans Eins sind, so zwar, dass das Plasma der ersteren sich anl' die (in natürlicher Lage) untere Kante eines jeden Bandes furtsetzt und hier zuweilen in dessen ganzer Ausdehmung zu verfolgen ist. Es frägt sich nun, ist wirklich jede einzelne Zelle mit zahlreichen Muskelbändern organisch verbunden oder bildet sie nur mit einem einzigen derselben eine Einheit, während die übrigen von benachbarten Zellen her nur übergreifen und vielleicht sekundär erst mit den Nachbarn in Verbindung treten. Dass ein Uebergreifen je eines Muskelbandes auf mehrere Zellen statthaben muss, ist wegen des grossen Unterschiedes im Bleitendurchmesser der Zellen und im Längendurchmesser der Bänder selbstverständlich und so möchte man zu der Auffassung hinneigen, dass zu jeder Zelle mur je ein Mnskelband m's rünglich organisch gehöre, mit ihr ein Ganzes bilde. Dem scheint aber die Verbindung aller Bänder mit je einer Zelle direkt zu widersprechen. Anch wäre der dritte Fall möglich, dass nicht alle über eine Zelle weglaufenden Muskelhänder, aber doch mehrere derselben zu dieser organisch gehören. Mag dem sein wie ihm wolle, jedentalls haben wir in diesen eigenartig gebauten Elementen nach Analogie der bei anderen Medusen beschriebenen Verbältnisse N e n rmuskelzellen vor uns. Diese Zellen bieten nun aber noch nach anderer Richtung hin höchst bemerkenswerthe Eigenschaften dar, lie mehr als die schon geschilderten beweisen, dass wir es in ihnen thatsächlich mit Apparaten zu thun haben, welche im Dienste des Nerven- und des Muskelsystems zugleich stehen. Bei starker Vergrösserung und besonders nach Anwendung schwacher Essigsäurelösmngen auf das frische Objekt, sowie an Chromkalipräparaten, lässt sich häufig erkennen, dass lie Körnchen des Plasma des Deckzellenkörpers nicht wirr durcheinander liegen, dass sie vielmehr parallel nebeneinander, von mnten nach oben ziehende Reihen darstellen, als ob sie den Weg leinster variköser Fädchen bezeichnen würden (Taf. XII, Fig. 13, 15, 22). Es lassen sich diese Fädchen bis an die aborale Zellgrenze und zuweilen bis in das äusserste Ende der Fortsätze hinein verfolgen, welche die zackige Beschaffenheit dieser Grenze verursachen (Taf. X1I, Fig. 13). Betrachtet man die Zellen mit starken Vergrösserungen von einer der Endflächen aus oder im optischen Querschnitt, so sieht man den Zellinlalt durchsetzt von wirr durcheinander laufenden Fadenzügen, welche dom Querschnitt jener Längsfaserung entsprechen (Taf. XII, Fig. 9). W i $\boldsymbol{l}^{*}$ 
habensomit in dem Deckentheil unserer Neurom uselzelleu ganz dieselbe Eigenschatt, welche ith vonden Besenzellen des schirmrandringes beschrieben habe: ihr Inhalt ist fadenartig differenzirt, in neurofibrilläresubstanz, in Neuroplasma nmgewandelt.

Die Muskelbänder erscheinen im frischen Zustande, wenu nicht überall, so doch an manchen Stellen dentlich quergestreitt (Taf. XII, Fig. 15 u. 1S). An Chromkalipräparaten dagegen zeigen sie nicht nur überall eine durchaus schöne Querstreifung, sondern zerfallen anch der Länge nach in Fibrillen, welche ans abwechselnd hellen nnd dunkeln Theilchen zusammengesetzt, verhalten sich also ganz wie die quergestreiften Muskelfasern der höheren 'Thiere. Leider bin ich nicht dazn gekommen, an Chromkalipräparaten nachzusehen, in welcher Art Beziehungen zwisehen den Querstreifen des Muskelbandes und der streifung der Nervenzelle vorhanden seien: an frischen Objekten trat mir die 'Thatsache auffallend entgegen, dass die eine häufig geradezu als die Fortsetzung der anderen aufzutreten schien. Es möchten hier histologisch äusserst wichtige Verhältnisse anfiudecken sein.

Die Ektodermzellen, welehe den Radiärmuskelzügeu und den der Muskulatur entbehrenden Bezirken der oralen Oberfläche des Schirmes a ufliegen. Untersucht man den Ektodermzellenbelag der Radialmuskeln in dem der cirkulären Muskulatur enthehrenden Theile des Schirmes oder anch das Epithel der oralen Schirmfläche in deren Nähe, so begegnet man höchst bemerkenswerthen Verhältnissen. Es sind die hier gelegenen Deckzellen in Gegensatz zu den soeben von der cirkulären Muskulatur beschriehenen sehr niedrig, nahezn platt. Inre Gestalt ist nicht eine bestimmte; im Ganzen ist sie wohl meist annähernd spindelförmig, aber stets bedingt durch die alsbald zu beschreibenden, von ihnen abgehenden Ansläufer (Taf. X, Fig. 1, 3, 4, S, 13). Das Eigenartige liegt in Inhalt dieser Zellen, welcher wie aus lauter feinsten Fäden zusammengesetzt erscheint, die bald in mehr concentrischen Zügen, bald wirr durcheinanderziehen, stets aber an den Rändern und an der Unterfläche der Zellen in grosser Menge austreten und daher diesen dort ein durchaus zerfasertes Aussehen verleihen. Es besteht dieser Inhalt somit aus Neuroplasma: er löst sich, ganz wie ich dies von den Besenzellen des Schirmrandringes beschrieben habe, in feinste Fädchen auf, welche ihrer varikösen Beschaffenheit nach nichts anderes a ls Nervenfädchen sind. Zuweilen sah ich von einer Zelle ausser den Bündeln von Fäden, in welche sie sich auflöst, auch ein oder das andere stärkere Nervenfädchen für sich abgehen (Taf. X, Fig. 4). Es streben diese Nervenfäden nun 
theils unmittelbar zu den Muskelelementen hiu, so weit deren in der Nähe oder unter den Zellen liegen, ohne dass ich inre Verbiudnng mit diesen nachgewiesen hätte, theils sammeln sie sich in Züge. welche mit anderen Zügen von Nervenfäden, die ron unter dem Epithel gelegenen Ganglimzellen abgehen, sich zu vereinigen seheinen. Das vor Allem Bemerkenswerthe ist num aber, dass die beschriebenen neurofibrillären Epithelzellen, welehe in ähnlieher Weise wie anf den Radialmuskelu nicht nur zu den Seiten derselben, sondern anch sonst an muskelfreien Bezirken der Unterseite des Schirmes, anch anf dem Magenstiele in ïhnlicher Weise getroffen werden, dass diese Zellen zuweilen ihren Eigenschaften nach durehaus in typiseheGanglienzellen übergehen: es liegen zwischen ihnen, wenn auch selten mul meist zerstrent, \%ellen, welche mehr oder weniger vollkommen die Eigenschaften solcher Gauglienzellen zeigen und finden sich alle möglichen Uebergänge zu diesen. Deratige zwischen den gewöhnlichen nemofibrillären Epithelzellen gelegene Ginglienzellen senden, yleich jenen, Anslïufer unter die Epitheldecke ab (vergl. 'Taf. X, Fig 7, gz). Weil nnter den Ejithel, wie wir noch näher besprechen werlen, gleichfalls ausgebildete Gangienzellen liegen und bei der ron mir angewendeten Untersuchmgsmethode (Einlegen ter Chromkalipräparate in Glycerin und Wasser), dnrch das nemofibrilläre Epithel dmehscheinen, so ist es oft schwer, jene im Epithel gelegenen von ihnen zu unterscheiden, festznstellen, dass sie nicht mit ihnen dieselbe Lage haben. Dass dies nicht der Fall ist, lass in der That typisehe Ganglienzelken im Epithel liegen, das beweist schon die Thatsache, dass bei der Präparation durch lleransfallen derselben hänfig iner form entsprechende Lücken im Epithel entstehen ('Taf. X. Fig. 7, 1). Nur sie stheinen sich in dieser Weise abzutremnen, während die nemotibrillatren Zellen in viel inngerer Terbindung untereinander stehen. Jies hängt damit zusammen, dass die typischen Ganglienzellen glattrandige, in der Form abgeschlossene Körper geworden sind, welehe mur nach der einen oder der anderen bestimmten Kichtung Auslänfer absenden, ،lie gleichtalls bestimmte Ungrenzung haben. Damit stelıt in Beziehung, dass ihr Inlalt weniger dentlich faserig erscheint als derjenige der gewöhmlichen neurofibrillïren Epithelien; er zeigt ferner ein stäreres Lichtbrechungsvermögen nnd färbt sich durch Carmin leichter, als sie. Das Kernkörperchen ilıes grossen Kerns ist von ausserordentlieher Grösse. Ansdrïcklich hervorgehohen muss indessen nochmals werden, dass man nicht ïberall und gewöhnlich nur zerstrent und einzeln als typische Ganglienzellen erseheinende Zellen zwischen den gewöhnlichen neurofibrillären Epithelien antrifft und dass die F'eststellung der 'Thatsache ihrer Existenz somit einige Mühe erfordert. Selbstreiständlich lässt sich ihr Vorkommen nur in folgender Weise erkiären: das 
Epithel der Subumbrella ist äberall, auf der quergestreiften wie auf der glatten Muskulatur, ein Nervenepithel. Es zeigt diese Eigenschaft auf das Dentlichste durch seime neurofibrilläre Beschaffenheit. Mit den Fäden der quergestreiften Muskulatur bildet der neurofibrillitre Theil der Subumbrella ein Ganzes (Neuromuskelzellen). Wie die Beziehungen der neurofibrillären Deckzellen zur radiären (glatten) Muskulatur beschaffen sind, ist noch nicht völlig aufgeklärt; jerlenfalls sind sie auch da wo sie dieser Muskulatur aufliegen (Taf. X, Fig. 1 u. 5) nicht in so holrem Grade unmittelbare wie dort, sondern es handelt sich auch hier um eine Verbindung durch die Nervenfüdeu, in welche sich die Zellen auflösen. Wie wir sehen werden, treten an beiden Orten an der oralen Fläche der Muskulatux typische Ganglienzellen auf. Schon die bei Besprechung des Schirmrandringes behandelten Verhältnisse lassen vermuthen, dass diese Ganglienzellen ursprünglich dem Epithel angehört halıen und dass sie vom Epithel her eingewandert seien. In noch höherem Grade lässt daranf die Thatsache schliesseu, dass die gewöhnlichen Deckzellen der Subumbrella nicht nur in derselben Weise wie z. B. die Besenzellen des Schirmrandringes sich als Nervenzellen darstellen, sondern dass sich zwischen ihnen ansserhalb des Gebietes der quergestreiften Muskulatur sogar Uebergänge zu typischen Ganglienzellen und ausgebildete solche Ganglienzellen finden. Diese Ganglienzellen sind nur eine höher entwickelte Form der gewöhnlichen neurofibrillären Deckzellen, wälrrend sie andererseits in ihren Eigenschaften mit subepithelialen völlig übereinstimmen können.

Die nicht auf oder in unmittelbarer Nähe der radiären Inskulatur gelegenen Epithelien bedürfen in Rücksicht auf die lrage nach der Verbreitung der geschilderten Verhältnisse einer näheren Untersuchung. Eine besondere Art der Umbildung zeigen dagegen die zwischen dem inittleren und den lateralen Zügen der Radialmuskeln gelegenen Gebiete (Taf. XI, Fig. 4 u. 5, d). Lie Epithelien sind hier theilweise zu Drüsenzellen (Taf. X, Fig. 9) umgewandelt. Ihr Inhalt besteht aus ziemlich grossen, meist durch gegenseitigen Druck polygonalen oder anch ohne diesen unregelmässigen und dann auch ungleich grossen Massen einer homogenen Substanz, welche sich in Carmin gerne roth färbt: ganz älmliche Verhältnisse, wie ich sie aus Drüsen von der oralen Fläche vou Beroë beschrieben habe. Die Drüsenzellen (Taf. XIII, Fỉg 1 bis 5, Fig. 10 u. 13) erscheinen theils cylindrisch, theils becherförmig; ihr unterer Theil ist oft noch von gewölnnlichem Protoplasma erfültt, wälırend sie oben die beschriebene Sekretmasse enthalten. Nicht immer ist der ganze Raum zwischen den Strängen eines Radialmuskels in dieser. Weise drüsig umgebildet, sondern man trifft auch hier, bemerkenswerther Weise, Nervenzellen mit faserig differenzirtem Inhalt und dazwischen einzelne Drüsenzellen (Taf. IX, Fig. 13). In anderen Fällen können 
sich letztere über die lateralen Muskelzüge hinaus erstrecken und noch jenseits derselben einzeln vorkommen. So zeigen dieselben bei geringerer Ausbildung des drüsigen Inhalts zuweilen auch einen Fuss, ämnlich dem contractilen Faden einer Neuromuskelzelle (Taf. XIII, Fig. 3), Verhältnisse, welche auf gemeinsame Anlage linzuweisen scheinen (vergl. anch Taf. X, Fig. 11, vom Magenstiel).

Ganglienzellen und Nerven unter dem Epithel der oralen Schirmfläche. Sie liegen wiederum in besonderer Menge in den liadien, auf der glatten Muskulatur und beiderseits von derselben und erstrecken sich, wie die Drüsen und das Nervenepithel, auch auf den Magenstiel. Sie sind ähnlich den vom Schirmrandring beschriebenen beschaffen, zeigen einen oder mehrere, an der Wurzel meist ziemlich dicke und oft sehr deutlich ans zalılreichen Nervenfibrillen zusammengesetzte Ausläufer: Die Ansläufer theilen sich vielfach in feinere Fäden oder Fibrillenbündel und diese ziehen mit den vom Nervenepithel herkommenden Fadenzügen zu den Muskelfasern (Taf. XII, Fig. 23) hin. dieselben häufig in querer Richtung krenzend oder beide zusammen hilden Züge von Nervenfasern, die neben den Muskelfasern und mit ihnen parallel, jedoch in unbestimmter Anordunng, vielfach durcheinanderziehend, anch in kleinere Bündel sich zertheilend, verlaufen. Der Reichthum an solchen subepithelialen Ganglienzellen, die übrigens häufig auch durch ihre Ausläufer untereinander in Terbindung stehen, ist ein wechselnder, an manchen Stellen aber ein so grosser, dass fast Zelle an Zelle liegt (Tat. XII, Fig. 23). Ihre Untersuchung gelingt am besten, wie auch diejenige des Nervenepithels, an Chromkalipräparaten, welche in Carmin gefärbt worden sinc, und darauf, um die Epitheldecke durchsichtig zn machen, längere Zeit in Glycerin und Wasser zu gleichen Theilen gelegen haben. Uebrigens sind sie auch an Usmiumsäurepräparaten deutlich zu erkeunen. In Tat. XI, Fig. 1 ist ein Präparat aus einer mit Osmiumsäure behandelten und in Alkohol aufbewahnten Carmarina dargestellt, welches noch andere Verhältnisse andentet. Es stanmt das Priparat aus dem oberen Theile des śchirmes, von der Greuze der cirkulären Muskulatur, welche dort gegen den Radialmuskelstrang hin anfhört. Zwischen die Muskelfäden hinein, uffenbar nm mit denselben in Verbindung zu treten, ziehen Nervenfaseru (n) von der nach dem Radialmuskelstrang zu gelegenen Seite her, theilweise deutlich von Ganglienzellen (Gz) ihren Ausgang nehmend, deren Ausläufer sich mit ihnen dentlich da und dort mischen; ein Theil der im Bogen nach auf-oder nach abwärts von der cirkulären Muskulatur ansziehenden Fäden aber gehört. so weit ich an Osmiumsäurepräparaten und olme Isolirung entscheiden konnte, noch dieser selbst an. In einer Richtung, welche parallel ist derjenigen der Radialmuskeln, laufen endlich dort Züge von Nervenfasem (nn), welche man als Radial- 
nerven bezeiehmen kann, wenn man im Auge behalt, dass es sich in ilnen nur eben 1 m nuregehnässige Faserzüge, nicht um umscluiebene, streng lokalisirte „Nerven" liandelt.

In Gebicte der radialen Muskeln liegen dic Ganglienzellen also zwisehen dem Epithel und den contractilen Elementen. Man findet ähnliche Kellen, wenngleich spärlicher, nun anch in Geljete der quergestreiften Muskulatur. Dieselben liegen auch hier unter der Epitheldeeke und zwar zwischen der neuroplastischen und contratilen Abtheihng der Neuromnskelzellen. Inre Fortsätze sind hier auf weite Strecken linziehend und manchfach anastomosirend zu verfolgen (Taf. XI, Fig. 11). Wenn ich nach Chromkalibehandlung Nenronuskelzellen isolirt hatte, so traf ich seln luäufig auf dem contractilen Muskelbande und mit demselben, bezw. mit ller Ansatzstelle des anl ilın von der Deckzelle her überfliessenden Plasma, tinen Nervenfaden von variköser Beschaffenheit und nit eingeschobener Nervenzelle, wie ich dies von Lizzia Köllikeri und von den T'oponenren selıon frülıer erwälnnt liabe.

Aus dem Mitgetheilten geht hervor, dass sich die Deckzellen der Subumbrella von Carmaina hastata, soweit ieh sie naher untersucht habe und soweit sie nieht zu Drüsenzellen umgewandelt sind, dureh neurof'ibrilläre Beschaffenheit ihres Inhalts als dem Nervensystem dienende Elemente erweisen. Im Gebiete der cirkulären Muskulatur sind sie mit den contractilen Apparaten zu wahren Neuromuskelzellen vereinigt. Ausserhalb lieses Gebietes tritt die Aullösung̈ der neurofibrillären Deckzellen in Nervenfäden oder ilu Uebergang in Nerventasern in den Vordergrund und die vom Sehirmrandringe beschriebenen Verhätnisse bieten nichts anderes als eine höhere Concentration dieser an der Unterfäele des Schixmesblattartig a ugebreiteten Einriehtungendar. Hier wie dort, am Sehirmeandringe wie an ler Sehirmunterfäele, liegen unter den beekzellen typische Ganglienzellen, welche angenseheinlieh at s jenensichentwickelt haben nud deren A usläuferuntersich und mit weiter lerziehenden, ebenfalls zuletzt yon Ganglienzellen herstammenden Nervenfäden überall dorteinen Nervenplexus bilden. In der Näheder liatdiargefäse ordnen sich Nervenfäden zu radialen zugen, welcheeinen Anlauf zur li idung von Radialuerven bezeielnen.

Histologiseh bemerkenswerth ist, dass die Faserung des neuroplastisehen Inhalts der Deckepitlıelien eine gröbere, deutlichere ist, als diejenige der Ganglien- 
zellen von typischer Ausbildung. Der letztere macht zugleich einen viel compakteren Eindruck als der erstere. Es scheint mir nicht zu bezweifeln zu sein, dass diese Unterschiede nur herrühren von einer feineren Ausbildung und Verfilzung und von einer dichteren Zusammenlagerung des Fadensystems in den vollkommneren Ganglienzellen.

\section{Das Nervensystem der übrigen Cycloneuren.}

Der Randwulst, welcher in gleicher Weise wie den Geryoniden bekanntlich auch den übrigen craspedoten Hledusen zukommt, wo er ganz oder in Theilen seines zelligen Inhalts wiederholt als Nervenring gedentet worden ist, schwillt hier zu Verdickungen an, die gewöhnlich verhältnissmässig viel bedentender sind als jene von Carmarina und die man geradezu als "Ganglien“ bezeichnet hat. Dass Randwulst und "Ganglien" ans Zellen bestehen, ist durch jene früheren Untersuchungen nachgewiesen. Anf einen im Innern des Zellenstranges gelegenen faserigen Ringnerven hat, wie bemerkt, Häckel Cunina rhododactyla untersucht '). Er sagt, am leichtesten und dentlichsten kömne man anch hier wieder den Nerven an den Simnesbläschen erkennen und hält für den Sinnesnerven einen sehr hellen und blassen cylindrischen Strang, welcher durch die Axe jedes Randbläschens geht. „Weit schwieriger ist es" bemerkt er, ,sich von der Existenz des Ringnerven zu überzengen, den ich auch hier, wie bei den Geryoniden, in einem blassen, hellen, fein längsgestreiften Strange zn finden glaube, der zwischen Ringgefäss und Knorpelring, in einer Furche des letzteren liegt." Dass ferner Harting den Ringnerven bei einer cycloneuren Meduse wirklich vor sich gehabt hat, unterliegt keinem Zweifel, wenn auch seine Darstellung des Verlaufs desselben in den Hörblüschen kaum richtig sein kann. Nach meinen Befunden bei den Geryoniden musste es mir von vornherein als wahrscheinlich erscheinen, dass sich ein limgnerv wirklich auch im Randwulste der übrigen Craspedoten finde. In der That fiel es mir bei einigen nicht schwer, ihn nachzuweisen. So isolirte ich ihn bei Oceaniden (Lizzia (Bongainvillea) Köllikeri), Aeginiden (Aegineta flavescens), Trachynemiden (Rhopalonema velatum) nnd bei Eucopiden (Eucope polystyla). Ueberall fand ich ihn zusammengesetzt aus Fasern mit eingeschalteten Zellen, ganz wie ich dies von Carmarina hastata geschildert habe. Nach der ausführlichen Beschreibung von Carmarina würde es an

1) Hä cke l, Geryoniden S. 136. 
sich unnöthige Wiederholung sein, die Banverhältnisse bei den genannten Formen eingehend zu behandehn, auch abgesehen davon, dass, seitdem ich die Grundzüge der Carmarina zukommenden Einrichtungen veröffentlichte, andere Arbeiten erschienen sind, welche diese Aufgabe übernommen haben (Hertwig, Böhm). Aus diesen Arbeiten ist, im Zusammenhalt mit meinen eigenen Beobachtungen und mit denjenigen von Häckel und Harting nunmehr zu schliessen, dass der Ringnerv eine allgemeine Eigenschaft der Craspedoten sei, wenn er auch bei einigen weniger ansgebildet ist als bei anderen, zuweilen nicht in einer strangartigen, sondern nur in einer flächenartigen, unter dem Epithel gelegenen Ansbreitung von Fasern besteht (Aequorea) "und ferner ergibt sich, dass überall das Epithel des Schirmrandes mit diesen Fasern in Verbindung steht. Ausser den Geisselzellen isolirte ich auch hier bei verschiedenen Formen neurofibrilläre Zellen, deren Inhalt sich in Nervenfädchen anflöst, welche in den Ringnerven übergehen. Die Ansicht Hertwig's, welche die Besenzellen von Carmarina für die Stützzellen erklären, ergibt sich schon nach den früher von mir mitgetheilten Thatsachen als eine unhaltbare. Bei Sarsia tubulosa, wo ich bei der ersten Untersuchung nur den leichter anfzufindenden, das Ringgefäss begleitenden Muskelstrang gesehen hatte, halue ich seitılem den Ringnerven gleichfalls isolirt. Der Ringmuskelstrang besteht ans glatten, spindelförmigen Fasern, welchen im mittleren Theile eine Plasmaanhäufung mit Kern aufgelagert ist. Er wird beim Zerzupfen des Randwulstes mit dem Ringnerven parallel laufend sichtbar. Da ich, wie bemerkt, auch bei Carmarina glatte, spindelförmige Muskelelemente am Schirmrancle gesehen habe, so möchte es sich herausstellen, dass ein solcher Ringmuskelstrang ein weit verbreitetes Vorkommniss sei. Die Fasern des Ringnerven sind viel feiner und zahlreicher als diejenigen des Ringmuskels und enthalten, wie überall, so auch bei Sarsia eingeschaltete Nervenzellen.

Bei Carmarina ebenso wie bei verschiedenen anderen Gruppen der Cycloneuren beschrieben Hertwig anch an der oralen Fläche des Stützblattes des Schirmrandringes Nervenfasern mit Ganglienzellen, bedeckt von Nervenepithel, an der zwischen Ringgefäss und Velum erwähnten muskelfreien Stelle. Sie bezeichnen diese Fasern als unteren Ringnerven und theilen mit, dass er gewöhnlich vermittelst durch die Stützlamelle hindurchtretender Fäden mit dem oberen Ringnerven in Verbindıng stehe, bei den Aeginiden aber wegen geringer Entwicklung der Scheidewand mit ihm theilweise verschmelze. Bei den Ocellaten (Lizzia) wurde er nicht aufgefunden. Bei Nachuntersuchung meiner Präparate habe ich diesen oralen Faserstrang bei Carmarina bestätigen können und ist seine Lage in Holzschnitt 30 bei n angedentet, wo übrigens der aborale Nervenstrang (N) zu weit von dem Stützblatte entfernt ge- 
zeichnet ist: beide Fisserzüge liegen diesem unmittelbar an und bilden thatsächlich einen einzigen Nerven, an welchem somit eine mächtigere aborale und eine viel weniger bedentende orale Abtheilung zn unterscheiden ist. Vollkommen gesondert von diesem Nerven verlaufen, wie ich beschrieben liabe, als vordere Stringe, auf ansehnlichen Strecken die Hörnerven; aber auch von diesen ist anzunehmen, dass sie in der Mitte zwischen je zwei Hörorganen ihre Fasern mit jenen des Centrahnerven vereinigen werden.

Was die Anschwellungen des Randwulstes, die "Ganglien" anbetrifft, so habe ich schon in meinem Münchener Vortrage bemerkt, dass ich in ihnen bei Sarsia und bei Lizzia (Bougainvillea) zahlreich angehäuft Zellen gefunden habe, welehe ich für Nervenzellen halte. Dieselben sind an reichlichsten nnmittelbar unter den Sinnesorganen anzutreffen. Sie sind meist klein, unscheinbar, multipolar, und würden kaum mit Bestimmtheit als Nervenzellen erkannt werden können, wenn nicht eben ihre Anhäufung an jener Stelle und vor Allem der Umstand für diese Eigenschaft sprechen würde, dass ich sie wiederholt mit den von Sarsia näher zu schildernden pigmentirten Sinneszellen in Verbindung zu isoliren vermochte. Böhm hat seitdem jede Beziehung jener Anschwellungen zum Nervensystem bestritten, wogegen ron Seiten Hertwig's, welche die von mir erwähnteu Zellen anch abbilden, Mittheilungen gemacht worden sind, die meine Anffassung bestätigen.

Zugleich habe ich damals geänssert, dass die den Axenstrang der Tentakel der Cycloneuren bildenden Zellen, wie sie von manchen Formen, insbesondere durch Häckel, als Knorpel beschrieben worden sind, wenigstens da, wo ich sie untersucht habe, nicht als Knorpel, sondern als Nervenzellen betrachtet werden müssen, welche dann wohl. gleich den Zellen des Spangenganglion, aus den Schirmrandring als eine Wucherung des Ektoderms, herstammen möchten. Hertwig erklären die letzteren mit. Häckel für Knorpelzellen und geben unter ihren Abbildungen einen Durchschnitt von Carmarina, weheher alle Zweifel an der Richtigkeit ihrer Behauptung, dass sie hier eine Fortsetzung der Auskleidung des Ringgefässes (also des Entoderms) seien, auszusehliessen seheint. Nach Häckel würden sie dagegen als Fortsetzung des von ihm sogenannten Ringknorpels anfzufassen sein. Aus meiner Darstellung geht hervor, dass die fraglichen Zellen auch nicht die entfernteste Aehnlichkeit mit Knorpelzellen haben, dass sie vielmehr Nervenzellen sind, demnach nur vom Ektoderm stammen können, und dass sie in der That eine radiäre Fortsetzung von Nervenzellen des Schirmrandringes bilden. Dass ich demnach und nach meinen Erfahrungen über den sogenannten Ringknorpel gegen die Annahme von „Knorpel“ im Körper der Mednsen überhanpt änsserst misstranisch geworden bin, ist wohl erklïr- 
lich. In der That habe ich, da wo ich gelegentlich nachgesehen habe, keinerlei Eigenschaften an den Zellen der Tentakelaxen von Cyclonemen erkennen können, welche berechtigten, sie als aus "Knorpelzellen" bestehend zu bezeichnen. Dagegen fand ich 1. A. z. B. bei Aegineta Havescens diese Zellen aus einem Plasma bestehend, welches durchaus neurofibrillären Charakter zn haben schien und welches seine aus feinsten Fasern bestehenden Fortsätze nach allen Richtungen an die Wand des Tentakels absendete. Da somit gerade unter den Aeginiden, wo die "Tentakelknorpel" die besondere Starrheit der Tentakel bedingen sullen, so eigenartige Verhältnisse sich finden, so darf wohl die Frage aufgestellt werden, ob wirklich die Annahme der Entodermnatur der Tentakelaxen für alle Cycloneuren gültig sei.

Die Subumbrella besteht bei allen von mir darauf untersuchten Arten, soweit ihre Elemente quergestreifte sind, ans Neuromuskelzellen, deren contractiler Theil aus spindelförmigen Fasern gebildet ist. Der Baı dieser quergestreiften Fasern ist, wie ich besonders bei Lizzia beobachtete, in allen Einzelheiten ebenso fein ausgeführt wie selbst derjenige der höchsten Thiere. Die Gestalt des epithelialen Abschnittes der Neuromuskelzellen ist gewöhnlich die von niedrigen, breiten Cylinderzellen. Zuweilen war die Muskelspindel im Bereiche desselben (bei Rhopalonema ist mir Derartiges aufgefallen) unterbrochen, d. i. der epitheliale 'Theil ging an seiner Basis nur nach zwei entgegengesetzten liichtungen hin in einen contractilen Fortsatz aus, während sein Boden nackt war, aus Plasma bestand.

Vie radiäre Mnskulatur habe ich genaner bei Sarsia untersucht: es werden dort die Radiärgefässe von glatten, spindelförmigen Muskelfäden begleitet, welchen wiederum ungefähr in der Mitte ihres Verianfs Plasma mit einem Kern in grösserer Anhäufung angelagert ist. Es unterliegt wohl keinem Zweifel, dass dieses Plasma, welches den Muskelfaden an einer Seite oft auf längere oder kürzere Strecken überzieht, nichts anderes sein kann als ein Ueberrest des Bildungsmaterials, aus welchem der contractile Faden sich abgesondert hat, genetisch aber gleichgesetzt werden muss einer plasmatischen Deckzelle des Ektoderms oder einem 'Theilprodukt einer solchen. Die Radialmuskestränge von Sarsia liegen den Radiärgefässen an der oralen Seite an und sind unschwer in ihre Fasern zu zerlegen, so dass man ihre wahre Natur leicht erkennen kann.

Eine subepitheliale Lage von Nervenzellen und varikösen Nervenfaser'n, dicht anliegend der oralen Seite der Fäden der circulären Muskulatur habe ich, wie schon erwähnt, bei Lizzia beobachtet und Hertwig beschrieben dasselbe hier, sowie ausser bei Carmarina auch bei Aeginiden und Vesiculaten.

Aus Allem ergibt sich, dass die Verhältnisse des Nerven- und Muskelsystems bei den übrigen Cyclonemen im Wesentlichen dieselben sind wie bei den Geryoniden, 
wenn sie auch bei diesen augenscheinlich weitaus die höchste Entwicklungsstufe erreicht haben, diejenigen des Nervensystems speciell darin, dass dasselbe in einem den Schirmrand einnehmenden ringförmigen concentrirten Theile, dem Centralapparat, und in einer die Unterfläche des Schirmes belegenden blattartigen peripherischen Ausbreitung besteht.

Es ist hier nicht meine Aufgabe, die sinnesorgane der Cyclonemren einer ausführlicheren Besprecliung zu unterziehen. Nur möchte ich eine meiner Beobachtungen kurz berı̄hren, welche eine besondere nähere Beziehung zu den allgemeinen von mir geschilderten Eimichtungen des Nervensystems hat, eine Thatsache, die nnmittelbar erinnert an die neurofibrilläre Umwandlung des Inhalts der Nervenepithelien des Schirmrandringes von Carmarina und die offenbar ferner in Zusammenhang steht mit dem Durchzogenwerden der Sinnesepithelien von Nervenfädchen überhaupt, wie ich es insbesondere von den Toponemen geschildert habe. Zerzupft man einen der den Ganglien aufsitzenden Pigmentflecke von Sarsia tubulosa, nachdem er gelrörig macerirt ward, so erhält man cylindrische, nach unten sich zuspitzende Zellen, welche in ilrer äusseren, breiten Grenzfläche braun gefärbt sind. Die Färbung rührt her von kleinen, tröpfchenähnlichen Pigmenttheilchen, welche so angeordnet sind, dass sie nur eine äusserste Lage, gewissermassen einen Deckel in der Zelle, eine äusserste Schicht in derselben bilden. Es fällt auf, dass die Grössendifferenzen zwischen diesen Theikchen nicht so bedentend sind. wie sonst unter Pigmentkörnchen in Sehorganen: ım Körnchen handelt es sich mun in der That in ihnen nicht, vielmehr um regelmässige kiugelchen, welche ausserdem für Licht nicht undurchdringlich sind, sondern wie kleine Linsen in Folge der Lichtbrechung glänzen, nach der Peripherie hin heller erscheinen als im Mitteltheile. Man möchte glauben, in jeden solchen Tröpfchen, trotz seiner Kleinheit, ein hestimmt geformtes organisches Ganzes vor sich zu haben. Starke Vergrösserungen zeigen num weiter, dass die Zelle in ihrem Innern längsgestreift ist und ferner, dass von jedem Pigmentkügelchen ein feinster Faden durch dieselbe nach abwärts zieht. Die Fädchen endigen nach oben in die Pigmentkügelchen, nach unten convergiren sie nach der Spitze der Zelle zu. Nach dem, was ich von den Nervenepithelien der Medusen überhaupt geschildert habe, kann es keinem Zweifel unterliegen, dass diese Fädchen Nervenfädchen sind. Es liegen nun unmittelbar unter den so beschaftenen sinnesepithelien in den Anschwellungen des Schirmrandes die Elemente, welche ich für Ganglienzellen erklärt habe. Man isolirt unter den ersteren solche, welche nach unten in eine fadenartige Fortsetzung übergehen, durch welche sie in Verbindung mit den multipolaren Nervenzellen stehen. Ausser den Pigmentzellen isolirte ich andere, welche ganz dieselben Beziehungen und 
ganz dieselbe Streifung wie sie zeigten, aber statt der Pigmenttröpfehen im breiten Aussentheil eine Schicht von ihnen im Uebrigen ähnlichen, nicht pigmentirten Theilchen als Inhalt hatten. Auf weitere Einrichtungen des Sarsia-Auges werde ich, wie auch auf andere beztigliche Ergebnisse meiner Untersuchungen an einem anderen Orte eingehen. 


\section{Zusammenfassung und Schlussfolgermengen.}

I. Meine physiologisehen Untersuchungen verlangen bei den T'oponeuren ein centrales Nervensystem, welches seine vorzüglichste Ausbildung zeigt im Gebiete der von mir sogenannten contractilen Zonen, d. i. in denjenigen Theilen der Randlappen, welehen die Randkörper unmittelbar ansitzen. Sie verlangen ferner, dass Zellen, welche eentraler Thätigkeit vorzustehen vermögen zugleich, wenn auch in geringer Zahl, oder wenn in grosser Zahl doch mit geringer Funktionsfähigkeit begabt, über den ganzen Schirm der Thiere verbreitet seien, in abnehmender Zahl, bezw. mit abnehmender Funktionsfähigkeit mit der Entfermug vom Rande gegen die Kuppe hin. Sie verłangen, dass leitencle Nerventasern im Schirme vorhanden seien, vorzüglich reichlich an dessen oraler Fläche, aber anch im Imern des Gallertgewebes der Umbrellit. Nicht mu durch die Zerschneidnngsversuche an verschiedenen Toponeuren, insbesondere anch durch die Art des Absterbens von Aurelia wurde in nachdrücklichster Weise ant die acht Bezirke in Schirminde hingewiesen, welche der Sitz der centralen Thätigkeit sein müssen. Die Stückchen Randgewebe, welche stets länger als alle übrigen Theile des Schirmes an Leben geblieben sind, und welche so nnverhältnissmässig zähe in Leben verharten, nachdem jene längst zerfallen waren (vergl. Holzschnitt 11, Seite 62), sie entspreehen in ihrer Lmgrenzmng durchaus den Abschnitten des Schirmrandes, in welchen jene Anhänfung von Zellen sich findet, die ich bei den Cytophoren als Nervenzellen bezeichnet habe. Diese Zellen sind mor]hologisch in so wenig ausgesprochenem Maasse in dieser Eigenschaft gekemneichnet, diass ich ohne Zuhülfenahme des Experiments kamm dizu gekommen wäre, ihnen diese Eigenschalt mit Sicherheit zuznschreiben. Allein mit dem Experiment zugleich spräehe, aneh wenn der Werth der morphologischen Eigensehaften dieser Zellen in Rücksicht anf ihre Dentung in dem fraglichen simne ein noch ge- 
ringerer wäre als er dies thatsächlich ist, der Umstand, dass ganz dieselben Zellen mnter dem Nervenepithel der Randkörper sich finden, wie auch ungekehrt dasselbe Nervenepithel wie dort im Gebiete ihrer Verbreitung ausgebildet ist. Die Bedeutung jener Zellen der Randkörper für das Nervensystem aber ist selbstverständlich, und es kann höchstens die Frage anfgeworfen werden, ob sie mehr als Zellen in Sinne derjenigen eines Sinnesganglions oder ob sie gleichfalls als Gehirnzellen aufzufassen seien.

Hat nun, von dieser Frage zmächst abgesehen, auch das Absterben constant einen abgegrenzten Bezirk der Randlappen schliesslich abgesehlossen und ist in der Mehrzahl der Fälle durch das Ausschneiden ganz desselben Bezirks Berwegungslosigkeit erfolgt, so ist das Letztere in vielen anderen Fällen nicht gesehehen und in jenen ersten trat mehr oder weniger leicht Erholung ein, welche aber nicht zum vollen danemrlen Leben sich gestalten konnte.

Die angedentete Möglichkeit, dass Zellen in derselben Zahl, aber mit geringerer Funktionsfähigkeit als in der Randkörpergegend begabt, die centralen Funktionen möchten übernehmen können, ist nicht von der Hand zı weisen. Dafür spricht die 'I'hatsache, dass die "Nervenzellen" augenseheinlich nichts Anderes sind, als umgewandelte amöloide. Beicle stammen nach Allem, was wir über die Entwicklnng der Medusen wissen, aus dem Ektoderm. Ein Weniges nur branchte zu fehlen an der. morphologisehen Ausbildung der Zellen der contractilen Zouen und auch sie würden keine morphologische Handhabe zu ihrer Dentung als Nervenzellen mehr geben.

Bei den Acytophoren finden sich nur sehr spärliche Zellen unter dem Epithel der muskelfreien Theile, allerdings reichlicher in Gebiete der Randlappen, als centralwärts von denselben. Diese Zellen sind äusserst unscheinbar. Dagegen ist das Nervenepithel im Gebiete der Randlappen sehr entwickelt und als Nervenzellen zu deutende Elemente finden sich anch hier im Bereich der Subumbrella. Es stellt sich die Frage, ob den letzteren nicht eine Bedentmng für die Gehirnthätigkeit zugeschrieben werden darf oder in wie weit man berechtigt ist, voranszusetzen, dass an dieser die Nervenepithelien selhst sich betheiligen.

II. Gegen die Annahme, dass die im Gebiete der Subumbrella, speciell die unter den Deckepithelien dort gelagerten Nerveuzellen als centraler Aktion im simne von Gehirnzellen fähig erklärt werden dürfen, sprechen die Verhältnisse bei den Cycloneuren, wo nur der Schimrand, nicht aber der, wenigstens bei der allerdings physiologisch nicht nntersuchten Carmarima so hoeh entwickelte Nervenbelag der Subumbrella als centraler Apparat in diesem Sinne anfgefasst werden darf. Nach den bis jetzt erlangten physiologischen Ergebnissen ist jener Belag nur als reflectorischer Funktion fähig anzuerkennen. Dürfen wir diese Erfahrungen auf die Topo- 
neuren übertragen, so haben wir auch hier Funktionsfähigkeit im sinne von Gehirnzellen in derselben Einrichtung nicht zu erwarten.

Vergessen darf freilich nicht werden, dass nach den Versuchen von Romanes an Tiaropsis indicans hier Gehirnthätigkeit über den Magenstiel und auch ïber den Schirm sich verbreitet findet; allein es steht diese Thatsache vereinzelt da und weil die zu Grunde liegenden morphologischen Einrichtungen nicht bekannt sind, so kann sie für unsere Frage nicht massgebend sein.

I1I. Eine Gehirnthätigkeit im Sinne derjenigen der höheren Thiere, also eine mit dem Vermögen bewussten Handelus ausgeführte Nerventhätigkeit, dürfte wohl bei den Metazöen nur da vorausgesetzt werden, wo gesonderte, für sich besteheude Zellen vorhanden sind, welche, wie ich mich in meiner Beroë-Arbeit ausdrückte, die Aufgabe haben, die durch die percipirenden sinneszellen aufgenommenen Eindrücke zu sammeln, aufzuspeichern and die Möglichkeit einer Wechselwirkung derselben zu bedingen ${ }^{1}$ ). Da aber eine solche Thätigkeit nur ganz allmälig sich entwickelt haben kann, so müssen auch die morphologischen Differenzirungen ganz allmälig vor sich gegangen sein. Ein einzelliger Organismus, ein Protozoon, wird percipirender, dirigirender und ausführender Apparat Alles in Allem sein können, allein zum Zwecke der Erreichung eines höheren Grades geregelter Thätigkeit wird eine Sonderung dieser Qualitäten in bestimmten Theilen desselben vorausgesetzt werden mussen. Ich glaube nicht fehl zu gehen, wemn ich die Direktion in den Kern verlege, wenn ich die Ausbildung des Kerns als die vollendete morphologische Wirkung der Nothwendigkeit einer c'entralleitung des Zellenlebens auffasse, welche in höherer Ansbildung mehr und mehr zu einer "psychischen" sich möglicherweise wird gestalten liönnen. Wo er morphologiseh nicht greifbar ist, mag anf gewisser Stufe der Ausbildung des Organismus ein meh" oder weniger bestimmter Theil des Plasma in seinem Sinne thätig sein. Wo aber eine Mehrheit von Zellen, wie bei den Metazoën, zn gemeinsamem Leben vereinigt ist, kann zwar jede einzelne derselben ihr Centralorgin für sich haben, allein auf der niedrigsten Stufe dieser Vereinigung wird ein Apparat fehlen, welcher für alle Zellen ein gemeinsamer ist, welcher die Erfahrungen aller einzelnen zu sammeln, aufzuspeichern, abzuwigen und für das Ganze zu verwerthen vermag. Auf diesem niedrigen Stadium der Ausbildung wird der Eindruck. welchen ein Theil des Ganzen erhält, dem Nachbarı und von diesem aus den äbrigen Nachbaru mitgetheilt in Folge der Berührung, durch Contiguität, wenn wicht durch, einstweilen nicht nachweisbare, feinste Plasmaverbindung. Bei solch einfacher Con-

1) a. a. 0. S. 80 . 
struction setzen wir voraus, dass in jeder einzelnen der den Gesammtorganismus zusammensetzenden Zellen ausser dem eentralen anch ein percipirender und ein ausführender Apparat vorhanden ist und die anf Reizung einer einzelnen Zelle erfolgende motorische Wirkung, ergreile sie nur diese selbst oder die Gesanmtheit aller übrigen, ist die einfachste Art einer Reflexaktion. So ganz einfache Verhältnisse würden nur bei einblättrigen Organismen thatsächlieh bestehen. Bei den Zoophyten, mit der Sonderung in Ektoderm und Entoderm sind dieselben schon etwas complicirter. Aber von der Complikation durch das Entoderm abgesehen, clüren wir bei den niedrigsten Zooplyten jene primitiven Verhältnisse voranssetzen. Aus den berülumten Versuchen 'Trembley's') geht hervor, dass bei Hydra jedes 'Theilstüek des Thieres dem anderen gleichwerthig ist. Jedes Stüekchen des Körper's ist hier für sieh lebensfähig, ist ein Ganzes für sich, mit allen Anlagen und Fähigkeiten des Gesammtorganismus. Dem Begriff lndividumm fellt in Anbetracht solcher Verhältnisse, in liücksieht darauf, dass jedes jener Stückchen weiter und weiter theilbar ist, immer die Eigenschaften des Ganzen behät, anch jeder Anhalt zur Anwendung bei diesem 'Thiere, es sei denn, dass wir ihn durch eine künstliche lefinition morphologisch in der Weise abgrenzen, wie ich dies als Nothbehelf gethan habe, eine Abgrenzung auf Grund welcher wir ihn auf' Theilstücke in morphologischem sinne überlaupt gar nicht, sondem nur auf das ganze Thier anwenden kömnten.

Ein gemeinsames Lebensorgan, wenn ich mich so ausdritcken darf, ein Gehirn, welches anf eine beschränkte Stelle des Körpers lokalisirt wäre, ist jedenfalls bei Hydra nicht vorhanden. Will man ein solches Organ hier dennoch annelımen, so muss man voranssetzen, dass es über den ganzen Körper verbreitet und olıue Nachtheil für seine Funktion theilkar ist wie der übrige Körper, dass es also noch sehr wenig complicirte Verbindungen seiner Theile ausgebildet hat. Man könnte bei solcher Voraussetzung denken an die zwischen mud unter den Epithelzellen gelegenen, von Kleinenberg als interstitielles Gewebe bezeichneten Zellen; allein es fehlt zu solcher Voraussetzung zunächst sicherer Anhalt, wenngleich die Zellen, welche bei höheren Thieren ein Gehirn bilden, überall aus dem Ektoderm stammen müssen und wenngleich die Annahme sehr natürlich ist, dass sich bei solchen, an deren Kürperoberfläehe noeh kein Theil vor dem anderen durch besondere Entwicklung von Sinnesorganen ausgezeichnet ist, anch centrale Zellen, sofern sich deren hier überhaupt differenziren, in gleichmässiger Lage über den ganzen Körper zuerst abseheiden.

1. A. Trembley, mémoires pour servir à l'histoire d'un genre de Polypiers d'eau douce, avec 13 planches. Leyde 1744 (en 2 vol. avee 20 pl. Paris 1744). 
Ob irgend ein Beginn centraler Differenzirung, wie aus gewissen Funktionen des Gesammtorganisnus allerdings geschlossen werden möchte, bei Hydra anzunehmen ist, steht dahin. Ich führe das Thier als Beispiel für sehr primitive Einrichtungen auf, weil es dis bei Weitem am besten bekamnte unter Seinesgleichen ist und weil es in diesen Einrichtungen wichtige Vergleichungspunkte vorzüglich mit Cyanea capillata darbietet.

Gleichviel ob in einem speciellen Falle der primitive Beginn der Bildung eines centralen Apparates in Abscheidung von Zellen anf der ganzen Körperoberflảche bestehe, oder ob er von vornherein auf eine bestimmte Stelle desselben beschränkt sei, immer muss er zusammengesetzt gedacht werden ans Zellen, welche untereinander contiunirlich verbunden sinct und deren Gesammtheit andererseits wiederum mit den Epithelzellen, bezw. mit den Sinneszellen der Körperoberfläche in Zusammenhang steht. Es ist jetzt anstatt des primitiven Zustandes unmittelbarer Contiguitä der Deckzellen allein ein Zustand mittelbarer Continuität derselben durch centrale Nervenzellen entstanden. Erst wenn solche vom Epithel gesonderte centrale Zellen gebildet sind, können wir an eine gemeinsame Centralleitung des Organismus im sinne jener der höheren Thiere denken und selbst eine rhythmische Contractionsthätigkeit eines Organismus als Ganzes, wie sie sich bei den lledusen findet, anch wenn dieselbe durchaus unwillkürlich, ohne Ablängigkeit von einem ,Gehirn“ ausgeführt würde, wäre nicht verständlich ohne gemeinsame Leitung durch unter sich rerbundene Nerrenzellen. Der Epithelialdecke oder einem Theil derselben kann unmöglich die Leitung auch nu dieser Thätigkeit zukommen. Unter den von mir untersuchten Medusen scheint Cyanea capillata in Beziehung auf Gehirnthätigkeit die weitaus am wenigsten entwickelte zu sein, schon nach den liesultaten, welche die Beobachtung ihrer Lebensänsserungen ergibt. Ihre Contractionen sind unter allen am wenigsten von willkürlichen Eingriften beeinflusst; sie geschehen gewöhnlich ausserordentlich regelmässig. in Intervallen, deren Laner unter Voraussetzung einer bestimmten Grösse des Thieres in einem Grade vorausbestimmbar ist wie nirgends sonst. Und doch zeigt anch sie, gleich den anderen Medusen, dass diese Contractionen nach Bedürfniss in sehr ausgiebigem Maasse der Herrschaft des Willens unterworfen werden können. Es kann somit selbst bei diesem in geistiger Bezielınng tiefstehenden Thiere an eine Beherrschung der Lebensänsserungen durch die Elemente der Epithelialdecke nicht entfernt gedacht werden.

IV. So verschieden die Formentwieklung beider Thiere ist und so wenig unmittelbare verwandtschaftliche Beziehungen zwischen beiden angenommen werden 
können, so sehr nahe stehen sich doch Cyanea und die Hyclren in Beziehung auf die Organisation des Körpers. Jedenfalls lässt sich keine cycloneure Merluse, so paradox dies klingt, so weit wenigstens unsere Kenntnisse n̈ber die bezüglichen Organisationsverhältnisse reichen, in demselben Maasse unmittelbar mit Hydra vergleichen, wie gerade Cyanea und zeigt uns diese Meduse ihrer einfachen, embryonalen Organisationsverhältnisse halber zugleich auf's Dentlichste, wie die Entstehnng auf bestimmte Stellendes Körpers lokalisirter Centralapparate einem besseren Verständniss zugeführt werden kann. Diese Entstehung ist offenbar in unmittelbarer Beziehung zu der Bildung der löheren Sinnesorgane zu denken und diese wiederum steht in Beriehng z 1 m Vermögender Ortsveränderung.

Das Vermögen der Ortsveränderung ist eine Anpassung zunächst an das Bedürfniss des Aufsuchens der Nahrung und damit eine Waffe $z \mathbf{m}$ Angriff und in zweiter Linie ein Mittel zur Vorsicht, zum Schutze. I)asselbe Bedürfniss ausgesprochen aktiver Lebensänssermugen gibt nun zugleich mit seinem Anftreten die Veranlassung zur Eutwicklıng der höheren Sinnesorgane, der Seh- lind Hörorgane und man kann desshalb diese letzteren geradezu als aktive Simnesorgane bezeichnen. Ein nicht zu höherer Sinnesfnnktion ausgebildetes Epithel überzieht gleichmässig die Larven unserer T'hiere; es mag zugleich als Decke und als allgemeines Simnesepithel dienen und dieselbe Einrichtung b]eibt erhalteu bei Zoophyten, welche ganz oder nahezu gauz des Vermögens der Ortsveränderung entbehren. Dass sie damit der Licht- und Schallempfindung durchans verlustig seien, soll nicht behauntet werden; im Gegentheil. es muss ihnen wenigstens erstere Empfindung bis zn einem gewissen Grade durchaus zugesprochen werden. allein sie ist eine minimale und bei den freilebenden Hydren, welche nur in beschränktem Maasse der Ortsveränderung fähig sind, wohl über den ganzen Kïrper verbreitet, bei den eingeschlossenen, testsitzenden Formen auf die freieu Theile, und sie ist wohl gebunden an die allgemeinen, zugleich anderen sinnesfunctionen in mehr oder weniger ausgiebigem Miasse dienenden Sinneszellen. Erst bei jenen Metazoen, welche als Mittel im Kampf nm's Dasein sich aktiver Thätigkeit in reichlicherem Maasse bedienen, welche in höherem Grade lokomotionsfähig sind, müssen sich nothwendig, nach dem Princi], der Arbeitstheilıng, die Sinnesorgane höher specifisch ausbilden und zugleich lokalisiren und die Lokalisirung findet statt an denjenigen Stellen des Körpers, welche für den Erfolg geregelter Ortsveränder'ung die passendsten sind.

Hand in Hand mit solcher Ausbildung eines bestimmten Abschnittes der epithelialen Elstodermzellen zu specifischen höheren Sinnesorganen muss noth wendig eine 
höhere Entwicklung von subepithelialen, centraler Function vorstehenden Nervenzellen gehen. Je höher die Ausbildung des Sinnesorgans ist, nm so bestimmter lokalisirt es sich, um so schärfer greuzt es sich von der Umgebung ab. Bei Cyanea ist diese Lokalisirmng des ausgeprägten Sinnesepithels noch eine sehr wenig vorgeschrittene; es verliert sich dasselbe ganz allmälig nach oben in Zellen, an welchen sich die Eigenschaften des Nervenepithels nicht mehr nachweisen lassen. Viel mehr ausgesprochene Concentration findet sich bei Aurelia amita und ganz dasselhe gilt für die centralen Nervenzellen. Diese sind bei Cyanea vorzugsweise entwickelt auf den Randkörpern selbst, allein, wie hier nachträglich hervorgehoben werden muss, auch auf diesen mit noch weniger ausgeprägten morphologischen Eigenschaften als bei den Cytophoren. Man würde sie ohne den Beweis der Vergleichung zur Hand zu hahen und anf Grund rein morphologischer Untersuchung nicht mit Sicherheit für Nervenzellen erklären kömnen. Das Experiment allein muss ihnen, unter Voranssetzung der Richtigkeit des Satzes, dass nirgends Epithelzellen, sondern nur von diesen gesonderte und sie verbindende Zellen einen centralen, den Gesammtkörper leitenden Apparat bei Metazoen herstellen können, diese Eigenschaft zuschreihen. Dies zugegeben, muss man auf Grund des Experiments und mit Unterstützung phylogenetischer Erwägungen aber wohl anch schliessen, dass die so gering ausgebildeten und so wenig zahtreich vorkommenden subepithelialen Zellen der aboralen Oberfläche des Schirmes dem centralen Nervensystem zuzurechenen seien.

Bei den Cytophoren hat sich das Gallertgewebe mit Zellen. Abkömmlingen des Epithels, durchsetzt. Diese Zellen zeigen auf den liandkörpern. und im Bereich des auf den Randlappen vorkommenden Nervenepithels deutlich, wemn anch gering genng ansgeprägt, Eigenschaften, welche sie als Nervenzellen erkennen lassen. ob sich âhnliche Zellen im übrigen Theile der Umbrella, wenngleich sparsam, finden, habe ich nicht untersncht, allein, falls solche in Zukunft nicht gefunden werlen, scheint mir, wie mehrfach herrorgehoben, wichts der Annahme entgegenzustehen, dass die dort vorhandenen amöboiden Zellen, sei es in ihrer Gesammtheit oder in einzelnen bevorzugten, ohne dass sie dies durch ausgeprägte morphologische Eigenschaften verrathen, die Funktion als Nervenzellen ausüben, denn das Experiment verlangt auf das Bestimmteste Nervenzellen in jenen Gebieten, und da wir in unseren Thieren erst den Beginn einer Ausbildung von Gehirnthätigkeit suchen müssen, so ist ron vornherein so wenig strenge Centralisation zu erwarten. wie entschiedene morphologische Ausbildung der Elemente im Sinne der Funktion. Die Funktion 
ist es, deren Bedürfniss überall die morphologische Differenzirung bedingt, und allmälig ausgeprägt gestaltet.

V. Hier muss eine Frage erörtert werden, welche schon früher gelegentlich berüht worden ist, die nämlich, ob die a uf den Randkörperngel egenen Zellen überlanpt als Gehirnzellen oder ob sie nur als Componenten von Sinnesganglien aufzufassen seien. Im letzteren Falle würde der Erfolg des Abschneidens der Randkörper, wie schon früher bemerkt, nur als eine Wirkung zu betrachten sein, wie sie anch sonst nach bedentenden Verletzungen des peripherischen Nervensystems anftritt, ohue dass die centrale Funktionsfähigkeit dadurch organiseh berührt wäre: ich habe im physiologischen Theile angenommen, dass sie allerdings dadurch berülurt werde, indem ich eine successive Zunahme des Erfolgs der Experimente anfstellte, je nachdem nur der Randkörper oder zugleich weniger oder mehr vom Rande in dessen Umgebung entfernt wnrde. Die morphologischen Verhältnisse scheinen dagegen auf den ersten Blick dafür zu sprechen, dass die Zellen der Randkörper als einem Sinnesganglion entsprechende Zellen anfgefasst werden: sie sind von den Zellen der Randlappen dadurch unterschieden, dass sie, so viel ich wenigstens entscheiden konnte, nur unter dem Epithel, nicht gleich jenem auch in der Gallerte liegen, und durch die zellenlose Gallerte ziehende Nervenfäden stellen ilıre Verbindung mit den Randlappen her. Bei Rhizostoma findet sieh sogar eine bedentende Anschwellung am Randkörperstiele, welche durchius den Eindruck eines Sinnesganglion maeht. Ist es ganz dieselbe Stelle, deren Quetschung bei Aurelia amrita zeitweilige Lähmung hervorgerufen hat, so könnte dieser Erfolg sicherlich anch auf Rechunng der Verletzung des dort in grösserer Masse entwickelten Theils des peripherischen Nervensystems gesetzt werden, und ich darf wohl sagen, dass solche Annahme anch mit der Thatsache sich vereinigen liesse, dass sich mit der Erheblichkeit der Verletzung die Reaktion steigert: denn angenommen, es beginne das Gehirn erst mit der Stelle des Schirmrandes, an welchem der Randkörper ansitzt, so wird auch eine geringe Verletzung dieses Randes nur vorn̈bergehende Lälımung hervorrnfen. Eine definitive Entseheidung ist hier unmöglich, wie denn die Schwierigkeit der Znrückführung der morphologisehen Einrichtungen aller Theile nnserer Thiere in dem relativen Werthe liegt, welchen sie als erst im Beginn der Differenzirung und Lokalisirung stehende haben müssen. Es erscheint nach den früher gegebenen Deduktionen als selbstverständlich, dass gerade anf dem Gebiete der Randlappen zuerst ausgeprägte centrale Nervenzellen sich entwickelt haben. Indem sich die Differenzirung höher anszubilden beginnt, darf vielleicht angenommen werden, dass die in der Peripherie, speciell zuerst die 
auf den Randkörpern gelegenen Nervenzellen allmälig zu der Bedeutung von Sinnesganglienzellen sich specifisch gestalten, so dass sich jetzt Sinnesganglion und Gehirn zuerst funktionell und dann auch morphologisch mehr und mehr scheiden. Dass eine solche Scheidung überall allmälig vor sich geht, muss wohl überhaupt angenommen werden. Wo die Grenze, das lässt sich nicht bestimmen und Beweise lassen sich nicht geben. Mehr als irgendwo würde aber also wahrscheinlich solche Differenzirung bei lihizostoma ausgeführt sein und die für Beroë noch zu besprechenden Terhältnisse würden mit solcher Deutung der 'Thatsachen, besonders in Rücksicht auf diesen Fall gleichfalls im Einklang stehen.

VI. Die A usbildung des Vermögens der Ortsveränderung bedingt, abgesehen von seiner Bedentung für die Entwicklung der Sinnesorgane und des centralen Nervensystems, selbstverständlich vor Allem eine Lokalisirung und bestimmte Ausbildung der contractilen Elemente des Körpers: je nach der Art der Ortsveränderung, je nach der Richtung in welcher dieselbe ausgeführt wird, muss sich die Muskulatur sondern, anordnen und ausbilden. Gerade in dieser Beziehnng sind die Bauverhältnisse rom Cyanea ausserordentlich belehrend.

Nerven- wie Muskelapparat gehen bei den Zoophyten aus dem Ektoderm hervor. Da wo zuerst eine morphologische Differenzirung angedentet ist, welche man an der Hand der Lebensänssermugen des Thieres als eine Scheidung in einen nerrösen und in einen contractilen Abschnitt erklären kam, sind beide Apparate als ein Gemeinsames über die ganze Aussenfläche des lörpers rerbreitet. So ist es bei Hydra. Da eine geregelte und in bestimmter, constanter Richtung vor sich gehende Ortsveränderung hier nicht stattfindet, so haben sich speciell die Iluskelelemente in keiner Weise etwa an bestimmten stellen des Förpers lokalisirt oder hervorragend entwickelt. Anders bei den frei schwimmenden Medusen. Hier hat sich die Musknlatur auf der unteren Fläche des schirmes lokalisirt und hoch ansgebildet, während sie anf' der aboralen Schirmfläche geschwunden ist. Ceberall betriftt dieser Schwund bei den T'oponeuren zngleich auch einen grösseren oder kleineren Abschnitt der unteren Fliche der Randlappen. Bei Cyanea gibt uns die tiefstehende Organisation noch anf's Deutlichste die Anhaltspunkte zur Verbindung mit den bei Hydra bestehenden Verhaltnissen: a us demselben Zellenfuss, weleher dort in gleicher Weise an allen Zellen des Ektoderms sich findet, ist bei Cyanea im Gebiete der Randlappen ein Nervenfaden hervorgegangen und hat sich andererseits auf dem zur Locomotion bestimmten Theile der Unterfläche des Schirmes ein II uskelfaden ent- 
wickelt. Erst an den Theilen der Randlappen, an welchen das Nervenepithel die höchste Ausbildung erreicht hat, ist der Nervenfuss verloren gegangen und sind jene Eimrichtungen anfgetreten, welche das Nervenepithel der Cytophoren durchans darbietet, darin bestehend, dass die Zellen desselben nach nnten spitz zulaufen und ohne Fuss in einen Nervenfaden sich verlängern. An der Untertläche der Randlappen von Cyanea dagegen finden sich noch Bezirke, wo der Nervenfuss allmälig seine charakteristischen Eigenschaften vollständig verliert und zuletzt zum Muskelfusse wird.

VII. Auf der aboralen Schirmobertläche lassen sich ausgesprochene Eigenschaften eines Nervenepithels bei Anrelia nur im Gebiete der Simnespolster, bei Cyanea aber anf der ganzen Ausdehnung der Randlappen erkennen. Cyanea bietet auch hierin gegenüber Aurelia wieder viel tiefer stehende Verhälnissedar. Das Princip der Concentration, diespecifische Ausbildung a uf kleinerem Rame, verbunden mit scharfer Abgrenzung von der Umgebung, ist hier noch viel weniger zu Geltung gelangt als dort. Bei Aurelia ist das Nervenepithel vou jenem der Umgebung durchaus verschieden, und die Verschiedenheit beginnt mit scharfer Grenze: ein plötzlicher Uebergang zwischen einem hochentwickelten Sinnesepithel und einem gewöhmlichen Deckenepithel, in welchem Nesselzellen und Becherzellen auftreten, ist gegeben, allerdings nur centralwärts, während distal allmälige Umbildung statt hat. Bei Cyanea zeigt sich aber auch proximalwärts ganz allmälige Abnahme der ausgesprochenen Eigenschaften des Nervenepithels und weit hinanf findet sich an den Zellen ein Fuss, von dem man in den Grenzgebieten in Zweifel ist, ob man an ihm morphologisch noch Eigenschaften anerkennen soll, die dazu berechtigen, ihn dem Nervensystem zuzurechnen. Ueberall aber trägt das Epithel noch die Geissel, welche bei den Cytophoren ansserhalb des Gebietes der Nervenepithelien verloren gegangen ist. Wo ist hier die (irenze zwischen sinnesepithel nnd gewöhnlichem Deckepithel? Gibt es überhaupt eine solche Grenze? Diese Fragen drängen sich auf.

Das den Körper von Cyanea bedeckende Geisselepithel, ein Erbtheil ans der Zeit des Larvenlebens, hat, wo es immer bei Larven vorkommt, wahrscheinlich nicht allein Bedentung als Bewegungsorgan, sondern es dient zugleich der Orientirung, es ist ein Sinnesepithel, welches zur Perception verschiedener Sinneseindrücke in einem gewissen minimalen Maasse befähigt sein mag, dessen F'unktion indessen aın meisten dem Tastsinne entsprechen dürfte. Es lässt sich diese Annahme durch gute Gründe stützen. Der Geisselfaden der Sinneszellen der ansgebildeten Mednsen ist nach mei- 
nen Beobachtungen die Fortsetzung eines Nervenfädchens und steht mit dem Zellkern in Verbindung. Das Sinnesepithel ist ein Ueberrest des Geisselepithels der Larve, und wem auch in dieser sich noch nicht ein ausgebildeter Nervenfaden in die Geissel fortsetzt, so ist doch anzunehmen, dass eine feinste plismatische Verbindung sie schon frühe mit dem Kerne in Beziehung setze. Es findet sich Geisselepithel bei den Cyeloneuren noeh am Schirmrande, bei den Toponeuren an Randkörpern und Randlappen, bei beiden an den T'entakeln. Anf' den übrigen 'Theilen der Schirmoberfläche ist es ausser Gebrauch gesetzt, nur bei Cyanea noch erhalten. Dass es hier ganz der Beziehungen zum Nervensystem entbehre, kamn ich nicht annehmen. Aber ebensowenig möchte ich ohne Weiteres zugeben, dass die aborale Körperoberfläche auch der höher stehenden Medusen, bei welchen die Differenzirnng in eiu ausgeprägtes Sinnes- und in ein Deckepithel viel mehr ausgesprochen ist, empfindungslos sei und ich bin, wie schon früher bemerkt, der Ansicht, dass sich von einer Wiederholung der Versuche mit elektriseher Reizung ein Resultat ergeben möchte, welches die Angaben von liomanes etwas modificiren dürfte. Sollte in ler That die früher unzweifelhaft über das ganze Thier verbreitete Empfindungsfühigkeit später aut' dem grössten Theil desselben vollkommen verloren gegangen sein, auf jener Fläche, welche den Beziehungen zur Aussenwelt in so hohem Maasse ausgesetzt ist und bei Thieren, deren Körper von so ausserordentlicher Zartheit ist wie meistens derjenige der Quallen? Und solite wirklich das bei Cyanea über den ganzen Körper verbreitete Geisselepithel als solehes nichts mit der Nerventhätigkeit zu thun haben? Sollte man nieht annehmen dürfen, dass es noch Vermittler jener algemeinen Simnesempfindung sei. welche vor der speeitischen Ausbildung und Lokalisirung vou Sinnesorganen bei unseren Thieren die Beziehungen zur Anssenwelt allein besorgt haben wird? Und endlich, sollten die Drüsen, die Nésselzellen und die Becherzellen, welche überall über die aborale Körperolsertläche der Medusen verbreitet sind, ohne Beziehung zum Nervensystem stehen? Es scheint mir alles dies undenkbar. Erscheint es als ganz natürlich, dass ein Theil der Körperoberfläche sich vorzüglich zum Zweck des Schutzes und der Vertheidigung zu einer Decke umbildet, die, wie bemerkt, z. B. hei älteren Exenplaren von Cyanea wenigstens im Kuppentheile sehr fest ist, und dass er sich weiter zu diesem Zwecke mit Waffen des Angrifts und der Vertheidigung ausrüstet, so ist doch zu erwarten, dass diese Waffen mit dem Nervensystem in Verbindnng stehen und dass anch die Zelleu, welehe ausserdem den Körper lecken, dessen Einfluss nieht entzogen seien ${ }^{1}$ ). Der Beweis eines Zusammenhanges ist mir nicht gelungen, und loch spricht

1) In Beziehung auf den Zusammenhang von Nesselzellen mit Nerrenelementen vergleiche man: Korotneff, Histologie de l'Hydre et de la Licernaire, Arch. de Zool. expériment. T. Y. $1870^{\circ}$ 
für denselben ausser den ausgesprochenen Gründen vor Allem noclı die aus den Experimenten zu erschliessende Thatsache, dass sellost die Abgrenzung des centralen Nervensystems keine scharfe ist und dass sich dessen Beclentung nur allmälig proximal veriert.

V1II. Verweigern uns die anf' dem grössten Theile der aloriılen Fläche des Nedusenschirmes gelegenen Epithelzellen einstweilen die Darlegung von morphologischen Eigenschaften, welche deren Beziehung zum Nervensystem durchaus sicher stellen, so ist dies nicht überall der Fall bei den oralen. Zunächst die Neuromuskelzellen, welche die quergestreite Muskelschichte zusammensetzen und welche bei Cyanea ihre gemeinsame Anlage mit den sinnesepithelien so deutlich erkennen lassen, zeigen insbesondere bei Carmarina durch die neurofibrilläre Beschaffenheit ihres nieht contractilen Deekentheils, dass dieser dem Nervensystem zugehört und dass sie in der That "Nenromuskelzellen" sind. Alle die Thatsachen, welche ich über die nemofibrilläre Differenzirung von Nervenepithelien und Ganglienzellen mitgetheilt labe, lassen über die Berechtigung dieser Dentung keinen Zweifel. Ganz abgesehen von der Einrichtung des Neuromuskelsystems bei Beroë, auf welche ich noch zu sprechen komme, würden die von mir bei den Medusen geschilderten morphologischen Thatsachen die Neuromusirelhypothese zur durchaus berechtigten Theorie gestalten. Nur muss ich, den Folgerungen Kleinenbergs für Hydra entgegen, schliessen, dass bei den Medusen das gauze äussere Keimblatt an ler Bildung der Neuromuskelschichte theilnimmt ').

Bei einem Ueberblick äber die Neuromuskelzellen sämmtlicher Mleduseu fällt aut, dass denselben allgemein der Gieisselfaden fehlt, welcher den ausgesprochenen Sinnesep,ithelien dieser Thiere meistens zukonmt, welcher aber auch den an der Bildung der Ringnerven betheiligten neurofibrillïren Epithelien des schirmrandringes abgeht. Dass darauf ein Unterschied in der Anfgabe der Perception beruhen muss, ist selbstverständlich. Indessen kaun ich nur für die Neuromuskelzellen eine Deutung dieser Aufgabe versuchen. Es erscheint als die einfachste Annahme die, dass der Neuromuskelappalat der Unterfläche des Schirmes dazu bestimut sei, die rhythmische Contraktionsthätigkeit des letzteren, soweit dieselbe unwillkürlich geschieht,

1) Hier mag angefügt werden, dass, wie bekannt, Kölliker das Muskelgewebe der Hydra znerst als solches bezeichnet hat. Seine Beziehung zu den Epithelzellen scheint er gleichfalls gesehen zu haben, spricht sich indessen darüber sehr unbestimmt aus. Er sagt: „Ich glauhe ausserdem gefunden zu haben, ohne jedoch fïr einmal mit voller Bestimmtheit mich aussprechen zu können, dass jede Faser oder Fibrille einzeln für sich im Iunern eines schmalen Basalfortsatzes der Zellen des Ektoderms sich entwickelt (Icon. histiolog. I1. Abth. 1s65). 
nuter Leitung der noch näher zu besprechenden, zwischen nervösem und contractilem Abschnitt der Neuromuskelepithelien gelegenen Nervenzellen selbstãndig zu besorgen. Dieser aus Neuromuskelepithelien und Ganglienzellen bestehende reflektorische Apparat muss auf der anderen Seite wiederum in Verbindung stehen mit den Gehirnzellen, deren Einfluss sich änssert in dem Auftreten angenscheinlich dem Willen unterworfener Contractiouen. Der reflektorische Apparat arbeitet indessen nicht etwa wie unser Herz, dem unmittelbaren Einfluss der Aussenwelt vollstandig entrn̈ckt, viehnehr wird der nervöse Theil der Neuromuskelzellen im Stande sein, Reize bestimmer Art direkt von der Anssenwelt her aufzunehmen und dem contractilen zuzuleiten, so dass unter Vermittelung der zwischen beiden gelagerten Ganglienzellen eine Regulirung der Contractionsthätigkeit erfolgen kann, von welcher die Gehirne nicht unmittelhar Kemntniss erhalten. Es darf vielleicht vorausgesetzt werden, dass die Perceptionstähigkeit les nervösen Abschnittes der Nenrommskelzellen vorzüglich eine anf solche lieize eingerichtete sei, welche für die Lokomotion von der gewöhnlichsten Bedeutung sind: etwa auf Druckwirkung, wie sie urch den Widerstand des Wasser's bei der Contraction gegeben ist. Ans der Thatsache, dass ein morphologisch ausgeprägt nervöser Abschnitt an den Neuromuskelzellen der Subumbrella, somit anf einem sehr ausgedehnten Theil der Oberfläche ihces Körpers vorhanden ist, geht hervor, dass, wie nach der niederen Stellung nnserer Thiere und bei der primitiven Ausbildung ihrer Centralapparate nicht anders erwartet werden kann, ein bedentender Theil ihrer Reaktionen gegenüber den Einwirkungen der Aussenwelt noch rein reflektorisch sei, eine Folgerung. welche ich auf trund morphologischer Untersuchnng in demselben sinne anch für Beroë gemacht habe.

A uf den radialen, ans glatten Elementen bestehenden II uskelzügen hat dieneurofibrilläre Bescluaftenheit des Epithels eine ganz ausserordentliche Entwicklnng erlangt und sie führt dort in ler Nähe der Muskelzüge geradezu zur Bildung von Nervenfasern, welche erst eine mittelbare Verhindung nun von den Muskeltäden gesonderter neurotibrillärer Epithelzellen mit diesen herzustellen scheinen. Ob an derart mit den neurofibrillären Epithelzellen verbundenen Muskeltäden noch eine besondere kernhaltige Plasmaanhäufung ausserdem vorhanden ist, habe ich nicht festgestellt. Ist sie vorhanden, so könnte sie wohl nur als aus einer Proliferation des nervösen Theils der ursprünglich einfachen Neuromuskelzelle hervorgegangen betrachtet werden, ein Vorgang, welcher mehr und mehr zur Bildung tiefliegender Muskellagen allmälig führen dürfte, die num vermittelst mehr oder weniger umschriebener Bündel von Nervenfibrillen mit dem abgesonderten Epithel in Verbindnug stehen würden. Der an der 
Muskelfaser sitzende Theil des nerrösen Abschnittes der ursprünglichen Neuromuskelzelle würde zuletzt wohl die motorische kndigmig des Nerven abgeben.

IX. Es führeu uns diese Fragen anf die nähere besplechung der bei allen voumir daranf genauer untersuchten Medusen oral von der contractilen Lage der Nenromuskelzellen in der Subumbrella gelegenen Nervenzellen. Bei Carmarina sind dieselben in ganz vorzüglichem Maasse entwickelt und sie bilden mit von ihnen ausgehenden Nervenfäden auch bei anderen Formen einen ansgezeichneten Nervemplexus. Ich habe diesen Plexus als das reflektorische Centralorgan der Subumbrella aufgefasst, als das Organ, welches die ron dem nervösen Theile der Neuromuskelzellen aufgenomnenen Eindrücke sammelt und einem grösseren Gebiete der contractilen Elemente, bezw. der Gesammtheit derselben mitzutheilen bestimnt ist, ein Organ also. welches die ursprünglich coordinirte Verbindung der Neuromuskelzellen in eine subordinirte umwandelt. Ist diese Anffassung eine selbstverständliche, so werden wir wohl ebenso selbstverständlich eine Entstehnngsweise des Plexus erwarten dürfen, welche einen ursprünglichen orginischen Znsammenlang mit dem Nenromuskelepithel zur Grundlage hat. I ie endgültige Feststellnng der Art, wie die Entstehung stattfindet, wird sich allerdings erst damn mit Erfolg in Angriff nehmen lassen. wenn uns bekannt sein wird, wie die Verbindung der Nervenfüden mit den M(nskelelementen beschaffen ist. Darüber haben wir his jetzt keine Kunde').

1) lnzwischen habe ich mir von Herrn Romanes Nachricht úber die von ihm citirte und auf Seite 111 von mir erwähnte Arbeit ron Schäfer erbeten. Romanes theilte mir mit, dass sie noch nieht erschienen sei, wohl aber ein Auszng von ihr, welchen er die Giite hatte, mir zuznsenden und von welchem er, da derselhe erst nach seiner Arbeit veröffentlicht worden ist, in der von mir vermutheten Weise Kenntniss gehabt haben muss: $>0$ bservations on the nervous system of Aurelia anritax, Proceedings Roy. Soc. Vol. XXVII. Se häfer beschreibt bei Aurelia eine Lage von Nervenfasern, welche die ganze untere Fläche der Unbrella bedeekt und zwischen dem Ektodermepithelium und der Muskelschichte liegt. In die Fasern sind bipolare Nervenzellen eingelagert; sie sind selten oder nie mehr als $t \mathrm{~mm}$ lang, verbinden sich mit benachbarten, verzweigen sich, und endigen spitz zulaufend; die Enden sind in enger Berïhrung mit den Hnskelfäden, aber zuweilen ist die Endigung zu einer platten, kernhaltigen Verbreiterung gestaltet wahrseheinlich einer primitiven Form einer motorisehen Endplatte. Es erinnert die Beschreibung dieser Endigung sehr an die Einrichtung, welche ich für Beroë geschildert habe, wonach der Ansatz der Nerven an Iluskelfasern unter Vermittelung den letateren aufliegender Kerne geschieht. Der Kern liegt unter dem Sarkolemma nnd die Hülle des Nervenfadens geht in dieses ïber. Statt des Kerns sieht man zuweilen eine granulirte Masse, wohl kernhaltiges Plasma. Ich verglich die Kerne mit den „Nervenendknospen * der Amphibien ( $\mathrm{K}$ ü h n e. Strieker's Handbuch der Itehre von den Geweben S. 155), bezw. den Kernen der Nervenendplatten der übrigen höheren Thiere (Beroë S. 70, Fig. 47; Fig. 67, A u. B). In anderen Fällen aber scheint sich die Nervenprimitivfibrille einfach an den Muskel anzusetzen. Diese beiden Arten der Verbindung gelten für den Fall, dass Nervenläden im Winkel an IIuskelfasern in deren Verlauf herantreteu, die zweite speciell aber für die Endigung des der Mlıskelhaut der Oralfläche anliegenden Nervenplexus, d. i. der Ausläufer der derselben aufliegenden Ganglienzellen (S. 71 u. 72 a. Fig. 45). Die dritte Art der Verbindung, wie sie in den Neuromuskelfaseru gegeben ist, wird noch besprochen werden.

S chäfer erwähnt das Nervenepitheliun von Randkörpern und Umgebung und die Auskleidung einer aboralen und einer oralen Grube durch dasselbe, hält aber Nervenfilz und Epithelzellen für das centrale Nervensystem. 
Indessen haben wir in den morphologischen Verhältnissen ausserdem Anhaltspunkte, welche den Versuch einer Erklärung jener Entstehung rechtfertigen mögen. Da nach meinen Beubachtungen die oralen Epithelzellen geradezu Nervenzellen sind, so kann es wohl keinem Zweifel unterliegen, llass die subepithelialen aus ihnen hervorgehen. Dres könnte geschehen entweder durch Proliferation des nervösen Theils der Neuromnskelzellen in der Kichtung ilıres Hölıendurchmessers oder dadurch, dass Epithelien ans der lieihe der übrigen, mit welchen sie in seitlicher Verbindung sind und bleiben, in die Tiefe treten. Wir können den ersteren Modus bezeichnen als den auf Proliferationsden zweiten als den auf Wandernngscontinuität beruhenden. Die Neuromuskelfasern von Beroë würden ein Beispiel ron Proliterationstontinnităt zeigen. Wir finden dort zwischen Epithel und Inskelfasern, eine continuirliche Verbindung herstellend, Nervenfasern und in dem Verlant derselben, sowie insbesondere an der Stelle des Uebergangs von Muskel- und Nervenfaser, Ganglienzellen eingeschaltet ${ }^{1}$ ). Offenbar ohne meine Schilderung der Neuromuskelfasern von Beroë zu kennen, hat Gegen ba ur bei Gelegenheit der Besprechung der Angaben von Kleineuberg über das Nemromuskelgewebe von Hydra in uer II. Auflage seines Grundrisses der vergleichenden Anatomie eine hypothetische Beurtheilung der aus der Neuromuskeltheorie zu ziehenden Schlüsse gegeben, welche in solcher Weise auf jene meine Schíderung hinanskonmt, dass man meinen sollte, er habe dieselbe seinen Aeusserungen geradezu zu Grunde gelegt. Er sagt do:t (Seite 32 ) , darin (in den Nenromuskelzellen der Hydra) erscheinen die ersten Anfänge der in höher differenzirten Zuständen in dem Zusammenhang von Ganglienzelle, Nerrenfaser und Iluskelfaser ausgespiochenen Einrielhtung. Wem wir annehmen, dass die in diesem fall (Nemromuskelzelle) nur als Fortsätze von Zellen erscheinenden Fasern einen Kern erhalten, indem das T'heilungsprodukt des Kernes der Zelle allmälig aut die Faser gelangt, dass ferner die Neuromnskelzelle nicht mehr so unmittelbar, sonderu durch einen gesonderten Fortsatz mit der somit gleichtalls selbständiger gewordenen contractilen Faser sich verbindet, so ist damit ein Uebergang zu jenem differenzirteren Zustande gegeben. Nerven wie Mluskeln erscheinen von diesem Gesichtspunkte aus als die Produkte der Sonderung einer und derselben Gewebsschichte, die wir weiter unten als „Ektoderm“ werden kennen lernen. Damit wird zugleich ein physiologisches Postulat erfüllt; denn es ist völlig undenkluar, dass Nerv oder Mnskel in ihren Elementen einmal vou einander gesondert bestanden und dass der die Funktionen beider bestimmende Zusammenlrang das Ergelmiss einer späteren Verbindung sei“. Wir würden uns also

I) Vergl. Beroë, Taf. VI. 
die Neuromuskelfiser entstanden denken durch Wucherung, Kernvermehrung und Verlängerung einer Neuromuskelzelle in rler Richtung ihres Höhendurchmessers : die mit dem Nervenfaden in Verbindung stehende Epithelzelle bleibt percipirende Sinneszelle, an der Uebergangsstelle zwischen Nerv und Iluskel hat sich ein Apparat gesondert, der als motorische Nervenzelle functionirt'). Dabei ist num aber die 'Thatsache hervorzuheben, dass jeweils mehrere Epithelzellen mit einer motorischen Nervenzelle, d. i. mit einer Muskelfiser in Verbindung stehen und wemn wir daher annehmen wollen, dass der Apparat aus einer einzigen Neuromuskelzelle hervorgegangen sei, so müssen wir schliessen, disss mit der Proliferation in genannter Richtung zugleich eine seitliche in der Weise stattgefunden habe, dass von derselben nur der nervöse, nicht aber der contractile Abschnitt der letzteren ergriffen worden sei, mit anderen Worten, dass aus einem nervösen Abschnitt der gegebenen Neuromuskelzelle deren mehrere hervorgegangen seien, während der contractile in der Einheit geblieben ist.

Auf die zweite Art der Entstehung subepithelialer Ganglienzellen, auf die anf Grund der Einwanderung stattfindende, seheinen die von mir bei Carmarina geschilderten Verhältnisse hinzuweisen: man müsste annehmen, dass von beispielsweise zwei nebeneinander gelegenen und untereinander seitlich zusammenhängenden Nemromuskelzellen die eine in die Tiefe tritt und, während sie mit dem Muskelelement in Verbindung bleibt, zur Nervenzelle wird, während die andere sich mnter Verlust ihres contraktilen Theils allmälig zur percipirenden Epithelzelle gestaltet. Für Carmarina, wo je eine nervöse Deckzelle mit zahlreichen contractilen Apparaten nachweisbar in Verbindung steht, würde nun auch der schwierigste Theil der Erklärung, die Frige, wie es möglich ist, dass eine einzige Ganglienzelle zahlreiche Muskelelemente beherrscht, hinwegfallen. Und es ist wohl anzmehmen, dass die Einrichtungen von Carmarina nur gewissermassen in gröberen Zügen Verhältnisse anfklären, welche, wemn anch nicht in ganz derselben morphologischen Bildung, so doch mit denselben Beziehungen auch anderwärts vorkommen, - Die Einrichtungen bei Carmarina, insbesondere die Bedentung des Epithels dieser Meduse als Nervenepithel sind es gewesen, welche mich zu solcher Erklärung der Entstehung subepithelialer Ganglienzellen geführt haben. Auf Grund derselben Beobachtung, welche ich am Schirmrandringe von Carmarina gemacht habe, wonach dort zu Ganglienzellen gestaltete Epithelzellen angenscheinhich in die Tiefe treten, haben Hertwig kürzlich gleichfalls eine Entstehung von Ganglienzellen aus in die Tiefe tretenden, mit den Nachbarn in Continuität stehenden Epithelzellen angenommen; allein sie stellen diese

1) Vergl. Beroë, Taf. VI, g der Abbildungen. 
Auffassung in Gegensatz zu der von ihnen bekämpften Neuromuskeltheorie, was meiner Ansicht nach in keiner Weise geboten ist. Auch ist durchaus nicht anzunehmen, dass die Entstehung von Ganglienzellen auf Grund von Einwanderung die einzige sei: der zweite Bildungsmodus, der auf Grund von Proliferation, wird eine nicht minder bedentende Rolle spielen und beide werden Hand in Hand gehen können. Gerade die Verhältnisse des Schirmrandringes sprechen in hohem Grade für eine Betheiligung der Proliferation: nur durch diese kann offenbar die Bildung des Ringnerven aus langen Nervenfäden erklärt werden, in welche von Stelle zu Stelle Ganglienzellen eingeschaltet sind.

X. Hat die quergestreifte Muskulatur des Schirmes die rhythmischen Contractionen desselben zn besorgen, so möchte die glatte, radiale, aktiver Erweiterung der Gefässe vorzngsweise vorstehen. Der Gegensatz im Ban dieser beiden Muske]arten und die aus ihrer Lage hervorgehenden Beziehungen der Thätigkeit zu diesem Bau geben ein hübsches Beispiel für die Annalme ab, dass die Entstehnng quergestreifter Muskulatur bei den Medusen wie in der ganzen Thierreihe offenbar ur einem höheren Grade der Thätigkeit den Ursprung verdankt. Ueberall, wo diese Thatigkeit eine selu bedeutende ist, mag sie eine "willkürliche“ oder eine "unwillkürliche“ sein, tritt Querstreifung auf, bei den Medusen in derjenigen Richtung, nach welcher die Zusamnenziehungen des Schirmes vorzüglich stattfinden (cirkuläre Muskulatur), nicht in der entgegengesetzten (radiäre Muskelzüge). An deutlichsten spricht hiefür die Beschaffenheit der so lebhafte Bewegungen ausführenden Muskulatur dex Arthropoden, der Muskulatur des Herzens der Wirbelthiere, im Gegensatze zu den übrigen „unwillkürlichen“ Muskelzügen und Muskelblättern. Dass ehenso bei den Zoophyten wiederum ein Zusammenhang zwischen contractilem Gewebe nud Bindegewebe besteht, indem beide von gewissen Grenzen ab sich nicht mehr trennen lassen und dass hier wiederum die Thätigkeit massgebend ist, indem ersteres sich überall nach denjenigen fichtungen aus einer mit ersterem gemeinsamen Anlage entwickelt, nach welehen vorzüglich Contractionsfähigkeit nothwendig war und sich ansgebildet hat, habe ich bei Beroë nachgewiesen. Nenerdings sind ähnliche Uebergänge zwischen Bindegewebe und Muskelgewebe auch bei Wirbelthieren erkaunt worden ${ }^{1}$ ).

XI. In Zusammenhang mit der Amnahme, dass Muskel- und Bindegewebe bei den Zoophyten durch Uebergänge verbunden seien, steht die Frage inwieweit das

1) W. Flemming, Ueher Formen u. Bedeutung der organischen Muskelzellen. Ztschr. f. wissensch. Zool. XXX. Bd. Suppt. 
Gallertgewebe der Medusen durchiehende Faseru als den Nervenstrom leitende, als Nervenfasern betrachtet werden dürfen, demn für Beroë bin ich zu dem weiteren Schluss gekommen, dass dort anch Nerven- und Bindegewebselemente von einer gewissen Grenze an wicht mehr unterscheidbar seien, wemn auch auf der anderen Seite, da wo bedentendere Differenzirung vor sich gegangen, diese Unterscheidung eine nicht schwierige ist. Zwischen zwei Blättern von Ektodermzellen hat sich bei den Medusen eine Lage von Gallertsubstanz ansgeschieden, welche nach Allem, was wir über ihre Entstehung wissen und erschliessen können, uur eben als ein Produkt der Ektodermzellen sellost autgefasst werden kam. Von einem Theil der Fasern, welche die Gallerte durchziehen, dürfen wir wohl annehmen, dass sie zwischen den Zellen der beiden Ektodermlager einfach ansgezogen worden seien, und dass sie von Anfang an leitender Verbindung derselben gedient haben. Bezügliche morphologische Verhältnisse sprechen deutlich hiefür besonders bei Cyanea. Andere Fasern zeigen Zellen eingeschaltet und können entweder gleichzeitig mit vorigem Process vor sich gegangener Proliferation ihren Ursprung verdanken, oder aber nachträglicher Verbindung vom Epithel her eingewanderter Zellen. Es ist nicht anders zu erwarten, als dass solche Entstehungsweise Fasern hervorrief, welche ursprïnglich ihre funktionelle Bedentung in keiner Weise offenbarten: morphologisch indifferente Fäden. Ein Theil derselben mag allmälig zu Stützfaseru, zu Bindegewebe, ein anderer zu morphologisch als solche dentlich differenzirten Nervenfäden sich umgestaltet haben. Muskeltisern, welche im lnnern des Gallertgewebes von Beroë eiue so bedeutende Entwicklung zeigen, sind wenigstens dentlich norphologisch erkenubar bei den Melusen bis jetzt nicht beobachtet. Wiederum ist es überall nur die Uebung der Funktion, welche die morphologische Differenzirung aus ursprünglich indifferent anssehendem Gewebe nach dieser oder nach jener Richtung hin hervorruft. Und so liegt es in ler Natur der Sache, dass anch sorgfältigste morphologische Untersuchung in vielen Fällen ummöglich wird entscheiden können, ob diese oder jene Fasern, ob diese oder jene Zelien da oder dorthin zu rechnen seien. Abgesehen von den Stellen, wo mir eine solche Unterscheidung zu machen nicht schwierig war, muss ich somit hiuweisen anf das Experiment, welches mir mit aller Bestimmtheit gezeigt hat, dass ein 'Theil der das Gallertgewebe der Toponeuren anch ausserhalb der liandlappen durchziehenden Fasern als solche zu betrachten seien, welche den Nervenstrom leiten.

Als Fasern aber, welche ich auch nach ihren morphologischen Eigenschaften als Nervenfasern zu denten berechtigt zu sein glaubte, habe ich solche mit plasmatischem Inhalt bezeichnet, sodann Ketten 'von durch Fäden verbundenen Zellen, und eudlich fand ich ausgesprochene variköse Nervenfasern, in welehe wiederum Zellen eingeschaltet sind. 
1)iese letzteren Terbältnisse erinnern durchans an das, was ich bei Beroë beschrieben habe: wie dort, so sind anch hier die in die Nervenfasern eingeschalteten Zellen ansserordentlich arm an Plasma (Ringnerv, Belegzellen des Stützblattes des Schirmrandringes bei Carmarina), so dass ich die Nerventasern von Beroë geradezu als Ketten von Ganglienkernen bezeichnet habe. Schon dadurch fatlen die Kierne besonders in die Angen, sind aber überhaupt überall hervorragend ausgebildet und auch als absolut gross zu bezeichnen. Bei den Toponeuren, wo das Nervensystem anf sehr tieter Stufe der Entwicklung steht, ist derartige Auszeichnung nicht zu bemerken. Bei den Mledusen wie bei Beroë beschrieb ich ferner die Nervenfasern als aus Hülle und Centralfaden zusammengesetzt; bei beiden werden die gröberen Varikositäten durch Erweiterungen der Hülle hergestellt (wahrscheinlich in Folge von Ansammlung eines Hlüssigen oder halbflüssigen Inhalts) und in ihnen ist der leitende Nervenfaden, Centralfaden, besonders dentlich. Bei Beroë durchziebt derselbe die Kerne, das Kernkörperchen durchsetzend. Ich habe die eingeschalteten Kerne hier wit stationen verglichen, in welchen die abgeschwächte durchziehende Depesche von Nenem deutlich gemacht wird, ein Vergleich, der nach den geschilderten Beobachtungen an Mledusen auch für diese Berechtigung haben möchte. Was ferner die feinsten Verzweigungen der Nervenfädchen angeht, so zeigen sich ganz dieselben Einrichtungen bei den Ctenophoren und bei den Toponeuren : jene eigenartige, nur dem Nervensystem eigene dichotomische Verzweignng oder Gabelung der Fihrillen bildet bei diesen einen dichten Filz unter dem Sinnesepithel der Randlappen, bei Beroë streben sie nur in lang ausgezogenen, ans einfacherer Terzweigung hervorgehenden Fäden zu ihm empor. Aber dieselben feinsten Verästelungen wie dort finden sich hier an den Anslänfern der Nervenzellen des Gallertgewebes und nach Goldbehandhung zeigt sich in diesem ein Plexus von gabelig sich verzweigenden und wiederum untereinander anastomosirenden Nerrenfädcben so fein, dass man erstaunt sein muss, derartige Veriältnisse bei so tiefstehendeu Thieren zu finden.

1) Es sind kürzlich zwei Sebriften erschienen, leren Verfasser Alles, was ich als Nervengewebe bei Beroë beschrieben hahe, nicht in diesen sinne anerkennen zu dürfen neinen. Der eine Autor erklärt meine Nervenzellen für , Bindegewebszellen mit varikösen Ausläufern (Buekers, Bijdragen tot de Kennis der Anatomie ron Cestum Veneris Les. Hoorn 1878, Dissertation). Die Entdeckung virikösen Bindegewebes mag den Herren in Leyden, welche die betreffende schritt preisgekrönt haben, hiezn wichtig genıg erschienen sein; Histologen möchte sie bis auf bessere Bestätigung meiner Angaben als eine Art solcher Bestätigung dienen. Ein anderer Autor (C'hun, das Nervensystem und die Nuskulatur der Rippenquallen, Abh. A. Senkenberg'schen Gesellsch. Bd. XI) erklirt Alles für Nuskelzellen und trägt sogar keiı Bedenken, mir in Hinblick auf seme misslungenen Goldpräparate eine Verwechslung körnigen Niederschlags ron Gold mit Nervenfibrillen zuznmuthen. Auf ähnliche liritik, welche auf Grund des negativen Erfolgs des bezüglichen Theiles seiner Untersuchung ron demselben ansserdem an meiner Arbeit geïbt wird, kann ich hier nicht eingehen. Die detaillirte Art, in welcher ich das Nervengewebe und sein Verhalten zur Huskulatur beschrieben habe, muss, wie ich glaube, einem Jeden, der mit den allgemeinen Eigenschaften der Gewebe hinreichend vertraut ist, Beweise genng vorführen, dass ich Nervenelemente vor mir hatte, auch wenn jch es 
Wemn die Nervenfasern der Toponemren nicht nur miter dem Sinnesepithel, sondern anch in der Subumbrella charakteristischer ausgebildet sind als imerhall, der Umbrella, so ist dies wohl durch die Art und die tiefe Stufe der Entwicklung des Nervensystems dieser 'Thiere und anch darans erklärlich, dass die Thätigkeit wenigstens der in der Subumbrella gelegenen Nervenfisern in unverhältnissmässig viel höherem Grade in Anspuch genommen sein mnss als die Thatigkeit jener des Gallertgewebes. Um so mehr darf aber erwartet werden, dass an grösseren Cycloneuren specielı darauf gerichtete Experimente, ähnlich wie dies für die Toponeuren festgestellః ist, rine Nervenleitung durch Fasern auch innerhalb der Umbrella nachweisen werden. Mir mag es genügen, dass zunächst bei den Toponemren dieser Nachweis geliefert ist und dass somit anch hierin volle Uebereinstimmmg mit den von mir bei Beroë anf Grund morphologischer Untersuchung geschilderten Thatsachen besteht. Uebereinstimmung herrscht endlich, wie noch hervorgehoben werden muss, anch mit den cyclonemren darin, dass die hier wie bei den Toponeuren experimentell nachgewiesenen Nervenbahnen nicht bestimmte, constant angeordnete Züge von Fasern, „Nerven“ im Sinne der höheren Thiere, sonderu dass sie überall vereinzelt verlaufende Fäden bilden, welche übrigens bei Carmarina, vom Ringnerven abgesehen, Anfänge einer Anordmung zu radiären Zügen zeigen, wie solche auch bei Beroë zu beobachten sind. Somit ist dem Experiment anch hierin durch die morphologische Untersuchung volles Genüge geleistet.

Aus der gemeinsamen Anlage von Nerven- und Mnskelgewebe und aus der geringen Differeuzirung der Gewebe äberhaupt. besonders bei den Toponeuren, mag sich auch die auf Seite 118 und 119 wach den Untersuchungen von Romanes mitgetheilte Thatsache erklären, dass sich Contractionswellen nicht schneller fortpflanzen als der Nervenstron. Darans ist nicht zu schliessen, dass beide anch morphologisch an dieselben Gewebselemente gebunden seien. sondern nur, dass die funktionelle Scheidung von zweierlei ans gemeinsamer Anlage hervorgegangenen Gewebselementen noch eine sehr jugendiche sei.

Es ist unzweifelhaft, dass Nervenfäden die Leitung im Medusenkörper vermitteln, und dass der subepitheliale Plexus die contractilen Elemente der Subumbrella verbindet und dort die Leitung besorgt, ist höchst wahrscheinlich. Fraglich ist es

nicht für nöthig bielt, diese Beweise ïberall besonders hervorzuheben. Aus früber hervorgehobenen Gründen habe ich aber schon vor der Keuntniss der genannten Schriften Widerspruch erwartet (vergl. die Einleitung) und da solcher von verschiedenen Seiten geiibter Widerspruch, selhst wenn er nur auf negativen Argumenten beruht, die unbedingte wissenschaftliche Verwerthung von Thatsachen bis auf Weiteres hindern kann, so füge ich, ausser dem Hinweis auf die Uebereinstimmung zwischen Nervenelementen von Nedusen mit jenen der Ctenophoren an, dass mein Freund Langerhans meine Untersuchungen an Beroë auf Capri genau verfolgt hat, und dass unser Urtheil über die Gewebselemente ein durchaus und selbstverständlich übereinstimmendes war. 
indessen, inwieweit ausserdem eine Leitung des lieizes durch Contignität der Muskelelemente, also ron Muskelelement zu Muskelelement mit in Betracht kommt. Die von mir beobachtete und rou Romanes bestätigte Thatsache, dass die Erregung von einer contractilen Zone sich anf die benachbarte überträgt, und les letzteren Angabe dass diese Cebertragung durch eine Contractionswelle geschieht, gibt dieser Frage berechtigten Anhalt. Jedenfalls handelt es sich in der subumbrella gerade der Toponeuren in Beziehung auf die Muskelelenente erst $\mathbf{m m}$ den Uebergang von der Contiguitäts- zur Continuitäts-Verbindung. Die Neuromuskelzellen bestehen noch ganz ebenso wie dort. wo noch gesonderte Nervenfasern und Zellen fehlen, aber es tritt hinzu die Verbindung der contractilen Abschnitte derselben untereinander durch Nervenfäden. Dass also die ursprünglichen Neuromuskelzellen als solche nicht mehr allein durchaus die Funktionen des Nerven- und Muskelgewebes vermitteln, ist selbstverstänllich, ganz abgesehen davon, dass auch das Gallertgerrebe von Nerventasern durchzogen wird.

XII. Die besprochene hervorragende Bedeutung der Kerne im Bau der Nervenfasern von Beroë, ihre besondere Ausbildung daselbst, ihre Beziehung zum Centralfaden haben mich schon früher in Verbindung mit anderweitigen Thatsachen dazu veranlasst, auszusprechen, dass man versucht sei, den Ker n als das nervöse Centralorgan der Zelle zu bezeichnen ${ }^{1}$ ). Die Verhältnisse des Nervensystems der Cyclonemren, nicht nu bei Carmarina, sondern auch bei den übrigen von mir untersuchten Formen, geben nene Belege fïr die Berechtigung der Dentung, welche ich den bei Beroë beobachteten Thatsachen gugeben habe: es sind wielerum die Kerne, welche in den Nervenfasern hier eine hesondere Rolle spielen, schon dadurch, dass sie, von anfiallend wenig Plasma nmgeben, in dieselben von Stelle zu Stelle eingeschaltet sind, allein anch dadurch, dass sie überill ron ansehnlicher Grösse erscheinen. Besondere Grösse ist weniger oder nicht auffallend in den Nervenepithelien, dagegen ansserordentlich in den typisch ausgebildeten Ganglienzellen des Schirmrandringes und der Subumbrella von Carmarina. Diese Grösse ist hier nicht nur eine absolut bedentende, sondern sie ist anch relativ hervorragend gegenüber der Menge des sie umgebenden Plasma. Zugleich ist das Kernkörperchen von ungemeiner Grösse und zeichnet sich durch bedentendes Lichtbrechungsvermögen ans. Nur mit einer anderen Kernart im Medusenkörper lassen sich diese Verhältnisse vergleichen, nämlich mit den Kieimbläschen, und dieselben Verhältnisse treffen wir nicht nur bei den Medusen, sondern überhampt im Thierreiche. Dimaus mag es sich erklären, dass ein hervorragender

1) Beroë S. 81 . 
Forscher die Eier von Medusen für Nervenzellen gehalten hat. Zum Vergleich habe ich anf Taf. XII, Fig. 14, Eier von Carmarina hastata im gallertigen Stützhlatte liegend abgebildet: sie unterscheiden sich von den Ganglienzellen wesentlich durch das Fehlen der Fortsätze, ohnedies würde eine Verwechslung beider unschwer möglich sein. Dieselbe hohe Ausbildung der Kerne der Ganglienzellen findet sich un als Riegel im ganzen Thierreiche: nicht nur sind in den Centralapparaten vieler Thiere, was wohl allgemein bekannt, aber nicht verwerthet ist. Kern und Kernkörperchen von ganz ansserordentlicher absolnter Grösse, sondern vieltach tritt auch das Zellylasma den Kiernen gegenüber ganz, autfallend zurïck, so dass man Theile von Gehirn oder von Ganglien antriflt, welche bei nicht genauer Untersuchung len Eindruck machen, als ob sie nur ans Kernen znsammengesetzt seien. Dass man dabei sofort anch an die Neurogliakerne denkt und diese mit solchen Vermehrungsprocess in Verbindumg bringen möchte, ist selbstverständlich. Jie chemische Composition des thierischen Zellkerns überhaupt, soweit wir sie kennen, weist vorzüglich Stotfe nach, welche anch in der Znsammensetzung der Hirnsubstanz eine besondere liolle spielen. Ans diesen und auderen Gründen ist zu schliessen, dass speciell die Zellkerne der sitz und der Herd der centralen Nerventhätigkeit seien; nnd dass diese Thätigkeit da, wo sie eine lebhafte ist mit einer ständig in gewaltigem Maasse vor sich gehenden Neubildung von Kernen verbunden sei, möchte ich aus verschiedenen Thatsachen erschliessen. Die Angaben über die Endignng von Nerrenfädchen auch in Kernen anderer Zellen mehren sich und die Rolle, welche die lierne bei der Bildung percipirender Sinnesorgane spielen, ist eine ganz hervorragende. Ist die Berleutung der Kerne für das Nervensystem aus den geschilderten Verhältnissen offenkundig, so hat sich mir aus meinen fortgesetzten Untersnchungen über seinen Ban insbesondere ans dem Stndium der radiären, im Kernkörperchen oder in kleineren Centralpunkten convergirenden Plasmafäden, welche in seinem Inneren zu erkennen sind, immer meln die Ansicht anfgedrängt, dass er überall als das C'entralorgan der Zelle wenigstens in dem Sinne eines Anregersund Leitersihrer Lebensrorgänge, als ihr "Lebensorgan" anzuselıen sei. Eine nähere Begründung und Ausführung der hier angedenteten Auttassungen werde ich, insbesondere, auf Grund specieller Mittheilungen über die Bauverhältnisse der Kerne der Ganglienzellen, an einem anderen Orte geben. Hier sei nur noch darant hingewiesen, dass die bervorragende Rolle, welche der Kern in den Eiern und anch in den Samentäden spielt, bei der grossen Bedeutung, welche diese Theile als Vermittler einer nngehenern Entwicklnng hahen, vollkommen verständlich wird, sowie man die Kerne eben als die Anreger dieser Entwicklung anffasst, eine Annahme, die in nenesten Beohachtungen bedentende Stützen findet. 
Die 'Thatsache, dass bei den Toponeuren eine besondere Ansbildung des lierns in den dem Nervensystem zugehörigen 'Theilen nicht zu erkennen ist, erklärt sich unschwer wiederum aus dem geringen Grade der Centralisation, welche hier sich ansgebildet hat und mmuittelbar daran reihen sich die bezüglichen Terhältnisse von Beroë, wo die Differenzirnng der Nervenelemente weiter als bei den Toponeuren, aber nicht so weit wie z. B. bei Carmarina vorgeschritten ist.

XHll. Spritht sich das ganz Allmälige, Stufenweise in der morphologischen Differenzirngg der ektodermalen Gewebselemente unserer. 'Thiere aus indifferenter Anlage je nach dem Grade des funktionellen Bedürnisses überall aus, so ist dies doch am dentlichsten und zugleich am schönsten der Fall in der Umbildung des Epithels zu specifischen sinnesapparaten, speciell bei den Toponenren.

Aus dem gewöhnlichen Deckepithel des Körpers entwickelt sich hier specifisches Sinnesepithel zum Zweck des Sehens, Hörens, Riechens (Schmeckens?), Tastens dicht nebeneinander in einer. Weise, dass man meist nicht bestimmen kann, wo das eine Organ vom anderen sich scheidet, oder wo die Grenze ist gegenüber jener allgemeinen Bedeckung. Das Geisselepithel, ein Ueberrest der Körperdecke der Larve, findet sich insbesondere erhalten an den Tentakeln, wo ihm vielleicht noch hervorragend Bedentung zum Tasten zukommt, sodann in den Gruben. deren Gestaltung Veranlassung geben musste, ihnen specifische Bedentung als Riech (Schmeck-?) organe zuzuschreiben. Allein in den hinteren Riechgrnben tinden sich zngleich die als Seh. spindeln von mir bezeichneten Gebilde nnd anch anf den liandkörperstielen, sowie an den Randlappen, liegen beide zwischen einander. Deutlich entstehen ausserdem die Spindeln aus den Geisselzellen. Bei Cyanea finclen sich auf der aboralen Schirmfläche verbreitet noch spindelförmige körper, welche vielleicht mit den Sehspindeln in unmittelbarer leziehung stehen. Diese scheinen ihre höchste Bedentung aber jedenfalls anf den Randkörpern zu erlangen, la wo die gewöhnlichen Geisselepithelzellen dadureh in den Jienst des Sehapparates treten, dass sie Pigment anfinehmen und zu mehreren je eine sehspindel mmschliessen, anf diese Weise also in ihrer Gesammtheit eine Art Chorioidea herstellend. Allein Lichtempfindung scheint hei den Cytophoren nieht nur auf der ganzen Oberflïche der Randkörperstiele, sondern anch auf den Randlappen und in den hinteren liechgruben vermittelt zu werden, also auf zwei räumlich getrennten Bezirken. Auf das lentlichste ist su die Differenzirung von specifischen Sinnesorganen aus einem ursprünghich wohl allen Sinnesempfindungen unvollkommen zugleich dienenden Simnesepithel erst im Werden begriffen, so sehr, dass es nicht einmal möglich ist, eine bestimmte Grenze für jedes Organ zu ziehen, 
abgesehen davon, dass die Bedentung, welche wir dem einen und dem anderen zuschreiben - es gilt dies für die Dentung des Geisselepithels als Riech-oder Tast. apparat - eben in Folge der geringen morphologischen Differenzirung, mehr auf Vermuthung als anf Beweis beruht. Am dentlichsten sind der Verbreitung nach noch die percipirenden Hörzellen von den übrigen Simneszellen abgegrenzt. Im Uebrigen sind sie von den Geisselzellen nur dmrch den Verlust der Geissel und durch geringeren Höhendurchmesser unterschieden.

Physiologisch interessant sind die Einrichtungen des Hörorgans bei Toponeuren. und bei Carmarina. bei den Toponearen muss entweder Erschütterung der Hörkrystalle die dem Hörsäckichen anfgelagerten Hörzellen von ihrer unteren (inneren) Fläche ans erregen oder es dient die Gesammtheit der Hörkrystalle dem Hören nur insofern, als sie den Hörzellen bei Druck der von aussen herintretenden Schallwellen einfach Widerstand bietet und so einen Anprall derselben ermüglichend, ihre Wirkung verstärkt. Es scheint mir, dass beide Arten der Leistung sich nicht ansschliessen. Eine eigenthümliche Analogie mit den Bauverhältnissen von Beroë ergibt sich wiederum im Vorhandensein jener blindendigenden Ausstülpungen voı Gefässen, welche zangenaitig, wenn auch bei den Toponenren nicht in unmittelbarer Nähe, gegen die Hörsäckchen hinragen, der von mir sogenannten Hörgefässe oder A mpullen ${ }^{2}$ ); man wird sie in beiden Fällen als Hülfsapparate des Hörorgans ansehen müssen, vielleicht insofern als die sie von der Anssenwelt abgrenzende, verhältnissmässig dünne Gallertlage dazu geeignet ist, durch ihre Excursionen die Wirkung der Schallwellen zu verstärken.

In ganz anderer Weise, aber doch im Wesentlichen nach demselben Princip wie bei den Toponeuren sind die Hörorgane von Carmarina gebant: hier kann der Hörstein nur die Anfgabe haben, einen Anprall der Wellen auf das Hörepithel zu ermöglichen. Die hier, wie geschildert, ungemein feinen Hörhaare werden zwar durch die Erschütterung der Wand des Hörbläschens, zngleich aber anch durch die Bewegung der in diesem enthaltenen Flüssigkeit erregt werden, denn die Abbildung von doppeltconturirten, starken und starren Hörhaaren, welche wie Borsten nach der Wand des Hörbläschens hinstreben, wie sie Hertwig geben, entspricht nach meinen Beobachtungen nicht dem Thatsächlichen und nuss als schematisch bezeichnet werden. Bei Rhopalonema, wo ich die Verhältnisse der Hörorgane im Wesentlichen übereinstimmend mit der Darstellung der genannten Antoren gefunden habe, umschliessen die Hörzellen gleichfalls den Otolithen von aussen: dieser sitzt zwischen den Hör-

1) Vergl. Beroë, Taf. I, Fig. 1, 2; Taf. II, Fig. 11 bei A. 
zellen fest und es ist somit seine Bedeutung nur wieder ebenso zn erklären wie bei Carmarina.

Sind alle diese Einrichtungen nach ganz anderem Princip construirt, als die Hörorgane anderer niederer Wirbelthiere, so findet sich, ohne dass irgend von einer Erklärung durch verwandtschaftliche Beziehnugen geredet werden kaun, doch dasselbe Princip wie bei den letzteren anch bei den ersteren vertreten. So hat Hensen ${ }^{\prime}$ zuerst bei einer Encope die Hörhaare in Innern des Hörbläschens von einer im Grunde desselben gelegenen Epithellage aus lnineinragend beschrieben: anf ihuen liegt der Hörstein und es wird hier also die Höremptindung anf ganz dieselbe Weise vermittelt wie bei Würmeru ınd Mollusken. Es lat diese Dentung verschieclene Widersprüche erfahren, wie denu z. B. Fritz Müller den Otolithen für eine Linse erklärt ${ }^{2}$ ), während Häckel die von Hensen als Hörhaare beschriebenen feinen, blassen Linien auf die Fasern der simnesnerven, die beiden äussersten derselben anf die Conturen des letzteren zurückführen zu dürfen meint, das Hörbläschen aber tür das nach seiner Meinung anch bei den Geryoniden den Utolithen umschliessende Sinnesganglion hält, welches von jenem Nerven getragen werde. Es gibt Häckel an, dass er diese Deutıng stützen könue durch eigene Beobachtung mehrerer Eucopiden (Phialidium viridicans und ferrugineum) und T'rachynemiden (lihopalonema velatum und umbilicatum) ${ }^{3}$ ). Hertwig endlich erklären die feinen Linien, welche Hensen als Hörhaare bezeichnet hatte, für clie Grenzen der Sinneszellen und glauben erst die Entdeckung der wirklichen Hörhaare zn machen. Ich kann dem gegenüber die Angaben Hensen's durchans bestätigen. lm Frïhjahre 1s76, als ich in Neapel 11. A. die Hörorgane mehrerer Encope-Arten untersuchte, habe ich nit starken Linsen die Linien, welche Hensen als Hörhare beschreibt, auf das Dent-

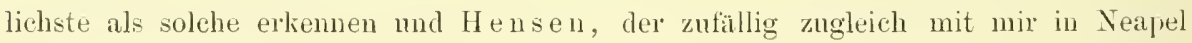
war, zeigen können.

lch führe diese Thatsachen hier desshalb an, un daranf hiuzuweisen: 1) dass die höheren Sinnesorgane (denn ganz dasselbe wie für die Hörorgane gilt nach meinen Erfahrungen anch für die Sehorgane) der Toponeuren und der Cyclonemen lieinerlei verwandtschaftliche Beziehungen haben und dass auch rerschiedene Giuppen der Cyclonemren unter sich derartiger Beziehungen in gleicher Weise baar sind; ') dass aber zweierlei physikalische Principien im Ban der Hörorgane bentitzt sind, von welchen das eine auf Erregung frei in die Hörkipsel hineinragender Hörzellen durch

1) Hensen, Studien über das Gehörorgan der Decapoden, Zeitschr, f. wissensch. Zool. Bu. XIII. 1863.

2) Fritz $\mathrm{M}$ ü $\mathrm{l} \mathrm{ler}$, Ueber die Randbläschen der Hydroidquallen, Archiv f, mikr. Anat. Bd. I. 1865.

3) Hä ckel, Geryoniden S. 59. 
den Hörstein, das andere auf Erregung nach aussen gerichteter, den Hörstein umschliessender Hörzellen beruht und von welchen beide bei den Cycloneuren Verwerthung finden, das zweite aber, wenngleich in anderer Ansführmng, anch bei den Toponeuren angewendet ist; 3) dass bei beiden Typen dieselben Mittel, nur in rerschiedener Weise zum Aufban benützt sind; 4) dass trotz Ausschlusses jeder verwandtschaftlichen Beziehung nicht nur das eine unter den bei den Cycloneuren zur (ieltung gekommenen Principien, sondern dessen ganze Ansführung bei den Hörorganen höherer wirbelloser Thiere (Würmer und Mollusken) wiederkehrt.

Die letztere 'Thatsache ist von ganz besonderer Wichtigkeit: sie zeigt anf das Dentichste, dass durch Anpassung, in Folge der Beziehung der Organismen zu bestimmten Wirkungen der Aussenwelt, auch ohne jede un mittelbare BIutverwandtschaft ganz dieselben Formen entstehen können, meiner Ansicht nach nicht etwa desshalb, weil das dem thierischen Organismus mitgegebene Material wenig bildungsfähig wäre, aber allerdings desshalb, weil offenbar mit H ülfedieses Materials nuringeringer Tariation Einrichtungen geschaffen werden können, welche einerganzbestimmten und constanten äusseren Anfordernug alle a llf's Beste genügend sind. Diese Anffassung schliesst auch die Erklärung fïr die Thatsache ein, dass überall dieselben Mittel zum Aufban der Organe verwendet werden, nur in verschiedener Weise. Die percipirenden Zellen haben im einen Fille die umgekehrte Lage gegenüber lem Hörstein und gegenüber dem übertragenden Medium wie im auderen. Es bietet dieses Terhältniss ein Seitenstn̈ck zu der umgekehrten Lage der Retinaelemente im Auge der Cephalopoden mod der Wirbelthiere, ein Beispiel, dem nenerdings innerhalb des Molluskentypus selbst interessanter. Weise ein nenes hinzugefügt worden ist, in welchem jene Lage wiederum dieselbe ist wie bei den Wirbelthieren ${ }^{1}$ ). Wir haben somit a) Fälle zu verzeichnen, in welchen trotz des Mangels aller inmittelbaren verwandtschaftlichen Beziehungen Formähnlichkeit oder sogar Formgleichleit entstanden ist und b) Falle, in welchen unter derselben Voranssetzung ähnliche Formen, aber in anderer Zusammenfügung entstanden sind.

Die Anatomie der Sinnesorgane bietet nach beiden Richtungen zahłreiche Beispiele dar. Wiederholt treten in den höheren Gliedern von Thiergruppen nach demselben Typus gebaute höhere sinnesorgane auf wie in anderen, welche mit jenen in keiner unmittelbaren Blutsverwandtschaft stehen oder es treten solche auf, die mit

1) Semper, Ueber Schneckenaugen vom Wirbelthiertypus, Arch. f. mikr. Anat. XIV. Bd. 
demselben Material, aber in anderer Anordnung zusammengesetzt sind. Wie die Cycloneuren zeigen, kam in letzterem Falle die Blutsverwandtschaft sogar nüher liegen als in ersterem.

Es kann nicht meine Aufgabe sein. die Tragweite dieser Thatsachen hier ausführlich zu erörtern. Allein es ergibt sich ans ihnen zunächst so viel, dass häufiger als man allgemein beachten mag, aualoge Formähnlichkeit homologe Formbeziehungen nachahmen wird. Zwar werden bei complicirter gebanten Organismen die übrigen Organisationsverhältnisse und die Art der Entwicklung vor Irrthümern in phylogenetischer Verwerthung sofort bewahren, allein auf tieferer Stufe ler ontogenetischen wie der phylogenetischen Entwicklung wird die Gefaln des Irrthums eine viel grössere sein, denn je einfacher die Organisation, je gleichmässiger die änsseren Verhältnisse und je gleichmässiger die Bedürfuisse, um so ähnlicher verden Formen sein können, olme dass diese Aehnlichkeit auf unmittelbare Blutsverwandtsehaft schliessen lässt und eben wegen der Einfachlıeit der Organisation fehlt hier die Möglichkeit der Probe durch Tergleichen der Formbildung versehiedener Organe und vieltach auch die Möglichkeit der Probe durch die Entwicklung.

Andererseits, je bestimmter, schärfer und nachbaltiger und je weniger modificirt durch dritte Momente die Einwirkungen der Aussenwelt anf ein gegebenes Organisationsmaterial ausgeübt werden, um so ähnlicher werden die Formbildungen sein können, welche sie erzengen, selbst wemn die Blutsverwandtschaft dieses Materials keine unmittelbare ist.

Eine solehe Einwirkung ist gegeben in jenen bestimmten, unwanclelbaren physikalischen Einthüssen, welche eben die Entstehung der Sinnesorgane auf dem Boden gegebenen Bildungsmaterials und in Folge des nöthigenden Bedürfnisses der Aupassung bedingen. Die Macht der Anpassung tritt hier gegenüber der Vererbung in ansserordentlichem Maasse in den Vordergrund: so gewaltig die Wirkungen der ersteren schon da sind, wo die manchfaltigen kleineren Beziehnngen des Lebens der Einzelwesen untereinander wechselweise in Frage kommen, so sehr diese durch wiederholte Uebung formverändernd und durch lange Uebung in bedentendem Maasse umgestaltend wirken: die Eintlüsse, welche jeden Organismus anf Grund der Anforderungen seines Existenzbedürfnisses in erster Linie beherrschen, die physikalischen Einflüsse der Medien, in welehen er lebt, sie stellen einfache, aber durch keine Gegenanfordertug paralysirte, immer in derselhen Weise mächtig wirkende Kräfte dar, welchen gegenüber von Seiten jenes gegebenen Materials nur in beschannktem llaasse verschierlene formgestaltnngen angepasst sein kömnen. Und so muss trotz der unendlichen limohfaltigkeit im Einzelnen, im Kleinen eine gewisse lnifurmität im grossen (ianzen der Organisition besteheu, so 
können dieselben Schemata in der Gestaltung wiederholt auftreten, ohne dass unmitte]bare Blutsverwandtschaft irgendwie dabei im Spiele wäre. Da notlıwendig in der $0^{*}-$ ganisation der Sinnesorgane diese mächtige, andauernde Wirkung elementarer physikalischer Kräfte an meisten zum Ausdruck kommt, so kann es eine vergleichende Anatomie dieser Organe, welche wesentlich auf Vererbung gegründet ist, nur innerhalb meist engerer Grupen der Thiere geben und unter allen anderen sind gerade ihre Formähnlichkeiten an wenigsten für Feststellung phylogenetischer Beziehungen zu verwerthen.

XIV. Fassen wir schliesslich die wesentlichsten Charakterzüge des Nervensystems der Medusen zusammen, so ergibt sich, dass dasselbe bei beiden ilrer Abtheilungen eine blattförmige Ausbreitung zeigt, welche bei den Cyclonenren die vorvorzüglichste Concentration an ganzen Schirmrande, bei den Toponeuren an und in den Randlappen, einschliesslich der Randkörper. anfweist. Eine bedeutendere Entwickhung erfährt die Concentration anch bei jenen, entsprechend der Forderung des Experiments, in den radial gelegenen Theilen des Schirmrandes, welchen die Sinnesorgane aufsitzen. Bei Cyclonemren wie bei Toponemren ist die blattartige Ausbreitung des Nervensystems in grösserer Ausdehnung vorzüglich auf der Unterfläche des Schirmes ausgeprägt erhalten und seine Entstehung ist hier in cleutlichster Weise in Zusammenhang mit dem Epithel und mit der Muskulatur erfolgt. Bei den Toponemen durchsetzen die centralen Nervenzellen das Gallertgewebe im Schirmrande. Die sämmtlichen Einrichtungen des Nervensystems zeigen, dass cycloneure und toponeme Medusen ummittelbare Verwandtschaftsbeziehungen nicht haben. Die Art der Ausbildung der Nervenelemente zeigt weiter anf das Deutlichste, dass, trotz jener Durchsetzung der Randlapjen von Nervenzellen, das Nervensystem der I'oponemen weniger hoch entwickelt ist als das der Cyclonemen und dasselbe ist zu schliessen aus dem Umstande, dass es bei jenen viel bestimmter körperlich abgegrenzt ist als bei diesen. Näher als an die Cyclonemren schliessen sich die Toponenren in dieser Beziehung an die Ctenophoren an. Wie sehr die bei Beroë von mir beschriebene Einrichtung des centralen Nervensystems mit den bei den Toponeuren gewonnenen Resultaten übereinstimmt, braucht nicht weiter hervorgehoben zu werden, elsensowenig, wie sehr die Voraussetzungen, mit welchen ich die bei Beroë begonnenen Untersuchungen anf die Medusen ausdehnte, sich im Einzelnen erfüllt haben ${ }^{1}$ ). Der ganze aus dem Ekto-

1) Die neuesten Autoren auf dem Gebiete der Medusenliteratur, Hertwig, kommen hier zu ganz denselben Schlüssen in Beziehung auf die phylogenetische Auffassung des Nervensystems, welche jch schon aus meinen Beobachtungen an Beroë gezogen und auf Grund welcher ich die Untersuchung auch der Medusen in Angriff genommen habe. Statt dies anzuerkennen, halten sie es für nothwendig, sich in der auf Seite 93 bezeichneten Weise 
derm hervorgegangenen 'Theil des Körpers enthält bei Beroë Nervenzellen. Wie bei der Larve das äussere Kieimblatt oder bei den niedrigsten Zoophyten zeitlebens das Ektoderm das Nervensystem herstellt, so hier die gesammte Körperdecke. Ein streng abgesondertes, körperlich differenzirtes Gehirn ist now nicht vorhanden, allein in der Gegend des Afterpoles sammeln sich die Nervenzellen in grösserer Menge, hier bietet sich also der Beginn einer grösseren Centrilisation dar: ein gesonclertes Gehiru ist im Werden hegriffen, aber noch nicht als besonderes Organ körperlich differenzirt, von der Ungebung abgegreuzt. Wieser Beginn höherer Centralisation des Nervensystems fand, wie selbstverständlich, statt in der Nähe der Sinnesorgane und wir haben somit bei Berö̈ ganz dieselben Verhältnisse wie bei den Toponeuren: nur weil bei letzteren acht am Rande gelegene Sinnesorgane vorhauden sind, haben sich bei ihnen am Rande acht Centralapparate anszubilden begonnen, statt des einen am aboralen Förperende gelegenen von Beroë. „Es bildet“, so drückte ich mich in Beziehung anf die letztere aus, „dieses Centrahnervensystem noch nicht ein örtlich abgegrenztes Ganzes und zeigt nur den Beginu einer Lokalisirung, denn anch die übrige Haut ${ }^{1}$ ) dürfte an seinen Funktionen theilnehmen. Die Auffassung der Hant oder eines 'Theils derselben als Centrahnervensystem bei unseren niedrigstehenden Thieren kanu nicht nu nichts Ueberraschendes haben, dieselbe steht vielmehr, wie schon angedeutet worder ist, in hohem Grade in Uebereinstimmung mit der antogenetischen Begründung der Descendenzlehre. Wir können das äussere Keimblatt des Embryo der höheren 'Thiere als Neuroderma bezeichnen, indem wir es als

zu meinen Arbeiten zu stellen. Zur Andeutung der Art, in welcher dies geschicht. sei erwähnt, dass u. A. eme von mir zum Zweck dur Beschreibung beiläufig angewendete, in keiner Weise auf phylogenetische Auftassung bezügliche Vergleichung des Gallertgewebes mit der Cntis dazu benützt wird, um mir die Meinung unterzuschieben, es stamme jenes aus dem Mesoderm (Monogr. S. 159). So auf den Kopf gestellt, ist mein Crtheil in der Frage beseitigt. Da auch meine Experinente zum Nachweis des Nervensystems dro Medusen den Herren mehrere Jalire unbekannt bleiben. so ist meiue ganze Thätigkeit für sie ohne alle Bedeutung nnd sie dürfen, ohne Rücksicht anf dieselbe zu nehmen, als die $\curvearrowright$ Reflexionen ", welche sie selbständig anf das Thema geführt luben, ungehinuert dieselben Gesichtspunkte entwickeln, die ich rorher als die Resultate und die Ziele meiner Untersuchungen ausgesprochen hatte. Die Engenaugkeit, mit wekler Hertwig in ihrer Monographie wiederholt die Angaben Anderer behandeln, zielse ich gerne zur Erklärnng bei. Leider ist dies nicht iiberall möglich. In der Monographie der Medusen und in der folgenden Abbandlıng (der Organismus der Medusen und seine Stellung zur Keimblättertleorie) werden meine $\mathrm{v}$ o $\mathbf{r}$ den ihrigen veröftentlichten Nachrichten über das Nervensystem der Nedusen (einen Versuch der Umkehrung des Verhältnisses: Monogr. S. 160 weise ich zurück mit dem Bemerken, dass zur Zeit meines Vortrags in Mïnchen von bezüglichen Arbeiten Hertwig's Niemand etwas gewusst hat, wie denn deren vorlä ufige Mittheilung erst im November-Heft der Jenaer Zeitschrift elschienen ist trotzdem oder weil diese mit jenen in so bohem Grade zusammenfallen, vollkommen ignorirt, oder nur da angezogen, wo die Jenaer Antoren glauben mir einen hakel anhängen zu können. Dass solehes Verfahren mit der Wissenschaft nichts zu thun hat, dass das lgnoriren meiner Untersuchungen speciell in einem Buche, welches sich „Monographie des Nervensystems der Mledusen nennt, und besonders unter den gegebenen Umständen nur eine Deutang zulässt, ist klar.

I) Als Haut bezeichnete ich der Einfachbeit wegen die Körperbedeckung einschliesslich des äusseren, nervenreicheren Theils der Gallerte. 
Körperdecke und zugleich als ausschliessliches Nervensystem desselben betrachten. das Ektoderm sehr niedriger Thiere fungirt zeitlehens als Hant- nnd als Nervensystem, d. h. es wird änssere Eindräcke anfnehmen und zur Wirknng führen, ohne dass sich schon morphologisch erkennbare Nervenelemente ansgebildet hätten. Bei etwas höher stehenden Thieren hat diese Ausbildung stattgefunden. Fs hat sich jetzt eine Substanz in den Ektodermzellen morphologisch sichtbar gesondert, welche dazu bestimmt ist, äussere Reize aufunohmen und zn leiten. Erst anf einer noch höheren Stufe del Eutwicklung des 'Thierstammes beginnt eine specifische Ansbildung einer Anzahl von Elementen des Ektoderms, welche sich zum Zwecke gemeinsamer Aktion, zum Centralnervensystem verbinden und sammelv."

Bei Ctenophoren wie bei Medusen ist das Nervensystem somit nichts anderes als eine primitive Differenzirung des Ektoderms und seiner Abkömmlinge, nnd der Unterschied zwischen beiden besteht wesentlich nur in der Verschiedenleit der Stellen des Körpers, an welchen dieselbe am weitesten vorgeschritten ist. Ein wichtiger Unterschied im Nervensystem der Toponeuren und von Beroë scheint darauf zu beruhen, dass dort das Gallertgewebe auf das Reichlichste von Muskelfasern durchzogen wird, welche, soweit sie nach anssen, gegen die aborale Körperoberfläche ziehen, als Nenromuskelfasern in Nervenfäden übergehen und dureh diese mit, dem Epithel in Verbindung stehen. Man wird aber kaum voraussetzen dürfen, dass die Anlage des Gallertgewebes von Beroë gegenüber jener der Hedusen eine so durchans verschiedene sei, dass der Unterschied nicht wesentlich anf die Thätigkeit des Organismus zurückzuführen sein möchte, welche in dem einen Falle deutlich Einrichtnngen zur Ausbildung gebracht habe, die im anderen in der Anlage vorhanden sind. In der That bieten sich, wie erwähnt, bei Beroë vollkommene Uebergänge zwischen Bindegewebe und Muskelgewebe dar und ist das letztere innerhalb der Gallerte wesentlich nach denjenigen Richtungen entwickelt, nach welchen hin vorzüglich Contractionen des Körpers stattfinden wüssen. Somit dürfte zu vermuthen sein, dass die Ctenophoren in Beziehung auf die Znsammensetzung der Gallerte ein Bild liefern, welches nichts anderes darstellt, als eine höhere Entwicklung des Banes, welcher auch bei den Toponeuren in der Anlage vorhanden sein wird. $\mathrm{Ob}$ und wie weit die in die Nenromnskelfasern von Beroë eingeschalteten allerdings sehr unscheinbaren Nervenzellen wiederum untereinander oder mit anderen durch Nervenfäden verbunden seien, in welchem Grade ihre Funktion als rein reflektorische zu betrachten sei, habe ich morphologiseh nicht genügend entschieden. Die ausserdem in der Gallerte vorhandenen Nervenzellen deuten anf centrale Thätigkeit auch in diesen Theilen hin; indessen glaubte ich auf Grund meiner Befunde annehmen zu dürfen, dass, je weiter ab vom C'entralorgan, 


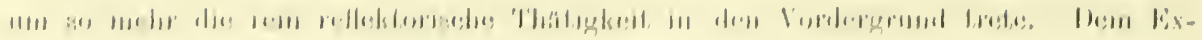

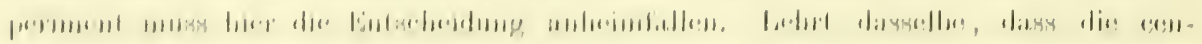

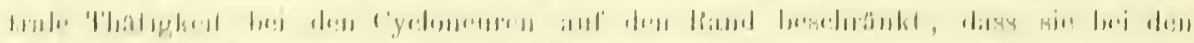

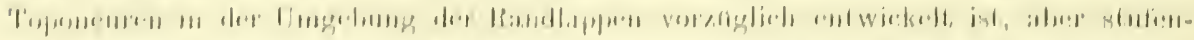

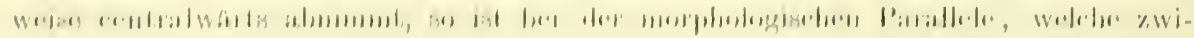

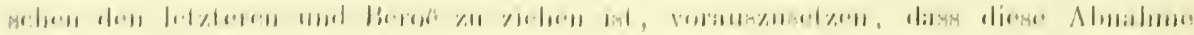

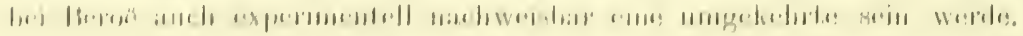

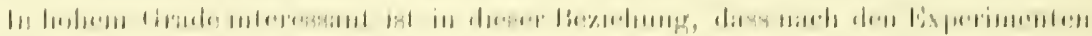

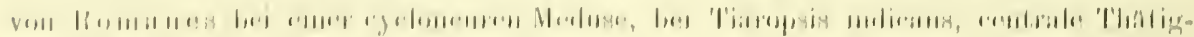

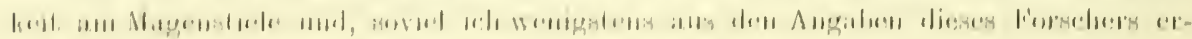

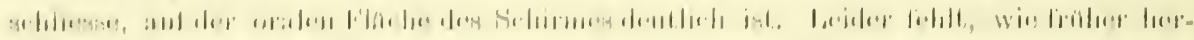

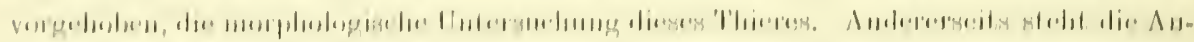

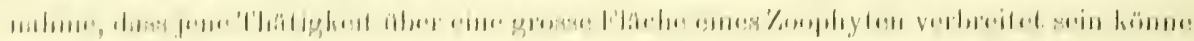

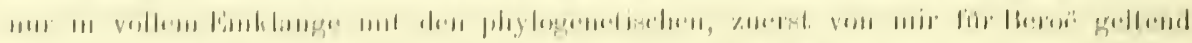

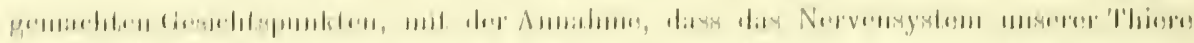

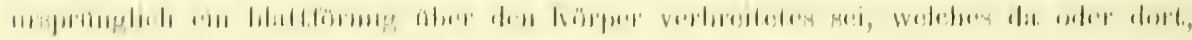

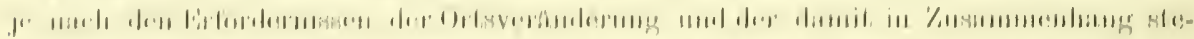

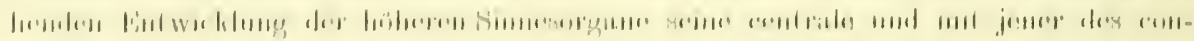

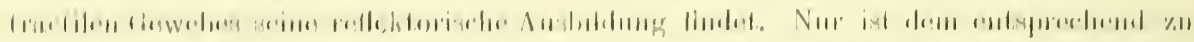

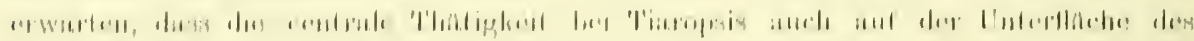

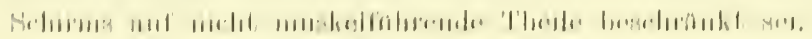

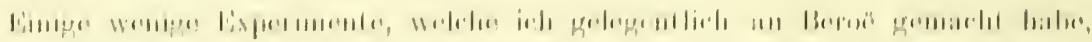

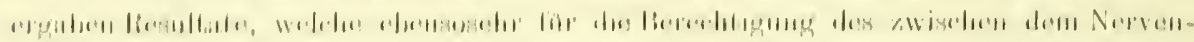

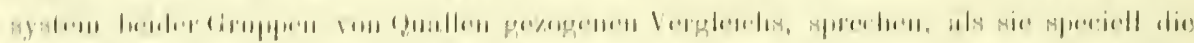

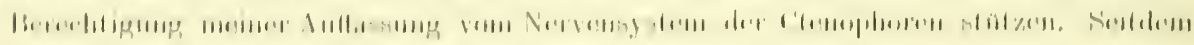

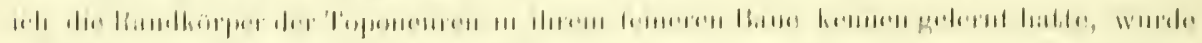

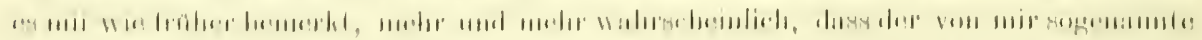

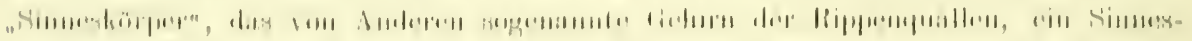

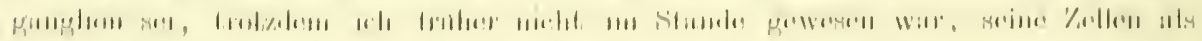

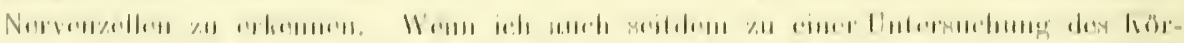

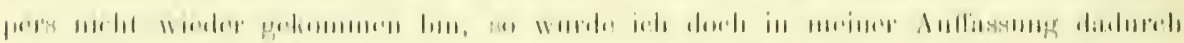

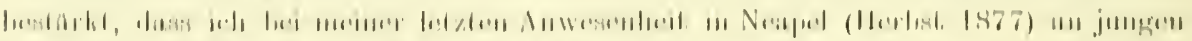

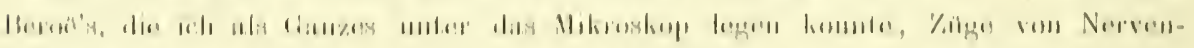

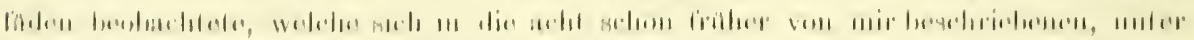

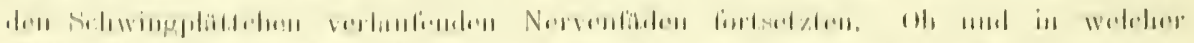

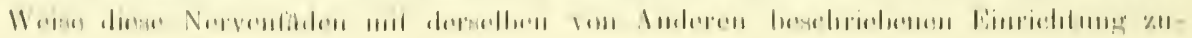


sammenzustellen seien und in wolcher Beziehung sie \%n den Nervenzellen dus (iallertgewebes insbesondere am Mlterpole stehen, werde ich bei nachster tielegenlacif za mëten haben. Dass aber die liewegnngen der Schwingplättchen von den Ninnesganglion nichl abhängig sind, sondern von den Nervenzellen des Gallerigewehnes, haben mir einige gelegentliche tixperimente anf dis Dentlichste gezeigh: schnitt ich cine Beroë in ihrer hallen Höhe quev dureh, so hörten die liewegungen der Selnwing-

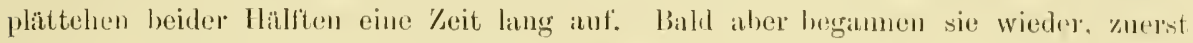
und weit lebhafter mul von vomberein regehmässiger an der oberen, damm aber ameh der muteren: hier anlangs muregelmässig, wenig coordinirt, aber bald leugrelmässig mol rasch wie dort. Mnrehschnitt ich die obere Hälite abermals qure dureh, so crgaben sieh dieselhen lischeinungen, wieder nit demselhen hozïglichen Unterschied in den beiden Theilstücken: das untere erholte sich später als das obere. Hin sehüler von mir, Herr ketzer, hat kïrzlich in Neapel diene lixperimente mit demselhen Ertolge hergestellt. Leh selbst holle bahl in der latge zu scin, ansgerlehntere Versuche an Kippenquallen anstellen zu könmen, lïge indessen hier noch an, datss anch die Art des Ahsterbens von Beroë vollkommen mit dem liär. Amelia amrita beschriebenen Vorgange übereinstimmt, indem dasselbe am oralen Ende dos Körpers loginnt und gegen dats Centralnervensystem hin fortsehreitet.

Gibt es nach meinen Erlahrungen wohl kaum irgend ein histologisches ()h)jekt, welches höhere Anforderungen an den Untersncher stellt, als die wenigg dillierenzirten Gewebe der toponenren Medusen und der lippenquallen, so ist es Genugthumng für die morphologische Arbeit anl diesem debicte, wemn einlaches mm derlem zugängliches Experiment ihre Ergehnisse zu erproben vermag. 


\section{Berichtigungen.}

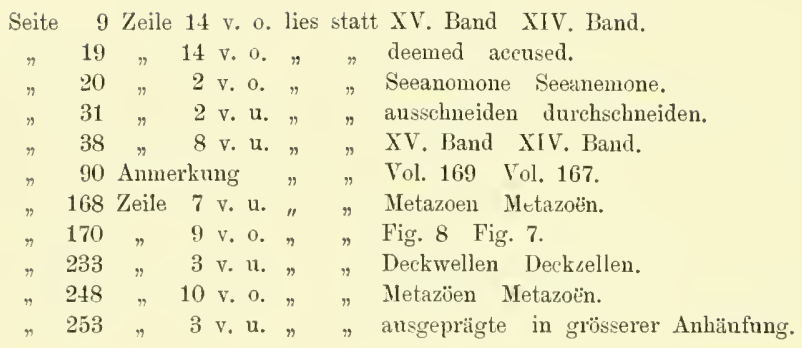





\section{Tafiel I.}

Sämmtliche Figuren mit Ausnahme ron 5 und 11 sind von A urejia aurita, 5 und 11 von Cyanea c apillata.

Allgemeine Bezeichnungen.

Ek Nervenzel]ensehicht.

N Nervenfilzschicht.

S Stïtzblatt.

En Eutoderm.
$P$ änsserer Pigmentfleck.

p imnerer Pigmentfleck.

Rig änssere Riechgrube.

H Hörner (Hörgefässe oder Ampullen).

Fig. 1. Der landkörper mit angrenzendem Schirmrandtheil in der aboralen Ansicht; von der Gegend der Wurzel bei $\mathrm{L}$ an aufwärts tiefe Einstellung, so dass das querverlaufende Wurzelrohr L im Querdurchschnitt zu sehen ist: gr Elstolermauskleidung der Tasche, in welcher der Randkörper liegt, g Lrsprung der Hörner aus dem Randkörperrohr. In Folge der tiefen Einstellung sind auch die Riechkappen gr’ lurch die Gefässe hindurch deutlich sichtbar. Vergr. 70.

Fig. 2. Aenssere Ansicht eines Randlappens mit dem Simnespolster P: in der Hitte desselben sieht man die Hörner $\mathrm{H}$ durchscheinen; weiter unten die äussere Riechgrube, durch deren Boden der Randkörper Rk sichtbar ist, I die Fortsätze der Randlappen (Ohrlappen). Vergr. 20.

Fig. 3. Optischer Querdurchschnitt der Hörner und des Kandkörpers, um deren Zusammenhang zu zeigen, in der oralen Ansicht: gr Ektodermanskleidung der Randkörpertasche, x Ektoderm, $x^{\prime}$ Entoderm.

Fig. 4. Seitenansicht eines Randkörpers.

Fig. 5. Randlappen von Cyanea capillata: R Röhrchen (Raudliörperrohr), welchem der Randkörper ansitzt (verg]. R und Rik Taf. II. Fig. T); d der untere Rand des den Randkörper deckenden Dächleins, f die denselben ron hinten deckenden Fallthüren; gr die den Riechkappen ensprechenden Gruluen; H Gefässtaschen entsprechend den Hörnern; L unterer Rand der Randlappen. Vergr. 2.

Fig. 6. Der Theil unterhalb o in Fig. 9. vergrössert. Vergl. diese Fignr.

Fig. 7. Unterer Abschnitt eines Randkörpers in seitlicher Ausicht (Optischer Längsschnitt): x Entodermüberzng des Krystallsäckchens nach oben.

Fig. 8. Dieselbe Ansicht wie in der vorigen Figur, aber bei Einstellung auf die Oberfläche. Im Stïtzblatte sieht man in diesem Präparat amöboide Zellen.

Fig. 9. Ansicht wie in Fig. 3, jedoch hei etwas höherer Einstellnng: I Verbindungsrolır zum Randkörper, welches in der Gegent von $\mathrm{L}$ horizontalen Verlanf nimmt (vergl. Fig. 1, 4, 6 und den Text).

Fig. 10, Theil des Ramilapnens von aussen in einem Noment, wo die Riechgrube nach abwärts gezogen ist.

Fig. 11. Stiick der Unterfläche von Cyanea capillata: r und l kreisförmig und radial verlaufende Muskelı, x Andeutung der Fangfüden. Natürliche Grösse. 


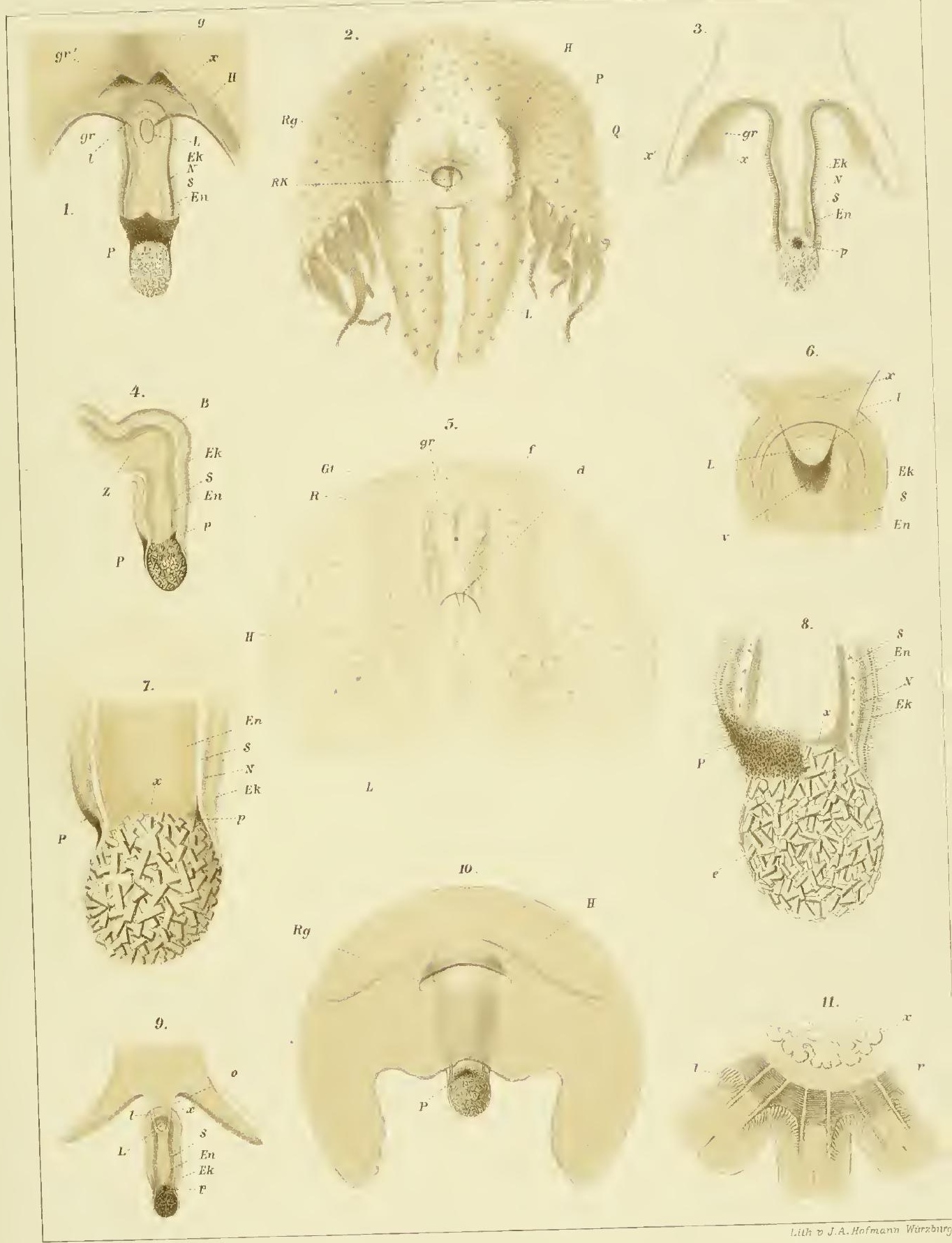






\section{Tafel II.}

Fig. 1, 2, 3 von lihizostoma Cuvieri, 4, 6, 8, 9 von A urelia aurita und 5 und 7 von Cyanea capillata.

Allgemeine Bezeichnungen.

D Decklappen.

Rg äussere Riechgrube.

Rk Randköıprer.
1 Schicht der Geisselzellen und Sehspindeln.

2 Nervenfilzschicht.

3 Stützblatt.

4 Entoderm des Randkörpers. Randkörpers.

Fig. 1 und 2. Rarliale Durchschnitte dureh den liandkörper und Umgebung, Fig. 1 stärker vergrössert als 2; bei $\mathrm{x}$ in Fig. 1 und der entsprechenden Stelle in Fig. 2 ist das Ektodermepithel da, wo es in die Riechtasche ibergeht, abgerissen; Rg in Fig. 2 bedeutet den hinteren Abschnitt der Randkörpertasche.

Fig. 3. Lin Ausschnitt des Schirmrandes mit dem Sinnespolster, welehes die äussere Riechgrube Rg trägt, unter derselben scheinen die Hörner und der liandkörper durch, der letatere ist bedeckt von dem Dächlein d; i Einschnitt zwischen den zwei Ohrlappen.

Fig. 4. Querdurehschnitt durch den Schirmrand in der Gegend des unteren Abschnittes der Riechgrube, oberhalb des Raudkörners, weleher im Präparate der äusseren Wand o der liechtasche noch anhängt; q Terbindungsblatt zwischen der Riechtasche und dem Ringgefäss b, welches an dieser Stelle im Schirmrande einen bogenförmigen Verlauf nimmt (vergl. Holzschnitt 19 und 20) und daher im Präparat zweimal im Querschnitt getroffen ist, ebenso wie die Hörner. ' $\mathfrak{I}^{\prime}$ Verloindungsblatt, welches vom Ringgefüss alggeht. Vergr. ctwa 30.

Fig. 5. Durchschnitt durch den aboralen Theil der Kuppe ron Cyanea capillata: e Epithel, z. Gallertgewebe mit untereinander maschenartig verbundenen Bindegewebsfasern, b Gallertschicht, welche von solchen Fasern frei ist. Tergr. 250.

Fig. 6. Ein Strick eines Durchschnittes ähnlich demjenigen der Fig. 4: man sieht darin kettenartig verbundene Zellen angerlentet. Vergr. 80.

Fig. 7 . Ralialer Durchsehnitt durch den Randkörper und UTmgelıng von Cyanea capillata: s wassersackartige Verlängrerung des Randkörperrohres.

Fig. 8. q ein Theil des Verbindungsblattes q der Fig. 4, wie es sich in der Gegend von w dieser Figur an die Auskleidung der Randkörpertasche (w) ansetzt; z zapfenartig frei endigende Zellwucherungen des Verbindungsblattes. Vergr. 250.

Fig. 9. Ein Strick des Schirmrandes in der Gegend eines durchschnittenen Gefässes g, um die Beziehungen des Verbindungsblattes q zur Entodermauskleidung dieses Gefässes nu zeigen, m Subumbrella. Die starke Punktirung unterhalb von g deutet einen grossen Reichthum von dort gelegenen Zellen an. Lupenvergrösserung. 

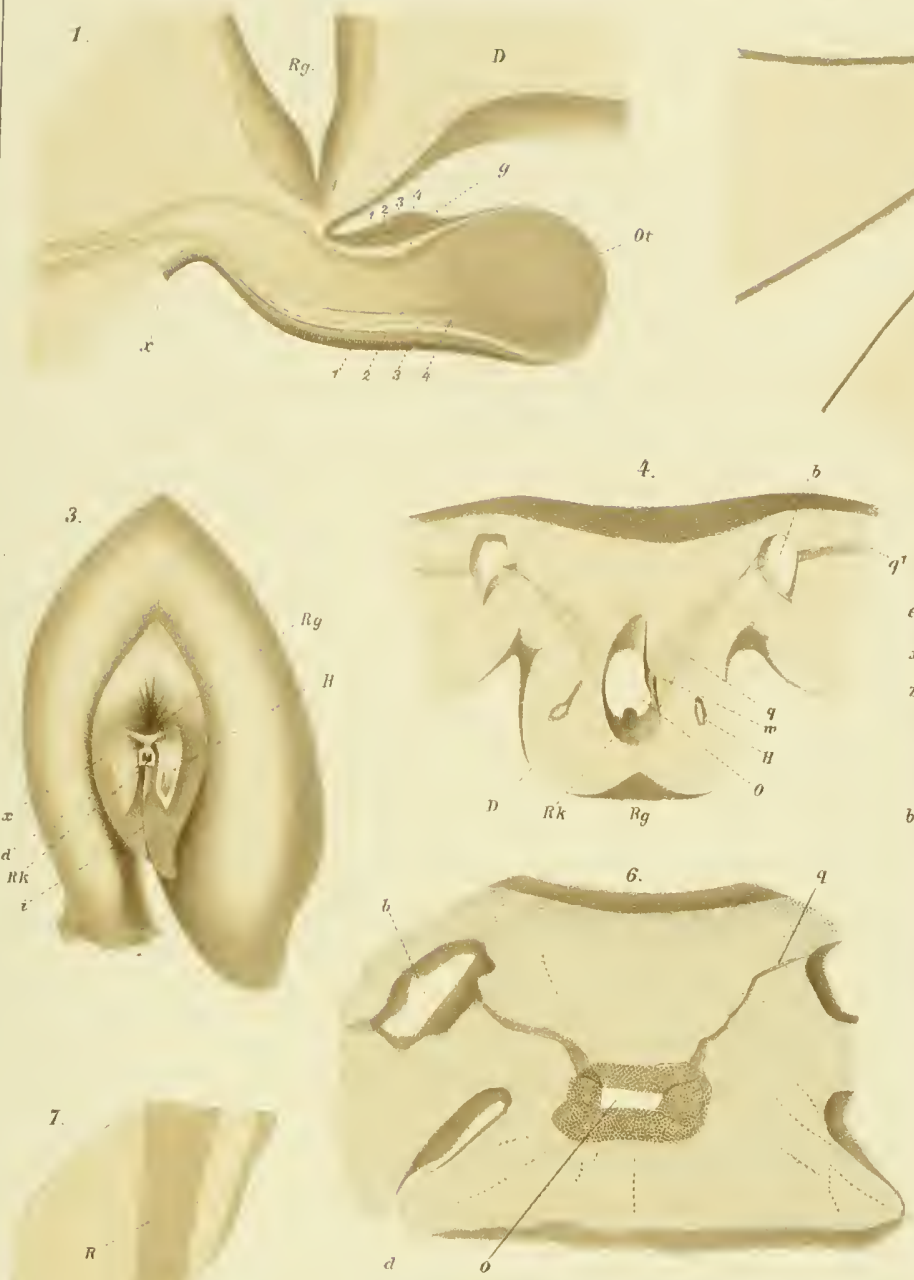

8.

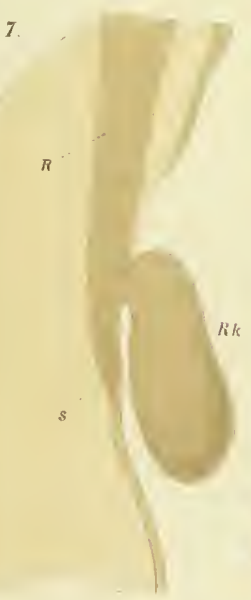

3.

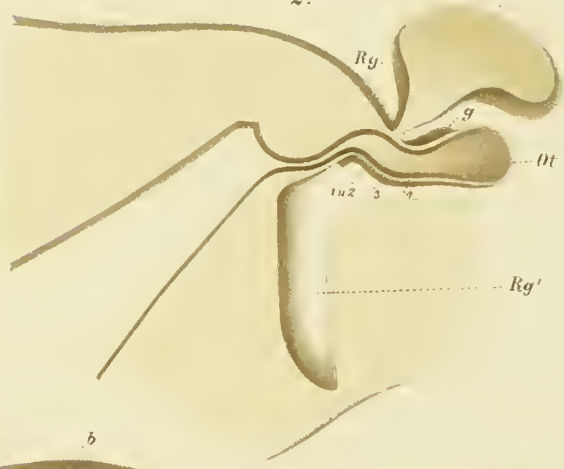

5

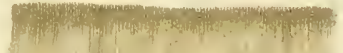

x....

$\mathrm{z}$

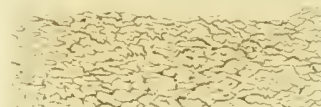

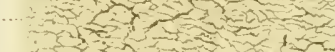

$=x^{2}-2+3 x+2<$

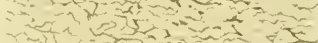

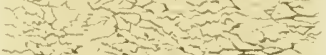

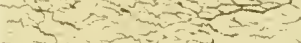

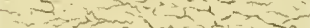

$\Rightarrow+3-39=2 x^{2}=$

$x=x+\frac{1}{2}=2$

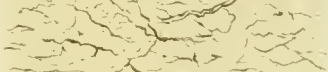

$\pi$ r

$=3 x+2$

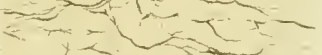

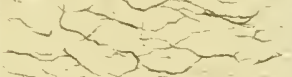

$+\frac{7}{3-3-2}+1$

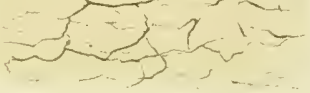

$q$

9.

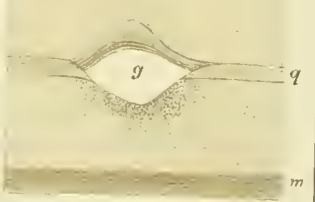





\section{Tafel III.}

Fig. I bis 13 von Pelagia noetiluea, 14 bis 22 von Aurelia aurita.

Allgemeine Bezeichnungen.

Ek Nervenzellenschicht.

is Stützblatt.

N Nervenfilzschicht.

En Entoderm.

Fig. I. Rarlialer Durchschnitt durch ıen Randkörper nnd ein Stïck des Schirmrandes, stark vergrössert: das Entoderm ist aus dem durchschnittenen, zum liandkörper hinzutretenden Gefässrohr theihweise herausgefallen, bei $\mathrm{x}$ ist ein isolirtes Stück desselben liängen geblieben; $\mathrm{y}$ Wassersackartige Fortsetzung des genaunten Gefässrohres.

Fig. 2. Randlïrper von ler aboralen Fläche gesehen, stark vergrössert: das Epithel oben etwas abgehoben und abgerissen; die Hörkrystalle aufgelöst, das Pigment ungleichnässig zerstrent (Chromkalipräparat).

Fig. 3. Oberer Theil des landkörpers, an welchem man die einzelnen Lagen der Waud iur optischen Durchsehnitte sieht.

Fig. 4. Seitenausicht des Randkörpers nach Entfernen des Ektodermepithels. y wie iu Fig. I. $\mathrm{x}$ ein Fetzen des Ektodermepithels ron der dem Randkörper benachbarten Wand der Randkörpertasche losgelöst.

Fig. 5. Neuromuskelzelle mit drei eigenthümlich gläzzenden Körpern als Inlualt.

Fig. f. Nervenepithel des Randkörpers aus der Gegend des Beginns des Hörsäekchens, um die zahlreichen Fädchen der Nervenfilzschicht zu zeigen : s Sehspindeln im optischen Querschnitt.

Fig. 7. Nervenzelle rom Randkörper.

Fig. 8. Randkörper in der oralen Ansicht: $y$ entspricht $y$ in Fig. 1 und 4.

Fig. 9. Optischer Querschnitt von Nervenzellen des Randlörpers: s entspricht dem Durchschnitt von sehr grossen Spindeln.

Fig. 10. Nervenepithel vom Randkörper: s Spindeln.

Fig. 11. Nervenepithel vom obersten Theil fles Hörsäckchens: a Präjarat von unten gesehen, b eine einzelue Zelle von der Seite.

Fig. 12. Neuromuskelzellen in der einen Zelle zwei eigenthümlich glänzende Körper (vrgl. Fig. 5).

Fig. 13. Ein Stiick des Muskelfarlens sehr stark vergrüssert (2000 mal).

Fig. 11-18. Subumbrellaelemente ans len Randtheile von Amrelia aurita, der Abschnitt e ist zu einer wie elastisch aussehenden Haut umgewandelt.

Fig. 19. Ektodermzellen nach Zusatz vou tioldlösung, vergh, den Text.

Fig. 20 unı 21. Hörzellen mit Hörkrystallen, Fig. 20 nach kurzer Einwirkung von Essigsäure.

Fig. 22. a, b, c Hörzellen bezw. Krystalle nach Zusatz von Essigsäure in Auflösung hegriffen. Vergrösserung für 20: 21, 22, 460, für alle übrigen histologischen Figuren etwa 1000. 


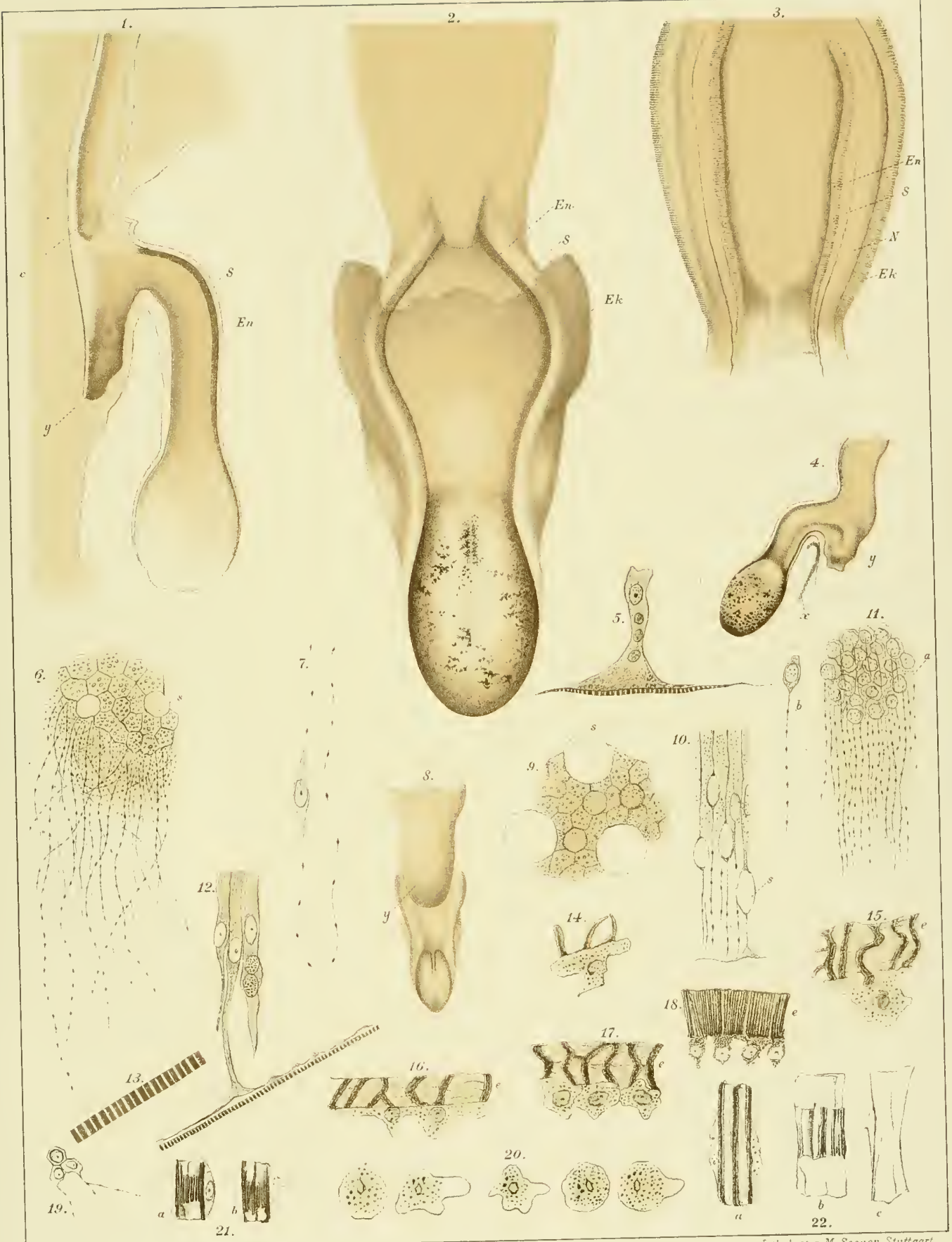





\section{Tafel IV.}

Die Abbildungeu sind von Aurelia anrita, Cyanea capillata und Rhizostoma Curieri.

Fig. 1, 3, 4, 6, 7, 14, 16, 18. Isolirte Nervenepithelien aus dem Randkörperstiel von Aurelia aurita.

Fig. 2. Durchschuitt dureh das Randkörperepithel (e) sammt Nervenfilzschicht (n) ron Aurelia aurita.

Fig. 5 und 11. Epithelien von der aboralen Fläche des unteres Randes der Raudlappen von Cyanea capillata: Fig. 11 im optischen Querschnitt.

Fig. 8. Nerrenepithel (e) mit Nervenfilzschicht (u) ans der Riechgrube rou Rhizostoma Cuvieri.

Fig. 9. Epithelzelle von der oralen Fläche des Randlappens von Cyanea capillata in der Gegend des obern Endes des Randkörperröhrehens. Beginn der Utmwandlung des Nervenepithels in Neuromuskelepithel.

Fig. 10. Nervenzelle aus der Subumbrella von Cyanea capillata.

Fig. 12. Epithel aus dem oberen Theil der Randkörpertasche ron Cyanea eapillata.

Fig. 13. Nerrenepithelien aus dem äusseru Pigmentfleck von Aurelia aurita: die dunklen Pünktchen im obers Theil der Geisselzellen sind Pigmentkörnchen, ebenso die Körnchen in den in Fig. 14 gezeichneten Zelleu.

Fig. 15. Ein Theil des Stïtzblattes (S) des Randkörperstieles von Aurelia aurita mit demselben aufliegenclen Nerrenzellen $(\mathrm{g})$ : im Bezirk $\mathrm{c}$ ist das Epithel weggenommen, nach oben ist es erhalten: e Epithelzellen bei Einstellung auf die Kerne, n Nervenfilzschicht.

Fig. 17. Ein Stück des Stützblattes des Raudkörperstiels von Aurelia aurita mit aufliegenden Nervenzellen (g): bei o beginnt das Epithel des Hörsäckchens; S optischer Querschnitt der sich umbiegenden Stützlamelle. Vergr. etwa 200.

Fig. 19 und 23. Epithel rou der oralen Fläche der die Randkürpertasche deckenden » Fallthïren « von Cyanea capillata, Fig. 23 im optischen Querschnitt.

Fig. 20. Stiitzblatt des Randlörperstiels von Aurelia aurita mit Nervenzelleu (gr); S wie in Fig. 17. Tergr. 500.

Fig. 21 a, b. Epithelzellen aus $d+m$ oberen Theil der Riechfurche ron Cyanea capillata, $\boldsymbol{c}$ von der aboralen Fläche des Liandlappeus, seitlich ron der Riechfurche.

Fig. 22. Nervenfüden aus der Subumbrella von Cyanea capillata.

Fig. 24, 25. Nervenzellen vom Randkörperstiel von Aurelia aurita. Fig. 24 Vergr. 1000. Fig. 25. 2000.

Alle äbrigen Figuren haben eine Vergrösserung von 1000. 
'Tut.II'

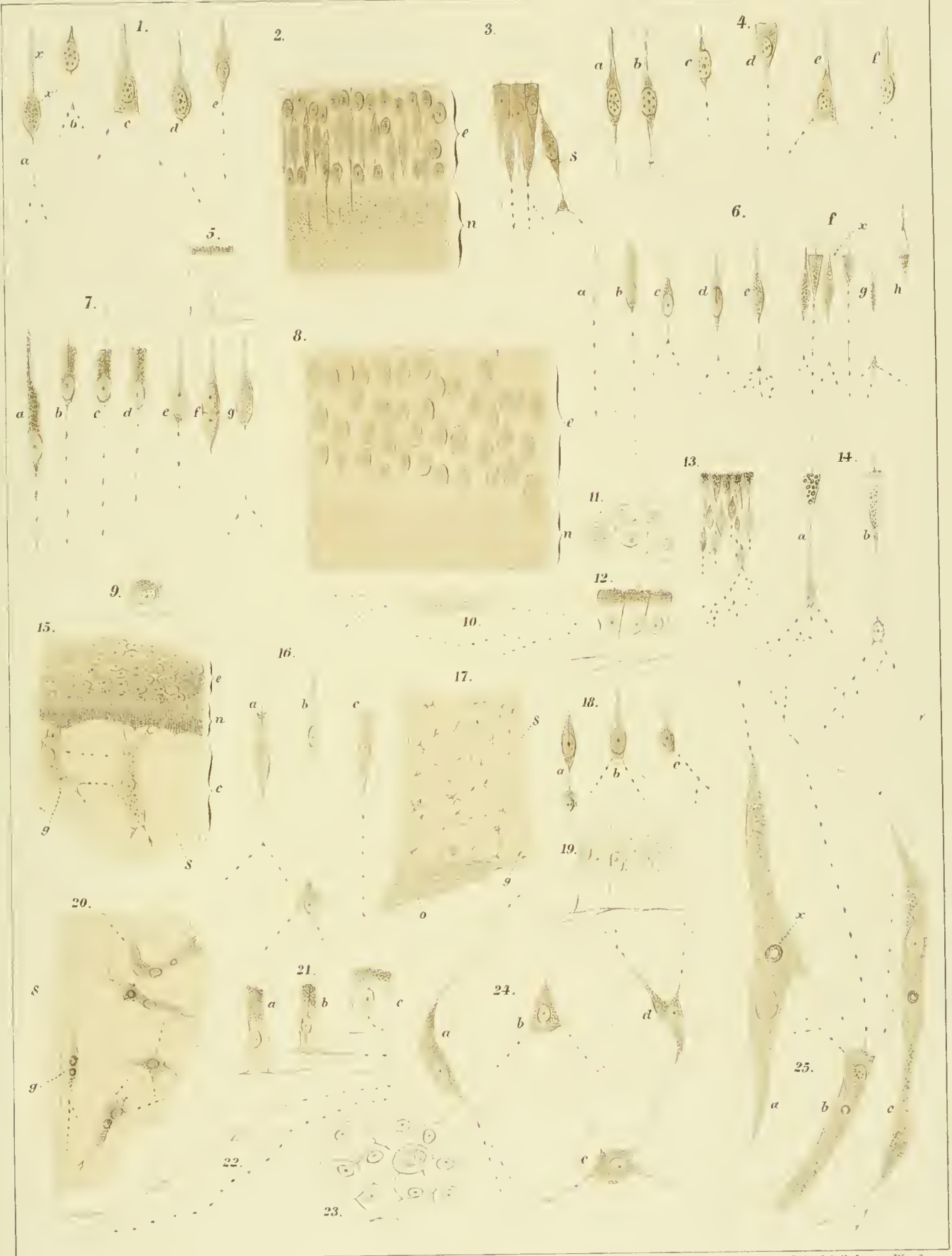






\section{Tafel V.}

Fig. 1, 2, 3 von Aurelia a urita, 4, 5, 9, 10 von Cassiopeaborbonica, 6, 7, 8 von Cyanea c apillat a.

Allgemeine Bezeichnungen.

lik Raudkörper.

1) Decklappen.
$\mathrm{Rg}$ änssere liechgrube.

Rit Riechtasche.

Fig. 1. Radialer Durchschnitt dureh den Schirmrand von Aurelia anrita mit Durchschueiduns les Randkörpers: gr Riechkappe, Hr Hanptradiürgefäss, H Horn (Hörgefïss oder Ampulle), r Ringžefäss.

Fig. 2. Ttärkere Vergrösserung der Stelle $\mathrm{x}$ Fig. 1. Vergr. 200.

Fig. 3. Stärkere Vergrösserung der Stelle y Fig. 1: bei a plasmatische Fasern, bei b und c feine nicht plasmatische Fasern. Tergr. 200.

Fig. 1. Durchsehnitt durch den Rand ron Cassiopea borbonica, die äussere hiechgrube ist seitlich getroffen. Il Muskelschicht, K orales Ganglion.

Fig. 5. Schnitt nahe der Stelle K der Fig. 4 stärlker vergrössert. Bezeichnung wie dort. I Nervenzellen, f' seine Fäden.

Fig. 6. Rantlappen von Cyanea capillata, orale Ansicht. Die im oberen Abschnitte des Lappens begimende Musknlatm ist weggelassen: rergl. đlazu Taf. 1. Fig. 11. Ii Randkörperrohr, nach unten den Ranikörper tragend; $\mathrm{F}$ heide Fallthüren etwas auseinandergezogen; 1 der freie Fand des Dächleins, welches abolal den Randlörper deckt.

Fig. 7. Stitck des Randlappens von Cyanea capillata. Bezeichnung wie in der vorigen Figur. Die Fallthïren in natiirlicher Lage.

F̈̈g. \&. Randkörperlappen von Cyanea carillata von oben gresehen, um die Riechfurche $\operatorname{Rg} z u$ zeigen; ïhrige Bezeichnung wie in Fig. 6. Man sieht Randkörper und Fallthüren durch den Boden der Riechfurche hindurch.

Fig. 9. Schirmrand ron Cassiopea borbonica ron der oralen Seite, um das linöpfthen (orales (ranglion) $\mathrm{K}$ zu zeigen, ron welchen die Muskelzïge radiür ausstrahlen.

Fig. 10. Querschnitt durch einen der »Ohrlappen« (p), in welche sich der Decklappen des Sinnespolsters von Cassiopea borbonica fortsetzt und dureh den damit in Verlindung stehenden Theil des Schirmandes (B). II Sulumbrella; $\mathrm{x}, \mathrm{x}^{\prime}, \mathrm{x}^{\prime \prime}$ Verbindnngsbläter. B Bindegewebsfasern. Der Durchschnitt ist etwa in der (iegend ron i Taf. II. Fig. 3 (Rhizostoma) quer durchgeführt zu denken. Vergr. 60. 
Taf.I:

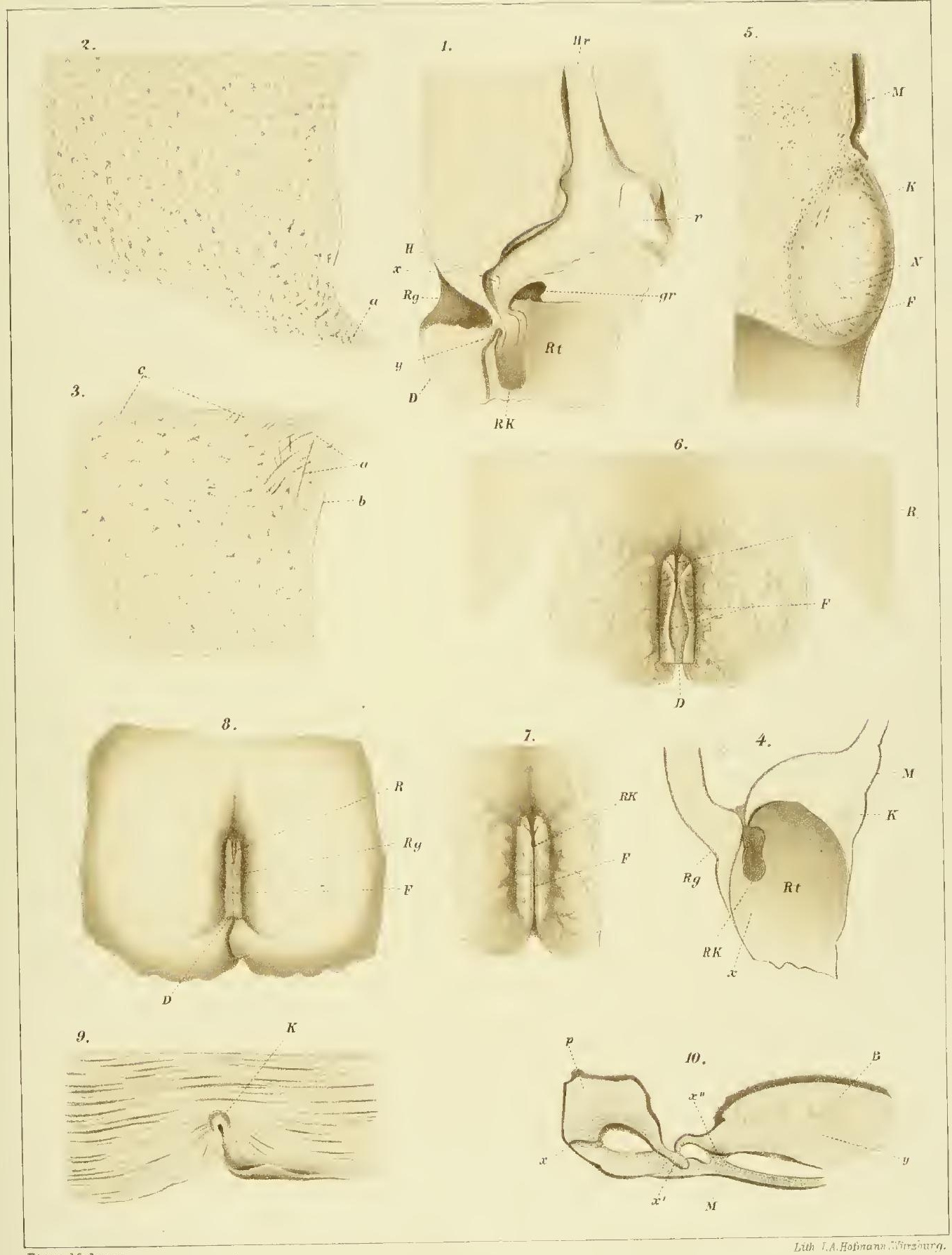





\section{Tafel VI.}

Fig. 1 von $\mathrm{Cyanea}$ capillata, 2 md 3 von Cassiopeaborbonica, 4 bis 7 Rbizostoma Cuvieri.

Allgemeine Bezeichnungen.

Rg äussere Riechgrube.

Rk Randkörper.

D Decklappen. q Verbindungsbänder.

lit Randkörpertasehe (Riechtasche).

Fig. 1. Querschnitt durch den Raudlappen von Cyanea capillata etwas unterhalb von R Taf. I. Fig. 5, unmittelbar oberhalb des Abgangs des Randkörpers vom Randkörperrohr (vergl. Taf. II. Fig. 7. R). Das Randkörperrohr (R) ist quer durchschnitteu, ebenso die Fallthüren (F) und die den Hörnern entsprechenden Gefässtaschen $(H)$, von welchen nur der innere Theil sichtbar ist (vergl. Taf. I. Fig. 5); besonders bei x Wucherungen der Ektodermepithelien in das Gallertgewebe hinein, von welehen Fäden abgehen (vergl, den Text).

Fig. 2. Ansicht des Gallertgewebes von Cassiopea borbonica ans dem Schirmrande entsprechend der Stelle, welche in Fig. 10. Taf. V. mit y bezeichnet ist; b Bindegewebe. Vergr. 200.

Fig. 3. Durchschnitt der Wand der Randkörpertasehe von Cassiopea borbonica aus der Gegend von $\mathrm{x}$ Fig. 4. Taf. V. Die Ansicht ist so, dass die Epithelialwand auf der dem Beschauer entgegengesetzten Seite gelegen ist; sie liegt an der dinnsten Stelle des Schnittes bei y frei, bei z scheint sie durch das dem Beschauer zugekehrte Gallertgewebe durch. Vergr. 200.

Fig. 4-7. Querschnitte dmreh das Sinnespolster von lihizostoma Cuvieri ans einer successiven Reihe von 14 Schnitten: Fig. 4 entpricht einem der obersten Schnitte, Fig. 5 dem 11 ten von unteu gerechnet, Fig. fi dem 10ten, Fig. 7 dem sten. Die Pünktehen entsprechen Nerrenzellen, $z$ in Fig. 4 dentet Bindegewebselemente an (vergl. z Fig. 1); Rt in Fig. 5 ist der oberste Theil (Fundus) der Randkörpertasche mit Epithelialauskleidung; in Fig. 7 ist der Randkörper (Rk) der Randkörpertasche anhängend querdurchschnitten. Die Qnerdurchschnitte mit Ausnahme ron Fig. 1 sind 12 mal vergrössert, Fig. 1 stärker. 
1.

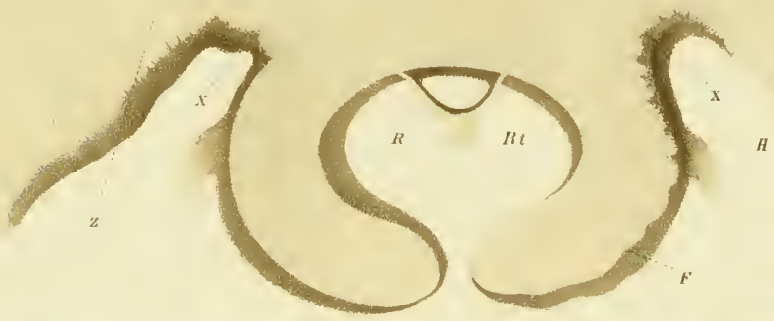

i

2.

b
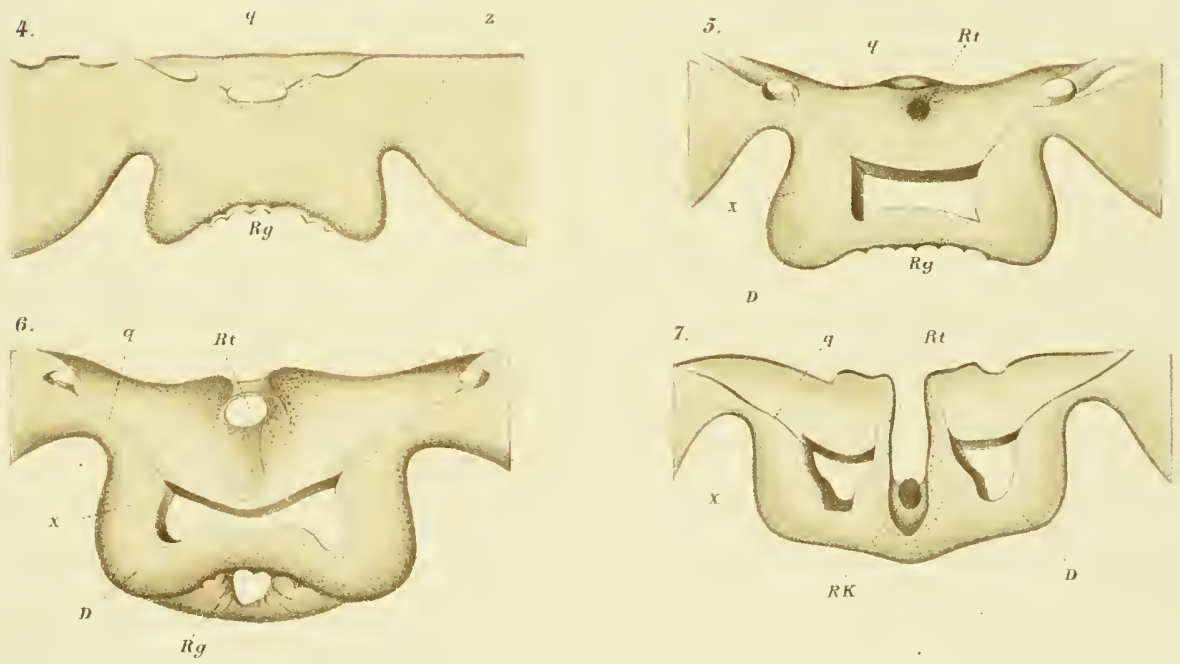
1 


\section{Tafel VII.}

Die Abbildungen betreffen Carmarina hastata.

Allgemeine Bezeichnungen.

R Schirmrandring.

$\mathrm{Hb]}$ Hörbläschen. $\checkmark$ Velum.

L Leiste des Gallertwand des Schirmandringes.

Fig. 1. Ein Stiick des Schirmrandes (aborale Ansicht) mit einem Abschnitt des Schirmrandringes, an welchem nach unten der obere Theil eines Tentakels (Tt) zu sehen ist, während obeu der untere Theil des entsprechenden radialen Muskelzugs ( $\mathrm{H}$ a e ckel's sogenannter Radialnerv), der Subumbrella zugehörig, durch die Umbrellar hindurch sichthar ist (Rm). Am unteren Rand des Schirmrandringes wird der hiugnerv (N) sichtbar, indem das diuriberliegende Epithel dort etwas entfernt ist. Oberhalb des Schirmrandringes liegt in der linken Hälfte der Zeichnung ein Hörbläschen. Darïber läuft vom Schirmundringe ausgehend, dicht unter den nicht sichtbaren Ektodermzellen, das Spangenganglion $(\mathrm{Sp})$.

Fig. 2. Ein Stïck des Schirmrandes (orale Ansicht) mit jenem Abschnitte des Schirmrandringes (R), welchem das 1Jörbläschen aufsitzt. Das Epithel des Schirmrandringes ist weggepinselt, ebenso die denselben erfülleuden Zellen, sammt dem Ringnerven, welcher bei $\mathrm{N}$ gelegen hatte, entfernt. Man sieht an der oralen Fläche der Gallertwand des Schirmrandringes die Leiste (L) und zahlreiche warzenartige Hervorragungen (w). Im Hörbläschen sieht man die zwei Hörnerven (Hn), welche im Bogen nach oben verlaufen nud an die hintere Wand des durchschimmernden Otholithensäckchens treten, um in den Hörzellen $(\mathrm{Hz})$ zu endigen; der Hörstein $(\mathrm{O} t)$ durchschimmernd. Das Hörbläschen deckt den unteren Theil des Zuges der Spangenganglienzellen (Sp), bei n Andeutungen der dieselben begleitenden Faserung; y obere, é untere Grenze der Stätzwand des Schirmrundriuges; bei $e^{\prime}$ noch lieste nach dem Abpinseln sitzien gebliebenen Epithels. Vergr. 70.

Fig. :3. Ein Stück des Schirmrandringes (li) (z Nesselzellen) mit dem Rarlialganglion (Gg), durch welches das Hörbläschen durehschimmert. Vom Radialganglion geht ein Zellenstrang, das Spangenganglion, nach aufwärts, nm welchen herum imnere dichtere (n) und äussere weuiger dichte Faserung. n entspricht wohl der Grenze der durchscheinenden, das Spangenganglion umgebenden Scheide. Oberlalb $\mathrm{x}$ ist das Deckepithel, welches sich bei Gg zur Ueberkleidung des Hörb]äschens verbreitert, weggenommen. Fïr Sp vergl. den 'Text S. 217.

Fig. 4. Ein Striek des Zuges der Spangenganglienzellen, welche Fortsätze (f) an die Wand abseuden, 口 Nervenfasern (?). Vergr. c00.

Fig. 5. Ebensolches Präparat. Vergr. 460.

Fig. 6. Ein Stïck der innern Oberflüche der Gallertwand des Schirmrandringes (y deren obere, e deren untere Grenze) mit der Leiste und den in Fïden sich fortsetzenden Warzen. Vergr. 105.

Fig. 7. Elsensolches Präparat, ohne die Leiste. Vergr. 305.

Fig. 8. Oberer Theil des Schirmrandringes rom Gallertschirm (G) theilweise abgezogen (m-n). Nach rechts ist noch der grösste Theil des deckenden Epithels vorhanden, worin einige Nesselzellen zu sehen sind; je mehr nach links, desto mehr fehlt von diesen Fpithel, bezw. vom Schirmrandring. Ueberall sieht man unter den Epithelzellen starre Fäden (F) hervortreten: die Stützfasern. Die Umbrella, G, ist, wach dem vorgelegenen Präparat, gefaltet gezeichnet. 

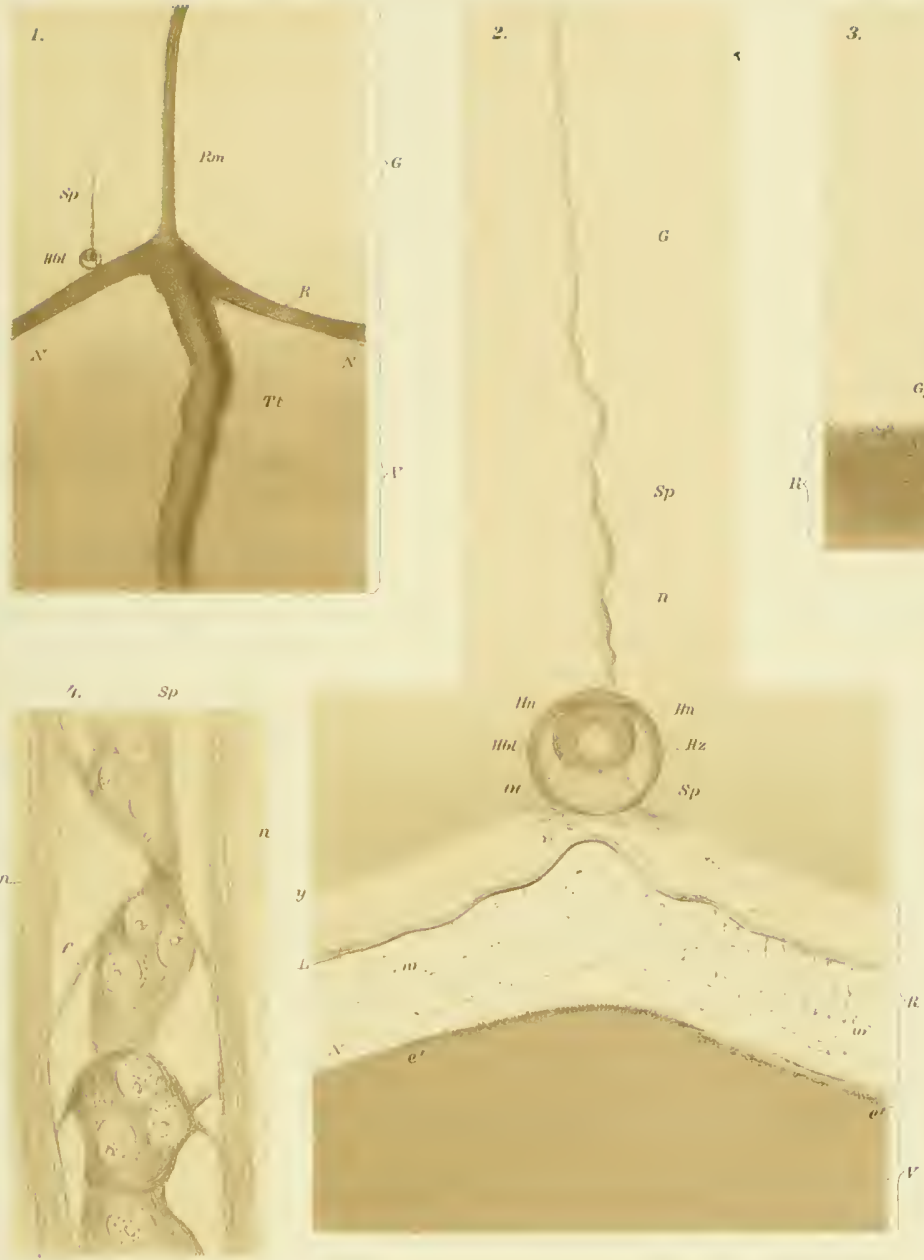

s.

6.

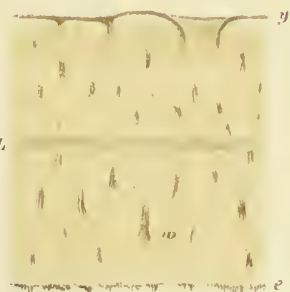

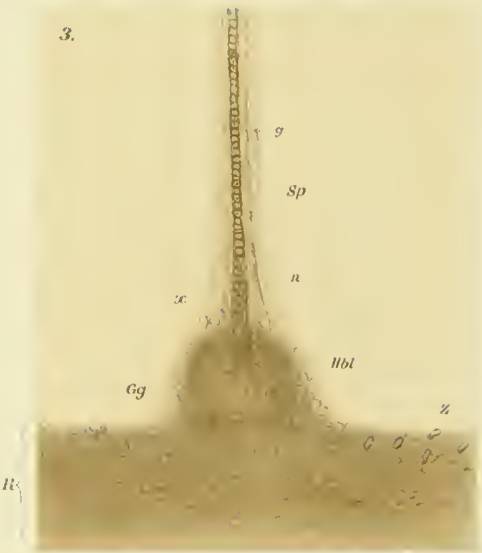

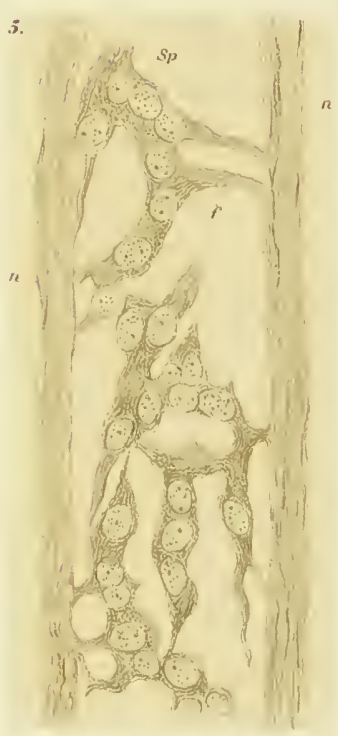

2.

$S p$

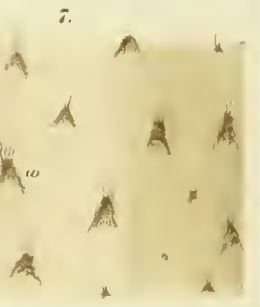

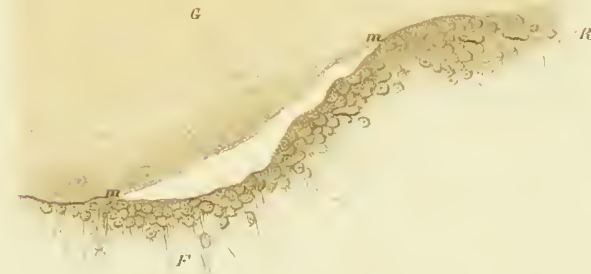





\section{Tafel VIII.}

Die Abildungen beziehen sich auf $\mathrm{Carmarina}$ hastata.

Allgemeine Bereichungen.

Giz Ganglienzellen.

N Ringnerr.

$\mathrm{R}$ sichirmrandring.
G Umbrella.

$\checkmark$ Velum.

L Leiste.

Fig. 1. Die äussere Wand des Schirmrandringes, d. i. das denselben deckende Epithel, in seiner ganzen Ausdehnung ron nnten nach oben. Oben Nesselzellen (z) zwischen den gewöhnlichen Epithelzellen; etwas weiter abwärts durchschimmernde Ganglienzellen. Zu unterst ist, besonders in der rechten Ecke, wo das Epithel entfernt ist, der Ringnert zu sehen. Vergr. 100.

Fig. 2. Ein Stïck des Schirmrandringes: rach oben ein Stück der Umbrella, nach unten des Velum damit in Verbindung. Tom Schirmrandring ist, wie rorhin, die äussere Wand zu sehen, oben mit Nesselzellen, zwischen welchen Drïsen (D) liegeu. Unten sieht man Ganglienzellen und deı Ringnerren durchschimmern. Im mittleren Theile ist ein Stïck der Epithelwand herausgebrochen: man sieht in den Ringkanal hinein, welcher ron den Füllzellen entleert ist. Dagegen sieht man an der aboralen Fläche der Gallertwand (n) unterhalb der Leiste Zellen des Ringganglion. Tergr. 125.

Fig. 3. Ein Stïck des unteren Abschnittes des vorigen Präparats, ohne Ringnerr, stärker rergrössert, ron der juneren Fläche des Schirmrandringes aus gesehen.

Fig. 4. Lnterer 'Theil der äusseren (Epithel-) Wand des Schirmrandringes stärler rergrössert (460), ron der oberen Flïche aus gesehen: man sieht den Ringuerren $(N)$ durchschimmeru. Bei E sind die Epithelzellen durch in denselben sichtbare faserige Differenzirung (Neuroplasma) als Nerrenepithel gekennzeichnet. (Chromkaliprä prarat.)

Fis. 5-11. Ganglienzellen, wie sie unter der Epithelialdecke des Schirmandringes liegen, stark (1000) rergrössert.

Fig. 12. Ein Stïck der Gallertwand des Schirmrandringes ron der Fläche, mit optischen Querdurchschnitten der dort auf den Warzen entspringenden Stützfasern und mit aufgelagerten Zellen.

Fig. 13. Ein Stück des unteren Abschnittes der äusseren Wand des Schirmrandringes ron innen gesehen, mit aufgelagerten Ganglienzellen. Vergr. 460. 


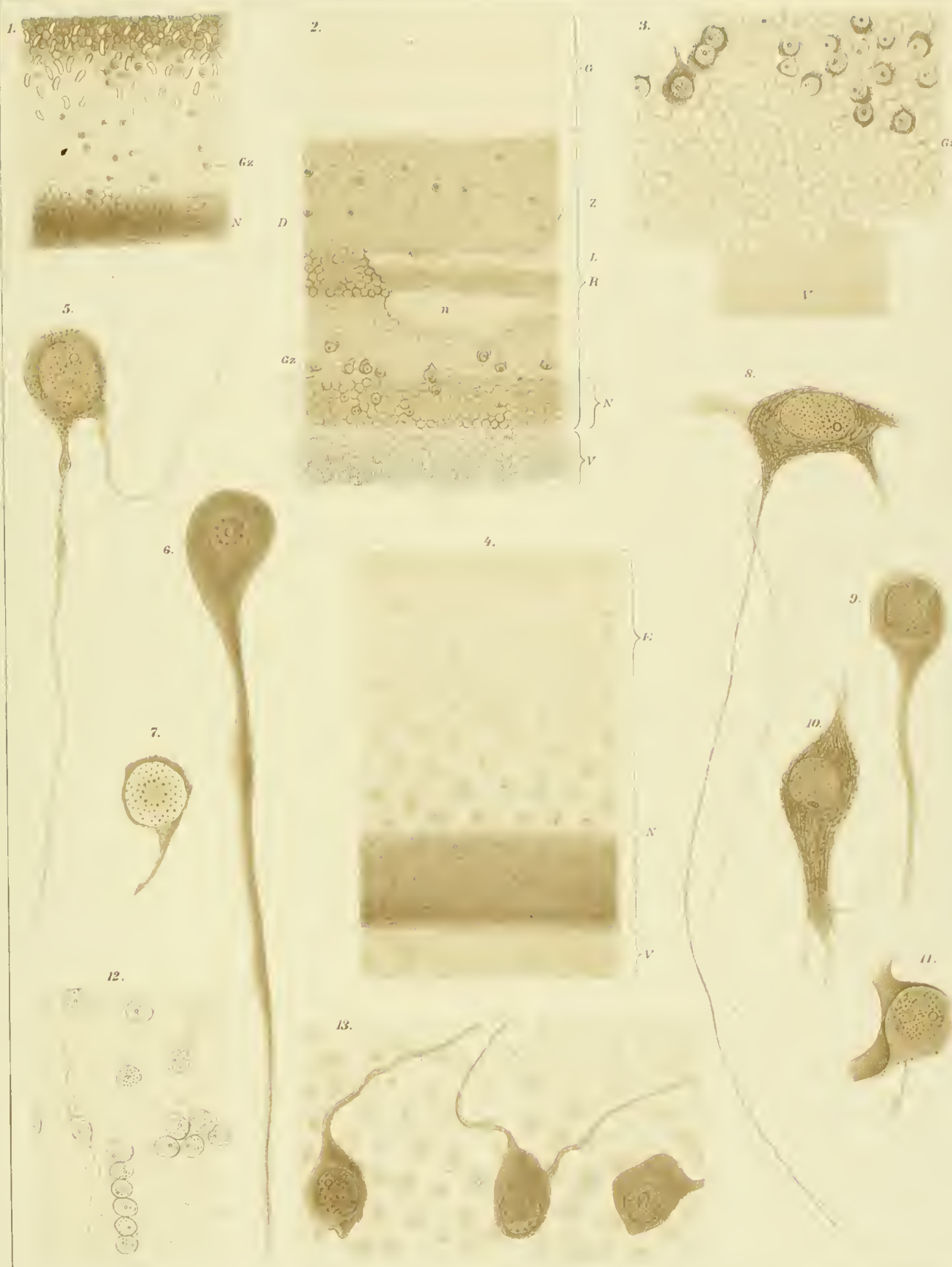






\section{Tafel IX.}

Die Abbildungen beziehen sich anf Carmarina hastata.

Fig. 1 und 4. liandtheil der Umbrella nach Ausziehen der Hörbläschen aus demselben: Fig. 1 von der aboralen, Fig. 4 ron der oralen Fläche aus geselıen. In Fig. I sieht man bei $\mathrm{x}$ eine Furche, welche herrührt von einem Eindruck, den das an jener Stelle auf der Aussenfläche der Umbrella gelegene Radialganglion hervorgerufen hat. Vergr. 70.

Fig. 2. Ein Theil des Spangenganglion stark vergrössert: $\mathrm{x}$ die dasselbe einschliessende Scheide, entsprechend $n$ lig. 3 auf Taf. VII, in die Stätzwand des Schirmrandringes (y) übergehend. 1 ausserhalb der Scheide gelegene Fasern (vergl. den Text). L Leiste der Stützwand.

Fig. 3. Epithelzellen and Drüsen der Epithelialwand des Sehirmrandringes: rergl. Fig. 2. Taf. VIII. D.

Fig. 5. Dieselben Zellen isolirt und rergrössert.

Fjg. 6. Epithelzellen rom oberen Theil der äusseren Wand des Schirmrandringes, in der Umwandlung zu Drüsenzellen begriffen.

Fig. 7. Nervenzellen aus dem Spangenganglion stark vergrössert: g fadenartig differenzirter Zelleninhalt, f Nerrenfäden, welehe rou demselben ansgehen: vergl. Taf. VII. Fig. 5 f. Die zwei Linien zu beiden Seiten bezeichnen die Grenzen der dort gelegenen Faserbündel (Taf. VII. Fig. 4 und $5 \mathrm{n})$.

Fig. 8. Ein stück des Schirmrandes mit einem Hörbläschen: die das Radialganglion und das Hörblïschen $(\mathrm{Hbl})$ deckenden Epithelzellen sind bis auf die Reste ek entfernt: dadurch wird siehtbar das Spangenganglion g, von der Scheide umhüllt, ansserhalb der letzteren Fasern, darunter das Hörbläschen (Hbl), sammt der äussern Grenze der Hörzellen (Hz). Das Spangenganglion geht nach unten in das liadialganglion $\left(\mathrm{g}^{\prime}\right)$ über: vergl. Gi Fig. 11. L Leiste der aboralen Fläche der Gallertwand des Schirmrandringes, n Ringnerv.

Fig. 9. Theil des Sehirmrandringes mit Hörbläschen und sspange« von der Umbrella abgezogen, das Hörbläschen aus ihr herausgezogen. N Hörnerv, rechts an einer Stelle durchgerissen. L Leiste. V Velum. Hbl Wand des Hörbläschens. Hz Hörzellen. Ot Otolith. G Spangenganglion, n dessen Scheile. Ausserhalb lerselben noch eiu Stück Gallertgewebe von der UTmbrella auhäugend.

Fig. 10. Füllzellen, a bis $m$ bei etwa $500, \mathrm{n}$ bis $\mathrm{p}$ bei lo00facher Tergrösserung.

Fig. 11. liadialganglion (Gi) mit einem Theil des Spangenganglion (G), beiderseits ron G die Hörnerveu.

Fig. 12. Kerne aus Füllzellen mit fadenartiger Differenzirung des Inhalts.

Fig. 13. Drïsenzellen von der nnteren Fläche des Schirmes zwischen den Zïgen eines Radialmuskels. Zwischen den Drüsen Epithel mit fadenartig differenzirtem Inhalt (Nervenepithelien). 

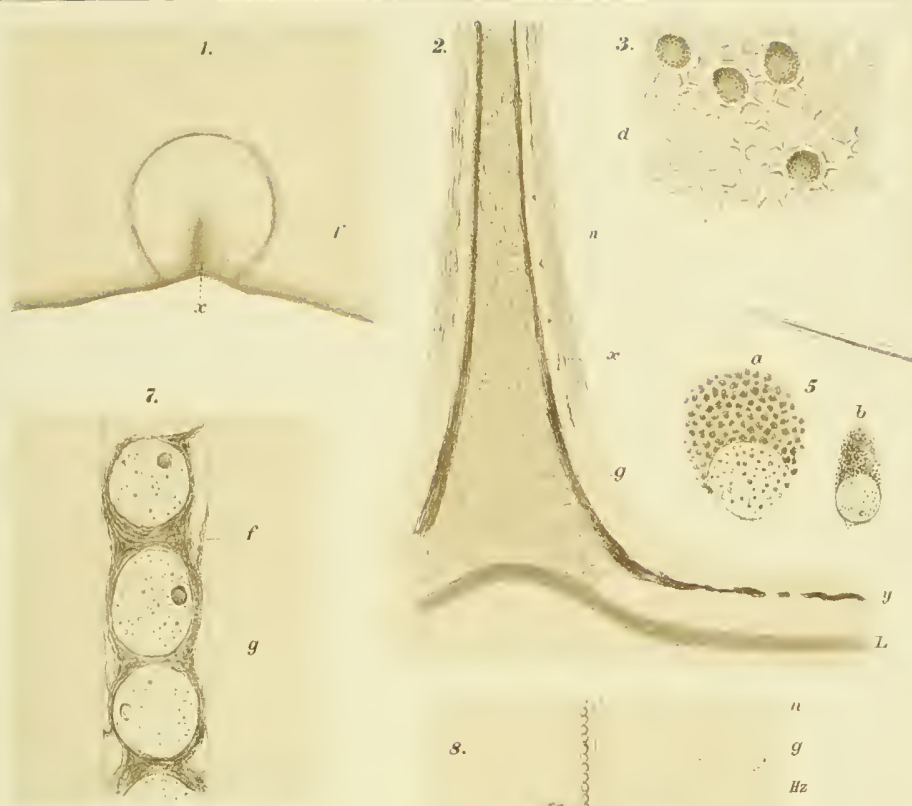

1.

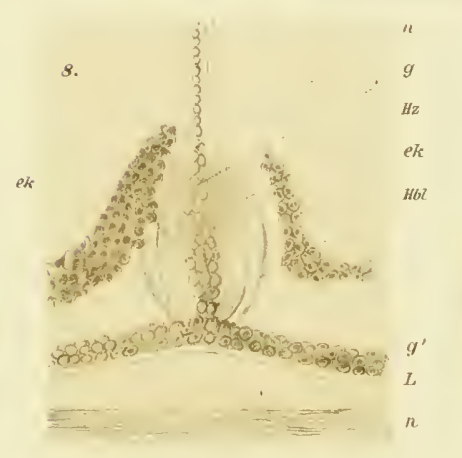

101

(6) 11

.
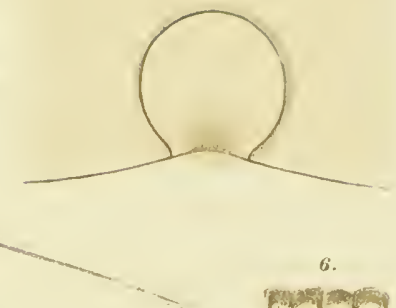




\section{Tatel X.}

Die Abbildungen beziehen sich anf Carmarina has tata.

Fig. 1. Fine Anzahl Fasern ans einem Radialmuskel (vergl. Fig. 10) mit den dieselben von unten deckenden Ektodermzellen E (Nervenepithelien). Vergr. 1000.

Fig. 2. liadial an dex Stelle des Sitzes eines Hörblïschens und dureh dasselbe gefïhrter Durchschnitt des preripherischen Theils des Sehirmes: $x$ Theil der äussern Schirmobertläche mit einem Stüek des Spangenganglion Sp; lig linggefäss, h hintere, v vordere Wand des Radiürgefässes; Sb Theil der oralen Schirmobertläche, soweit diese the Decke des Ringgefässes bildet; Rim Muskelzug, welcher auf diesem Theil der oralen Sehirmoberflïehe aufwärts zieht, bei h von anssen nach innen durchseheinend (der Iläckel'sehe liadialnerv); Hbl Hörbläschen in die Gallertwand G eingebettet; 0 Otholith mit aufliegendem sinnesepithel; $\mathrm{H}_{n}$ einer der von hinten und oben an dasselbe herantretenden Hörnerven; V Velum; y Stelle wo der abgerissene Schirmrantring sass. Vergr. 45.

Fig. 3 und $\diamond$. Neuroepithelzellen von der Fläche gesehen, dem Rarlialmuskelzug entnommen.

Fig. 4. Ebensolehe Ektodermzelle mit einem anftallend starken einzeln abtretendem Nervenfädchen n. Vergr. 1000.

Fig. 5. Ein Stïck des Rauliahnuskelzuges nit aufgelagerten Neuroepithelzellen, von der Seite gesehen. Vergr. 1000.

Fig. 6. Nervenzellen aus der Deeke des liadialganglion (vergl. den Text).

Fig. 7. Ein Stïek Epithel der Unterfäche des Schimes ans deren oberem Theile, wo keine cirkuläre Muskulatur mehr rorhanden ist, ans der Gegend neben einem Radialmuskel. Zwischen den Neuroepithelzellen sielıt man mehr oder weniger vollkommen typische Ganglienzellen (gz); bei 1 Löcher im Epithel, entsprechend herausgefallenen Nervenzellen; links bei Rm ein Stïck des Radialmuskels, weleher unter dem Epithel liegt. D Drüsen. Vergr. 460.

Fig. 9. Ein stiick der Unterfläche des Schimes entsprechend der Gegend d Fig. + Taf. XI: m, m entsprieht den Muskelzïgen l, I der genannten Figur, die Muskelfasem sind aber theilweise entfernt; der mittlere Kag von Fäden entspricht $m$ in jener Figur, bei d Drüsen mit hyalinem, bei D ebensolehe mit körnigem, durch Carmin sich rothfürbenden Inhalt.

Fig. 10. Hin Stück des in Fig '2 an der linteren Wand des Ringgefässes sichtbaren Radialmuskels, stärker vergrössert $(305)$ : rehts und links, hei E sieht man an demselben Ektodermzellen (Nervenepithel), ein Theil der Zellenlage, welche ihn von unten deckt. Im unteren Theile der Figur bei $\mathrm{M}$ ist die radiüre Muskulatur beleckt von ler eirkulären Muskulatur der Subumbrella m (im oberen Theile ist diese entferut).

Fig. 11. Zelle von der Oberfäehe des Magenstiels, in der Lmbildung zu einer Drüsenzelle begriffen.

Fig. 12. Epithel vom oberen Theile der Sehimuntertiache ans der Nühe eines Radialmushelzuges.

Fig. 13. Epithel ebendaher, zwisehen den Epithelzellen eigentlı̈mlich glänzende Körper (x). 


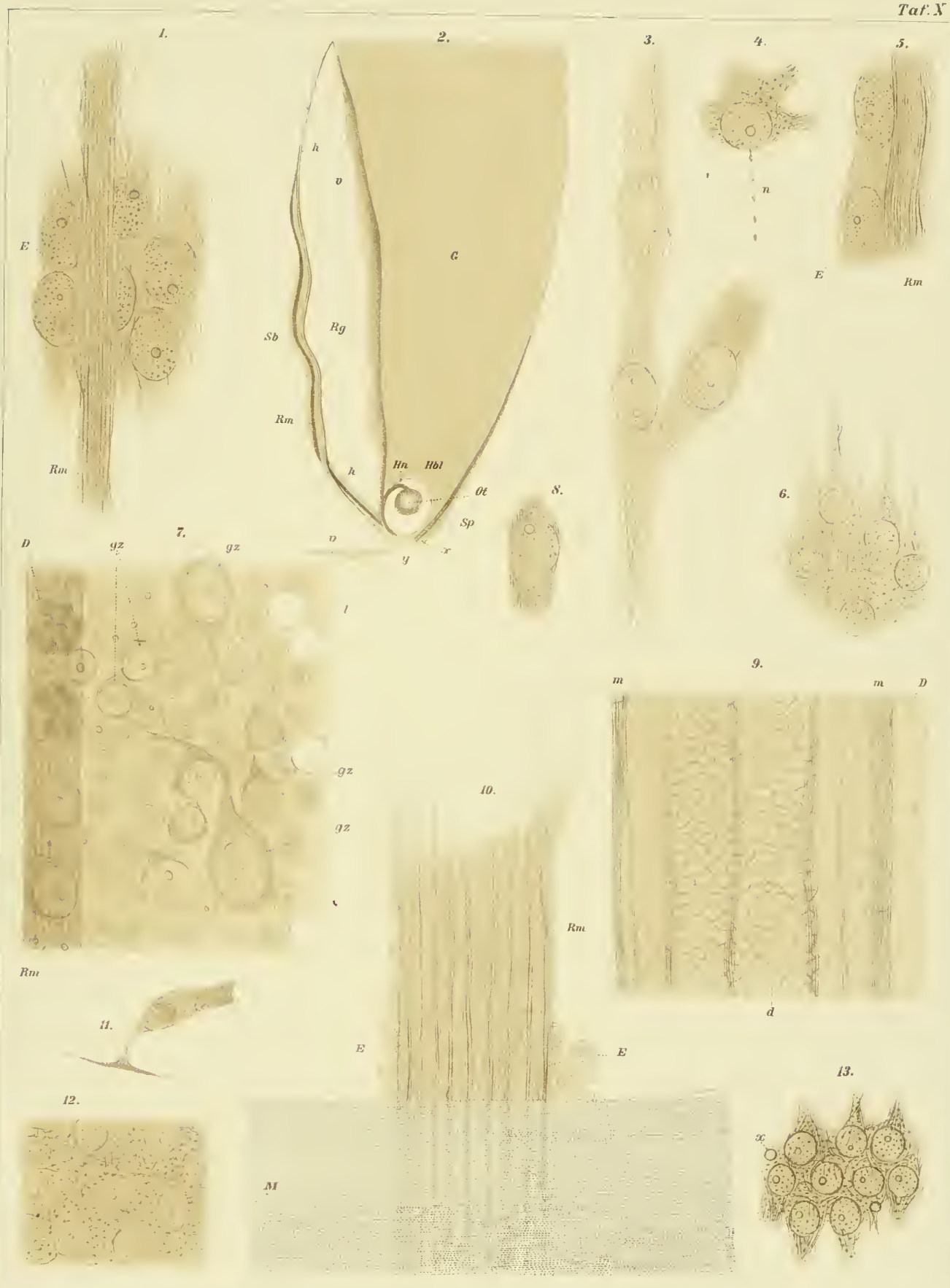





\section{Tilfel XI.}

Die Abbildungen beziehen sich auf Caruarina hastata.

Fig. 1. Muskel- und Nervenelemente neben dem liadialmuskelzug aus dem oberen Theile des Schirmes: m Muskelfasem, n Nervenfasern, Gz Ganglienzellen.

Fig. 2. Ringnerv mit Epithel: $\mathrm{T}$ Nerv, a Spindelzellen, b Besenzellen, c Gabelzellen, $\mathrm{k}$ Kerne von in Fasern eingeschlossenen Nervenzelleu mit wenig Zellinhalt, I Lüicken, aus welchen solche Elemente heransgefallen sind.

Fig. 3. Ringnery mit in die Fasern eingeschlossenen Nervenzellen.

Fig. 4. Ein Stiick des Radiahnuskelzugs mit den medianen (m) und den lateralen (l) Muskelfaser- . zügen.

Fig. 5. Ein Stuick ron Carmarina hastata vou der Unterfläche: V Velum, t Tentakel, N Ringnerr, $\mathrm{x}$ medianer, l later"ile liadialmuskelzïge; d nur von Drüsen belegter Abschnitt, entsprechend d Fig 4.

Fig. 6. Besenzellen vom sichirmrandring.

Fig. 7 und 10. Epithelzellen ven demselbeu.

Fig. 8. Muskelfasern ron demselben.

Fig. 9. a Nervenfaser mit eingeschlossener Nervenzelle. b Nervenfaser mit einer Epithelzelle, welche ganglienzellenälnlich geworlen, nit ihrem Körper ans der Reihe der übrigen in die Tiefe getreten ist; c ebensolche Zelle. Sämmtliche Zellen rom Ringnerveu.

Fig. 11. Nervenzellen der Subumbrella, der Muskelschichte aufliegend.

Fig. 12. Ein Stück der Gallertwand des Schirmrandringes mit derselben anfliegenden Nerrenzellen bzw. Kernen (K), z von der Gallertwand entspringende Warzen. 

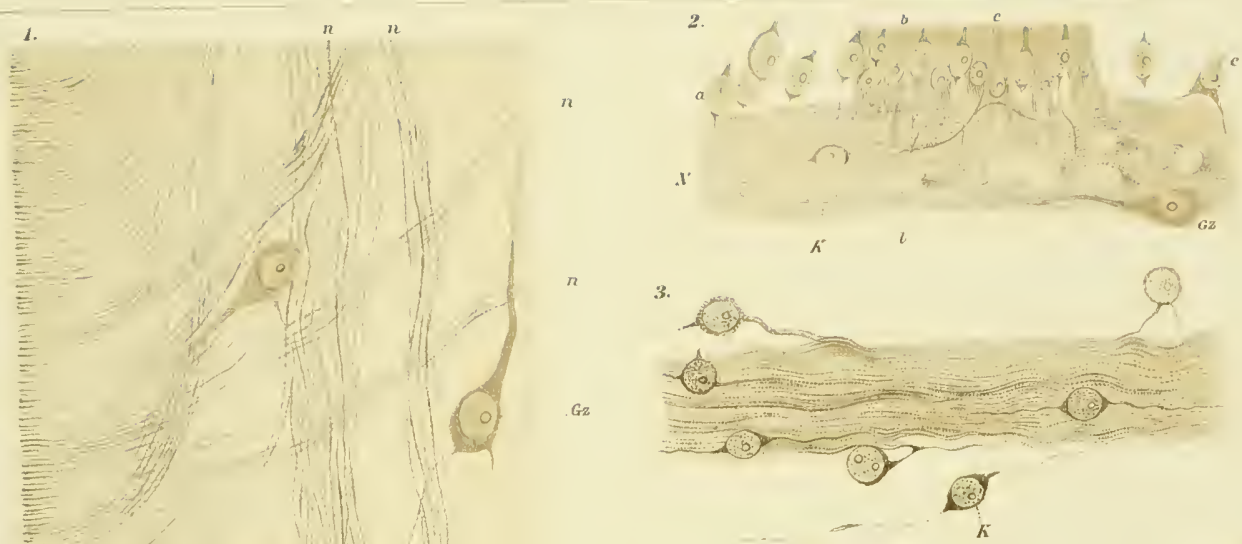

.
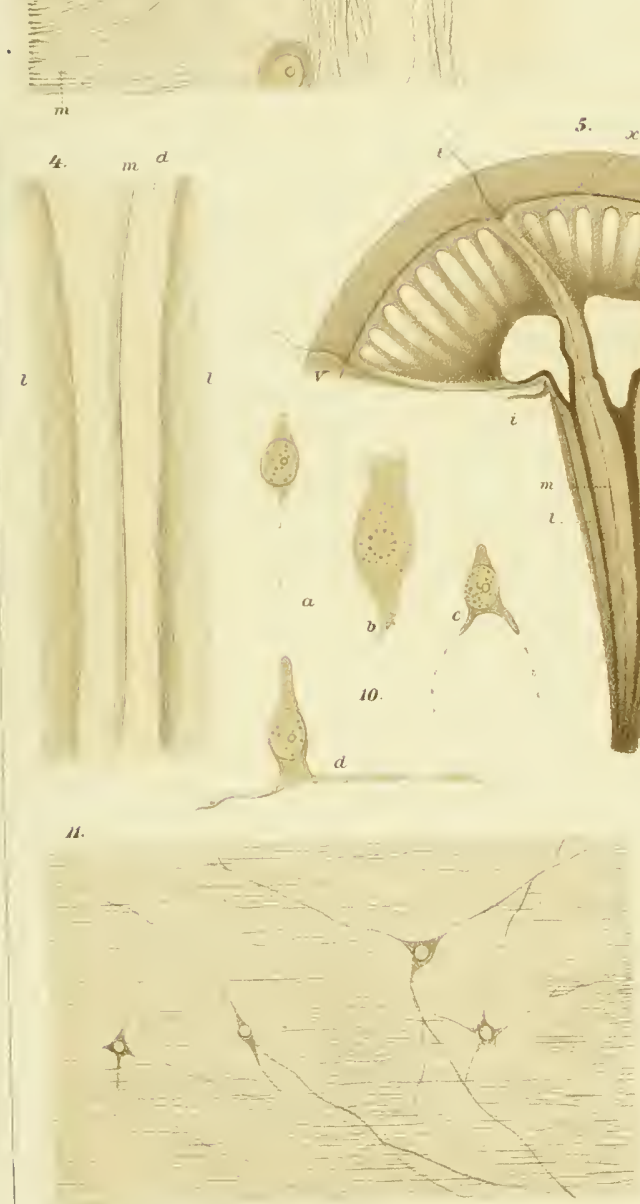

12.
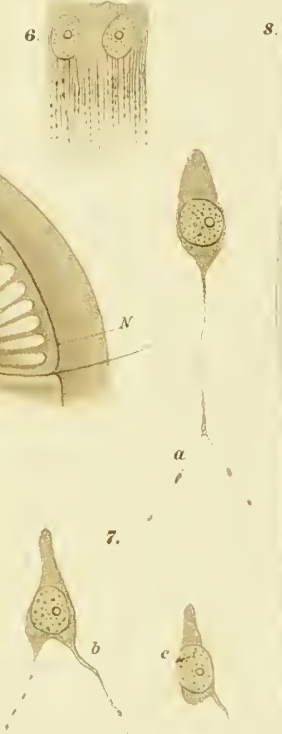

$s$
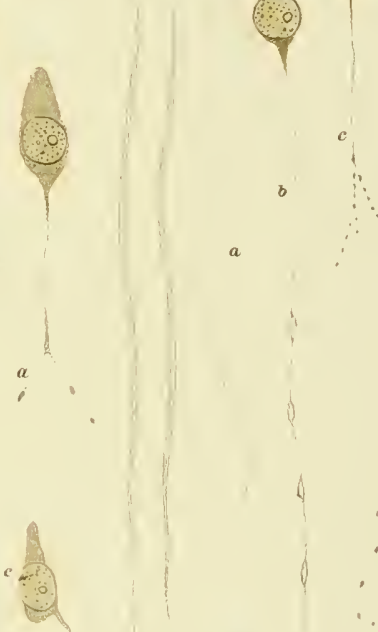

$17 \quad-1000$ U.

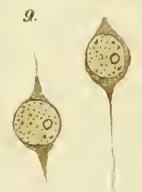


. 


\section{Tafel XII.}

Die Abbildungen beziehen sich anf Carmarina hastata.

Fig. 1 und 5. Hörorgan nach Behandeln mit Essigsänre: bei 1 ist das Hörbläschen etwas geschrumpft, der Otholith anfgelöst, die Nesselzellen sind stärker hervorgetreten nnd ebenso die Fasern der Hömerven; in Fig. 5 sind Otholith und Hörzellen gänzlich aufgelöst, an Stelle der letzteren sieht man kleine glänzende Körnchen (p) : bei $\mathrm{K}$ ist eine Anzahl Kerne auffallend deutlich aufgetreten. Vergr. 150.

Fig. 2, 6, 7, 9, 11, 13, 16, 17, 20, -1, 22. Neuromuskelzellen in verschiedenen Ausichten und Vergrössermugen: in 9, 13 und 17 (Vergr. 1040) sieht man nach Behandeln mit Chromkali im Zellkörper feine Fälen; ebenso in 22.

Fig. 3. Otholith nach Einwirkung von Essigsïure in Anfösung hegriften.

Fig. 4. Ein Stück der Innenwand des Hörsäckchens mit einem Theil des Hörnerven vach beginnender Einwirkung ron Essigsämre: w die das Hörsäckichen anskleidenelen Epithelzellen; im Hörnerven (Hu) sind drei halbgeschrumpfte Nervenzellen zu sehen. Vergr. 230.

Fig. 6. Ein Stückchen der Subumbrella von der Unterfläche des Schirmes aus gesehen, eiu Theil des neuroplasmatischen Abschnittes der Neuromuskelzellen (z) ist entfernt, so dass die contractilen Platten (m) sichtbar werten.

Fig. S. Besenzellen (Nerrenepithelien) ron der Oberfläche des Schirmrandringes nach Einwirkung verdünnter Essigsäure. Vergr. 1000.

Fig. 10. Ein Stïekchen einer Muskelplatte nach Behandeln mit Chromkali, um die Querstreifung zu zeigen. Vergr. 1000.

Fig. 12. Epithelzellen ron der Oberflïche des Schirmrandringes über dem Ringuerven: a eine Spindelzelle, b zwei Bestnzellen, welche aber nach abwärts in je einen einfachen Fortsatz übergehen. Vergr. 1000.

Fig. 14. Ovarialblatt mit Eiern, das Gallertblatt ganz Uurchsetzend, wie die Löcher zeigen, aus welchen die Eier herausgefallen sinc, die Punkte sind durchschnittene Bindegewebsfasern. Tergr. 90.

Fig. 15. Ein Stück einer Mnskelplatte frisch: man sieht an dem einen Rande Querstreifung. Verg. 1000.

Fig. 20. Eine Neuromuskelzelle von ler oralen Schirmflïche aus gesehen, mit durch sie theilweise bedcckten Stiicken der Muskelplatten (vrgl. Fig. 6). 

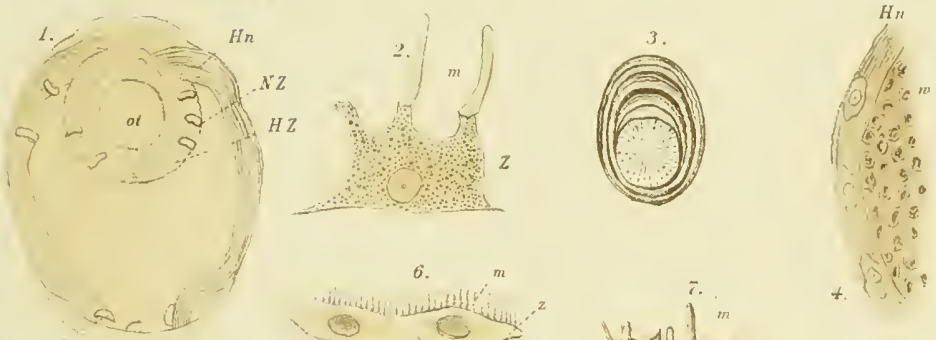

.

NZ
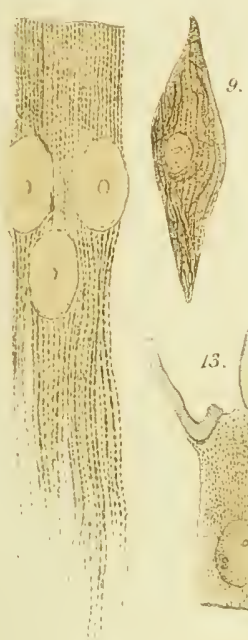

$\frac{5}{0} \frac{9}{9}$

7.
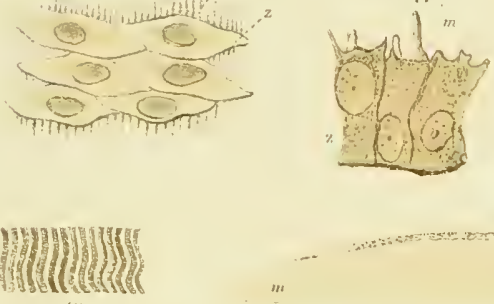

8
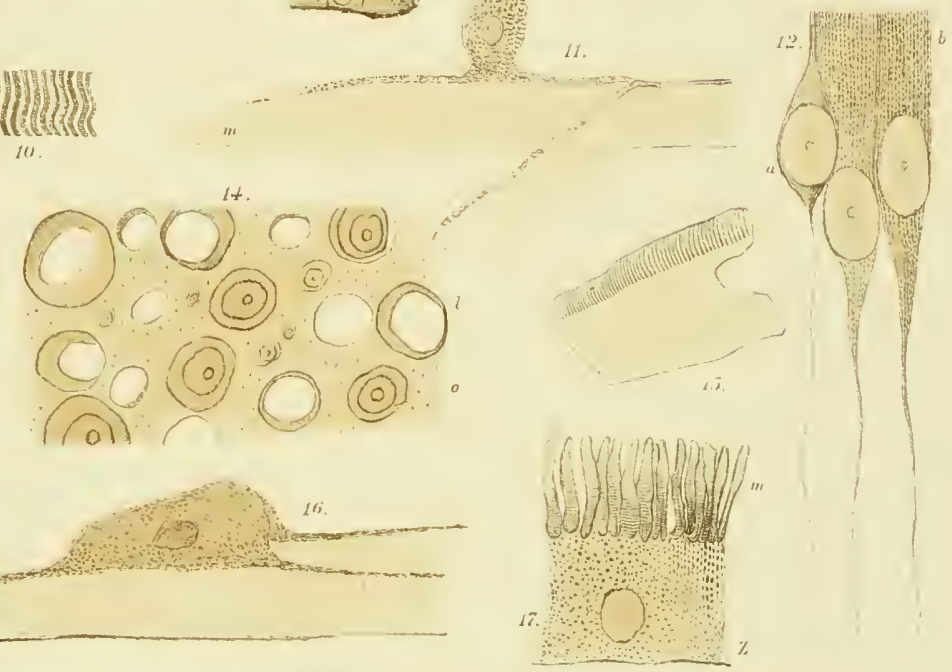
13. $1 \int^{m}{ }^{m}$
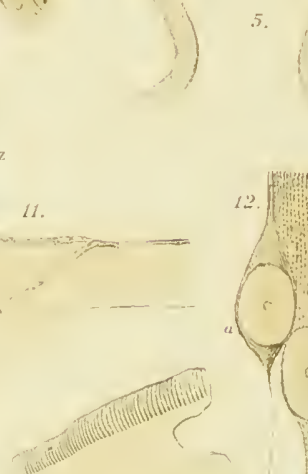

$H_{n}$
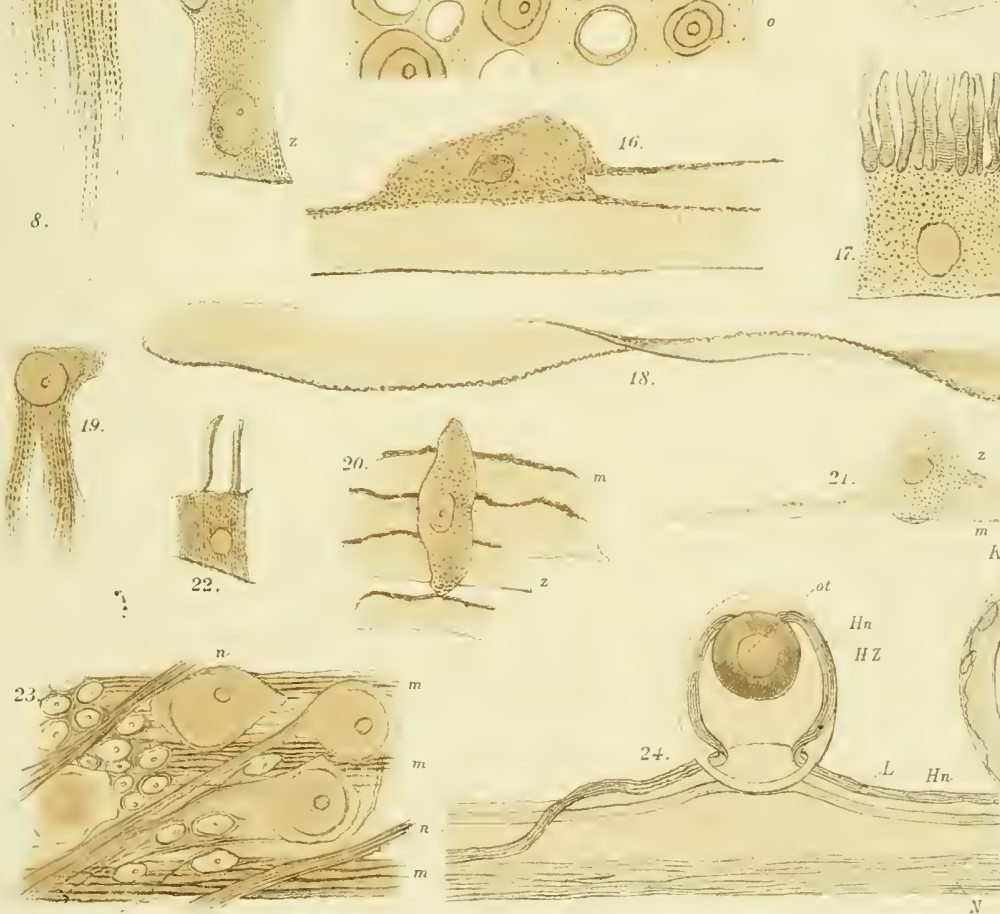



\section{Tafel XIII.}

Die Abbildungen beziehen sich auf Carmarina hastata.

Fig. 1-5, 10, 13. Drüsenzellen von den radialen Bezirken der Schirmunterflïiche (d, Fig. 4, Taf. Xl.) theils in der seitlichen, theils in der Fläeheuansicht.

Fig. 6. Wand des Hörbläschens mit Zellenbelag: im Innern die zwei Hörnerven zum Hörepithel hinzutretend, welches die Kapsel deckt, die den Otholithen früher umgab: clieser ist aufgelöst. Vergr. 240.

Fig. 7, 9, 12, 15. Hörzellen, bei 12 noch in Verbindung mit dem Hörnerven n. Vergr. 650 und 1000 .

Fig. 8. Wie Fig. 6, aber das Hörbläschen sitzt noch in der Schirmwand, man sieht den Eintritt der Hörwerven; Nesselzellen im Hörepithel. Vergr. 125.

Fig. 11. Die zwei Hörnerven, in Verbindung mit deren Fasern je eine Hörzelle steht: die Hörzellen sitzen der Otholithenkapsel anf, welche etwas geschrumpft ist, der Otholith ist aufgelöst. Vergr. 600 .

Fig. 14. Epithel von der aboralen Fläche des Schirmrandringes an der Girenze des Segels. 


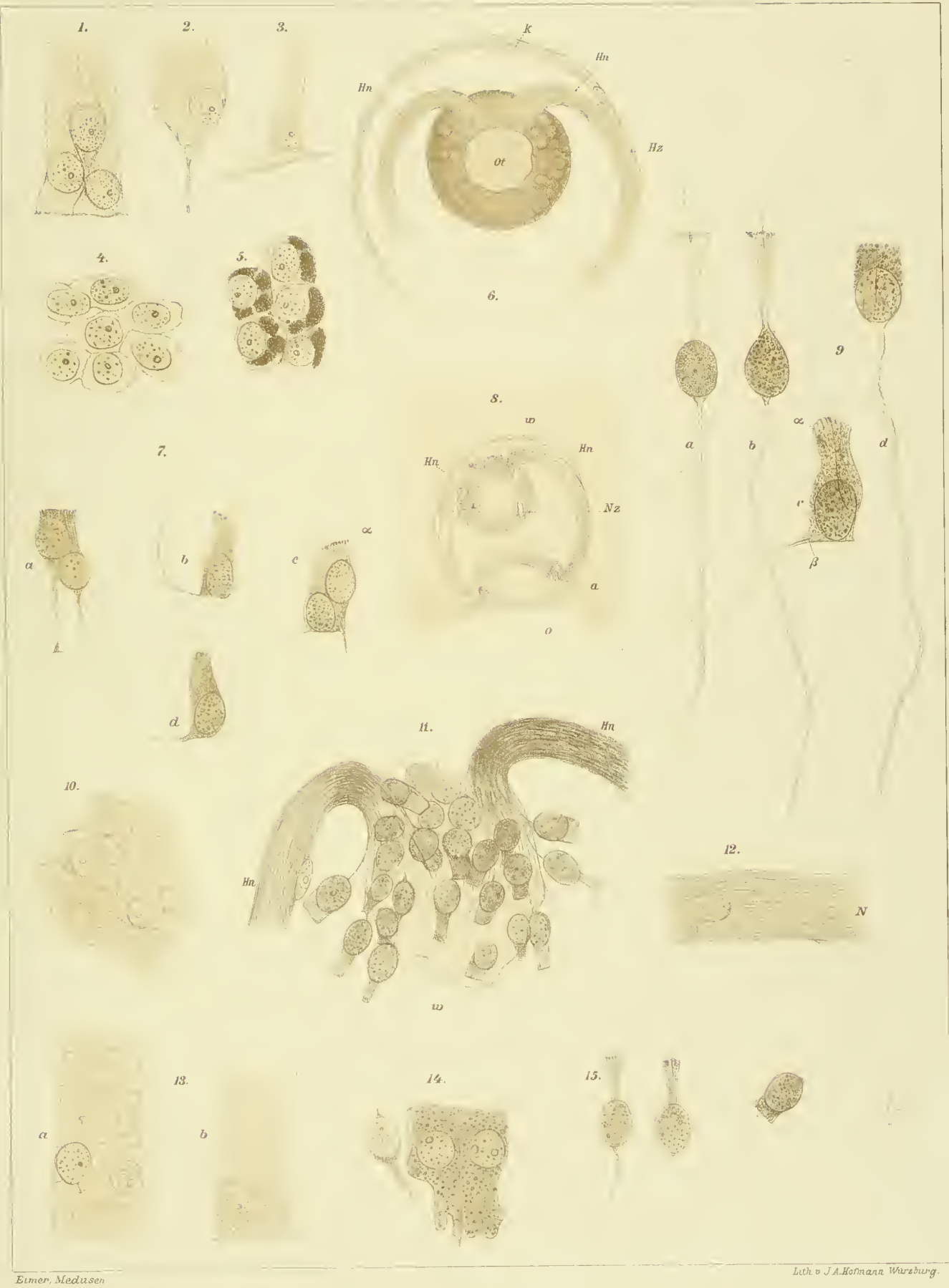





